\title{
Die strafrechtliche Behandlung von Eltern minderjähriger Täter.
}

Strafbares Unterlassen im Rahmen der unechten Unterlassungsdelikte und § 171 StGB

\author{
Dissertation \\ zur Erlangung des Doktorgrades der Juristischen \\ Fakultät \\ der Georg-August-Universität zu Göttingen
}

\author{
vorgelegt \\ von \\ Christine Geisler \\ aus Göttingen
}

Göttingen 2003 
Berichterstatter: Prof. Dr.Loos

Mitberichterstatter: Prof. Dr. Maiwald

Tag der mündlichen Prüfung: 12.02.2003 


\section{Vorbemerkung}

Diese Arbeit hat der Juristischen Fakultät der Georg-August-Universität Göttingen im Wintersemester 2002/2003 als Dissertation vorgelegen.

Meinem Doktorvater, Herrn Prof. Loos, danke ich sehr herzlich für die Betreuung während des gesamten Zeitraums der Bearbeitung. Insbesondere bedanke ich mich für die immer vorhandene Bereitschaft zur Diskussion und für die hilfreichen Anregungen und Denkanstöße. Seine jederzeit gewährte fachliche und persönliche Unterstützung hat mich bereichert und mir - keinesfalls nur in strafrechtlicher Hinsicht neue Blickwinkel erschlossen.

Herrn Prof. Maiwald danke ich für die zügige Erstellung des Zweitgutachtens.

Herzlich bedanken möchte ich mich auch bei Herrn Privatdozenten Dr. Krack für seine freundlichen Ratschläge zur Veröffentlichung dieser Arbeit.

Besonderer Dank gilt meiner Familie für die stetige und umfassende Unterstützung vom ersten bis zum letzten Tag der Erstellung der Arbeit und für das geduldige Korrekturlesen.

Die Verwertung der Literatur war bis zum Januar 2002 möglich. 


\section{Inhaltsverzeichnis}

$\begin{array}{ll}\text { 1. Teil. Einführung } & 1\end{array}$

$\begin{array}{ll}\text { A. Einleitung } & 1\end{array}$

B. Die Strafbarkeit des Aufsichtspflichtigen in der neueren Geschichte und der Gegenwart 4

I. Straf- und Polizeirecht der deutschen Länder im 19. Jahrhundert 4

$\begin{array}{ll}\text { II. Das RStGB für das Deutsche Reich } & 7\end{array}$

1. Erste Fassung vom 15. Mai 1871

2. Erweiterung der Vorschriften des RStGB 8

3. Weitere Entwicklung in Entwürfen und Reformvorschlägen 11

4. Entwicklung während des Zweiten Weltkriegs 14

$\begin{array}{ll}\text { III. Entwicklung von } 1945 \text { bis heute } & 17\end{array}$

IV. Zusammenfassung der geschichtlichen Entwicklung 21

2. Teil. Die Grundvoraussetzungen der elterlichen Strafbarkeit 23

A. Verfassungsrechtliche Voraussetzungen für eine Strafbarkeit der Eltern 23

B. In Betracht kommende Unterlassungsdelikte $\quad 29$

I. Die Unterscheidung von echten und unechten Unterlassungsdelikten 29

1. Die unechten Unterlassungsdelikte als erfolgsbezogene Delikte 29

2. Die unechten Unterlassungsdelikte als gesetzlich nicht geregelte Delikte 31

3. Stellungnahme 31

II. Für die Problematik in Frage kommende Unterlassungsdelikte 33

1. Echte Unterlassungsdelikte 33

2. Gesetzlich geregelte unechte Unterlassungsdelikte 33

3. Gesetzlich nicht geregelte unechte Unterlassungsdelikte 34 
A. Der Rechtsgrund für die Garantenstellung

I. Die Begründung von Garantenstellungen

II. Einordnung der elterlichen Garantenstellung

1. Die Deliktsverhinderungspflicht als Aufsichtspflicht

2. Die Eltern als Beschützergaranten

3. Eltern zugleich als Beschützer und Überwacher

4. Die Eltern als Überwachergaranten

a) Garantenstellung aus der Herrschaft über eine gefährliche Person

aa) Einleitung

bb) Herleitung und Art des Herrschaftsverhältnisses

(1) Faktische Herleitung

(2) Rechtliche Herleitung

cc) Konsequenzen der Herrschaft für die Überwachungspflicht

(1) Erscheinungsform der Herrschaft

(2) Das durch die Überwachung geschützte Rechtsgut

dd) Der nach $\S 13$ StGB verpflichtete Personenkreis

b) Herrschaft über das strafunmündige Kind

c) Herrschaft über den strafmündigen Jugendlichen 78

d) Strafmündigkeit als geeignetes Herrschaftskriterium?

e) Unterschiedliche Behandlung des Jugendlichen und des Heranwachsenden

1. Die Aufsichtspflicht als primäre und die Eingriffspflicht als sekundäre Garantenpflicht

2. Art der Aufsicht bei der Überwachergarantenstellung

3. Umfang der Aufsichtspflicht. Die zivilrechtliche Aufsichtspflicht i.S.d. § 832 BGB 
4. Einschränkung der Aufsichtspflicht der Eltern durch Pflichtendelegation 99

$\begin{array}{ll}\text { II. Ziel der Garantenpflicht } & 104\end{array}$

$\begin{array}{ll}\text { III. Die geforderte Handlung i.S.d. § } 13 \text { StGB } & 108\end{array}$

1. Die Art der gebotenen Handlung 109

2. Der gebotene Handlungszeitpunkt und die Abgrenzung zum Versuch 113

a) Beginn der Handlungspflicht 113

b) Ende der Handlungspflicht 117

3. Die Möglichkeit, durch die Handlung das Delikt zu verhindern 119

C. Vorsatz und Fahrlässigkeit 122

I. Vorsätzliches Unterlassen der Deliktshinderung 122

1. Allgemeines 122

2. Varianten vorsätzlichen Unterlassens der Deliktsverhinderung 126

3. Vorsätzliches Beseitigen der Verhinderungsmöglichkeit -

$\begin{array}{ll}\text { Omissio libera in causa } & 127\end{array}$

II. Fahrlässiges Unterlassen der Deliktshinderung 128

1. Dogmatische Einordnung des fahrlässigen Unterlassens 128

2. Voraussetzungen des fahrlässigen Unterlassungsdelikts $\quad 129$

a) Verletzungserfolg 130

b) Sorgfaltspflichtverletzung und Erfolgsabwendungspflicht 131

aa) Unmöglichkeit der genauen Abgrenzung der Tatbestandsmerkmale 131

bb) Umfang der Sorgfaltspflicht 133

cc) Strafrechtliche Haftung auch ohne Sorgfaltspflichtverletzung des Vordermannes

c) Erlaubtes Risiko 136

d) Fehlende Aufmerksamkeit hinsichtlich der erforderlichen Handlung 138

e) Die Zumutbarkeit 139

3. Varianten fahrlässigen Unterlassens der Deliktsverhinderung 140

4. Täterschaft und Teilnahme beim fahrlässigen Unterlassungsdelikt 143

a) Täterschaft 143

b) Ausschluß der Täterschaft durch einen vorsätzlich 
I. Untersuchung von Deliktsgruppen danach, ob sie für elterliches Unterlassen in Betracht kommen

1. Erfolgsdelikte

2. Erfolgsdelikte mit spezialisierter Begehungsweise

3. Verhaltensgebundene Delikte

4. Sonderdelikte

5. Eigenhändige Delikte

6. Zueignungsdelikte

II. Beispiele für elterliches Unterlassen

1. Vorsätzliches Unterlassen

2. Fahrlässiges Unterlassen

E. Die Zumutbarkeit der gebotenen und möglichen Handlung

I. Zumutbarkeit als tatbestandsausschließendes Kriterium

II. Grenzen elterlicher Einschreitenspflicht

III. Ähnlichkeiten und Unterschiede zu § 139 StGB

4. Teil. Die Beteiligungsform. Eltern als Täter oder Teilnehmer durch Unterlassen ?

I. Das Nichteinschreiten gegen die vorsätzliche rechtswidrige Haupttat des Minderjährigen

1. Einführung

2. Allgemeine Schwierigkeiten bei der Bestimmung der Beteiligungsform

3. Der Zeitpunkt des Eingreifens als Maßstab für die unterschiedlichen

Voraussetzungen der Beteiligungsform

4. Übernahme der Täterschaftskriterien von den Begehungsdelikten

a) Tatherrschaftstheorie 
bb) Die Erfolgsverhinderungsmöglichkeit als Tatherrschaftsmerkmal

cc) Soziale Tatherrschaft

dd) Ergebnis

b) Subjektive Abgrenzungslehre

5. Einheitliche Annahme einer Täterschaft oder einer Teilnahme

a) Annahme einer grundsätzlichen Beihilfe des Unterlassenden

aa) Grünwald

bb) Ranft

b) Annahme einer grundsätzlichen Täterschaft des Unterlassenden

aa) Darstellung der Ansicht

bb) Wesentliche Einwände und Schwierigkeiten bei der Annahme einer Unterlassungstäterschaft des Garanten

(1) Der Strafrahmen - Vergleich zwischen der Unterlassungstäterschaft und der aktiven Teilnahme

(2) Konsequenz- Strafbarkeit des Versuchs

(3) Konsequenz- Jeder aktiver Gehilfe zugleich ein Unterlassungstäter?

(4) Nachfolgende Beihilfe des Garanten

c) Modifizierung der "Einheitstäterlehre" durch Roxin

aa) Teilnahme wegen fehlenden Unterlassungstatbestands

bb) Teilnahme bei fehlender Erfolgsabwendungspflicht

cc) Beihilfe

d) Differenzierung nach Art der Garantenpflicht

aa) Darstellung

bb) Kritik

6. Probleme der Mittäterschaft zwischen sämtlichen an der Tat Beteiligten

a) Mittäterschaft zwischen dem untätigen Elternteil und dem aktiv handelndem Minderjährigen

b) Die Mittäterschaft der Eltern bei gleichzeitiger Pflichtverletzung (Gemeinsame Pflichtverletzung durch Unterlassen)

aa) Mittäterschaft durch gemeinsames Unterlassen beider Elternteile

(1) Bestehen eines Unterlassungsvorsatzes

(2) Die Unterlassung des einen als Beihilfe zur Unterlassung des anderen 
bb) Mittäterschaft zwischen dem tätigen und dem unterlassenden Elternteil (Gemeinsame Pflichtverletzung durch aktives Tun des einen und Unterlassen des anderen)

II. Sonderstellung des Jugendlichen: Der Jugendliche als Vollverantwortlicher im Sinn der Teilnahmetheorien?

III. Das Nichteinschreiten gegen Gehilfenbeiträge des zu überwachenden Minderjährigen

B. Der strafunmündige bzw. nichtverantwortliche Minderjährige

I. Täterschaft oder Teilnahme gegenüber der Tat des strafunmündigen Kindes

II. Abgrenzung zwischen der mittelbaren und der unmittelbaren Täterschaft durch Unterlassen

\section{Teil. Die Strafbarkeit der Eltern gemäß $§ 171$ StGB}

1. Schutzzweck und geschütztes Rechtsgut

a) Systematik 234

b) Geschütztes Rechtsgut 235

c) Das Kind bzw. der Jugendliche als Schutzobjekt 237

2. Täterkreis 238

3. Tathandlung: Gröbliche Verletzung der Fürsorge- und Erziehungspflichten 239

a) Allgemeines $\quad 239$

b) Inhalt der Fürsorge- und der Erziehungspflichten 240

c) Die gröbliche Pflichtverletzung 243

4. Taterfolg: Gefahr einer Schädigung in der psychischen Entwicklung 250

a) Der Gefahreintritt als tatbestandlicher Erfolg 251

b) Allgemeines 251

c) Der Begriff des kriminellen Lebenswandels 254 
e) Konkrete Gefahr

aa) Eintritt der konkreten Gefahr 258

bb) Verursachung der Gefährdung 260

cc) Kausalität und Zurechnung 261

dd) Zumutbarkeit 262

4. Subjektiver Tatbestand 262

II. § 171 StGB als echtes Unterlassungsdelikt 264

III. Allgemeines Konkurrenzfragen 267

$\begin{array}{ll}\text { IV. Rechtsfolgen } & 267\end{array}$

B. Vergleich zwischen der Strafbarkeit nach $\S 171$ StGB und nach den unechten $\begin{array}{ll}\text { Unterlassungsdelikten } & 269\end{array}$

$\begin{array}{ll}\text { I. Inhaltliche Unterschiede } & 269\end{array}$

$\begin{array}{ll}\text { II. Konkurrenzverhältnis } & 270\end{array}$

6. Teil. Verfassungsrechtliche und kriminalpolitische Aspekte 272

A. Verfassungsrechtliche Überprüfung der gefundenen Ergebnisse 272

B. Zur tatsächlichen Lage der Kinder- und Jugendkriminalität und deren Behandlung 274

$\begin{array}{ll}\text { I. Rechtsprechung } & 274\end{array}$

II. Die Polizeiliche Kriminalstatistik (PKS) 275

III. Die Studie von Ostendorf 1997

IV. Folgerungen für ein Strafbedürfnis $\quad 278$

V. Bedeutung des Elternhauses für die Kinder- und Jugenddelinquenz 280

C. Die These von der Unzulänglichkeit der bestehenden Strafbestimmungen 282

I. Inhaltliche Bedenken gegen $\S 171$

II. Negative Auswirkungen auf die Familienstruktur 285

III. Bestrafung als kontraproduktiver Mechanismus 289 
VI. Keine Anwendung der bestehenden Strafnormen durch die Justiz

V. Fehlende Akzeptanz in der Gesellschaft

VI. Schwierigkeiten im Strafverfahren

VII. Zweifel hinsichtlich der präventiven Wirkung einer Strafbarkeit

D. Außerstrafrechtlichen Maßnahmen

I. Verfassungsmäßige Pflichten hinsichtlich des Einsatzes von Strafe

II. Alternativen zur Strafbarkeit

2. Kinder- und Jugendhilfe, $\S \S 27$ ff. SGB VIII

3. Sanktionierung von Eltern durch Schadensersatzansprüche ?

4. Positive Generalprävention auf gesellschaftlicher Ebene

III. Alternativen aus dem Polizeirecht 


\section{- Literaturverzeichnis -}

Abelein, Manfred

Aden, Menno

Albilt, Hans-Joachim

Albrecht, Hans- Jörg

Allenspach, Esther

Amtlicher Entwurf

Androulakis, Nikolaos

Konstantinos

Arzt, Gunther

Bärwinkel, Richard
Recht auf Bildung, in: DÖV 1967, S. 375 ff.

Die Haftung der Eltern für die unerlaubten Handlungen ihrer Kinder im französischen und deutschen Recht, Bonn 1972

Haften Eltern für ihre Kinder ? Zur Haftung von Aufsichtspersonen Minderjähriger, Reihe Rechtswissenschaft Bd. 38, Pfaffenweiler 1987

Kindesmißhandlung und strafrechtliche Sozialkontrolle, in: ZfJ 1981, S. 4 ff.

Kinder in Sekten- zivil- und strafrechtliche Aspekte, in: Strafrecht als Herausforderung, Festschrift für Niklaus Schmid, Hrsg. JürgBeat Ackermann, Zürich 1999

Amtlicher Entwurf eines Allgemeinen Deutschen Strafgesetzbuchs nebst Begründung, Berlin 1925

Studien zur Problematik der unechten Unterlassungsdelikte, München/ Berlin 1963

Zur Garantenstellung beim unechten Unterlassungsdelikt

(1. Teil), in: JA 1980, S. 553 ff.

(2. Teil), in: JA 1980, S. 647 ff.

(2. Teil, 2. Hälfte) in: JA 1980, S. 712 ff.

Zur Struktur der Garantieverhältnisse bei den unechten Unterlassungsdelikten, Berlin 1968, S. 17 ff., 166 ff. 
Baumann Jürgen/

Weber, Ulrich

Baumann/ Weber/ Mitsch

Becker, W.

Beitzke, Günther

Benfer, Jost

Behrendt, Hans-Joachim

Blau, Bruno

Blei, Hermann

derselbe

Bockelmann, Paul/

Volk, Klaus

Böhm, Alexander

Börker, Rudolf
Strafgesetzbuch Allgemeiner Teil, 9. Auflage, Bielefeld 1985

Strafrecht, Allgemeiner Teil, 10. Auflage, Bielefeld 1995

Erziehungspflicht und Strafrecht, in: NJW 1952, S. 1082 f.

Nochmals zur Reform des elterlichen Sorgerechts, FamRZ 1979, S. $8 \mathrm{ff}$.

Rechtseingriff von Polizei und Staatsanwaltschaft, 2. Auflage, München 2001

Die Unterlassung im Strafrecht, Baden-Baden 1979

Die Kriminalität in Deutschland während des zweiten Weltkriegs, in: ZStW 1952, Bd. 64, S. 31 ff.

Strafrecht, Bd. 1, Allgemeiner Teil, 18. Auflage, München 1983

Garantenpflichtbegründung beim unechten Unterlassen, in: Festschrift für Hellmuth Mayer, Hrsg. Friedrich Geerds, Wolfgang Naucke, Berlin 1966, S. 119 ff.

Strafrecht Allgemeiner Teil, 4. Auflage, München 1987

Korreferat zu Kaufmann, Methodische Probleme der Gleichstellung des Unterlassens mit der Begehung, in: JuS 1961, S. $177 \mathrm{ff}$.

Der Irrtum des Unterlassungstäters über die Rechtspflicht zum Handeln, in: JR 1956, S. 87 ff. 
Boscher, Walter

Brammsen, Joerg

Brammsen, Joerg/

Otto, Harro

Brückner, Carsten

Brunner, Rudolf/

Dölling, Dieter

Busch, Manfred

Busch, Richard

Busse, Klaus-Henning

Bussmann, Kai-Detlef

Dahlgrün, Waltraut-Barbara
Haftung Minderjähriger und ihrer aufsichtspflichtigen Eltern, Eine Übersicht über die Rechtsprechung, in: VersR 1964, S. 888 ff.

Die Entstehungsvoraussetzungen der Garantenpflichten, Schriften zum Strafrecht Bd. 65, Berlin 1984

Die Grundlagen der strafrechtlichen Haftung des Garanten wegen Unterlassens

(I), in: Jura 1985, S. 530 ff.

(II), in: Jura 1985, S. 592 ff.

(Schluß), in: Jura 1985, S. 646 ff.

Das Angehörigenverhältnis im Straf- und Strafprozeßrecht, Europäische Hochschulschriften Bd.2741, Frankfurt am Main 2000

Jugendgerichtsgesetz, 10. Auflage, Berlin/ New York 1996

Aufsichtspflicht und Haftung in der Jugendhilfe, in: ZfJ 1996, S. $456 \mathrm{ff}$.

Zur gesetzlichen Begründung der Strafbarkeit unechten Unterlassens, in: Festschrift für Hellmut von Weber, Hrgs. Hans Welzel, Hermann Conrad, Armin Kaufmann, Hilde Kaufmann, Bonn 1963, S. 192 ff.

Täterschaft und Teilnahme bei Unterlassungsdelikten, Göttingen 1974

Verbot familialer Gewalt gegen Kinder, Köln 2000

Die Aufsichtspflicht der Eltern nach $\S 832$ BGB: Entwicklung und Probleme, München 1980 
Dalke, Albert

Diederichsen, Uwe

Eggert, Karl Heinz

Eisenberg, Ulrich

Engelsing, Herbert W.

Engisch, Karl

Feltes, Thomas

Forster, Peter

Franke-Gricksch, Sibylle

Frehsee, Detlev

Frehsee, Detlev
Strafrecht und Strafverfahren, 37. Auflage, Berlin 1961

Das Mehmet-Menetekel, in: NJW 1998, S. 3471 ff.

Die Zumutbarkeit normgemäßen Verhaltens bei den Fahrlässigkeits- und unechten Unterlassungsdelikten im Strafrecht, Göttingen 1969

Jugendgerichtsgesetz, 8. Auflage, München 2000

Eigenhändige Delikte, Strafrechtliche Abhandlungen, Heft 212, Breslau 1926

Literaturbesprechung von Armin Kaufmann, Die Dogmatik der Unterlassungsdelikte, in: JZ 1962, S. 189 ff.

Jugendrecht im Konflikt zwischen Norm und Erziehung, München/ Wien 1978

Die Zumutbarkeit des Handelns bei Gefahr von Strafverfolgung, Erlangen 1971

Sinn und Bedeutung des $§ 170 \mathrm{~d}$ StGB (Kindesvernachlässigung) im geltenden und künftigen Strafrecht, mit Ausblicken auf das österreichische und schweizerische Recht, Köln 1970

„Strafverfolgung“ von strafunmündigen Kindern, in: ZStW 100 (1988), S. $290 \mathrm{ff}$.

Fehlfunktionen des Strafrechts und der Verfall rechtsstaatlichen Freiheitsschutzes, in: Konstruktion der Wirklichkeit durch Kriminalität und Strafe, Hrsg. Detlev Frehsee, Gabi Löscher, Gerlinda Smaus, Baden-Baden 1997 
Freund, Georg

Frey, Dieter

Frisch, Wolfgang

Fuchs, Albrecht

Fünfsinn, Helmut

Gallas, Wilhelm

Gallas, Wilhelm

Garbers, Nikolaus

Geilen, Gerd

derselbe

Georgakis, Jannis

Glaue, Olga
Erfolgsdelikt und Unterlassen. $\mathrm{Zu}$ den Legitimationsbedingungen von Schuldspruch und Strafe, Köln 1992

Die Zumutbarkeit im Strafrecht, Saarbrücken 1961

Tatbestandsmäßiges Verhalten und Zurechnung des Erfolges, Heidelberg 1988

Studien zur elterlichen Aufsichtspflicht, Bielefeld 1995

Der Aufbau des fahrlässigen Verletzungsdelikts durch Unterlassen im Strafrecht, Frankfurt am Main 1985

Strafbares Unterlassen im Fall einer Selbsttötung, in: JZ 1960, S. $686 \mathrm{ff}$.

Die strafrechtliche Verantwortlichkeit der am Bau Beteiligten, Heidelberg 1963

Täterschaft und Teilnahme in der Erscheinungsform des Unterlassens, Hamburg 1963

Unterlassene Verbrechensanzeige und ernsthafte Abwendungsbemühung- BGHSt 19, 295, in: JuS 1965, S. 426 ff.

Stillschweigen des Angehörigen beim Mordkomplott, in: FamRZ 1964, S. 385 ff.

Hilfspflicht und Erfolgsabwendungspflicht im Strafrecht, Leipzig 1938

Schutz der Jugend in der Öffentlichkeit, Gütersloh 1958 (Wegweiser für die Jugendhilfe, Heft 6) 
dieselbe

dieselbe

Glogauer, Werner

Göhler, Erich

Göppinger, Hans

Gössel, Karl Heinz

Götz, Volkmar

Gropp, Walter

Grünwald, Gerald

derselbe

derselbe

Haas, Volker

Haft, Fritjof
Die Sicherstellung der Erziehung durch Eltern und Staat, Gütersloh 1959 (Wegweiser für die Jugendhilfe Heft 10)

Jugendliche Rechtsbrecher, 2. Auflage ， Gütersloh 1959 (Wegweiser für die Jugendhilfe Heft 14)

Kriminalisierung von Kindern und Jugendlichen durch Medien, 2. Auflage, Baden-Baden 1991

Zur strafrechtlichen Verantwortlichkeit des Betriebsinhabers, in: Hrsg. Hans-Heinrich Jescheck, Hans Lüttger, Festschrift für Eduard Dreher, Berlin/ New York 1977, S. 611 ff.

Kriminologie, 5. Auflage, München 1997

Zur Lehre vom Unterlassungsdelikt, in: ZStW Bd. 96 (1984), S. $319 \mathrm{ff}$.

Allgemeines Polizei- und Ordnungsrecht, 12. Auflage, Göttingen 1995

Strafrecht, Allgemeiner Teil, 2. Auflage, Berlin/ Heidelberg 2001

Der Vorsatz des Unterlassungsdelikts, in: Festschrift für Hellmuth Mayer, Hrsg. Friedrich Geerds, Wolfgang Naucke, Berlin 1966

Die Beteiligung durch Unterlassen, in: GA 1959, S. 110 ff.

Das unechte Unterlassungsdelikt, Göttingen 1957

Jugendkriminalität in Deutschland, in: Die Polizei 1998, S. 165 ff.

Strafrecht, Allgemeiner Teil, 7. Auflage, München 1996 
Hanack, Ernst-Walter

Hardwig, Werner

Hellmer, Joachim

Henkel, Heinrich

derselbe

Herzberg, Rolf Dietrich

derselbe

Hillenkamp, Thomas

Horn, Eckhard

Höynck, Theresia/ Sonnen, Jugendstrafrecht als Spielball im Prozeß politischer Bernd-Rüdeger

Hruschka, Joachim

Hsü, Yü-hsiu
Die Reform des Sexualstrafrechts und der Familiendelikte, in: NJW 1974, S. 1 ff.

Über den Begriff der Täterschaft, in: JZ 1965, S. 667 ff.

Hangtäterschaft und Berufsverbrechertum, in: ZStW 73, 441

Zumutbarkeit und Unzumutbarkeit als regulatives Rechtsprinzip, in: Festschrift für Edmund Mezger, Hrsg. Karl Engisch/ Reinhart Maurach, München/ Berlin 1954

Das Methodenproblem bei den unechten Unterlassungsdelikten,

Die Unterlassung im Strafrecht und das Garantenprinzip, Berlin 1972

Die Kausalität beim unechten Unerlassungsdelikt, in: MDR 1971, S. $881 \mathrm{ff}$.

Vorsatztat und Opferverhalten, Göttingen 1981

Konkrete Gefährdungsdelikte, Köln 1973 in: MschrKrim 1961, Bd. 44, S. 178 ff.
Meinungsbildung, in: ZRP 2001, S. 245 ff.

Über Tun und Unterlassen und über Fahrlässigkeit, in: Festschrift für Paul Bockelmann, Hrsg. Arthur Kaufmann, Klaus Volk, München 1979, S. 421 ff.

Garantenstellung des Betriebsinhabers zur Verhinderung strafbarer Handlungen seiner Angestellten ?, Pfaffenweiler 1986 
Immel, Burkhard

Die Notwendigkeit eines Sondertatbestands im Umweltstrafrecht, in: ZRP 1989, S. 105 ff.

Immenga, Ulrich

Aufsichtsverletzung und Gleichberechtigung, in: FamRZ 1969, S. $313 \mathrm{ff}$.

Jähnke, Burkhard/ Laufhütte, Leipziger Kommentar, 11. Auflage, 8. Lieferung, Bd. $1 \S \S 1-55$, Heinrich Wilhelm/ Odersky, Berlin/ New York 1993

Walter (Hrsg.)

Jakobs, Günther

Strafrecht Allgemeiner Teil, 2. Auflage, Berlin/ New York 1991

Jayme, Erik

Die Familie im Recht der unerlaubten Handlungen, Frankfurt am Main/ Berlin 1971

Jarass, Hans D./

Grundgesetz für die Bundesrepublik Deutschland, 3. Auflage,

Pieroth, Bodo München 1995

Jescheck, Hans-Heinrich/

Die Behandlung der unechten Unterlassungsdelikte im deutschen

Goldmann, Heinz Gerd und ausländischen Strafrecht, in: ZStW 1965, Bd. 77, S. 109 ff.

Jescheck, Hans-Heinrich/

Lehrbuch des Strafrechts, Allgemeiner Teil, 5. Auflage, Berlin

Weigend, Thomas 1996

Kaltofen, Jürgen

Der tatbestandsmäßige Aufbau der Verletzung der Aufsichtspflicht, Mainz 1965

Jobst, Heinz

Der Streit um die Zumutbarkeit im Strafrecht, Würzburg 1934

Kaufmann, Armin

Die Dogmatik der Unterlassungsdelikte, Göttingen 1959

derselbe

Methodische Probleme der Gleichstellung des Unterlassens mit der Begehung, in: JuS 1961, S. 173 ff.

Kielwein, G.

Unterlassung und Teilnahme, in: GA 1955, S. 225 ff. 
Kienapfel, Diethelm

Kintzi, Heinrich

Kinzig, Jörg

Korth, Manfred

Krug, Heinz

Lackner, Karl/ Kühl, Kristian
Klimmek, Ulrich

Der Praktische Fall. Strafrecht: Der Skiunfall, in: JuS 1966, S. $286 \mathrm{ff}$.

Kinder als Tatverdächtige, in: DriZ 1997, S. 32 ff.

Der Hang zu erheblichen Straftaten - und was sich dahinter verbirgt, in: NStZ 1998, S. 14 ff.

Verletzung der Sorgepflicht gegenüber Kindern und Jugendlichen, Frankfurt am Main 1970

Vertrauen ist gut, Kontrolle ist besser- Jugendgerichtshilfe und Vertrauenskredit, in: ZfJ 1996, S. 311 ff.

Gesetz über die Jugendwohlfahrt, Kommentar, München 1963

Strafgesetzbuch mit Erläuterungen, 23. Auflage, München 1999

Landsberg, J. F./ Reicher, Die Probleme des Jugendschutzes und die moderne Gesetzgebung, Heinrich Lennep 1911

Landscheidt, Christoph Zur Problematik der Garantenpflichten aus verantwortlicher Stellung in bestimmten Räumlichkeiten, Berlin 1985

Lazarus, Horst

Subjektive Familienstruktur und Jugendkriminalität, Rheinstetten 1976

Lemberger, Friedrich

Die kriminologische Wirklichkeit des Begriffs des gefährlichen Gewohnheitsverbrechers, München 1962

Lenckner, Theodor

Wertausfüllungsbedürftige Begriffe im Strafrecht und der Satz „,nulla poena sine lege“, in: JuS 1968, S. 304 ff. 
Lenckner, Thomas/ Cramer, Schönke/ Schröder, Strafgesetzbuch, 26. Aufl., München 2001

Peter/ Eser, Albin/ Stree,

Walter

Lilie, Hans

Garantenstellungen für nahestehende Personen, in: JZ 1991, S. $541 \mathrm{ff}$.

Loos, Fritz/

Rechtszeitige Anzeige und Rücktritt bei $\S 138$ Abs. 1 StGB, in:

Westendorf, Ritva Jura 1998, S. 403 ff.

Luther, Gerhard

Zur Problematik des $§ 170$ d StGB, in: NJW 1954, S. 493 ff.

Maiwald, Manfred

Der Begriff der Leichtfertigkeit als Merkmal erfolgsqualifizierter Delikte, GA 1974, S. 255 ff.

derselbe

Grundlagenprobleme der Unterlassungsdelikte, in: JuS 1981, S. $473 \mathrm{ff}$.

derselbe

Die Unzumutbarkeit- Strafbarkeitsbegrenzendes Prinzip bei den Fahrlässigkeitsdelikten?, in: Festschrift für Horst SchülerSpringorum, Hrsg. Peter-Alexis Albrecht, Köln 1993, S. 475 ff.

Marxen, Klaus

Rechtliche Grenzen der Amnestie, Beiträge zu neueren Entwicklungen in der Strafrechtswissenschaft, Bd. 13, Heidelberg 1984

Maunz, Theodor/ Duerig, Grundgesetz, Kommentar, Bd. 1, München 1958

Gunter/ Herdegen, Matthias/

Herzog, Roman

Maurach, Reinhart/

Zipf, Heinz

dieselben
Strafrecht Allgemeiner Teil, Teilband 1, 8. Auflage, Heidelberg 1992

Strafrecht Allgemeiner Teil, Teilband 2, 7. Auflage, Heidelberg 1989 
Maurach, Reinhart/

Schroeder, Friedrich

Christian/

Maiwald, Manfred

dieselben

Meyer-Bahlburg, Hartwig

Mayer, Hellmuth

Meister, Hans-Georg

Metzen, Peter Matthias

Moritz, Heinz Peter

Mrozynski, Peter
Strafrecht, Besonderer Teil, Teilband 1, 8. Auflage, Heidelberg 1995

Strafrecht, Besonderer Teil, Teilband 2, 7. Auflage, Heidelberg 1999

Beitrag zur Erörterung der Unterlassungsdelikte. Um echte und unechte Unterlassungsdelikte, Hamburg 1962

Strafrechtsreform für heute und morgen, Berlin 1962

Echtes und unechtes Unterlassungsdelikt, in: MDR 1953, S. 649ff.

Die Problematik und Funktion der fakultativen Strafmilderung für die Begehung durch Unterlassen, Köln 1977

Die wichtigsten Neuregelungen im Kindschaftsrecht, in: JA 1998, S. $704 \mathrm{ff}$.

Krankheit- Hang- schädliche Neigungen, in: MschKrim 1985, S. $1 \mathrm{ff}$.

Münch, Ingo von/ Philip Grundgesetz-Kommentar, Bd. 1, Präambel- Art. 20, 4. Auflage, Kunig München 1992

Neese, Gottfried Leitsätze für ein deutsches Jugendrecht, Stuttgart/ Berlin 1938

Nagler, Johannes Verbrechensprophylaxe und Strafrecht, Leipzig 1911

derselbe

Die Verletzung der Pflicht zur Fürsorge für Jugendliche, in: GS 116 (1942), S. 1 ff. 
Neubacher, Frank

Neuhaus, Heike

Neuheuser, Stephan
Kinderdelinquenz, in: ZRP 1998, S. 121 ff.

Das Recht der Jugendhilfe, in: Jura 1990, S. 624 ff.

Die Strafbarkeit von Eltern minderjähriger Mehrfachstraftäter wegen Verletzung der Fürsorge- und Aufsichtspflicht ( $\$ 171$ StGB), in: NStZ 2000, S. 174 ff.

Neumann, Ulfried/ Albrecht, Nomos Kommentar zum Strafgesetzbuch, Baden-Baden, Hans-Jörg (Redaktion) 3. Ergänzungslieferung, Februar 1996

Niethammer, Emil Strafbares Unterlassen, in: ZStW Bd. 57, 1938, S. 28 ff.

Nitze, Paul

Die Bedeutung der Entsprechensklausel beim Begehen durch Unterlassen (§ 13 StGB), Berlin 1989

Ostendorf, Heribert

Die strafrechtliche Inpflichtnahme von Eltern wegen Verletzung der Fürsorge- und Erziehungspflicht, Baden-Baden 1999

Otto, Harro

Mittäterschaft beim Fahrlässigkeitsdelikt, in: Jura 1990, S. 47 ff.

Derselbe

Täterschaft, Mittäterschaft, mittelbares Täterschaft, in: Jura 1987, S. $246 \mathrm{ff}$.

Derselbe Grundkurs Strafrecht, 4. Auflage, Berlin/ New York 1992

Derselbe Buchbesprechung zu Wolfgang Schöne, Unterlassene Erfolgsabwendungen und Strafgesetz, in: MschrKrim 1975, Bd. 58, S. 129 f.

Otto, Harro

Buchbesprechung zu Bernd Schünemann, Grund und Grenzen der unechten Unterlassungsdelikte, und zu Rolf-Dietrich Herzberg, Die Unterlassung im Strafrecht und das Garantenprinzip, in: MschrKrim 1974, Bd. 57, S. 123 ff. 
Derselbe

Derselbe

Palandt

Pauli, H. A.

Peters, Hans Bettermann, Hans Carl Nipperdey, Ulrich Scheuner, Berlin 1960

Polizeiliche Kriminalstatistik Die Kriminalität in der Bundesrepublik Deutschland, Polizeiliche 1997 Kriminalstatistik 1997, Hrgs.: Presse- und Informationsamt der Bundesregierung, Bonn 1998

Polizeiliche Kriminalstatistik Die Kriminalität in der Bundesrepublik Deutschland, Polizeiliche 2000 Kriminalstatistik 2000, Hrsg.: Bundesinnenministerium, Berlin 2001

Popitz, Heinrich

Phänomene der Macht, Tübingen 1986

Preisendanz, Holger

Strafgesetzbuch, Lehrkommentar, 30. Auflage, Berlin 1978

Puppe, Ingeborg

Die strafrechtliche Verantwortlichkeit für Irrtümer bei der Ausübung der Notwehr und für deren Folgen, in: JZ 1989, S. $728 \mathrm{ff}$.

Ranft, Otfried Garantiepflichtiges Unterlassen der Deliktshinderung, in: ZStW Bd. 94 (1982), S. 815 ff. 
derselbe

derselbe

Rebmann, Kurt (Redaktion)

Renzikowski, Joachim

Robbers, Gerhard

Gogall, Klaus

Reimann, Werner

Röwer, Heinz-Hugo

Roxin, Claus

derselbe

derselbe

Derselbe
Das garantiepflichtige Unterlassen der Taterschwerung, in: ZStW Bd. 97 (1985), S. 268 ff.

Rechtsprechungsübersicht zu den Unterlassungsdelikten, Teil 2, in: JZ 1987, S. 908 ff

Münchner Kommentar zum BGB, Bd. 8, Familienrecht II, §§ 1589-1921, KJHG, 3. Auflage, München 1992

Restriktiver Täterbegriff und fahrlässige Beteiligung, Siebeck 1997

Strafpflichten aus der Verfassung, in: Aufgeklärte Kriminalpolitik oder Kampf gegen das Böse ?, Bd. I: Legitimationen, Hrsg. Klaus Lüderssen, Baden-Baden 1998

Dogmatische und kriminalpolitische Probleme der Aufsichtspflichtverletzung in Betrieben und Unternehmen (§ 130 OWiG), in: ZStW 98 (1986), S. 573 ff.

Inwieweit muß sich ein Kind im Schadensersatzprozeß die Versäumung der Aufsichtspflicht durch seine Eltern anrechnen lassen ?, Jena 1937

Die Zumutbarkeit als spezielles täterschaftliches Merkmal beim Handeln durch Unterlassung, in: NJW 1958, S. 1528 f.

Täterschaft und Teilnahme, 7. Auflage, Berlin/ New York 2000

Strafrecht Allgemeiner Teil, Bd. 1, 3. Auflage München 1997

Zur Kritik der finalen Handlungslehre, in: ZStW 1974, S. 515 ff.

Unterlassung, Vorsatz und Fahrlässigkeit, Versuch und Teilnahme im neuen Strafgesetzbuch, in: JuS 1973, S. 197 ff. 
Rudolphi, Hans-Joachim

Derselbe

Derselbe

Rudolphi, Hans-Joachim/

Horn, Eckhard/

Samson, Erich/

Günther, Hans-Ludwig

Dieselben

Sangenstedt, Christof

Schaffstein, Friedrich

Schmidhäuser, Eberhard

Schmidt, Richard
Die Gleichstellungsproblematik der unechten Unterlassungsdelikte und der Gedanke der Ingerenz, Göttingen 1966

Probleme der strafrechtlichen Verantwortlichkeit von Amtsträgern für Gewässerverunreinigungen, in: Festschrift für Hanns Dünnebier, Hrsg. Ernst-Walter Hanack, Peter Rieß, Günther Wendisch, Berlin/ New York 1982, S. 561 ff.

Häusliche Gemeinschaften als Entstehungsgrund für Garantenstellungen ?, in: NStZ 1984, S. 149 ff.

Systematischer Kommentar zum Strafgesetzbuch, Allgemeiner Teil, Bd. 1, § 1-79 b, 7. Auflage, 35. Lieferung, Neuwied/ Kriftel/ Berlin, Januar 2001

Systematischer Kommentar zum Strafgesetzbuch, Besonderer Teil, Bd. 2, $\S \S 80-358,5$. bzw. 6. Auflage, 41. Lieferung, Neuwied/ Kriftel/ Berlin, November 1997

Garantentenstellung und Garantenpflicht von Amtsträgern, Frankfurt am Main (Berlin/ New York) 1989

Die unechten Unterlassungsdelikte im System des neuen Strafrechts, in: Gegenwartsfragen der Strafrechtswissenschaft, Festschrift für Wenzeslaus Gleispach, Hrsg. Georg Dahm, Wilhelm Gallas, Leipzig 1936, S. 70 ff.

Strafrecht, Allgemeiner Teil, 2. Auflage, Tübingen 1975

Verbrechen an dem Seelenleben des Menschen, in: GS 42 (1889), S. $57 \mathrm{ff}$. 
Schmidt-Bleibtreu, Bruno/

Klein, Franz

Schmitt, Rudolf

Schmitt Glaeser, Walter

Schneider, Gert

Schneider, Hans Joachim

Schneider, Maria Cecilia

Schneider, Ursula

Schöne, Wolfgang

Schönke, Adolf/

Schröder, Horst

Dieselben
Kommentar zum Grundgesetz, 8. Auflage, Neuwied 1995

Zur Systematik des Unterlassungsdelikts, in: JZ 1959, S. 432 ff.

Das elterliche Erziehungsrecht in staatlicher Reglementierung, Bielefeld 1980 (zitiert: Schmitt Glaeser, Erziehungsrecht)

Die Verletzung der Fürsorge- und Aufsichtspflichten über Kinder und Jugendliche im anglo-amerikanischen und deutschen Zivilund Strafrecht unter Berücksichtigung des deutschen Strafgesetzbuchentwurfs 1962, Hamburg 1967

Kriminalpolitik an der Schwelle zum 21. Jahrhundert, Schriftenreihe der Juristischen Gesellschaft zu Berlin, Heft 155, Berlin, New York 1998

Geisteskrankheit und Gefährlichkeit, Strafrechtliche Behandlung von Gefährlichkeit im Fall nicht bejahter Verantwortlichkeit, Aachen 1998

Körperliche Gewaltanwendung in der Familie, Berlin 1987

Unterlassungsbegriff und Fahrlässigkeit, in: JZ 1977, S. 150 ff.

Strafgesetzbuch, 7. Auflage, München/ Berlin 1954

Strafgesetzbuch, 17. Auflage, München 1974

Schröder, Horst

Die Addition strafloser Handlungen zu einer Straftat, in: JZ 72, S. 651 
Schulte, Christoph

Schultz, Michael

Derselbe

Schünemann, Bernd

Derselbe

Schwab, Dieter

Schwarz, Joachim

Schwarz, Otto/ Dreher, Eduard Strafgesetzbuch, 33. Auflage, München 1972

Schwoerer, Julius

Seelmann, Kurt

Derselbe

Seibert, Claus

Seier, Jürgen
Garantenstellung und Solidarpflicht, Frankfurt am Main 2001

Aufhebung von Garantenstellungen und Beteiligung durch Unterlassen- BGH, NJW 1984, 2639, in: JuS 1985, S. 270 ff.

Amtswalterunterlassen, Strafrechtliche Abhandlungen, Neue Folge, Bd. 52, Berlin 1984

Grund und Grenzen der unechten Unterlassungsdelikte, Göttingen 1971

Die Unterlassungsdelikte und die strafrechtliche Verantwortlichkeit für Unterlassungen, in: ZStW Bd. 96, 1984, S. $287 \mathrm{ff}$.

Familienrecht, 8. Auflage, München 1995

Die unterlassene Verbrechensanzeige, Göttingen 1966
Zur Bedeutung des in Art. 6 GG den Eltern garantierten Grundrechts für Entscheidungen aus den $\S \S 1634,1671,1672$, 1696 BGB, in: FamRZ 1969, S. 367 ff.

Alternativkommentar zum Strafrecht, Bd. 1, $\S \S 1-21$, Neuwied 1990

Opferinteressen und Handlungsverantwortung in der Garantenpflichtdogmatik, in: GA 1989, S. 241 ff.

Schädliche Neigungen, in: MDR 1962, S. 171 ff.

Der Einheitstäter im Strafrecht und im Gesetz über Ordnungswidrigkeiten (Teil 2), in: JA 1990, S. 382 ff. 
Sowada, Christoph

Spendel, Günter

J. von Staudinger

Stoffers, Kristian F.

Stoffers, Manfred

Stratenwerth, Günter

Stree, Walter Dombois, Hans
Stree, Walter

Täterschaft und Teilnahme beim Unterlassungsdelikt, in: Jura 1986, S. 399 ff.

Zur Dogmatik der unechten Unterlassungsdelikte, in: JZ 1973,

S. $137 \mathrm{ff}$.

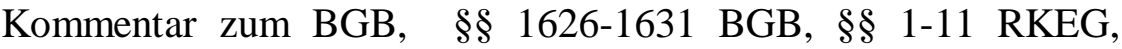
$\S \S 1631 \mathrm{a}-1665$ BGB, 12. Auflage, 1997 Berlin

Stein, Erwin/ Joest, Wilfried/ Elternrecht: Studien $\mathrm{zu}$ einer rechtsphilosophischen und evangelisch-theologischen Grundlegung, Heidelberg 1958

Die Begehung schlichter Tätigkeitsdelikte durch Unterlassen, de lege lata et ferenda, in: MDR 1971, S. $260 \mathrm{ff}$.

Streitige Fragen der psychischen Beihilfe im Strafrecht, Jura 1993, S. $11 \mathrm{ff}$.

Social Marketing als Methode der Kriminalprävention, in: HansDieter Schwind, Friedhelm Berckhauer, Gernot Steinhilper, Beiträge zur ressortübergreifenden Kriminalprävention aus Forschung, Praxis und Politik, Heidelberg 1980, S. $421 \mathrm{ff}$.

Strafrecht, Allgemeiner Teil I, 3. Auflage, Köln 1981

Probleme der Hehlerei und der Vernachlässigung der Aufsichtspflicht (zu: OLG Neustadt, NJW 1962, 2312), in: JuS 1963, S. 427 ff.

Garantenstellung kraft Übernahme, in: Festschrift für Hellmut Mayer, Hrsg. Friedrich Geerds/ Wolfgang Naucke, Berlin 1966, S. 146 
Struensee, Eberhard

Die Struktur der fahrlässigen Unterlassungsdelikte, in: JZ 1977, S. $217 \mathrm{ff}$.

Sturm, Richard

Das Vierte Gesetz zur Reform des Strafrechts, in: JZ 1974, S. 1 ff.

Stutte, H./ Dauner, I.

Brandstiftungen Strafunmündiger, in: MschrKrim 61 (1978), S. $328 \mathrm{ff}$.

Teckhoff, Jörg

Garantenstellung des Wohnungsinhabers bei Angriffen auf einen Gast, in: JuS 78, S. 308 ff.

Tröndle, Herbert

Strafgesetzbuch und Nebengesetze, Kommentar, 48. Auflage, München 1997

Tröndle, Herbert/ Fischer, Strafgesetzbuch und Nebengesetze, Kommentar, 50. Auflage, Thomas München 2001

Vogel, Joachim Norm und Pflicht bei den unechten Unterlassungsdelikten, Strafrechtliche Abhandlungen, Neue Folge, Bd. 83, Berlin 1993

Äußerungen zum Vorentwurf Zusammenstellung der gutachterlichen Äußerungen über den 1911 Vorentwurf zu einem Deutschen Strafgesetzbuch, Berlin 1911 (zitiert: Äußerungen zum VE 1911)

Wassermann, Rudolf

Alternativkommentar zum Strafvollzugsgesetz,

3. Auflage, Neuwied 1990

Wehrle, Stefan Fahrlässige Beteiligung am Vorsatzdelikt- Regressverbot ? Basler Studien zur Rechtswissenschaft, Reihe C: Strafrecht, Bd. 5, Basel/ Frankfurt am Main 1986

Weichert, Thilo Sicherungsverwahrung- verfassungsgemäß ?, in: StV 1989, S. $265 \mathrm{ff}$. 
Welp, Jürgen

Welzel, Hans

derselbe

Wessels, Johannes/

Beulke, Werner

Westendorf, Ritva

Reinhard Wiesner/

Thomas Mörsberger/

Helga Oberloskamp/

Jutta Struck

Wingen, Max

Wintterlin, Kurt

Wolff, Ernst Amadeus

Wollweber, Horst
Vorangegangenes Tun als Grundlage einer Handlungsäquivalenz der Unterlassung, Berlin 1968

Das Deutsche Strafrecht, 10. Auflage, Berlin 1967

11. Aufl., Berlin 1969

Zur Problematik der Unterlassungsdelikte, in: JZ 1958, S. 494 ff.

Strafrecht, Allgemeiner Teil, 30. Auflage, Heidelberg 2000

Die Pflicht zur Verhinderung von Straftaten durch Anzeige, Frankfurt am Main 1999

SGB VIII, Kinder- und Jugendhilfe, Kommentar, 2. Auflage, München 1990

Familienpolitik, Grundlagen und aktuelle Probleme, Stuttgart 1997

Das Züchtigungsrecht Erwachsener gegenüber jugendlicher Ungebühr, Tübingen 1933

Kausalität von Tun und Unterlassen, Heidelberg 1965

Kinderdelinquenz und Jugendkriminalität als pädagogisches/ sozialpädagogisches Problem, in: Kinderdelinquenz und Jugendkriminalität, Hrsg. Horst Wollweber, Paderborn/ München/ Zürich/ Wien 1980 


\section{Teil. Einführung}

A. Einleitung und Fragestellung

Kinder- und Jugendkriminalität ist seit Jahrzehnten Gegenstand vieler Untersuchungen. Es wurde und wird kontrovers diskutiert, wie die jungen Täter zu behandeln seien. Auch wenn die Ursachen für kriminelles Verhalten von Kindern und Jugendlichen oft im Elternhaus angesiedelt werden ${ }^{1}$, fehlt bislang jedoch der nächste Schritt, und zwar die Untersuchung darüber, wie mit den Eltern eines kriminellen Nachwuchses umzugehen ist. Viel zu wenig wird berücksichtigt, daß das Dilemma sehr oft bei den Eltern beginnt. Soweit Überlegungen im Hinblick auf eine wirkungsvollere Erziehung und Sozialisation durch die Eltern angestellt werden, bleiben strafrechtliche Erwägungen regelmäßig außer Betracht. Es wird fast nie angedacht, ob auch für die Eltern eine Strafbarkeit besteht oder bestehen sollte, wenn sie Straftaten ihrer Kindern dulden. Diese Lücke soll mit der vorliegenden Arbeit geschlossen werden.

Nicht jedes strafrechtlich relevante Verhalten von Kindern und Jugendlichen ist dabei von Bedeutung. Es gibt jedoch Taten, bei denen sich regelmäßig die Frage erhebt, ob die Eltern tatsächlich nicht davon gewußt haben oder ob sie wissentlich nicht gegen das Tun ihrer Kinder eingeschritten sind. Man denke dabei etwa an Kinder, die regelmäßig bei Ladendiebstählen oder Trickdiebstählen aufgegriffen werden oder Steine auf die Eisenbahnschienen legen ${ }^{2}$. Das gleiche gilt für solche Jugendliche, die regelmäßig in Schlägereien oder Betäubungsmitteldelikte verwickelt sind oder sich offen als Mitglieder verbotener extremistischer Vereinigungen zeigen. Nicht nur vorsätzliches Tun von Kindern und Jugendlichen ist für die elterliche Verantwortlichkeit relevant. Davon zeugen viele Unfälle im

\footnotetext{
1 Vgl. Wollweber, Kinderdelinquenz, S. 154f. m.w.N.; Lazarus, Subjektive Familienstruktur, S. 20; Ursula Schneider, Gewaltanwendung in der Familie, S. $43 f f ., 113$.

${ }^{2}$ Meyer-Bahlburg, Erörterung der Unterlassungsdelikte, S. 92.
} 
Straßenverkehr, die darauf zurückzuführen sind, daß nachlässige Eltern ihre Kinder unbeaufsichtigt auf der Straße spielen lassen ${ }^{3}$.

Es mag zunächst rechtsstaatlich bedenklich klingen, Eltern wegen einer mangelhaft ausgeübten Aufsichts- und Erziehungspflicht strafrechtlich zu belangen. Das Recht der Eltern aus Art. 6 Abs. 2 GG, ihr Kind weitgehend frei von staatlicher Reglementierung zu erziehen ${ }^{4}$, beruht auf dem Grundgedanken, daß in aller Regel den Eltern das Wohl des Kindes mehr am Herzen liegt als irgendeiner anderen Person oder Institution ${ }^{5}$. Die tägliche Anschauung bietet aber genug Anlaß, gerade dies zu bezweifeln. $\mathrm{Ob}$ aus den Medien, der Fachpresse oder aus dem eigenen Erleben heraus weist die Vielzahl von Fällen darauf hin, daß Eltern oftmals nicht um das Kindeswohl bemüht sind. Das Fehlverhalten der Eltern wiegt um so schwerer, als letztlich deren Kinder - als Produkte einer mißlungenen Erziehung- ihr restliches Leben mit den Folgen einer mangelnden Sozialisation zu kämpfen haben ${ }^{6}$, die sie oft genug in die Spirale einer kriminellen Karriere führt. Bedenkt man, welches Potential dadurch verloren geht, daß Eltern ihre Kinder vernachlässigen und ihnen nicht die Erziehung angedeihen lassen, die sie verdienen, oder sie sogar sehenden Auges in die Kriminalität abdriften lassen, ist es um so angebrachter darüber nachzudenken, ob nicht zuallererst die Eltern für die Delikte ihrer Kinder zur Rechenschaft zu ziehen sind, weit mehr als die Kinder selbst ${ }^{7}$.

Ziel dieser Untersuchung ist es $\mathrm{zu}$ klären, ob und inwieweit eine Bestrafung der Eltern bei einer Straffälligkeit ihrer minderjährigen Abkömmlinge nach geltendem Recht möglich ist. Die Problematik des Themas fußt auf dem Umstand, daß Kinder gar nicht und Jugendliche nur begrenzt strafrechtlich zur Verantwortung gezogen werden können. So stellt sich die Frage, ob nicht die Eltern diese rechtliche Verantwortung zu tragen haben. Dabei soll es in dieser Arbeit nur um Eltern gehen, die die Straftaten ihrer Kinder ignorieren, dulden oder nicht unterbinden. Ein

\footnotetext{
${ }^{3}$ So schon Reimann, Versäumung der Aufsichtspflicht, S. 11.

${ }^{4}$ Vgl. Schwoerer, FamRZ 69, 367 (369) m.w.N.

5 Schwab, Familienrecht, S. 202, Rn. 385; BVerfGE 61, 358 (371); Landsberg, Jugendschutz, S. 9.

${ }^{6}$ Vgl. Haas, Die Polizei 1998, 165 (170).

${ }^{7}$ So schon Landsberg, Jugendschutz, S. 9.
} 
aktives Handeln der Eltern, etwa durch Anstiftung der Kinder bzw. mittäterschaftliches Handeln der Eltern sowie durch Begünstigung gem. $\S 257$ StGB soll hingegen nicht Thema dieser Arbeit sein.

Der Kern der Arbeit liegt auf der Untersuchung des unechten Unterlassens durch die Eltern. Hiervon abzugrenzen ist im weiteren die Vernachlässigung der Fürsorge- und Erziehungspflicht gemäß $\S 171$ StGB. Während im erstgenannten Teil die Strafbarkeit der Eltern erst aus der Unterlassungsdogmatik herzuleiten ist, steht im zweiten Teil eine mögliche Strafbarkeit der Eltern grundsätzlich fest, weil $\S 171$ das problematische Verhalten unter Maßgabe des „kriminellen Lebenswandels" bereits ausdrücklich im Tatbestand aufgeführt hat. Dabei wird auf die jeweilige Schutzrichtung der Tatbestände einzugehen sein mit der Fragestellung, welches Rechtsgut geschützt werden soll, die Rechtsgüter Dritter, die durch Straftaten des Kindes betroffen sind oder vielmehr das Kind selbst, um ihn vor einem kriminellen Lebenswandel zu bewahren.

Die gewonnenen Ergebnisse sollen schließlich darauf untersucht werden, ob die bestehende Gesetzeslage ausreicht oder ob weitere gesetzgeberische Tätigkeit auf dem Gebiet zu fordern ist.

Letztlich stehen also die Eltern, nicht ihre delinquenten Kinder oder deren Opfer, im Mittelpunkt dieser Untersuchung. Die Eltern sollen verstärkt an ihre Verpflichtungen gegenüber ihren Kindern und gegenüber der Gesellschaft erinnert und bei der Erfüllung dieser Verpflichtungen unterstützt werden. Ob dazu das Strafrecht ein Mittel ist, wird sich zeigen. 
B. Die Strafbarkeit des Aufsichtspflichtigen in der neueren Geschichte ${ }^{8}$ und der Gegenwart

Zunächst soll erörtert werden, ob und inwieweit es bereits in der neueren geschichtlichen Entwicklung Tatbestände gegeben hat, welche die aufsichtspflichtigen Personen mit Strafe bedrohten, wenn - ihrer Aufsicht unterstehende- Kinder oder Jugendliche infolge nachlässiger Beaufsichtigung strafbare Handlungen begingen?. Damit wird zugleich deutlich werden, worauf die heute geltenden Bestimmungen zurückzuführen sind.

In der geschichtlichen Entwicklung zeigten sich zwei unterschiedliche Ausrichtungen: Zum einen existierte, vor allem im Polizeirecht, eine Strafbarkeit der Aufsichtspflichtigen, die dem Schutz der Öffentlichkeit vor Straftaten Minderjähriger dienen sollte. Zum anderen entstanden Straftatbestände, die mit der Bestrafung der nachlässigen Aufsichtspflichtigen den Minderjährigen selbst schützen sollten. Während erstere Schutzrichtung lange Zeit die vorherrschende war, setzte sich der Gedanke des Schutzes des Minderjährigen erst verhältnismäßig spät durch ${ }^{10}$.

I. Straf- und Polizeirecht der deutschen Länder im 19. Jahrhundert

In den Landesrechten der deutschen Staaten zur Mitte des 19. Jahrhunderts, soweit sie eine Verantwortlichkeit für mangelnde Aufsicht oder fremde Delikte sanktionierten, dominierten solche Vorschriften, die dem Wohl der Allgemeinheit dienten und Rechtsgüter Dritter schützten. Um den Schutz des Minderjährigen ging es nur vereinzelt.

8 Zur älteren Geschichte der Deliktsverhinderungspflicht siehe Brammsen, Entstehungsvoraussetzungen, S. 33ff. und Klimmek, S. 55ff.

${ }^{9}$ Zur neueren geschichtlichen Entwicklung der zivilrechtlichen Aufsichtspflicht siehe Dahlgrün, S. 3 u. 6 ff., Fuchs, Elterliche Aufsichtspflicht, S. 77ff.; Reimann, Versäumung der Aufsichtspflicht, S. 2ff.

${ }^{10}$ Auf die Strafbarkeitsentwicklung der Kindesmißhandlung bzw. -verwahrlosung wird im hier gesteckten Rahmen jedoch nur soweit eingegangen, als sie im Zusammenhang mit der Begehung von Delikten der Minderjährigen steht, § 171 StGB; vertiefend aber Klimmek, S. 59f. 
Das Recht der deutschen Länder unterschied zwischen der direkten Strafe für den Gewalthaber, die dieser für sein eigenes Unrecht erhielt, und der Strafe, die der Gewalthaber nur anstelle des ihm untergeordneten Minderjährigen für dessen Unrecht erhielt ${ }^{11}$.

So wurde die pflichtwidrige Nichtüberwachung dann bestraft, wenn die gewaltbefohlene Person nicht vom Betteln abgehalten wurde (vgl. $\S 341$ Abs. 1 PreußStGB von 1851, Art. 89 PreußPolStGB von 1861). In diesem Fall wurde der Gewalthaber dafür verantwortlich gemacht, daß er zu einer fremden unrechtmäßigen Handlung beigetragen hatte ${ }^{12}$. Fraglich ist, ob es dabei um den Schutz der Allgemeinheit vor dem Betteln oder um den Schutz der gewaltbefohlenen Person ging. Nach Ansicht Kaltofens lag der Schwerpunkt hier bei beim Schutz des Gewaltunterworfenen, weil der Verstoß gegen die Aufsichtspflicht geahndet wurde. Um die Straftat des Bettelns als solche, die durch die mangelnde Aufsicht erst ermöglicht wurde, ging es in dieser Vorschrift nicht. Kaltofen zufolge handelte es sich daher um einen Vorgänger des jetzigen $\S 171 \mathrm{StGB}^{13}$.

Nach anderen Vorschriften mußte der Gewalthaber hilfsweise für die Folgen der fremden Tat einstehen, so bei Forst-, Jagd- und Fischereidelikten (vgl. $\S \S 10$ ff. Preuß HDG) ${ }^{14}$. In diesen Fällen mußte der Gewalthaber dann für die Geldstrafe aufkommen, wenn der Schutzbefohlene vermögenslos war. Es fand also nur eine subsidiäre Haftung des Aufsichtspflichtigen statt. Sinn der Vorschrift war unter anderem zu unterbinden, daß der Gewalthaber, anstatt die Straftat selbst $\mathrm{zu}$ begehen, einer seiner Gewalt unterstehenden Hausgenossen vorschob. So wurde bei einem Forst- oder Felddiebstahl zunächst vermutet, daß der Gewalthaber an der Begehung mitgewirkt habe oder ihre Begehung zumindest fahrlässig gefördert habe. Er konnte sich der Haftung nur entziehen, wenn er diese Schuldvermutung widerlegte ${ }^{15}$. Angesichts des

\footnotetext{
${ }^{11}$ Da die Aufsichtspflichten über die eigenen Kinder hinausging und auch minderjährige Hausangehörige miteinbezog, ist in diesem Zusammenhang treffender vom Gewalthaber anstatt von den Eltern zu sprechen.

${ }^{12}$ Vgl. Kaltofen, S. $3 f f$.

${ }^{13}$ Kaltofen, S. 5 m.w.N.

${ }^{14}$ Preußisches Gesetz, den Diebstahl an Holz und anderen Waldprodukten betreffend, von 1852.

${ }^{15}$ Kaltofen, S. $8 \mathrm{ff}$.
} 
Erfordernisses der eigenen Schuld des Aufsichtspflichtigen ist hier von einer, wenn auch subsidiären Haftung für eigenes Unrecht auszugehen ${ }^{16}$. Der Zweck dieser Regelung diente nur dem Schutz der Allgemeinheit.

Eine unmittelbare Haftbarkeit des Gewalthabers lag gem. § 12 Preuß. FDG $^{17}, \S 5$ Abs. 2 bzw. $\S 3$ Abs. 2 Preuß. FGPG ${ }^{18}$ vor, wenn eine Verurteilung des Minderjährigen nach einem Forstdiebstahl u.ä. wegen seiner Schuldunfähigkeit nicht möglich war. Diese Geldstrafenhaftung stellte im Gegensatz zur subsidiären Haftung für den Gewaltunterworfenen eine unmittelbare Strafe für den Gewalthaber dar ${ }^{19}$. Diese strafrechtliche Verantwortlichkeit sollte dazu dienen, daß der Gewalthaber seiner Aufsichtspflicht gegenüber den schuldunfähigen Hausgenossen nachkam und drohende Unrechtshandlungen verhütete. Außerdem sollte das Benutzen Schuldunfähiger als Werkzeuge zur Tatausführung verhindert werden, bei der der Gewalthaber als mittelbarer Täter im Hintergrund blieb und nicht überführt werden konnte ${ }^{20}$. Zweck dieser Vorschriften war damit der Schutz der Allgemeinheit. Damit kann man diese Vorschriften als frühe Vorläufer des späteren $§ 143$ StGB ansehen $^{21}$.

Der Schutz des Gewaltunterworfenen selbst wird das erste Mal durch das bayrische Strafgesetzbuch von 1813 im $\S 204$ erfaßt. Danach wird bestraft, wer die ihm zustehende Gewalt zur Mißhandlung oder sonst unerlaubten Zwecken mißbraucht ${ }^{22}$.

\footnotetext{
${ }^{16}$ Umstritten war die rechtliche Einordnung dieser Haftung. So wurde sie ursprünglich als zivilrechtliche gesetzliche Bürgschaft des Gewalthabers betrachtet. Es setzte sich aber bald die Ansicht durch, daß es sich um eine strafrechtliche Haftung handelte, nicht zuletzt, weil es sich nicht um eine bürgerlich-rechtliche Schuld des Hausgenossen handelte, sondern dieser aufgrund öffentlichen Rechts eine Verpflichtung zur Zahlung der Geldstrafe hatte; dargestellt bei Kaltofen, S. 11 ff.; vgl. RGSt 1, 334 (336).

${ }^{17}$ Preußisches Gesetz betreffend den Forstdiebstahl, vom 15. April 1878.

${ }^{18}$ Preußisches Feld- und Forstpolizeigesetz vom 1. April 1880.

${ }^{19}$ Kaltofen, S. 17.

${ }^{20}$ Kaltofen, S. 18.

${ }^{21}$ Siehe unten III.

${ }^{22}$ Klimmek, S. $58 f$.
} 
II. RStGB für das Deutsche Reich

1. Erste Fassung vom 15. Mai 1871

Das RStGB enthielt in seiner ersten Fassung keinen allgemeinen Tatbestand, der das Nichthindern von Straftaten von Aufsichtsbefohlenen unter Strafe stellte ${ }^{23}$. Statt dessen gab es nur den, wörtlich aus dem PrStGB (§ 341) übernommenen $\S 361$ Ziff. 4, 3. Alt. RStGB ${ }^{24}$. Danach war der Gewalthaber zu bestrafen, der es unterließ, ihm anbefohlene Personen am Betteln zu hindern:

\section{$\$ 361$ Ziff. 4, 3. Alt. RStGB}

„Wer bettelt oder Kinder zum Betteln anleitet oder ausschickt, oder Personen, welche seiner Gewalt und Aufsicht untergeben sind und zu seiner Hausgenossenschaft gehören, vom Betteln abzuhalten unterlässt, wird mit Gefängniß bis zu sechs Wochen bestraft.“

Dadurch wurde eine schuldhafte Pflichtverletzung bestraft, die zum Erfolg (Betteln) führte. Subjektive Voraussetzung war, daß der Gewalthaber das Betteln entweder vorausgesehen hatte oder er schuldhaft-fahrlässig nicht bedacht hatte, daß dies durch mangelnde Überwachung geschehen könnte ${ }^{25}$. Obwohl nicht ausdrücklich auch das fahrlässige Unterlassen unter Strafe gestellt war, setzte $§ 361$ Z. 4, Alt. 3 nach herrschender Ansicht keine Kenntnisse des Gewalthabers vom Betteln des seiner Gewalt unterworfenen Hausgenossen voraus und war damit auch fahrlässig zu verwirklichen ${ }^{26}$. Überdies gab es für $\S 361 \mathrm{ff}$. StGB a. F. keine dem $\S 15$ des heutigen StGB ähnliche Regelung, die

\footnotetext{
${ }^{23}$ Kaltofen, S. 23.

${ }^{24}$ Kaltofen, S. 3, 21; Schneider, S. 15.

${ }^{25}$ Es wurde jedoch hinsichtlich des Vorsatzes eine Unterscheidung zwischen dem aktiven Ausschicken oder Anhalten zum Betteln und dem bloßes Gewährenlassen des Bettelns gemacht. Während das Ausschicken und Anhalten nur vorsätzlich geschehen konnte, war das Gewährenlassen, also das unterlassene Abhalten vom Betteln auch fahrlässig begehbar. So jedenfalls die Auslegung des $\S 361$ Ziff. 4 in der Begründung zum E 1925, S. 428, § 379.

${ }^{26}$ Kaltofen, S. 23.
} 
bestimmte hätte, daß grundsätzlich nur die vorsätzliche Begehung strafbar gewesen wäre.

Da es sich hier nicht nur um die unterlassene Beaufsichtigung allein, sondern um den schuldhaften Beitrag zu der Verwirklichung eines strafbaren Erfolges handelte, stellte dieses Nichtabhalten vom Betteln nach der herrschenden Meinung ein unechtes Unterlassungsdelikt dar ${ }^{27}$; auf die Begründung einer nach heutigen Begriffen dafür erforderlichen Garantenstellung wurde nicht eingegangen. Der Tatbestand des nicht verhinderten Bettelns diente allerdings nicht nur als - zweifelhafter Ersatz für die mangelnde Strafbarkeit der Beihilfe zum Betteln. Durch die Bestrafung der „fahrlässigen“ Beihilfe zum Betteln überschritt er auch die dogmatischen Grenzen der Teilnahmelehre ${ }^{28}$. Auch diese Vorschrift hatte nur einen öffentlichkeitsschützenden Charakter und sollte nicht den Bettelnden selbst schützen ${ }^{29}$.

Von dem Straftatbestand des $§ 361$ Ziff. 4, Alt. 3 RStGB abgesehen, war im RStGB eine Bestrafung des Gewalthabers nur über die allgemeinen unechten Unterlassungsdelikte möglich ${ }^{30}$. Wenn der Gewalthaber seine Aufsichtspflicht verletzte und zumindest damit rechnete, daß die Straftat begangen werden würde, kam eine Bestrafung als Mittäter, mittelbarer Täter oder Gehilfe durch Unterlassen in Betracht, anderenfalls konnte eine Bestrafung wegen der Fahrlässigkeitstat erfolgen. Auch die allgemeinen Unterlassungsdelikte des RStGB dienten nur dem Schutz der Allgemeinheit, nicht dem des Minderjährigen.

\section{Erweiterung der Vorschriften des RStGB}

Schon kurz nach dem Inkrafttreten des RStGB im Jahre 1871 stellte sich heraus, daß die Gesetzeslage hinsichtlich anderer durch Kinder und Jugendliche begangene Straftaten unzureichend $\operatorname{war}^{31}$. Zum einen bestand in vielen Fällen keine strafrechtliche Verantwortlichkeit der

\footnotetext{
${ }^{27}$ Kaltofen, S. 24, 30; a. A. Engelsing, S. 46.

${ }^{28}$ So zumindest Kaltofen, S. 24f.; anders allerdings, wenn man eine Täterschaft durch Unterlassen für möglich hält.

${ }^{29}$ Vgl. Franke-Gricksch, S. 50.

${ }^{30}$ Kaltofen, S. 26; zur geschichtlichen Entwicklung s. Metzen, S. 12 ff.

${ }^{31}$ Kaltofen, S. 27.
} 
Eltern: Für Delikte, die nur vorsätzlich begehbar waren, kamen die allgemeinen Vorschriften über Täterschaft und Teilnahme nicht zur Anwendung, weil die Eltern die Straftaten ihrer Kinder meist nicht voraussahen und somit nur fahrlässig der Straftat Vorschub leisteten ${ }^{32}$. Dadurch konnten Eigentumsdelikte wie Diebstahl und Sachbeschädigung nicht geahndet werden. Hinzu kam das praktische Problem, daß sich der Vorsatz der Eltern oft nicht nachweisen lie $\beta^{33}$. Wo man also auf der einen Seite die Eltern nicht zur Verantwortung ziehen konnte, war dies aufgrund der Schuldunfähigkeit auch nicht bei den Kindern möglich.

Es kam deshalb schon zu Anfang der 70er Jahre des 19. Jahrhunderts zu einer lebhaften Diskussion hinsichtlich des Ausfüllens dieser Gesetzeslücke: Im Rahmen der Diskussion zur Veränderung des $§ 55$ RStGB (Schuldfähigkeit) wurde auch $\mathrm{zu}$ der Altersgrenze Stellung genommen. Man entschloß sich für eine Beibehaltung der bestehenden Altergrenze, schuf in Absatz 2 allerdings die Möglichkeit, über das Landesrecht gegen schuldunfähige Kinder Zwangserziehungsmaßnahmen anzuordnen.

Da man die Herabsetzung der Altersgrenze für Schuldfähigkeit ablehnte, blieb nur die Erweiterung der elterlichen Verantwortlichkeit. In diesem Zusammenhang wurde in den Motiven zu einer neuen Vorschrift, dem künftigen $§ 361$ Z. 9, ausgeführt: „Häufig liegt die nächste Ursache der Verletzung der Strafgesetze durch Kinder auf Seiten der Eltern und jener Personen, in deren Gewalt und Aufsicht die Kinder stehen, indem diese, wenn nicht durch Anstiftung im eigentlichen Sinne, so doch durch präsumtives Einverständnis, durch schuldhaftes Geschehenlassen an den Handlungen betheiligt erscheinen. ... In dieser Beziehung soll, soweit nicht die allgemeinen Bestimmungen über Thäterschaft und Theilnahme ausreichen, durch $\$ 361$ Nr. 9 des Entwurfs die nöthige Ergänzung geboten werden. ... Wo die Ursache des Übels in der eigenen fehlerhaften Willensrichtung des jugendlichen Übelthäters liegt, ist fast immer ein

\footnotetext{
32 Motive zu $\$ 361$ Ziff. 4, 9. Alt. RStGB: „...soll, soweit nicht die allgemeinen Bestimmungen über Thäterschaft und Teilnahme ausreichen, durch $\S 361 \mathrm{Nr}$. 9 des Entwurfs die nöthige Ergänzung geboten werden.", zitiert bei Kaltofen, S. 31.

${ }^{33}$ Kaltofen, S. 27.
} 
Zusammenhang mit verwahrloster Erziehung, Mangel an der erforderlichen Zucht und Aufsicht nachweisbar" ${ }^{34}$.

Im Jahre 1876 wurde daher $\S 361$ Ziffer 9. Alt. geschaffen, der den Gewalthaber bestrafte, wenn er die aufsichtsunterworfene Person schuldhaft nicht von Diebstählen und anderen Delikten abhielt ${ }^{35}$.

\section{§361 Z. 9 RStGB}

„Mit Haft wird bestraft, wer Kinder oder andere unter seiner Gewalt stehenden Personen, welche seiner Aufsicht untergeben sind und zu seiner Hausgenossenschaft gehören, von der Begehung von Diebstählen, sowie von der Begehung strafbarer Verletzungen der Zoll- oder Steuergesetze oder der Gesetze zum Schutze der Forsten, der Feldfrüchte, der Jagd oder der Fischerei abzuhalten unterläßt. (...)“

Der Gewalthaber wurde nicht nur wegen der unterlassenen Beaufsichtigung, sondern wegen seines Beitrags zum schädigenden (strafbaren) Erfolg seines Aufsichtsbefohlenen bestraft. Es handelte sich daher ebenfalls um ein unechtes Unterlassungsdelikt ${ }^{36}$. Aus den Motiven ist $\mathrm{zu}$ vermuten, daß eine Strafbarkeit nur wegen Vorsatzes bestehen sollte, da besonders der Unwertgehalt des elterlichen Einverständnisses zu der Tat des Gewaltunterworfenen hervorgehoben wurde ${ }^{37}$. Allerdings ist dies nicht mit Bestimmtheit zu sagen; immerhin ist Ziff. 9 der Ziff. 4, 3. Alt. nachgebildet, die, wie erwähnt, auch für fahrlässiges Unterlassen galt.

An der damaligen Gesetzeslage wurde kritisiert, daß das RStGB die Vernachlässigung der Aufsichtspflicht nur bei Bagatelldelikten bestrafte, etwa bei Bettelei oder Diebstählen, nicht aber bei schwereren Straftaten wie Körperverletzung ${ }^{38}$.

\footnotetext{
${ }^{34}$ Drucksachen des Reichstags 1875/76, S. 165, Drucksache 54.

${ }^{35}$ Gesetz vom 26.2.1876, RGBI. S. 25-38; Kaltofen, S. 28.

${ }^{36}$ Kaltofen, S. 30.

${ }^{37}$ Drucksachen des Reichstags 1875/76, S. 165, Drucksache 54.

${ }^{38}$ V. Hippel, Äußerungen zum VE 1911, S. 410f.; vgl. Kaltofen, S. 31.
} 
3. Weitere Entwicklung in Entwürfen und Reformvorschlägen

Gleichzeitig wurde das Fehlen eines Tatbestandes, der die Kindesvernachlässigung als solche bestrafte, gerügt ${ }^{39}$. Es zeigte sich insgesamt eine Sensibilisierung für die Gefahren und Schädigungen, die die Einwirkung auf den Geist und den Körper des Kindes durch Eltern oder andere Personen haben kann. Schon 1889 forderte Richard Schmidt eine allgemeine Ahndung von Verletzungen der menschlichen Psyche ${ }^{40}$. Duensing erhob 1903 die Forderung nach einem Straftatbestand, der Verstöße gegen die Fürsorgepflicht der Erziehungspflichtigen bestrafte und dadurch das Wohl des Minderjährigen schützte - eine Forderung, die danach immer wieder erhoben wurde. Frieda Duensing stand noch auf dem Standpunkt, daß es in erster Linie um das Interesse des Staates an einer gesunden körperlichen und geistigen Entwicklung des Kindes ging, und rechnete den von ihr geforderten Tatbestand daher noch $\mathrm{zu}$ den „Verbrechen und Vergehen wider die öffentliche Ordnung ${ }^{\star 41}$. In der Folgezeit setzte sich jedoch die Auffassung durch, daß das Interesse des Minderjährigen Vorrang vor dem staatlichen Interesse hatte. Es ging mehr und mehr darum, den Minderjährigen davor zu schützen, daß der Fürsorgepflichtige seine körperliche, geistige oder sittliche Entwicklung ungünstig beeinflußte ${ }^{42}$.

So nahm auch von Lilienthal kritisch Stellung zum Vorentwurf des Strafgesetzbuches von 1909, weil besondere Vorschriften über die Mißhandlung von Kindern und Schutzbefohlenen fehlten. Er ließ auch die Frage anklingen, ob nicht ein weit über den Rahmen der Körperverletzung hinausgehender Jugendschutz durch ein eigenes Gesetz nötig wäre ${ }^{43}$.

Im Gegenentwurf zum Vorentwurf von 1911 wurde erstmals der Gedanke von Familienpflichten und ihrer Ahndung behandelt ${ }^{44}$. Gem. $\S 233$ des GE 1911 war die Verletzung der Erziehungs- und

\footnotetext{
${ }^{39} \mathrm{Vgl}$. Kaltofen, S. 31.

${ }^{40}$ Schmidt, GS 42, 57 (62).

${ }^{41}$ Vgl. Kaltofen, S. 32.

${ }^{42}$ Kaltofen, S. 32.

${ }^{43}$ Franke-Gricksch, S. 50.

${ }^{44}$ GE 1911, S. 224, 228; Franke-Gricksch, S. 51.
} 
Unterhaltspflicht unter Strafe zu stellen; diese Vorschrift fand sich im Abschnitt über Verletzungen des Personenstandes, der Ehe und der Familie und kann als Vorgänger des $§ 171$ StGB betrachtet werden ${ }^{45}$ :

\section{$\$ 233$ des Gesetzesentwurfs von 1911}

Wer die ihm gesetzlich obliegende Pflicht zur Erziehung oder zur Unterhaltung eines anderen derart verletzt, daß der zu Erziehende der Gefahr der Verwahrlosung ausgesetzt wird, oder daß der zu Unterhaltende in eine Notlage gerät oder aus fremden Mittel unterstützt werden muß, wird mit Gefängnis bis zu sechs Monaten bestraft.

Diese Gedanken zum Schutz des Minderjährigen wurden in die Gesetzesänderung von 1912 im wesentlichen nicht aufgenommen. Allerdings erfaßte man die böswillige Kindesvernachlässigung als § 223a Abs. 2 RStGB, den späteren $\S 223 b \mathrm{RStGB}^{46}$.

Vorherrschend blieb in der Gesetzgebung jedoch weiterhin der Schutz der Allgemeinheit ${ }^{47}$. Auch in dieser Schutzrichtung gab es weitergehende Überlegungen. § 276 des Entwurfs von 1919 fordert die Ausgestaltung des „Nichthinderns von Straftaten“ $\mathrm{zu}$ einem allgemeinen Vergehenstatbestand zum Schutz der öffentlichen Ordnung. Erstmals erschien in einem Entwurf damit ein umfassender Tatbestand der Aufsichtspflichtverletzung ${ }^{48}$ :

\section{$\S 276$ des Entwurfs von 1919}

„Wer es vorsätzlich unterläßt oder wer es fahrlässig unter Verletzung seiner Aufsichtspflicht unterläßt, Kinder oder Jugendliche, die unter seiner Aufsicht stehen oder zu seiner häuslichen Gemeinschaft gehören, von der Begehung einer mit Strafe bedrohten Handlung abzuhalten, wird mit Gefängnis bis zu sechs Monaten oder Geldstrafe bis zu 3000 Mark bestraft. “

\footnotetext{
${ }^{45}$ GE 1911, S. 67.

${ }^{46}$ Franke-Gricksch, S. 52; Schneider, S. 15.

${ }^{47}$ Angesichts der Folgen des 1. Weltkriegs wurden die Bedenken, die Familiengewalt einzuschränken, aufgegeben. Jedenfalls erweitern die §§ 56 ff. RJWG von 1922 den Erziehungsanspruch des Kindes gegen seine Eltern durch einen öffentlich-rechtlichen Erziehungsanspruch gegen den Staat; Schneider, S. 16.
} 
Die späteren Entwürfe von 1922 bis 1936 enthielten keinen den Vorschlägen von 1911 und 1919 entsprechenden allgemeinen Tatbestand, der die Aufsichtspflichtverletzung umfassend behandelte. Außerdem wurde auch $\S 361$ Ziff. 9 nicht übernommen ${ }^{49}$. Eine Begründung dazu lautete, daß die Übernahme von $\S 361$ Ziff. 9 und seine Erweiterung auf das Nichthindern von Straftaten überhaupt eine allzu große Ausdehnung der Strafbarkeit von Aufsichtspersonen bedeuten würde. Die strafwürdigen Fälle würden durch die allgemeinen Teilnahmevorschriften gedeckt; ansonsten sei das Eingreifen des Vormundschaftsgerichtes das richtige Mittel $^{50}$. Nach E 1925 sind die in $\S$ 361 Ziff. 9 aufgeführten Delikte weniger Ausdruck einer asozialen Gesinnung des Täters als ein Beweis dafür, daß er seine familienrechtlichen Erziehungspflichten nicht erfüllt hat. Folglich sei nicht eine Bestrafung sinnvoll, sondern das Eingreifen des Vormundschaftsgerichts ${ }^{51}$.

Der Entwurf von 1930 enthielt einen $\S 265$ a, der inhaltlich als ein Vorläufer des $\S 171$ StGB angesehen werden kann ${ }^{52}$ :

\section{$\$ 265$ a des Entwurfs von 1930}

Wer wissentlich und gewissenlos die Gesundheit eines Kindes oder Jugendlichen durch Überanstrengung gefährdet, wird mit Gefängnis bis zu einem Jahr bestraft. Ebenso wird bestraft, wer wissentlich und gewissenlos die Gesundheit einer Person, für die er zu sorgen hat, durch Vernachlässigung dieser Pflicht gefährdet.

Allerdings beschränkte sich dieser Entwurf nur auf Gesundheitsschäden des Kindes ${ }^{53}$, wobei fraglich ist, ob auch Schäden an der geistig-seelische Gesundheit damit gemeint sind, wie sie durch die Verübung von Delikten

\footnotetext{
${ }^{48}$ Kaltofen, S. 34ff.; Schneider, S. 16.

${ }^{49}$ Kaltofen, S. 37.

${ }^{50}$ Kaltofen, S. 37.

${ }^{51} \S 371$ E Radbruch 1922; E 1925, S. 428 (§ 379).

52 Franke-Gricksch, S. 53.

${ }^{53}$ BGH NJW 52, 282 (282); Schneider, S. 16.
} 
eintreten können. Daher ist $\S 265$ a E 1930 im hier gesteckten Rahmen eher nachrangig.

Trotz der regen Diskussion und dem Vorliegen konkreter Entwürfe erfolgte insgesamt keine Änderung des RStGB. Die strafrechtliche Verantwortlichkeit blieb auf $\S 361$ Ziff. 4 und 9 RStGB beschränkt. Lediglich hinsichtlich von Nebenstrafgesetzen (Tier- und Naturschutz) wurde die Strafbarkeit der Aufsichtspflichtigen verschärft ${ }^{54}$.

\section{\$ 9 TierschutzG}

Abs. 1

Wer ein Tier quält oder roh mißhandelt, wird mit Gefängnis bis zu zwei Jahren und mit Geldstrafe oder mit einer dieser Strafen bestraft.

Abs. 3

Mit Geldstrafe bis zu einhundertfünfzig Reichsmark oder mit Haft wird, soweit die Tat nicht schon unter die Strafandrohung der Abs. 1, 2 fällt, bestraft, wer vorsätzlich oder fahrlässig ...

Ziff. 4 es unterläßt, Kinder oder andere Personen, die seiner Aufsicht unterstehen oder zu seiner Hausgemeinschaft gehören, von einer Zuwiderhandlung gegen die Vorschriften dieses Gesetzes abzuhalten.

4. Entwicklung während des Zweiten Weltkriegs

$\mathrm{Da}$ in Kriegszeiten mit dem Anwachsen der Kinder- und Jugenddelinquenz $\mathrm{zu}$ rechnen und somit ein besonderer Schutz für Kinder und Jugendliche erforderlich ist, hatte man bereits im 1 . Weltkrieg erfahren ${ }^{55}$. Daher kam es 1943 zur Schaffung von neuen Straftatbeständen mit unterschiedlicher Schutzrichtung, da es dem

\footnotetext{
${ }^{54}$ Kaltofen, S. 40; TierschG vom 24.11.1933, RGBI. Bd. I, S. 988.

55 Blau, ZStW 64 (1952), S. 65; zur Erhöhung der Kriminalität während des 2. Weltkrieges: Blau, ZStW 64 (1952), S. 42ff;; Kaltofen, S. 44; Wintterlin, Züchtigungsrecht, S. 8.
} 
Gesetzgeber durch die Kriegsverhältnisse nun besonders dringlich erschien, die Beaufsichtigung von Kindern und Jugendlichen sicherzustellen.

Strafbar wurde die als $\quad \begin{array}{lllll}139 & \text { b } & \text { RStGB } & \text { kodifizierte }\end{array}$ Aufsichtspflichtverletzung, wenn es durch sie zu einer Straftat des Kindes bzw. Jugendlichen kam. Dies war zum ersten Mal ein allgemeiner Straftatbestand, der jegliche Straftaten Minderjähriger erfaßte. Durch die Einführung der Strafbestimmung sollte „das Verantwortungsbewußtsein der Aufsichtspersonen gesteigert, ihr Gewissen geschärft und ihre Regsamkeit geweckt werden“56. Man erhoffte sich offenbar durch die genauere Beaufsichtigung der Jugend eine Eindämmung der Jugendkriminalität insgesamt ${ }^{57}$. Die Vorschrift sollte also der Verbrechensverhütung und damit dem Schutz der öffentlichen Ordnung dienen. § 139 b RStGB ging hervor aus $\S 4$ der „Verordnung zum Schutze der Jugend“" vom 4.10.1940 ${ }^{58}$. Durch die JugendstrafrechtsVO vom 6. November 1943 wurde die Vorschrift in fast gleichlautender Fassung als $\S 139$ b in das RStGB eingefügt ${ }^{59}$ :

\section{$\S 139$ b RStGB}

„Wer einen noch nicht Achtzehnjährigen, dessen Beaufsichtigung ihm obliegt, nicht gehörig beaufsichtigt, wird mit Gefängnis bis zu sechs Monaten oder mit Haft oder Geldstrafe bestraft, wenn der zu Beaufsichtigende eine mit Strafe bedrohte Handlung begeht, die der Aufsichtspflichtige durch gehörige Aufsicht hätte verhindern können. Dies gilt nicht, soweit in sonstigen Vorschriften eine andere Strafe angedroht ist.

Aufsichtspflichtig im Sinne dieser Vorschrift ist derjenige, dem die Sorge für die Person des Kindes oder Jugendlichen obliegt und dem das Kind

\footnotetext{
${ }^{56}$ Nagler, GS 116, 1 (10).

${ }^{57}$ Kaltofen, S. 45.

${ }^{58}$ RGBI. I, S. 1336.

59 Es erfolgte lediglich die Änderung der Formulierung von „wenn der zu Beaufsichtigende eine strafbare Handlung begeht“ in „wenn der zu Beaufsichtigende eine mit Strafe bedrohte Handlung begeht“. Es sollte dadurch verdeutlicht werden, daß sich die Strafbarkeit des Aufsichtspflichtigen ebenso wie die des Teilnehmers nach den Grundsätzen der mit Wirkung vom 15.6.1943 eingeführten limitierten Akzessorietät (RGBI. I, S. 339-341) richtete, vgl. Kaltofen, S. 47; Schneider, S. 16.
} 
oder der Jugendliche zur Erziehung oder Pflege ganz oder überwiegend anvertraut ist “. 60

Aus der „VO zum Schutz von Ehe, Familie und Mutterschaft“ vom 9. März $1943^{61}$ ging am 18. März 1943 der $§ 170$ d RStGB hervor ${ }^{62}$, der die Kindesvernachlässigung unter Strafe stellte. Der nationalsozialistische Gesetzgeber bezog sich damit vor allem auf die Frauen, in deren Händen während der Abwesenheit ihres im Kriegseinsatz befindlichen Mannes die ganze Verantwortung für die Aufsicht des Kindes lag. Es wurde als besonders verwerflich angesehen, wenn eine Frau, deren Ehemann an der Front Dienst tat, ihre „Mutterpflichten“ verletzte. Die Moral der „kämpfenden Truppe“ sollte gestärkt werden. Es ging dem nationalsozialistischen Gesetzgeber dabei nicht um einen stärkeren Schutz des Kindes als Individuums, sondern um einen stärkeren Schutz der Familie als Keimzelle der Volksgemeinschaft, so daß der Tatbestand unter die Familiendelikte eingeordnet wurde ${ }^{63}$. Im übrigen hätte eine durch Vernachlässigung herbeigeführte Gefährdung von Körper und Geist den Rahmen der Körperverletzung gesprengt ${ }^{64}$.

\section{$\S 170 d R S t G B$}

„Wer das körperliche oder sittliche Wohl eines Kindes dadurch gefährdet, daß er in gewissenloser Weise seine Fürsorge- und Erziehungspflichten gröblich vernachlässigt, insbesondere das Kind ohne ausreichende Nahrung oder Wartung läßt, wird mit Gefängnis bestraft, soweit die Tat nicht nach anderen Vorschriften mit schwererer Strafe bedroht ist. "

\footnotetext{
${ }^{60}$ RGBI. I, 1336.

${ }^{61}$ RGBI. I, S. 140; Schneider, S. 16.

${ }^{62}$ RGBI. I, S. 169; Franke-Gricksch, S. 54.

${ }^{63}$ Ostendorf, S. $33 \mathrm{f}$.

${ }^{64}$ Schneider, S. 62.
} 
III. Entwicklung von 1945 bis heute

Bedenken gegen die Gültigkeit dieses unter der NS-Herrschaft zustande gekommenen Gesetzes lassen sich trotz des deutlichen ideologischen Hintergrundes nach heute ganz h.M. nicht halten ${ }^{65}$. Der Bundesgesetzgeber hat den $\S 170 \mathrm{~d}$ RStGB durch das 3. StRÄnderungsG vom 4.8.1953 ausdrücklich in Kraft belassen ${ }^{66}$.

Mit dem 4. StrRG vom 23.11.1973 wurde die Bestimmung des damaligen $\S 170 \mathrm{~d}$ StGB neu gefaßt ${ }^{67}$. Er schützte nunmehr auch Kinder und Jugendliche bis zum vollendeten 16. Lebensjahr.

Im Zuge der Reformbewegung der 60er und 70er Jahre im deutschen Strafrecht wurde im E 1962 eine Konkretisierung (§ 198 AE) ${ }^{68}$ bzw. im E 1968 eine Streichung der Bestimmung vorgeschlagen, weil man die Tatbestandsmerkmale des $\S 170$ d $\quad$ StGB als $\mathrm{zu}$ vage und eine Durchsetzung der Ziele der Vorschrift durch das Strafrecht als sinnlos erachtete $^{69}$. Dieser Vorschlag hat sich jedoch nicht durchsetzen können.

Durch das 6. StrRG vom 26.1.1998 wurde $\S 170$ d StGB a. F. zu $\S 171$ StGB gleichen Inhalts $^{70}$.

Im Jahre 1953 wurden die $\S \S 139$ b, 361 Ziffer 9 durch das StRÄG neu gefaßt. Daraus ging $\S 143$ StGB für die Bestrafung bei Vergehen oder Verbrechen des Aufsichtsbefohlenen hervor. §361 Ziff. 9 blieb in veränderter Form erhalten und beschränkte sich nur noch auf die Übertretungen des Aufsichtsbefohlenen ${ }^{71}$. Durch das EGStGB von 1974 ist $\S 361$ Ziff. 9 StGB weggefallen.

Im übrigen hat $\S 832$ BGB als Vorbild für den $\S 143 \mathrm{StGB}$ a.F. gewirkt ${ }^{72}$. Die in Abs. 2 erläuterte Aufsichtspflicht entspricht jener der $\S \S 1626$ ff. $\mathrm{BGB}^{73}$.

\footnotetext{
${ }^{65}$ Vgl. Franke-Gricksch, S. 54f.; BayObLG NJW 52, 988 (988) m.w.N.

${ }^{66}$ Vgl. Franke-Gricksch, S. $54 f$.

${ }^{67}$ BGBI. I, S. 1725.

${ }^{68} \S 198$ AE 1962.

${ }^{69}$ Ostendorf, S. 35; AE 1968, BT Sexualdelikte usw., zu § 198 E 1962.

${ }^{70}$ BGBI. I, S. 164 (168).

${ }^{71}$ LK (9. Aufl.)-Herdegen, § 143, Rn. 1.

Kaltofen, S. 47; Schneider, S. 17ff.

${ }^{72}$ Glaue, Jugendliche Rechtsbrecher, S. 10, Schneider, S. 18f.; vgl. BT-Drucks. VI/ 1552.
} 


\section{Mangelnde Beaufsichtigung Jugendlicher (\$ 143 StGB a.F.)}

(1) Wer einen noch nicht Achtzehnjährigen, dessen Beaufsichtigung ihm obliegt, nicht gehörig beaufsichtigt, wird mit Gefängnis bis zu einem Jahr oder mit Geldstrafe bestraft, wenn der zu Beaufsichtigende eine als Verbrechen oder Vergehen mit Strafe bedrohte Handlung begeht, die der Aufsichtspflichtige durch gehörige Aufsicht hätte verhindern können. Dies gilt nicht, soweit in sonstigen Vorschriften eine andere Strafe angedroht ist.

(2) Aufsichtspflichtig im Sinne dieser Vorschrift ist derjenige, dem die Sorge für die Person des Kindes oder des Jugendlichen obliegt, oder dem das Kind oder der Jugendliche zur Erziehung und Pflege ganz oder überwiegend anvertraut ist. “

Es handelte sich nach h. M. um ein echtes Unterlassungsdelikt ${ }^{74}$. Bestraft wurde die nicht gehörige, d.h. die unterlassene Beaufsichtigung eines unter 18jährigen. Die nicht gehörige Beaufsichtigung war als solche erst strafbar, wenn der $\mathrm{zu}$ Beaufsichtigende eine als Verbrechen oder Vergehen mit Strafe bedrohte Handlung beging, die der Aufsichtspflichtige durch eine gehörige Beaufsichtigung hätte verhindern können. Bei der Straftat des Kindes oder des Jugendlichen handelte es sich also um eine Bedingung der Strafbarkeit für den Aufsichtspflichtigen $^{75}$. Der Tatbestand erforderte nicht, daß der zu Beaufsichtigende wegen seiner Tat bestraft wurde oder strafbar sei. Es genügte auch die Tat eines Strafunmündigen oder eines nicht strafreifen Jugendlichen $^{76}$. 143 kam nur subsidiär zur Anwendung und trat auch dann hinter einer anderen Möglichkeit der Bestrafung zurück, wenn diese eine geringere Strafe androhte. Eine andere Bestrafung des Aufsichtspflichtigen kam in Frage, wenn er selbst Täter oder Teilnehmer an der Straftat des zu Beaufsichtigenden war $^{77}$.

\footnotetext{
${ }^{73}$ LK (9. Aufl.)-Herdegen, § 143, Rn. 7.

${ }^{74}$ Dreher/Schwarz, § 143, 1); S/S, 7. Aufl., § 143, I.

${ }^{75}$ LK (9.Aufl.)-Herdegen, § 143, Rn. 3.

${ }^{76}$ LK(9.Aufl.)-Herdegen, § 143, Rn. 4.

${ }^{77}$ LK(9.Aufl.)-Herdegen, § 143, Rn. 5; Pauli, NJW 1960, 2229 (2229).
} 
$\S 143$ StGB ist durch das 4. StrRG vom 23.11.1973 weggefallen ${ }^{78}$. Nach den Verhandlungen des Bundestages wurde die Vorschrift des $\S 143$ StGB bereits bei den Vorarbeiten zum Entwurf 1962 als mißglückt angesehen. Insbesondere die Verwendung der objektiven Strafbarkeitsbedingung wurde kritisiert. Weiter erschien es bedenklich, daß auch die fahrlässig unterlassene Aufsicht des Aufsichtspflichtigen unter Strafe gestellt war, und zwar auch dann, wenn es sich bei der Tat des Jugendlichen um eine Fahrlässigkeitstat handelte ${ }^{79}$. Dadurch bestand faktisch eine Strafbarkeit des Aufsichtspflichtigen wegen fahrlässig begangener Beihilfe, die sonst in Europa ihresgleichen suchte ${ }^{80}$.

Man war der Auffassung, daß $\S 1666$ BGB Handhabe für ausreichende vormundschaftsgerichtliche Maßnahmen böten. Im übrigen hafte der Aufsichtspflichtige schon zivilrechtlich aus $§ 832$ BGB für den Schaden. Auch familienpolitische Gründe sprächen gegen eine derartige Vorschrift: Das Strafrecht solle die Eltern nicht $\mathrm{zu}$ extremen Aufsichtsmaßnahmen zwingen, die sie aus ernst zu nehmenden Gründen für unangebracht hielten ${ }^{81}$.

Weitere gesetzliche Vorschriften zum Schutz von Kindern und Jugendlichen finden sich in den $\S \S 174 \mathrm{ff}, 221,225$ StGB, im Gesetz über die Verbreitung von jugendgefährdenden Schriften und Medieninhalte, im SGB VIII (Kinder- und Jugendhilfe) sowie im Jugendgerichtsgesetz $(\S 38 \text { Jugendgerichtshilfe })^{82}$. Keine dieser Vorschriften behandelt jedoch die Unterlassung der Deliktshinderung durch Erziehungspflichtige, sie sind also für den vorliegenden Kontext nicht bedeutsam.

\footnotetext{
${ }^{78}$ BGBI. I, S. 1725.

${ }^{79}$ So auch Dahlke, Strafrecht, § 143, 2).

${ }^{80}$ BT-Drucks. $1970 \mathrm{VI}, 1552$.

${ }^{81}$ BT-Drucks. 1970 VI, 1552; zur Kritik an § 143 auch Welzel, S. $429 f$.

${ }^{82}$ Die Jugendgerichtshilfe soll im Verfahren gegen den Jugendlichen die erzieherischen, sozialen und fürsorgerischen Gesichtspunkte zur Geltung bringen. Sie dient aber in erster Linie dazu, angemessene Rechtsfolgen zu finden, und kann daher nur bedingt als eine Schutzvorschrift zugunsten des Jugendlichen betrachtet werden, vgl. Eisenberg, JGG, § 38, Rn. 14.
} 
In das Jugendschutzgesetz (JÖSchG) von 1985 wurde immerhin eine dem $\S 171$ ähnliche Bestimmung aufgenommen: Gemäß $\S 12$ Abs. 4 Nr. 1 JÖSchG macht sich ein Veranstalter oder Gewerbetreibender, also jemand, der nicht erziehungsberechtigt ist, strafbar, wenn er eine Zuwiderhandlung des Absatzes 1 begeht ${ }^{83}$, und er das Kind oder den Jugendlichen wenigstens leichtfertig in seiner körperlichen, geistigen oder sittlichen Entwicklung schwer gefährdet.

\section{$\S 12 J O ̈ S c h G$}

Abs. 1

Ordnungswidrig handelt, wer als Veranstalter oder Gewerbetreibender vorsätzlich oder fahrlässig

1. entgegen $\$ 3$ einem Kind oder Jugendlichen den Aufenthalt in einer Gaststätte gestattet,

2. entgegen $\$ 4$ Abs. 1 ein alkoholisches Getränk oder Lebensmittel an ein Kind oder Jugendlichen abgibt oder ihm den Verzehr gestattet ,...

5. entgegen $\S 6$ Abs. 1 oder 4 einem Kind oder Jugendlichen die Anwesenheit bei einer öffentlichen Filmveranstaltung gestattet, ....

Abs. 4

Mit Freiheitsstrafe bis zu einem Jahr oder mit Geldstrafe wird bestraft, wer als Veranstalter oder Gewerbetreibender

1. eine in Absatz 1 bezeichnete vorsätzliche Zuwiderhandlung begeht und dadurch wenigstens leichtfertig ein Kind oder einen Jugendlichen in seiner körperlichen, geistigen oder sittlichen Entwicklung schwer gefährdet, ...

Hinsichtlich der Gefährdung ähnelt die Vorschrift zwar stark dem $\S 171 \mathrm{StGB}$, die Strafandrohung des $\S 12$ Abs. 4 JÖSchG betrifft aber gerade nur solche Personen, die nicht Erziehungsberechtigte sind. Sie bezieht sich somit auf Handlungen, die mit einer Fürsorge- und Erziehungspflichtverletzung nichts $\mathrm{zu}$ tun haben. Eine Vorschrift zur Disziplinierung von Erziehungsberechtigten gibt es somit im JÖSchG

\footnotetext{
${ }^{83}$ z.B. Ausschank von Alkohol an Jugendliche, Gestattung der Anwesenheit bei einer öffentlichen Filmveranstaltung.
} 
nicht. Es handelt sich dabei um eine bewußte Aussparung. Man lehnte im Rahmen der Beratungen zum Jugendschutzgesetz die Anwendung strafrechtlichen Zwangs auch aus pädagogischen Gründen $a b^{84}$.

Weitere gesetzliche Regelungen, die den Verstoß gegen Aufsichts- oder Erziehungspflichten unter Strafe stellen, sind nicht ersichtlich.

IV. Zusammenfassung der geschichtlichen Entwicklung

Somit stehen heute für eine Bestrafung von Eltern, die die Straftaten ihrer Kinder nicht verhindern, zwei Möglichkeiten offen. Zum einen die Bestrafung nach allgemeinen Vorschriften des StGB über das Unterlassen der Deliktshinderung, zum anderen die Bestrafung nach $\S 171 \mathrm{StGB}$.

Der Blick in die Geschichte offenbart, daß zunächst die öffentliche Sicherheit und das Allgemeinwohl im Vordergrund standen und der Minderjährige als schutzbedürftiges Individuum erst spät durch eigene Tatbestände einbezogen wurde.

Es läßt sich auch nicht verbergen, daß die Unterlassungsdelikte, vor allem die Straftatverhinderungspflicht, abhängig von den verfassungsrechtlichen Wertentscheidungen der jeweiligen Zeitepoche waren und sind ${ }^{85}$. Besonders deutlich wird dies bei der Reichweite der Unterlassungsstrafbarkeit zwischen den beiden Polen eines liberalen bzw. totalitären Strafrechts, worauf bereits Schulte hingewiesen hat: Der Nationalsozialismus verlieh mit der Erweiterung der unechten Unterlassungsdelikte seinem Willen Ausdruck, das „völkische Gemeinschaftsbewußtsein“ zu stärken, und verordnete somit von staatlicher Seite eine Solidarität innerhalb der „Volksgemeinschaft“ ${ }^{\star 86}$. Schünemann weist außerdem auf die im Totalitarismus steigende Anzahl der an eine bestimmte Täterqualifikation anknüpfenden echten Unterlassungsdelikte $\operatorname{hin}^{87}$. Demgegenüber war der Kreis der

\footnotetext{
${ }^{84}$ Vgl. Becker, NJW 52, 1082 (1082).

${ }^{85}$ Brammsen, Entstehungsvoraussetzungen, S. 33.

${ }^{86}$ Schulte, Garantenstellung und Solidarität, S. 24f.

${ }^{87}$ Schünemann, ZStW 96 (1984), 287 (299).
} 
Garantenpflichtigen in der ausgehenden Weimarer Zeit, in welcher der Liberalismus allerdings bereits an Bedeutung verloren hatte, eher klein zu nennen ${ }^{88}$.

Es zeigt sich insgesamt, daß die meisten Argumente und Ideen in Bezug auf die elterliche Strafbarkeit der unterlassenen Deliktshinderung entweder schon einmal Gesetz (vgl. nur $§ 143$ StGB a.F.) oder zumindest schon einmal vorgeschlagen waren, daß also die jüngste Entwicklung, die sich in Richtung von restriktiven Denkmodellen bewegt ${ }^{89}$, inhaltlich kaum Neues zu bieten hat. Dies ist hinsichtlich der Diskussion, ob die gegenwärtige Gesetzessituation zufriedenstellend ist, zu berücksichtigen.

\footnotetext{
${ }^{88}$ Schulte, Garantenstellung und Solidarität, S. 24.
}

${ }^{89}$ Frehsee, Fehlfunktionen des Strafrechts, S. 14. 


\section{Teil. Die Grundvoraussetzungen der Strafbarkeit}

A. Verfassungsrechtliche Voraussetzungen für eine Strafbarkeit der Eltern

Ausgangspunkt aller folgenden Erwägungen über eine Bestrafung von Eltern muß sein, ob sich eine solche mit dem elterlichen Erziehungsrecht aus Art. 6 GG vereinbaren läßt.

Nach Art. 6 Abs. 2 S. 1 GG sind „Pflege und Erziehung der Kinder ... das natürliche Recht der Eltern und die zuvörderst ihnen obliegende Pflicht“". Das elterliche Erziehungsprimat wird in Literatur und Rechtsprechung allgemein anerkannt ${ }^{90}$. Das Bundesverfassungsgericht hat den Vorrang der Eltern bei der Erziehung ihrer Kinder stets hervorgehoben ${ }^{91}$. Darin zeigt sich vor allem eine strikte Abwendung von einer alles umfassenden Staatlichkeit totalitärer Systeme, insbesondere nach den Erfahrungen des Nationalsozialismus, aber auch angesichts der erzwungenen Erziehung der Kinder im Kommunismus, eine Abwendung, die von niemandem ernstlich in Zweifel gezogen wird ${ }^{92}$.

Trotz des Spannungsverhältnisses zwischen Elternrecht und staatlicher Eingriffsbefugnis stehen die beide Funktionskreise sich nicht gegensätzlich gegenüber. Sie sind vielmehr als grundsätzlich verschiedene Rechte zum Wohl des Kindes miteinander koordiniert ${ }^{93}$. Die Frage nach der Einschränkbarkeit des Elternrechts läßt sich am besten verdeutlichen, wenn man die beiden Pole, zwischen denen sich die Diskussion abspielt, beleuchtet. Von den Anfängen her gibt es zwei Ansätze, nach denen das Recht zur Erziehung von Kindern sich bestimmt $^{94}$, den individualistischen und den kollektivistischen. Nach der individualistischen Staats- und Rechtstheorie (,so wenig Staat wie möglich“) muß der Grundsatz gelten: Elternrecht bricht Staatsrecht. Die private Erziehung hat hier also den Vorrang vor der öffentlichen

\footnotetext{
${ }^{90}$ statt vieler Maunz in Maunz-Dürig, Art. 6, Rn. 26; Schmidt-Bleitreu/ Klein, Art. 6, Rn. 8.

${ }^{91}$ BVerfGE 4, 52 (56); 7, 320 (323); 24, 119 (135 ff., 143 ff.).

${ }^{92}$ Schmitt Glaeser, Erziehungsrecht, S. 37; Peters, Elternrecht, in Die Grundrechte IV, 1. Halbbd., S. 369 (374).

${ }^{93}$ Stein/ Joest, Elternrecht, S. 40.

${ }^{94}$ Zur geistesgeschichtlichen Entwicklung siehe Stein/ Joest, Elternrecht, S. $13 \mathrm{ff}$.
} 
Erziehung. Dem Staat steht entweder überhaupt kein Recht auf Erziehung zu oder nur ein subsidiäres Erziehungsrecht für den Fall, daß die Eltern nicht fähig oder nicht willens sind, die Kinder zu erziehen ${ }^{95}$. Gilt für den Individualismus der Satz ,,in dubio pro parentibus“, so lautet der Grundsatz der kollektivistischen Theorie ,in dubio pro re publica“. Das Staatsrecht geht nach letzterem Verständnis also dem Elternrecht vor. In diesem Fall will der Staat die Erziehung selbst prägen, anstatt sich zu bescheiden, nur die Voraussetzungen zur selbsttätigen Entfaltung des Individuums zu schaffen ${ }^{96}$.

Vor diesem Hintergrund ist die Frage zu beantworten, welchen Inhalt Art. $6 \mathrm{GG}$ hat und zu welchem Zweck eine Einschränkung des Elternrechts erfolgen darf. Art. 6 GG spricht von der „Pflege und Erziehung der Kinder“. Unter Erziehung versteht man sowohl im Sinne des Art. 6 GG, im BGB und in der Sozialwissenschaft den Vorgang, der die körperliche, geistige und seelische Entwicklung eines Kindes in Bahnen lenkt und auf ein bestimmtes Ziel hinleitet ${ }^{97}$. Eine genauere Ausformung des Erziehungsinhalts findet sich im 4. Buch (Familienrecht) des BGB:

\section{$\S 1626$ BGB (Elterliche Sorge, Grundsätze)}

Abs. 1 Die Eltern haben die Pflicht und das Recht, für das minderjährige Kind zu sorgen (elterliche Sorge) ...

Abs. 2 Bei der Pflege und Erziehung berücksichtigen die Eltern die wachsende Fähigkeit und das wachsende Bedürfnis des Kindes zu selbständigem verantwortungsbewußtem Handeln. Sie besprechen mit dem Kind, soweit es nach dessen Entwicklungsstand angezeigt ist, Fragen der elterlichen Sorge und streben Einvernehmen an. ...

\section{$\S 1631$ Abs. 1 BGB (Inhalt der Personensorge)}

Die Personensorge umfaßt insbesondere die Pflicht und das Recht, das Kind zu pflegen, zu erziehen, zu beaufsichtigen und seinen Aufenthalt zu bestimmen.

\footnotetext{
${ }^{95}$ Stein/ Joest, Elternrecht, S. 20.

${ }^{96}$ Stein/ Joest, Elternrecht, S. 24.

${ }^{97}$ MüKo, § 1631, Rn. 10; Palandt-Diederichsen, § 1631, Rn. 2; Maunz in Maunz-Dürig, Art. 6, Rn. 24; Eva Maria v. Münch in v. Münch, Art. 6, Rn. 26.
} 
Die Erziehungsmittel sind die Instrumente der Erziehung, etwa Lob und Tadel, Unterweisung und Anleitung, Zureden und Überzeugen, Verhalten des Erziehenden als Vorbild, Ge- und Verbote, Sanktionen ${ }^{98}$. Liegt der Anwendung der Erziehungsmittel ein bestimmtes Raster zugrunde, spricht man von einer Erziehungsmethode. Wahl und Anwendung des einzelnen Erziehungsmittels unterliegen einem wertgeleiteten Verhaltensmuster, erfolgen also aus einer bestimmten geistigen Grundeinstellung des Erziehenden ${ }^{99}$. Das Erziehungsziel stellt schließlich das angestrebte Ergebnis der Erziehung dar. Hierbei ist zwischen formalen und materialen Erziehungszielen zu unterscheiden. Unter der (einfach-gesetzlichen) Festlegung eines formalen Erziehungsziels versteht man die Heranbildung des Kindes zu einer selbständigen Persönlichkeit ${ }^{100}$. Dementgegen liegt ein materiales Erziehungsziel vor, wenn eine ganz bestimmte Art von Persönlichkeit herangebildet werden soll. Der formale Begriff erwartet also nur das Bestehen einer Form, der materiale Begriff hingegen fordert eine konkrete Form. Während das formale Erziehungsziel verfassungsrechtlich allgemein als unbedenklich eingestuft wird, soll nur die Verordnung materialer Erziehungsziele vom Grundgesetz untersagt $\operatorname{sein}^{101}$. Danach sei die Erziehung des Kindes zu einem selbständig handlungsfähigen Menschen verfassungsrechtlich unbedenklich, weil nichts darüber ausgesagt werde, wie das Verhaltensmuster des schließlich Erwachsenen beschaffen sein müsse. Schmitt Glaeser wendet dagegen ein, daß auch derartige Ziele nicht frei von Werten seien und somit ein Unterschied zwischen formalem und materialem Erziehungsziel verwischt sei: Die Erziehung zu einer selbständigen Persönlichkeit stelle bereits auf ein ganz bestimmtes Menschenbild ab. Dies sei bereits eine Wertentscheidung. Die formalen Erziehungsziele seien also jedenfalls nicht deshalb verfassungsmäßig, weil sie etwa wertneutral wären ${ }^{102}$. Die Zivilrechtslehre tendiert dazu, als formale Erziehungsziele solche einzuordnen, die einem gewissen

\footnotetext{
${ }^{98}$ MüKo, § 1631, Rn. 10; Palandt-Diederichsen, § 1631, Rn. 6.

${ }^{99}$ Schmitt Glaeser, Erziehungsrecht, S. 8.

${ }^{100}$ Staudinger-Salgo, § 1631, Rn. 10.

${ }^{101}$ Beitzke, FamRZ 1979, 8 (10).

102 Schmitt Glaeser, Erziehungsrecht, S. 8f.
} 
Minimalkonsens dessen entsprechen, was in einer pluralistischen Gesellschaft als selbstverständlich und vernünftig gilt ${ }^{103}$.

Je kollektivistischer eine Staatsideologie angelegt ist, je stärker also das Individuum zurückgedrängt wird, desto intensiver ist der Staat bemüht, die Kinder und Jugendlichen ,,in seine Regie zu übernehmen“, vor allem die Erziehungsziele, aber auch die Erziehungsmethoden möglichst lückenlos festzulegen. Die Regelung des Familien- und Erziehungsrechts kann also als ein Gradmesser für die Freiheitlichkeit des Herrschaftssystems angesehen werden ${ }^{104}$.

Der Zusammenhang des familiären Bereichs mit den Grundbedürfnissen der Gesellschaft bedarf daher einer Ausgestaltung, die dem Grundgesetz entspricht. Nach BVerfGE 4,7 (15f.) ist das Menschenbild des Grundgesetzes nicht das eines isolierten souveränen Individuums. Das Grundgesetz hat sich vielmehr für eine Gemeinschaftsbezogenheit und gebundenheit der Person entschieden, ohne dabei deren Eigenwert anzutasten. Daraus ergibt sich eine Gratwanderung zwischen einer ausufernden und damit gemeinschaftszerstörenden individuellen Beliebigkeit und einer allumfassenden und damit individuumszerstörenden kollektivistischen Staatlichkeit ${ }^{105}$. Dabei ist das Gleichheitspostulat durchaus kritisch zu betrachten. Denn diese bedroht in besonders großem Maße die Personalität des Menschen, die in Art. 6 GG und dem dort verankerten Erziehungspostulat ihre Wurzel hat. „Ein Gleichheitspostulat kann niemals die Rechtfertigung für Menschenplaner sein, die auch Köpfe abschneiden, wenn das individuelle Maß nicht in den Plan paßt. In der Erhaltung und Entwicklung menschlicher Individualität (und Planwidrigkeit!) liegt die richtungsbestimmende (absolute) Forderung des Freiheitspostulats, das seinen Kern im unantastbaren Freiheitsraum für den einzelnen zu privater Lebensgestaltung hat “106. Demgegenüber hat der Nationalsozialismus in den Mittelpunkt seines Jugendpflegerechtes nicht den Minderjährigen selbst, sondern die „Gemeinschaft des Volkes“ gestellt. Aus dem subjektiven Recht des Kindes auf Erziehung wurde die

\footnotetext{
${ }^{103}$ Vgl. kritisch dazu Schmitt Glaeser, Erziehungsrecht, S. 9.

${ }^{104}$ Schmitt Glaeser, Erziehungsrecht, S. 38.

${ }^{105}$ Schmitt Glaeser, Erziehungsrecht, S. 40.

${ }^{106}$ Schmitt Glaeser, Erziehungsrecht, S. 40f.
} 
Pflicht der Eltern, ihre Kinder ,zu tüchtigen Volksgenossen“ zu erziehen $^{107}$. Der Frage, inwieweit der einzelne Jugendliche gefährdet oder verwahrlost war, kam dabei nur nebensächliche Bedeutung $\mathrm{zu}^{108}$.

Ist nun festgestellt, daß Erziehungsziele, Erziehungsmittel und Erziehungsmethoden sich nicht vom Staat festlegen, sondern nur von den Eltern verantworten lassen, ist $\mathrm{zu}$ untersuchen, was $\mathrm{zu}$ geschehen hat, wenn die Eltern sich unverantwortlich verhalten ${ }^{109}$. Denn so positiv es zu werten ist, daß Eltern umfassend für ihre Kinder da sind und einstehen: Die Eltern bleiben ,Schicksal“ ihrer Kinder auch im Schlechten ${ }^{110}$.

Auch wenn Art. 6 Abs. 2 S. 1 GG den Eltern einen vorrangigen Erziehungsanspruch einräumt, heißt dies nicht, daß den Eltern ein ausschließlicher Erziehungsanspruch zustände. Dies wird schon durch das Wort „zuvörderst“ deutlich. Neben den Eltern sind, wenn auch subsidiär, andere Pflichtträger vorhanden. Die elterliche Sorge ist zudem nicht ohne Kontrolle. Gem. Art. 6 Abs. 1 S. 2 GG wacht die staatliche Gemeinschaft über die Betätigung des Erziehungsrechtes, was in Art. 6 Abs. 3 seine härteste Konsequenz erhält: Darin wird das Recht des Staates konstituiert, die Kinder von der Familie zu trennen, wenn die Erziehungsberechtigten versagen oder wenn die Kinder aus anderen Gründen zu verwahrlosen drohen. Schließlich erfährt das elterliche Erziehungsrecht durch Art. 7 GG eine Einschränkung zumindest im Außenbereich des familiären Lebens ${ }^{111}$, indem das Schulwesen unter die Aufsicht des Staates gestellt wird.

Das Recht der Eltern auf Erziehung ihrer Kinder ist, wie jedes Recht, nicht auf Willkür angelegt. Art. 6 Abs. 2 GG spricht sowohl vom Recht als auch von der Pflicht der Eltern zur Kindeserziehung. Diese Pflichtenbindung unterscheidet das Elternrecht von allen anderen Grundrechten. Daher wird schon seit langer Zeit der Begriff der „Elternverantwortung“ verwendet ${ }^{112}$. Art. 6 Abs. 2 darf danach nur für ein solches Handeln in Anspruch genommen werden, ,das bei weitester

\footnotetext{
${ }^{107}$ Staudinger-Salgo, § 1631, Rn. 26; Neese, Leitsätze, S. 75.

${ }^{108}$ Neese, Leitsätze, S. 76.

${ }^{109} \mathrm{Vgl}$. Schmitt Glaeser, Erziehungsrecht, S. 43.

${ }^{110}$ Schmitt Glaeser, Erziehungsrecht, S. 47

${ }^{111}$ Schmitt Glaeser, Erziehungsrecht, S. 44.

${ }^{112}$ BVerfGE 10, 59 (67, 76ff.) unter Hervorhebung der elterlichen Gleichberechtigung.
} 
Anerkennung der Selbstverantwortlichkeit der Eltern noch als Pflege und Erziehung gewertet werden kann, nicht aber für das Gegenteil: die Vernachlässigung des Kindes“. Art. 6 Abs. 2 GG schützt daher die freie Entscheidung der Eltern darüber, wie sie ihrer elterlichen Verantwortung gerecht werden wollen. Er schützt aber nicht jene Eltern, die sich dieser Verantwortung entziehen ${ }^{113}$. Dabei geht es nicht allein um das legitime Interesse der staatlichen Gemeinschaft an der Erziehung der Jugend, sondern in erster Linie um die Umsetzung der eigenen Grundrechte des Kindes selbst: Als Wesen mit eigener Menschenwürde und mit dem Recht auf freie Entfaltung seiner Persönlichkeit steht dem Kind der Schutz des Staates aus Art. 1 Abs. 1 und Art. 2 Abs. 1 GG zu.

Es geht jedoch nicht nur um die Rechte der Eltern gegenüber ihren Kindern, sondern auch gegenüber den Rechtsgütern Dritter. Aus den Prinzipien des öffentlichen Schulwesens und des Persönlichkeitsrechtes ergeben sich immanente Schranken des natürlichen Elternrechts ${ }^{114}$.

Im vorliegenden Kontext muß nicht diskutiert werden, ob der Staat grundsätzlich schon bei sozialschädlichen Verhaltensweisen innerhalb der Familie eingreifen muß. Es dürfte jedenfalls feststehen, daß elterliche Erziehung faktisch nicht über das Strafrecht erzwungen werden kann, auch wenn dies verfassungsrechtlich zunächst nicht ausgeschlossen ist. Wie weit das Strafrecht seinerseits gegen die Eltern vorgehen darf, um die mißbilligten Folgen der nicht verhinderten Jugenddelinquenz einzudämmen, ist im folgenden zu klären. Im letzten Teil dieser Arbeit wird die rechtliche Situation daraufhin zu untersuchen sein, ob sie mit dem Verfassungsrecht übereinstimmt oder ob das Strafrecht als legitimes Mittel ausscheidet ${ }^{115}$.

\footnotetext{
${ }^{113}$ Schmitt Glaeser, Erziehungsrecht, S. 40.

${ }^{114}$ Stein/ Joest, Elternrecht, S. 41.

${ }^{115}$ Die Legitimitätsfrage schließt die Frage nach der Zweckmäßigkeit ein: Legitim im verfassungsrechtlichen Sinne ist nur ein verhältnismäßiger Eingriff in das geschützte Grundrecht. Zur Verhältnismäßigkeit gehört in erster Linie die Geeignetheit, d.h.
} 
B. In Betracht kommende Unterlassungsdelikte

Um ein Verhalten der Eltern, die ihre Kinder nicht von der Begehung von Delikten abhalten, strafrechtlich zu erfassen, gelangt man zwingend zur Befassung mit den Unterlassungsdelikten.

I. Die Unterscheidung von echten und unechten Unterlassungsdelikten

In Betracht kommt zunächst die Anwendung unechter

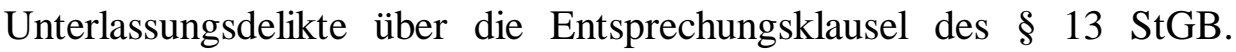
Danach ist ein Unterlassen dann strafbar, wenn der Unterlassende eine rechtliche Pflicht zum Handeln gehabt hätte und wenn bei seinem Eingreifen der Erfolg verhindert worden wäre. Es ist jedoch umstritten, welche Delikte als unechte Unterlassungsdelikte einzustufen sind. Für die Untersuchung der unechten Unterlassungsdelikte ist daher zu beleuchten, welche Delikte überhaupt damit gemeint sind und wie sie von den echten Unterlassungsdelikten abzugrenzen sind. Dieser Streit ist hier insoweit von Relevanz, als er möglicherweise darüber entscheidet, ob die Strafmilderung aus $\S 13$ Abs. 2 StGB für die später zu behandelnden Tatbestände möglich ist, da die echten Unterlassungsdelikte diese Milderung nicht vorsehen ${ }^{116}$.

1. Die unechten Unterlassungsdelikte als erfolgsbezogene Delikte

Nach der Ansicht der Rechtsprechung und eines Teils der Literatur entscheidet das Erfordernis des Erfolgseintritts zwischen echtem und unechtem Unterlassungsdelikt. Danach sind echte Unterlassungsdelikte (Omissivdelikte) jene Straftaten, bei denen ein bestimmtes Handeln des Garanten gesetzlich geboten ist, der Täter jedoch diese Handlung nicht vornimmt. Der Verstoß gegen die Gebotsnorm durch die Nichtvornahme der geforderten Handlung genügt also für die Erfüllung des Delikts. Auf den Eintritt des schädigenden Erfolges soll es dabei nicht ankommen ${ }^{117}$.

Zweckmäßigkeit der Maßnahme. Legitim ist ein Mittel nur, wenn es den gewünschten Zweck auch erreichen kann.

${ }^{116}$ Gössel, ZStW 96, 287 (303).

${ }^{117}$ BGHSt 14, 280 (281); Jescheck/ Weigend, § 58 III 2, S. 605; Wessels, AT, Rn. 696. 
Zwar soll auch durch die echten Unterlassungsdelikte letztlich ein negativer Erfolg verhindert werden. Die Verhinderung dieses Erfolges ist dort aber gerade nicht Pflicht des Unterlassenden und somit kein Tatbestandsmerkmal. So erfordert etwa $\S 323 \mathrm{c}$ nur die bestmögliche Hilfeleistung, nicht die tatsächliche Rettung des Verunglückten ${ }^{118}$. Daher entsprechen dieser Auffassung nach die echten Unterlassungsdelikte den schlichten Tätigkeitsdelikten ${ }^{119}$. Andere echte, gesetzlich geregelte Unterlassungsdelikte sind danach auch die $\S \S 123$, 2. Alt., 138 Abs. 1 und 142 Abs. 2 StGB.

Dieser Meinung nach gehört demgegenüber bei den unechten Unterlassungsdelikten (delicta comissiva per omissionem) der Eintritt des Erfolges immer zum Tatbestand. Dies ergibt sich daraus, daß dem Unterlassenden als Garant die Pflicht zur Erfolgsabwendung auferlegt wird. Das Gebot richtet sich hier also nicht nur auf die Vornahme einer bestimmten Handlung, sondern direkt auf die Erfolgsabwendung ${ }^{120}$. Somit bilden diesem Ansatz nach die unechten Unterlassungsdelikte ein Spiegelbild der Begehungsdelikte und zumeist das Gegenstück zu den Erfolgsdelikten. Ein Garant, der die ihm auferlegte Pflicht zur Erfolgsabwendung verletzt, verwirklicht einen Straftatbestand, der im Gesetz als Begehungsdelikt konstruiert ist und dem primär eine Verbotsnorm zugrunde liegt ${ }^{121}$. Da die unechten Unterlassungsdelikte gegenüber den echten das zusätzliche Tatbestandsmerkmal des Erfolgseintritts verlangen, wird von Jescheck die Bezeichnung der „unechten“ Unterlassungsdelikte als „qualifizierte“ und die der echten als „einfache“ Unterlassungsdelikte vorgeschlagen ${ }^{122}$.

Unverzichtbare Voraussetzung des unechten Unterlassungsdelikts ist diesem Ansatz nach die Garantenstellung des Täters: Während bei den echten Unterlassungsdelikten jeder, der in die tatbestandlich beschriebene Lage kommt, zum Handeln verpflichtet ist, muß bei den unechten Unterlassungsdelikten nur derjenige tätig werden, der als

\footnotetext{
${ }^{118}$ Vgl. Jescheck/ Weigend, § 58 III 2, S. 605.

${ }^{119}$ Gössel, ZStW 96, 287 (302); Jescheck/ Weigend, § 58 III 2, S. 605.

${ }^{120}$ SK-Rudolphi, Vor $\S 13$, Rn. 8, 10.

${ }^{121}$ Wessels, AT, Rn. 697.

122 Jescheck/ Weigend, § 58 III 2, S. 606.
} 
Garant eingestuft worden ist ${ }^{123}$. Damit können nur solche Personen das unechte Unterlassungsdelikt verwirklichen, die einer besonderen rechtlichen Pflicht zur Erfolgsverhinderung - der Garantenpflicht unterliegen. Der Täterkreis des unechten Unterlassungsdelikts ist somit, im Gegensatz zum echten Unterlassen als Jedermannsdelikt, begrenzt.

Die große Masse der unechten Unterlassungsdelikte ist durch die kodifizierten Begehungstatbestände mitgeregelt ${ }^{124}$. $\mathrm{Zu}$ den wenigen unechten, gesetzlich geregelten Unterlassungsdelikten gehören die $\S \S 221$ Abs. 1 Nr. 2, 225 Abs. 1 und $357 \mathrm{StGB}^{125}$.

2. Die unechten Unterlassungsdelikte als gesetzlich nicht geregelte Delikte

Der in der Literatur vertretenen Gegenansicht nach unterscheiden sich die echten und unechten Unterlassungsdelikte nur nach dem rein formalen Kriterium der gesetzlichen Regelung. Danach sind die echten Unterlassungsdelikte im Gesetz geregelt, während jedes aus dem Begehungstatbestand $\mathrm{zu}$ bestrafende Unterlassen ein unechtes Unterlassungsdelikt darstellt ${ }^{126}$. Dementsprechend sind alle gesetzlichen Unterlassungsdelikte ,echt“", auch wenn der Erfolgseintritt Tatbestandsmerkmal ist. Damit müßten die im Gesetz geregelten, nach erster Ansicht unechten Unterlassungsdelikte, z.B. § 225, § 315 c Abs. 1 Nr. 2 g, § 357 StGB, hier als echte Unterlassungsdelikte eingestuft werden.

\section{Stellungnahme}

Fraglich ist, welche Konsequenzen die unterschiedlichen Lösungen tatsächlich haben. Tatsächlich kommen die beiden Ansichten in den meisten Fällen zum gleichen Ergebnis. Sie sind sich darin einig, die nicht

\footnotetext{
${ }^{123}$ Brammsen/Otto, Jura 85, 530 (532).

124 Bärwinkel, S. 22; daher ist Schmidhäuser, der eine eigene Einteilung der Unterlassungsdelikte vornimmt, der Auffassung, man müsse, wenn überhaupt, vom unechten Begehungsdelikt sprechen, AT, 16/18.

${ }^{125}$ Vgl. Bärwinkel, S. 22, nach dessen Ansicht auch § 171 darunter fällt.
} 
gesetzlich geregelten, aber mit dem Begehen gleichzusetzenden Unterlassungstatbestände als unechte Unterlassungsdelikte zu qualifizieren. Unterschiedliche Ergebnisse gibt es folglich nur hinsichtlich der gesetzlich bestimmten Unterlassungsdelikte.

Aber auch dort ist nur eine kleine Gruppe betroffen: Für die teils als echte, teils als unechte Unterlassungsdelikte eingestuften gesetzlich geregelten Delikte (vgl. § 225, § 315 c Abs. 1 Nr. 2 g, § 357) gilt $\S 13$ Abs. 2 StGB auch dann nicht, wenn man sie als unechte Unterlassungsdelikte verstände, weil der Gesetzgeber für diese Fälle den Strafrahmen bereits abschließend festgelegt hat ${ }^{127}$. Somit wäre es hinsichtlich der Anwendbarkeit des $\S 13$ Abs. 2 StGB gleichgültig, ob man diese gesetzlich festgelegten Tatbestände als echte oder unechte Unterlassungsdelikte einstufen würde.

$\mathrm{Zu}$ prüfen ist aber noch, ob die übrigen unechten, gesetzlich geregelten Unterlassungsdelikte ansonsten durch die dargestellten Auffassungen unterschiedlich behandelt würden. Das ist hier nicht gegeben, so daß sich eine weitere an dieser Stelle Diskussion erübrigt.

Für die später erforderliche Einordnung des $\S 171$ StGB in die Unterlassungsdelikte soll jedoch bereits jetzt eine Entscheidung zwischen den Auffassungen getroffen werden: Der Gedanke, das echte Unterlassen unterscheide sich vom unechten allein durch die schriftliche Fixierung des Tatbestandes, greift zu kurz. Die Gleichstellung des unechten Unterlassens mit dem Begehen kann nur erfolgen, wenn der Unterlassende eine Garantenstellung innehat, die beim echten Unterlassen fehlt. Dort ist bereits jedermann handlungspflichtig, der in die tatbestandlich beschriebene Situation kommt, während das unechte Unterlassen nur von demjenigen verübt werden kann, dem eine Garantenpflicht auferlegt wurde. Das echte Unterlassen weicht außerdem vom unechten dadurch ab, daß es nicht einen tatbestandlichen Erfolg voraussetzt, sondern nur ein bestimmtes Handeln. Dem gegenüber ist der Tatbestand eines unechten Unterlassungsdelikts als Spiegelbild des Begehungsdelikts immer als Erfolgsdelikt qualifiziert. Im Gegensatz zum

${ }^{126}$ Armin Kaufmann, Dogmatik, S. 206 ff. und JuS 61, 173 (173f.): S/S-Stree, Vor § 13, Rn. 137; Welzel, S. 202f. 
echten Unterlassen genügt ein bloßes Tun daher gerade nicht: Dem Unterlassenden wird immer die Pflicht zur Erfolgsabwendung auferlegt.

II. Für die Problematik in Frage kommende Unterlassungsdelikte

Fraglich ist nun, welche Straftatbestände für die vorliegende Problematik der unterlassenen Deliktshinderung überhaupt in Betracht kommen. Aus dem geschichtlichen Rückblick ist schon zu ersehen gewesen, welche Möglichkeiten sich eröffnen.

1. Echte Unterlassungsdelikte

Durch den Wegfall des $\S 143$ StGB vor nunmehr 25 Jahren ist das einzige unstreitig echte Unterlassungsdelikt, das sich mit einer strafrechtlichen Verantwortlichkeit der Eltern für die Taten ihrer Kinder beschäftigt, aus dem Strafgesetzbuch entschwunden ${ }^{128}$.

Von den gesetzlich geregelten Unterlassungsdelikten kommt weiter $\S 171$ StGB als echtes Unterlassungsdelikt in Frage, das sich mit elterlichen Handlungspflichten befaßt. Allerdings wird auf $\S 171 \mathrm{im}$ 5. Teil der Arbeit gesondert eingegangen. Erst dort soll auch untersucht werden, ob es sich bei $\S 171$ StGB tatsächlich um ein echtes oder um ein unechtes Unterlassungsdelikt nach der hier gewählten Unterteilung handelt.

Andere echte Unterlassungsdelikte, die die Eltern durch eine unterlassene Deliktshinderung verwirklichen könnten, sind nicht ersichtlich.

2. Gesetzlich geregelte unechte Unterlassungsdelikte

Als gesetzlich geregeltes Unterlassungsdelikt kommt nur $\S 171 \mathrm{StGB}$ in Betracht; wie schon erwähnt, soll die Einordnung dieser Vorschrift jedoch einem späteren Kapitel vorbehalten bleiben.

\footnotetext{
127 Jescheck/ Weigend, § 58 V 4, S. 611f.; Schmidhäuser, 12/14.

${ }^{128}$ Zur Einordnung des $\S 171$ StGB siehe unten, Teil 4.
} 
3. Gesetzlich nicht geregelte unechte Unterlassungsdelikte

Neben $\S 171$ StGB kommt für das zu untersuchende Verhalten der Erziehungsberechtigten nur noch eine Bestrafung durch die unechten Unterlassungsdelikte in Betracht.

Dafür ist es erforderlich, sich noch einmal den Ablauf deutlich zu machen: Der Aufsichtspflichtige hindert das Kind oder den Jugendlichen nicht daran, ein Delikt $\mathrm{zu}$ begehen. Fraglich ist, ob der Aufsichtspflichtige für dieses durch den anderen begangene Delikt bestraft werden kann.

Es ist also nur darauf abzustellen, inwieweit dem Aufsichtspflichtige die Tat des Kindes oder Jugendlichen zugerechnet werden kann. Die Fülle der Begehungstatbestände ist zunächst durch das Merkmal der Gleichwertigkeit von Tun und Unterlassen einzuschränken. Nicht alle Begehungstatbestände können durch Unterlassen begangen werden ${ }^{129}$. Fraglich ist, ob alle Delikte, die rein praktisch durch ein Kind oder einen Jugendlichen begangen werden können, auch den diesen nicht hindernden Eltern zugerechnet werden können. Hier ist zwischen den verschiedenen Straftatbeständen zu differenzieren. Als Beispiele, bei denen eine Verantwortlichkeit der Eltern denkbar wäre, bieten sich vor allem die Nichthinderung von Körperverletzungen, Sachbeschädigungen oder bei Brandstiftung an. Problematisch sind Zueignungs- bzw. Eigentumsdelikte, z.B. $\S \S 242,246$ StGB, weil es den Aufsichtspflichtigen zumeist an der erforderlichen Zueignungsabsicht (auch bei der Zueignung zugunsten des Dritten) fehlen dürfte; gleiches gilt für die Absicht bei $\S 263$, dem Dritten einen vermögenswerten Vorteil zu verschaffen. Insoweit kann nur eine Beihilfe zur Tat des Minderjährigen durch Unterlassen angenommen werden. Es ist insgesamt jedoch eine große Anzahl an Delikten allein im Bereich der Garantenstellung kraft Autorität möglich, die in dieser Konstellation begangen werden können ${ }^{130}$. Allerdings scheiden aber von vornherein solche Delikte aus, die nur durch einen volljährigen Täter, z.B. einen Amtsträger, begangen werden können.

\footnotetext{
${ }^{129}$ Vgl. Busch, Weber-FS, S. 192 (195, 201ff.).

${ }^{130}$ Vgl. Henkel, MSchrKrim 44, 178 (S. 182).
} 
Welche Tatbestände des Besonderen Teils grundsätzlich von der Anwendung ausgeschlossen werden müssen, kann abschließend erst dann beantwortet werden, wenn festgestellt worden ist, welche Begehungsform der Aufsichtspflichtige durch das Unterlassen der Deliktshinderung verwirklicht wird ${ }^{131}$. 


\section{Teil. Die Verwirklichung von unechten Unterlassungsdelikten durch die Eltern}

\section{A. Rechtsgrund für die Garantenstellung}

\section{Begründung der Garantenstellungen}

Im Gegensatz zu den echten Unterlassungsdelikten, bei denen der Gesetzgeber eine bestimmte Situation beschrieben hat, in der jeder, der sich darin befindet, zum Handeln verpflichtet ist, fehlt eine solche Bestimmung bei den unechten ungeregelten Unterlassungsdelikten ${ }^{132}$. Wohl kann jedem verboten werden, einen bestimmten rechtsgutsverletztenden Erfolg durch eine Handlung herbeizuführen; demgegenüber ist nicht jeder verpflichtet, einen schädlichen Erfolg abzuwenden ${ }^{133}$. Verpflichtet sind bei den unechten Unterlassungsdelikten vielmehr nur die Garanten. Zur Begründung der Garantenpflichten sind verschiedene Theorien entwickelt worden.

Ihnen liegt die Überzeugung zugrunde, daß in den Tatbeständen, die an sich nur ein positives Tun erfassen, nicht nur bestimmte Tätigkeiten verboten, sondern zugleich auch bestimmte Handlungen geboten sind ${ }^{134}$. Um die verfassungsrechtlichen Bedenken zu zerstreuen, wurde diese Erkenntnis in $\S 13$ StGB als Generalklausel kodifiziert ${ }^{135}$. Danach ist die unterlassene Abwendung einer straftatbestandlich erfaßten Rechtsgutsverletzung nur strafbar, wenn der Täter für das Ausbleiben des Erfolges rechtlich einzustehen hat. Damit können nur solche Personen Täter werden, die einer besonderen rechtlichen Pflicht zur Erfolgsverhinderung -der Garantenpflicht- unterliegen. Der Täterkreis ist somit begrenzt.

\footnotetext{
${ }^{132}$ Brammsen/Otto, Jura 85, 530 (532).

${ }^{133}$ Vgl. Bärwinkel, S. 18.

${ }^{134}$ Brammsen/Otto, Jura 85, 530 (532).

135 Vgl. Brammsen/Otto, Jura 85, 530 (532); dazu hat Lenckner, JuS 68, 304 (305) ausgeführt: „Wäre es möglich, die unechten Unterlassungsdelikte im Besonderen Teil besser und deutlicher zu regeln, als dies durch eine Generalklausel im Allgemeinen Teil geschehen kann, müßte dieser Weg schon aus verfassungsrechtlichen Gründen beschritten werden.“
} 
Die Kriterien, nach denen sich diese Garantenpflicht ergibt, sind umstritten. Fest steht, daß es sich um eine Rechtspflicht handeln muß, rein sittliche Pflichten genügen nicht ${ }^{136}$. Fraglich ist aber, woraus diese Rechtspflicht ersichtlich wird ${ }^{137}$. Jakobs hat zutreffend festgestellt, daß die Lösungsvorschläge zum Haftungsgrund unübersehbar detailliert geworden sind ${ }^{138}$. Daher sollen hier nur im Ansatz die verschiedenen Herleitungen behandelt werden.

Nach der älteren Lehre von der formellen Rechtspflicht (Rechtsquellenlehre), die zunächst von Reichsgericht und Literatur gleichermaßen vertreten wurde, konnten allein außerstrafrechtliche Rechtsquellen eine Garantenpflicht begründen. Danach ergab sich die Erfolgsverhinderungspflicht ursprünglich nur aus Vertrag und Gesetz ${ }^{139}$. Später wurde auch die Pflicht aus vorangegangenem gefährlichen Tun miteinbezogen, sofern es sich um eine gesetzeswidrige Gefährdung handelte ${ }^{140}$, sowie die enge Lebensgemeinschaft ${ }^{141}$.

Bald jedoch erwies sich der von der Rechtsquellenlehre gesteckte Rahmen als $\mathrm{zu}$ eng $^{142}$. Es zeigte sich, daß sich die strafrechtliche Pflichtwidrigkeit nicht einfach aus der Verletzung einer außerstrafrechtlichen Rechtsnorm ableiten ließ. So wies Schaffstein darauf hin, daß nicht der rechtsgültige Vertragsabschluß, sondern die tatsächliche Übernahme der Schutzfunktion entscheidend war $^{143}$. Ebenso beruht die Garantenpflicht nicht allein auf einer gesetzlichen Fürsorgepflicht der Ehegatten, sondern konnte sich auch bei Nichtverheirateten aus der engen Lebensgemeinschaft ergeben ${ }^{144}$. Daher

${ }^{136}$ RGSt 66, 71 (73); BGHSt 7, 268 (271); LK-Jescheck, § 13, Rn. 19; a.A. RGSt 69, 321 (323), aber von der nationalsozialistischen Ideologie gefärbt; vgl. dazu auch Schünemann, ZStW 96 (1984), 287 (305).

${ }^{137}$ Darstellung der Auffassungen bei Brammsen, Entstehungsvoraussetzungen, S. 45, Rn. 1.

${ }^{138}$ Jakobs, AT, 29/28; Überblick über die Lösungsvorschläge in der dortigen Fn. 53.

${ }^{139}$ BGHSt 2, 150 (153); Zur Entwicklung der Rechtsquellenlehre ausführlich Schulte, Garantenstellung und Solidarität, S. 44ff.; siehe auch Metzen, S. $32 \mathrm{ff}$.

${ }^{140}$ RGSt 63, 392 (394); Otto/ Brammsen, Jura 85, 530 (532) m.w.N.; Schmidhäuser, $16 / 36$.

${ }^{141}$ RGSt 74, 309 (311).

${ }^{142}$ Metzen, S. 33.

${ }^{143}$ Schaffstein, Gleispach-FS, S. 79.

${ }^{144}$ BGHSt 19, 167 (168). 
kam zumindest die Literatur zum Ergebnis, daß kein zwingender Zusammenhang zwischen den - meist zivilrechtlichen - Rechtspflichten und den strafrechtlichen Geboten der Erfolgsabwendung besteht ${ }^{145}$, während die Rechtsprechung des Bundesgerichtshofs an der, immerhin großzügig gehandhabten Rechtsquellenlehre festhielt ${ }^{146}$. Die Voraussetzungen der Garantenpflicht wurden mit der Ablösung von einer außerstrafrechtlichen Sonderpflicht durch die Rechtsprechung allerdings in freier, autonomer Weise bestimmt ${ }^{147}$. Gegenüber dieser in den fünfziger Jahren kulminierenden freien Rechtsschöpfung auf dem Gebiet der Unterlassungsstrafbarkeit sind in neuerer Zeit gravierende Bedenken angemeldet worden, was $\mathrm{zu}$ einer gewissen Restriktionstendenz des Bundesgerichtshofes führte ${ }^{148}$.

In Bezug auf die Eltern wäre die Rechtsquellenlehre auch in ihrer ursprünglichen Reinform über $\S 1626$ BGB zu einer Garantenstellung der Eltern gelangt.

Im Schrifttum gewannen aufgrund der eben genannten Argumente die materiellen Garantenlehren an Bedeutung, die nicht auf die äußerliche Regelung in einem Gesetz, sondern auf inhaltliche Kriterien für das Entstehen einer Handlungspflicht abstellen. Sie richten sich nach dem begründeten Vertrauen, daß jemand in ein Tun eines anderen haben darf, auf sozialethische Verpflichtungen, auf die Herrschaft über den Erfolgsgrund oder die Gefahrschaffung ${ }^{149}$.

Durchgesetzt hat sich die von Armin Kaufmann begründete Funktionenlehre, die Zweiteilung in Beschützer- und Überwachungsgaranten $^{150}$. Während der Beschützergarant eine Schutzfunktion für bestimmte Rechtsgüter hat, ist es die Pflicht des Überwachungsgaranten, beliebige Rechtsgüter vor einer bestimmten Gefahrenquelle, für die er verantwortlich ist, zu schützen. Die Stellung

\footnotetext{
${ }^{145}$ Otto, AT, S. $174, \S 9$, I 4 b) aa).

${ }^{146}$ Vgl. Lackner, § 13, Rn. $7 \mathrm{ff}$.

${ }^{147}$ Schünemann, ZStW 96, 287 (293).

${ }^{148}$ Schünemann, ZStW 96, 287 (293ff.).

${ }^{149} \mathrm{Vgl}$. den Überblick bei Otto/ Brammsen, Jura 85, 530 (533) m.w.N.

150 Siehe Übersicht bei Brammsen, Entstehungsvoraussetzungen, S. 31, 134 m.w.N.; Armin Kaufmann, Dogmatik, S. 283; vertreten von: Brückner, S. 64; Jescheck/ Weigend, $\S$ 59, IV 2, S. 621; Schmidhäuser, AT, 16/40; Rudolphi, NStZ 84, 149 (151); S/S-Stree, $\S 13$, Rn. 9.
} 
als Beschützergarant erfordert eine natürliche Verbundenheit, ein besonderes Gemeinschaftsverhältnis oder einen bestimmten Übernahmeakt. Demgegenüber ergibt sich die Stellung als Überwachungsgarant aus Ingerenz, tatsächlicher Sachherrschaft über bestimmte Gefahrenquellen oder aus der Verantwortung für fremdes Verhalten ${ }^{151}$. Danach müßte die elterliche Pflicht zur Deliktshinderung sich aus der Stellung als Überwachungsgaranten ableiten, soweit man ihnen die Verantwortung für fremdes Verhalten - das ihrer Kinder auferlegt.

Ferner sind die soziologisch fundierten Garantenlehren zu nennen. Darin wird davon ausgegangen, daß die soziale Rolle eines Individuums als ein Bündel von Verhaltensanweisungen entscheidend für die Garantenpflichten ist $^{152}$. Diese Verhaltensanweisungen enthalten jedoch keine genauen Kriterien, die eine Bestimmung von Garantenpflichten zweifelsfrei ermöglichen, und können somit vor dem Bestimmtheitsgrundsatz nicht bestehen. Dies ist auch hinsichtlich der sozialmethodologischen Theorien festzustellen, die sich mit den Verhaltenserwartungen im Alltagsleben auseinandersetzen ${ }^{153}$. Auch nach diesen Lehren wäre von Eltern jedenfalls zu erwarten, daß sie ihre Kinder von der Begehung von Straftaten abhalten. Damit würden auch die soziologisch bzw. sozialmethodologisch begründeten Lehren $\mathrm{zu}$ einer Garantenstellung für die zu untersuchende Tätergruppe der Eltern gelangen.

Fraglich ist hier, ob eine Entscheidung zwischen den Auffassungen für die weitere Untersuchung erforderlich ist. Nach jeder der genannten Lehren läßt sich eine Garantenpflicht der Eltern bestimmen, darüber zu wachen, daß von ihren minderjährigen Abkömmlingen keine Gefahren ausgehen. Nur die Herleitung dieses Ergebnisses ist unterschiedlich. Da es aber für die Ausgestaltung der Garantenpflicht, ihren Umfang und ihre verfassungsrechtliche Rechtfertigung auf die Begründung entscheidend

\footnotetext{
${ }^{151}$ Vgl. Rudolphi, NStZ 84, 149 (150f.); Otto/ Brammsen, Jura 85, 530 (533); S/S, § 13, Rn. 11ff.; Preisendanz, § 13, 3 f.

152 Otto, AT, S. 152 ff. m.w.N.; dargestellt bei Otto/ Brammsen, Jura 85, 530 (535) m.w.N.

${ }^{153}$ Otto, AT, S. 154 ff. m.w.N.; so auch Brammsen, Entstehungsvoraussetzungen, S. 9off.
} 
ankommen kann, ist hier eine Entscheidung wenn nicht unumgänglich, so aber doch zumindest zweckdienlich ${ }^{154}$.

Ein entscheidender Nachteil der Rechtsquellenlehre ist, wie oben bereits festgestellt wurde, daß sie mit den ihr zur Verfügung stehenden Garantenstellungen nicht umfassend genug und somit auf weitere Auslegung angewiesen ist ${ }^{155}$. Dadurch wird die konkrete Bestimmung von Garantenpflichten erschwert bzw. unmöglich. Schünemann spricht daher rückblickend von einem ,historischen Wildwuchs verschiedenartigster Garantenstellungen“, die im Laufe der Zeit in einer dem Zeitgeist entsprechenden Rechtsfindung und ohne systematischen Zusammenhang geschöpft wurden ${ }^{156}$.

Die verschiedenen Ansätze der materiell begründeten Garantenlehren sind hingegen durchaus in der Lage, einzelne Aspekte der Garantenhaftung überzeugend zu erklären. Das Problem der materiellen Lehre liegt darin, daß sie keinen dogmatischen Haftungsgrund für die Unterlassungsstrafe aufweisen kann und ihr -speziell hinsichtlich der Funktionenlehre- keine genaue Differenzierung zwischen Beschützerund Überwachergaranten gelingt ${ }^{157}$. Tatsächlich fördert die Einteilung in Obhuts- und Überwachungspflichten die Klarheit, liefert aber nicht schon selbst den Geltungsgrund der einzelnen Garantenstellungen ${ }^{158}$. Das gelingt aber auch der formellen Lehre nicht. Dazu hat Jakobs ausgeführt: „Die förmliche Rechtsquelle ist bei dieser Einteilung (nach den Funktionen) jedoch nebensächlich. Insbesondere schafft ein Gesetz nicht ex nihilo eine Garantenstellung, sondern kann allenfalls die Grenzen einer ... Zuständigkeit klären. So sind die zumeist genannten Gesetze, z.B. § 1626 I BGB, für Garantenpflichten nicht in dem Sinn für die genannten Pflichten konstitutiv, daß ohne die Normen des positiven Rechts eine Pflicht entfiele. Hätte der Gesetzgeber diese Pflichten als selbstverständliche Pflichten nicht positiviert, wohl aber die Institution

\footnotetext{
${ }^{154}$ vgl. Landscheidt, Problematik der Garantenpflichten, S. $62 f$.

${ }^{155}$ Frey, Zumutbarkeit, S. 38, weist darauf hin, daß die Garantenstellung eigentlich einen Verstoß gegen den nulla-poena-Grundsatz darstelle. Allein entspreche es dem Wesen der unechten Unterlassungsdelikte, daß diese Bestimmtheit durch eine konkrete und erschöpfende Umschreibung nicht erreicht werden könne.

${ }^{156}$ Schünemann, ZStW 96 (1984), 287 (304).

${ }^{157}$ Schultz, JuS 85, 270 (271); ders. Amtswalterunterlassen, S. 145.

${ }^{158}$ Schünemann, ZStW 96 (1984), 287 (305) m.w.N.
} 
des Eltern-Kind-Verhältnisses anerkannt, so würde das Manko an Positivierung die Garantenstellung nicht beeinträchtigen“.

Weiter führt Jakobs aus, daß sich nur mit einem materialen Prinzip klären lasse, ob eine gesetzliche Pflicht eine Garantenpflicht oder aber eine schwächere Pflicht sei. Zwar sei es verfehlt, die Garantenpflichten ohne Blick auf die normative Lage bestimmen zu wollen. Die strafrechtlich relevante Wirklichkeit sei ohne Berücksichtigung der rechtlichen Gestaltung nicht auszumachen“159. Jakobs weist aber darauf hin, daß die gesellschaftlichen Grundinstitutionen - hier speziell das Eltern-KindVerhältnis- zumindest ansatzweise positiviert seien. Aus diesem Grunde würden die Pflichten üblicherweise unter Verwechslung von Grund und Folge nicht aus der Institution, sondern aus dem Gesetz „hergeleitet“, was jedoch im Hinblick auf die überaus zahlreichen gesetzliche Pflichten, die keine Garantenpflichten seien, eine recht unvollkommene Deutung sei ${ }^{160}$.

Auch Arzt weist darauf hin, daß nicht alle außerhalb des StGB stehenden gesetzlichen Vorschriften, die Pflichten zum Schutze von Rechtsgütern Dritter und zur Überwachung von Gefahrenquellen statuieren, zugleich Garantenpflichten seien. Dies müsse vielmehr durch Auslegung des $\S 13$ StGB ermittelt werden. Andernfalls würden Zivil- und öffentliches Recht dem Strafrecht Garantenpflichten geradezu aufdrängen können ${ }^{161}$. Indem man auf die rechtliche Grundlage der Handlungspflicht blickt, die sich nicht aus Rechtssätzen ergeben muß, sondern auch allgemeinen Rechtsgrundsätzen entstammen kann, gelangt man somit $\mathrm{zu}$ einer Verbindung der formellen mit der materiellen Betrachtungsweise ${ }^{162}$. Zudem herrschen zwischen den formellen und materiellen Lehren viele Überschneidungen, im Einzelfall gehen verschiedene Garantenstellungen ineinander über $^{163}$. So zeigt Jakobs auf, daß der Schutz einer Person auch die Überwachung der ihr drohenden Gefahren, während die Überwachung einer Gefahrenquelle zugleich Schutz für die jeweils

\footnotetext{
159 Jakobs, Strafrecht AT, 29/28.

${ }^{160}$ Jakobs, Strafrecht AT, 29/58.

${ }^{161}$ Arzt, JA 80, 647 (650).

162 Jescheck/ Weigend, § 59 IV 2, S. 621; LK-Jescheck, § 13, Rn. 19; Stree, in MeyerFS, S. 146; Schultz, JuS 85, 270 (271); S/S-Stree, § 13, Rn. 8.

${ }^{163}$ Wessels, AT, Rn. 716.
} 
Gefährdeten bedeutet ${ }^{164}$. Die Zweiteilung sollte also auch nicht als grundsätzliche Abkehr von der klassischen Fünfteilung aufgefaßt werden. Die Frage, wie man zu einem Beschützer oder Überwacher wird, führt zur klassischen Fünfteilung -Gesetz, Vertrag, Übernahme, Lebensgemeinschaft, Gefahrschaffung- zurück ${ }^{165}$.-

Damit bleibt festzuhalten, daß es noch nicht abschließend geklärt ist, aus welchem Grundgedanken die Garantenpflichten herzuleiten sind und ob das Problem überhaupt auf ein einheitliches Prinzip zurückgeführt werden kann. Das bedeutet auch, daß nicht sicher ist, ob die Garantenpflicht ausschließlich strafrechtlichen Regeln folgt oder ob auf vorwiegend außerstrafrechtliche Regeln zurückgegriffen werden muß ${ }^{166}$. Daher kann und soll hier kein abschließendes Ergebnis über das Grundprinzip der Garantenpflicht getroffen werden.

Die derzeit überzeugendste und praktikabelste Lösung stellt der Ansatz Armin Kaufmanns dar, nach Beschützer- und Überwachergaranten zu unterscheiden. Er gewährleistet eine ausreichende Bestimmtheit und trägt zugleich den gesellschaftlichen bzw. ethischen Anforderungen Rechnung. Diese Einteilung der Garantenpflichten nach der Funktionenlehre soll daher im folgenden als Arbeitshypothese verwendet werden.

\section{Einordnung innerhalb der Garantenstellungen}

1. Die Deliktsverhinderungspflicht als Aufsichtspflicht

Einig ist sich die Lehre, daß den Eltern aus dem Recht und der Pflicht, die Kinder zu erziehen, die Verpflichtung zukommt, darüber zu wachen, daß diese nicht rechtswidrig strafrechtlich geschützte Rechtsgüter verletzen ${ }^{167}$. Diese Garantenpflicht wird zumeist als Aufsichtspflicht bezeichnet. Die strafrechtliche Aufsichtspflicht wird dabei in Literatur und Rechtsprechung inhaltlich an die zivilrechtliche Aufsichtspflicht

\footnotetext{
164 Jakobs, AT, 29/27.

${ }^{165}$ Arzt, JA 80, 647 (648).

166 Lackner, § 13, Rn. 12; vgl. auch Schünemann, ZStW 96, 287 (299).

${ }^{167}$ Vgl. Bärwinkel, Garantieverhältnisse, S. 168.
} 
angelehnt, aber nicht weiter erörtert. Man setzt die Aufsicht ohne Hinterfragen als eigentliches Wesen der Garantenpflicht voraus.

Fraglich ist aber zunächst, wie die Garantenpflicht desjenigen, der eine Herrschaftsmacht über jemanden besitzt, zu qualifizieren ist. Dabei stellt sich eine Vielzahl von Fragen: Muß es sich tatsächlich um eine Aufsicht über das Kind oder den Jugendlichen handeln, und muß diese Aufsicht über eine Person stets mit einem Einschreiten gekoppelt sein ? Geht es nur um die Aufsicht über das Kind oder den Jugendlichen zur Verhinderung von Verletzungen und Schäden, oder gar um seine richtige Erziehung ? Gehen die Pflichten des Garanten über die bloße Aufsicht hinaus oder bleiben sie dahinter zurück ? Fraglich ist auch, ob es zur elterlichen Aufsichtspflicht gehört, daß der Taterfolg um jeden Preis verhindert wird, oder ob es genügt, wenn die Eltern im Vorfeld vorbeugende Maßnahmen ergriffen haben. Weiter ist von Bedeutung, ob es sich um eine Pflicht handelt, die dem Schutz von Rechtsgütern Dritter dient oder dem Schutz des Kindes selbst.

Sinnvoll erscheint es, sich zunächst dem Begriff der Aufsicht zuzuwenden. Betrachtet man den Begriff der Aufsicht losgelöst von irgendwelchen Rechtsquellen, so versteht man unter Aufsicht gemeinhin die ständige oder regelmäßige Beobachtung einer Person oder einer Sache mit der Möglichkeit, auf die Person oder Sache einzuwirken. Von der reinen Beobachtung unterscheidet die Aufsicht sich dadurch, daß ein Zugriff möglich ist. Dies läßt sich auch am Sprachgebrauch festmachen: Wer eine Sache nur beobachtet, d.h. observiert, hat eine Distanz zu ihr, er bleibt im Sinne des Wortes „Beobachter“. Wer hingegen die Aufsicht führt, ist selbst Teil des Geschehens. Ausgehend von einer Umschreibung als „Beobachtung mit Eingriffsmöglichkeit“ fällt unter die Aufsichtspflicht sowohl die Obhutspflicht des Beschützergaranten als auch die Überwacherpflicht des Gefahrquellengaranten. Man muß daher zunächst zum Ergebnis kommen, daß die Obhuts- und die Überwachergarantenpflicht für die Eltern die gleiche Aufsichtspflicht erfordern. Die Mutter, die ihr Kind draußen beim Spielen überwacht, um $\mathrm{zu}$ verhindern, daß das Kind mit seinem Ball die Fensterscheibe des Nachbarn zerstört (Überwachergarantin), verhält sich nicht anders als die Mutter, die ebenfalls nachsehen geht, um sicher zu sein, daß das Kind 
sich nicht beim Spielen verletzt (Beschützergarantin). Sowohl bei der Überwacher- als auch bei der Obhutspflicht wird die Person oder die Sache „besichtigt“”, um Gefahrensituationen $\mathrm{zu}$ erkennen und $\mathrm{zu}$ vermeiden, die im Zusammenhang mit ihr - von außen kommend oder von ihr selbst ausgehend - stehen. Aufsicht kann daher als ein Oberbegriff verstanden werden, der sich in die sichernde und schützende Aufsicht aufgliedert.

Im Rahmen der Überwachergarantenstellung bekommt der Aufsichtsbegriff einen besonderen Sinn: Überwacht wird im sprachlichen Sinne gerade nicht eine zu schützende Person oder Sache, sondern eine Person oder Sache mit Risikopotential für ihre/ seine Außenwelt. Überwachung enthält daher, anders als die neutrale Aufsicht, einen negativen Beiklang. Überwacht wird das Kind, damit es „keine Dummheiten macht“", und nicht deshalb, damit es nicht beim Spielen stürzt. Der Begriff des Überwachens hat mit dem Behüten nichts gemein. Ein Ausdruck, der der Aufsicht mit ihrem ambivalenten Charakter nahekommt, ist allenfalls der des „Aufpassens“. „Paß’ auf, daß das Kind nicht hinfällt !““ und: „Paß’ auf, daß das Kind nicht die Scheibe des Nachbarn einwirft.“

Es bleibt festzustellen, daß der Begriff der Aufsicht zur Beschreibung der elterlichen Pflicht nicht falsch ist, jedoch nur wenig über den Inhalt der Pflicht aussagt. Es wäre auch ein Irrtum zu glauben, die Unterscheidung von Überwacher- und Beschützergarantenpflicht würde an dieser Ungewissheit etwas ändern. Da grundsätzlich alle Garantenstellungen gleichwertig sind, wird von den Garanten auch gleich viel verlangt. Selbst, wenn es im folgenden gelingt, den Nachweis zu erbringen, daß es sich bei der hier in Frage stehenden Aufsichtspflicht um eine Überwachergarantenpflicht handelt, ist daher für deren Inhalt noch nichts gewonnen.

\section{Die Eltern als Beschützergaranten}

Einer Ansicht nach dient eine Garantenpflicht der Eltern, das Kind oder den Jugendlichen an seinen Straftaten zu hindern, nur dem Schutz des 
Kindes/ Jugendlichen vor sich selber ${ }^{168}$. Es handelt sich danach um eine reine Beschützergarantenstellung. Nach dem ganz überwiegenden Teil der Lehre ergibt sich für die Eltern die Garantenpflicht aus der Überwachung einer Person kraft Herrschaftsmacht ${ }^{169} . \mathrm{Zu}$ untersuchen ist im folgenden, welcher der beiden Schutzrichtungen der Vorrang eingeräumt werden soll.

Otto und Brammsen gehen von einer Beschützergarantenstellung aus, und zwar davon, daß der Schutz des Kindes im Vordergrund stehe und die Deliktshinderung nur als Nebenzweck der Allgemeinheit zugute komme $^{170}$. Die Autoren meinen, daß Minderjährige in der Regel ihre zumeist weitreichenden Folgen regelwidrigen Verhaltens - auch für die Entwicklung ihrer eigenen Persönlichkeitsstruktur - nicht absehen könnten. Die Deliktsverhinderungspflicht dient danach nur dem Schutz des Kindes bzw. Jugendlichen vor sich selbst.

Allerdings wird nicht unterschieden zwischen strafmündigen und strafunmündigen Minderjährigen. Eine Differenzierung hinsichtlich der Einsichtsfähigkeit, die von den Autoren hier abgelehnt wird, wäre jedoch erforderlich. Bei einem strafmündigen Jugendlichen muß man nämlich, im Gegensatz zu einem strafunmündigen Kind, von einer zumindest ansatzweisen Persönlichkeitsfestigung ausgehen; ein Delikt durch einen strafmündigen Jugendlichen hat also eine andere Qualität. Es wäre unzutreffend, den Jugendlichen nur als Opfer seiner selbst zu betrachten.

Ebenso wäre es voreilig, bei jeder Straftat des Jugendlichen eine Gefährdung der Entwicklung seiner Persönlichkeitsstruktur anzunehmen. An dieser Stelle einen Schutz für die Persönlichkeitsstruktur aufbauen zu wollen anstatt die Interessen der Umwelt einfließen zu lassen, erscheint daher zu einseitig.

Der hier postulierte Bezug zur Gefährdung der Persönlichkeitsstruktur erinnert zudem stark an den Tatbestand des $\S 171$ StGB, der bei psychischer Gefährdung des Minderjährigen aufgrund eines strafbaren

168 Otto/ Brammsen, Jura 85, 530 (542); Brammsen, Entstehungsvoraussetzungen, S. 153; Sonderfall, weil der aktive Täter voll verantwortlich war: KG JR 1969, 27;

${ }^{169}$ Bärwinkel, Garantieverhältnisse, S. 168; Schünemann, Grund und Grenzen, S. 323ff.; LK-Jescheck, § 13, Rn. 41 f.

170 Otto/ Brammsen, Jura 85, 530 (542); Brammsen, Entstehungsvoraussetzungen, S. 153. 
Lebenswandels die Erziehungspflichtigen bestraft. Der von Otto und Brammsen geforderte Schutz ist also durch eben diese Vorschrift ausdrücklich kodifiziert. Die Konstruktion einer unechten Unterlassungstat durch die Eltern mit gleicher Schutzrichtung wie $§ 171$ StGB wäre umständlich und überflüssig. Weiter ist $\mathrm{zu}$ bedenken, daß $\S 171$ StGB eine Altersgrenze enthält ${ }^{171}$; diese würde man ignorieren und dem Analogieverbot des Strafrechts zuwider handeln, wenn man der Auffassung von Brammsen und Otto folgte. Im übrigen werden keine weiteren Erklärungen geliefert, und es sind auch keine weiteren Ansätze ersichtlich. Die Auffassung kann daher nicht überzeugen.

\section{Eltern zugleich als Beschützer und Überwacher}

Denkbar wäre ein Kompromiß, bei dem der Aufsichtspflichtige gleichermaßen verantwortlich für die Rechtsgüter seines Kindes und für die durch dieses gefährdeten Rechtsgüter von Dritten wäre; dann wäre er gewissermaßen Beschützergarant und Überwachergarant in einer Person. Das ist so lange nicht problematisch, als diese beiden Garantenstellungen nicht in einer einzigen Situation zusammentreffen. Man müßte für die hier relevante Gruppe von Fällen aber davon ausgehen, daß die Straftat des Kindes, die von den Eltern nicht verhindert wird, zugleich sowohl das Kind als auch den Dritten schädigt. Fraglich ist, wie man eine solche Doppelpflicht der Eltern technisch konstruieren könnte. Ein fest umrissenes Schutzgut läge nicht vor, sondern immer gleich zwei. Fraglich ist, ob diese beiden Schutzgüter gleichzeitig verletzt sein müßten, um eine Strafbarkeit begründen zu können. Es ist nämlich dafür von Bedeutung, ob die Gefährdung des einen Schutzgutes auch stets die Gefährdung des anderen zur Folge hat.

Weiter müßten die Eltern gleichzeitig als Beschützer- und als Überwachergarant agieren. Arzt sieht eine doppelte Garantenpflicht der Eltern insofern, als diese die Kinder gegen Straftäter und gegen sich selbst, wenn sie selbst straffällig werden, zu schützen haben. Es liege dann gleichzeitig eine Bewacher- und eine Beschützerpflicht vor $^{172}$.

\footnotetext{
${ }^{171}$ Erfaßt werden nur Jugendliche bis 16 Jahre.

${ }^{172}$ Arzt, JA 1980, 647 (652).
} 
Daraus leitet Arzt ab, daß man bisweilen keine deutlichen Abgrenzungen zwischen den verschiedenen Garantenverhältnissen vornehmen könne. Dabei berücksichtigt er jedoch nicht, daß es sich bei dem Schutz des Kindes vor sich selbst nicht um eine Überwacherpflicht mit Schutzrichtung für die Außenwelt, sondern vielmehr ebenfalls um eine Beschützerpflicht zugunsten des Kindes handelt. Bei dem von Arzt genannten Fall wären Eltern also sowohl wegen der Straftat an dem Kind als auch wegen der Straftat des Kindes selbst Beschützergaranten zum Schutze des Kindes. Eine Lösung ist somit nicht gewonnen.

Das Agieren der Eltern sowohl als Bewacher wie auch als Beschützer könnte überdies ein widersprüchliches Verhalten der Eltern erfordern. Dabei ist $\mathrm{zu}$ berücksichtigen, daß der Überwachergarant die Gefahrenquelle ungeachtet eines bestimmten Opfers von der Außenwelt abzuschirmen hat, während der Beschützergarant ein bestimmtes Opfer zu schützen hat, unabhängig davon, welche Gefahr diesem droht ${ }^{173}$. Die Eltern müßten einerseits die Umgebung des Kindes vor dem Kind schützen, zugleich müßten sie aber das Kind vor seiner Umgebung schützen. Es wären unter Umständen unterschiedliche Handlungsweisen erforderlich, die sich gegenseitig ausschließen: Eltern, die sehen, daß ihr 14jähriger Sohn gerade ein Auto aufbricht, müssen zum einen ihrer Beschützerpflicht nachkommen, indem sie den Jugendlichen vor dem gesellschaftsschädigenden Tun und damit vor einer Gefährdung seiner Persönlichkeitsentwicklung bewahren. Als Beschützergaranten muß es ihnen auch darum gehen, den Jugendlichen möglichst schonend von der Ausführung der Tat abzubringen und gegebenenfalls sogar dafür zu sorgen, daß er keine rechtlichen, insbesondere strafrechtlichen, Konsequenzen $\mathrm{zu}$ befürchten hat; die entstandenen Schäden am aufgebrochenen Fahrzeug oder der Verlust der darin enthaltenen Gegenstände für den Inhaber sind dabei nachrangig. Als Überwachergaranten müssen die Eltern hingegen ihr Augenmerk in erster Linie auf die Rechtsgüter des Autohalters richten und Schaden davon abwenden. Die Möglichkeit, daß der Jugendliche als Folge der Intervention staatlich belangt wird oder seine psychische Verfassung

${ }^{173}$ Arzt, JA 80, 647 (648). 
oder seine Haltung zu seinen Eltern sich negativ verändert, dürfen dafür zunächst keine Rolle spielen ${ }^{174}$.

Gegen eine doppelte Garantenstellung spricht schließlich, daß der Schutz des Minderjährigen vor sich selbst, wie oben dargestellt, an dieser Stelle nicht in den Vordergrund zu stellen ist.

\section{Die Eltern als Überwachergaranten}

a) Garantenstellung aus der Herrschaft über eine gefährliche Person

aa) Einleitung

Nach der ganz herrschenden Ansicht in der Literatur ist die elterliche Pflicht, Straftaten durch ihre Abkömmlinge zu unterbinden, als Überwachergarantenpflicht aufzufassen ${ }^{175}$. Immerhin deutet schon der Sprachgebrauch darauf hin, daß es sich um eine Überwacherpflicht handelt: Niemand käme auf den Gedanken, davon zu sprechen, er überwache das Kind, damit es sich nicht verletze. Vielmehr wird das Kind überwacht, damit es ,nichts anstellt ${ }^{\star 176}$.

Die Garantenstellung soll sich danach aus der Überwachung von Personen, d. h. aus der Überwachung kraft Herrschaftsmacht, ergeben. Die Herrschaftsmacht muß daher ein Kriterium sein, das die Verantwortlichkeit für das Handeln einer anderen Person, hier des Minderjährigen, zu begründen vermag. Dazu muß die Herrschaft eine Legitimation haben. Es liegt bei der Untersuchung nicht fern, die Garantenstellung aus der Herrschaft über Personen mit jener über Sachen zu vergleichen ${ }^{177}$. Während die Herrschaft über Sachen aber etwas Selbstverständliches ist, erscheint die Herrschaft über Menschen in einem

\footnotetext{
${ }^{174}$ Es ist natürlich auch denkbar, die Verhinderung eines Delikts stets als Nutzen für das Kind oder den Jugendlichen anzusehen, selbst wenn es bzw. er mit Gewalt oder durch die Polizei an einer Straftat gehindert wird.

175 Bärwinkel, Garantieverhältnisse, S. 168; Brückner, S. 65; LK-Jescheck, § 13, Rn. 41f.; Maiwald, Jus 81, 473 (480); Preisendanz, § 13, 4.dd; Rudolphi, Dünnebier-FS, S. 575f.; Schünemann, Grund und Grenzen, S. 323ff.; Teckhoff, JuS 78, 308 (311).

${ }^{176}$ Vgl. schon Nagler, GS 1916, 1 (6), der deutlich zwischen der Pflege, die alle positiven Aspekte der Charakterbildung und Lebensführung umfaßt, und der Aufsicht, die das Abgleiten auf falsche Bahnen, insbesondere Kriminalität, verhindern soll.

177 Sangenstedt, Garantenstellung und Garantenpflicht, S. 405.
} 
freiheitlich verfaßten Gemeinwesen von vornherein heikel. Sie bedarf einer genauen rechtlichen Ausgestaltung ${ }^{178}$.

Charakteristisch für die Garantenstellung aus der Herrschaft über eine Sache ist, daß die Sache Risiken für die Umwelt birgt, die sich der Gewaltinhaber zurechnen lassen muß. Wer als Eigentümer, Besitzer oder Halter der faktische Inhaber eines Industriebetriebes, einer technischen Anlage oder eines Tieres ist, hat die Möglichkeit zur fortlaufenden planmäßigen Einwirkung auf die Sache. Die Rechtsordnung hat diese Gewalthabe mit der Kompetenz verknüpft, andere von jeder eigenmächtigen direkten Einflußnahme auf die Sache auszuschließen ${ }^{179}$. Selbst an sich harmlose Gegenstände des eigenen Organisationskreises können infolge des vermittelnden Verhaltens Dritter in einen schadensträchtigen Verlauf verwickelt werden, wie etwa der spitze Bleistift auf dem Schreibtisch, das Messer in der Küchenschublade, die Axt im Schuppen, die Leiter im Garten ${ }^{180}$. Da nahezu alles Baustein irgendeines Delikts sein kann ${ }^{181}$, müssen Kriterien gefunden werden, nach denen sich der Umfang der Aufsicht und der Haftung bemißt ${ }^{182}$.

Die gleiche Problematik ergibt sich bei der Herrschaft über Menschen. Sie ist im Grundsatz ähnlich geartet wie die über Sachen. Auch die Herrschaft über Menschen kann zu einer strafrechtlichen Verantwortlichkeit des Aufsichtspflichtigen führen, wenn dieser den anderen Menschen beherrscht hat, er ihn also in der Weise kontrollieren konnte, wie er eine Sache kontrolliert hätte. In der Kontrolle des Menschen aber liegt auch zugleich eine wesentliche Abweichung zur Kontrolle einer Sache: Im Gegensatz zur Sache ist der „,beseelte“ Mensch noch nicht unter Kontrolle, wenn sein Körper dies ist. Denn beim Menschen tritt, anders als bei der Sache, die Fähigkeit hinzu, einen eigenen Willen $\mathrm{zu}$ bilden, und das Bedürfnis, diesen Willen auch durchzusetzen. Eine Kontrolle über den fremden Willen ist allein durch eine äußere Herrschaft über die Person nicht zu bewerkstelligen. Auf der

\footnotetext{
${ }^{178}$ Schünemann, Grund und Grenzen, S. 324; ähnlich: Herzberg, Unterlassung, S. $320 f$.

${ }^{179}$ Sangenstedt, Garantenstellung und Garantenpflicht, S. 381.

${ }^{180} \mathrm{vgl}$. Freund, Erfolgsdelikte, S. 227.

181 vgl. Freund, Erfolgsdelikte, S. 227; Welp, Vorangegangenes Tun, S. 285; Frisch, Tatbestandsmäßiges Verhalten, S. $240 f$.
} 
anderen Seite wäre es zu viel verlangt, wollte man vom Garanten auch eine Herrschaft über den Willen fordern ${ }^{183}$. Der Wunsch nach der Beherrschung des fremden Willens resultiert in diesem Fall daraus, das Verhalten des anderen planbar und vorhersehbar zu machen, um die Aufsicht einfacher durchführen zu können. Die Beherrschung des Willens ist aber weder zum Schutz der gefährdeten Rechtsgüter erforderlich noch im Sinne einer aufgeklärten Gesellschaft erstrebenswert. Es muß also genügen, daß das äußere Verhalten der beherrschten Person mit dem normgemäßen Verhalten übereinstimmt, ohne daß die Willenentschlüsse als solche verändert werden müssen ${ }^{184}$.

Diese Einflußnahme auf eine andere Person setzt zunächst voraus, daß die $\mathrm{zu}$ beherrschende Person nicht selbst voll verantwortlich ist ${ }^{185}$. Eine Herrschaftsstellung gegenüber (geistig gesunden) Volljährigen ist wegen der Selbstverantwortlichkeit Erwachsener folglich ausgeschlossen ${ }^{186}$.

Bei der Garantenstellung aus der Herrschaft über Personen handelt es sich fast ausnehmend um die Herrschaft über sogenannte ,gefährliche Personen“, also um Menschen, von denen ein besonderes Risiko für ihre Umwelt ausgeht. Wie sich noch zeigen wird, fallen nicht nur Kinder oder Geisteskranke unter eine solche Herrschaft, jedoch ist Hintergrund aller Aufsichtspflichten das spezifische Gefahrenpotential, das sich ergibt, wenn die betreffenden Personen sich frei in der Gesellschaft bewegen. Gefährlichkeit läßt sich auf verschiedene Weisen definieren. Fraglich ist,

\footnotetext{
182 Hierzu auch Maiwald, Jus 81, 473 (480), der die Frage stellt, weshalb nur manche Formen der Herrschaft eine Garantenstellung begründen und manche nicht.

${ }^{183}$ So aber wohl Brammsen, Entstehungsvoraussetzungen, S. 224; Schünemann, Grund und Grenzen, S. 324.

184 Dies wäre wieder eine Frage der Erziehung, also ein Aspekt, der von Eltern im Rahmen der Beschützergarantenstellung umgesetzt werden muß.

${ }^{185}$ Vgl. Immel, ZRP 89, 105 (198).

${ }^{186}$ A. A. aber noch KG JR 69, 27 (27f.). Ein Vater verhinderte nicht, daß sein 21jähriger Sohn zu seinen -des Vaters- Gunsten eines Falschaussage tätigte. Eine Garantenstellung aus der Beschützerfunktion des Elternteils gegenüber dem Kind wurde zwar zutreffend wegen der Volljährigkeit des Sohnes abgelehnt. Das KG bejaht eine Garantenstellung des Vaters dann jedoch mit der zweifelhaften Begründung (S. 28), hier sei eine Pflicht aus dem familiären Zugehörigkeitsbewußtsein - vergleichbar mit der Hilfspflicht aus enger Lebensgemeinschaft - zu bejahen, weil gerade die Familienbande Grund für die Falschaussage gewesen seien; dazu ablehnend Lackner, JR 69, 27f.; Brammsen/Otto Jura 85, 592 (599); Herzberg, Unterlassung, S. 321f.; Schünemann, Grund und Grenzen, S. 333.
} 
ob es sich um einen Zustand handelt, der bewiesen werden kann oder muß $\beta^{187}$. Der Begriff der Gefährlichkeit ist in der Literatur zur Garantenstellung über Personen sehr verbreitet, wird jedoch nirgends weiter ausgeführt. Von Gesetzes wegen erscheint er nur im Unterbringungsrecht im Rahmen des $§ 63$ StGB. Gefährlichkeit bedeutet in diesem Fall, daß von der Person eine rechtswidrige Tat befürchtet wird. Die Umschreibung einer Person als gefährlich stellt dabei ein umfassendes Unwerturteil dar ${ }^{188}$.

Die besondere Gefährlichkeit des Minderjährigen beruht auf seiner mangelnden Fähigkeit, die Gefährlichkeit seines Verhaltens richtig einzuschätzen. Die von dem Minderjährigen ausgehende Gefährdung Dritter verändert sich im Laufe der Kindheit. Mit der Selbständigkeit wächst die Fähigkeit des Minderjährigen, die Gefährlichkeit seiner Handlungen einzuschätzen. Soweit der Minderjährige aufgrund ihres Alters und der damit im Regelfall verbundenen Selbständigkeit für Dritte keine besondere Gefahr mehr darstellt, bedarf er keiner umfassenden Aufsicht durch einen anderen $m e h r^{189}$.

Die Verantwortlichkeit für ein fremdes Tun erfordert weiter, daß der unmittelbar handelnde Täter mit dem Herrschaftsinhaber auf besondere Weise verbunden ist. Nur dann kann man erwägen, daß der Aufsichtspflichtige Herrschaft über denjenigen Handlungsablauf haben könnte, für den er verantwortlich gemacht werden soll ${ }^{190}$. Dafür ist die Innehabung einer im sozialen Alltagsleben allgemein anerkannten Aufsichts- oder Autoritätsstellung gegenüber einer anderen Person erforderlich. Nur eine solche Stellung gestattet eine Unterbindung der Betätigung deliktischer Willensentschlüsse anderer Personen durch die Ausübung von Machtmitteln ${ }^{191}$. Für Eltern ist eine solche Stellung

\footnotetext{
${ }^{187}$ Schneider, Geisteskrankheit und Gefährlichkeit, S. 25.

188 Schneider, Geisteskrankheit und Gefährlichkeit, S. 27.

${ }^{189}$ Fuchs, Elterliche Aufsichtspflicht, S. 195.

${ }^{190}$ Herrschaft soll hier aber nicht zwingend i.S. einer Tatherrschaft verstanden werden; vgl. Schünemann, Grund und Grenzen, S. 324.

191 Brammsen/ Otto, Jura 85, 592 (599); Herzberg, Unterlassung, S. 320; Jakobs, AT, 29/35; Rudolphi, Dünnebier-FS, S. 575; Teckhoff, JuS 78, 308 (311).
} 
gegenüber ihren minderjährigen Abkömmlingen anerkannt ${ }^{192}$. Durch die Verantwortlichkeit für das deliktische Handeln des Kindes oder Jugendlichen wird dem Erziehungspflichtigen somit eine Schutzpflicht gegenüber den Rechtsgütern Dritter auferlegt, die er durch Beaufsichtigung und Hinderung des seiner Herrschaftsmacht unterliegenden Minderjährigen erfüllen muß.

Auf eine genauere Beleuchtung solcher Herrschaftsverhältnisse zwischen Personen, insbesondere jenes zwischen Eltern und Kind, wird jedoch in der Literatur größtenteils sowie in der Rechtsprechung gänzlich verzichtet ${ }^{193}$. Vielmehr wird dort die Beherrschung der Umsetzung fremder Willensentschlüsse einfach vorausgesetzt. Einzig Schünemann und, darauf aufbauend, Sangenstedt haben sich des Themas genauer angenommen.

Bei der Beschäftigung mit der Frage, wie fremdes Verhalten für einen Dritten beherrschbar und damit zurechenbar sein kann, ergibt sich zunächst das Hindernis, daß das Strafrecht auf der personalen Verantwortlichkeit des Individuums aufbaut und eine Übernahme von fremdem Unrecht nicht kennt. Grundsätzlich ist es daher ausgeschlossen, für die Fehlentscheidungen eines Menschen einen anderen verantwortlich zu machen ${ }^{194}$. Etwas anderes kann nur da gelten, wo die Verantwortung für das rechtswidrige Verhalten eines Menschen durch die Rechtsordnung einem Dritten auferlegt wurde ${ }^{195}$. Die Rechtsordnung hat dies hinsichtlich von Kindern, Jugendlichen, Geisteskranken oder bei aus sonstigen Gründen nicht bzw. nicht voll Verantwortlichen getan ${ }^{196}$.

\footnotetext{
${ }^{192}$ Zur Herleitung aus tatsächlichen und rechtlich-normativen Gesichtspunkten siehe unten.

${ }^{193}$ Darauf weist auch Brammsen, Entstehungsvoraussetzungen, S. 151, hin.

${ }^{194}$ Brammsen/Otto, Jura 85, 530 (541); SK-Rudolphi, § 13, Rn. 32; Schünemann, Grund und Grenzen, S. 324.

${ }^{195}$ SK-Rudolphi, § 13, Rn. 32; Immel, ZRP 89, 105 (108); Freund, Erfolgsdelikt, S. 247; Herzberg, Unterlassung, S. $320 f$.

${ }^{196}$ Vgl. Frisch, Tatbestandsmäßiges Verhalten, S. 358 und 368; Busch, ZfJ 96, 456 (457).
} 
bb) Herleitung und Art des Herrschaftsverhältnisses

(1) Faktische Herleitung

Die erste Voraussetzung für die strafrechtliche Verantwortung für eine Person ist, daß der Dritte auf Grund einer ihm von der Rechtsordnung eingeräumten Aufsichts- und Befehlsgewalt die Herrschaft über den anderen ausübt. Allein diese Herrschaft über Personen vermag eine Verantwortlichkeit eines Dritten für deren rechtswidriges Verhalten zu begründen ${ }^{197}$. Daher ist es unumgängliche Voraussetzung, daß der Aufsichtspflichtige eine Position innehat, die ihm die tatsächliche Möglichkeit gewährt, auf eine in dem ihnen „überantworteten“ besonderen sozialen Einflußbereich befindliche Person unmittelbar einzuwirken ${ }^{198}$. Diese Garantenfunktion kann sich nur dort entwickeln, wo das „,menschliche Risikopotential“ ${ }^{\text {“199 }}$ dem Zugriff des Verpflichteten in einer Intensität ausgesetzt ist, die der Herrschaft des Begehungstäters über seine physischen und psychischen Kräfte entspricht. Diese spezifische Fremd-Verfügbarkeit läßt sich nur dort bejahen, wo der Betroffene faktisch in einen Familienverband oder eine andere, seiner Erziehung, Ausbildung, Versorgung und/ oder sicheren „Verwahrung“ dienende Einrichtung wie eine Schule, eine Fürsorgeheim oder eine psychiatrische Anstalt integriert ist. Er muß sich also in ihm institutionell vorgegebenen Verhältnissen befinden, die es dem Garanten erlauben, einen ungehinderten planmäßigen Einfluß auf seine Lebensführung zu nehmen $^{200}$.

Die Einwirkung auf den beaufsichtigten Menschen erfolgt im einzelnen, indem der Aufsichtspflichtige entweder den Kausalverlauf in seiner gegenständlichen Ausführung beherrscht oder er die handelnde Person derart in seiner Gewalt hat, daß ihre Handlungen als Ausfluß seiner Herrschaftsmacht erscheinen ${ }^{201}$. Letzteres beschreibt Sangenstedt als Situation, in der „das Verhältnis des Omittenden zu dem die

\footnotetext{
197 SK-Rudolphi, § 13, Rn. 32; Immel, ZRP 89, 105 (108); Freund, Erfolgsdelikt, S. 247; Herzberg, Unterlassung, S. 320f.

${ }^{198}$ Brammsen, Entstehungsvoraussetzungen, S. 134.

${ }^{199}$ So Sangenstedt, Garantenstellung und Garantenpflicht, S. 401

200 Sangenstedt, Garantenstellung und Garantenpflicht, S. 401.

${ }^{201}$ Schünemann, Grund und Grenzen, S. 324; ähnlich AK-Seelmann, § 13, Rn. $127 f$.
} 
Risikoentwicklung ,transportierenden' Substrat im

Unterlassungszeitpunkt vergleichbar strukturiert ist wie die Beziehung des Akteurs zum potentiellen Gefahrenherd seiner eigenen physischpsychischen Sphäre im Moment des verbotenen Handelns“202. Der Bedrohungsprozeß für ein Rechtsgut muß sich danach in einem Bereich befinden, über den der Täter eine ähnlich absolute Entscheidungsfreiheit innehat, wie sie dem Menschen über die Steuerung seiner Körperbewegungen zukommt. Dem Unterlassenden ist dann der Unrechtserfolg wie einem Begehendem zuzurechnen, wenn er es versäumt, das von ihm beherrschte Risikopotential gegen die Hervorbringung schädlicher Außenwirkungen abzusichern ${ }^{203}$. Denn hier droht sich ein schadensträchtiger Verlauf zu ereignen, der nach den entscheidenden normativen Vorgaben den Organisationsbereich des Aufsichtspflichtigen gerade nicht verlassen soll $^{204}$. Solange dem Garanten in diesem Bereich die Freiheit des Handelns gegeben ist, trifft ihn daher die Verantwortung ${ }^{205}$.

Auch die Herrschaft über den Grund des Erfolges, wie sie Schünemann grundlegend erforscht hat, gibt als solche noch kein eigenes Kriterium für eine Garantenpflicht ab. Es bleibt unklar, wieso aus dem Innehaben der Herrschaft auch eine rechtliche Pflicht entspringt ${ }^{206}$ :

Zur Herrschaftsmacht über die gefährliche Person kommt entscheidend die institutionell gewollte Hilflosigkeit des durch die gefährliche Person Bedrohten hinzu: Hilflos ist der bedrohte Außenstehende, weil die Rechtsordnung ihm keine Eingriffsrechte in Bezug auf den minderjährigen Täter einräumt. Der Außenstehende hat bloß geringe Möglichkeiten, die in Betracht kommenden Schadensentwicklungen direkt an der Wurzel zu bekämpfen, weil er sich in dem fremden

\footnotetext{
${ }^{202}$ Sangenstedt, Garantenstellung und Garantenpflicht, S. 379.

${ }^{203}$ Hier soll auch zugleich der Unterschied zu den echten Unterlassungstatbeständen liegen, da sie gerade nicht voraussetzen, daß die Gefährdung im Omissionszeitpunkt ein der faktischen Bestimmungsmacht des Normadressaten unterworfenes Einflußfeld durchläuft. Die § 138 und $\S 323 \mathrm{c}$ statuieren vielmehr reine Solidaritätspflichten, die in ihrer Genese unabhängig davon sind, ob sich der erfolgsrelevante Risikofaktor im Organisations- und Verfügungskreis des Abwendungspflichtigen aufhält. Sangenstedt, Garantenstellung und Garantenpflicht, S. $379 f$.

${ }^{204}$ Freund, Erfolgsdelikt, S. 257.

${ }^{205}$ Göhler, Dreher-FS, S. 620.
} 
Organisationskreis grundsätzlich nicht zu schaffen machen darf. Er ist in seiner Unversehrtheit vielmehr davon abhängig, daß die Gefahrenzone von deren Inhaber eingedämmt wird ${ }^{207}$. Erst bei unmittelbarer Gefahr hat er die Möglichkeit, von seinem Notwehrrecht Gebrauch zu machen, welches wiederum gegenüber Kindern eingeschränkt wird durch den Gedanken „Schutzwehr statt Trutzwehr“. Der durch ein Kind Gefährdete darf also das Kind allenfalls zurechtweisen, hat aber keine Handhabe, das Kind beispielsweise nach Hause zu schicken und ihm gegenüber einen Stubenarrest auszusprechen; das dürfen nur die dazu Berechtigten.

Das fehlende Recht des Dritten, sich in die fremde Erziehung einzumischen, ist durchaus gewollt: Art. 6 Abs. 2 GG spricht grundsätzlich nur den Eltern das Erziehungsrecht zu. Eingriffe von außen in das elterliche Erziehungsrecht bedeuten daher auch normativ unangemessene Lösungen des zu regelnden Konflikts ${ }^{208}$.

Diese institutionell gewollte Hilflosigkeit des Opfers muß daher ausgeglichen werden durch die besondere Verantwortung der Eltern ${ }^{209}$. Freund spricht in diesem Zusammenhang davon, daß die mit der Innehabung eines bestimmten Organisationskreises ausgeübte Freiheit nicht auf Kosten der anderen gehen soll ${ }^{210}$. Niemand soll also die elterliche Rechte in Anspruch nehmen können, ohne zugleich den Preis dafür akzeptieren zu müssen, nämlich die Inpflichtnahme für die Risiken, die daraus erwachsen, daß der Garant der Erziehungspflicht nicht gerecht wird. Je mehr der Garant die Außenwelt von Eingriffen in seine Erziehungssphäre ausschließen kann, desto stärker wird seine Verantwortung gegenüber dem möglichen Opfer.

Von einer „Herrschaft über die Hilflosigkeit des Opfers“ zu sprechen, ist aber zu weitgehend. Der Garant trägt für die institutionell gewollte

\footnotetext{
${ }^{206}$ Seelmann, GA 1989, 241 (244).

${ }^{207}$ Sangenstedt, Garantenstellung und Garantenpflicht, S. 383; ähnlich auch Göhler, Dreher-FS, S. 620.

${ }^{208}$ Freund, Erfolgsdelikt, S. 248; Seelmann, GA 1989, 241 (255f.).

209 Das haben auch Otto und Brammsen festgestellt, auch wenn sie die Auffassung vertreten, daß die Eltern auch bei den Straftaten ihrer Kinder Beschützergaranten bleiben: Sie weisen darauf hin, dass Eltern ja sowohl im Innen- als auch im Außenverhältnis als Erziehungsberechtigte angesehen werden wollen; dies führe zu einer gegenseitigen Erwartungshaltung zwischen Eltern und Umwelt, Otto/ Brammsen, Jura 85, 540 (542).
} 
Hilflosigkeit des Dritten als solche keine Verantwortung, denn die Hilflosigkeit resultiert nur aus der ihm zugesprochenen Freiheit der Kindeserziehung.

Ansetzend bei dem gefährdeten Dritten, dessen rechtliche Mittel zur Abwehr beschränkt sind, haftet der Überwachergarant auch zum Teil für das enttäuschtes Vertrauen, das seine Außenwelt in Gestalt des Dritten in seine Überwachung der gefährlichen Person gesetzt hat. So legen Rudolphi ${ }^{211}$, Wolff ${ }^{212}$ und Welp ${ }^{213}$ allen Garantenpflichten das Vertrauensprinzip zugrunde. Jedem Opfer sei zumindest ein Vertrauendürfen dahingehend $\mathrm{zu}$ unterstellen, von den schädlichen Auswirkungen von Gefahren verschont $\mathrm{zu}$ bleiben $^{214}$. Um enttäuschtes Vertrauen geht es auch bei Arzt ${ }^{215}$ und Stree ${ }^{216}$, die eine Garantenstellung daraus herleiten, daß das Opfer auf eigene Sicherungsmaßnahmen verzichtet, weil es von einer Übernahme durch den Garanten ausgehen darf. Gegen ein so starkes Abstellen auf ein Vertrauendürfen kann allerdings sprechen, daß dadurch die Garantenfunktionen verwischt werden $^{217}$. Das Vertrauen in die Gefahrabwendung wurde ursprünglich dem durch den Obhutsgaranten Beschützten zugesprochen; es wurde nicht im Hinblick auf die Interessen Außenstehender entwickelt, die der Überwacher einer gefährlichen Sache oder Person zu schützen hat.

Das Bedürfnis nach einem Ausgleich zwischen der Hilflosigkeit des Opfers und der Freiheit der Eltern, über ihren Organisationskreis zu bestimmen, erscheint berechtigt, weil den es möglicherweise Betroffenen nicht durchweg zugemutet werden darf, die unter Umständen ganz massiven Gefahren, die von Nichtverantwortlichen oder nicht voll Verantwortlichen ausgehen können, hinzunehmen ${ }^{218}$. Zum einen ist der Außenstehende bei einem Angriff durch ein Kind schon dadurch in seiner Verteidigung beschränkt, daß er dem Grundsatz „Schutzwehr statt

\footnotetext{
${ }^{210}$ Freund, Erfolgsdelikt, S. 249.

${ }^{211}$ Rudolphi, NStZ 84, 149 (150f.).

${ }^{212}$ Wolff, Kausalität, S. 41.

${ }^{213}$ Welp, Vorangegangenes Tun, S. $117 \mathrm{ff}$.

${ }^{214}$ Vgl. Seelmann, GA 1989, 241 (244 m.w.N.).

${ }^{215}$ Arzt, JA 1980, 553 (560), 712 (714, 717).

${ }^{216}$ Stree, Mayer-FS, S. 158.

${ }^{217}$ Brammsen, Entstehungsvoraussetzungen, S. 227; Seelmann, GA 1989, 241 (244).

${ }^{218} \mathrm{Vgl}$. Freund, Erfolgsdelikt, S. 248.
} 
Trutzwehr" folgen und dadurch seine Rechtsgüter einer gewissen Gefährdung preisgeben muß ${ }^{219}$. Hinzu kommt, daß Außenstehende oft gar nicht in der Lage wären, die für sie selbst entstehenden Gefahren richtig einzuschätzen. Es ist folglich auch deshalb sachgerecht, prinzipiell die Eltern, die ohnehin für ihre Kinder zu sorgen haben und sie deshalb besonders gut kennen (sollten), zur Gefahrabwendung heranzuziehen. Auf diese Weise werden genau die Personen in die Pflicht genommen, die jedenfalls im allgemeinen die Gefahren am besten sehen, einschätzen und durch Ergreifen geeigneter Maßnahmen richtig entschärfen können ${ }^{220}$. Außerdem liegt es den Eltern daran, daß nicht ein Dritter unberufenermaßen in ihre Erziehung, $\mathrm{zu}$ der auch Aufsichtsmaßnahmen gehören, „hineinpfuscht ${ }^{‘ 221}$ - als Kehrseite müssen sie auch die Gewähr bieten, daß der Dritte nicht durch mangelnde Aufsicht beeinträchtigt wird. Der Außenstehende hat außer bei einer Notwehrlage keine Eingriffsrechte; weder die vermutete Einwilligung der Eltern noch eine Geschäftsführung ohne Auftrag i.S.d. §§ 677 ff. BGB kommt in Frage ${ }^{222}$.

Es ist damit festzuhalten, daß die Herrschaft über eine Person und die institutionell vorgegebene Hilflosigkeit der Opfergruppe zusammentreffen müssen, um eine Garantenpflicht zu begründen.

Besondere Bedeutung für die Garantenstellung aus einem Herrschaftsoder Autoritätsverhältnis kommt der Art des Autoritätsverhältnisses zu. Solche Verhältnisse gibt es nicht nur zwischen Eltern und Kindern, sondern auch zwischen Lehrern und Schülern, dem Personal einer psychiatrischen Klinik und den Patienten, Strafvollzugsbeamten und Häftlingen, Betriebsinhabern und ihren Mitarbeitern ${ }^{223}$. Man kann die garantieauslösenden Herrschaftsverhältnisse beim Überwacher über Personen also in zwei Arten teilen: Die Aufsicht über nicht (voll)

\footnotetext{
${ }^{219}$ Tröndle/ Fischer, § 32, Rn. 19.

${ }^{220}$ Freund, Erfolgsdelikt, S. 248; so auch schon Wintterlin, Züchtigungsrecht, S. 11.

${ }^{221}$ Wintterlin, Züchtigungsrecht, S. 11.

222 Vgl. Wintterlin, Züchtigungsrecht, S. 23, 27, der allerdings nur auf das Züchtigungsrecht abstellt.

${ }^{223}$ Brammsen, Entstehungsvoraussetzungen, S. 225; Jescheck, ZStW 1965 (77), 109 (136); Meyer-Bahlburg, Erörterung der Unterlassungsdelikte, S. 91; Sangenstedt, Garantenstellung und Garantenpflicht, S. 401.
} 
verantwortlich agierende Subjekte und die Autoritäts- und Befehlsgewalt über Untergebene im Rahmen sonstiger „besonderer Gewaltverhältnisse $^{\text {‘224 }}$. Fraglich ist, ob sich diese beiden Arten von Herrschaftsverhältnissen wesentlich unterscheiden oder ob es sich nicht vielmehr um einen einzigen Typus von Herrschaft handelt. Es ist daher zu diskutieren, ob die Art der Autorität immer die gleiche ist und sich lediglich ihr Durchsetzungsmittel ändert.

Autorität wird gemeinhin als ein soziales Verhältnis angesehen, in dem die Macht, der Vorrang oder die Überlegenheit einer Person aufgrund von gewissen Eigenschaften als legitim anerkannt wird und diese Anerkennung auf freiem Entschluß oder Einsicht in diese Legitimität beruht. Daraus ergeben sich Loyalität, Vertrauen, sogar Unterordnung und Gehorsam gegenüber dem Träger von Autorität. Sie verschafft ihrem Träger innerhalb eine bestimmten Kreises Geltung und bewirkt, daß seine Weisung das Denken und Handeln dieses Kreises bestimmt. Da Autorität nicht nur einen Träger voraussetzt, sondern auch jemanden, der sie akzeptiert, ist Autorität von bloßer Macht oder Stärke zu unterscheiden $^{225}$.

Zur näheren Beschreibung der Autorität kann es beitragen, wenn man die Gegenseite der Herrschaft betrachtet, nämlich den Gehorsam. Denn die Gehorsampflicht der Kinder oder der anderen Herrschaftsunterworfenen kann man als Gegenstück zur Herrschaft und Autorität der Eltern oder anderer Herrschaftsinhaber begreifen. Ohne Gehorsam ist keine Herrschaft möglich. Der Gehorsam erfolgt entweder durch das Erwirken von Einsicht oder wird durch Zwang herbeigeführt. Im Fall der Autorität gegenüber Kindern lassen sich Zwang und Liebe nicht immer voneinander unterscheiden. In vielen Fällen findet daher beim minderjährigen Herrschaftsunterworfenen ein Wechselspiel von Einsicht und Unterwerfung statt, bei dem sich die Beweggründe für den Gehorsam gegenüber der Autorität aus verschiedenen Gründen zusammensetzen $^{226}$. Hier stellt sich, ebenso wie bei der Herrschaftsmacht, die Frage, wo festgelegt ist, welche Person welcher

\footnotetext{
${ }^{224}$ Sangenstedt, Garantenstellung und Garantenpflicht, S. 401.

${ }^{225}$ Landscheidt, Problematik der Garantenpflichten, S. 104; Popitz, Phänomene der Macht, S. $11 \mathrm{ff}$.

${ }^{226}$ vgl. Popitz, Phänomene der Macht, S. 10f., 43.
} 
anderen Person Gehorsam schuldet. Im Hinblick auf die Gehorsamspflicht von Kindern gibt es dazu keine rechtlichen oder so gut wie keine sonstigen Anhaltspunkte. Dem entgegen nimmt die Gehorsamspflicht in anderen Autoritätsverhältnissen selbständigen Raum ein: Im Verhältnis von Arbeitnehmer und Arbeitgeber läßt sich die Gehorsamspflicht des Arbeitnehmers sogar arbeitsrechtlich begründen ${ }^{227}$. Rogall macht aber geltend, $d a ß$ in Zeiten eines angespannten Arbeitsmarktes der Arbeitnehmer den Weisungen des Arbeitgebers auch ohne eine besondere Pflicht Folge leisten wird ${ }^{228}$.

Das $\mathrm{Ma}$ des Gehorsams ist von dem Maß der Herrschaftsgewalt abhängig und wird von ihr bestimmt ${ }^{229}$. Denn Autorität, auch die elterliche, bedeutet letztlich immer nur die Fähigkeit, bei einem anderen Gehorsam hervorzurufen. Es wäre jedoch zu weitgehend, Gehorsam mit einer Beherrschung eines fremden Willens gleichzusetzen. Bei den Herrschaftsverhältnissen geht es nicht darum, einen Willen zu verändern, sondern nur, ein bestimmtes Verhalten zu erreichen. Daß dabei die Einflußnahme auf den Willen der Person das praktikabelste Mittel ist, tut nichts zur Sache. Für das sich nach außen zeigende Verhalten ist es nicht erforderlich, daß der Beherrschte auch den fremden Willen als eigenen übernimmt. Auch wenn er innerlich nicht zustimmt, ist es möglich, der Forderung nach einem bestimmten Verhalten Folge zu leisten.

Die Art der Autorität bestimmt sich maßgeblich danach, welche Möglichkeiten ihr Inhaber hat, sie durchzusetzen. Damit zeigt sich, daß die unterschiedliche Herkunft der Herrschaft, sei es aufgrund der fehlenden Verantwortlichkeit einer Person, sei es aus einem besonderen Gewaltverhältnis, im Strafrecht allenfalls für die Folgen und Möglichkeiten bei Ungehorsam relevant ist.

Vergleicht man die elterliche Autorität, den Gehorsam herbeizuführen, mit jener von Lehrern, Betriebsinhabern ${ }^{230}$, militärischen Vorgesetzten,

\footnotetext{
${ }^{227}$ Rogall, ZStW 98 (1986) 573, 616.

${ }^{228}$ Rogall, ZStW 98 (1986) 573, 617.

229 Die menschliche Freiheit zur selbstverantwortlichen Entscheidung des Herrschaftsunterworfenen wird also in diesen Fällen überlagert durch die Herrschaft des fremden Befehlsapparates, vgl. Schünemann, Grund und Grenzen, S. 330.

${ }^{230}$ Vgl. $§ 130$ OWiG:
} 
Schiffsoffizieren $^{231}$, Justizvollzugsbeamten ${ }^{232}$, Anstaltspersonal ${ }^{233}$ und Fahrlehrern $^{234}$, stellt sich die Frage, ob hier nicht ein gravierender Unterschied liegt. Der Lehrer kann beispielsweise mit dem Verweis von der Schule drohen, der Betriebsinhaber mit der Entlassung des Arbeitnehmers, der militärische Vorgesetzte mit Strafen aus dem WehrStGB.

Demgegenüber soll und kann Zwang im familiären Zusammenleben nur bedingt eingesetzt werden. Maßnahmen, die dem Arbeitgeber möglich sind, wie die Entlassung des Arbeitnehmers, stehen den Eltern nicht zur Verfügung $^{235}$. Autoritätsverhältnisse innerhalb hierarchisch aufgebauter und rechtlich weitgehend normierter staatlicher Organisationen sind daher insgesamt einfacher zu handhaben als solche rein sozio-kultureller Herkunft $^{236}$, weil die Mittel genauer definiert sind und umgesetzt werden können, ohne daß eine Erklärung oder Rechtfertigung gegenüber dem Untergebenen verlangt wird (auch wenn diese wünschenswert ist).

(1) Wer als Inhaber eines Betriebes oder Unternehmens vorsätzlich oder fahrlässig die Aufsichtsmaßnahmen unterläßt, die erforderlich sind, um in dem Betrieb oder Unternehmen Zuwiderhandlungen gegen Pflichten zu verhindern, die den Inhaber als solchen Treffen und deren Verletzung mit Strafe oder Geldbuße bedroht ist, handelt ordnungswidrig, wenn eine solche Zuwiderhandlung begangen wird, die durch gehörige Aufsicht verhindert oder wesentlich erschwert worden wäre. Zu den erforderlichen Aufsichtsmaßnahmen gehören auch die Bestellung, sorgfältige Auswahl und Überwachung von Aufsichtspersonen. (...)

${ }^{231} \S 108$ SeemannsG, 26.7.1957, BGBI. II, S. 713:

Abs. 1 Der Kapitän und die anderen Vorgesetzten haben die ihnen unterstehenden Personen gerecht und verständnisvoll zu behandeln und Verstößen gegen die Gesetze und guten Sitten entgegenzutreten. Sie dürfen die Jugendlichen nicht körperlich züchtigen oder mißhandeln und haben sie vor körperlicher Züchtigung ... zu schützen sowie darauf zu achten, daß von den Jugendlichen auch während der Freizeit gesundheitliche und sittliche Gefahren nach Möglichkeit ferngehalten werden; siehe auch RGSt 71, 176 (177).

${ }^{232}$ RGSt 53, 292 (293).

233 BGH NJW 83, 462 (462).

${ }^{234}$ OLG Hamm NJW 79, 993 (993f.).

${ }^{235}$ Allerdings wird auch hinsichtlich des Betriebsinhabers als Überwachergaranten i.S.d. $\S 130$ OWiG eingewandt, daß dieser es letztlich nicht verhindern könne, wenn seine Mitarbeiter - unter Inkaufnahme der arbeitsrechtlichen Konsequenzen- die Tätigkeit für den Geschäftsherren einstellen; Jakobs, AT 29/36. Es wird auch eingewendet, daß das Prinzip der Eigenverantwortlichkeit weder durch die Weisungsbefugnis noch durch den überlegenen Wissensstand des Geschäftsherren beseitigt werde, SK-Rudolphi, $\S 13$, Rn. 35a. 
Im Eltern-Kind-Verhältnis gibt es demgegenüber einen Aspekt, der in vielen Fällen mehr zählt als jegliche Art der Repression. Es handelt sich dabei um die Einwirkung auf das Kind durch Liebe und Zuneigung. Die darauf gegründete Autorität haben die Eltern sich erarbeitet, und sie hat eine überaus starke, weil irrationale Macht. Die Familie arbeitet mit moralischen Verpflichtungen, die weitaus stärker sind als es rechtliche sein könnten ${ }^{237}$. Die davon ausgehende Macht läßt sich, wenn sie vorhanden ist, mit den - rechtlichen - Mitteln, die etwa einem Arbeitgeber zur Verfügung stehen, nicht vergleichen. Sie kann dazu führen, daß das Kind entgegen seiner eigenen Meinung handelt, weil es den Eltern einen Gefallen tun möchte oder schlicht aus Vertrauen ${ }^{238}$ gegenüber den elterlichen Entscheidungen.

Die hier dargelegte Autorität der Eltern bildet daher die Grundlage für die Garantenpflicht als Überwachergaranten.

\section{(2) Rechtliche Herleitung}

Schließlich stellt sich die Frage, ob sich das faktisch bestehende Herrschaftsverhältnis der Eltern über ihre Kinder auch in der Rechtsordnung ausreichend niedergeschlagen hat. Denn nach allgemeiner Ansicht vermag nur eine von der Rechtsordnung eingeräumte Herrschaft über eine gefährliche Person die Verantwortlichkeit des Garanten für das rechtswidrige Verhalten dieser Person zu begründen ${ }^{239}$. Dies gründet sich darauf, daß die Rechtsordnung nur denjenigen für das Verhalten seiner Mitmenschen verantwortlich machen kann, den sie mit ausreichenden Machtmittel ausgestattet hat. Voraussetzung für eine Aufsichtspflicht ist daher stets eine aus der Rechtsordnung hervorgehende Autoritäts- oder Aufsichtsstellung ${ }^{240}$.

Was die Ausgestaltung dieser Herrschaft durch die Rechtsordnung betrifft, besteht weitgehend Unklarheit. Lilie hat bereits darauf

\footnotetext{
${ }^{236}$ Otto/ Brammsen, Jura 85, 592 (599).

${ }^{237}$ Korth, ZfJ 96, 311 (312).

${ }^{238}$ Zum Vertrauensband zwischen Eltern und Kind siehe ausführlich Korth, ZfJ 96, 311 (312).

${ }^{239}$ Rudolphi, Dünnebier-FS, S. $575 f$.

${ }^{240}$ Immel, ZRP 89, 105 (198); Teckhoff, JuS 78, 308 (311).
} 
hingewiesen, daß verbindliche und allgemein anerkannte Rechtsquellen für Garantenstellungen unter Angehörigen bislang nicht gefunden wurden $^{241}$. Die rechtlichen Grundlagen für das elterliche Herrschaftsrecht wurden oben bereits angesprochen. Nach Art. 6 Abs. 2 GG gehören zum „natürlichen Elternrecht“ die Pflege und Erziehung der Kinder ${ }^{242}$. Nach Schünemann ist dies die unproblematische Grundlage für die rechtliche Rechtfertigung der Herrschaftsmacht der Eltern ${ }^{243}$. Das Recht und die Pflicht der Kindererziehung ergeben sich weiter aus 1626 Abs. 1 und $\S 1631$ BGB. Das Erziehungsrecht der Eltern ist als absolutes Recht i.S.d. $\S 823$ Abs. 1 BGB anerkannt und wird strafrechtlich geschützt durch $\S 235 \mathrm{StGB}^{244}$.

Es gibt jedoch einen wesentlichen Vorbehalt, aus Art. 6 Abs. 2 GG bzw. $\S 1626$ Abs. 1 BGB eine Garantenstellung aus Überwachung abzuleiten: Das in Art. 6 Abs. 2 GG bzw. § 1626 Abs. 1 BGB normierte Elternrecht dient maßgeblich dem Kindeswohl und stellt wesentlich ein Recht im Interesse des Kindes dar ${ }^{245}$. Art. 6 Abs. 2 S. 2 rechtfertigt eine Ausübung des staatlichen Wächteramtes demgemäß nur zum Wohle des Kindes ${ }^{246}$. Fraglich ist daher, wie sich daraus überhaupt ein Schutz auch zugunsten der Rechtsgüter Dritter ableiten lassen soll. Setzte man eine, um den Taterfolg verhindern zu können, positivierte Garantenstellung der Eltern unbedingt voraus, und käme man hier zum Ergebnis, daß das nicht aus Art. 6 Abs. 2 GG möglich ist, müßte man Brammsen und Otto recht geben, und eine Garantenstellung aus der Beschützerpflicht, wegen des Schutzes des Kindes vor sich selbst, bejahen.

Auf diesen Widerspruch macht auch Schulte aufmerksam, indem er es in Zweifel zieht, wenn sich aus dem Kindeswohl i.S.d. § 1631 BGB eine Pflicht zur Verhinderung von Straftaten nach $\S \S 180,181$ StGB a. F. herleiten lassen soll. In den betreffenden Strafnormen gehe es nicht um das Kindeswohl, sondern um die öffentliche Sittlichkeit ${ }^{247}$. Schulte

\footnotetext{
${ }^{241}$ Lilie, JZ 91, 541 (544).

242 Vgl. Bärwinkel, Garantieverhältnisse, S. 168, Fn. 19; Schünemann, Grund und Grenzen, S. 325.

243 Schünemann, Grund und Grenzen, S. 325.

${ }^{244}$ Franke-Gricksch, S. 7.

245 Jarass/ Pieroth, Art. 6, Rn. 25; BVerfGE 64, 180 (189); 72, 122 (137); 59, 360 (376).

246 Jarass/ Pieroth, Art. 6, Rn. 32; BVerfGE 60, 79 (88); FamRZ 89, 145 (146).

${ }^{247}$ Schulte, Garantenstellung und Solidarität, S. 43.
} 
spricht sich in diesem Zusammenhang deutlich gegen diese Umdeutung der Schutzbestimmung des $\S 1631$ BGB aus und legt dar, daß aus den Erziehungsrechten und -pflichten keine Garantenpositionen zur Erhaltung von fremden Rechtsgütern, insbesondere von gesellschaftlichen Sittlichkeitsvorstellungen, erwachsen. Man leite sonst unzulässigerweise aus einer Beschützergarantenstellung eine Überwachergarantenstellung $a b^{248}$.

Die Tatsache, daß vor allem der Schutz des Kindes im Gesetz kodifiziert ist, stellt jedoch kein wirkliches Argument gegen die Herleitung der Bewachergarantenpflicht aus Art. 6 Abs. 2 GG dar. Die vom Gesetzgeber zugunsten des Kindes vorgenommene Schwerpunktsetzung bedeutet nämlich nicht den Ausschluß anderer Schutzgüter. Hinsichtlich des vom Gesetzgeber betonten Schutzes des Kindes in den $\S \S 1626,1631$ BGB muß man berücksichtigen, daß die elterliche Sorge gewöhnlich eher dazu erforderlich ist, das Kind vor Schäden durch die Außenwelt zu behüten als umgekehrt. Das ergibt sich aus der Natur der Sache, da man ein Kind und wohl auch noch den Jugendlichen grundsätzlich als hilflose Person betrachten muß, die gefährdet wird, anstatt selbst zu gefährden. Daher ist die Schwerpunktsetzung im GG und BGB nachvollziehbar. Dies bedeutet hingegen nicht, daß die Eltern nicht auch in einer Überwachungsfunktion tätig werden müssen.

Es gibt auch im Gesetz Hinweise, die eine Stellung als Überwachungsgaranten rechtfertigen. So müssen Eltern dann zivilrechtlich gem. $\S 832$ BGB für ihre Kinder einstehen, wenn diese Rechtsgüter Dritter verletzten. Zudem enthält das Recht der Personensorge aus $\S 1631$ Abs. 1 BGB zugleich die Verpflichtung des Personensorgeberechtigten, solche Situationen zu verhindern, aus denen gegen ihn eine Haftung gem. $§ 832$ BGB erwachsen könnte ${ }^{249}$. Die Beaufsichtigung dient folglich i. V. m. $§ 832$ BGB dem Schutz Dritter ${ }^{250}$. Auch hat schon Meyer-Bahlburg festgestellt, daß sich Fürsorge- und Obhutsverhältnisse von sonstigen Aufsichtsverhältnissen kaum trennen

\footnotetext{
248 Schulte, Garantenstellung und Solidarität, S. 44.

${ }^{249}$ Palandt-Diederichsen, § 1631, Rn. 1.

250 Palandt-Diederichsen, $\S 1631$, Rn. 5; zum Schutz Dritter durch $\S 832$ siehe ausführlich unten 3. Teil, B II.
} 
lassen. Seiner Meinung nach hat $\S 171$ StGB Doppelfunktion ${ }^{251}$. Auch wenn man so weit nicht gehen mag, fest steht, daß im Begriff der Erziehung des Kindes oder des Jugendlichen i.S.d. § 1631 BGB bereits auch zu einem großen Teil die Aufsicht enthalten ist. Erziehung ist die formende geistig-seelische Einwirkung der Eltern auf das Kind, die die Anlagen und Fähigkeiten des Kindes zur Entfaltung bringt und es zur Reife der Selbstbestimmung führt ${ }^{252}$. Während Erziehung dabei vor allem auch Reagieren auf kindliches oder jugendliches Fehlverhalten bedeutet, setzt die Aufsicht bereits vorher an. Ohne zuvor ausgeübte elterliche Aufsicht gibt es kein Reagieren, d.h. auch keine Erziehung ${ }^{253}$. Im Begriff der ordnungsgemäßen Erziehung ist daher notwendigerweise bereits die Aufsicht des Kindes enthalten. Aufsichtspflicht und Erziehungspflicht korrelieren also $^{254}$, wobei die Erziehung von der Aufsicht abhängig ist; denn nur wenn der Erziehungsberechtigte beobachtet hat, wie sich das Kind verhält, weiß er, ob er regulierend, d.h. erziehend, tätig werden muß $\beta^{255}$. Insoweit stellt es keinen Widerspruch dar, wenn Art. 6 Abs. 2 GG vor allem das Erziehungsrecht als Ausgangspunkt für alle weiteren Maßnahmen betrachtet.

Schließlich ist noch das Argument zu entkräften, daß der Begriff der faktischen Herrschaft $\mathrm{zu}$ ungenau sei, um daraus eine rechtlich bedeutsame Garantenstellung abzuleiten. Maiwald sowie Brammsen und Otto weisen darauf hin, daß es zumindest zahlreiche Formen faktischer Herrschaft gäbe, die keine Garantenpflicht begründeten ${ }^{256}$. Es sei nicht ersichtlich, warum einige Formen Garantenpflicht begründen und andere nicht. Auch wenn der Herrschaftsgedanke durchaus geeignet sei, die Pflichtenposition innerhalb einzelner Garantenstellungen zu umreißen, sei er als Grundprinzip der Garantenhaftung nicht hinreichend tragfähig ${ }^{257}$. Das gleiche Abgrenzungsproblem zwischen verschiedenen

\footnotetext{
251 Meyer-Bahlburg, Erörterung der Unterlassungsdelikte, S. 93.

252 LK-Dippel, § 170 d, Rn. 7 m.w.N.;.

253 Wie noch zu untersuchen sein wird, stellt die Aufsichtspflicht innerhalb der Überwachergarantenpflichten die erste Stufe dar, vgl. B I. 1.

${ }^{254}$ Vgl. Neuheuser, NStZ 2000, 174 (175).

255 Dennoch muß nicht jede falsche Erziehung auf einen Mangel an Aufsicht zurückzuführen sein.

${ }^{256}$ Otto/ Brammsen, Jura 85, 530 (534); Maiwald, JuS 81, 473 (480).

${ }^{257}$ Otto/ Brammsen, Jura 85, 530 (534); Maiwald, JuS 81, 473 (480).
} 
Arten der Herrschaft sieht auch Schünemann. Er verweist auf Fälle, in denen kein Eltern-Kind-Verhältnis oder kein Arbeitnehmer-ArbeitgeberVerhältnis bestehe, aber dennoch eine Person auf die andere so starken Einfluß ausübe, daß sie sie „unter der psychologischen Fuchtel“ habe ${ }^{258}$, ohne daß daraus eine Garantenstellung abgeleitet werden könne.

Diese richtigen Einwände machen aber nur deutlich, daß auf eine rechtliche, auch gewohnheitsrechtliche, Grundlage bereits im Hinblick auf die Herrschaft über eine Person nicht verzichtet werden darf, will man die Frage nach der Garantenstellung nicht verfassungswidrig von Einzelfall zu Einzelfall entscheiden. Im Gegensatz zu der Problematik, die sich stellt, wenn in Freundschaften oder Lebensbeziehungen Herrschaftsverhältnisse auftreten, dürfte jedoch an der rechtlichen Unterworfenheit der Kinder unter das Lebenskonzept ihrer Eltern kein Zweifel bestehen. Den übrigen zwischenmenschlichen Beziehungen geht eine solche rechtliche Befehlsgewalt ab. Sie bieten zwar eine Beeinflussungsmöglichkeit, weisen aber keine gefestigte Herrschaftsstruktur auf und können daher auch keine Garantenpflicht erzeugen $^{259}$.

Die Gefahr, daß die Bestimmung der elterlichen Garantenpflicht dem rechtsfreien Raum überlassen bleibt und dem beliebigen Wandel unterworfen ist, besteht nicht ${ }^{260}$. Bei der bestehenden Gesetzeslage käme

\footnotetext{
${ }^{258}$ Schünemann, Grund und Grenzen, S. 329.

259 Schünemann, Grund und Grenzen, S. 329.

${ }^{260}$ Kritisch: Lilie, JZ 91, 541 (544f.). Lilie weist darauf hin, daß der Begründung von (Schutz-)Garantenstellungen im Familienrecht durch gewohnheitsrechtliche Quellen methodische Bedenken entgegenständen. Außerdem seien im Familienrecht die Rechtsprechung und Literatur einem schnellen Wandel unterworfen, der die Entstehung von Gewohnheitsrecht verhindere. Wenn Lilie in Bezug auf Beschützergaranten feststellt, daß ein tatsächlich praktiziertes Vertrauen noch keine Beschützergarantenstellung begründe, weil das Vertrauen sonst zum ordre public in der Garantenhaftung werde, kann das auch auf die Überwachergarantenstellung übertragen werden: Das bloße Bestehen eines Autoritätsverhältnisses begründet noch keine Überwachergarantenstellung. In der Tat ergeben sich bereits bei nicht genau definierten Autoritätsstrukturen, wie etwa bei nur arbeitnehmerähnlichen Beschäftigungen schon Schwierigkeiten dahingehend, ob die Autorität für eine Garantenstellung genügt. Diese Problematik stellt sich jedoch für die vorliegende Situation nicht. Das Eltern-KindVerhältnis ist klar definiert, die elterliche Autorität ist dem Grunde nach nicht ernstlich anzuzweifeln.
} 
wohl niemand auf den Gedanken, daß Eltern gegenüber ihren Kindern nicht Schutz- und Aufsichtspflichten hätten. Es bestehen keine Bedenken, daß die Rechtsordnung die Eltern mit ausreichenden Machtmitteln ausgestattet hat, um die Kinder zu beaufsichtigen, und daß sie die Eltern daher auch für deren Verhalten zur Verantwortung ziehen darf. Unsere Rechtsordnung geht unbestritten von einer elterlichen Autorität aus und behandelt sie als so selbstverständlich, daß sie nur inzident im Gesetz Ausdruck findet. In vielen Gesetzen sind Regelungen enthalten, die das elterliche Herrschaftsrecht voraussetzen ${ }^{261}$. Anzufangen ist bei den Regelungen des BGB, wonach etwa für den beschränkt geschäftsfähigen Minderjährigen die gesetzlichen Vertreter, also in der Regel die Eltern, nach den $\S \S 106$ ff. BGB die wesentlichen Entscheidungen treffen. Das Familienrecht in seiner Gesamtheit betrachtet die Eltern als in der Beziehung auf ihr Kind beherrschend und räumt dem Kind auch aus diesem Grund eigene (Schutz-)Rechte ein. Auch das Gesetz zum Schutze der Jugend in der Öffentlichkeit (JÖSchG) geht von einer zentralen Stellung der Eltern aus, indem es beispielsweise fordert, daß Kinder und Jugendliche, die an jugendgefährdenden Orten aufgegriffen werden, einem Erziehungsberechtigten zuzuführen sind, vgl. $\S 1$ Abs. 1 Nr. 2 JÖSchG. Das Jugendgerichtsgesetz (JGG) sieht in $\S 50$ Abs. 2 die Ladung des Erziehungsberechtigten zur Hauptverhandlung gegen den Jugendlichen vor. Das Kinder- und Jugendhilfegesetz (SGB VIII) gewährt nach $\S 28$ SGB VIII dem Erziehungsberechtigten Hilfe zur Erziehung. Schließlich normiert auch das Polizeirecht in $\S 6$ NGefAG für die Aufsichtsverpflichteten eine Zusatzverantwortlichkeit für das Verhalten von unter 14 Jahre alten Personen $^{262}$.

Im Hinblick auf die Moralvorstellung weist Schulte, Garantenstellung und Solidarität, S. 41, auf den recht deutlichen Wandel in der Gesellschaft hin, der zum Fortfall der Unzuchtsverhinderungspflicht der Eltern geführt hat. Allerdings ist die Sexualmoral ein dem gesellschaftlichen Wandel besonders stark unterworfenes Gut. Daraus können keine Schlüsse auf andere Wertvorstellungen gezogen werden.

${ }^{261}$ Bärwinkel, Garantieverhältnisse, S. 168, Fn. 19, und Meyer-Bahlburg, Erörterung der Unterlassungsdelikte, S. 93. nennen auch noch § $143 \mathrm{StGB}$ a. F. Eine Heranziehung dieser Vorschrift zur Begründung einer Garantenstellung war jedoch noch zur Geltungszeit des $\S 143$ ausgesprochen bedenklich.

${ }^{262}$ Götz, Rn. 210 ff. 
Somit ist im Ergebnis festzustellen, daß die bestehende Positivierung den Erfordernissen der Bestimmtheit genügt. Es kann daher als zutreffend angesehen werden, von einer Autoritätsstellung der Eltern auszugehen, die eine Überwachergarantenstellung zur Folge hat.

Welche Rechte oder Pflichten daraus angeleitet werden können, ist damit hingegen noch nicht gesagt.

cc) Konsequenzen der Herrschaft für die Überwachungspflicht

(1) Erscheinungsform der Herrschaft

Die Herrschaft der Eltern über ihre Kinder hat weitreichende Folgen. Vergleicht man, wie Sangenstedt, die Gefährdung durch eine gefährliche Sache mit der Gefährdung durch eine gefährliche Person ${ }^{263}$, so ist daraus abzuleiten, daß der Aufsichtspflichtige sich die Folgen so anrechnen lassen muß, als sei er selber der Täter. Zeigt sich die Handlung des Überwachten, also des Kindes, als Erscheinungsform des eigenen Handelns, ist der Täter also so zu behandeln, als sei er selbst unmittelbar ursächlich für die Folgen. Die Aufsicht über einen anderen Menschen wird behandelt wie eine Art Selbstkontrolle. Wird der Unterlassende aber so behandelt, als steuere er seine eigene Körperbewegung, so gilt für sein Verhalten die übliche Regel: ,Du sollst niemanden verletzen'.

Bezeichnet man folgerichtig als entscheidenden Gesichtspunkt der strafrechtlichen Haftung ,die Herrschaft des Garanten über den Grund des Erfolges ${ }^{264 ، “}$ oder sieht ihn als „Zentralgestalt des Geschehens ${ }^{265 ، “}$ gerät man in die Gefahr, die Garantenstellung durch Täterschaftskriterien zu beschreiben, ohne ihren Kern zu ergründen. Brammsen weist daher auf die enge inhaltliche Verwandtschaft zwischen dem mittelbaren Begehungstäter kraft „organisatorischen Machtapparates“ und dem Garanten hin und fordert ein objektivierbares Abgrenzungskriterium zwischen Unterlassungstäterschaft und mittelbarer Täterschaft durch Begehen $^{266}$.

\footnotetext{
${ }^{263}$ Vgl. Sangenstedt, Garantenstellung und Garantenpflicht, S. 383.

${ }^{264}$ Sangenstedt, Garantenstellung und Garantenpflicht, S. 379f.; Schünemann, Grund und Grenzen, S. 217, 259.

${ }^{265}$ Rudolphi, Gleichstellungsproblematik, S. 99.

${ }^{266}$ Brammsen, Entstehungsvoraussetzungen, S. 225; vgl. 4. Teil, B.
} 
Tatsächlich ist die Ähnlichkeit zwischen diesen Arten der Erfolgsverwirklichung groß. Dies muß aber nicht zur Auflösung der Unterschiede führen ${ }^{267}$. Während bei der mittelbaren Täterschaft der unmittelbar Handelnde entweder einen Mangel im Vorsatz, in der Rechtswidrigkeit oder in der Schuld aufweist, liegt ein solcher Mangel bei der Herrschaft über eine Person grundsätzlich nicht vor. Außer beim Strafunmündigen oder Schuldunfähigen, die hier als Sonderfälle gelten dürfen, handelt der aktive Täter neben dem Garanten vorsätzlich, rechtswidrig und schuldhaft.

Die Funktion des Garanten gegenüber dem vorsätzlich, rechtswidrig und schuldhaft handelnden Aktivtäter hat Sangenstedt zutreffend als die eines „Zusatzgaranten“ beschrieben. Als Zusatzgaranten bezeichnet Sangenstedt denjenigen, der die Kompetenz hat, jederzeit einzuschreiten und die Pflicht hat, für seine Sphäre denselben Sicherheitsstandard zu bieten wie jeder andere Bürger ${ }^{268}$. Ähnlich beschreibt auch Freund die Stellung des Herrschaftsinhabers: Dem nicht (voll) Verantwortlichen muß eine Person zur Seite gestellt werden, die Gewähr für die Entschärfung der aus dem Verantwortlichkeitsmangel resultierenden Gefährlichkeit bietet und das Defizit an Verantwortlichkeit kompensiert $^{269}$. Der Garant steht nicht an der Stelle des aktiven Täters, sondern neben ihm. Eine Gleichsetzung mit der mittelbaren Täterschaft kommt daher nicht in Frage.

Für die nicht verhinderte Straftat des Schuldunfähigen können hingegen tatsächlich mittelbare Täterschaft und die Täterschaft aus Garantenstellung zusammentreffen ${ }^{270}$.

(2) Das durch die Überwachung geschützte Rechtsgut

Auch wenn die Überwachergarantenstellung nunmehr hergeleitet ist, steht deshalb noch nichts Abschließendes über das dadurch zu schützende Rechtsgut fest. Bisher wurde mit der h. L. als

\footnotetext{
${ }^{267}$ Das meint wohl auch Frisch, Tatbestandsmäßiges Verhalten, S. 358, wenn er schreibt, daß im Verhältnis zu nichtverantwortlichen Personen die gleichen Grundsätze gelten, die auch den Nichtgaranten dazu verpflichten, einen anderen nicht bei der Deliktsbegehung zu fördern.

${ }^{268}$ Sangenstedt, Garantenstellung und Garantenpflicht, S. 401.

${ }^{269}$ Freund, Erfolgsdelikt, S. 248.
} 
selbstverständlich davon ausgegangen, daß es bei der Überwachergarantenstellung um die Rechtsgüter Dritter geht. Muß aber denn ein bestimmtes Rechtsgut durch die Überwacherpflicht geschützt werden? Grundsätzlich dient jeder strafrechtliche Tatbestand dem Schutz von Rechtsgütern. Es kann also davon ausgegangen werden, daß die Verhinderung von Straftaten durch die Überwachung einer gefährlichen Person dem Schutz von bestimmten, im einzelnen noch zu untersuchenden Rechtsgütern dient.

In der Literatur wird ganz überwiegend davon ausgegangen, daß es sich bei der Überwacherpflicht um eine Schutzpflicht zugunsten Dritter handelt $^{271}$. Zumindest denkbar wäre es jedoch, daß allein die Rechtsgüter des zu Überwachenden geschützt werden sollen. Dafür, daß es nur um den Überwachten und um seine Schutzgüter geht, könnte immerhin sprechen, daß es Eigenheit des Überwachergaranten ist, stets bei der gefährlichen Person zu bleiben. Allein auf sie ist sein Blick gerichtet, sie ist das Zentrum seiner Bemühungen. Auf der anderen Seite werden besondere Anforderungen an die Aufsichtspflicht des Überwachergaranten erst dann gestellt, wenn die gefährliche Person so in die Sphäre eines Dritten gelangt, daß sie diesem Schaden zufügen kann. $\mathrm{Zu}$ klären ist jedoch, woraus sich gegenüber vollkommen fremden Personen eine solche Schutzpflicht ergibt, zumal, wenn diese sich zu Ungunsten der Person auswirkt, der gegenüber der Handlungspflichtige auch eine Obhutspflicht zu erfüllen hat. Dazu wurde bereits im Rahmen der Diskussion, ob eine Überwacher- oder eine Obhutspflicht vorliegt, erörtert, daß es sinnwidrig wäre anzunehmen, daß die Überwachung einer gefährlichen Person nur ihr selbst dienen soll. Bei der Einstufung der Person als „gefährlich“ geht es nämlich gerade nicht darum, daß die Person eine Gefahr für sich selbst darstellt. In dem Falle würde man wohl nicht von einer gefährlichen, sondern von einer gefährdeten Person sprechen.

\footnotetext{
${ }^{270}$ Dazu jedoch ausführlich 4. Teil B.

${ }^{271}$ Grundlegend Nagler, GS 116, 1 (11); Bärwinkel, Struktur der Garantieverhältnisse, S. 168; Boscher, VersR 64, 888 (889); Freund, Erfolgsdelikt, S. 251, 256; MeyerBahlburg, Erörterung der Unterlassungsdelikte, S. 93; wohl auch Frisch, Tatbestandsmäßiges Verhalten, S. 364.
} 
Für die Diskussion um das Schutzgut ist zu berücksichtigen, daß das Gefahrenpotential, das von einer gefährlichen Sache oder Person ausgeht, völlig neue Bindungen und Verpflichtungen zwischen einander unbekannten Personen schafft. Durch die Aufsichtspflicht wird dem Garanten immerhin eine besondere Verantwortung für einen Dritten aufgebürdet, mit dem er in keinerlei Verbindung steht. Liegt darin, daß man die Rechtsgüter des Dritten als Schutzobjekt anerkennt, womöglich die Schaffung einer Schutzpflicht für Dritte ? Wird der Überwachergarant über die gefährliche Person damit zum Obhutsgaranten für Dritte, und schafft man dadurch eine neue, systemwidrige Art von Obhutspflicht?

Um es kurz zu machen, das ist nicht der Fall. Der aus jeder beliebigen Strafvorschrift resultierenden Schutz für Rechtsgüter Dritter, um den es hier letztlich geht, darf nicht verwechselt werden mit der Obhutspflicht eines Garanten für einen anderen. Die durch eine Strafnorm geschützten Güter sind unabhängig davon geschützt, ob das Delikt durch Tun oder durch Unterlassen begangen wird. Beispiel: Für die Schutzrichtung des $\S 223$ StGB spielt es keine Rolle, ob der Vater eines minderjährigen Sohnes einen Dritten selbst mißhandelt oder ob der Vater es unterläßt, seinen minderjährigen Sohn an der Mißhandlung eines Dritten zu hindern. In beiden Fällen soll durch $\S 223$ StGB die körperliche Unversehrtheit des Dritten geschützt werden. Es ist für das geschützte Rechtsgut des Dritten unerheblich, ob es durch einen aktiv Handelnden verletzt wird oder ob der Schaden darauf zurückzuführen ist, daß ein untätiger Garant den Erfolgseintritt nicht verhindert. Der Gefährdete wird also nicht allein dadurch, daß der Angriff ausgerechnet durch Unterlassen erfolgt, zu einem besonders zu schützenden Subjekt. Er bleibt genauso von der Rechtsordnung geschützt, wie wenn er durch aktives Tun gefährdet würde.

Ein wesentlicher Unterschied zu einer Obhutspflicht für einen Dritten liegt außerdem darin, daß der Überwachergarant allein zur Eindämmung des Gefahrenherdes aufgerufen ist. Er hat lediglich dafür Sorge zu tragen, daß der Risikoprozeß die Grenzen seines sächlichen Organisationskreises 
nicht überschreitet und auf eine fremde Interessenssphäre übergreift ${ }^{272}$. Der Gefahrquellengarant schützt dritte Personen also nur dann, wenn sie mit seinem Organisationsbereich in Berührung kommen. Er schützt nur gegen Gefahren, die von der bestimmten Quelle ausgehen. Er schützt Dritte jedoch nicht gegen alle weiteren Angriffe durch die Außenwelt. Beispiel: Der Vater schützt durch seine Aufsicht den Passanten nur vor den Schneebällen, die sein eigener Sohn wirft bzw. werfen könnte. Gegen die Schneeballwürfe durch andere Kinder muß er ihn nicht als Garant schützen.

Den Obhutsgaranten zeichnet überdies die Pflicht aus, sich um den Schutz einer ganz bestimmten Person oder Personengruppe zu kümmern (individueller Schutz). Demgegenüber schützt der Gefahrquellengarant eine ihm unbekannte Menge von Personen (genereller Schutz).

Obhutsgarant für den Dritten könnte der Unterlassende aber möglicherweise durch Ingerenz werden. Ingerenz ist das tatsächliche Herbeiführen einer Gefahrenlage. Die Gefahr kann durch Tun oder Unterlassen herbeigeführt werden ${ }^{273}$. Es wäre aber ein Zirkelschluß, aus dem untätigen Verhalten eines Überwachergaranten eine Ingerenz abzuleiten. Denn das Unterlassen ist erst dann strafrechtlich relevant, wenn der Unterlassende zu diesem Zeitpunkt bereits Garant ist. Zwar ist der Unterlassende zum Zeitpunkt des Unterlassens bereits Überwachergarant für die gefährliche Person, aber er ist eben nicht Beschützergarant für den durch die gefährliche Person Bedrohten. Das wird er auch nicht dadurch, das er sich im folgenden passiv verhält. Eine Obhutsgarantenstellung wird daher gegenüber dem Dritten nicht begründet. Andernfalls wäre jeder Überwachergarant zugleich Obhutsgarant für eine unbestimmte Anzahl von Personen ${ }^{274}$.

\footnotetext{
${ }^{272}$ Vgl. Sangenstedt, Garantenstellung und Garantenpflicht, S. 385. Ob ein weiterer Unterschied darin zu sehen ist, daß der Beschützergarant bis zuletzt den Schaden verhindern muß, während die Pflicht des Überwachergaranten räumlich und zeitlich begrenzt ist, ist zweifelhaft. Sangenstedt, , a.a.O. ist der Meinung, daß der Überwacher nach dem durch inn unverschuldeten Eintritt des schädigenden Ereignisses nur noch gemäß § 323c dafür sorgen müsse, eine weitere Schadenseskalation zu verhindern.

${ }^{273}$ Tröndle/ Fischer, § 13, Rn. 11.

${ }^{274}$ Dies deckt sich auch mit den Erkenntnissen über die echten Unterlassungsdelikte: Aus Handlungspflichten, die den Tatbeständen echter Unterlassungsdelikte zugrunde liegen, insbesondere $\S 138$ und $\S 323 \mathrm{c}$ entsteht keine Garantenstellung.. Also führt auch
} 
Es bleibt also dabei, daß der Garant zwar dem Dritten Rettung schuldet, jedoch nicht aus Obhuts-, sondern aus Überwachergarantenstellung. Die Handlung, die dem Überwachergaranten zum Schutz des Dritten abverlangt wird, entspricht in dieser Konstellation allerdings derjenigen, die auch ein Obhutsgarant für den Dritten leisten müßte.

dd) Der nach $\S 13$ verpflichtete Personenkreis

Untersuchen muß man weiter, ob Eltern automatisch durch ihre natürliche Stellung zu ihrem Kind als Überwachungsgaranten einzustufen sind, oder ob es Ausnahmen von diesem Grundsatz bzw. Einschränkungen dieser Pflicht gibt. Fraglich ist, ob das zivilrechtlich begründete Sorgerecht darüber entscheidet, wer von den Eltern als Überwachergarant verantwortlich zu machen ist.

Dies ist im Normalfall unproblematisch, da beiden Elternteilen gleichermaßen das Sorgerecht zufällt ${ }^{275}$. Unverheiratete Eltern können die gemeinsame Sorge durch eine öffentlich beurkundete Sorgerechtserklärung erlangen, vgl. $§ 1626 \mathrm{a}-\mathrm{e} \mathrm{BGB}^{276}$. Jeder Elternteil ist dabei eigenständiger Garant, der unabhängig vom anderen für seine Versäumnisse haftet. Dieser Pflicht zur elterlichen Sorge kann sich ein Elternteil auch nicht entziehen. Er hat darauf nicht nur ein Recht, sondern ist auch dazu verpflichtet ${ }^{277}$. Andernfalls wäre auch eine Garantenstellung wie im vorliegenden Kontext nicht möglich, wenn Eltern sich quasi von ihren Kindern lossagen könnten.

Die vollständige Überlassung der Aufsicht an einen Elternteil kann nur dann möglich sein, wenn der eine Ehepartner zur Aufsichtsführung überhaupt nicht in der Lage ist, also etwa wochen- oder monatelang von zu Hause abwesend ist; die bloße Obhut durch den anderen Elternteil während des Tages befreit hingegen nicht von den allgemeinen Aufsichtspflichten. So kann sich etwa der Vater nicht durch Übertragung der Aufsichtspflicht auf die Mutter entlasten und umgekehrt, sondern

ein Verstoß gegen § 323c nicht zu der Annahme der Ingerenz; vgl. BGH 3, 65 (67); BGH JR 56, 347 (347f.) m. Anm. Maurach; BGH NJW 83, 350 (351).

${ }^{275}$ BVerfGE 31, 194 (205).

${ }^{276}$ Moritz, JA 98, S. 704 (707); andernfalls kann die Kindesmutter über die nicht erfolgte Sorgerechtserklärung eine schriftliche Auskunft des Jugendamtes verlangen, § 58a SGB VIII, die ihr ermöglicht, allein das Sorgerechts auszuüben. 
muß sich in der Freizeit die Gelegenheit nehmen, sein Kind etwa beim Spiel zu beobachten oder Erkundigen darüber einzuziehen, von Albilt als „Feierabendaufsicht“ beschrieben ${ }^{278}$. Ergeben sich daraus Ansatzpunkte zum Einschreiten, muß er sich auch um entsprechende Maßnahmen kümmern $^{279}$. Allerdings wird der Schwerpunkt der Aufsichtspflicht wohl bei dem Elternteil liegen, der das Kind ständig überwacht ${ }^{280}$.

$\mathrm{Zu}$ beachten ist, daß es keine elterliche Gesamtverantwortung gibt, sondern für beide Elternteile das Prinzip der Einzelverantwortung gilt. Die Eltern sind gleichberechtigte Träger der Personensorge, und so sind sie auch ebenso gleichberechtigt in ihrer Verantwortung. Jeder wird wegen des von ihm selbst verwirklichten Unrechts bestraft, und nicht deshalb, weil der andere seine eigene Aufsichtspflicht nicht ordnungsgemäß erfuillt hat. Daraus folgt, daß das Versäumnis des einen Elternteils nicht automatisch dem anderen als eigenes anzulasten ist. Zugleich darf der zugunsten des einen Elternteils geführte Entlastungsbeweis nicht ohne weiteres auch dem anderen zugute kommen $^{281}$.

Das Sorgerecht bleibt durch eine Scheidung unberührt. Die gemeinsame elterliche Sorge wird in der Regel auch bei der Trennung der Eheleute und nach der Auflösung der Ehe fortgeführt. Das ist immer dann der Fall, wenn die Eltern keinen Antrag auf alleinige Sorgerechtserteilung beim Familiengericht stellen ${ }^{282}$.

Schwieriger wird es in den Fällen, in denen nur noch dem einen Elternteil das Sorgerecht zufällt, weil dem andern das Sorgerecht entzogen wurde. Dies kann vorliegen etwa bei Scheidung ${ }^{283}$, Trennung ${ }^{284}$, aber auch in

\footnotetext{
${ }^{277}$ Palandt-Diederichsen, § 1626, Rn. 7.

${ }^{278}$ Albilt, S. 195.

${ }^{279}$ OLG Köln, VersR 55, 347 (349); BGH VersR 68, 903 (903); BGH VersR 58, 562 (563); BGH VersR 66, 368 (368f.); Albilt, S. 194f.; Boscher, VersR 64, 888 (889); Dahlgrün, S. 189f.; Immenga, FamRZ 69, 313 (314f.)

${ }^{280}$ Vgl. Immenga, FamRZ 69, 313 (314f.).

${ }^{281}$ Albilt, S. $152 f$.

${ }^{282}$ Moritz, JA 98, S. 704 (707).

${ }^{283}$ Sorgerechtsentscheidung gem. § 1671 IV 1 BGB, wonach grds. die elterliche Sorge dem einen Elternteil übertragen wird; nach BVerfGE 61, 358 ist auch das gemeinsame Sorgerecht möglich. ${ }^{284}$ vgl. § 1672 BGB.
} 
anderen Fällen ${ }^{285}$. Von der Trennung der Eltern an kann jeder Elternteil die Aufhebung der gemeinsamen Sorge beantragen, § 1671 BGB, woraufhin eine Sorgerechtsentscheidung gem. § 1671 II BGB erfolgen $\mathrm{mu} \beta^{286}$.

Fraglich ist dann, ob auch der nicht sorgeberechtigte Elternteil noch eine Garantenstellung für das Kind innehat. Dafür spricht, daß die elterliche Verantwortung trotz der gescheiterten Ehe weiterbesteht, die Beziehung zum Kind von der Beziehung zwischen den Ehegatten unabhängig ist ${ }^{287}$. Unter Umständen fehlen dem nicht-sorgeberechtigten Elternteil aber die rechtlichen Mittel, die zur Erziehung erforderlichen Maßnahmen ohne das Sorgerecht durchzusetzen.

Fest steht zunächst, daß mit dem Sorgerecht nicht auch das Elternrecht aus Art. 6 Abs. 2 GG entfällt. Aus diesem erwächst dem nichtsorgeberechtigten Elternteil nämlich gem. $\S 1634$ I $\quad$ BGB das Verkehrsrecht, d.h. die Befugnis zum Umgang mit dem Kind ${ }^{288}$. Die Beziehungen eines Kindes zu seinen Eltern und das daran anknüpfende Elternrecht erschöpfen sich also nicht in der elterlichen Gewalt, wie sie das bürgerliche Recht durch das Sorgerecht normiert. Sogar Eltern, denen das Sorgerecht wegen eigenen Versagens entzogen worden ist, verlieren noch nicht jeden Anspruch auf verfassungsrechtlichen Schutz ${ }^{289}$. Dies kommt vor allem darin zum Ausdruck, daß sie bei Versagen oder Ausfall desjenigen Elternteils, dem zunächst die elterliche Gewalt übertragen worden ist, berechtigt und verpflichtet sind, die Pflege und Erziehung des Kindes wieder $\mathrm{zu}$ übernehmen (vgl. $\S \S 1671$ i.V.m. 1696; $\S 1678$ Abs. 2, 1680 BGB $)^{290}$ und somit in einer Reservestellung bleiben $^{291}$.

${ }^{285}$ Ruhen der elterlichen Sorge gem. § 1675 BGB. Der Elternteil hat das Sorgerecht noch inne, ist aber nicht zur Ausübung berechtigt. Das Ruhen der elterlichen Sorge kommt in Betracht, wenn der Elternteil die Sorge auf längere Zeit nicht ausüben kann, § 1674 BGB, z.B. bei längerer Strafhaft; vgl. Schwab, Familienrecht, S. 266, Rn. 513.

${ }^{286}$ Moritz, JA 98, S. 704 (707).

${ }^{287}$ Vgl. Wingen, Familienpolitik, S. 114.

${ }^{288}$ BVerwG, FamRZ 87, 807 (808); BVerfGE 64, 180 (188); 31, 194 (207f.); Schwab, Familienrecht, S. 204, Rn. 387; nach älterer Auffassung als Restbestand des Personensorgerechts, vgl. BGHZ 42, 364 (370); 51, 219 (221); Schwoerer, FamRZ 69, 367 (367).

${ }^{289}$ BVerfGE 31, 194 (207).

${ }^{290}$ BVerfGE 31, 194 (207f.) (= FamRZ 71, 421). 
Wegen der Zweiteilung des Elternrechts in Rechte und Pflichten bleiben mit dem Elternrecht konsequenterweise auch die elterlichen Pflichten im Grundsatz bestehen ${ }^{292}$. Dadurch kann man eine Einflußnahme im Sinne der Garantenstellung aus Herrschaftsmacht auch für den nicht sorgeberechtigten Elternteil bejahen. Dabei ist zu berücksichtigen, daß es bei der Beeinflußbarkeit des Kindes durch den Elternteil in starkem Maße auf persönliche Gefühle ankommt, die sich nicht durch die gerichtliche Zuweisung des Sorgerechts steuern lassen ${ }^{293}$. Gerade dieser Einfluß soll durch das verbleibende Umgangsrecht auch aufrechterhalten werden. Die Bindung und Verbindung zwischen Kind und nichtsorgeberechtigten Elternteil soll fortbestehen und entsprechend berücksichtigt werden, insbesondere einer Entfremdung vorgebeugt werden $^{294}$. Daraus ist zu folgern, daß eine tatsächliche Herrschaftsmacht auch ohne Sorgerecht weiterbesteht, die eine rechtliche Herrschaftsmacht mit sich zieht ${ }^{295}$. Auf die tatsächliche Einwirkungsmöglichkeit stellt schließlich auch der BGH ab: „Bei geschiedener Ehe hat auch der Elternteil, dem das Recht der Sorge für die Person des Kindes nicht zusteht, nach natürlicher Lebensanschauung und kraft gesetzlicher Bestimmung auf Grund der elterlichen Gewalt die Pflicht, das Kind zu beaufsichtigen und erzieherisch zu betreuen, wenn es sich bei ihm aufhält und er eine Einwirkungsmöglichkeit auf das Kind hat. Dieses ist daher

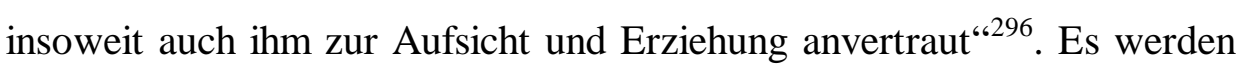
Anklänge an die Übernahme der Garantenstellung aus Vertrag deutlich, die hier dazu führen, aus der rein tatsächlichen Lage eine rechtliche Pflicht abzuleiten. Denn bei der freiwilligen Übernahme der Aufsicht über eine Person kommt auch ohne Vertrag eine Garantenstellung zustande. Die Gemeinschaft verläßt sich darauf, daß Inhaber der

291 BVerwG, FamRZ 87, 807 (808); BVerfGE 64, 180 (188); so nun auch die nichtehelichen Väter durch das KindRG vom 16.12.1997, BGBI. I 1997, 2942 (2945).

${ }^{292}$ Schwab, Familienrecht, S. 273, Rn. 526; BVerfGE 64, 180 (188).

${ }^{293}$ Vgl. auch BVerfGE 64, 180 (188).

${ }^{294}$ BVerfGE 31, 194 (206); 64, 180 (188).

295 A. A. aber OLG Düsseldorf NJW 1959, 2120 (2120f.), wobei allerdings eine Erziehungsschwäche des betreffenden Elternteils vorlag, bei dem das Kind Wohnung und Verpflegung erhielt.

${ }^{296}$ Leitsatz, BGHSt 1, 343 (343f.). 
tatsächlichen Gewalt über die Person die von ihr ausgehenden Gefahren beherrscht ${ }^{297}$.

So kommt auch Schünemann zum Ergebnis: Bei solchen ,irregulären Verhältnissen““298 kann es auf das Sorgerecht nicht ankommen, da allein die faktische Herrschaft über die andere Person entscheidet. Wenn etwa die Mutter nach der Scheidung die elterliche Gewalt zugesprochen bekommt ( $\$ 1671$ BGB) und der Vater ihr das Kind rechtswidrig entzieht (§ 235 StGB), so treffen den Vater als tatsächlichen Gewalthaber auch die strafrechtlichen Garantenpflichten. Er kann sich nicht damit herausreden, daß er zur Erziehung des Kindes gar nicht berechtigt sei. Die Sorgerechtsregelung betrifft damit nur gewissermaßen das Innenverhältnis von Vater, Mutter und Kind, während für das „Außenverhältnis“ zu den Mitbürgern nur entscheidend ist, wer die tatsächliche Gewalt über das Kind ausübt ${ }^{299}$. Ebenso dürfte die Situation, $\mathrm{zu}$ bewerten sein, wenn ein Elternteil trotz des fehlenden Sorgerechts Einfluß auf das Kind und Kenntnis von dessen Straftaten hat. Damit ist die Garantenstellung unabhängig von einer veränderten Sorgerechtssituation.

Die Garantenstellung des nichtehelichen Vaters wird teilweise abgelehnt ${ }^{300}$. Nach ganz überwiegender Ansicht ist er jedoch ebenso zu behandeln wie der eheliche Vater auch ${ }^{301}$. Einschränkungen danach, daß der Vater nicht in einer engen Lebensgemeinschaft mit dem Minderjährigen lebt, betreffen jedoch allenfalls die Deliktsverhinderungsmöglichkeit, nicht aber die Garantenstellung als solche. Insbesondere durch die Einführung des $§ 1626$ a BGB ${ }^{302}$ wird die Stellung des nichtehelichen Vaters gestärkt.

Eine andere Frage ist es, ob auch Personen, die nicht die natürliche Elternstellung innehaben, wie etwa die Stiefeltern, eine Stellung als

\footnotetext{
${ }^{297}$ Jescheck/ Weigend, § 59 IV 3 c), S. 623, § 59 IV 4. c), S. 628.

${ }^{298}$ Der Anteil der nicht verheirateten Eltern lag 1994 in den alten Bundesländern bei 12,4 $\%$, in den neuen Bundesländern bei 41,4\%. 1995 gab es 2,2 Mio. alleinerziehende Mütter und 451 Tsd. alleinerziehende Väter, vgl. Moritz, JA 98, 704 (704). Unter diesen Umständen kann von „irregulären Verhältnissen“ wohl nicht mehr gesprochen werden. ${ }^{299}$ Schünemann, Grund und Grenzen, S. 325; Brammsen, Garantenpflichten, S. 158.

${ }^{300}$ Freund, Erfolgsdelikt, S. 275; Jakobs 29/62.

${ }^{301}$ Brückner, S. 68 m.w.N.

${ }^{302}$ KindRG vom 16.12.1997, BGBI. I 1997, 2942 (2945).
} 
Überwachergarant einnehmen. Dies ist vom BGH bejaht worden ${ }^{303}$. So wird verlangt, daß auch ein Stiefvater im Rahmen des Möglichen und Zumutbaren Sorge zu tragen hat, daß Personen seines Hausstandes Dritte nicht verletzen. Dies soll unabhängig davon gelten, ob eine Aufsichtspflicht gem. $\S 832$ BGB besteht, sofern dem Stiefvater nur eine Verfügungsgewalt über die Person zukommt ${ }^{304}$. In diesen Fällen wird allerdings eine aus der Haus- und Familiengemeinschaft erwachsende Garantenstellung angenommen, ohne daß Familienbeziehungen bestehen müssen $^{305}$. In der Tat wäre es merkwürdig, wenn der Stiefvater dem gefährlichen Treiben des in seiner Familiengemeinschaft aufwachsenden Stiefsohnes tatenlos zusehen könnte, während er bei einem länger zu Besuch in der Familie weilenden Kind i.d.R. vertragsmäßig zur Aufsicht und zum Eingreifen verpflichtet wäre ${ }^{306}$. Selbst wenn es an verpflichtenden zivilrechtlichen Vorschriften fehlt, begründet die tatsächliche freiwillige Übernahme der Fürsorge für das Stiefkind die Garantenpflicht $^{307}$.

Auch Brammsen weist auf die in diesen Fällen bestehende Garantenpflicht der Stiefeltern gegenüber dem minderjährigen Stiefkind $\operatorname{hin}^{308}$. Brammsen geht dabei davon aus, daß es dem Stief-Elternteil gerade darauf ankäme, als Erziehungsberechtigter angesehen zu werden, so daß eine faktische Erziehungsgewalt auch ohne eine natürliche Beziehung bestehen können soll.

Anders ist $\mathrm{zu}$ entscheiden, wenn der Stiefelternteil erst $\mathrm{zu}$ einem Zeitpunkt in die Lebens- und Hausgemeinschaft eintritt, $\mathrm{zu}$ dem das Stiefkind etwa kurz vor der Volljährigkeit stehend - in seiner Persönlichkeitsentwicklung und Selbständigkeit bereits so weit fortgeschritten ist, daß der Stiefelternteil keinen tatsächlichen Einfluß mehr auf die Entwicklung des Jugendlichen nehmen kann und will ${ }^{309}$. Es fiele auch schwer, einem Stiefvater die praktisch unmögliche

\footnotetext{
${ }^{303}$ BGH VersR 54, 118 (118); vgl. Brückner, S. 55, 105.

${ }^{304}$ BGH VersR 54, 118 (118); Boscher, VersR 64, 888 (890).

${ }^{305}$ auch ein stillschweigend geschlossener Vertrag mit der Kindesmutter wird erwogen;

BGH VersR 54, 118 (118).

${ }^{306}$ BGH VersR 54, 118 (118).

${ }^{307}$ Brückner, S. 105.

${ }^{308}$ Brammsen, Entstehungsvoraussetzungen, S. 155.

${ }^{309}$ Brückner, S. 105.
} 
Garantenpflicht über einen 17jährigen aufzubürden, zu dem er keine Beziehung hat und der ihn möglicherweise ablehnt.

Auch der nach „Roma-Art“ geheiratete Lebensabschnittsgefährte eines Elternteils, der unabhängig von einer evl. Verwandtschaft faktisch die Fürsorge- und Erziehungspflichten nicht nur aus Gefälligkeit und nicht nur vorübergehend (mit-)übernommen hat, soll Garant sein ${ }^{310}$.

b) Herrschaft über das strafunmündige Kind

Für die Garantenstellung kraft Autorität ist erforderlich, daß die tatsächliche Gewalt von einer solchen Intensität ist, daß eine oben beschriebene Verpflichtung aus ihr hervorgeht. Man wird dies für strafunmündige Kinder wohl bejahen können, aber nur in einem beschränkten Maße auch für strafmündige Jugendliche.

Dadurch daß in unserer Rechtsordnung die fehlende Eigenverantwortlichkeit strafunmündiger Kinder angeordnet wird $^{311}$, ist eine Garantenstellung aufgrund der vorstehend entwickelten Grundlagen unproblematisch $^{312}$. Daß die Aufsichtspflicht über strafunmündige Kinder durch ihre Eltern den Verkehrspflichten in bezug auf Sachen entspräche $^{313}$, ist allerdings $\mathrm{zu}$ weitgehend und $\mathrm{zu}$ ungenau, vielmehr muß auf die oben dargestellte, besondere Beziehung zwischen Eltern und Kindern abgestellt werden.

c) Herrschaft über den strafmündigen Jugendlichen

Nicht geklärt und umstritten ist dagegen die Frage, ob die Garantenpflicht auch zur Verhinderung von Straftaten strafmündiger Personen existiert ${ }^{314}$.

Hier interessiert die Gruppe der Jugendlichen (14-17 Jahre). Es kann als feststehend gelten, daß die Rechtsordnung bei Jugendlichen davon ausgeht, sie hätten bereits einen eigenen, rechtlich relevanten Willen, der die Beeinflussung durch die Erziehungspflichtigen erschwert. So wird im

\footnotetext{
${ }^{310}$ Vgl. Neuheuser, NStZ 2000, 174 (175), der dies zwar nur für § 171 feststellt. § 171 Abs. 2 stellt jedoch auf die hier maßgebliche Garantenstellung i.S.d. § 13 ab.

${ }^{311}$ Brammsen/Otto, Jura 85, 530 (542).

${ }^{312}$ Immel, ZRP 89, 105 (198).

${ }^{313}$ so Sangenstedt, Garantenstellung und Garantenpflicht, S. 404; Schünemann, ZStW 96 (1984), 287 (310).
} 
Zivilrecht diskutiert, ob für einige Lebensbereiche dem Willen des Kindes/ Jugendlichen ab einem bestimmten Alter nicht eine rechtliche Bedeutung zukommen soll. Dies bezieht sich auch auf Entscheidungen, die weitgreifende Auswirkungen auf das künftige persönliche Leben des Kindes haben und gegen die Neigung des Kindes nicht vernünftig getroffen werden können: So trägt das Gesetz dem Bedürfnis des Minderjährigen Rechnung, indem etwa ab Vollendung des 14. Lebensjahres die Entscheidung über das religiöse Bekenntnis ihm selbst zusteht. $\mathrm{Ab}$ der Vollendung des 16. Lebensjahres kann der Minderjährige ein Testament errichten, vgl. § 2229 Abs. 1, § 2247 Abs. 4 BGB; auch eine Einwilligung in eine Heilbehandlung ist dem Minderjährigen erlaubt, sofern er die „natürliche Einsichtsfähigkeit“ in die Tragweite des Eingriffs besitzt ${ }^{315}$.

Schünemann unterscheidet daher zwischen der konstitutionellen (natürlichen) und der partiellen (rechtlichen) Unmündigkeit ${ }^{316}$. Die konstitutionelle Unmündigkeit soll danach vorliegen bei allen Personen, die in ihren geistigen Fähigkeiten aufgrund von Jugend oder Krankheit hinter dem Minimum dessen zurückbleiben, was gesellschaftlich noch toleriert werden kann. Für die Taten dieser Personen sind dann die Inhaber der faktischen Herrschaftsgewalt verantwortlich, hier also die Eltern oder sonstige Erziehungsberechtigte ${ }^{317}$.

Partiell unmündig soll dagegen sein, wer nur rechtlich unmündig ist ${ }^{318}$. Unter diese Gruppe sind die strafmündigen Minderjährigen $\mathrm{zu}$ fassen. Die partielle Unmündigkeit führt nach der Darstellung Schünemanns nur zu einer gegenständlich begrenzten Herrschaftsbeziehung, wie bei $§ 357$ $\mathrm{StGB}^{319}$. Bei $\S 357$ StGB hat der Vorgesetzte nur solche rechtswidrigen Taten des Untergebenen zu verantworten, die sich innerhalb seines

\footnotetext{
314 Schünemann, ZStW 96 (1984), 287 (310).

${ }^{315}$ Schwab, Familienrecht, S. 242f, Rn. $462 f$.

${ }^{316}$ Schünemann, Grund und Grenzen, S. 324; ähnlich: Immel, ZRP 89, 105 (108). Kritik an dieser Darstellung übt Brammsen, Entstehungsvoraussetzungen, S. 69ff., $224 \mathrm{f}$.

317 Schünemann, Grund und Grenzen, S. 329.

${ }^{318}$ Schünemann, Grund und Grenzen, S. 324f.

${ }^{319} \S 357$ (Verleitung eines Untergebenen zu einer Straftat): Abs. 1 „Ein Vorgesetzter, welcher seine Untergebenen zu einer rechtswidrigen Tat im Amt verleitet oder zu verleiten unternimmt oder eine solche rechtswidrige Tat seiner Untergebenen geschehen läßt, hat die für diese rechtswidrige Tat angedrohte Strafe verwirkt.“
} 
dienstlichen Herrschaftsbereichs abspielen. Gegenständlich begrenzt ist diese Herrschaftsbeziehung also durch die räumlich und zeitlich begrenzte Arbeitstätigkeit des Untergebenen, außerhalb derer der Vorgesetzte keine Macht über den ihn hat. Fraglich ist, inwieweit die Unmündigkeit des Jugendlichen in diesem Sinne gegenständlich begrenzt sein soll. Gegenständlich begrenzt bedeutet im Sinne von Schünemann jedoch nichts weiter als das Gegenteil von ,natürlich', da es eine derartige räumliche oder zeitliche Begrenzung der Herrschaft von Eltern über ihre Abkömmlinge gerade nicht gibt. Zum Verhältnis zwischen den Eltern und dem strafmündigen Jugendlichen führt Schünemann aus, daß die Herrschaftsgewalt sich durch die rechtliche Befehlsgewalt, die sich aus dem Elternrecht ergibt, konkretisiere ${ }^{320}$. Der Jugendliche als solcher sei zwar, anders als der Strafunmündige, frei verantwortlich für seine Handlungen, seine Freiheit werde aber ,durch die Eingliederung in den fremden Befehlsapparat" durch die Herrschaftsmacht der Eltern überdeckt ${ }^{321}$.

Das Bestehen der rechtlichen Herrschaftsmacht sagt aber noch nichts darüber aus, ob auch eine faktische Herrschaftsmacht gegeben sein muß. Fraglich ist, ob es auf die tatsächliche Durchsetzung der Herrschaft, die beim strafunmündigen Minderjährigen viel unproblematischer ist als beim strafmündigen, ankommen kann. Insoweit argumentiert Schünemann, daß der Begriff der Herrschaft außer einer rechtlichen Befehlsgewalt immer noch eine tatsächliche Beeinflussungsmöglichkeit voraussetze, die mit wachsendem Alter abnehme. Bei den Straftaten von verantwortlich Handelnden liege der Grund des Erfolges in ihrem deliktischen Willen. Sobald hier die Beeinflußbarkeit fortfalle, müsse die Herrschaft über die Person enden. Das fortbestehende nudum ius alleine könne für die Garantenstellung nicht genügen ${ }^{322}$. Die daraus folgenden Konsequenzen hat er aber nicht beleuchtet.

Fraglich ist, ob der Verlust der Herrschaftsmacht zum Verlust der Garantenstellung führt ${ }^{323}$. $\mathrm{Zu}$ untersuchen ist zunächst, wann der Fall gegeben ist, in dem Eltern die Herrschaftsmacht über ihre Abkömmlinge

\footnotetext{
${ }^{320}$ Schünemann, Grund und Grenzen, S. 329.

${ }^{321}$ Schünemann, Grund und Grenzen, S. 330.

${ }^{322}$ Schünemann, Grund und Grenzen, S. 330.

${ }^{323}$ So jedenfalls Schünemann, Grund und Grenzen, S. 325.
} 
nicht mehr innehaben. Nach Schünemann genügt noch nicht jedes kleine „Aufmucken“, um die elterliche Gewalt zu untergraben, vielmehr müssen sich alle Arten der erzieherischen Einflußnahme als aussichtslos erweisen $^{324}$.

Stellt man darauf ab, daß die Herrschaftsmacht faktisch durchsetzbar sein muß, müßten alle Eltern privilegiert werden, die unfähig oder nicht willens sind, die Herrschaftsmacht auszuüben. Eltern, die früher resignieren oder die nicht bereit sind, alle Erziehungsmittel auszuschöpfen, dürften dann mangels Herrschaftsmacht nicht zur Verantwortung gezogen werden ${ }^{325}$. Entfällt also zugleich mit der Herrschaft die Garantenstellung, entfällt auch die Möglichkeit einer Strafbarkeit. Dies ist aber kein zufriedenstellendes Ergebnis: Man schützt dadurch solche Eltern, die aus Gleichgültigkeit ihre Herrschaftsmacht so lange nicht angewendet haben, bis sie wegen der Verwahrlosung ihrer Kinder ohnehin nicht mehr auszuüben war.

Dieser Schluß läßt sich vermeiden, indem man das Unterlassen der Eltern vorverlegt an einen Zeitpunkt, zu dem ihnen die Ausübung der Herrschaftsmacht noch möglich war ${ }^{326}$. Dies läßt sich damit begründen, daß die Aufsichtspflicht der Eltern regelmäßig bereits im Vorfeld vor dem Delikt ihres Kindes besteht. Die Eltern haben von Anfang an Sorge zu tragen, daß sie ihren Einfluß auf ihre Kinder ausüben können. Der Verlust der Herrschaftsmacht erfolgt nicht automatisch, sondern in einem allmählichen Prozeß. Bereits hier müssen die Eltern ihre- zu diesem Zeitpunkt noch bestehende Herrschaftsmacht - einsetzen, nicht erst, wenn es zu spät ist und sie jeden Zugang zu ihrem Abkömmling verloren haben. Diese Ausführung gelten in erster Linie für den fahrlässigen Verlust der Herrschaft und damit für das fahrlässige Unterlassen der Deliktshinderung. Doch kann das vorsätzliche Aufgeben der Herrschaftsmacht zur Annahme eines Vorsatzes beim späteren Unterlassen führen, wenn in der Aufgabe der Herrschaftsmacht zugleich die billigende Inkaufnahme eines künftigen Delikts durch das Kind liegt.

\footnotetext{
${ }^{324}$ Schünemann, Grund und Grenzen, S. 325.

${ }^{325}$ Differenzierend: MüKo, § 832, Rn. 18.

${ }^{326}$ Schünemann spricht das Problem zwar an, bietet aber keine Lösung, vgl. Grund und Grenzen, S. 325.
} 
Auf der anderen Seite ist zu fragen, ob ein unverschuldeter Verlust der Herrschaftsmacht die Garantenstellung nicht geradezu zwingend aufheben muß. Es erscheint unbillig, Eltern, die ihre Kinder in echter Sorge erziehen, zu bestrafen, wenn sie bei der Erziehung Fehler machen oder die Kinder ihnen entgleiten. Für die Frage, ob Autorität ausgeübt wird oder nicht, kommt es aber weder auf den Vorsatz noch auf das Verschulden an. Selbst wenn man beim unverschuldeten Herrschaftsverlust eine Garantenstellung bejaht, bedeutet das für die erfolglos bemühten Eltern noch längst keine Strafbarkeit. Also auch dann, wenn die Eltern die Herrschaftsmacht über das Kind verloren haben, besteht eine Eingreifenspflicht. In diesem Fall wird es aber entweder an einer Eingriffsmöglichkeit fehlen, da die Eltern kein Mittel haben, die Tat ihres Abkömmlings zu unterbinden, oder die einzige mögliche Gegenhandlung stellt sich als unzumutbar dar. Das Eingreifen, etwa durch die Warnung des Opfers oder durch die Inanspruchnahme des Vormundschaftsgerichts ${ }^{327}$ oder gar der Polizei ${ }^{328}$, kann unter Umständen rechtlich nicht durchgesetzt bzw. zugemutet werden ${ }^{329}$.

Rogall setzt für den nicht-beeinflußbaren Untergebenen in einem Betrieb bei der Zurechnung des Erfolges an. Es gehöre nicht zur Erfolgsabwendungspflicht des Betriebsinhabers, daß er seine Autorität auch durchsetzen könne und das Direktionsrecht vom Untergebenen tatsächlich respektiert werde. Diese ex ante ungewissen Umstände könnten keinen Einfluß auf die Pflichtenlage haben. Erweise sich der Untergebene als nicht beeinflußbar, hätte er sich also von keiner Zuwiderhandlung abhalten lassen, so schließe das nicht die Pflicht, wohl aber die Zurechnung des Erfolges aus ${ }^{330}$. Das läßt sich wohl für den Betriebsinhaber bejahen, gilt aber für Eltern, die die dauerhafte Einwirkungsmöglichkeit auf ihre Abkömmlinge haben, nicht unmittelbar. Abschließend ist zu sagen, daß auch für strafmündige Jugendliche stets eine Garantenstellung besteht. Daß diese per se schwächer sei als jene

\footnotetext{
${ }^{327}$ Bejaht wird eine Zumutbarkeit aber von Boscher, VersR 64, 888 (889).

328 Schünemann, Grund und Grenzen, S. 325, der davon ausgeht, daß eine solche Maßnahme der Aufrechterhaltung der Herrschaftsmacht dienen kann; das Einschalten der Polizei wird jedoch zumeist in Fällen der konkreten Gefahr für ein Rechtsgut geschehen, so daß diese Frage eher die Deliktshinderung als solche betrifft.

${ }^{329}$ Das gilt aber auch für den verschuldeten Verlust der Herrschaftsmacht.
} 
hinsichtlich der strafunmündigen Kinder, kann nicht gesagt werden, da von einer Gleichwertigkeit der Garantenstellungen ausgegangen werden muß. Es gibt nur eine Handlungspflicht oder es gibt keine, ein „Mehr“ oder ein „Weniger“ von Pflicht ist nicht konstruierbar. Daß sich hinsichtlich des Alters des Pflichtunterworfenen und der Umstände des Einzelfalls der Umfang der Eingreifenspflicht ändert, hat für das generelle Bestehen der Garantenstellung keine Bedeutung.

d) Strafmündigkeit als geeignetes Herrschaftskriterium ?

Fraglich ist jedoch, ob es für die Beherrschbarkeit auf die Strafmündigkeit des unter 18jährigen ankommt. Wenn es bei der Strafmündigkeit lediglich um das Recht des Staates auf Strafe gegenüber dem Jugendlichen ginge, wäre sie als Kriterium für das Innenverhältnis zwischen Eltern und Kind, d.h. für die Herrschaft über das Kind, möglicherweise unerheblich.

Durch $\S 19$ StGB hat der Gesetzgeber festgelegt, daß jedenfalls alle Kinder unter 14 Jahren nicht strafrechtlich verantwortlich für die von ihnen begangenen Taten sein sollen. Jugendliche über 14 Jahre sind nach der Wertung des Gesetzgebers demgegenüber gem. § 3 JGG bedingt strafmündig, abhängig von ihrer Verstandesreife, ethischen Reife und Widerstandsfähigkeit gegenüber äußeren Einflüssen. Ab dem 18. Lebensjahr gilt der junge Mensch (Heranwachsende) als unbedingt strafmündig ${ }^{331}$.

Da der Gesetzgeber bewußt Altersgrenzen für Strafunmündigkeit und Strafmündigkeit gezogen hat, spricht etliches dafür, daß hierbei auch Überlegungen, die die Beherrschbarkeit des Minderjährigen berühren, eingeflossen sind. Denn mit der Strafmündigkeit, also der Frage nach seiner Reife, das Unrecht einzusehen, hat es unmittelbar zu tun, ob der Minderjährige vernünftigen Argumenten durch den Erwachsenen zugänglich ist, sein Verhalten vorhersehbar ist, ob er also beherrschbar

\footnotetext{
${ }^{330}$ Rogall, ZStW 98 (1986) 573, (619) m.w.N.

${ }^{331} \mathrm{Daß}$ die inn treffenden Sanktionen gem. $\S 105$ JGG bis zum Erreichen des 21. Lebensjahrs noch aus dem Jugendrecht stammen können, ändern an der Einstufung des Heranwachsenden als strafmündig nichts. Eine Beeinträchtigung der Schuldfähigkeit des Heranwachsenden ist - auch bei Entwicklungsrückstand - nur im Rahmen der
} 
ist. Je mehr Reife und Eigenverantwortlichkeit dem Jugendlichen ab seinem 14. Lebensjahr zugestanden bzw. auferlegt wird, desto geringer muß der Einfluß oder zumindest die rechtliche Wirkung des Einflusses der Eltern auf ihn sein. Die Eigenverantwortlichkeit nimmt mit den Jahren stetig zu. Mit dem Erreichen der Volljährigkeit tritt sodann die volle Strafmündigkeit ein. Zugleich findet die elterliche Aufsichts- und Befehlsgewalt ein Ende ${ }^{332}$.

Insoweit ist die Strafmündigkeit als ein geeignetes Kriterium anzusehen, um die Verantwortlichkeit des Minderjährigen zu bestimmen.

e) Unterschiedliche Behandlung des Jugendlichen und des Heranwachsenden

Unbestritten ist, daß die im Elternrecht wurzelnden Rechtsbefugnisse mit fortschreitendem Alter des Kindes abnehmen und mit der Volljährigkeit des Kindes erlöschen ${ }^{333}$. Einhellig anerkannt ist somit, daß die rechtliche Herrschaft der Eltern mit Eintritt der Volljährigkeit endet und zugleich deren Garantenpflicht aus der Überwachung einer gefährlichen Person endet.

In diesem Zusammenhang ist $\mathrm{zu}$ klären, ob nicht dadurch eine Strafbarkeitslücke entsteht, daß die Verantwortlichkeit der Eltern zwar wegen fehlender Herrschaftsmacht endet, nämlich aufgrund der Annahme einer Eigenverantwortlichkeit des Volljährigen, auf der anderen Seite aber dem Heranwachsenden ${ }^{334}$ eben diese Eigenverantwortlichkeit abgesprochen wird, wenn man ihn gemäß $\S 105$ JGG wie einen Jugendlichen behandelt. Während die Eltern also beim Jugendlichen strafrechtlich zur Verantwortung gezogen werden, so werden sie es beim Heranwachsenden selbst in den Fällen nicht, in denen seine sittliche und geistige Entwicklung der eines Jugendlichen entspricht. Hier könnte man davon sprechen, daß den Eltern die

allgemeinen Regeln der $\S \S 20,21$ StGB zu berücksichtigen, vgl. Eisenberg, JGG, § 3 Rn. 2.

${ }^{332}$ SK-Rudolphi, § 13, Rn. 34; zur Problematik der Behandlung des Heranwachsenden siehe unter $\mathrm{e})$.

333 Jarass/ Pieroth, Art. 6, Rn. 26; BVerfGE 59, 360 (382): abgestufte partielle Mündigkeitsregelungen sind zulässig; 72, 122 (137); Bärwinkel, Garantieverhältnisse, S. 169; Schünemann, Grund und Grenzen, S. 327.

${ }^{334}$ I.S.d. § 1 Abs. 2 JGG. 
Verantwortung für das Tun des nun Volljährigen genommen, aber diese Verantwortung - indem sie ihm nicht übertragen wird - ohne Bezugsperson vorhanden bleibt. Es ist jedoch nicht ersichtlich, wie man sich aus diesem Dilemma befreien soll: Aufgrund seiner Volljährigkeit steht es dem Heranwachsenden frei, zu tun, was ihm beliebt. Seine Eltern haben keinerlei Rechte oder Pflichten mehr, um sein Verhalten zu beeinflussen, und es wäre auch vollkommen unzulässig, ihre Garantenstellung hier auszudehnen. Der Heranwachsende hingegen unterfällt trotz seiner Volljährigkeit unter Umständen noch dem Jugendstrafrecht und damit - trotz seiner generellen Strafmündigkeit nicht der vollen Verantwortlichkeit für sein Tun. Auch daran zu rütteln, ergibt keinen Sinn. Als Fazit muß man für die Zeitspanne, in der die Eltern nicht mehr und die Heranwachsenden möglicherweise noch nicht voll verantwortlich sind, von einer Straftatverhinderungspflicht der Eltern absehen.

5. Garantenstellung aus der Stellung als Wohnungsinhaber

Weiterhin ist für die Eltern neben der Garantenstellung kraft Autorität auch eine solche aus der Herrschaft über die Wohnung möglich. Das setzt im hier gesteckten Rahmen voraus, daß der Jugendliche seine Delikte in der elterlichen Wohnung begeht. Da dies nur einen Teil der möglichen Delikte des Jugendlichen betrifft ${ }^{335}$ und hinsichtlich der Wohnungsherrschaft als solcher die Eltern-Kind-Beziehung unmaßgeblich ist, bedarf diese Garantenpflicht hier nur der Vollständigkeit halber der Erwähnung. Die Pflicht zur Verhinderung einer Straftat, die unter Umständen einen Wohnungsbesitzer trifft ${ }^{336}$, kann also für Eltern -zusätzlich zu der Garantenpflicht kraft Autoritätgegenüber ihren Kindern bestehen.

\footnotetext{
${ }^{335}$ Delikte im eigenen Elternhaus, bei denen Rechtsgüter Außenstehender gefährdet werden, sind im übrigen eher unwahrscheinlich.

${ }^{336}$ Dazu Blei, AT, S. 329; ders. Mayer-FS, S. 132; Bärwinkel, Struktur, S. 168; Lackner, $\S 13$, Rn. 15 m.w.N.; Landscheidt, Problematik der Garantenpflichten, S. $101 \mathrm{ff}$.; Rudolphi, NStZ 84, 149 (154); Herzberg, Unterlassung, S. 331ff; nur bejaht bei schweren Straftaten und als Schutz vor einem anderem Gast: BGHSt 27, 10 (17f.); nur bei gefährlicher Beschaffenheit der Wohnung: BGHSt 30, 391 (396); OLG Stuttgart, NJW 81, 182 (183).
} 
B. Inhalt und Umfang der Garantenpflicht

\section{Inhalt der Garantenpflicht}

$\mathrm{Zu}$ untersuchen ist, ob die Garantenpflicht nur die Pflicht zur Beaufsichtigung des Jugendlichen oder auch jene Pflicht erfaßt, diesen direkt an der Deliktsverwirklichung zu hindern. Diese Frage betrifft die Garantenpflicht in ihrem Kern, denn sie entscheidet darüber, was die elterliche Garantenstellung im Ernstfalle leisten muß. Nicht zu trennen ist das Problem von der gebotenen Handlung, da diese von der Garantenpflicht bestimmt wird.

1. Die Aufsichtspflicht als primäre und die Eingriffspflicht als sekundäre Garantenpflicht

Worin besteht also die Garantenpflicht aufgrund von Herrschaft ? Erfordert sie in jedem Fall die Verhinderung des tatbestandlichen Erfolges, oder genügt für das pflichtgemäße Handeln auch schon ein anderes Tätigwerden?

Wie schon erläutert, soll durch den Garanten bei dem Überwachten ein Verhalten herbeigeführt bzw. aufrechterhalten werden, das nicht die Rechtsgüter anderer beeinträchtigt. Fraglich ist, ob dieser Pflicht gegenüber den Rechten Dritter schon mit dem Erfüllen der Aufsichtspflicht genüge getan wird. Dazu ist der Begriff des Aufsichtführens zu klären. In erster Linie geht es bei der Aufsicht um die ständige oder regelmäßige Beobachtung einer Person. Sie dient vom Wortlaut her sowohl dem Schutz des zu Beaufsichtigenden als auch dem Schutz von Dritten ${ }^{337}$. Von der reinen Beobachtung unterscheidet die Aufsicht sich aber wie bereits erwähnt dadurch, daß dem Garanten ein Zugriff möglich ist. Der Aufsichtspflichtige ist gerade nicht distanzierter Beobachter, sondern nimmt selbst - zumindest geistig - Anteil am Geschehen. Der Überwachte weiß das regelmäßig. Er muß damit rechnen, daß ein Eingriff durch den Herrschaftsinhaber erfolgt. Die

${ }^{337}$ Fuchs, Elterliche Aufsichtspflicht, S. $152 f$. 
Überwachung hat daher anders als die bloße, unter Umständen sogar heimliche, Beobachtung den Effekt, daß der Überwachte die Situation kennt und sein Verhalten danach ausrichten kann. Daher reicht die Aufsicht in der Regel aus, um den Herrschaftsunterworfenen in die gewünschte Richtung zu lenken. Gerade Kinder und Jugendliche beobachten genau, wie weit sie gehen können, und sie stoppen zumeist das unerwünschte Verhalten, sobald sie auf echten Widerstand stoßen.

Wie Aufsicht ausgeübt wird, hat bereits Schünemann beschrieben. Bei bloßen persönlichen Beziehungen wird nach seiner Ansicht der Wille des unmittelbar Handelnden durch die Bindung nicht beherrscht, sondern nur motiviert $^{338}$. Sangenstedt greift dies auf, indem er feststellt, daß das Tun der überwachten Person nur mittelbar steuerbar sei durch das Auslösen eines entsprechenden Motivationsdruckes durch den Aufsichtspflichtigen $^{339}$. Es wird also auf die überwachte Person eingewirkt, indem sie so gesteuert wird, daß ein abweichendes Verhalten sofort bemerkt würde und dagegen angesteuert werden könnte. Die Aufsicht ist ihrer Natur nach also nur eine indirekte Beeinflussung. Sie stellt gerade keinen deutlichen Eingriff dar, weil sie nicht nach außen wirkt; sie wirkt nur unterschwellig und beinhaltet als solche noch keine Verbote oder Zurechtweisungen, sondern Anregungen, Ermahnungen und das Geben einer Vorbildfunktion. Die Aufsicht hat also ihre Ausprägung innerhalb der Eltern-Kind-Beziehung. Somit kann man die Aufsicht als Fürsorge- und Erziehungsausübung gem. Art. 6 GG Abs. 2 „,in Reinform“ betrachten. Es ist also festzuhalten, daß die grundlegende Pflicht sich darin erschöpft, präsent zu sein.

Dazu ein Vergleich: Der Polizeihund, der einen ertappten Dieb in Schach hält, überwacht diesen durch seine bloße Anwesenheit und vielleicht durch Knurren und Bellen. Beißen wird der Hund den Dieb hingegen nur dann, wenn dieser Anstalten macht, sich zu entfernen. Dasselbe gilt für den Überwacher einer gefährlichen Person. Die Hauptaufgabe besteht darin, das fremde Verhalten zu kontrollieren und abzuschätzen, ob es

${ }^{338}$ Grund und Grenzen, S. 329; so auch Brammsen, Entstehungsvoraussetzungen, S. 225. 
sich noch im Bereich des Zulässigen hält. Erst, wenn dieses Mittel versagt, kommen unter Umständen schärfere Maßnahmen in Betracht.

Was soll nun geschehen, wenn die Aufsicht nicht ausreicht, um das deliktische Handeln zu unterbinden: Ist dann ein darüber hinausgehendes Verhalten des Garanten erforderlich?

Auch wenn man die Aufsichtspflicht als Hauptpflicht betrachtet, steht fest, daß sie ohne die Möglichkeit des Garanten, in das Geschehen einzugreifen, leer läuft. Wenn die bewachte Person ,aus dem Ruder läuft“", muß der Bewacher weitere Maßnahmen einleiten. Kann aus der bloßen Aufsichtspflicht daher abgeleitet werden, daß Eltern nicht nur intern tätig werden, sondern beim Versagen dieser Aufsicht weitere Schritte ergreifen ?

Die elterliche Garantenpflicht endet nicht dort, wo die Aufsicht versagt, sondern sie tritt vielmehr in eine andere Stufe $\operatorname{ein}^{340}$. Daher entspringt der Aufsichtspflicht eine Pflicht zum Eingreifen. Jene Eingriffpflicht, die über das Aufsichtführen hinausgeht, ist somit eine Sekundärpflicht. Sie stellt durch unmittelbares Reagieren auf die Aktion des Kindes den Kontakt des Erziehungsberechtigten mit der Außenwelt her und verknüpft die familiäre Welt mit der äußeren Welt. Die Verknüpfung kann etwa darin liegen, daß die Eltern persönlich in das Geschehen eingreifen, etwa durch Dazwischengehen bei einer Schlägerei.

Ihre weiteste Ausführung erlebt die aus der Aufsicht abgeleitete Handlungspflicht, wenn gar nicht mehr die Eltern eingreifen, sondern Dritte, die von den Eltern dazu motiviert worden sind: Dies wäre der Fall, wenn die von den Eltern alarmierte Polizei eingreift. Hierin ist die dritte Stufe im Pflichtensystem des Überwachergaranten zu sehen.

Es können also folgende Stufen der Überwachergarantenpflicht unterschieden werden:

a) Aufsicht im engeren Sinn (persönlicher Bereich, beschränkt auf Eltern-Kind-Verhältnis)

\footnotetext{
${ }^{339}$ Vgl. Sangenstedt, Garantenstellung und Garantenpflicht, S. 401.

${ }^{340}$ Das Ziel des Verhaltens ist zu diesem Punkt der Überlegungen aber noch völlig offen.
} 
b) Eingreifen der Eltern (Kontakt nach außen, Bezug zu außenstehenden Dritten)

c) Eingreifen von legitimierten Dritten (Abgabe der Ausführung an Dritte)

2. Art der Aufsicht bei der Überwachergarantenstellung

Es wurde erläutert, daß es sich bei der Pflicht der Eltern, Straftaten ihrer Kinder zu unterbinden, um eine Überwacherpflicht handelt. Dementsprechend ist die Aufsicht am Begriff des Überwachens zu messen.

Für die Überwachung als solche findet sich kaum ein Synonym. „Kontrolle“ könnte ein sinnverwandtes Wort sein. Auch die Kontrolle wird nach dem Sprachgebrauch in erster Linie nicht zum Wohle des Kontrollierten, sondern aus anderen Gründen durchgeführt. Man denke an die Fertigungskontrolle in einer Fabrik, die Führerscheinkontrolle im Straßenverkehr oder die Kontrolle von Gesetzestexten bei den Prüflingen einer juristischen Prüfung. Es ist also nicht ganz richtig, wenn man die Überwacherpflicht mit der Aufsichtspflicht gleichsetzt, weil jede Überwachung Aufsicht einer Gefahrenquelle bedeutet, aber nicht jede Aufsicht sich auf das Beaufsichtigen einer gefährlichen Person oder Sache bezieht ${ }^{341}$.

Dies führt $\mathrm{zu}$ der Frage, worin sich die Aufsichtspflicht für Überwachergaranten von jener für Obhutsgaranten unterscheidet. Möglicherweise leiten sich aus der Grundpflicht, nämlich der Aufsichtspflicht, für Überwacher und Beschützer unterschiedliche Einzelpflichten (Sekundärpflichten) ab.

Auch wenn Überwacher- und Obhutsgaranten beide der Aufsichtspflicht unterliegen, so mutet das Überwachen einer Person wesentlich rigider in seinen Folgen bei einer Zuwiderhandlung an als das Beaufsichtigen. Aufsicht und Obhut scheinen sich sprachlich darin $\mathrm{zu}$ erschöpfen, daß stets im Vorfeld einer gefährlichen Handlung die richtigen Maßnahmen ergriffen werden, um eine Gefahr erst gar nicht entstehen zu lassen. 
Demgegenüber erweckt der Begriff der Überwachung den Eindruck, als würde der Eintritt einer Zuwiderhandlung erst abgewartet, um diese anschließend mit einer Maßnahme zu unterbinden. Das Überwachen hat den Schwerpunkt bei der Reaktion auf eine erwartete Übertretung.

Fuchs spricht insoweit davon, daß typisches Merkmal einer Aufsichtsmaßnahme sei, daß die Eltern zu ,repressiven“ Maßnahmen greifen. Es sei die Unterscheidung zu machen zwischen positivanleitender Erziehung und negativ-verbietender Aufsicht. Kennzeichnend für die eher der Aufsicht zuzuordnenden Maßnahmen sei weiterhin, daß die Eltern sie ergriffen, um in einer bestimmten Situation einen Schaden abzuwenden $^{342}$.

Es kann allerdings mittlerweile als gesichert anerkannt werden, daß die Obhutspflicht der Überwacherpflicht in ihren Anforderungen an den Garanten in nichts nachsteht. Die Schlußfolgerung, aus einer sprachlichen Auslegung eine strengere Pflicht in der Überwacherpflicht zu sehen, wäre daher unzutreffend. Der Inhalt der Überwachungspflicht kann daher nicht sinnvoll durch Abgrenzung zur Obhutspflicht ermittelt werden.

3. Umfang der Aufsichtspflicht. Die zivilrechtliche Aufsichtspflicht im Sinne des $\S 832$ Abs. 1 BGB

Um den Inhalt und Umfang der Garantenstellung genauer zu beleuchten, ist es hilfreich, wenn nicht sogar unumgänglich, Parallelen zu der zivilrechtlichen Aufsichtspflicht zu ziehen. In der Rechtsprechung in Strafsachen und der strafrechtlichen Literatur wird die elterliche Aufsichtspflicht nicht näher behandelt, sondern nur als Garantenpflicht vorausgesetzt.

Es bietet sich an, die strafrechtliche Aufsichtspflicht der Eltern mit der Aufsichtspflicht des $\S 832$ BGB zu vergleichen.

\footnotetext{
${ }^{341}$ Der inhaltliche Unterschied verkommt immer dann zum bloßen Wortspiel, wenn sich aus dem Kontext ergibt, ob die Aufsicht zum Schutz der beaufsichtigten Sache oder zum Schutz anderer Rechtsgüter ausgeübt wird.

${ }^{342}$ Fuchs, Elterliche Aufsichtspflicht, S. 175.
} 
$\S 832$ Abs. 1 BGB

Wer kraft Gesetzes zur Führung der Aufsicht über eine Person verpflichtet ist, die wegen Minderjährigkeit oder wegen ihres geistigen oder körperlichen Zustandes der Beaufsichtigung bedarf, ist zum Ersatz des Schadens verpflichtet, den diese Person einem Dritten widerrechtlich zufügt. Die Ersatzpflicht tritt nicht ein, wenn er seiner Aufsichtspflicht genügt oder wenn der Schaden auch bei gehöriger Aufsichtsführung entstanden sein würde.

Da die strafrechtliche Aufsichtspflicht, ihrem Inhalt, ihrer Zielrichtung und ihrem Umfang nach an keiner Stelle des Strafgesetzes definiert oder strafrechtsspezifisch beschrieben wird, ist ein echter Vergleich mit der Pflicht aus $§ 832$ BGB nicht möglich. Es kann nur untersucht werden, ob die Ausfüllung des strafrechtlichen Pflichtbegriffs mit einem Begriff aus dem Zivilrecht zulässig ist bzw. ob eine zivilrechtliche Pflicht zugleich eine strafrechtlichen Pflicht darstellen kann. Für den Fall, daß dies zu bejahen ist, können die für die zivilrechtliche Aufsichtspflicht erforschten Inhalte auch für die Inhalte der strafrechtlichen Garantenpflicht verwendet werden.

Bevor also auf den eigentlichen Inhalt der zivilrechtlichen Aufsichtspflicht eingegangen werden kann, muß geklärt werden, ob die Übernahme dieses Begriffs für die strafrechtliche Pflicht überhaupt in Frage kommt.

Fraglich ist, ob die gleichen Maßstäbe, die im Zivilrecht für die Pflichten der Eltern gelten, auch im Strafrecht angewendet werden können ${ }^{343}$. Für jedwede Pflicht der Eltern zur Aufsicht ist auf das Eltern-Kind-Verhältnis abzustellen. Das Verhältnis zwischen Eltern und Kind ist vor allem zivilrechtlich (familienrechtlich) ausgestaltet. Daher können, wenn überhaupt, nur die zivilrechtlichen Regeln hier einschlägig sein. Dabei ist aber zu beachten, daß in der Zuhilfenahme der zivilrechtlichen Aufsichtspflichten für die Zwecke des Strafrechts kein Rückgriff auf die Rechtsquellenlehre liegt: Die Aufsichtspflicht des Garanten im Rahmen des Unterlassungsdelikts soll nicht etwa auf zivilrechtliche Normen

${ }^{343}$ So jedenfalls Seelmann, GA 1989, 241 (244). 
zurückgeführt und durch sie begründet werden. Der Inhalt der strafrechtlich ausgerichteten Aufsichtspflicht soll vielmehr mit Hilfe des Zivilrechts ausgefüllt und näher beschrieben werden.

Die Beschreibung der Aufsicht muß sogar durch das Zivilrecht geschehen: Andere Aufsichtspflichten als diejenigen aus dem Zivilrecht gibt es für Eltern nicht. Mittel der Aufsicht und Beobachtung können daher auch hier nur solche sein, die das Zivilrecht kennt. Die Behandlung der elterliche Aufsicht muß sich in ihren Grundzügen daher aus der

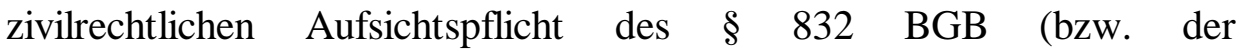
familienrechtlich ausgestalteten Pflicht des $§ 1626$ BGB) ergeben. Zwar berücksichtigt $\S 832$ BGB nur die deliktsrechtliche Seite der Aufsichtspflicht. Er hat jedoch bereits im Strafrecht als Vorbild gewirkt, und zwar in der durch das 4. StrRG von 1973 entfallenen Vorschrift des $\S 143 \mathrm{StGB}^{344}$. Danach war strafbar, wer seiner Aufsichtspflicht nicht nachkam, wenn der zu Beaufsichtigende bei dieser Gelegenheit eine Straftat beging ${ }^{345}$. Im Abs. 2 der Vorschrift wurde die zivilrechtliche Aufsichtspflicht sogar deutlich als Maßstab gesetzt ${ }^{346}$. Dies ist ein weiterer Hinweis darauf, daß es sich bei der Garantenpflicht zur Überwachung des Minderjährigen um die gleiche Aufsichtspflicht handelt wie bei $\S 832$ BGB $^{347}$. Es kann daher gesagt werden, daß sich die zivilrechtliche Aufsichtspflicht mit der strafrechtlichen Aufsichtspflicht des Überwachergaranten deckt.

Die zivilrechtliche Aufsichtspflicht, die Inhalt des $\S 832$ BGB ist, stellt einen Teil der in den $\S \S 1626,1631$ BGB kodifizierten elterlichen Personensorge dar ${ }^{348}$. Die Personensorge gliedert sich nach

\footnotetext{
${ }^{344}$ Kaltofen, S. 55ff.; Schneider, S. 18.

${ }^{345}$ Siehe oben 1. Teil, B III.

${ }^{346}$ LK (9. Aufl.)-Herdegen, § 143, Rn. 7; Schwarz/Dreher, § 143, 2).

347 A.A. jedoch Hsü, Garantenstellung des Betriebsinhabers, S. 205: Seiner Meinung nach ist das Zivilrecht, insbesondere das Recht der unerlaubten Handlungen, in weiten Teilen von den Wertungen des Strafrechts abhängig und trifft insoweit gar keine eigenen Wertungen, die es dem Strafrecht entgegenstellen könnte.

${ }^{348} \S 1626$ BGB (Elterliche Sorge, Grundsätze)
}

Abs. 1 Die Eltern haben die Pflicht und das Recht, für das minderjährige Kind zu sorgen (elterliche Sorge). ....

Abs. 2 Bei der Pflege und Erziehung berücksichtigen die Eltern die wachsende Fähigkeit und das wachsende Bedürfnis des Kindes zu selbständigem 
$\S 1631$ Abs. 1 BGB auf in die Pflege, d. h. Sorge für das leibliche Wohl, und die Erziehung, d.h. die Sorge für die geistige und seelische Entwicklung des Kindes ${ }^{349}$. Das Recht und die Pflicht, das Kind zu beaufsichtigen, nennt das Gesetz als besondere Elemente der Personensorge ${ }^{350}$. Während die $\S \S 1626,1631$ BGB jedoch überwiegend den Kindesinteressen zu dienen bestimmt sind $^{351}$, wurde die Vorschrift des $\S 832$ ausschließlich im Interesse der Allgemeinheit geschaffen ${ }^{352}$.

Im Gegensatz zu $§ 1631$ BGB, wonach die elterliche Sorge neben der Beaufsichtigung vor allem die gesamte Erziehung des Kindes umschließt, ist die Pflichtenzuweisung in $\S 832$ BGB auf einen Aspekt begrenzt: $\S 832$ BGB stellt klar, daß ausschließlich mangelnde Aufsicht anspruchsbegründend wirken soll ${ }^{353}$. In der zivilrechtlichen Literatur wird deshalb teilweise die Ansicht vertreten, die Aufsichtspflicht in $\S 1631$ BGB sei eine andere als in $\S 832$ BGB. Die Pflicht der Erziehung habe einen anderen Charakter als jene der Beaufsichtigung. Nach Ansicht von Fuchs betrifft $\S 1631$ nur die familienrechtliche Pflicht zum Schutze des Kindes, und bei $\S 832 \mathrm{BGB}$ geht es nur um den Schutz von Dritten $^{354}$. Demgegenüber meint Jayme, die familienrechtliche Aufsichtspflicht sei mit der deliktischen inhaltlich identisch; die unterschiedliche Schutzrichtung wirke sich nicht auf den Inhalt der Aufsichtspflicht aus ${ }^{355}$.

Nach Fuchs ist also nicht jede Verletzung der familienrechtlichen Pflicht zugleich eine Verletzung der deliktischen Aufsichtspflicht ${ }^{356}$. Hier werden jedoch möglicherweise Ursache und Wirkung vertauscht: Ob die

verantwortungsbewußtem Handeln. Sie besprechen mit dem Kind, soweit es nach dessen Entwicklungsstand angezeigt ist, Fragen der elterlichen Sorge und streben Einvernehmen an....

§ 1631 Abs. 1 BGB (Inhalt der Personensorge)

Die Personensorge umfaßt insbesondere die Pflicht und das Recht, das Kind zu pflegen, zu erziehen, zu beaufsichtigen und seinen Aufenthalt zu bestimmen.

${ }^{349}$ Schwab, Familienrecht, S. 227, Rn. $428 f$.

${ }^{350}$ Schwab, Familienrecht, S. 228, Rn. 430; zum Umgang auch S. 247, Rn. 471.

${ }^{351}$ Beitzke, FamRZ 1979, 8 (10).

352 Albilt, S. 64.

${ }^{353}$ Albilt, S. 63; Dahlgrün, S. 55.

${ }^{354}$ Fuchs, Elterliche Aufsichtspflicht, S. 154.

355 Jayme, Die Familie, S. $150 f f$.

${ }^{356}$ Fuchs, Elterliche Aufsichtspflicht, S. 161. 
Aufsichtspflicht sich als deliktische herauskristallisiert, hängt doch im wesentlichen davon $a b$, ob durch das Tun des Kindes ein Dritter gefährdet worden ist oder nicht. Das ist zum Beginn einer gefährlichen Handlung noch gar nicht absehbar. Es stellt sich daher die Frage, wie für den Aufsichtspflichtigen erkennbar sein soll, welcher Pflicht er nun nachzukommen habe, der deliktischen oder der familienrechtlichen. Denn das müßte er ja wissen, wenn die Pflichten unterschiedlichen Umfang oder Inhalt hätten. Damit kann es für den Inhalt der Pflicht auf den Schutzzweck nicht ankommen. Es müßten zudem Beispiele dafür gefunden werden können, daß die Aufsicht zum Schutz des Dritten eine andere ist als zum Schutz des Kindes. Gerade das kann nicht gelingen ${ }^{357}$.

Zur näheren Bestimmung der insoweit als einheitlich zu betrachtenden Pflicht ist die Trennung der Begriffe Erziehung und Aufsicht erforderlich:

Die Aufsicht ist nicht gleichbedeutend mit Erziehung, aber eng mit ihr verwoben. Es besteht eine Wechselbeziehung, wonach die Anforderungen an die Aufsicht um so geringer sind, je besser der Aufsichtsbefohlene erzogen ist, und umgekehrt ${ }^{358}$. Erziehung ist vor allem das Einwirken auf den Willen, Aufsicht das Einwirken auf das Handel ${ }^{359}$. Dadurch daß der Aufsichtspflichtige bereits potentiellen Gefahrensituationen im Vorfeld entgegentreten und somit seinem Kind nicht nur verbietend, sondern auch erklärend gegenübertreten muß, erweisen sich sämtliche Aufsichtsmaßnahmen letztlich auch als Erziehungsmaßnahmen. Dies soll ein Beispiel verdeutlichen: Eine Mutter, die ihrem 15jährigen Sohn einen Wurfpfeil wegnimmt, mit dem er auf einen Spielkameraden zielt, übt eine Maßnahme der Aufsicht aus und erzieht ihn sogleich, indem sie sein Verhalten als unerwünscht

\footnotetext{
357 Darin spiegelt sich das gleiche Problem wieder, den Pflichtenumfang des Obhutsgaranten von dem des Überwachergaranten abgrenzen zu wollen, vgl. 3. Teil B I 2. ${ }^{358}$ Albilt, S. 73; Dahlgrün, S. 56.

${ }^{359}$ Fuchs, Elterliche Aufsichtspflicht, S. 174.
} 
kennzeichnet $^{360}$. Hinzu kommt, daß eine schlechte oder vernachlässigte Erziehung eine besondere Aufsichtspflicht begründen kann ${ }^{361}$.

Die beste Abgrenzung hat Fuchs gegeben. Kennzeichnend für die eher der Aufsicht zuzuordnenden Maßnahmen ist danach, daß die Eltern sie ergreifen, um in einer bestimmten Situation einen Schaden abzuwenden. Dagegen verfolgen Eltern mit der Erziehung des Kindes das Ziel, daß es später als Erwachsener selbständig und selbstverantwortlich handeln kann. Aufsichts- und Erziehungsmaßnahmen unterscheiden sich nicht nur in ihren Zielen. Die Aufsichtsmaßnahme betrifft immer eine konkrete Situation, während sich die Erziehung ihrer Natur nach auf das gesamte Verhalten des Kindes bezieht. Die Aufsichtsmaßnahmen sind daher konkreter als die Erziehungsmaßnahmen ${ }^{362}$. Aufsichtsmaßnahmen haben einen zeitlichen Bezug zum schadensauslösenden Delikt des Minderjährigen, Erziehungsmaßnahmen dagegen zielen auf eine langfristige Wirkung $a b^{363}$.

Daß es sich im Einzelfall ausgesprochen schwierig gestaltet, Aufsicht und Erziehung zu trennen, zeigt sich immer wieder in Rechtsprechung und Literatur, auch wenn dort die Trennung grundsätzlich anerkannt wird $^{364}$. So hat der Bundesgerichtshof sich $\mathrm{zu}$ folgendem Grundsatz bekannt: Beaufsichtigung im Sinne des $\S 832$ BGB als Abwehr von Gefahren, die Dritten von dem Kind her drohen, sei nicht gleichbedeutend mit Erziehung und Fürsorge für das Kind ${ }^{365}$. Dem hat die Literatur, so auch Dahlgrün und Albilt ${ }^{366}$, zugestimmt.

Auf der anderen Seite hat die Rechtsprechung die Abgrenzung von Aufsicht und Erziehung wieder verwischt, indem sie fordert, daß sich die Aufsichtspflicht nach dem Erfolg der Erziehung zu richten habe ${ }^{367}$. Dagegen läßt sich einwenden, daß die Eltern auf diese Weise gemäß

\footnotetext{
${ }^{360}$ Albilt, S. 74.

${ }^{361}$ Aden, Die Haftung der Eltern, S. 145.

${ }^{362} \mathrm{Vgl}$. insoweit auch die unterschiedliche Wirkung der Aufsicht aus $\S 13 \mathrm{StGB}$ und der Fürsorge- und Erziehungspflicht aus $\S 171 \mathrm{StGB}, 5$. Teil B I.

${ }^{363}$ Fuchs, Elterliche Aufsichtspflicht, S. 175.

${ }^{364}$ Vgl. Fuchs, Elterliche Aufsichtspflicht, S. 120f., 174.

${ }^{365} \mathrm{BGH}$ VersR $58,85$.

${ }^{366}$ Dahlgrün, S. 55; Albilt, S. 64.

${ }^{367}$ BGH NJW 84, 2574; OLG Oldenburg, VersR 57, 306; Dahlgrün, S. 56f.; Fuchs, Elterliche Aufsichtspflicht, S. $120 f$.
} 
$\S 832$ BGB auch für den Erfolg ihrer Erziehung einstehen müßten (,Risikohaftung für den erzieherischen Mißerfolg“), obwohl dies nicht der gesetzlichen Regelung entspricht ${ }^{368}$. Insbesondere im Hinblick auf die strafrechtliche Übernahme der im Zivilrecht gebildeten Pflichten wäre dies ausgesprochen heikel. Es findet sich auch die Formulierung, wonach Eltern ihre Aufsichtspflicht durch eine ordnungsgemäße Erziehung zu erfüllen haben ${ }^{369}$. Fuchs bemängelt daran zu Recht die fehlende Erklärung, wie sich dies mit der grundsätzlichen Trennung von Aufsicht und Erziehung vereinbaren lasse ${ }^{370}$. Dennoch kann eine endgültige, vor allem sprachlich befriedigende Abgrenzung wohl nicht gefunden werden. Dazu ist die inhaltliche Verbindung der Begriffe zu stark.

Das Maß und der Inhalt der Aufsicht ${ }^{371}$ richtet sich danach, was nach Alter, Eigenart und Charakter des Minderjährigen und nach den von ihm ausgehenden Gefahren zum Schutz Dritter erforderlich war und den Aufsichtspflichtigen nach ihren Verhältnissen zugemutet werden konnte $^{372}$. Schlechte Charaktereigenschaften des Kindes erfordern erhöhte Aufsichtsmaßnahmen; je geringer die bisherigen Erziehungserfolge waren, desto intensiver muß die Aufsicht ausgeübt werden $^{373}$. Zu berücksichtigen ist auch, daß Kinder und Jugendliche dazu neigen, Vorschriften und Anordnungen nicht $\mathrm{zu}$ beachten und sich unbesonnen zu verhalten ${ }^{374}$.

Es ist deshalb $\mathrm{zu}$ fragen, was verständige Eltern nach vernünftigen Anforderungen unternehmen müssen, um die Schädigung Dritter durch ihr Kind zu verhindern ${ }^{375}$. Für die Haftung gem. § 832 BGB kommt es nicht darauf an, ob der Erziehungsberechtigte allein seiner

\footnotetext{
${ }^{368}$ MüKo-Mertens, § 832, Rz. 18.

${ }^{369}$ BGH NJW 1990, 2553 (2553f.).

${ }^{370}$ Fuchs, Elterliche Aufsichtspflicht, S. 121.

${ }^{371}$ Dazu eingehend Albilt, S. 89ff., 330ff.; Beispiele auch bei Dahlgrün, S. 112ff.; Fuchs, Elterliche Aufsichtspflicht, S. $123 \mathrm{ff}$.

${ }^{372}$ BGH VersR 65, 137 (138); BGH VersR 60, 355 (356); BGH FamRZ 64, 84 (85); BGH VersR 62, 783 (783); Aden, Haftung der Eltern, S. $152 f$.

${ }^{373}$ BGH VersR 60, 355 (356); Boscher, VersR 64, 888 (889).

${ }^{374}$ Busch, ZfJ 96, 456 (459).

${ }^{375}$ BGH FamRZ 64, 84 (85); BGH VersR 62, 783 (783); Busch, ZfJ 96, 456 (459).
} 
Aufsichtspflicht genügt hat. Entscheidend ist vielmehr, ob dies im konkreten Fall und in Bezug auf die zur widerrechtlichen Schadenszufügung führenden Umstände geschehen ist $^{376}$. Die Möglichkeit, das Kind beim Spielen zu beobachten, genügt grundsätzlich nicht zur Wahrnehmung der Sorgfalt des Aufsichtspflichtigen, da ein Eingreifen bei einer sich plötzlich verwirklichenden Gefahr nicht möglich ist ${ }^{377}$. Es hängt zudem sehr vom Einzelfall ab, ob ein Kind die Gefahr beherrscht ${ }^{378}$, so daß keine feste Altersgruppe festgelegt werden kann.

Eine Exkulpation ist aber grundsätzlich immer möglich. So wird darauf hingewiesen, daß es im Zivilrecht keine Verantwortlichkeit eines „Kinderhalters“ analog $§ 7 \mathrm{StVG}$ gibt $^{379}$.

Letztlich muß zwischen zwei schutzwürdigen Interessen abgewogen werden. Jedes Glied der Familie hat ein Recht auf freie Entfaltung der Persönlichkeit. Dieses Recht wäre unzulässig beschnitten, wenn man die Eltern in Aufsichtsmaßnahmen über ihre Kinder, die sie zum Schutze Dritter zu ergreifen haben, überfordern würde. Ebenso benötigt das Kind zur psychischen und physischen Entwicklung ein Mindestmaß an freier und ungehemmter - nicht hemmungsloser - Bewegungsmöglichkeit und könnte Schaden leiden, wenn man es durch allzu strenge Aufsicht gängeln würde ${ }^{380}$. Eine permanente Kontrolle und Bevormundung des Kindes bzw. Jugendlichen wird daher rechtlich nicht nur nicht erwartet, sondern ist geradezu unerwünscht ${ }^{381}$.

Das Kind soll gerade lernen, in einer Welt zurecht zu kommen, die durchaus Möglichkeiten des Mißbrauchs bietet. Lediglich bestimmte, wegen kindlicher Besonderheiten zu gewärtigende und als besonders gravierend anzusehende Gefahren gilt es zu entschärfen ${ }^{382}$. Bei älteren

\footnotetext{
${ }^{376}$ BGH VersR 65, 137 (138); BGH VersR 57, 799 (799f.).

${ }^{377}$ BGH VersR 65, 137 (138); auch nach vorherigem Ermahnen, BGH FamRZ 68, 192 (193); OLG Celle, NJW 70, 202 (202); OLG Köln, VersR 69, 44 (45); a.A. aber LG Kiel, VersR 57, 812 (812); BGH VersR 57, 340 (341); Boscher, VersR 64, 888 (890).

${ }^{378}$ BGH FamRZ 68, 192 (193).

${ }^{379}$ BGH FamRZ 64, 84 (85); BGH VersR 62, 783 (783); vgl. Dahlgrün, S. 2a.

${ }^{380}$ Vgl. BGH FamRZ 64, 84 (85); Boscher, VersR 64, 888 (889); vgl. Albilt, S. 84; ausführlich Freund, Erfolgsdelikt, S. 249.

${ }^{381}$ Sangenstedt, Garantenstellung, S. 408.

${ }^{382}$ Freund, Erfolgsdelikte, S. 244.
} 
Jugendlichen soll sich die elterliche Aufsicht erst recht nur da aktualisieren, wo für sie ein hinreichender Anlaß gegeben ist, wenn der Jugendliche etwa schon mehrfach straffällig auffällig geworden ist ${ }^{383}$. Fehlt es an einem solchen Anlaß, und lehnt der Personensorgepflichtige es ab, sich in ,aufdringlich-intensiver Weise ${ }^{\text {‘384 }}$ in die Freizeitgestaltung seines Sprößlings einzumischen, ist ihm seine Untätigkeit selbst dann nicht als garantiewidriges Versäumnis abgekreidet werden, wenn der Jugendliche die „Großzügigkeit“ seiner Eltern zu einem kriminellen Tun mißbraucht.

Schließlich wird das „In-die-Welt-Setzen“ von Kindern und deren Erziehung - jedenfalls gegenwärtig noch- nicht nur im Interesse des Fortbestandes der menschlichen Gemeinschaft als positiv bewertet, vgl. Art. 6 GG. Es wäre deshalb unangemessen, den Eltern den mit einer Entschärfung aller etwaigen von den Kindern ausgehenden Gefahren verbundenen Aufwand allein aufzubürden. Vielmehr muß auch die Gesellschaft bestimmte Risiken ertragen, die das Dasein von Kindern nun einmal mit sich bringt ${ }^{385}$. Die freie Entfaltung des Kindes einerseits und die Risiken für Dritte, denen die Rechtsordnung weitestgehend Garantie für körperliche Integrität und Schutz des Eigentums gewährt ${ }^{386}$, müssen im Rahmen der Aufsicht abgewogen werden.

Aufsichtsmittel sind im einzelnen die Belehrungen, Warnungen, Mahnungen und Anweisungen, Gebote und Verbote bis hin zur unmittelbaren Beaufsichtigung (Begleitung und direkte Einwirkung), schließlich das Unmöglichmachen bzw. Nichterlauben einer schadensgeneigten Handlung (Wegnahme oder sichere Verwahrung der gefährlichen $\operatorname{Sache}^{387}$ ), als ultima ratio die Inanspruchnahme fremder

\footnotetext{
${ }^{383}$ Zur Aufsicht über zwei schwererziehbare Jugendliche, die aus einem Heim entwichen waren, und zur zivilrechtlichen Haftung des Heimes für die entstandenen Schäden durch den Diebstahl von zwei Kanus: Hans. OLG Hamburg, JZ 88, 570 (Denkwürdig sind die Ausführungen des Gerichts zu dem „romantischen Abenteuer" der Jugendlichen, die im Sinne der „als wertvoll anerkannten Jugendliteratur wie z.B. Tom Sawyer" eine mehrtägige Flußfahrt unternahmen).

${ }^{384}$ so Sangenstedt, Garantenstellung, S. 408.

${ }^{385}$ Freund, Erfolgsdelikt, S. 249.

${ }^{386}$ Boscher, VersR 64, 888 (889).

${ }^{387}$ Busch, ZfJ 96, 456 (459).
} 
Erziehungshilfe $^{388}$. Es ist jeweils das mildeste Mittel anzuwenden, am Anfang stehen die Belehrungen. Ermahnungen wird man Verwarnungen folgen lassen, diese wiederholen und ihnen durch erprobte Erziehungsmaßnahmen Nachdruck verleihen müssen. Als wirkungsvolle Maßnahme hat sich das Abnehmen von gefährlichem Spielgerät bewährt. Darunter fallen besonders Gegenstände wie Autoschlüssel, Brennflüssigkeiten, Chemikalien, Fahrtenmesser, Feuerzeuge, Gummischleudern, Luftgewehre oder -pistolen, Pfeil- und Bogen, Schußwaffen, Stichwaffen, Wurfpfeile und Zündhölzer ${ }^{389}$. Wenn auch das Wegnehmen dieser Gegenstände nichts hilft, wird man den Kindern nur erlauben dürfen, in Blickweite der Wohnung zu spielen, als letztes Mittel, den Kindern das Aufsuchen der Straße überhaupt zu verbieten ${ }^{390}$. Es ist natürlich auch eine kumulative Anwendung der verschiedenen Maßnahmen möglich.

Mit diesem Katalog läßt sich der Inhalt der Aufsichtspflicht in seinen Grundzügen umreißen, wobei stets auf die besonderen Umstände des Einzelfalls einzugehen ist und sich eine pauschale Lösung verbietet.

4. Einschränkung der Aufsichtspflicht der Eltern durch Pflichtendelegation

Für Eltern ergibt sich im Gegensatz zu anderen Überwachungsgaranten eine besonders umfangreiche Pflicht. Während Lehrer ihre Garantenpflicht nur im schulischen Bereich beobachten müssen ${ }^{391}$ und sich die Unterlassungshaftung des Vorgesetzten auf den dienstlichen Bereich beschränkt ${ }^{392}$, diese also nur eine partielle Aufsichtspflicht haben, gilt für Eltern eine räumlich und zeitlich wesentlich umfassendere

\footnotetext{
${ }^{388}$ Albilt, S. 97; Boscher, VersR 64, 888 (889); Busch, ZfJ 96, 456 (459).

${ }^{389}$ Busch, ZfJ 96, 456 (459).

${ }^{390}$ Boscher, VersR 64, 888 (889).

${ }^{391}$ SK-Rudolphi, § 13, Rn. 33; Schünemann, Grund und Grenzen, S. 325.

${ }^{392}$ BGHSt 3, 349 (351); Rogall, ZStW 98 (1986) 573 (618); Schünemann, Grund und Grenzen, S. 328.
} 
Verantwortlichkeit. Sie haben im Gegensatz zu anderen Garanten eine generelle Überwachungspflicht ${ }^{393}$.

Unter den Lebensbedingungen der modernen Gesellschaft ist jedoch kein Mensch imstande, sämtliche Gefahrenquellen innerhalb seiner Domäne ständig selber zu überwachen ${ }^{394}$. Es besteht daher für die Eltern die Möglichkeit, ihre Aufsichtspflicht und damit ihre Garantenstellung wenigstens zeitweise an einen sogenannten Sekundärgaranten abgeben zu können, indem sie das Kind einer anderen Aufsichtsperson, z.B. Kindergärtner, Lehrer, Nachbar, Tagesmutter, übergeben ${ }^{395}$. Eltern sind nicht verpflichtet, ununterbrochen selbst über ihr Kind Aufsicht zu führen, was auch aus praktischen Gründen undurchführbar wäre. Während Eltern ihr zivilrechtliches Sorgerecht nicht auf Dritte übertragen können, ist es möglich, andere an der Erfüllung der Sorgepflichten, also hier speziell der Aufsichtspflicht, zu beteiligen ${ }^{396}$.

Damit unter der Einsetzung eines Sekundärgaranten nicht die Funktionstüchtigkeit der Garantie leidet, ist die Wirksamkeit der Delegation davon abhängig, daß der „Ersatzmann“ gleichermaßen befähigt erscheint, eine effiziente Risikoeindämmung zu gewährleisten, wie sein Vorgänger ${ }^{397}$. Es ist daher zunächst zu fragen, welche Rolle die Auswahl der Aufsichtsperson spielt. Da für die Aufsichtsführung die tatsächliche Aufsicht entscheidet, kommt es nicht darauf an, ob sie durch Vertrag oder aus Gefälligkeit zustande kommt. Aus diesem Grund sind auch Alter und volle Geschäftsfähigkeit der Aufsichtsperson ohne Belang ${ }^{398}$. Um der eigenen Aufsichtspflicht zu genügen, müssen die Eltern eine für die Aufgabe geeignete Aufsichtsperson auswählen. Das bedeutet, daß sie zum einen zuverlässig sein muß, zum anderen auch die physischen Voraussetzungen und die intellektuellen Fähigkeiten

\footnotetext{
${ }^{393}$ Vgl. Landscheidt, Problematik der Garantenpflichten, S. 106.

${ }^{394} \mathrm{Vgl}$. Sangenstedt, Garantenstellung und Garantenpflicht, S. 384.

${ }^{395}$ Vgl. Freund, Erfolgsdelikt, S. 261; Glaue, Schutz der Jugend in der Öffentlichkeit,

S. 16; Sangenstedt, Garantenstellung und Garantenpflicht, S. 406.

${ }^{396}$ Die tatsächliche Fürsorge, die das Kind bei fremden Personen genießt, und das Sorgerecht, das bei den Eltern verbleibt, fallen also auseinander; Schwab, Familienrecht,

S. 230, Rn. 435;

${ }^{397}$ Vgl. Sangenstedt, Garantenstellung und Garantenpflicht, S. 384.

${ }^{398}$ Albilt, S. 186.
} 
innehaben muß, die Aufsicht auszuüben ${ }^{399}$. Wer einen Nachbarn als Aufsicht einsetzt, dessen Desinteresse an den Handlungen des Kindes ganz offenbar ist oder etwa die Großeltern ${ }^{400}$, die durch Gebrechlichkeit zur ausreichenden Aufsicht unfähig sind, oder ein sichtlich überfordertes älteres $\mathrm{Kind}^{401}$, dürfte wohl kaum seiner Aufsichtspflicht genügt haben $^{402}$.

Der Wahl einer geeigneten Aufsichtsperson muß es jedoch gleichstehen, wenn die Eltern ihr Kind in der Schule dem Lehrpersonal übergeben. Denn im schulischen Bereich obliegt nicht den Eltern, sondern dem Staat das Auswahlrecht über die Aufsichtsperson ${ }^{403}$. Jedoch ruht auch hier die elterliche Verantwortung nicht vollständig. Haben Eltern beispielsweise Kenntnis davon, daß der Lehrer, dem sie ihr Kind bei einem Klassenausflug anvertrauen sollen, überfordert ist und eine ausreichende Aufsicht durch ihn nicht gewährleistet sein wird, ist es zumindest fraglich, ob sie trotzdem diese - ihnen immerhin vom Schulsystem vorgegebene- Aufsichtsperson akzeptieren dürfen, ohne selbst zumindest fahrlässig zu handeln.

Für die Bestimmung einer Aufsichtsperson ist entscheidend, daß durch die Eltern eine bewußte und willentliche Übertragung der Aufsichtspflicht auf die andere Person stattfindet. So genügt das „Umherlaufenlassen von Kindern in der Hoffnung, es werde sich schon jemand finden, der von sich aus die Aufsichtsführung übernehme“ nicht $^{404}$.

War eine solchermaßen sorgfältige Auswahl der Aufsichtsperson gegeben, ist $\mathrm{zu}$ fragen, ob damit die elterliche Verantwortung ruht. Ebenso ist es möglich, daß sie nur als gelockert anzusehen ist und den Eltern ein Teil der Aufsichtspflicht erhalten bleibt. Fraglich ist also, ob die Eltern noch in irgendeiner Weise verantwortlich für ihre Kinder sind,

\footnotetext{
399 Albilt, S. 188; BGH VersR 68, 903 (903); anders Glaue, Schutz der Jugend in der Öffentlichkeit, S. 16.

${ }^{400}$ Vgl. dazu Brammsen, Entstehungsvoraussetzungen, S. $170 \mathrm{ff}$.

401 Die Beaufsichtigung durch ältere Kinder ist aber grds. möglich und führt zur Exkulpation, Dahlgrün, S. 198; OLG München VersR 54, 545 (546).

402 Albilt, S. 189 m.w.N.; ähnlich Becker, NJW 52, 1082 (1082).

${ }^{403}$ vgl. Glaue, Die Sicherstellung der Erziehung, S. 12.

${ }^{404}$ Albilt, S. 186.
} 
wenn sie sich unter der Aufsicht eines sorgfältig ausgesuchten Dritten befinden ${ }^{405}$.

Für einen längeren Zeitraum der Aufsicht wurde eine prinzipielle Aufsichtspflicht der direkten Aufsichtsperson bejaht. Weilt demnach ein Kind längere Zeit bei einer Familie zu Besuch, erwächst für sie in der Regel eine vertragliche Aufsichtspflicht ${ }^{406}$.

Wenn sich eine Familie dazu erbietet, das Kind von Verwandten, etwa zur Ferienzeit, in ihre Gemeinschaft aufzunehmen, wird sie damit auch ihre Bereitschaft erkennen lassen, dieses Kind $\mathrm{zu}$ beaufsichtigen, um Schädigungen Dritter zu vermeiden, für die die Eltern möglicherweise einzustehen hätten. Dies gilt um so mehr, als die Eltern, für die Gastfamilie erkennbar, die unmittelbaren Aufsichtsmöglichkeit über das Kind abgeben. Dies geschieht nicht zuletzt in dem Vertrauen, daß die Verwandten die entsprechenden Maßnahmen ergreifen und auf das Kind einwirken werden, notwendigenfalls Nachricht an die Eltern geben werden $^{407}$.

Somit sind die Eltern während dieses Zeitraums nicht mehr verantwortlich für die Taten ihrer Kinder. Es gibt jedoch Einschränkungen: Die Eltern müssen zuvor abwägen, ob es ohne Sorgfaltsverstoß verantwortet werden kann, das Kind mit Rücksicht auf sein Alter und seine Charaktereigenschaften und die persönlichen Verhältnisse in der Gastfamilie aus dem eigenen Hauskreis abzugeben ${ }^{408}$.

Es spricht nichts dagegen, diese, für einen längeren Zeitraum entwickelten Grundsätze, auch für eine kürzere, also etwa stundenweise, Beaufsichtigung anzuwenden. Da die Aufsichtspflicht der Eltern aber nur ruht, wenn sie dafür gesorgt haben, daß die Pflicht adäquat von einer dritten Person übernommen wird, müssen sie zuvor gegebenenfalls notwendige Zusatzmaßnahmen zum Schutze Dritter und des Kindes treffen. Dazu gehört die besondere Aufklärung über Umstände, die vom Normalfall abweichen und nur dem Übertragenden bekannt sind; denn

\footnotetext{
${ }^{405}$ Möglicherweise entfällt nicht schon die Garantenstellung als solche, sondern erst die Zurechnung über § $13 \mathrm{StGB}$ für das vom Kind dort verübten Delikts.

${ }^{406}$ BGH VersR 54, 118 (118) (obiter dictum); a.A. LG Heilbronn, VersR 55, 414f.; ablehnend: Boscher, VersR 64, 888 (889).

${ }^{407}$ Boscher, VersR 64, 888 (889); Glaue, Die Sicherstellung der Erziehung, S. 12.

${ }^{408}$ Boscher, VersR 64, 888 (889).
} 
nur mit diesen Informationen kann die Aufsichtsperson wissen, daß sie ein gesteigertes $\mathrm{Ma} \beta$ an Aufsicht walten zu lassen hat ${ }^{409}$. Dies können zum einen besondere Eigenarten und Neigungen des Kindes sein, die einer besonderen Beachtung bedürfen. Es kann sich aber auch fehlendes Wissen und Fähigkeiten handeln, die dem Kind durch das Verschulden der Eltern fehlen. So können Versäumnisse der Eltern, etwa unterlassene Einschreiten gegen gefährliche Spiele oder Unarten (z.B. Vorliebe des Kindes zum Zündeln ${ }^{410}$ ) oder die mangelnde Unterrichtung in Dingen des Verkehrs, zu Vorkommnissen führen, für die sie einzustehen haben, obwohl sich das Kind in der Obhut eines anderen befand ${ }^{411}$. Verübt etwa das Kind für sein Alter ganz unerwartete Handlungen (z.B. Autofahren bei einem 8jährigen ${ }^{412}$ ), mit denen die Eltern, nicht aber die Aufsichtspersonen rechnen konnten, wird man also dafür die Eltern und nicht die Aufsichtsperson verantwortlich machen müssen. Dasselbe gilt natürlich, wenn das Kind bestimmte Fähigkeiten noch nicht beherrscht, die es nach seinem Alter beherrschen können müßte (z.B. selbständiges Bewältigen des Schulweges).

Ein ähnlich gestaltetes Verhältnis der Eltern gegenüber ihren Kindern bzw. der Aufsichtsperson wurde auch angenommen, wenn diese eine Lehre durchlaufen und dabei in die Hausgemeinschaft des Lehrherren aufgenommen werden. In einem Fall, der das OLG Köln in den 50er Jahren beschäftigte, hatte ein 17jähriger kaufmännischer Lehrling Kraftfahrzeuge entwendet, während er bei seinem Lehrherren wohnte. Fraglich für die Haftung nach $\S 832$ BGB war, wem die Aufsichtspflicht über den Jugendlichen zukam ${ }^{413}$. Von den Eltern wurde im Rahmen ihrer Aufsichtspflicht erwartet, daß sie sich von Zeit zu Zeit auch an Ort und Stelle davon überzeugten, ob ihr Kind in der Hausgemeinschaft des Lehrherren auch weiterhin die gebotene Obhut und Aufsicht hat. Die gelegentlichen Rückfragen wurden als nicht ausreichend angesehen, so daß eine Verletzung der Aufsichtspflicht durch die Eltern bejaht

\footnotetext{
409 Albilt, S. 190.

${ }^{410}$ Albilt, S. 125, zitiert die Zeitschrift Eltern, Januarausgabe 1983, wonach im Jahr 1982 rund 10.000 „Zündelschäden“ auf das Konto von Kindern bis 14 Jahre ging.

${ }^{411}$ Boscher, VersR 64, 888 (889).

${ }^{412}$ Vgl. Meyer-Bahlburg, Erörterung der Unterlassungsdelikte, S. 92.

${ }^{413}$ OLG Köln VersR 57, 401 (401); Boscher, VersR 64, 888 (889).
} 
wurde $^{414}$. Einem solchen Ergebnis würde man wohl in der heutigen Zeit nicht mehr zustimmen.

Insgesamt werden die Beobachtung von Vorsorge-, Mitteilungs- und Kontrollpflichten sowie Kontrollbesuche $\mathrm{zu}$ fordern $\operatorname{sein}^{415}$. Die Aufsichtspflicht gilt -in abgestufter Intensität- somit für alle unter elterlicher Gewalt stehenden Kinder, unabhängig davon, ob sie sich zu Hause aufhalten oder nicht ${ }^{416}$. Damit kommt man bei der vorliegenden Fragestellung zum Ergebnis, daß die elterliche Aufsichtspflicht nicht gänzlich mit der Übertragung auf dritte Personen ruht ${ }^{417}$.

\section{Ziel der Garantenpflicht}

Fraglich ist, welches das Ziel des Garantenhandelns ist: Muß der Garant den Erfolg abzuwenden, oder genügt es zur Pflichterfüllung, ernsthaft gegen das schädigende Verhalten vorzugehen, selbst wenn der Erfolg trotzdem eintritt?

$\mathrm{Ob}$ vom Garanten verlangt wird, den Erfolg stets abzuwenden, ist umstritten. Die Rechtsprechung ${ }^{418}$ und der Großteil der Literatur ${ }^{419}$ stellen darauf ab, ob der Erfolg dem Unterlassenden objektiv zurechenbar war. Eine Kausalität durch Unterlassen im Sinne eines realen Bewirkens wird überwiegend abgelehnt. Statt dessen wird die Haftung des Garanten davon abhängig gemacht, ob das gedachte Tun den Erfolg mit einer an Sicherheit grenzenden Wahrscheinlichkeit nach abgewendet hätte ${ }^{420}$. Das ist der Fall, wenn der Täter es unterlassen hat, eine Bedingung zu setzen, die nicht hinzugedacht werden konnte, ohne daß der Erfolg entfiele ${ }^{421}$.

\footnotetext{
${ }^{414}$ Hier kam dazu, daß die Eltern nur $8 \mathrm{~km}$ entfernt wohnten und ein Verbleib des Jugendlichen über das Wochenende bei dem Lehrherren nicht erforderlich gewesen wäre. OLG Köln VersR 57, 401 (402); Boscher, VersR 64, 888 (889).

${ }^{415}$ So auch Busch, ZfJ 96, 456 (459) und Dahlgrün, S. 46f.

${ }^{416}$ Dahlgrün, S. 48.

${ }^{417}$ Albilt, S. 192.

${ }^{418}$ BGH MDR 1956, 144 (144); OLG Hamm NJW 1959, 1551; BGH NStZ 1981, 218.

${ }^{419}$ Jescheck/ Weigend, § 59 III, S. 618 f.; Tröndle/ Fischer, § 13, Rn. 5; , S/S-Stree, $\S 13$, Rn. 3, 61.

${ }^{420}$ Jescheck/ Weigend, § 59 III, S. $618 \mathrm{f}$.

${ }^{421}$ Otto/ Brammsen, Jura 85, 646 (652) m.w.N.
} 
Fraglich ist, ob für die unterlassene Deliktsverhinderung besondere, von diesem Grundsätzen abweichende Maßstäbe angelegt müssen. Bei der unterlassenen Deliktsverhinderung hängt es zwar zunächst einmal vom Verhalten des Aktivtäters ab, ob der Erfolg eintritt. Es gelten aber die gleichen Maßstäbe für das sonstige Unterlassen, weil es für die Zurechnung keinen Unterschied macht, ob dem Unterlassen eine menschliche aktive Vortat oder nur ein Unglück vorausgegangen ist.

Möglicherweise genügt es, daß der Garant überhaupt hindernd eingreift und damit zeigt, daß er die Rechtsordnung anerkennt und sich ihr gemäß verhalten will. Dagegen spricht, daß ein irgendwie geartetes Tun dem Rechtsgüterschutz nicht ausreichend Rechnung trägt. Unternimmt der Garant, der die Möglichkeit der Verhinderung hat, eine Handlung, die von vornherein den schädigenden Erfolg nicht stoppen kann, ist nicht einzusehen, warum ihn dies schon gegenüber dem gar nicht Handelnden privilegieren sollte: Die Mutter bittet ihr kleines Kind im Kaufhaus, dem Vordermann nicht mit dem Wagen in die Fersen zu fahren, obwohl sie genau weiß, daß die bloße Bitte nicht genügen wird, um das uneinsichtige Kind zu stoppen.

Der Garant muß also zumindest sein Bestes geben, wobei auch die subjektive Tatseite nicht $\mathrm{zu}$ vernachlässigen ist: Ein nur halbherziges Bemühen, gewissermaßen ,pro forma“ ist keine relevante Handlung im Sinne der Deliktsverhinderung. Auf der anderen Seite führt das erfolglose, weil falsche Bemühen des Garanten mit Willen zur Erfolgsabwendung nur zu einer Strafbarkeit wegen Fahrlässigkeit. Wer mit Gebotserfüllungstendenz falsch handelt oder unbewußt zu wenig tut, kann nur wegen fahrlässigen Unterlassens bestraft werden ${ }^{422}$.

Fraglich ist, ob eine Garantenpflicht auch dann besteht, wenn der Garant durch sein Eingreifen die drohende Gefahr nur verringern, aber nicht mit an Sicherheit grenzender Wahrscheinlichkeit abwenden kann. Das würde bedeuten, die Pflicht des Garanten nur auf die Fälle sicherer Erfolgsabwendung zu beschränken. Immer dann, wenn das Ausbleiben des Erfolges nicht mit Sicherheit erwartet werden könnte, bestände auch keine Eingreifenspflicht. Das kann so nicht bejaht werden. Der Garant hat vielmehr alles ihm Mögliche zur Rettung des Rechtsgutes zu

$\overline{422}$ Jescheck/ Weigend, § 59 II, S. 616. 
unternehmen, zu dessen Schutz er verpflichtet ist ${ }^{423}$. Andernfalls ist er zumindest wegen versuchter Unterlassung strafbar ${ }^{424}$.

Es bleibt somit zunächst festzustellen, daß im Grundsatz die Pflicht besteht, den schädigenden Erfolg zu verhindern. Die Erfolgsverhinderungspflicht gilt jedoch keineswegs unbegrenzt ${ }^{425}$. Sie ist vielmehr durch die verschiedene Kriterien begrenzt, die im folgenden noch einmal kurz angesprochen werden sollen:

- Verhinderungsmöglichkeit und Zumutbarkeit

Als Garant haftet nur derjenige, der die faktische Möglichkeit hat, die Gefahr für das Rechtsgut zu vermindern. Das bedeutet, daß nur derjenige Garant eine Handlungspflicht hat, der überhaupt die Möglichkeit hat, den Erfolg zu verhindern.

Beispiel: Die Mutter sieht aus dem 8. Stockwerk des Wohnhauses, wie ihr minderjähriger Sohn einen anderen niederschlägt und auch von dem am Boden Liegenden nicht abläßt. Die Mutter bleibt untätig, der Niedergeschlagene erleidet schwere Verletzungen. Auch wenn die Mutter im Beispiel untätig geblieben ist, hätte sie doch auch durch ein Handeln keine Bedingung setzen können, die das Ausbleiben der Verletzungen bei dem Opfer verhindert hätte. Trotz des Erfolgseintritts ist sie von der strafrechtlichen Verantwortlichkeit befreit, wenn sie dem

\footnotetext{
${ }^{423}$ Zur Frage, ob die Pflicht darin besteht, den Erfolg als solchen zu verhindern, hilft ein Blick auf die echten Unterlassungsdelikte weiter. Selbst bei den echten Unterlassungsdelikten, bei denen bereits der Verstoß gegen einen gesetzlichen Handlungsbefehl für die strafrechtliche Haftung ausreichen soll, genügt es nicht, diesem Handlungsbefehl nachzukommen. Es muß auch ernsthaft gegen den Erfolg gehandelt werden: Wer beispielsweise i.S.d. § 367 Abs. 1 Nr. 11 StGB bösartige Tiere frei herumlaufen läßt, genügt seinen Pflichten nicht schon, wenn er den Tieren hinterherläuft; er muß sie auch fangen, siehe Herzberg, Die Unterlassung, S. 23. Dieser Gedanke muß erst recht für die unechten Unterlassungsdelikte gelten, weil sie, anders als die echten Unterlassungsdelikte, keine Handlungsanweisung geben, sondern nur das Ausbleiben eines konkreten Erfolges verlangen.

${ }^{424}$ vgl. unten 3. Teil B II.

425 Das ausschließliche Abstellen auf den Erfolg wäre bedenklich. Georgakis weist darauf hin, daß man dann gezwungen wäre, ex post das Urteil über die Gebotenheit des Tätigkeitsinhaltes zu fällen. Damit wäre es für den zur Erfolgsabwendung Verpflichteten zum Zeitpunkt des Akutwerdens seiner Pflicht unmöglich zu wissen, was er praktisch tun muß. Erst nachträglich und abhängig davon, ob der Erfolg eingetreten ist oder nicht,
} 
Geschehen aus einer so weiten Entfernung zugeschaut hat, daß sie nicht hinzueilen konnte, und sie außerdem keine Zeit hatte, telefonisch Hilfe zu rufen.

Zusätzlich besteht eine weitere Einschränkung in der Zumutbarkeit der Handlung, soweit man diese nicht als Teil der Schuld versteht ${ }^{426}$.

- Der Erfolg tritt trotz der Handlung des Garanten ein

Der Erfolg muß sich aber in der durch den Garanten zu verantwortende Gefahr realisiert haben, und nicht aus anderen Gründen eingetreten $\operatorname{sein}^{427}$. Eine strafrechtliche Zurechnung scheidet also dann aus, wenn der Garant angemessen tätig wird, seiner Pflicht also nachkommt, und der schädigende Erfolg trotzdem eintritt.

Es kommt also darauf an, wie das Geschehen nach dem pflichtgemäßen Tätigwerden des Garanten eigentlich hätte ablaufen müssen. Hätte sein Tun den Erfolg nach gewöhnlichem Geschehensablauf verhindert, liegt kein Verstoß gegen die Erfolgsverhinderungspflicht vor.

Beispiel: Beobachtet die Mutter eine Schlägerei zwischen ihrem halbwüchsigen Sohn und einem Dritten und geht dazwischen, ist ihr der Erfolg nicht zuzurechnen, wenn anschließend ein weiterer Jugendlicher den Dritten schlägt und ihn verletzt.

Im ersten Beispiel der Mutter, die die Schlägerei aus der hochgelegenen Wohnung betrachtet, kann ebenfalls die Zurechenbarkeit des Erfolges bezweifelt werden: Selbst, wenn die Mutter die ihr möglichen Handlungen vorgenommen hätte (Das telefonische Alarmieren der Polizei und das sofortige NachUnten-Laufen, um den Sohn von weiteren Tritten abzuhalten), wären die Verletzungen schon eingetreten, bis die Mutter oder die Polizei am Tatort angelangt wären.

könnte das Verhalten des Garanten danach überprüft werden, ob es der Rechtspflicht genügt hat. Georgakis, Hilfspflicht und Erfolgsabwendungspflicht, S. 27.

${ }^{426}$ siehe 3. Teil, E.

${ }^{427}$ Otto/ Brammsen, Jura 85, 646 (652); OLG Hamm NJW 59, 1551. 
- Erlaubtes Risiko ${ }^{428}$

Eine Begrenzung der Haftung des Aufsichtsgaranten besteht außerdem in der Hinsicht, daß er dort untätig bleiben darf, wo das Unterlassen selbst als „erlaubt-riskant“ einzuschätzen ist. Das gilt insbesondere hinsichtlich der elterlichen Fürsorge aus $\S 1626$ Abs. 2 S. 1 BGB, wonach es $\mathrm{zu}$ einer sinnvollen Erziehung gehört, daß dem Minderjährigen Spielräume gewährt werden und gerade keine permanente Kontrolle stattfindet ${ }^{429}$. In Anbetracht der vielfältigen Möglichkeiten der Verstrickung des eigenen Organisationskreises der Eltern in das rechtsgütergefährdende Verhalten ihrer Kinder stößt man auf das Problem, daß der Aufwand, der erforderlich wäre, um jegliche Gefahren für andere auszuschließen, in keinem Verhältnis zu dem positiven Ertrag für den Rechtsgüterschutz stände ${ }^{430}$. Das Mißtrauen gegenüber dem überwachten Kind oder Jugendlichen würde zum Prinzip erhoben und würde die Eltern-KindBeziehung dauerhaft schädigen, wenn nicht zerstören ${ }^{431}$. Solange das Dasein von Kindern von der Rechtsordnung gem. Art. 6 GG als positiv eingeschätzt wird, muß auch die Gesellschaft bestimmte Risiken ertragen, die das Dasein von Kindern nun einmal mit sich bringt ${ }^{432}$.

Als Garant haftet folglich nur derjenige, dem es möglich und zumutbar ist, die über das erlaubte Maß hinausgehende Gefahr für das Rechtsgut zu vermindern, wenn sich in dem Erfolg jene Gefahr realisieren würde. Die reine Nichtabwendung des tatbestandlichen Erfolges durch den Garanten sagt daher noch nichts Abschließendes darüber aus, ob der Garant sich pflichtwidrig verhalten hat ${ }^{433}$. Der Erfolgseintritt bietet nur die wesentliche Voraussetzung, die bei einer Pflichtverletzung vorliegen muß.

\footnotetext{
${ }^{428}$ Dazu siehe ausführlicher 3. Teil C. II 2 c).

${ }^{429}$ Sangenstedt, Garantenstellung und Garantenpflicht, S. $407 f$.

${ }^{430}$ Freund, Erfolgsdelikte, S. 227.

${ }^{431}$ Freund, Erfolgsdelikte, S. 228; Hillenkamp, Vorsatztat, S. 206.

${ }^{432}$ Freund, Erfolgsdelikt, S. 249.

${ }^{433}$ Georgakis, Hilfspflicht und Erfolgsabwendungspflicht, S. 28.
} 
III. Die geforderte Handlung i.S.v. § 13 StGB

Das elterliche Fehlverhalten liegt darin, den Taterfolg nicht $\mathrm{zu}$ verhindern, obwohl dies durch eine bestimmte Handlung möglich ist. Es stellen sich zwei wesentliche Fragen. Erstens: Wie, d.h. durch welches Eingreifen soll die Tat verhindert werden ? Zweitens: Wann soll eingegriffen werden ? Die erste Frage betrifft die zur Abwehr des Erfolges gebotene Handlung, die zweite den Zeitpunkt dieser Handlung.

1. Die Art der gebotenen Handlung

Als Handlungen der Garanten kommen alle Aktivitäten in Betracht, die geeignet sind, den Angriff auf das Rechtsgut des Dritten abzuwehren. Welche Handlung gefordert wird, hängt vom jeweiligen, in Frage stehenden Straftatbestand $a b^{434}$. Der Tatbestand des Unterlassungsdelikts bezeichnet das Ziel, das durch aktives Eingreifen erreicht werden soll, gibt das Rechtsgut an, das zu schützen ist und kennzeichnet ausdrücklich oder stillschweigend die gebotene Handlung selbst ${ }^{435}$. Zudem sind die Umstände des Einzelfalls dafür maßgebend, welche Handlung in concreto erforderlich ist ${ }^{436}$. Nach Rogall muß die geforderte Handlung ihrem Inhalt nach außerdem dem Ausmaß und dem Umfang der Herrschaft entsprechen ${ }^{437}$. Da die Herrschaft über eine andere Person sowohl den Zugriff auf Denkstrukturen des anderen wie auch den Zugriff auf sich nach außen manifestierende, d.h. körperliche Verhaltensweisen, betreffen kann, sind verschiedenste Arten der Einwirkung möglich.

Dabei ist $\mathrm{zu}$ berücksichtigen, daß die faktische Möglichkeit der Erfolgsabwendung nicht immer gleichzeitig eine rechtliche, d.h. rechtlich zulässige, ist. Die rechtliche Zulässigkeit von erzieherischen Maßnahmen ist häufig umstritten und wird insbesondere dann abgelehnt, wenn das

\footnotetext{
${ }^{434}$ Die für $\S 139$ III entwickelten Maßnahmen, die für das ernsthafte Bemühen der Tatverhinderung erforderlich sind, können auch hier als Maßstab gelten, vgl. Westendorf, S. 231.

435 Jescheck/ Weigend, § 59 I, S. 615.

${ }^{436}$ S/S-Stree, Vor $§ 13$, Rn. 140.
} 
elterliche Züchtigungsrecht Anwendung findet ${ }^{438}$. Auch ist eine Drohung mit dem Hinauswurf aus der elterlichen Wohnung gegenüber dem fürsorgeberechtigten oder zumindest unterhaltsberechtigtem Minderjährigen nicht erlaubt; in diesem Falle würden sich die Eltern ggf. nach $\S 171$ StGB strafbar machen, in diesem Fall durch Begehen.

Als geringste Stufe des Einschreitens kann ein positives Einwirken, gut Zureden, ein „Ans-Gewissen-Appellieren“ ausreichen. Durchaus als wirksames Mittel ist auch das Versprechen von Gegenleistungen („Wenn du das nicht tust, bekommst du ...") einzustufen. Das Mittel ist zwar pädagogisch nicht wertvoll und wird früher oder später versagen, muß aber dennoch als gebotene Handlung im Sinne der Unterlassungsdelikte betrachtet werden. Denn es kann im konkreten Fall bewirken, daß der jugendliche Täter vorerst von seinem Vorhaben abläßt. Mehr wird von den Eltern in dieser Hinsicht nicht verlangt. Daß sich durch dieses Verhalten die das nächste Mal zur Tatverhinderung erforderliche Handlung viel schwieriger und massiver darstellen wird, steht auf einem anderen Blatt.

Die nächste Stufe enthält den Einsatz von zumindest psychischem Zwang: So sind Drohungen mit den Behörden (Polizei, Jugendamt) denkbar, wenn der Ausspruch eines so bewehrten Verbotes geeignet ist, seelische Hemmungen hervorzurufen ${ }^{439}$. Möglich ist ebenso die Drohung mit Hausarrest oder Taschengeldentzug. Dabei mag offenbleiben, wie kontraproduktiv sich ein solches Vorgehen auswirkt. Beim Taschengeldentzug etwa besteht die Gefahr, daß der Jugendliche nun erst recht stiehlt, um seine materiellen Wünsche zu befriedigen.

Letzte Mittel sind die Anwendung von physischem Zwang und die Anzeige bei der Polizei oder einer sonstigen Behörde.

\footnotetext{
${ }^{437}$ Nach Rogall muß die geforderte Handlung muß ihrem Inhalt nach dem Ausmaß und dem Umfang der Herrschaft entsprechen, Rogall, ZStW 98 (1986), 573 (619)

${ }^{438}$ Albrecht, ZfJ 81, 4 (7); Gropp, Strafrecht AT, Rn. 196f.; Maurach/ Schroeder/ Maiwald, BT 2, § 63 IV, Rn. 52; zu den Grenzen elterlichen Züchtigungsrechtes: MüKo, $\S 1631$, Rn. $21 \mathrm{ff}$.
} 
Der körperliche Zwang kann darin bestehen, daß die Tatwaffe oder ein sonstiges zur Tatausführung notwendiges Mittel weggenommen wird, daß der Jugendliche eingeschlossen wird, bis die kritische Situation vorüber ist, oder daß er auf sonstige Weise in seiner Bewegungsfreiheit eingeschränkt wird, indem man das Fahrrad oder Mofa wegschließt, mit dem er wegfahren will, oder die Schlüssel versteckt ${ }^{440}$. $\mathrm{Zu}$ denken ist auch an rein körperlichen, passiven Widerstand durch das Versperren der Tür durch den eigenen Körper.

Der Einsatz von körperlichem Zwang ist zur Verhinderung eines Erfolges im Rahmen des unechten Unterlassungsdelikts ein mögliches und zulässiges Mittel, wenn den Eltern objektiv kein anderes Mittel mehr zur Steuerung des kindlichen Verhaltens verfügbar ist ${ }^{441}$. Es soll jedoch schon jetzt darauf hingewiesen werden, daß das gleiche Mittel zur Erziehung des Kindes oder Jugendlichen insbesondere im Rahmen des $\S 171$ StGB weder sinnvoll noch zulässig ist ${ }^{442}$.

$\mathrm{Zu}$ den letzten Mitteln, die dem Garanten zur Verfügung stehen, ist auch das Einschalten von Behörden zu zählen. Es gibt wohl kaum etwas Gravierenderes, als wenn Eltern ihr eigenes Kind dem Jugendamt oder der Polizei überantworten. Inwieweit dieses Mittel zumutbar ist, wird später zu untersuchen sein.

$\mathrm{Zu}$ den gebotenen Handlungen mögen einige Beispiele verdeutlichen, welche Schwierigkeiten sich für Eltern daraus ergeben können:

In einem frühen Reichsgericht-Fall ${ }^{443}$ hatte der 20jährige, kurz vor der Volljährigkeit stehende Sohn sich mit dem Vater entzweit. Er verließ das Elternhaus und zog zu seiner verheirateten Schwester am gleichen Ort. Seinen Unterhalt verdiente er in einer Fabrik. Bei einem Wirtshausstreit erschoß er einen anderen Gast. Der Vater wurde von der Witwe aus $\S 832$ BGB verklagt. Während Landgericht und Oberlandesgericht der Klage stattgaben, wies das Reichsgericht die Klage ab. Maßgeblich war

\footnotetext{
${ }^{439}$ Schwarz, S. 166; BGH NJW 73, 861 (862): Hier ging es darum, daß eine Frau ihren Ehemann nicht abhielt, bei ihrem Arbeitgeber einzubrechen und zu stehlen.

${ }^{440}$ Vgl. BGH NJW 73, 861 (862).

${ }^{441}$ Ursula Schneider, Gewaltanwendung in der Familie, S. 206.

${ }^{442}$ Dazu siehe unten 5. Teil A 3 b).

${ }^{443}$ RG Urt. v. 15.12.1913, Warn.Rspr. 1914 Nr. 217, zitiert bei Dahlgrün, S. 48.
} 
hier, ob der Vater den Sohn in die Hausgemeinschaft hätte zurückholen müssen. Nach Ansicht des OLG hätte er im Rahmen seiner Aufsichtspflicht den Sohn mit allen Mitteln zur Rückkehr in das Elternhaus bewegen müssen. Hätte der Vater das getan, wäre ihm nach Ansicht des Gerichts auch nicht entgangen, daß der Sohn im Besitz eines Revolvers war. Um die Rückkehr zu erreichen, hätte der Vater nach Ansicht des OLG den Sohn nicht nur durch die beiden Töchter wiederholt zur Heimkehr auffordern müssen. Er hätte auch den Pfarrer um dessen Einfluß bitten oder den Arbeitgeber seines Sohnes veranlassen müssen, diesem den Lohn zu sperren ${ }^{444}$.

Das RG sah den Vater hingegen als entlastet an, weil er alle ihm Mögliche getan habe, um den Sohn zur Rückkehr ins Elternhaus zu veranlassen. Zwangsmaßnahmen hielt das RG angesichts der geordneten Erwerbs- und Unterkunftsverhältnisse des Sohnes für ungerechtfertigt. Ein weiterer Grund gegen Zwang sei, daß ein solcher gegenüber dem fast erwachsenen Sohn unweigerlich zur Feindschaft zwischen Vater und Sohn geführt hätte. Dem Vater könne daher nicht vorgeworfen werden, daß er von der Existenz des Revolvers nichts gewußt habe ${ }^{445}$.

Demgegenüber hat das OLG Köln in einer Entscheidung von 1956 Eltern nicht als entlastet angesehen, da sie keine schwerwiegenden Gründe dafür vorbringen konnten, daß sie die Hausgemeinschaft mit ihrem Sohn aufgehoben hatten ${ }^{446}$.

Dort war der 17jährige Sohn als kaufmännischer Lehrling seit längerem im Haushalt seines Lehrherren aufgenommen worden. Wohnung und Betrieb des Lehrherren befanden sich lediglich 7 bis $8 \mathrm{~km}$ vom Elternhaus entfernt. Der Arbeitsanfall war nur gering. In seiner reichlichen Freizeit verübte der Jugendliche zahlreiche Autodiebstähle. Die Eltern wurden aus $\S 832$ BGB verurteilt.

\footnotetext{
${ }^{444}$ RG Urt. v. 15.12.1913, Warn.Rspr. 1914 Nr. 217, zitiert bei Dahlgrün, S. 50; Aden, Haftung der Eltern, S. 140, beschreibt einen ähnlichen Fall aus Frankreich, in dem die Haftung eines Vaters untersucht wurde, der seinen minderjährigen Sohn nach dessen Auszug nicht ins Elternhaus zurückgeholt hatte. Der Sohn beging während dieser Zeit einen Raubmord.

${ }^{445}$ RG Urt. v. 15.12.1913, Warn.Rspr. 1914 Nr. 217, zitiert bei Dahlgrün, S. 50.

${ }^{446}$ OLG Köln, VersR 57, $401 f$.
} 
Die Eltern versuchten sich mit dem Argument zu entlasten, daß allein der Lehrherr für die Taten ihres Sohnes verantwortlich sei. Das OLG sah die Aufsichtspflichtverletzung der Eltern aber darin, daß ,sie sich ohne zwingende Notwendigkeit der Aufsichtspflicht über ihren Sohn entäußern wollten“. Die Aufnahme des 17jährigen in die Hausgemeinschaft des Lehrherren sei wegen der geringen Entfernung zum Arbeitsplatz und auch wegen des den Eltern erkennbaren geringen Arbeitsanfalls nicht dringend geboten gewesen. Keinesfalls habe dazu an den Wochenenden eine Notwendigkeit bestanden, an denen der Jugendliche die Diebstähle vor allem verübte ${ }^{447}$.

Einen ähnlichen Fall schildert Aden unter Rückgriff auf ein französisches Urteil: Ein 20jähriger war bei einem Makler angestellt und unterschlug einen größeren Geldbetrag. Der Vater wurde zum Schadensersatz an den Makler verurteilt, unter anderem deshalb, weil er es versäumt habe, sich beim Arbeitgeber nach dem Verhalten des Sohnes zu erkundigen. Er hätte dann nämlich erfahren, daß dieser nicht ganz zufrieden mit ihm $\operatorname{war}^{448}$.

2. Der gebotene Handlungszeitpunkt und die Abgrenzung zum Versuch

a) Beginn der Handlungspflicht

Der Garant hat die Handlungspflicht grundsätzlich sofort zu erfüllen. Ihm steht jedoch dann ein zeitlicher Spielraum für sein Eingreifen zur Verfügung, wenn die spätere Pflichterfüllung den Erfolg noch auf gleiche Weise verhindern würde. Die zeitliche Grenze liegt dort, wo das Eingreifen dem Garanten nicht nur möglich, sondern es ihm vielmehr geboten ist und somit der Versuch der Unterlassung beginnt ${ }^{449}$.

Die früheste Annahme des Versuchs liegt dort, wo die erste mögliche Rettungshandlung unterlassen wird, die späteste dort, wo die letzte Rettungschance nicht wahrgenommen wird. Hier soll der Mittelweg gewählt werden, den auch die herrschende Meinung vertritt ${ }^{450}$ : Der

\footnotetext{
${ }^{447}$ OLG Köln, VersR 57, $401 f$.

${ }^{448}$ Aden, Haftung der Eltern, S. 136.

${ }^{449}$ S/S-Eser, § 22, Rn. 50.

${ }^{450}$ LK-Jescheck, § 13, Rn. 47; Schünemann, ZStW 96 (1984), 287 (316); S/S-Eser, § 22 , Rn. 50.
} 
Versuchsbeginn ist an dem Zeitpunkt anzusetzen, an dem durch die Verzögerung der Rettungshandlung entweder eine unmittelbare Gefahr für das geschützte Handlungsobjekt entsteht oder eine bereits entstandene Gefahr sich vergrößert und ein weiteres Zuwarten als „unmittelbares Ansetzen" erscheint ${ }^{451}$.

Beobachten Eltern etwa, wie der Sohn alles für eine Diebestour erforderliche Werkzeug zusammenträgt und wie er am Telefon mit seinen Kumpanen die Details des Eindringens in das fremdes Besitztum bespricht, liegt die erste Möglichkeit des Einschreitens darin, ihn am Fortgehen zu hindern. Zeitlich weiter hinten liegt die Möglichkeit, das Tatopfer telefonisch zu informieren. Eine weitere, spätere Chance besteht darin, dem Sohn hinterher zu fahren und ihn noch kurz vor der Tatbegehung von der Tat abzubringen, oder aber gar die Polizei zu verständigen. - Hier wird man bereits, wenn der Sohn das Haus verläßt, von einer akuten Gefährdung des Tatopfers sprechen müssen, da das Risiko, das Opfer telefonisch nicht erreichen und warnen zu können, bzw. das Risiko, daß die Polizei nicht mehr rechtzeitig an den Tatort gelangt, mit jeder verstrichenen Minute steigt.

Die Einschätzung, welche Handlungsmöglichkeiten Erfolg versprechen, ist jedoch stets eine Frage des Einzelfalls. Erschwert wird die Einschätzung, zu welchem Zeitpunkt eine Handlung erforderlich ist, insbesondere die Frage, ab wann das avisierte Rechtsgut tatsächlich gefährdet ist, dadurch, daß die Eltern in vielen Fällen nur durch ein sehr frühes Einschreiten, nämlich ein Tätigwerden im Vorfeld der Tathandlung, wirksame Mittel einsetzen können, um eine Tat ihres Kindes zu verhindern. Zumeist finden die Taten nicht unter den Augen der Eltern $\operatorname{statt}^{452}$. Für das Unterlassungsdelikt ginge es jedoch zu weit, vom Garanten eine seherische Gabe zu verlangen, die ihn in die Lage versetzt, die allerersten Anzeichen einer geplanten Straftat zu erkennen.

\footnotetext{
${ }^{451}$ Schünemann, ZStW 96 (1984) 287 (316) m. w. N.

${ }^{452}$ Es geht daher zu weit, den Angehörigen eine besondere Verantwortung deshalb zuzusprechen, da sie am ehesten von einem geplanten Verbrechen erführen und dadurch die besten Möglichkeiten hätten, das Delikt zu verhindern (vg. Schwarz, S. 168). Im Gegenteil sind die Eltern in den vielen Fällen diejenigen, die davon als letzte erfahren.
} 
Hinzu kommt die Schwierigkeit, daß viele Taten von jugendlichen Tätern spontan ausgeführt werden ${ }^{453}$.

Der Zeitpunkt für ein rechtzeitiges Eingreifen kann auch nicht dahin vorverlegt werden, daß Eltern ihren Erziehungspflichten nachkommen und ihre Abkömmlingen dadurch gar nicht erst dazu ansetzen, Straftaten zu begehen. Die elterliche Aufgabe, den Jugendlichen so zu erziehen, daß er die Anweisungen und Regeln seiner Eltern auch dann befolgt, wenn diese nicht anwesend sind, stellt gerade keine Pflicht im Sinne des unechten Unterlassens dar und kann nicht zur Handlungspflicht erstarken. Das gilt selbst dann, wenn Eltern sich erhebliche Erziehungsfehler zuschulden kommen lassen und es versäumen, dem Kind oder Jugendlichen eine ausreichende Sozialisierung angedeihen zu lassen, so daß diesem erwartungsgemäß die notwendigen Regeln für das gesellschaftliche Miteinander fehlen. Auch wenn als Folge davon ein delinquentes Verhalten des Kindes eintritt, kommt eine Bestrafung wegen unechten Unterlassens nicht in Frage. Dies liefe auf eine Bestrafung hinaus, die allein auf mangelnder Erziehung aufbauen würde und die Eltern aufgrund eines Lebensführungsunrechts zur Verantwortung ziehen würde. Schließlich gibt es nicht einmal dafür eine absolute Sicherheit, daß ein Kind oder Jugendlicher, dem seine Eltern tatsächlich Grenzen gesetzt und Ermahnungen erteilt haben, in der konkreten Situation die Grenzen auch einhält und die Ermahnungen auch befolgt. Vielmehr ist ein Abweichen davon sogar alterstypisch und gehört in gewissen Grenzen zu einer normalen Entwicklung dazu.

Je nach Art des Delikts können zudem aus tatbestandlicher Sicht verschiedene Zeitpunkte zur Verhinderung des Erfolges vorgegeben sein: Beim Betrug beispielsweise genügt es für die Straflosigkeit des Täters, wenn er entweder den Vermögensinhaber über den durch den Aktivtäter hervorgerufenen Irrtum aufklärt oder aber auf andere Weise den Vermögensschadens verhindert ${ }^{454}$.

Für den Garanten hat die grundsätzliche Wahl des Mittels, welches er zur Deliktsverhinderung einsetzen will, und damit auch die Wahl seines Handlungszeitpunktes unter Umständen den Vorteil, daß inzwischen

453 Gerade die spontane, ungeplante Umsetzung einer Idee wird im Rahmen der Strafverhandlung als Zeichen einer jugendtypischen Delinquenz gewertet. 
Dritte oder weitere Umstände den Erfolgseintritt verhindern; in diesem Fall entfällt die Pflicht zum Handeln ${ }^{455}$. Das bedeutet eine gewisse Privilegierung für solche Eltern, in deren Umfeld weitere Personen vorhanden sind, die sich des Kindes/ Jugendlichen annehmen. Die Grenze liegt allerdings dort, wo die Eltern bereits durch ihre Untätigkeit das fremde Rechtsgut gefährden und als bereits der Versuch erfüllt ist.

Auch wenn man zugunsten des Garanten den spätest möglichen Zeitpunkt zum Eingreifen ausreichen läßt ${ }^{456}$, muß der Garant es sich anlasten lassen, wenn sein Eingreifen dann fehlschlägt und weiteres Handeln zeitlich nicht mehr in Frage kommt. Denn verlangt wird vom Garanten eine im Hinblick auf die Erfolgsabwendung finale und optimale Tätigkeit, so daß er das Risiko eines zu späten Aktivwerdens trägt.

Um auf das Beispiel der Eltern zurückzukommen, die ihrem Sohn bei der Einbruchsvorbereitung zusehen: Entscheiden die Eltern sich nach (zu) langem Zögern für einen anonymen Anruf bei der Polizei, trifft diese jedoch zu spät ein, um das Delikt zu verhindern, sind die Eltern, da sie nur eine unbrauchbare Handlung vorgenommen haben, wegen des vollendeten Delikts strafbar. Gleiches gilt, wenn die Eltern ihre Handlungspflicht verletzen, indem sie zwar rechtzeitig, aber auf andere Weise unzureichend reagieren, z. B. durch Informieren einer zur Tatverhinderung ungeeigneten Behörde.

Jedenfalls wegen Versuchs haften die Eltern dann, wenn sie ihrer Handlungspflicht wie beschrieben zu spät oder gar nicht nachgekommen sind, aber die Tat letztlich durch das Einschreiten Dritter oder durch sonstige von den Eltern nicht $\mathrm{zu}$ vertretende Umstände verhindert wird $^{457}$.

Da die für das aktive Tun entwickelten Versuchsgrundsätze auch für die Unterlassung Anwendung finden, ist allerdings auch der Rücktritt nach $\S 24$ StGB möglich. Der Unterlassende kann dadurch mit strafbefreiender Wirkung vom Versuch zurücktreten, daß er die erforderliche

\footnotetext{
${ }^{454}$ Nitze, S. 181.

${ }^{455} \mathrm{~S} / \mathrm{S}$-Stree, Vor $\S 13$, Rn. 153.

${ }^{456}$ so Armin Kaufmann, Dogmatik, S. 210 ff.; Welzel, S. 221.

${ }^{457}$ Westendorf, S. 96.
} 
Rettungshandlung doch noch vornimmt ${ }^{458}$. Haben die Eltern im genannten Beispiel gewartet, bis ihr Abkömmling sich Einlaß in die fremde Wohnung verschafft, verhindern sie aber doch noch durch ihr persönliches Einschreiten oder den Anruf bei der Polizei das Eintreten des schädigenden Erfolges, so liegt ein strafbefreiender Rücktritt vom Versuch vor.

b) Ende der Handlungspflicht

Fraglich ist, ob der Garant nur innerhalb der vor der Tatausführung liegenden Zeitspanne zum Handeln verpflichtet ist, nämlich nur solange, wie die schädigende Handlung noch nicht begonnen hat, oder ob er auch danach noch in der Pflicht steht. Nach Sangenstedt besteht die Verpflichtung zum Eingriff nur vor dem Ingangsetzen des Kausalverlaufs; anschließend gebe es keine Eingreifenspflicht mehr. Sangenstedt begründet dies wie folgt: Der Überwachergarant sei allein zur Eindämmung des Gefahrenherdes aufgerufen, d.h. er habe Sorge lediglich dafür zu tragen, daß der Risikoprozeß die Grenzen seines sächlichen Organisationskreises nicht überschreite und auf eine fremde Interessensphäre übergreife. Sei es dazu bereits gekommen, so sei es dem Sicherungspflichtigen nur noch gem. $§ 323$ c StGB geboten, eine weitere Schadenseskalation $\mathrm{zu}$ verhüten ${ }^{459}$. Die strafrechtlichen Verbote und auch die über $\S 13$ StGB begehungsgleichen Omissionen zielen nach Sangenstedt nicht darauf $a b$, die Schaffung von Risiken für tatbestandlich geschützte Rechtsgüter schlechthin $\mathrm{zu}$ untersagen. Vielmehr sollen sie das Ingangsetzen oder Fördern von Kausalprozessen verhindern, deren verhängnisvoller Verlauf im Handlungszeitpunkt gerade für den Garanten vorhersehbar ist ${ }^{460}$.

Die Garantenverantwortlichkeit für die Entschärfung gefährlicher Kausalverläufe dauert danach prinzipiell nicht an, wenn das Geschehen den Gewaltbereich des Sachherren verlassen und insbesondere die Opfersphäre schon erreicht hat. Die Untätigkeit des Garanten erfolge in dieser Phase nicht mehr unter den Bedingungen, auf welchen die objektive Zurechnung des Integritätsverlustes beim Begehungsdelikt

\footnotetext{
${ }^{458}$ Schünemann, ZStW 96 (1984) 287 (316) m. w. N.

${ }^{459}$ Sangenstedt, Garantenstellung und Garantenpflicht, S. 385.
} 
beruht und unter denen also das Unterlassungsunrecht gleichwertig sei. Die Verbindung des Omittenden zu dem bedrohlichen Ereignis erschöpfe sich jetzt in der bloßen Möglichkeit, dem Vorgang eine Wende zu geben, wie sie jeder andere auch habe. Doch gerade das garantiebegründende Merkmal der Bestimmungsmacht des Unterlassenden über den Verfügungskreis, in dem der destruktive Prozeß mittlerweile fortwirke, fehle. Die Zuordnung zu der Gefahrenzone sei, sobald die gefährliche Entwicklung in eine fremde Herrschaftssphäre eingedrungen sei, abgeschlossen $^{461}$.

Gegen Sangenstedt ist anzuführen, daß es nicht einleuchtet, den Garanten von dem Zeitpunkt an, an dem die Gefahr in Person des Jugendlichen Aktivtäters sich materialisiert hat und an das Opfer herangetreten ist, aus der strafrechtlichen Verantwortlichkeit zu entlassen. Es ist nicht richtig, wenn Sangenstedt anführt, daß der Garant nach Eintritt der Tatausführung seine quasi überlegene Stellung als Deliktsverhinderer seines Abkömmlings verloren habe. Vielmehr ist gar nicht ersichtlich, daß dem Garanten vor der Tatausführung wesentlich mehr Möglichkeiten der Verhinderung zur Verfügung ständen als dem außenstehenden Dritten. Wohl ist dem Gedanken zuzustimmen, daß der Garant, weil er seinen Abkömmling besser kennt als der Außenstehende, eher wissen kann, wie er Einfluß auf ihn ausüben kann. Die Garantenstellung definiert sich im Kern aber nicht darüber, wer die besten tatsächlichen Möglichkeiten zur Tatverhinderung hat, sondern richtet sich nach den rechtlichen Möglichkeiten. Und diese sind auch nach dem Fortwirken des destruktiven Prozesses nach außen beim Garanten unverändert. Der Garant hält noch immer, im Gegensatz zum Außenstehenden, die volle Erziehungs- und Aufsichtspflicht, und nach wie vor ist ihm rechtlich erlaubt, was dem Außenstehenden gegenüber dem Kind oder Jugendlichen nicht erlaubt ist. Dieses Recht und diese Verpflichtung des Garanten wirkt für die stattgefundene Handlung des Abkömmlings und für den Schadenseintritt nach, so daß ihm auch die Pflicht zur Verhinderung des in Gang gesetzten Kausalverlaufs zukommt ${ }^{462}$.

\footnotetext{
${ }^{460}$ Sangenstedt, Garantenstellung und Garantenpflicht, S. 387.

${ }^{461}$ Sangenstedt, Garantenstellung und Garantenpflicht, S. $385 f$.

${ }^{462}$ Ein Argument gegen die auch nach der Tathandlung des Vordermanns bestehen bleibende Verantwortlichkeit der Eltern könnte darin liegen, daß der Garant dadurch zum
} 
Bei weiteren Handlungen des jugendlichen Vordermannes gegenüber dem gleichen Opfer müßte wiederum auch Sangenstedt zum Ergebnis kommen, daß hier den Garanten die volle Deliktsverhinderungspflicht trifft.

3. Die Möglichkeit, durch die Handlung das Delikt zu verhindern

Wie die oben genannten Beispiele zeigen, ist es für Eltern unter Umständen sehr schwierig, überhaupt eine Handlung zu finden, mit der das Kind von seinem Tun abgehalten werden $\mathrm{kann}^{463}$. Von der Rechtsordnung kann daher nur gefordert werden, was möglich ist ${ }^{464}$. Voraussetzung des strafbaren Unterlassens ist folglich, daß die Eltern sowohl physisch als auch intellektuell in der Lage sind, das Verhalten des Kindes zu beeinflussen. Dazu müssen die Eltern handlungsfähig sein, also zunächst körperlich dazu in der Lage sein. Dies ist bei einer Lähmung oder sonstigen körperlichen Behinderung nicht unbedingt ausgeschlossen, sofern ein ermahnendes Gespräch mit dem Kind oder ein Rufen der Polizei als gebotene Handlung in Betracht kommt.

Eine Unmöglichkeit, die Handlung durchzuführen, liegt jedoch dann vor, wenn der Garant nicht in sinnvoller Weise eingreifen kann. Sinnvoll ist nur eine solche Tätigkeit, die zur Rettung des gefährdeten Rechtsguts Entscheidendes beiträgt. Die Möglichkeit einer Rettung reicht dazu aus ${ }^{465}$. Daß eine Handlung auch dann sinnvoll sein kann, die den unvermeidbaren Erfolgseintritt lediglich zeitlich verzögert, ist hingegen abzulehnen ${ }^{466}$. Sinnlos ist ein Tätigwerden nämlich, wenn stärkere Kräfte

Obhutsgaranten für das Tatopfer gemacht würde. Tatsächlich muß sich nach der hier vertretenen Auffassung der Überwachergarant, nachdem von der überwachten Person keine Gefahr mehr ausgeht, „wie ein Obhutsgarant“ um das Opfer kümmern. Der Schwerpunkt des Handelns bleibt dennoch bei der Verhinderung der vom Aktivtäter verursachten Gefahr, deren Ausweitung er lediglich durch sein Tun einzudämmen hat. Seine Handlungspflicht endet, sobald die Tat des Vordermanns keine weiteren Kreise mehr ziehen kann.

${ }^{463}$ So weist Diederichsen, NJW 98, 3471 (3473), darauf hin, daß Eltern viele Widerstände überwinden müssen, um den Kindern Alternativen zur Konsumwelt als Lebenswert zu vermitteln.

${ }^{464}$ S/S-Stree, Vor $§ 13$, Rn. 141.

${ }^{465}$ S/S-Stree, Vor $\$ 13$, Rn. 142.

${ }^{466}$ So aber wohl S/S-Stree, Vor $§ 13$, Rn. 142. 
der Erfolgsabwendung entgegenstehen oder der Garant eine Straftat nicht verhindern kann, z.B. seine Kräfte nur ausreichen, den omnimodo facturus für wenige Sekunden aufzuhalten ${ }^{467}$.

Der Bundesgerichtshof weist in BGHSt 6, 46 (57) darauf hin, daß ein Einschreiten bei älteren Kindern oft unmöglich ist, die zwar noch bei ihren Eltern wohnen, sich aber schon aus dem Autoritätsverhältnis gelöst haben und sehr bestimmt und bestimmend auftreten. Gerade eine alleinstehende Mutter werde zuweilen in einer Lage sein, die ein Einschreiten von vornherein zur Erfolglosigkeit verurteile ${ }^{468}$. Als ähnlich sinnlos wurde auch die Tatverhinderung durch eine Ehefrau betrachtet, die keinen Einfluß auf ihren Mann ausüben konnte: Er mißhandelte und verachtete sie, so daß sie den Versuch, ihn durch Bitten von seinem Vorhaben, einem Raub abzuhalten, als aussichtslos unterlie $\beta^{469}$.

Halten die Eltern hingegen nur die Möglichkeit, etwas gegen die Tat tun zu können, für nicht gegeben, ist es eine Einzelfallfrage, ob die Handlung nicht zumindest die Möglichkeit eröffnet hätte, das Delikt zu verhindern. Es ist zu berücksichtigen, daß eine zeitliche Verzögerung die Dinge in nicht vorhersehbarer Weise ändern kann. Der Garant soll sich zumindest bei seiner Untätigkeit nicht darauf berufen können, sein Eingreifen hätte wegen der Tatentschlossenheit des zu Beaufsichtigenden ohnehin keinen Sinn gehabt. Die Eltern sind verpflichtet, Lösungsmöglichkeiten zu finden oder sich jedenfalls darum zu bemühen. Sie haben kein Recht auf Resignation $^{470}$.

Bei fehlender Nähe zur Gefahrenstelle wird gewöhnlich die Möglichkeit des Eingreifens abgelehnt ${ }^{471}$. Ob eine Verhinderungsmöglichkeit besteht, hängt damit aber letztlich davon $a b$, an welchen Ort man die Gefahrenstelle verlegt: Wenn der Jugendliche zuerst von zu Hause mit seinen Freunden am Telefon einen Treffpunkt für den gemeinsamen Diebeszug vereinbart, liegt die Gefahrenstelle bereits im Elternhaus, und nicht in der - für die Eltern unzugänglichen - fremden Wohnung, in die dann schließlich eingebrochen wird. Auch Möglichkeiten des mittelbaren

\footnotetext{
${ }^{467}$ BGH MDR/D 73, $369 \mathrm{~m}$. Anm. Blei JA 73, 463.

${ }^{468}$ BGHSt 6, 46 (57).

469 BGH NJW 64, 1330 (1330); Geilen, JuS 65, 426 (427).

${ }^{470} \mathrm{vgl}$. Schwarz, S. 165.

${ }^{471}$ S/S-Stree, Vor § 13, Rn. 142; Wessels, AT, Rn. 708.
} 
Eingreifens sind heranzuziehen und können zur Bejahung eines Unterlassens führen $^{472}$, etwa durch einen Telefonanruf.

Die Handlungspflicht muß auch nicht persönlich erfüllt zu werden. Der Handlungspflichtige kann und muß sich sogar der Hilfe Dritter bedienen, wenn diese allein das Erforderliche tun können. Die Eltern werden aber mit der Übertragung der Pflicht nicht von der eigenen Verpflichtung frei, sondern haben im Rahmen des Erforderlichen und Zumutbaren über die Pflichterfüllung durch Dritte zu wachen ${ }^{473}$.

Bei der Möglichkeit der Deliktsverhinderung kommt es schließlich allein auf die objektive Lage an. Die Gefahr und das Mittel zu ihrer Beseitigung müssen nach außen erkennbar sein ${ }^{474}$.

Fraglich ist, inwieweit die Möglichkeit, das Delikt zu verhindern, die tatsächliche Kenntnis von einer geplanten bzw. begonnenen Tat, voraussetzt. $\mathrm{Ob}$ der Unterlassende von der Gefahrensituation oder den verfügbaren Hilfsmitteln Kenntnis hat oder hätte haben müssen, berührt nach herrschender Meinung den objektiven Tatbestand nicht, sondern allenfalls den Vorsatz bzw. die Fahrlässigkeit ${ }^{475}$. Nach anderer Ansicht ${ }^{476}$ schließt die fehlende Kenntnis, auch wenn sie auf Nachlässigkeit beruht, die Verhinderungsmöglichkeit der Garanten aus ${ }^{477}$.

Da bei der Prüfung der objektiven Tatbestandsmäßigkeit nur die Handlung zu bestimmen ist, deren Vornahme dem Täter möglich war, kann es darauf, ob er sich dieser Möglichkeit bewußt war, jedoch nicht ankommen ${ }^{478}$. Alles weitere ist eine Frage von Vorsatz und Fahrlässigkeit. Das ist auch stimmig. Andernfalls wären die Garanten, die keine Kenntnis von der Tat haben, pauschal straflos, auch wenn dies auf fahrlässige Nachlässigkeit gegenüber dem Kind bzw. Jugendlichen

\footnotetext{
472 Baumann/Weber, AT, S. 200.

${ }^{473}$ BGHSt 19, 286; BGH NJW 64, 1631; Hamm VRS 52, 64; Karlsruhe NJW 77, 1930.

${ }^{474}$ S/S-Stree, Vor $\S 13, R n .143$.

${ }^{475} \mathrm{~S} / \mathrm{S}$-Stree, Vor § 13, Rn. 143; Wessels, AT, Rn. 709; Baumann/Weber, AT, S. 200; Stratenwerth, AT, S. 390, Rn. 58; Maurach/Zipf, AT, § 46, Rn. 113; SK-Rudolphi, § 13, Rn. 3; Maiwald, JuS 81, 473 (478).

${ }^{476}$ Jescheck/ Weigend, § 59 II, S. 617; Welzel, S. 212; Armin Kaufmann, Dogmatik, 35ff.; Schöne, JZ 77, 150 (153).

${ }^{477}$ Vgl. 3. Teil, C. I 1.

${ }^{478}$ Stratenwerth, AT, S. 390, Rn. 58.
} 
zurückzuführen ist ${ }^{479}$. Würde man für das Unterlassen die Kenntnis von der zum Handeln verpflichtenden Situation fordern, müßte dies zur Leugnung unbewußt fahrlässig begangener Unterlassungstaten führen ${ }^{480}$. Baumann bringt - wenn auch für den Obhutsgaranten- das Beispiel von dem Vater, der tatenlos vor dem brennenden Haus steht und nicht weiß, daß sein Kind in den Flammen umkommt. Hierbei ist es sehr wohl relevant, ob der Vater wissen könnte, daß sich sein Kind im Haus befindet, oder ob ihm vielmehr sorgfaltswidrig diese Kenntnis fehlt und er somit die Rettungshandlung fahrlässig unterläßt $\mathrm{t}^{481}$.

\section{Vorsatz und Fahrlässigkeit}

\section{Vorsätzliches Unterlassen der Deliktshinderung}

\section{Allgemeines}

Für die Form des Vorsatzes gelten die für die Begehungsdelikte aufgestellten Regeln entsprechend, wobei die andersartige Struktur der Unterlassungsdelikte $\mathrm{zu}$ berücksichtigen ist $^{482}$. Nach h. L. muß der Vorsatz sich sowohl auf den eintretenden Erfolg, auf die Garantenstellung als auch auf die Verhinderungsmöglichkeit erstrecken $^{483}$. Bei der unterlassenen Deliktsverhinderung erstreckt sich der Vorsatz des Garanten insbesondere darauf, daß der aktiv handelnde Vordermann den von ihm avisierten Taterfolg erzielen werde. Hinsichtlich des Unterlassungserfolges genügt es, daß dieser zwar vom Unterlassenden nicht gewünscht, aber als mögliches Ergebnis der Handlung des unmittelbaren Täters akzeptiert wird (dolus eventualis). Gegenüber einem solchen Unterlassen ist der innere Vorbehalt, den Erfolg nicht als Folge der eigenen Verursachung zu wollen, grundsätzlich unbeachtlich $^{484}$. Dabei muß geprüft werden, ob die Untätigkeit der Eltern

\footnotetext{
${ }^{479}$ Gerade dies dürften aber die klassischen Fälle elterlichen Fehlverhaltens sein.

${ }^{480}$ Baumann/Weber, AT, S. 200.

481 Baumann/Weber, AT, S. 200.

482 Dazu Stratenwerth, AT, S. 295, Rn. 75.

${ }^{483}$ MDR/D 71, 361; OLG Köln NJW 73, 861; Stratenwerth, AT, S. 395, Rn. 69 ff.

${ }^{484}$ BGH NJW 73, 861 (862).
} 
oder die Geringfügigkeit des Widerstandes, den sie gegen das Verhalten des Jugendlichen geleistet haben, der Ausdruck ihres Einverständnisses mit diesem Verhalten oder nur das Ergebnis von Rat- und Hilflosigkeit gewesen ist ${ }^{485}$.

Dem entgegen vertritt Armin Kaufmann die Ansicht, daß beim Unterlassen ein Vorsatz wie bei den Begehungsdelikten nicht möglich ist $^{486}$. Zur Verwirklichung des subjektiven Tatbestandes soll es bereits genügen, daß dem Täter bei Kenntnis der tatbestandsmäßigen Situation und Erkennbarkeit der Handlungsmöglichkeit der Entschluß zum Eingreifen fehlt. Die Auffassung Kaufmanns wird zu Recht vom Großteil der Literatur abgelehnt ${ }^{487}$.

Die in manchen Tatbeständen geforderte Absicht, etwa die Verdeckungsabsicht bei $\S 211$ StGB oder die Bereicherungsabsicht bei $\S 263$ StGB, ist als zielgerichtetes Unterlassen zu verstehen. Dem Täter muß es insoweit darauf ankommen, durch sein Nichteingreifen den Erfolg eintreten zu lassen ${ }^{488}$.

Für die Annahme eines Vorsatzes muß der Täter also zunächst die tatbestandsmäßige Situation kennen, aus der seine Pflicht zum Handeln entsteht. Die Eltern müssen also erstens wissen, daß es ihr Abkömmling ist, der dort handelt, und zweitens, daß eine Straftat durch den Abkömmling bei weiterem ungestörten Kausalverlauf eintreten wird. Weitere Voraussetzung für das vorsätzliche Unterlassen ist es, daß der Täter die tatsächlichen Möglichkeiten zur Verhinderung oder Erschwerung des Eintritts des Erfolges erkennt. Es kommt daher auf die konkrete Feststellung an, ob der Täter an diese Möglichkeit gedacht und sie auch für geeignet gehalten hat, den Erfolg abzuwenden ${ }^{489}$. Dabei muß der Täter auch das Bewußtsein haben, die erwartete Handlung werde den Erfolg mit hoher Wahrscheinlichkeit verhindern ${ }^{490}$.

\footnotetext{
${ }^{485}$ RG 77, 125 (127).

${ }^{486}$ Armin Kaufmann, Dogmatik, S. 110, 149, 309.

${ }^{487}$ Engisch, JZ 62, 189 (190f.); Jescheck/ Weigend, § 59 VI 3, S. 632; Roxin, ZStW 74, 515 (530); ZStW 78, 258 (159); Spendel, JZ 73, 137 (139); S/S-Cramer, § 15, Rn. $93 f$.

${ }^{488}$ Stratenwerth, AT, S. 393, Rn. 67; a. A. Grünwald, H. Mayer-FS, S. 289.

489 BGH NJW 73, 861 (862); Bockelmann/ Volk, AT, S. 143; Herzberg, MDR 71, 881 (881f.).

${ }^{490}$ BGH NJW 94, 1357; Bespr. Loos, JR 94, 510 (512); Welzel, S. 204.
} 
Umstritten ist, ob der Vorsatz die Pflicht zum Handeln selbst umfassen muß. Es ist davon auszugehen, daß nur die pflichtbegründenden Umstände vom Vorsatz umfaßt sein müssen, nicht die Pflicht selbst. Derjenige also, der bei Kenntnis der seine Handlungspflicht begründenden Umstände glaubt, zum Tätigwerden nicht verpflichtet zu sein, unterliegt einem Gebotsirrtum i. S. d. § 17, nicht etwa einem Tatbestandsirrtum nach $\S 16 \mathrm{StGB}^{491}$. Letzterer liegt nur vor, wenn der Unterlassende gar keine Möglichkeit kennt, helfend einzugreifen.

Für die Abgrenzung von Eventualvorsatz und bewußter Fahrlässigkeit gelten die gleichen Maßstäbe wie beim Begehungsdelikt ${ }^{492}$. Die Abgrenzung des Vorsatzes von der Fahrlässigkeit ist am konkreten Fall nur schwer vorzunehmen. Bei der vorliegenden Eltern-Kind-Problematik kann vor allem eingewendet werden, daß Eltern oftmals von der Freizeitgestaltung ihrer Kinder nichts Genaues wissen und demzufolge nicht über die begangenen Straftaten informiert sind, also auch deren Verwirklichung nicht wissentlich und willentlich geschehen lassen können. Wenn Eltern nicht wissen, wo sich ihr Abkömmling tagsüber, insbesondere aber nachts, aufhält, kommt die Annahme eines Vorsatzes für die unterlassene Deliktshinderung nicht in Betracht. Der Umstand, daß die Eltern sich gegebenenfalls wissentlich jeder Möglichkeit des Einflusses und der Verhinderungsmöglichkeit begeben, genügt für die Annahme eines Vorsatzes grundsätzlich nicht. Inwieweit ein vorsätzliches Ausschalten der eigenen Verhinderungsmöglichkeit im Vorfeld der Tat zur Annahme einer vorsätzlichen Unterlassung führen kann, wird unter c) näher geprüft.

Anders ist die Lage, wenn Eltern durchaus damit rechnen, daß ihr Abkömmling zum wiederholten Male kurz vor der Begehung einer Straftat steht. Wird etwa ein rechtsextremer Jugendlicher von einer Gruppe von „Freunden“ abgeholt, um anschließend unter Verwendung verfassungsfeindlicher Symbole und dem Rufen von volksverhetzenden Parolen durch die Straßen zu ziehen, und hat er gegenüber seinen Eltern zuvor die Bereitschaft signalisiert, sich bei dieser Gelegenheit ein Opfer

\footnotetext{
491 S/S-Cramer, § 15, Rn. 96.

492 Stratenwerth, S. 295, Rn. 73.
} 
für eine Körperverletzung zu suchen, fällt es schwer, den Eltern eine Kenntnis von den Taten absprechen zu wollen. Hier kann ein Vorsatz allenfalls dadurch abgelehnt werden, daß konkrete Taten des Jugendlichen noch nicht feststehen.

Der Umstand, daß ein Eingreifen den Eltern in dem aufgeführten Beispiel möglicherweise nicht zuzumuten ist, hat allerdings Folgen für den Vorsatz: Versteht man die Unzumutbarkeit als ein die geforderte Handlung begrenzendes Kriterium mit tatbestandsausschließender Wirkung ${ }^{493}$, verhält sich derjenige, der aufgrund von Unzumutbarkeit nicht eingreift, wie jemand, der nicht in der Lage ist, die rettende Handlung auszuführen. Eltern, die von der bevorstehenden Vorsatztat ihres Abkömmlings wissen und den Erfolgseintritt nicht wollen, aber dennoch nicht handeln, weil es für sie unzumutbar ist, handeln nicht nur nicht pflichtwidrig, sondern auch nicht vorsätzlich. Anders ist es, wenn die Eltern eine Handlung für unzumutbar halten, die ihnen durchaus zuzumuten wäre. In dem Fall unterliegen sie lediglich einem Verbotsirrtum gem. $§ 17$ StGB, da es um die normative Einschätzung des geforderten Tuns, nicht um eine Verkennung der Sachlage geht.

In deutlicherem Maße ist bei Eltern von einem Vorsatz auszugehen, deren Kind regelmäßig bei Trickdiebstählen aufgegriffen und dann von der Polizei unter Mahnungen zu Hause ,abgeliefert“ wird. Versprechen die Eltern den Polizeibeamten immer wieder auf' s Neue, künftige Taten des Kindes zu verhindern, lassen das Kind aber bereits am nächsten Tag wieder unbeaufsichtigt in die gefährdete Zone in der Innenstadt, wo das Kind - für jeden erwartungsgemäß - weitere Taten verübt, kann hier relativ problemlos ein dolus eventualis bejaht werden ${ }^{494}$.

Für die Annahme einer Billigung der Taten durch das Kind oder den Jugendlichen spricht es weiter, wenn die Eltern es ihm gewähren, sich zu bewaffnen (etwa mit einem Messer, Schlagwerkzeug oder einer Gaspistole) und sich so in der Öffentlichkeit zu bewegen. Hier wird die Stichhaltigkeit des Gegenarguments mancher Eltern, das Kind habe die Gegenstände nur zum Selbstschutz dabei, je nach der

\footnotetext{
${ }^{493}$ Vgl. S/S-Stree, Vor $\S 13$, Rn. 155; zur Unzumutbarkeit im einzelnen siehe unten, 3. Teil E. I.

${ }^{494}$ AG Köln (unveröff. Entscheidungen) vom 7.4.1999, 613 Ls 97/98 und 28.4.1999, 532 Ds 82/99.
} 
Bedrohungssituation und der Art der mitgeführten Waffe zu beurteilen sein. Es spricht ebenfalls für eine (vorsätzliche) Billigung der Straftaten des Abkömmlings, wenn Eltern es nicht hinterfragen, daß ihr Kind teuere Kleidung oder andere Markenartikel besitzt, die sie ihm nicht gekauft haben und die das Kind sich mit dem Taschengeld nicht hätte leisten können. Wenn Eltern jedoch der Bekleidung und den Freizeitgegenständen ihrer Kinder nur aus Nachlässigkeit und Desinteresse keine ausreichende Beachtung schenken, genügt dies für sich allein nicht, um einen Vorsatz in Bezug auf Eigentums- und Vermögensdelikte zu begründen.

2. Varianten vorsätzlichen Unterlassens der Deliktsverhinderung

$\mathrm{Zu}$ unterscheiden ist zwischen der vorsätzlichen Nichthinderung der Vorsatztat und der vorsätzlichen Nichthinderung der Fahrlässigkeitstat des Kindes oder Jugendlichen.

Hinsichtlich der Fahrlässigkeitstat des zu Beaufsichtigenden kann diskutiert werden, ob stets nur eine fahrlässige Täterschaft des Garanten durch Unterlassen in Betracht kommt. Nach Wehrle kann auch eine vorsätzliche Beteiligung am Fahrlässigkeitsdelikt nur $\mathrm{zu}$ einem Fahrlässigkeitsvorwurf führen ${ }^{495}$. Daß jedoch auch ein vorsätzliches Unterlassen nicht ausgeschlossen sein kann, zeigt folgendes Beispiel:

Die Mutter hält ihren strafmündigen Sohn vorsätzlich nicht davon ab, ein $\mathrm{Kfz} \mathrm{zu}$ führen, und nimmt dadurch die Verletzung von anderen Verkehrsteilnehmern vorsätzlich in Kauf. Verletzt der Sohn fahrlässig im Straßenverkehr einen Dritten, ist auch eine vorsätzliche Beteiligung der Mutter an der Fahrlässigkeitstat des Sohnes möglich. Sie ist dann nicht wegen fahrlässiger Körperverletzung durch Unterlassen strafbar, sondern wegen vorsätzlicher Körperverletzung durch den (vorsätzlich) nicht verhinderten, vom Sohn fahrlässig herbeigeführten Taterfolg ${ }^{496}$.

\footnotetext{
${ }^{495}$ Vgl. Wehrle, S. 87.

${ }^{496}$ Renzikowski, S. $266 \mathrm{ff}$.
} 
3. Vorsätzliches Beseitigen der Verhinderungsmöglichkeit - Omissio libera in causa?

Grundsätzlich muß die Handlungsmöglichkeit zu dem Zeitpunkt gegeben sein, zu dem das Eingreifen des Handlungspflichtigen erforderlich wird; ist dann sinnvolles Handeln unmöglich, so entfällt die Handlungspflicht. Dies wurde bereits im Rahmen der Voraussetzungen des vorsätzlichen Unterlassungsdelikts ausgeführt. Anderes gilt jedoch, wenn der Handlungspflichtige die Verantwortung dafür trägt, daß er im entscheidenden Moment nicht in der Lage war, das Erforderliche zu tun. In diesen Fällen wird dem Täter vorgeworfen, daß er sich vorsätzlich oder fahrlässig von seiner Handlungsmöglichkeit ausgeschlossen hat. Das kann sowohl durch aktives Tun wie auch durch Unterlassen geschehen ${ }^{497}$. Dieser Vorwurf der omissio libera in causa wird nicht nur dann erhoben, wenn es um selbstverursachte Schuldunfähigkeit geht, sondern er kann auch bei selbstverschuldeter Verhinderungsunmöglichkeit greifen, etwa, wenn der Bahnwärter sich so weit von der Schranke entfernt, daß er sie nicht schließen kann, als der Zug kommt ${ }^{498}$.

Der Verlust der Eingriffsmöglichkeit ist bisher in der Literatur vorwiegend im Zusammenhang mit dem fahrlässigen Herrschaftsverlust über Gegenstände behandelt worden, so daß der Begriff der omissio libera in causa nicht vorkommt. Dabei ist der Gedanke Herzbergs bedeutsam, daß das Ende der aktuellen Beherrschung des Kausalverlaufs nicht auch das Ende der besonderen Verantwortlichkeit bedeute. Stehe fest, daß die drohenden Schadensfolgen Auswirkungen eines vorwerfbaren Versäumnisses seien, müsse der Verantwortliche den Folgen immer entgegentreten, wo immer er noch könne ${ }^{499}$. Dies leuchtet auch ein, insbesondere, wenn man dazu die Formulierung Schünemanns heranzieht, wonach der Sachherr alle Maßnahmen zur Abwehr zu ergreifen hat, die seinen Herrschaftsbereich aus dem schädlichen Kausalverlauf heraushalten ${ }^{500}$. Daraus kann mit Herzberg geschlossen

\footnotetext{
${ }^{497}$ S/S-Cramer, Vor § 13, Rn. 144; Androulakis, Unterlassungsdelikte, S. 156.

${ }^{498}$ Androulakis, Unterlassungsdelikte, S. 156.

${ }^{499}$ Herzberg, Unterlassung, S. 325.

${ }^{500}$ Schünemann, Grund und Grenzen, S. 289.
} 
werden, daß der Sachherr notfalls ,hinter seiner Sache herlaufen“ und ihre Auswirkungen abschneiden müsse ${ }^{501}$. Fraglich ist, wieso die gleiche Folge nicht auch den Überwachergaranten über Personen treffen sollte, erst recht, wenn sein Unterlassen vorsätzlich geschieht.

$\mathrm{Zu}$ diesen Überlegungen paßt der von Hruschka genannte Fall des Bademeisters, der am Vorabend eines Unglücks exzessiv „feiert“ und der die Folge seines Umtrunks, nämlich seine Handlungsunfähigkeit, zumindest mit Eventualvorsatz herbeiführt ${ }^{502}$. Am folgenden Tag ist ein Mensch beim Baden im See vom Tod durch Ertrinken bedroht. Der Bademeister B bleibt am Ufer, weil er, wie durchaus von ihm in Kauf genommen, in seiner schlechten körperlichen Verfassung den Ertrinkenden nicht erreicht hätte ${ }^{503}$. Der Mensch, der sonst hätte gerettet werden können, ertrinkt. Fraglich ist, ob B der Tötung des Menschen durch Unterlassen schuldig ist. Immerhin war es ihm nicht möglich, die rettende Handlung zu vollbringen. Nun hat B jedoch sein Unvermögen hier sei angenommen: vorsätzlich - dadurch selbst herbeigeführt, daß er am Abend zuvor gefeiert hat. Man kann bereits die aktive Handlung des Feierns als eine Verletzung der dem B auferlegten Handlungspflicht einstufen; dann würde der Tatbestand des Unterlassungsdelikts bereits durch diese, der eigentlichen Untätigkeit vorangehende aktive Handlung erfüllt werden ${ }^{504}$.

Wie sich eine omissio libera in causa für diese Konstellationen im Genauen darstellen könnte, ist noch ein unerforschtes Gebiet, auf das hier nicht tiefer eingegangen werden kann.

\section{Fahrlässiges Unterlassen der Deliktshinderung}

1. Dogmatische Einordnung des fahrlässigen Unterlassens

Das Gesetz betrachtet die vorsätzliche Verwirklichung als Regelfall der Verwirklichung tatbestandlichen Unrechts. Die fahrlässige Begehung -

\footnotetext{
${ }^{501}$ Herzberg, Unterlassen, S. 325.

502 Vgl. Hruschka, Bockelmann-FS, S. 421. Der Fall wurde im Vorliegenden stark abgewandelt.

${ }^{503}$ Hruschka, Bockelmann-FS, S. 421.

${ }^{504}$ Vgl. Hruschka, Bockelmann-FS, S. 421.
} 
und damit auch die fahrlässige Unterlassung - ist nur dann strafbar, wenn dies im Gesetz ausdrücklich bestimmt ist, $\S 15 \mathrm{StGB}^{505}$. Diese gesetzlichen Bestimmungen, nach denen auch die fahrlässige Begehung strafbar sein soll, finden sich im Besonderen Teil. Bei den Fahrlässigkeitsdelikten wird ebenso wie bei den Vorsatzdelikten zwischen Erfolgsdelikten, Gefährdungsdelikten und Tätigkeitsdelikten sowie zwischen Begehungs- und Unterlassungsdelikten unterschieden ${ }^{506}$. Neben den fahrlässigen Erfolgsdelikten wie § 222 StGB (Fahrlässige Tötung) und § 229 StGB (Fahrlässige Körperverletzung) spielt im Bereich der Gefährdungsdelikte die fahrlässige Verwirklichung der $\S 315$ b Abs. 1, 5 StGB (Fahrlässiger Eingriff in den Straßenverkehr) und $\S 315$ c Abs. 1, 3 Nr. 2 StGB (Fahrlässige Straßenverkehrsgefährdung) eine erhebliche Rolle ${ }^{507}$. In Betracht kommt für die hier vorliegende Thematik außerdem $§ 306$ d StGB (Fahrlässige Brandstiftung).

2. Voraussetzungen des fahrlässigen Unterlassungsdelikts

Im fahrlässigen Unterlassungsdelikt fallen die Merkmale des Unterlassungsdelikts und des Fahrlässigkeitsdelikts zusammen und sind miteinander $\mathrm{zu}$ kombinieren ${ }^{508}$. Voraussetzungen des fahrlässigen Unterlassens sind damit der Eintritt des tatbestandsmäßigen Erfolges, die Nichtvornahme der gebotenen Handlung, die Verhinderungsmöglichkeit, das Vorliegen einer Garantenstellung, die objektive Sorgfaltspflichtverletzung, der Pflichtwidrigkeitszusammenhang, das Entsprechen von Tun und Unterlassen, die Zumutbarkeit des erwarteten Verhaltens, die Rechtswidrigkeit und schließlich Schuld, einschließlich der subjektiven Fahrlässigkeit. Dabei ist zu berücksichtigen, daß es Überschneidungen zwischen einigen Merkmalen geben kann ${ }^{509}$.

$\mathrm{Zu}$ den einzelnen Voraussetzungen kann teilweise auf die bisherigen Ausführungen zum Unterlassungsdelikt verwiesen werden, so daß im

\footnotetext{
${ }^{505}$ Baumann/Weber/Mitsch, 22, Rn. 1.

${ }^{506}$ S/S-Cramer, § 15, Rn. 120.

${ }^{507}$ Baumann/Weber/Mitsch, § 22, Rn. 1.

${ }^{508}$ Vgl. Fünfsinn, S. 49, Fn. 85. Zu Ähnlichkeit und Unterscheiden von Fahrlässigkeit und Unterlassen siehe Androulakis, Unterlassungsdelikte, S. $132 \mathrm{ff}$.

${ }^{509}$ Fünfsinn, S. $50 \mathrm{ff}$.
} 
Folgenden nur ausgewählte Merkmale des fahrlässigen Unterlassens untersucht werden sollen.

a) Verletzungserfolg

Zum Tatbestand des Fahrlässigkeitsdelikts gehört der Eintritt des tatbestandsmäßigen Erfolgs, der ebenso wie bei den Vorsatzdelikten ein Verletzungs- oder konkreter Gefährdungserfolg sein kann ${ }^{510}$.

Zum Erfolg ist für das Fahrlässigkeitsdelikt festzustellen, daß er nicht die unmittelbare Folge des Verhaltens des zu Beaufsichtigenden sein muß. Es genügt, wenn das zu beaufsichtigende Kind oder der Jugendliche eine, wenn auch entferntere Ursache für eine Rechtsgutsverletzung gesetzt hat. $\mathrm{Ob}$ man darin so weit gehen will, wie der Bundesgerichtshof es in einer zivilrechtlichen Entscheidung 1966 getan hat $^{511}$, ist allerdings fraglich: In dem Fall hatte ein Vater seinem 12jährigen Sohn das Spiel mit Wurfpfeilen gewährt. Der 12jährige gab einen Pfeil an einen 6jährigen weiter, der daraufhin ein anderes Kind durch das Werfen des Pfeils am Auge verletzte. Hier wurde ein Zusammenhang mit einer fehlenden Beaufsichtigung des 12jährigen bejaht. Der Vater habe dafür sorgen müssen, daß sein Sohn den Pfeil nicht an andere weitergab. Auch wenn der 12jährige Sohn einsichtig genug sei, selbst mit dem Spielgerät keinen Schaden zu verursachen, so sei er nicht in der Lage, darüber zu befinden, ob auch ein anderer gefahrlos damit spielen könne. Daß die Weitergabe eines Pfeils an einen zur verständigen Beherrschung dieses Spielzeugs noch nicht fähigen Spielgefährten eine Schädigung Dritter zur Folge habe, sei keinesfalls ungewöhnlich. Die Verletzung des 6jährigen sei daher vom Sohn des Beklagten adäquat verursacht ${ }^{512}$.

In dem zitierten Fall kam noch hinzu, daß der 12jährige Sohn sich den Pfeil ohne Zutun der Eltern selbständig als Spielgerät beschafft hatte. Nach Ansicht des BGH war es durchaus zweifelhaft, ob eine Verletzung der Aufsichtspflicht schon darin erblickt werden könne, daß dem Aufsichtspflichtigen der Erwerb des gefährlichen Werkzeugs unbekannt geblieben sei. Jedenfalls war nach Auffassung des BGH die Verletzung der Aufsichtspflicht aber darin zu erblicken, daß der Beklagte sich nicht

\footnotetext{
510 Jescheck/ Weigend, S. 582.

${ }^{511}$ BGH VersR 1966, 368 (368).
} 
im hinreichenden Maße darum gekümmert habe, womit sich sein Kind in der Freizeit beschäftigte. Dann hätte er von dem gefährlichen Spiel erfahren und hätte nicht untätig bleiben dürfen ${ }^{513}$.

Bereits zivilrechtlich ist fraglich, ob hier noch ein Pflichtwidrigkeitszusammenhang hergestellt werden kann, wenn ein 12jähriger ein Spielgerät an ein anderes Kind weitergibt, das wiederum einen anderen damit verletzt. Es bestehen gleich mehrere Zweifel. Setzt man bereits bei der Vorhandlung zu dem schädigenden Ereignis an, führt dies $\mathrm{zu}$ einer nicht absehbaren Kausalkette, die auch dann nicht abbrechen würde, wenn der Pfeil immer weiter gegeben worden wäre. Unbestreitbar besteht die Wahrscheinlichkeit, daß mit einem bestimmte Spielgerät ein Schaden verursacht wird, wobei die Wahrscheinlichkeit von der Art des Spielgeräts abhängt. Stuft man sie, wie bei einem Pfeil, als besonders hoch ein, muß man jedoch nicht auf die Überwachung des Kindes abstellen sondern vielmehr auf die Verwahrung des gefährlichen Gegenstandes. Hinzu kommt noch, daß es fraglich ist, ob die Eltern eines 12jährigen von der Existenz eines solches Spielgerätes ausgehen mußten. Es war dem Kind ohne weiteres möglich, sich das Gerät von seinem Taschengeld zu kaufen und schon unterwegs damit Schaden anzurichten, ohne daß die Eltern eine Eingriffsmöglichkeit bekommen hätten. Eine Pflicht derart, daß die Eltern auch neben der Verantwortung für ihre Kinder auch noch die Verpflichtung für dritte Schadensverursacher übernehmen müssen, ginge insbesondere im Strafrecht zu weit.

b) Sorgfaltspflichtverletzung und Erfolgsabwendungspflicht

aa) Unmöglichkeit der genauen Abgrenzung der Tatbestandsmerkmale

Das Fahrlässigkeitsdelikt erfordert als zentrales Kriterium die objektive Sorgfaltspflichtverletzung, die sich aus der Vorhersehbarkeit und der Vermeidbarkeit zusammensetzt. Die Vorhersehbarkeit betrifft den Umstand, daß der Täter das Wissen von der Tatbestandserfüllung hätte haben können und müssen, wenn er die nötige Sorgfalt darauf verwendet hätte $^{514}$. Für die Vermeidbarkeit der Tatbestandserfüllung gilt: Hatte der Täter auch bei sorgfaltsgerechtem Verhalten gar keine Möglichkeit, die

\footnotetext{
${ }^{512}$ BGH VersR 1966, 368 (368).

${ }^{513}$ BGH VersR 1966, 368 (369).
} 
Verwirklichung des Tatbestandes zu vermeiden, so kann ihm kein Fahrlässigkeitsvorwurf gemacht werden ${ }^{515}$.

Beim fahrlässigen Unterlassungsdelikt besteht die Besonderheit, daß sich die objektive Sorgfaltspflicht mit der Erfolgsabwendungspflicht aus dem Unterlassen deckt oder sich die Pflichten jedenfalls kaum sinnvoll voneinander trennen lassen ${ }^{516}$. Das vom Garanten beim fahrlässigen Unterlassungsdelikt erwartete Eingreifen zur Abwendung einer Gefahr, also der Inhalt der Erfolgsabwendungspflicht, korreliert mit der Pflicht zur sorgfaltsgemäßen Vornahme der erforderlichen Rettungshandlung. Die Pflichterfüllung aus der Garantenstellung und das durch das Fahrlässigkeitsdelikt geforderte sorgfaltsgemäße Verhalten bestimmen und begrenzen sich wechselseitig ${ }^{517}$. Beide Pflichten lassen sich nur im Rückgriff auf die Pflichten einer ,,vernünftigen“ Person in der bestimmten personalen Rolle des Täters erfassen; diese Erfolgsabwendungspflicht hat eine objektive (generelles soziales Können) und eine subjektive Seite (spezielles individuelles Können) ${ }^{518}$. $\mathrm{Da}$ die Fahrlässigkeit das pflichtwidrige Verhalten in vorhersehbares und vermeidbares Verhalten unterteilt, was zumindest nicht explizit für die Erfolgsabwendungspflicht geschieht, ist dabei unschädlich. Auch beim Unterlassungsdelikt setzt die Abwendung des Erfolges voraus, daß der Täter die Rechtsgutsverletzung voraussehen kann und physisch wie psychisch in der Lage ist, den Eintritt der Rechtsgutsverletzung zu verhindern $^{519}$.

Auch wenn man den Versuch unternehmen kann, die Pflichten begrifflich auseinanderzuhalten, fallen sie tatsächlich meist zusammen, weil die Garantenpflicht nur durch sorgfaltsgemäßes Verhalten erfüllt

\footnotetext{
${ }^{514}$ Tröndle/Fischer, § 222, Rn. 15.

${ }^{515}$ Baumann/Weber/Mitsch, § 22, Rn. 13.

${ }^{516}$ Fünfsinn, S. 98; Lackner/Kühl, § 15, Rn. 54; a. A. S/S-Cramer, § 15, Rn. 143.

${ }^{517}$ Stratenwerth, AT, S. 434, Rn. 2.

${ }^{518}$ Frey, Zumutbarkeit, S. 35.

519 Damit muß man allerdings zum Ergebnis kommen, daß das fahrlässige Unterlassungsdelikt lediglich ein „vorsätzliches Unterlassungsdelikt“ ohne die Voraussetzungen des Vorsatzes ist; die Fahrlässigkeit muß nicht mehr selbst definiert werden, sondern ist stets durch die Erfolgsabwendungspflicht im "normalen Unterlassen“ enthalten. Das fahrlässige Unterlassungsdelikt ist somit ein Minus zum vorsätzlichen Unterlassungsdelikt.
} 
werden $\mathrm{kann}^{520}$. Anders gesagt: Eine Verletzung der Erfolgsverhinderungspflicht liegt beim fahrlässigen Unterlassungsdelikt erst dann vor, wenn dem Garanten eine objektive Sorgfaltspflichtverletzung zur Last fällt ${ }^{521}$. Es ist folglich mit der wohl h. L. von einem inhaltlichen Zusammenfallen von Garantenpflicht und Sorgfaltspflicht auszugehen ${ }^{522}$.

bb) Umfang der Sorgfaltspflicht

Die Sorgfaltspflichten werden für die meisten Lebensbereiche entweder unmittelbar durch Gesetz (etwa die StVO und StVZO für den Straßenverkehr, das BImSchG für den Betrieb von Anlagen, oder $\S 121$ OWiG für die mangelhafte Beaufsichtigung gefährlicher Tiere), aber auch durch Verhaltensanweisungen und Regelwerke von Berufsverbänden, wie etwa die DIN-Normen, oder die von Sportverbänden aufgestellten Regeln festgelegt ${ }^{523}$. Fehlen normierte Regeln, wird bei der Bestimmung der Sorgfaltspflicht auf die allgemeine Pflicht zur Vermeidung von Rechtsgutsverletzungen Bezug genommen $^{524}$. Den abstrakten Gefährdungsdelikten kommt insoweit eine Indizfunktion $\mathrm{zu}$.

Nur generelle Unvorhersehbarkeit und Unvermeidbarkeit führen zum Wegfall des Tatbestandes. Kann der Täter infolge gerade ihm persönlich fehlender Fähigkeiten die Tatbestandsverwirklichung nicht vorhersehen und nicht vermeiden, kommt lediglich ein Schuldausschluß in Betracht $^{525}$. Dabei begnügt sich die Rechtsprechung mit der Vorhersehbarkeit des Erfolges als Ergebnis des Kausalverlaufs, während die Lehre außerdem die Vorhersehbarkeit des Kausalverlaufs in ihren wesentlichen Zügen fordert ${ }^{526}$. Nach der Lehre ist jedoch die Kenntnis

\footnotetext{
${ }^{520}$ Fünfsinn, S. 98; Lackner/Kühl, § 15, Rn. 54.

${ }^{521}$ Herzberg, Unterlassung, S. 326.

522 Gallas, Strafrechtliche Verantwortlichkeit, S. 32; Henkel, Metzger-FS, 249, 283; Jescheck/ Weigend, § 59 VII, S. 633.

${ }^{523}$ vgl. Baumann/Weber/Mitsch, § 22, Rn. 38.

${ }^{524}$ vgl. Baumann/Weber/Mitsch, § 22, Rn. 38; Fünfsinn, S. 49.

${ }^{525}$ Baumann/Weber/Mitsch, § 22, Rn. 41.

${ }^{526}$ Puppe, JZ 89, 728 (732).
} 
aller Einzelheiten ebensowenig erforderlich wie beim vorsätzlichen Erfolgsdelikt ${ }^{527}$.

Die Eltern müssen also beispielsweise keine genaue Vorstellung darüber haben, ob der Unfall dadurch verursacht wird, daß ein Autofahrer beim Ausweichen des auf die Straße gelaufenen Kindes Dritte verletzt oder ob er selbst durch das Rammen einer Straßenlaterne zu Schaden kommt. Ebenso wenig kommt es darauf an, ob die Vorstellung der Eltern eine Beteiligung eines Autofahrers, eines Fahrradfahrers oder eines Fußgängers umfaßt.

Es ist letztlich stets eine Frage des Einzelfalls, wann die Sorgfaltspflicht verletzt ist ${ }^{528}$. Hierzu können die oben unter den Garantenpflichten entwickelten Maßstäbe herangezogen werden.

Bei der Entscheidung über die objektive Sorgfaltswidrigkeit stellt die Literatur die Frage, ob und inwieweit besondere Fähigkeiten und besonderes Wissen des Täters (Sonderwissen) zu berücksichtigen sind. Im Rahmen der objektiven Sorgfalt ist stets auf den gewissenhaften besonnenen Menschen abzustellen. So wie beim Straßenverkehrsdelikt vom gewissenhaften Autofahrer und bei der Körperverletzung durch medizinische Behandlung vom gewissenhaften Arzt ausgegangen wird, so geht es hier um die gewissenhaften und besonnenen Eltern. Dabei geht es je nach dem Alter und dem Reifegrad des Kindes/ Jugendlichen um Eltern eines beispielsweise 6jährigen, 12jährigen oder 17jährigen. Denn die Anforderungen, die an die Aufsicht zu stellen sind, ändern sich mit dem zunehmenden Alter des Abkömmlings ununterbrochen und müssen bereits im Rahmen der objektiven Sorgfalt berücksichtigt werden.

Ein Sonderwissen bezieht sich einerseits auf besondere Eigenschaften des Abkömmlings, zum Beispiel hinsichtlich einer besondere Vorliebe des Kindes zu Zündeln oder des Dranges des Jugendlichen, selbst einmal ein Fahrzeug steuern zu wollen.

\footnotetext{
${ }^{527}$ S/S-Cramer, § 15, Rn. 180; Jescheck/ Weigend, § 57 III, S. 587; Puppe, JZ 89, 728 (732).

${ }^{528}$ Vgl. BGH VersR 65, 385: Ein 11jähriger fuhr mit Rollschuhen einem Mopedfahrer auf der falschen Straßenseite entgegen, der Mopedfahrer wich aus und verunglückte tödlich. Das Erfordernis einer stärkeren Überwachung und Ermahnung des rollschuhlaufenden Kindes durch die Eltern wurde abgelehnt.
} 
Andererseits kann das Sonderwissen auch Umstände betreffen, die nicht in der Person des Abkömmlings selbst begründet sind: Ist der Vater Polizeibeamter und weiß im Gegensatz zu den Eltern der anderen Jugendlichen, daß an dem Treffpunkt seines Sohnes mit Drogen gehandelt wird, ist der Kauf von Drogen durch seinen Sohn für ihn vorhersehbar. Fraglich ist, ob hier für die objektive Sorgfaltswidrigkeit auf die Kenntnisse des durchschnittlichen Polizeibeamten oder des durchschnittlichen Vaters auszugehen ist. Man wird konsequenterweise auf das Sonderwissen eines Vaters, der von Beruf Polizist ist, abstellen müssen. Damit handelt der Vater objektiv sorgfaltswidrig, wenn er trotz seiner Kenntnis nichts gegen den Aufenthalt seines Sohnes an jenem Ort unternimmt.

cc) Strafrechtliche Haftung auch ohne Sorgfaltspflichtverletzung des Vordermannes

$\mathrm{Zu}$ einer Sorgfaltspflichtverletzung des Garanten kann es auch ohne ein pflichtwidriges Verhalten des zu Beaufsichtigenden kommen. Dies ist zum einen gegeben, wenn der $\mathrm{zu}$ Beaufsichtigende aufgrund seiner geringen Reife den Inhalt und Umfang der ihm in einer bestimmten Situation obliegenden Sorgfaltspflicht noch nicht erkennt und versteht, da er die Folgen seines Tuns nicht vorhersehen und somit auch nicht vermeiden kann. Denkbar sind in diesem Zusammenhang Fälle, in denen das unbeaufsichtigte Kind, welches die Gefahren, die aus dem Straßenverkehr resultieren, noch nicht kennt, blindlings auf die Straße läuft und es durch einen Unfall die Körperverletzung eines Dritten verursacht. Hierbei ist der Erfolgseintritt dem Garanten trotz fehlenden sorgfaltswidrigem Handelns des Kindes unmittelbar zurechenbar ${ }^{529}$. Die Sorgfalt richtet sich zunächst stets nach dem für den Verkehrskreis maßgeblichen Maßstab ${ }^{530}$, der bei einem Kind sicherlich niedriger liegt als bei einem Jugendlichen und bei einem Jugendlichen wiederum niedriger als bei einem Erwachsenen. Hinzu kommen die individuellen Fähigkeiten des einzelnen. Die Frage, ob das Kind oder der Jugendliche eine Sorgfaltspflichtverletzung begeht, hat mit der Strafmündigkeit also

\footnotetext{
${ }^{529}$ Nicht zu verwechseln ist diese Konstellation mit der mittelbaren Täterschaft, die jedoch, anders als hier, vorsätzliches Verhalten des Hintermannes voraussetzt.
} 
nichts und mit dem Alter nur bedingt zu tun, sondern ist in erster Linie von den individuellen Kenntnissen und Fähigkeiten des Kindes/Jugendlichen abhängig.

Zum anderen verletzt der Aufsichtspflichtige auch dann eine die ihm obliegende Sorgfalt, wenn er im Gegensatz zu seinem Schützling, der sich der Gefahr seines Handelns schuldlos nicht bewußt ist, aufgrund einer Wissensüberlegenheit von der Gefährlichkeit dieses Tuns weiß und ihn dennoch handeln läßt. Die Wissensüberlegenheit hat wiederum mit den eben beschriebenen individuellen Kenntnissen und Fähigkeiten des unmittelbar Handelnden nichts zu tun. Herzberg hat hierzu das Beispiel eines Vaters angeführt, der bemerkt, daß sein Sohn einem Dritten arglos ein Beil besorgt. Der Vater weiß zufällig, daß der Dritte damit einen Mord begehen will. Daher kann er sich nicht darauf berufen, daß die Hingabe des Beils ohne dieses Wissen, hier also durch seinen arglosen Sohn, ein erlaubtes Risiko sei, eine Fahrlässigkeitstat des Sohnes somit nicht vorläge und er, der Vater, keine Sorgfaltspflichtverletzung begehe. Vielmehr muß er als Garant schon die Hingabe des Beils durch den Sohn verhindern. Anders ist nach Herzberg zu entscheiden, wenn sowohl Vater als auch Sohn davon überzeugt sein dürfen, daß das Beil zu nichts anderem als zum Holzhacken verwendet werden soll ${ }^{531}$.

\section{c) Erlaubtes Risiko}

Dem Umstand, daß die Grenzen des Freiraums, den Kinder und Jugendliche benötigen, schwierig für Eltern zu ziehen sind, wird durch den Grundsatz des erlaubten Risikos Rechnung getragen. Kausale Handlungen werden dann vom Fahrlässigkeitsvorwurf ausgeschlossen, wenn sie für die Aufrechterhaltung des sozialen Lebens und Verkehrs unerläßlich sind (soziale Adäquanz des Unterlassens) ${ }^{532}$. Die Grundsätze eines durch soziale Adäquanz erlaubten Risikos erfahren jedoch dann eine Ausnahme, wenn im Einzelfall erkennbar wird, daß ein Vertrauen auf das Funktionieren der zur Gefahrenbegrenzung konkretisierten Sorgfaltsregeln nicht oder nicht mehr gerechtfertigt ist ${ }^{533}$.

\footnotetext{
${ }^{530}$ S/S-Cramer, § 15, Rn. 133.

${ }^{531}$ Herzberg, Unterlassung, S. 326.

532 S/S-Cramer, § 15, Rn. 146 m. w. N.

${ }^{533}$ S/S-Cramer, § 15, Rn. 147.
} 
In diesem Zusammenhang werden auch die Schutzmaßnahmen diskutiert, die der für eine Gefahrenquelle verantwortliche Garant zu treffen hat. Zwar gibt es eine Unzahl von gefährlichen Gegenständen, die so verwahrt werden müssen, daß Kinder nicht sich selbst oder andere schädigen, bei denen die Obhutspflicht aber nicht so weit geht, daß auch die Verhinderung eines vorsätzlichen deliktischen Angriffs eines Dritten unter Verwendung des gefährlichen Gegenstandes erreicht wird. Andererseits gibt es Gegenstände, die so gefährlich sind, daß eine Überwachungspflicht auch dem Zweck dient, deren vorsätzliche Verwendung durch andere $\mathrm{zu}$ verhindern. Das gilt auch für Kraftfahrzeuge, die nach $\S 14$ Abs. 2 StVO gegen unbefugte Benutzung zu sichern sind. Folglich kann nach $\S 229$ bestraft werden, wer sein Fahrzeug nicht sichert und einem Dritten dadurch eine Unfallfahrt ermöglicht ${ }^{534}$. Hier trifft Eltern, die es ihren Abkömmlingen ermöglichen, unzulässigerweise das familieneigene $\mathrm{Kfz}$ zu fahren, sogar eine doppelte Verhinderungspflicht, nämlich aus der Garantenstellung aus der Herrschaft über den Abkömmling und aus der Garantenstellung, die sich aus dem Besitz der gefährlichen Sache ergibt. Kann sich der Täter beim Mißbrauch eines Fahrzeugs bisweilen dadurch entlasten, daß der Fahrer eine ausreichende Fahrpraxis hatte und der schädigende Erfolg nicht vorhersehbar war, ist eine solche Entlastung der Eltern beim jugendlichen Fahrer nicht möglich.

Abschließend ist mit Hruschka und Wehrle darauf hinzuweisen, daß auch bei Garanten die Verantwortlichkeit nicht unendlich weit ausgedehnt werden kann. Es muß auch Rücksicht auf die allgemeine Handlungsfreiheit des Garanten genommen werden: So kann ein Vater nicht immer und überall die Pflicht haben, sich die Handlungsfähigkeit zur erhalten und die Aufmerksamkeit zu schärfen, weil seinem Kind Gefahren drohen bzw. von dem Kind Gefahren ausgehen könnten. Es muß, wie Hruschka zutreffend bemerkt, schon einen Anlaß geben, wenn die Rechtsordnung ein solches Verhalten von ihm erwartet ${ }^{535}$.

\footnotetext{
${ }^{534}$ Vgl. Hamm NJW 81, 2456; S/S-Cramer, § 15, Rn. 154.

${ }^{535}$ Hruschka, Bockelmann-FS, S. 421, 429; Wehrle, S. 64.
} 
d) Fehlende Aufmerksamkeit hinsichtlich der erforderlichen Handlung

Eine weitere Voraussetzung des fahrlässigen Unterlassungsdelikts ist der Mangel an Aufmerksamkeit hinsichtlich der Möglichkeit der Tatverhinderung. Im Gegensatz zum vorsätzlichen Delikt fehlt es beim fahrlässigen Delikt am Wissen oder am Wollen der Tatbestandsverwirklichung. Man unterscheidet vielmehr zwischen der unbewußten und der bewußten Fahrlässigkeit.

Bei der unbewußten Fahrlässigkeit kennt der Täter die tatsächlichen Umstände nicht, die den Tatbestand begründen. Alle Fehlvorstellungen, die den Vorsatz des Täters ausschließen, können Grundlage einer Verantwortlichkeit wegen unbewußter Fahrlässigkeit sein ${ }^{536}$. Unbewußt fahrlässig in bezug auf eine Körperverletzung sowohl des Kindes als auch Dritter im Straßenverkehr handeln also Eltern, die gar nicht merken, daß ihr Kind den Hof verlassen hat und auf der Straße spielt.

Bei der bewußten Fahrlässigkeit hingegen kennt der Täter das Vorliegen der Umstände, die zur Tatbestandsverwirklichung führen. Anders als beim Vorsatz ist dem Täter die Tatbestandsverwirklichung unerwünscht und vertraut er auf ihre Vermeidung ${ }^{537}$. Bewußt fahrlässig verhalten sich die Eltern dann, wenn sie zwar merken, daß das Kind auf der Straße spielt, aber darauf vertrauen, daß kein Auto kommen wird.

Wenn das strafbare Unterlassen danach bestimmt wird, daß der Täter eine Handlung unterläßt, von deren Ziel er Kenntnis hat, dann müßte bei einer Rechtsgutsverletzung, die der Untätige nicht erkannt hat, eine Strafbarkeit wegen fahrlässiger Nichtabwendung ausscheiden. Dies müßte selbst dann gelten, wenn der Eintritt der Rechtsgutsbeeinträchtigung von dem Untätigen hätte erkannt werden können $^{538}$. Aus diesem Gedanken heraus folgert Armin Kaufmann, die Unterlassungsfahrlässigkeit könne nur bei der bewußten Fahrlässigkeit möglich sein. Nur in diesem Falle habe der Garant den Gebotserfüllungswillen, sei er also gewillt, das von der Rechtsordnung gesteckte Ziel zu erreichen. Nur da er Kenntnis von der erforderlichen

\footnotetext{
${ }^{536}$ Baumann/Weber/Mitsch, § 22, Rn. 7.

${ }^{537}$ Baumann/Weber/Mitsch, § 22, Rn. 8.

${ }^{538}$ Schöne, JZ 1977, 150 (152).
} 
Handlung habe, werde er von dem Gebot der Sorgfalt umfaßt ${ }^{539}$. Diese Beschränkung der Unterlassungsfahrlässigkeit auf die bewußte Fahrlässigkeit ist weitgehend auf Ablehnung gestoßen ${ }^{540}$.

Anhand eines weiteren Beispiels von Hruschka ${ }^{541}$ wird deutlich, daß es gerade zur Sorgfaltspflicht eines Garanten gehört, eine Gefahrensituation nicht $\mathrm{zu}$ verkennen oder zu übersehen, so daß den Garanten auch die Unkenntnis von der erforderlichen Handlung nicht schützt: Erneut ist im See des Bademeisters B ein Mensch vom Tod durch Ertrinken bedroht. Da der Bademeister nachlässig handelt, beobachtet er nur die Uferzone und bemerkt die Person in der Mitte des Sees gar nicht, so daß diese ertrinkt $^{542}$. Fraglich ist, ob B den Tatbestand der Tötung des anderen Menschen durch Unterlassen verwirklicht hat. Das bloße Verkennen der Gefahrenlage genügt für die Annahme einer Fahrlässigkeit. Die Unkenntnis muß ihm aber zurechenbar sein, was voraussetzt, daß die Vermeidung der Unkenntnis dem Täter geboten ist. Zurechenbarkeit der Unkenntnis setzt voraus, daß der Täter die Unkenntnis hat vermeiden können und vermeiden müssen. Hier wird man sagen müssen, daß B als Bademeister den ganzen See beobachten muß, ja daß gerade darin seine Aufgabe besteht. Ein Bademeister, der nur das größtenteils ungefährliche Ufer überwacht, genügt seinen Rettungspflichten nicht. Er ist gerade dafür angestellt, dieser Unkenntnis entgegenzutreten ${ }^{543}$.

\section{e) Die Zumutbarkeit}

Es ist umstritten, ob die Zumutbarkeit bei den Fahrlässigkeitsdelikten ein regulatives Prinzip darstellt, um die Sorgfaltspflichten sachgerecht zu umgrenzen $^{544}$. In dieser Arbeit wird die Ansicht vertreten, daß es sich bei der objektiven Sorgfaltspflicht und der Erfolgsverhinderungspflicht um die gleiche Verpflichtung handelt. Im Rahmen des vorsätzlichen Unterlassens wurde die Zumutbarkeit bereits als ein die Erfolgsabwendungspflicht begrenzendes Kriterium eingestuft. Daher ist

\footnotetext{
${ }^{539}$ Armin Kaufmann, Dogmatik, S. 170ff., S. 304.

540 Struensee, JZ 77, 217 (217) m. w. N.

${ }^{541} \mathrm{Vgl}$. bereits oben 3. Teil, C. I. 3.

${ }^{542}$ Abgewandelt: siehe Hruschka, Bockelmann-FS, S. 421, 424.

${ }^{543}$ Hruschka, Bockelmann-FS, S. 425.

${ }^{544}$ Maiwald, Schüler-Springorum-FS, S. 475 (485).
} 
es folgerichtig, auch beim fahrlässigen Unterlassungsdelikt in der Zumutbarkeit die Begrenzung der objektiven Sorgfaltspflicht zu sehen ${ }^{545}$. Maiwald hat anhand der Rechtsprechung des Reichsgerichts zum „Leinenfängerfall“546 in Frage gestellt, im Hinblick auf welchen Erfolg eine Zumutbarkeit ex ante bestimmt werden soll ${ }^{547}$. In dem genannten Fall wurde zugunsten des Kutschers, der seine Passagiere mit unberechenbaren Pferden transportierte, weil er Angst vor dem Verlust seines Arbeitsplatzes hatte, eine Unzumutbarkeit angenommen. Dabei wurde die $\mathrm{zu}$ erwartende und erwartungsgemäß eingetretene Körperverletzung von Passagieren oder Dritten gegen den Arbeitsplatzverlust des Kutschers abgewogen. Maiwald weist zutreffend darauf hin, daß man hier ebenso von einer möglichen Tötung von Personen durch einen Kutschenunfall hätte ausgehen können. Bei einem Blick auf diese Folge wäre eine Zumutbarkeit der Fahrt wohl nicht mehr angenommen worden. Daraus ist zu folgern, daß bei der Abwägung der Interessen die höchstmögliche in dieser Situation in Betracht kommende Gefahr für die Rechtsgüter Dritter berücksichtigt werden muß.

\section{Varianten fahrlässigen Unterlassens der Deliktsverhinderung}

Das fahrlässige Unterlassen kann auf zwei Weisen verwirklicht werden. Fahrlässigkeit kann vorliegen bei der Beurteilung der tatbestandsmäßigen Situation und bei der Durchführung der Erfolgsabwendungshandlung ${ }^{548}$. Die tatbestandsmäßige Situation kann durch die Eltern etwa dadurch verkannt werden, daß sie eine Gefahr für die Rechtsgüter Dritter sorgfaltswidrig gar nicht wahrnehmen, indem sie etwa beim Spazierengehen nicht darauf achten, daß das Kind sich gefährlich nahe dem Bordstein nähert und gleich auf die Straße laufen wird. Bei der Durchführung der Erfolgsabwendung kann eine Fahrlässigkeit durch die Eltern darin liegen, daß sie nicht bemerken, daß ihre Ermahnungen nicht dazu geeignet sind, den Jugendlichen von Straftaten abzuhalten. Oftmals

\footnotetext{
${ }^{545}$ Vgl. Frey, Zumutbarkeit, S. 35: „Zumutbarkeit ist die Begrenzung der objektiven Sorgfaltspflicht und somit der Erfolgsabwendungspflicht.".

${ }^{546}$ RG 30, 25.

${ }^{547}$ Maiwald, Schüler-Springorum-FS, S. 475 (483).

${ }^{548}$ Vgl. Fünfsinn, S. 98; Welzel, S. 222.
} 
dürfte eine Kombination von beiden Ansätzen, sozusagen eine doppelte Sorgfaltswidrigkeit, vorliegen: Die Eltern verhalten sich fahrlässig sowohl hinsichtlich des Erkennens der Tatumstände wie auch hinsichtlich der erforderlichen Rettungshandlung.

Das elterliche fahrlässige Unterlassen der Deliktsverhinderung ist mit verschiedenen Begehungsweisen des Kindes bzw. des Jugendlichen kombinierbar.

a) In den Fällen der vorsätzlichen Nichthinderung einer Fahrlässigkeitstat nimmt der Elternteil es mindestens billigend in Kauf, daß der zu Beaufsichtigende fahrlässig ein Delikt verwirklicht. Wie schon oben dargestellt, kommt dafür beim strafmündigen Aktivtäter eine Strafbarkeit der Eltern wegen Beteiligung an der Vorsatztat in Frage, andernfalls eine mittelbare Täterschaft.

b) Vom vorsätzlichen Nichtabhalten ist das fahrlässige Nichtabhalten des Kindes bzw. Jugendlichen von der Vorsatztat zu unterscheiden. Hierbei ist eine fahrlässige Verwirklichung des vom Kind oder Jugendlichen erfüllten Delikts nur dann möglich, wenn eine fahrlässige Begehung unter Strafe steht. Verhindern Eltern also eine Sachbeschädigung oder einen Diebstahl nur fahrlässig nicht, so können sie nicht bestraft werden. Beim fahrlässigen Nichtabhalten des schuldunfähigen Kindes ist zu berücksichtigen, daß hier beim Garanten eine unmittelbare strafrechtliche Haftung wegen Fahrlässigkeit entsteht.

Bei der fahrlässigen Verwirklichung eines eigenhändigen Delikts durch den Abkömmling ist hingegen eine Strafbarkeit der Garanten nicht möglich. Beispiel: Eltern verhindern fahrlässig nicht die vorsätzliche Trunkenheitsfahrt der Tochter, indem sie den Autoschlüssel nicht fortnehmen. Eine (fahrlässige) Täterschaft am Delikt der Tochter scheidet wegen der Eigenhändigkeit aus. Eine Beihilfe zur Trunkenheitsfahrt der Tochter durch Unterlassen kommt deshalb nicht in Frage, weil die Beihilfe vorsätzlich erfolgen müßte. 
c) Schließlich bleibt die Gruppe des fahrlässig nicht verhinderten Fahrlässigkeitsdelikts. Dafür sind vor allem Fälle mit Bezug zum Straßenverkehr relevant. Man denke an die vielen Unfälle, die durch Kinder mitverursacht werden, etwas dadurch, daß ein Kind, ohne sich umzuschauen, auf die Straße läuft und den Autofahrer zum Ausweichen zwingt. Dies sind Fälle, in denen unter Umständen fahrlässiges Unterlassen (durch fehlende Beaufsichtigung des Kindes) $\mathrm{zu}$ einer fahrlässigen Tat des Kindes führen kann; da das Kind strafunmündig ist, liegt eine unmittelbare fahrlässige Gefährdung durch den Erwachsenen vor; das Kind ähnelt - man verzeihe den Vergleich- einer (un)kontrollierbaren Sache, wie etwa einem Hund.

In diesem Zusammenhang ist der folgende Fall zu nennen. Das OLG Düsseldorf verurteilte einen Familienvater wegen fahrlässiger Körperverletzung, nachdem der -von der Tochter- laufengelassene Familienhund einen Unfall verursacht hatte ${ }^{549}$ : Die 12jährige Tochter ließ das Tier wiederholt frei laufen und verlor oft die Kontrolle über den Hund, ohne daß sie sich anschließend weiter um sein Verbleiben kümmerte. In diesen Fällen lief der Hund selbständig zum Haus der Familie zurück, wobei er eine Straße überqueren mußte. Dem Vater waren diese Vorkommnisse auch bekannt. Schließlich trat die altbekannte Situation ein weiteres Mal ein, und der Hund verursachte auf der Straße einen Unfall mit einer Radfahrerin, die dabei verletzt wurde. Hier hat das OLG Düsseldorf den Vater sowohl als Tierhalter als auch als sorgeberechtigten Elternteil der fahrlässigen Körperverletzung für schuldig befunden ${ }^{550}$.

Bei den fahrlässig nicht verhinderten Fahrlässigkeitsdelikten ist auch an fahrlässige Brandstiftungen durch Kinder zu denken. Die Abgrenzung von vorsätzlicher und fahrlässiger Brandstiftung ist bei Kindern oft nicht möglich, so daß im Zweifel von einer fahrlässigen Begehung ausgegangen werden muß ${ }^{551}$. Tatzeiten sind nach einer Studie von Stutte und Dunzer die Nachmittage bzw. frühe Abendstunden ${ }^{552}$. Auffällig ist,

\footnotetext{
549 OLG Düsseldorf, NJW 1987, 201; ähnlich, aber ohne Beteiligung eines Kindes: "Terrier-Fall“ des OLG Bremen, NJW 1957, 72 ff.

${ }^{550}$ OLG Düsseldorf, NJW 1987, 201.

${ }^{551}$ Stutte/ Dauner, MschrKrim 61 (1978), 328 (329).

552 Stutte/ Dauner, MschrKrim 61 (1978), 328 (331).
} 
daß es sich durchgehend um unterrichtsfreie Zeiten handelt, also Zeiten, in denen eine ausreichende Überwachung der Kinder weder durch Unterricht noch durch die Eltern gegeben war.

4. Täterschaft und Teilnahme beim fahrlässigen Unterlassungsdelikt ${ }^{553}$

a) Täterschaft

Bei fahrlässigen Unterlassungsdelikten wird die Täterschaft nicht anders bestimmt als bei den sonstigen Fahrlässigkeitsdelikten. Wie bei den Begehungsdelikten müssen allerdings noch die besonderen Täterschaftsmerkmale des Unterlassungstäters, wie sie in $\S 13$ StGB aufgeführt sind, hinzutreten ${ }^{554}$. Täter ist damit grundsätzlich jeder, der in vermeidbarer Weise unvorsätzlich eine Gefahr geschaffen hat, die sich in einer normwidrigen und tatbestandlichen Rechtsgutbeeinträchtigung verwirklicht hat. Vom Täter des Vorsatzdelikts unterscheidet sich der Täter des Fahrlässigkeitsdelikts allein dadurch, daß er das Geschehen nicht bewußt auf einen Erfolg hinsteuert, dennoch aber als Subjekt des tatbestandlich erfaßten sozialen Sinngehaltes erscheint. Er ist derjenige, der die Rechtsgutsverletzung unmittelbar zu verantworten hat, weil er in der Lage ist, den Erfolg zu vermeiden ${ }^{555}$.

Nach h. L. wird somit eine Differenzierung zwischen Täterschaft und Teilnahme abgelehnt und von einem Einheitstäter ausgegangen. Jede vermeidbare Mitverursachung ist Täterschaft ${ }^{556}$. Dies gilt zumindest unbestritten für die Verursachungsdelikte wie die fahrlässige Tötung, Körperverletzung oder Brandstiftung. Bei den Sonderdelikten und den eigenhändigen Delikten gilt dies naturgemäß nicht: Aus dem gleichen Grund, aus dem der Außenstehende nicht vorsätzlicher Täter sein kann, weil ihm die Sonderpflicht fehlt, kann er nicht Täter des entsprechenden Fahrlässigkeitsdelikts sein. Strafbarkeitserweiternde Vorschriften, die

\footnotetext{
${ }^{553} \mathrm{Zu}$ Täterschaft und Teilnahme der Eltern bei der unterlassenen

Deliktsverhinderung siehe 4. Teil.

${ }^{554}$ Maurach/ Zipf, AT 2, § 47, Rn. 115

${ }^{555}$ Vgl. Otto, JuS 1974, 702 (705).

${ }^{556}$ Otto, JuS 1974, 702 (704); vgl. derselbe Jura 1990, 47 (48); Wehrle, S. 14.
} 
auch Sonderdelikte erfassen, sieht das Gesetz nur für vorsätzliches Verhalten vor, vgl. $§ 160 \mathrm{StGB}^{557}$.

Die h. M. lehnt die Möglichkeit einer fahrlässigen Mittäterschaft ab, da es an einem gemeinsamen Tatentschluß und an der finalen Steuerung des Geschehens auf den Erfolg hin (Tatherrschaft) fehle. Otto hält eine fahrlässige Mittäterschaft zumindest dann für möglich, wenn die Täter aufgrund eines gemeinschaftlichen Planes pflichtwidrig eine Gefahr nicht beseitigen und sich diese Gefahr realisiert (Beispiel: Bauarbeiter sperren trotz einer bevorstehenden Sprengung die Straße nicht, sondern beschließen, lieber in der Baubude zu bleiben und Karten zu spielen; durch die Sprengung kommt auf der Straße jemand zu Schaden) ${ }^{558}$. Eine besondere Rechtsfolge ist aber mit der Annahme einer Mittäterschaft durch fahrlässiges Verhalten nicht verbunden.

b) Ausschluß der Täterschaft durch einen vorsätzlich Handelnden/ Regreßverbot

Beim Zusammenwirken von Eltern und deren Abkömmlingen an derselben Tat kommt grundsätzlich eine Verdrängung der fahrlässig die Deliktsverhinderung unterlassenden Eltern durch den vorsätzlich handelnden Jugendlichen in Frage.

Wer sorgfaltswidrig und vermeidbar als Garant für die Abwehr von Gefahren für die tatbestandlich geschützten Rechtsgüter Dritter seine Pflicht verletzt, haftet als Täter eines Fahrlässigkeitsdelikts, es sei denn, eine andere Person, die sich des Risikos in vollem Umfang bewußt ist, schließt ihn von der Herrschaft über das Geschehen aus. Das kann dadurch geschehen, daß diese Person nunmehr den Kausalverlauf gemäß ihren Plänen lenkt oder aber dadurch, daß sie dem ursprünglich Verpflichteten gegen dessen Willen die Möglichkeit nimmt, das Geschehen zu beeinflussen. Insoweit setzt die Eigenverantwortung des Handelnden der strafrechtlichen Haftung anderer eine Grenze ${ }^{559}$. Die Haftung für die mittelbare Erfolgsverursachung muß aus Gründen des

\footnotetext{
${ }^{557}$ Wehrle, S. $14 \mathrm{f}$.

${ }^{558}$ Otto, Jura 1990, 47 (49).

${ }^{559}$ Otto, JuS 1974, 702 (706).
} 
erlaubten Risikos und der Eigenverantwortlichkeit der Beteiligten die Ausnahme bleiben ${ }^{560}$.

Doch auch die vorsätzliche Steuerung des Geschehens durch einen Dritten entlastet den ursprünglich Verantwortlichen nicht, wenn dieser z. B. verpflichtet ist, bestimmte Gefahren abzuwenden, unabhängig davon, ob Dritte sie vorsätzlich oder fahrlässig begründen, oder Rechtsgüterverletzungen durch Personen $\mathrm{zu}$ verhindern, deren Beaufsichtigung ihm anvertraut ist ${ }^{561}$.

Zwar soll es einer auf Hegel zurückgehenden Lehre von der objektiven Zurechnung nach bei der fahrlässigen Beteiligung am Vorsatzdelikt an der Beherrschbarkeit durch den Unterlassenden fehlen. Seine Handlung reiche nur so weit wie die Willensherrschaft. Sie ende, wo ein anderer vorsätzlicher Täter die Tat in die Hand nehme (sogenanntes Regreßverbot $)^{562}$. Diese Konstruktion wird allerdings durch die vorsätzliche mittelbare Täterschaft widerlegt, denn sie ermöglicht Fälle, in denen die Tat als Willenswerk zugleich des Vordermanns und des Hintermanns angesehen wird. Ein Regreßverbot ist nicht aufrechtzuerhalten, wo Aufsichtspflichten gegenüber schuldunfähigen und eingeschränkt schuldfähigen Personen bestehen; hierin liegt kein Widerspruch zum Grundsatz der Eigenverantwortlichkeit ${ }^{563}$.

Gegen die Haftbarkeit desjenigen, der als Garant seinen Aufsichtspflichten gegenüber seinem Kind nicht nachkommt und es diesem dadurch ermöglicht, fahrlässig einen Erfolg herbeizuführen, ist folglich nichts einzuwenden. Für den Umfang der Sorgfaltspflichten der gegenüber (un)eingeschränkt eigenverantwortlichen Personen Aufsichtspflichtigen ist der Grundsatz der Eigenverantwortlichkeit aber allemal bedeutsam ${ }^{564}$.

\footnotetext{
${ }^{560}$ Wehrle, S. 63.

${ }^{561}$ Otto, JuS 1974, 702 (706).

${ }^{562}$ Wehrle, S. 43.

${ }^{563}$ Wehrle, S. $105 \mathrm{f}$.

${ }^{564}$ Wehrle, S. $105 \mathrm{f}$.
} 
5. Fahrlässiges Beseitigen der Verhinderungsmöglichkeit

Setzen sich Eltern selbst fahrlässig außerstande, die von ihrem Abkömmling ausgehende Gefahr $\mathrm{zu}$ verhindern, indem sie sich etwa nicht über sein Freizeitverhalten und seinen Aufenthaltsort informieren und dadurch nicht einmal eine theoretische Zugriffsmöglichkeit haben, ist das fahrlässige Unterlassen unmittelbar anwendbar. Eines Rückgriffs auf die omissio libera in causa bedarf es nicht: Bei den Fahrlässigkeitsdelikten genügt grundsätzlich jede Sorgfaltswidrigkeit des Täters, die die Verletzung (quasi-)kausal herbeiführt und mit der Verletzung einen Pflichtwidrigkeitszusammenhang aufweist ${ }^{565}$. Man vermeidet dadurch die mit der omissio libera in causa generell verbundenen Bedenken und insbesondere das Problem, daß das tatbestandliche Geschehen nicht beliebig weit vorverlagert werden kann, ohne daß der erforderliche Zusammenhang zwischen der Nichtvornahme einer gebotenen Handlung mit dem Schadenseintritt entfiele ${ }^{566}$.

Die Fahrlässigkeitshaftung der Eltern greift damit besonders in den Fällen, in denen eine konkrete Erfolgsabwendung deshalb nicht mehr möglich war, weil die Eltern im Vorfeld die nötigen Aufsichtsmaßnahmen versäumt haben.

\section{Die Gleichstellungsproblematik}

Die Strafbarkeit durch Unterlassen setzt gemäß der Entsprechensklausel des $\S 13$ voraus, daß eine Gleichwertigkeit des Unterlassens mit dem Begehen vorliegt. Nicht jeder Straftatbestand, der durch aktives Tun verwirklicht werden kann, kann auch durch reines Nichtstun erfüllt werden.

\footnotetext{
${ }^{565}$ Vgl. Fünfsinn, S. 203.

${ }^{566}$ Vgl. Fünfsinn, S. 205. Dieses Problem stellt sich letztlich aber auch bei der unmittelbaren Annahme eines fahrlässigen Unterlassens.
} 
I. Untersuchung von Deliktsgruppen danach, ob sie für das elterliche Unterlassen in Betracht kommen

Das Gleichstellungsproblem des $\S 13$ StGB zeigt sich in der Umsetzung auf die einzelnen Vorschriften des Besonderen Teiles des Strafgesetzbuches ${ }^{567}$. Bestimmte Straftatbestände des Besonderen Teils scheiden als Delikte, die Eltern durch eine unterlassene Deliktsverhinderung begehen können, aus, weil sie insgesamt durch Unterlassen nicht begehbar sind ${ }^{568}$. Es kann also nur eine begrenzte Auswahl der Straftatbestände geben, die für das elterliche Unterlassen in Frage kommen.

Eine gesetzliche Regelung dafür, welches Delikt durch Unterlassen begangen werden kann und welches nicht, gibt es nicht. Es bleibt somit der Rechtsprechung und der Lehre überlassen, die Entsprechung von Unterlassen und tatbestandsmäßiger Begehung zu präzisieren. Dabei ist bei jeden Tatbestand gesondert $\mathrm{zu}$ betrachten, ob die in den Handlungsmodalitäten liegenden Unrechtsmerkmale auch dem Unterlassungstäter zugänglich sind. Zweifellos wird dadurch die dem unechten Unterlassungsdelikt ohnehin anhaftende Unsicherheit vermehrt $^{569}$.

\section{Erfolgsdelikte}

Hinsichtlich der Erfolgsdelikte (schlichten Verursachungsdelikte ${ }^{570}$ ) ergeben sich keine Schwierigkeiten. Bei ihnen gibt es jeweils einen Taterfolg, der nach einhelliger Ansicht sowohl durch aktives Tun als auch durch Unterlassen herbeigeführt werden kann. Die Handlungsweise knüpft an keine besonderen Modalitäten an. Als Beispiele seien hier $\S 212$ („Töten), § 223 („Körperlich Mißhandeln) und § 303 StGB (,Beschädigen“) angeführt ${ }^{571}$. Bei ihnen ist anerkannt, daß sie ohne weiteres einem Unterlassen zugänglich sind. Nach überwiegender

\footnotetext{
${ }^{567}$ Busse, S. 45; Jescheck/ Goldmann, ZStW 77, 109 (138).

${ }^{568}$ Busse, S. 24.

${ }^{569}$ Stratenwerth, AT, Rn. 1036.

${ }^{570}$ Seier, JA 1990, 382 (385).

${ }^{571}$ vgl. Engelsing, S. 43.
} 
Ansicht soll hier die Entsprechungsklausel sogar ganz ohne Bedeutung $\operatorname{sein}^{572}$. Die Erfolgsdelikte dürften $\mathrm{zu}$ den klassischen Tatbeständen zählen, die durch unterlassenen Deliktshinderung verwirklicht werden.

2. Erfolgsdelikte mit spezialisierter Begehungsweise

Für die Tatbestände des Besonderen Teils, die eine spezialisierte Begehungsweise erfordern, gilt, soweit diese nur erfolgsbezogene Bedeutung hat, nichts anderes. Eine Begehung durch Unterlassen ist nach Seier auch für $\S 224$ StGB möglich. Sowohl bei der Verwendung von Gift als Mittel zur Körperverletzung als auch beim Verwenden eines gefährlichen Werkzeugs zur Körperverletzung schlage sich kein besonderer Aktunwert nieder. Diese Qualifikationen sollen vielmehr der erhöhten Gefährlichkeit des Angriffs auf die körperliche Integrität Rechnung tragen und können somit als erfolgsbezogen eingestuft werden $^{573}$.

Nach Nitze kommt es hingegen beim gefährlichen Werkzeug auf die vom Täter gewollte Verwendungsweise an. Drohe jemand auf einem Sportplatz von einem Speer getroffen zu werden und unterlasse der Täter die mögliche Warnung, könne die Verwendungsweise des Speers dem Täter nicht zugerechnet werden. Die gesteigerte Gefährlichkeit sei nicht maßgebend; der Gesetzlichkeitsgrundsatz verbietet eine solche Auslegung für das Unterlassen ${ }^{574}$. Zum gleichen Ergebnis kommt Nitze auch hinsichtlich der 3. Alt. "mittels einer das Leben gefährdende Behandlung” 575. Außerdem schieden die Begehungsweisen „mittels eines hinterlistigen Überfalls“ und „von mehreren gemeinschaftlich“ aus, weil hier kein über die Körperverletzung hinausgehender, vom Täterhandeln unabhängiger Erfolg vorausgesetzt werde. Unterlassen mehrere Garanten gleichzeitig die erforderliche Handlung, ergibt sich aus

\footnotetext{
572 Baumann/ Weber AT, S. 252; Tröndle/ Fischer, § 13, Rn. 17; Roxin, JuS 1973, 197 (199); S/S-Stree, § 13, Rn. 4; a.A. Seier, JA 1990, 382 (385).

${ }^{573}$ Seier, JA 1990, 382 (385).

${ }^{574}$ Nitze, S. $166 f$.

${ }^{575}$ Nitze, S. 167.
} 
der Mehrzahl keine Gefahrsteigerung, da jeder Unterlassende isoliert von dem anderen als Nebentäter zu sehen ist ${ }^{576}$.

Hinsichtlich der schweren Körperverletzung des § 226 StGB besteht hingegen Einigkeit darin, daß die Körperverletzung durch den besonderen Erfolgswert qualifiziert wird. Die erhöhte Strafwürdigkeit entspringt nicht, wie zuvor von Nitze hinsichtlich der gefährlichen Körperverletzung befürchtet, einer Vorsatzvermutung, sondern ist allein aus der Schwere des Erfolges abzuleiten ${ }^{577}$. Auf die hier relevante Fallgruppe bezogen hieße dies, der Vater sieht beispielsweise $\mathrm{zu}$, wie sein Sohn einem anderen eine Flüssigkeit einflößt, die zur Erblindung führt $^{578}$.

$\mathrm{Ob}$ der Mord unter die Erfolgsdelikte mit spezialisierter Begehungsweise fällt oder vielmehr den verhaltensgebundenen Delikten unterfällt, ist unklar. Das Erfüllen der Mordmerkmale ist, unabhängig von der Einordnung, durch Unterlassen möglich ${ }^{579}$. Nitze differenziert hier nach der Art der Mordmerkmale: Die grausame Begehung soll durch Unterlassen möglich sein, weil hier der Erfolg sowohl im Tod des Opfers als auch in den Qualen des Opfers bestehe ${ }^{580}$. Auch die Schuldmerkmale der „Habgier“ und der „,niederen Beweggründe“ könnten sich im Unterlassen wiederspiege ${ }^{581}$. Dem entgegen stellt nach Auffassung Nitzes die „heimtückische Begehungsweise“ und die Begehung mit „gemeingefährlichen Mitteln“ nicht auf den Erfolg des Todeseintritts beim Opfer ab, so daß eine Begehung durch Unterlassen ausscheidet ${ }^{582}$.

\section{Verhaltensgebundene Delikte}

Anders liegt es bei den sogenannten verhaltensgebundenen Delikten, z.B. $\S \S 242,185,263 \mathrm{StGB}^{583}$. Bei ihnen weist das speziell gefaßte

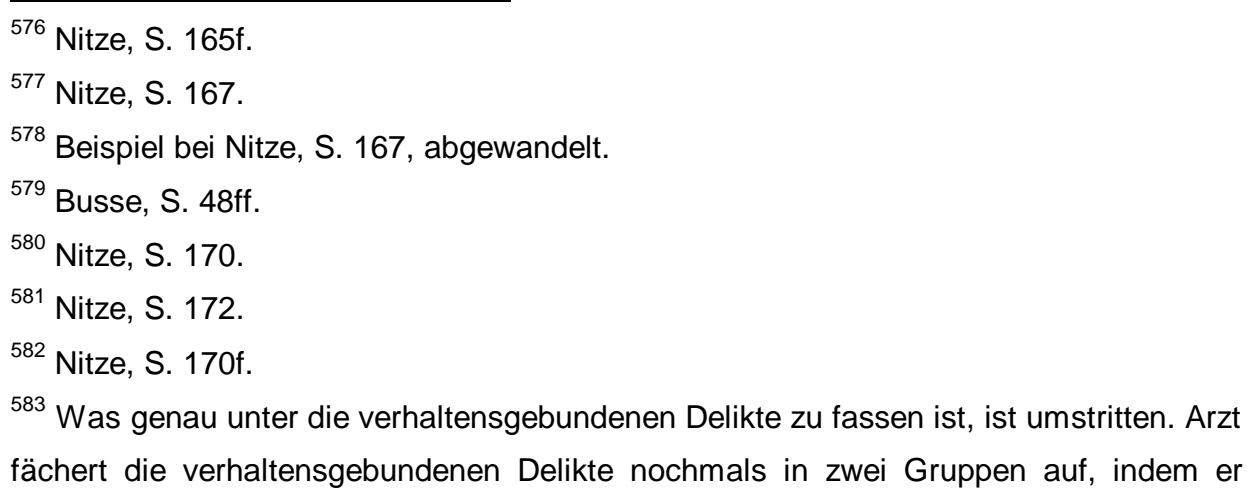


Handlungsmerkmal einen besonderen sozialen Sinngehalt auf, der durch Passivität nicht ohne weiteres erfüllt werden kann. Ob das Nichteingreifen in einem Geschehensablauf etwa als „Täuschen“ oder „Beleidigen“ beurteilt werden kann, läßt sich nämlich nicht in abstracto aus der Garantenstellung herleiten, sondern ist vielmehr eine Frage der Auslegung des jeweiligen Tatbestandes ${ }^{584}$. In manchen Fällen reicht die Verhaltensgebundenheit so weit, daß allenfalls eine Beihilfe durch Unterlassen in Betracht kommt ${ }^{585}$. Die Abgrenzung $\mathrm{zu}$ den verhaltensgebundenen, den eigenhändigen und den Zueignungsdelikten ist weitgehend unklar.

\section{Sonderdelikte}

Im Rahmen der Sonderdelikte kann nur Täter sein, wem eine - meist außerstrafrechtliche - Sonderpflicht obliegt, beispielsweise als Arzt gem. $\S 203$ StGB, als Amtsträger gem. $\S \S 331 \mathrm{ff}$. StGB oder als Betreuer von Vermögensinteressen i.S.d. $\S 266 \mathrm{StGB}^{586}$. Da die Begehung eines Sonderdelikts durch einen Minderjährigen fast ausgeschlossen ist, erübrigt sich ein weiteres Eingehen auf eine mögliche Strafbarkeit wegen Teilnahme durch die unterlassenden Eltern.

\section{Eigenhändige Delikte}

Bei den eigenhändigen Delikten setzt der Tatbestand einen körperlich oder doch wenigstens persönlich zu vollziehenden Akt voraus, den der

Erfolgsdelikte mit handlungsspezifischen Unwertelementen und Delikte mit erfolgsdeliktischen Bausteinen unterscheidet, Arzt, JA 1980, 712 (716f.). Unter die erste Gruppe soll $\S 211$ fallen. Unter die zweite wird unter anderem $\S 263$ gefaßt. $§ 263$ läßt sich gegenüber dem reinen Erfolgsdelikt des $\S 303$ dadurch abgrenzen, daß $\S 263$ nur die Schädigung durch Täuschung kriminalisiert, während die Schädigung nach § 303 auf jede beliebige Weise erfolgen kann. Arzt legt aber nur wenige Anhaltspunkte für dieses Erfordernis dar, zumal er einzig mit $\S 211$ argumentiert. Dies überzeugt nicht. Weitere Differenzierungen der verhaltensgebundenen Delikte sind müßig, da vom Gesetzgeber nicht berücksichtigt. Die Schaffung von nochmaligen Untergruppen führt auch nicht zu einer besseren Handhabbarkeit der Tatbestände im Rahmen der Unterlassung.

${ }^{584}$ Roxin, JuS 73, 197 (199).

585 Seier, JA 1990, 382 (385).

${ }^{586}$ S/S-Cramer, Vor 25, Rn. 84. 
Täter selbst vornehmen muß, weil sonst das besondere Handlungsunrecht der betreffenden Deliktsart fehlen würde ${ }^{587}$. Bei den eigenhändigen Delikten fehlt es regelmäßig an der Rechtsgutsverletzung, statt dessen wird ein bestimmtes sozialwidriges Verhalten unter Strafe gestellt. Ein Unterlassen knüpft aber stets an einer Rechtsgutsverletzung an, denn diese ermöglicht die Gleichstellung der für diesen Erfolg Verantwortlichen ${ }^{588}$.

Bei den eigenhändigen Delikten können nur die selbst körperlich oder persönlich handelnden Personen Täter, Mittäter oder mittelbare Täter sein. Die Teilnahme ist dagegen unbeschränkt möglich ${ }^{589}$. Das bedeutet für den vorliegenden Kontext, daß Erziehungsverpflichtete, die ihre Schutzbefohlenen nicht von eigenhändigen Delikten abhalten, nur wegen Beihilfe durch Unterlassen bestraft werden können. Wenn z.B. der Vater nichts dagegen unternimmt, daß der Sohn die Tochter sexuell (blutschänderisch) mißbraucht, kann der Vater nur Teilnehmer, nie Täter dieses Delikts sein ${ }^{590}$.

Welche Delikte im einzelnen als eigenhändige verstanden werden, ist stark umstritten und kann an dieser Stelle nicht diskutiert werden ${ }^{591}$. Eigenhändige Delikte sind aber zunächst diejenigen Tatbestände, die die eigene körperliche Beteiligung des Täters an der Tat verlangen, z.B. der Vollrausch (§ 323a), das unerlaubte Sich-Entfernen vom Unfallort ( 142), die Trunkenheit am Steuer ( $§ 316, \S 315$ c Abs. 1 Nr. 1a) oder der Beischlaf von Verwandten ( $\S 173$ ). Weiter werden allgemein dazu gezählt die Tatbestände, die zwar nicht körperliches, aber doch personales Handeln verlangen, etwa die Beleidigung $(\S 185)^{592}$, sowie die Aussagedelikte, bei denen das Prozeßrecht das Handeln in eigener Person

\footnotetext{
587 Jescheck/ Weigend, § 26, II 6, S. 266; vgl. Haft, JA 1979, 651 (652); LK-Roxin, § 25, Rn. 40 .

${ }^{588}$ Engelsing, S. 47 ; Roxin, Täterschaft, S. 479.

589 Jescheck/ Weigend, § 26, II 6, S. 267; Maurach/ Zipf, AT 2, § 47, Rn. 116.

${ }^{590}$ Busse, S. $54 f$.

${ }^{591}$ Haft, JA 1979, 651ff.; Roxin, Täterschaft, S. 481ff., LK-Roxin, § 25, Rn. $40 \mathrm{ff}$.

592 Auch Roxin zählt die Beleidigung zu einer, nicht durch Unterlassen täterschaftlich begehbaren Deliktsgruppe Roxin, Täterschaft, S. 481. Es ist allerdings anzuzweifeln, wieso der Beleidigung ein besonderes personales Handeln zugrunde liegen soll. Es ist nicht einsehbar, weshalb nicht eine Beleidigung durch Unterlassen dadurch verübt werden kann, daß eine Mutter ihr Kind, das die Nachbarin mit üblen Schimpfworten versieht, weiterreden läßt, anstatt es zurechtzuweisen.
} 
vorschreibt $(\S \S 153,154,156){ }^{593} . \mathrm{Zu} \S 154$ hat das Kammergericht im Jahre 1969 eine Entscheidung gefällt. Ein Vater hatte seinen Sohn in dem gegen den Vater gerichteten Prozeß wegen einer Übertretung nach der StVO nicht von einer unwahren Aussage als Zeuge abgehalten. Das Gericht hat den Vater gem. § 154 StGB wegen Beihilfe durch Unterlassen verurteilt ${ }^{594}$.

$\mathrm{Da}$ die (mittelbare) Täterschaft bei den eigenhändigen Delikten unmöglich ist, muß in den Fällen, in denen der Schutzbefohlene strafunmündig ist, eine Bestrafung des Erziehungsverpflichteten wegen Täterschaft entfallen, so daß nur Beihilfe in Frage käme. Eine unerträgliche Strafbarkeitslücke tut sich dadurch allerdings nicht auf: Ist von den als eigenhändige Delikte diskutierten Tatbeständen ohnehin kaum einer dabei, dessen Durchführung durch einen strafunmündiges Kind denkbar wäre (Fahnenflucht, Amtsanmaßung, Meineid); allenfalls könnte man an eine Trunkenheitsfahrt des Kindes oder -fragwürdig- eine Beleidigung denken. Ein Fahren ohne Fahrerlaubnis des Kindes etwa wäre für die Eltern durch $\S 21$ I Nr. 2 StVG über das „Gewährenlassen“ strafbar.

\section{Zueignungsdelikte}

Problematisch ist die Frage, inwieweit Zueignungsdelikte durch Unterlassen begangen werden können. Für eine täterschaftliche Begehung der meisten Zueignungsdelikte müßte es dem Garanten zunächst möglich sein, durch Unterlassen eine Wegnahme herbeizuführen (vgl. $\S \S 242,249$ StGB). Fraglich ist, ob das Tatbestandsmerkmal des "Wegnehmens" durch Unterlassen erfüllt werden kann. Dies wird von Stratenwerth bestritten ${ }^{595}$. Roxin räumt hingegen ein, daß man die bloße Entziehung der Sache, also den Gewahrsamsbruch, dem pflichtwidrig untätigen Garanten ebenso

\footnotetext{
${ }^{593}$ Jescheck/ Weigend, § 26, II 6, S. 267.

${ }^{594}$ KG JR 1969, 27 (27): Denkwürdig an der Entscheidung ist allerdings der Umstand, daß der Sohn bereits über 21 Jahre alt war, so daß eine Garantenpflicht des Vater eigentlich ausschied. Sie wurde sehr zweifelhaft mit dem engen Verwandtschaftsverhältnis begründet; Stratenwerth, AT, Rn. 1036.

${ }^{595}$ Stratenwerth, AT, Rn. 1036.
} 
zurechnen könne wie einem Begehungstäter ${ }^{596}$. Für diese Ansicht spricht, daß der Gewahrsamsbruch und die neue Gewahrsamsbegründung als Erfolg der Wegnahme zu betrachten sind; dieser Erfolg kann auch durch Unterlassen erreicht werden. Daher ist festzustellen, daß die Wegnahme durch täterschaftliches Unterlassen verwirklicht werden kann.

Abgelehnt wurde bislang die Unterlassungstäterschaft beim Zueignungsdelikt jedenfalls dann, wenn eine Zueignungsabsicht erforderlich war; diese fehlte regelmäßig beim Unterlassenden. Bislang setzten die $\S \S 242$ ff. StGB (mit Ausnahme von $\S 246$ ) voraus, daß dem Täter darauf ankam, sich die Sache selbst zuzueignen. Der Täter mußte dazu den zielgerichteten Willen haben, sich die Sache selbst anzueignen, d.h. Eigenbesitz zu begründen und wie ein Eigentümer über die Sache zu verfügen. Gerade bei der unterlassenen Deliktsverhinderung durch die Eltern liegt jedoch die Absicht, sich die fremde Sache selbst anzueignen, fast nie vor. Es besteht allenfalls ein bedingter Vorsatz in Bezug auf die Aneignung durch den zu überwachenden Aktivtäter. Dies genügte bisher für die elterliche Zueignungsabsicht und damit für das täterschaftliche Unterlassen nicht ${ }^{597}$.

Die Aufnahme der Drittzueignung in die Zueignungstatbestände durch das 6. StRÄG hat diese Lage zum Teil geändert. Da nun auch für die Absicht der Eltern der zielgerichtete Wille genügt, daß sich ein Dritter die Sache zueignen möge, ist zumindest in diesen Fällen eine täterschaftliche Begehung der Zueignungsdelikte durch Unterlassen möglich. Das täterschaftliche Unterlassen dürfte allerdings nicht allzu häufig sein und vor allem im Rahmen der Beweisbarkeit der Absicht der Eltern auf Probleme stoßen.

\section{Beispiele für elterliches Unterlassen ${ }^{598}$}

Ein Katalog von Beispielen soll die verschiedenen Konstellationen verdeutlichen, die sich beim unechten Unterlassen ergeben können.

\footnotetext{
${ }^{596}$ Roxin, Täterschaft, S. $481 \mathrm{f}$.

${ }^{597}$ Freund, Erfolgsdelikt, S. 25 ; Roxin, Täterschaft, S. 481.

${ }^{598}$ Zur Bestimmung der Beteiligungsform der Eltern siehe 4. Teil.
} 


\section{Vorsätzliches Unterlassen}

a) Der Vater des Schülers $S$ unternimmt nichts, als er sieht, wie $S$ die Bremsleitungen am Auto seines Lehrers L durchschneidet. L stirbt in einem Verkehrsunfall, weil die Bremsen seines Autos versagen ${ }^{599}$.

Hier wäre der Vater als Täter durch Unterlassen nach §§ 212, 13 StGB, mindestens aber als Teilnehmer am fremden Tötungsdelikt (vgl. den 4. Teil dieser Arbeit) einzustufen.

b) Der 15jährige $S$ fordert seinen naiven Spielkameraden $\mathrm{K}$ auf, den am Auto des Lehrers herunterhängenden Bremsschlauch abzuschneiden. K, der von Autos keine Ahnung hat, tut dies in der Annahme, eine gute Tat zu vollbringen, weil der Schlauch ,im Wege ist“.

Variante 1: Der Vater V1 des S schaut untätig $\mathrm{zu}^{600}$.

$\mathrm{S}$ ist mittelbarer Täter, V1 ist Täter durch Unterlassen (Nichthinderung des S).

Variante 2: Der Vater V2 des K schaut untätig zu.

$\mathrm{K}$ ist unmittelbarer, aber vorsatzloser Täter. $\mathrm{S}$ ist mittelbarer Täter. V2 ist Täter durch Unterlassen (Nichthinderung des K).

c) Vater V greift nicht ein, als seine minderjährige Tochter $\mathrm{T}$ Bücher von ihrer geschäftsunfähigen Freundin $\mathrm{F}$ an ein anderes Mädchen $\mathrm{M}$ weiterverschenkt. A weiß, daß T sich irrtümlich für die Eigentümerin der Bücher hält und daß die Eltern der F mit der Schenkung durch F nicht einverstanden sind ${ }^{601}$.

Tochter $\mathrm{T}$ hat $\S 246$ mangels Vorsatzes nicht erfüllt. Sind die Unrechtsmerkmale dem V im Sinne einer mittelbaren Täterschaft zuzurechnen ? Es fehlt zwar an einer Zueignung der Bücher durch V selbst, seit dem 6. StRÄG genügt für § 246 aber die Zueignung an einen Dritten, hier also an M. Es besteht daher eine Strafbarkeit des V gemäß $\S \S 246,13 \mathrm{StGB}$.

\footnotetext{
${ }^{599}$ vgl. Busse, S. 325.

${ }^{600} \mathrm{vgl}$. Busse, S. 328.
} 
d)

Vater V sieht seinem 12jährigen Sohn und dessen Freund $\mathrm{F}$ beim Briefmarkentauschen zu und bemerkt, daß sein Sohn den anderen Jungen gehörig übers Ohr haut. V läßt den Betrug vorsätzlich und mit Bereicherungsabsicht zu.

Da $\mathrm{V}$ als Überwachergarant die Straftat seines Sohnes zu unterbinden hat, geht die von seinem Sprößling vorgenommene Täuschungshandlung aus seinem Verantwortungsbereich hervor und ist ihm als eigene zuzurechnen $^{602}$. Auf die Erregung des Irrtums bei $\mathrm{F}$ hatte $\mathrm{V}$ ebenfalls Einfluß: Zur Verhinderung des Irrtums bei $\mathrm{F}$ hätte es nämlich genügt, wenn $\mathrm{V}$ dem $\mathrm{F}$ den wahren Wert der Briefmarken erklärt hätte. Schließlich hat V sogar den Austausch der Briefmarken zugelassen und dadurch die schädigende Vermögensverfügung des F erreicht. Da V auch mit Bereicherungsabsicht gehandelt hat, steht einer Bestrafung wegen $\S \S 263,13$ StGB nichts entgegen.

\section{Fahrlässiges Unterlassen}

a) Vater V sieht am Nachmittag wie schon oft zuvor seinen 8jährigen Sohn beim Spielen mit Streichhölzern vor der Scheune des Nachbarn. Obwohl er bemerkt hat, daß die Scheune vormittags frisch mit Heu gefüllt wurde und obwohl das Scheunentor offensteht, läßt er seinen Sohn gewähren, weil er ihn für umsichtig genug hält, nicht zu dicht an das Heu heranzugehen. Noch am gleichen Nachmittag zündet das Kind im Eingangsbereich der Scheune einen Haufen Heu an, was zum Abbrennen der gesamten Scheune führt ${ }^{603}$.

\footnotetext{
${ }^{601}$ vgl. Busse, S. 348.

${ }^{602}$ Seier, JA 1990, 382 (385).

${ }^{603}$ Einen ähnlichen Fall aus der französischen Ziviljustiz beschreibt Aden, Haftung der Eltern, S. 136: Ein geistesgestörter Minderjähriger wurde abends von seinen Eltern, Landwirten, in den Stall geschickt, um etwas zu holen. Um sich Licht zu machen, entzündete er ein Streichholz und warf es achtlos weg. Daraus entstand größerer Brand, der auf Nachbargehöfte überschlug. Der Vater haftete aufgrund mangelnder Aufsicht, weil er den Geisteszustand seines Sohnes gekannt und zudem gewußt hatte, daß dieser vor einiger Zeit versucht hatte, die Scheune des Nachbarn anzuzünden.
} 
$\mathrm{V}$ ist wegen fahrlässiger Brandstiftung gem. $\S 306 \mathrm{~d}$ StGB durch Unterlassen strafbar, denn er hat es fahrlässig unterlassen, seinen Sohn an der Tat zu hindern. Der Taterfolg war für ihn aufgrund der unmittelbaren Nähe des zündelnden Kindes zum brennbaren Material vorhersehbar und vermeidbar. Er durfte auch nicht damit rechnen, daß ein 8jähriger sich der Gefahren durch Feuer schon bewußt war.

Wären bei dem Brand auch Menschen zu Schaden gekommen, käme auch eine fahrlässige Körperverletzung oder Tötung durch Unterlassen in Betracht $^{604}$.

b) Die Mutter läßt beim Spazierengehen ihr 6jähriges Kind dicht am Straßenrand herumlaufen. Das Kind läuft auf die Straße, der herannahende Autofahrer weicht aus, fährt gegen einen Pfosten und verletzt sich schwer ${ }^{605}$.

$M$ ist wegen $\S 229$ StGB durch Unterlassen strafbar, weil sie als Überwachergarantin verhindern mußte, daß das Kind den Straßenverkehr gefährdete; ein Unfall war für die M vorhersehbar und auch vermeidbar.

E. Die Zumutbarkeit der gebotenen und möglichen Handlung

I. Die Zumutbarkeit als tatbestandsausschließendes Kriterium

Schließlich muß den Eltern die vorzunehmende Handlung auch zumutbar sein. Weitgehend besteht in Rechtsprechung und Schrifttum darin Einigkeit, daß die Strafbarkeit der Begehung von unechten Unterlassungsdelikten unter dem Vorbehalt der Zumutbarkeit der unterlassenen Handlung steht ${ }^{606}$.

Umstritten ist allerdings, ob es sich bei der Unzumutbarkeit um einen Teil des Tatbestandes oder um einen allgemeinen

\footnotetext{
${ }^{604}$ Vgl. Freund, Erfolgsdelikt, S. 251.

605 ähnlich BGH NJW 1957, 869= VersR 57, 340 (340); BGH VersR 61, 838 für das wiederholte Fußballspielen auf der Straße; vgl. auch das Beispiel bei Freund, Erfolgsdelikt, S. 251: Eltern lassen es sehenden Auges zu, daß ihr 8jähriges Kind bei Dunkelheit mit einem unbeleuchteten Fahrrad auf der Straße fährt.

${ }^{606}$ BGH NStZ 84, 164 m. w. N.; a. A. LK-Jescheck, Vor § 13, Rn 91.
} 
Schuldausschließungsgrund handelt; die Rechtsprechung vertritt keine klare Linie ${ }^{607}$.

Richtigerweise ist davon auszugehen, daß die Zumutbarkeit Bestandteil des Tatbestandes ist, weil sie festlegt, welche Handlung vom Täter gefordert werden $\mathrm{kann}^{608}$. Die Zumutbarkeit des Handelns begrenzt neben der Erforderlichkeit die Pflicht, zum Schutz gefährdeter Rechtsgüter tätig zu werden. Mittels des Zumutbarkeitskriteriums werden besondere Anforderungen an die jeweiligen Tatbestandsmerkmale gestellt $^{609}$.

Unzumutbares Handeln ist rechtlich ebenso wenig geboten wie sinnloses Handeln. Die in § 323c StGB ausdrücklich erfolgte Gleichbehandlung des Zumutbaren mit dem Erforderlichen gilt auch für die unechten Unterlassungsdelikte. Derjenige, dem ein Tun unzumutbar ist, ist genausowenig zum Tun verpflichtet wie der, dem es nicht möglich ist ${ }^{610}$. Bei der Unzumutbarkeit des Handelns ist demgemäß das Unterlassen bereits nicht tatbestandsmäßig.

$\mathrm{Da}$ die Erfolgsabwendungspflicht nicht stets hinreichend bestimmt ist, sondern vielmehr im Einzelfall mittels der Zumutbarkeit konkretisiert werden muß, zeigt sich oft schon an den Formulierungen. Sprachlich ist oft eine Trennung von Erfolgsabwendungsmöglichkeit und Zumutbarkeit kaum vorzunehmen; ob eine Handlung subjektiv möglich oder zumutbar ist, wird synonym gebraucht. Dies zeigen insbesondere die unten (II.) dargestellten Beispiele aus der Rechtsprechung des Reichsgerichts und des frühen Bundesgerichtshofs ${ }^{611}$.

\footnotetext{
${ }^{607}$ Röwer, NJW 58, 1528 (1528); S/S-Stree, Vor § 13, Rn. 155 m. w. N.

${ }^{608}$ vgl. Karlsruhe MDR 75, 771 (772); Forster, S. 121; Kienapfel, JuS 1966, 286 (291, Anm. 32) ; S/S-Stree, Vor § 13, Rn. 155; Tröndle/ Fischer, § 13, Rn. 15 f.; kritisch Eggert, S. 99ff, da die Handlungspflicht von der Garantenstellung abhänge. ${ }^{609}$ Eggert, S. 85; Frey, Zumutbarkeit, S. 38; Röwer, NJW 58, 1528 (1528).

${ }^{610}$ Kienapfel, JuS 1966, 286 (291, Anm. 32); Stree, Vor § 13, Rn. 155; a. A. Westendorf, S. 272; Welzel, JZ 58, 494 (495).

${ }^{611}$ vgl. RGSt 58, 97 (98); RGSt 77, 125 (127); BGHSt 6, 46 (57); KG JR 50, 407 (408).
} 


\section{Grenzen der elterlichen Einschreitenspflicht}

Unzumutbar ist eine Handlung, wenn sie eigene billigenswerte Interessen in erheblichem Umfang beeinträchtigen würde und diese Interessen in einem angemessenen Verhältnis zu dem drohenden Erfolg stehen. Dabei entscheidet eine Abwägung zwischen dem drohenden Erfolg und den gefährdeten Interessen ${ }^{612}$. Je schwerer das drohende Übel, desto mehr kann an persönlichen Opfern zugemutet werden ${ }^{613}$.

$\mathrm{Ob}$ ein Interesse eines Handlungspflichtigen billigenswert ist, kann demnach erst festgestellt werden, wenn es in ein Verhältnis zu den anderen, im Konfliktsfall bestehenden Interessen gebracht worden ist. Das Interesse muß also als solches und auch im Verhältnis zu den anderen Interessen billigenswert $\operatorname{sein}^{614}$.

$\mathrm{Zu}$ berücksichtigen ist im Rahmen der Abwägung auch die Erfolgsaussicht der Rettungshandlung für die fremden Interessen. Bietet die geforderte Handlung nur geringe Erfolgsaussichten, brauchen die eigenen Interessen nicht so sehr wie bei großen Rettungschancen geopfert $\mathrm{zu}$ werden $^{615}$. Je weniger wahrscheinlich also die Tatverhinderung erscheint, desto geringer wird das Erfordernis der Aufopferung der eigenen Interessen des Garanten. Maßgebend für die Beurteilung ist die Lage des Einzelfalls ${ }^{616}$.

Die Fragen, die sich zum Umfang der Zumutbarkeit stellen, lassen sich anschaulich an der Rechtsprechung des Reichsgerichts und des frühen BGH zeigen ${ }^{617}$, auch wenn die dort betroffene Problematik der Kuppelei im heutigen Strafrecht keinen Raum mehr hat ${ }^{618}$.

\footnotetext{
${ }^{612}$ BGH NStZ 84, 164; BGHSt 6, 46 ( 57); Geilen, FamRZ 64, 385 (389); S/S-Stree, Vor $\S 13$, Rn. 155 f.; Tröndle/Fischer, § 13, Rn. 16; Forster, S. 92.

${ }^{613}$ BGHSt 4, 20 (23); zur Frage, ob es um das individuelle psychische Können des einzelnen Täters oder vielmehr nur auf den Durchschnittsbürger ankommt, Jobst, Der Streit um die Zumutbarkeit, S. 53.

${ }^{614}$ Forster, S. 92.

${ }^{615}$ BGH NStZ 94, 29; S/S-Stree, Vor § 13, Rn. 156.

${ }^{616}$ BGHSt 6, 46 (57); BGH NStZ 84, 164.

${ }^{617}$ Ausführlich: Schulte, Garantenstellung und Solidarität, S. 41.

${ }^{618}$ Schutzgut der Kuppeleitatbestände nach den $\S \S 180$ ff. StGB a. F. war die „sittliche Ordnung" (vgl. BGHSt 6, 46, 49, 53f., Schulte, Garantenstellung und Solidarität, S. 43), die in dieser Form nicht mehr als schutzwürdig eingestuft wird.
} 
1) Eltern erfuhren, daß die volljährige Tochter $T$ nachts mit ihrem Freund in ihrem Zimmer in der elterlichen Wohnung geschlechtlich verkehrte. Die Eltern verboten ihr dies energisch. Als die $\mathrm{T}$ daraufhin mit dem Verlassen der elterlichen Wohnung drohte, unternahm das Ehepaar, das seine Tochter sehr liebte und sie nicht verlieren wollte, keine weiteren Schritte $^{619}$. Das Kammergericht hat ein massiveres Vorgehen, nämlich die Entfernung der Tochter aus der Wohnung oder die Veranlassung von Maßnahmen der Fürsorgeerziehung, als unzumutbar betrachtet, da die Eltern sich auch zunächst gegen das Übernachten des Freundes gesträubt hatten und es deshalb zu familiären Auseinandersetzungen gekommen war. Ihr Sträuben hätten die Eltern erst aufgegeben, als die Tochter die Drohung ausgesprochen habe, das Haus zu verlassen, eine Drohung, deren Ernstlichkeit durch den bereits einmaligen zeitweisen Auszug der Tochter belegt gewesen sei. Hinzu sei gekommen, daß die Tochter so „verwöhnt“" worden, d.h. ohne Beruf gewesen sei, daß ein Abgleiten in die Prostitution zu befürchten war, wenn sie in der Großstadt ganz auf sich allein gestellt sein würde ${ }^{620}$.

2) In einem weiteren Fall, in dem der Ehemann duldete, daß seine Frau in der ehelichen Wohnung mit einem Dritten Unzucht trieb, hat das Reichsgericht es als einen zu berücksichtigenden Umstand angesehen, daß der Ehemann im Falle seines Einschreitens den Verlust der Wohnung oder eine Schädigung seines Geschäftes befürchten mußte ${ }^{621}$. Es hat weiterhin darauf abgestellt, ob der Ehemann sich durch ein Einschreiten einem mit Tätlichkeiten seiner Frau und deren Liebhaber verbundenem Auftritt aussetzen würde, dem er sich nicht gewachsen fühlte; kurzum, die Angst des Ehemanns vor den Folgen seines Einschreitens genügte hier für die Annahme der Unzumutbarkeit ${ }^{622}$.

3) In einem anderen Fall, in dem der wegen kupplerischen Zuhälterei angeklagte Ehemann das Verbleiben seiner Frau in einem Bordell

\footnotetext{
${ }^{619} \mathrm{vgl}$. Eggert, S. 81; gebildet nach KG JR 1950, 407.

${ }^{620} \mathrm{KG}$ JR 1950, 407 (408).

${ }^{621} \mathrm{RG} 58,97$ (98); RG 58, 226 (227); Eggert, S. 83.

${ }^{622}$ RG 58, 97 (98); RG 58, 226 (227); Eggert, S. 83; vgl. Welzel, JZ 58. 494 (496).
} 
duldete, hat das Reichsgericht dahingehend Bedenken angemeldet, ob es dem Angeklagten zugemutet werden könne, im Wege der Klage gegen seine Ehefrau vorzugehen. Ein derartiger Zwang würde dem Wesen des ehelichen Verhältnisses widersprechen ${ }^{623}$. Hinsichtlich eines Sohnes, der in der elterlichen Wohnung mit seiner Freundin geschlechtlich verkehrte, hat das Reichsgericht festgestellt, daß Eltern in der Regel wegen des Widerstreits gegen die Pflichten, die sich aus dem Familienverhältnis ergeben, nicht zugemutet werden kann, polizeiliche Hilfe gegen den eigenen Sohn in Anspruch $\mathrm{zu}$ nehmen $^{624}$. In einem weiteren „Kuppeleifall“ hat das OLG Celle zu bedenken gegeben, daß die von den Eltern zu verlangende Maßnahme, gegen den Freund der Tochter einzuschreiten, auch angesichts der ländlichen Verhältnisse auch gegen die Tochter richten und die Familienverhältnisse an die Öffentlichkeit ziehen könnte ${ }^{625}$.

Eggert bringt schließlich noch einen Fall aus einem anderen Bereich: Fräulein $\mathrm{K}$ ist Kassiererin in einem Warenhaus. A, ihr Verlobter, ist Leiter der Abteilung, in der K arbeitet. Eines Tages beschließt K, Geld aus der von ihr verwalteten Kasse zu entwenden. Als sie ihren Entschluß dem A mitteilt, entrüstet sich dieser über ihren Plan. Daraufhin erklärt ihm die $K$, daß sie sich entloben werde, falls $A$ ihr Vorhaben vereiteln würde. A verhindert nunmehr den Diebstahl nicht. Bestrafung des A wegen Beihilfe zum Diebstahl durch Unterlassen ${ }^{626}$ ?

Es zeigt sich, daß der Inhalt der Zumutbarkeit, unabhängig von der Einordnung in den Tatbestand oder die Schuld, immer stark abhängig von gesellschaftlichen Prozessen und moralischen Wertvorstellungen ist. Auch das richterliche Ermessen spielt sicherlich eine Rolle ${ }^{627}$. In allen Fällen geht es um ein gefordertes Verhalten, das dem Garanten aus emotionalen Gründen nur erschwert möglich ist. Eggert hat also recht, wenn er davon spricht, daß die Ausdehnung des Zumutbarkeitsgedankens

\footnotetext{
${ }^{623} \mathrm{RG}$ 58, 226 (226f.); Eggert, S. 84.

${ }^{624}$ RG 77, 125 (127); Eggert, S. 84.

${ }^{625}$ OLG Celle, Nds. Rpfl. 1950, 92 (92f.).

${ }^{626}$ Eggert, S. 82.

${ }^{627}$ Jobst, Der Streit um die Zumutbarkeit, S. 60 f.
} 
für den Bereich der unechten Unterlassungsdelikte mit der besonderen psychologischen Situation zu begründen ist, die dem Unterlassenden die Entscheidung zum rechtstreuen Verhalten in weit erheblicherem Maße erschwert als dem aktiv Handelnden ${ }^{628}$.

Die bereits oben dargestellten Mittel, die den Erziehungspflichtigen zu Gebote stehen, um die Tat zu verhindern, lassen sich in drei Gruppen einteilen. Es gibt solche Mittel, deren Anwendung immer zumutbar ist, solche, die unter Umständen unzumutbar sein können und schließlich solche, die immer unzumutbar sind: Stets zumutbar sind die oben als erste Gruppe genannten Mittel des Zuredens und Ermahnens. Es ist keine Konstellation denkbar, die Eltern davon abhalten könnte.

In die zweite Gruppe fallen Handlungen, die ein erhöhtes Maß an Zeit oder Intensität erfordern: Je nach Einzelfall kann es aus beruflichen oder anderen Gründen unzumutbar sein, daß Eltern für eine ständige Aufsicht für ihr Kind sorgen ${ }^{629}$. Zu erwähnen ist in diesem Zusammenhang die wirtschaftliche Lage der Eltern (geringes Einkommen) ${ }^{630}$, ihre gesteigerte Inanspruchnahme durch Versorgung eines mehrköpfigen Haushalts ${ }^{631}$ und die Belastung mit Berufpflichten ${ }^{632}$, auch in Form von Mitarbeit im Geschäft oder der Gastwirtschaft des Ehepartners ${ }^{633}$.

Die dritte Gruppe umfaßt schließlich Handlungen, die für die Eltern unzumutbar sind. So wird es weitgehend als unzumutbar betrachtet, die Polizei oder andere staatliche Stellen gegen nächste Angehörige in Anspruch zu nehmen und diese der Strafverfolgung auszusetzen ${ }^{634}$. Als einer der Gründe wird genannt, daß die Eltern den Abkömmling durch ein solches Verhalten selbst aus der Familiengemeinschaft ausschließen

\footnotetext{
${ }^{628}$ Eggert, S. 117.

${ }^{629} \mathrm{Vgl}$. Albilt, S. $155 \mathrm{ff}$.

${ }^{630}$ RGZ 98, 246 (248); OLG Bremen VersR 58, 64 (64); Boscher, VersR 64, 888 (888); Landsberg, Jugendschutz, S. 9f.

${ }^{631}$ Drei Kinder: BGH VersR 57, 340 (340); OLG Bremen VersR 58, 64 (64); vier Kinder: BGH VersR 66, 368; fünf Kinder: BGH VersR 65, 385.

${ }^{632}$ BGH VersR 57, 340 (340); OLG Köln FamRZ 62, 124 (125).

${ }^{633}$ AG Mellrichstadt VersR 55, 464 (464).

${ }^{634}$ RGSt 77, 125 (127); ähnlich RGSt 58, 226 (227); BGHSt 6, 46 (57) eine aus heutiger Sicht kuriose Entscheidung; BGH NJW 64, 731 (732); KG JR 50, 407 (408); Bremen NJW 1957, 72 (73); Köln NJW 73, 861 (862); Karlsruhe MDR 75, 771 (772); S/S-Stree, Vor § 13 , Rn. 156; im Zivilrecht ebenso: Dahlgrün, S. 159; Albilt, S. 146.
} 
und sich selbst jedes eigenen Erziehungseinflusses begeben würden ${ }^{635}$. Beachtenswerte Interessen der Erziehungspflichtigen innerhalb der Abwägung können etwa sein, den Abkömmling vor Strafe zu bewahren, ihn durch eine Anzeige nicht der Verachtung der Umwelt auszusetzen, ihn vor Schande und Bloßstellung zu schützen, nicht die familiäre Atmosphäre zu vergiften, weiter mit ihm zusammenleben zu können oder finanziell auf ihn angewiesen zu sein ${ }^{636}$. Diese Erwägungen werden bei schweren Delikten jedoch erst nachrangig zu berücksichtigen sein.

$\mathrm{Ob}$ eine im allgemeinen mit der Gefahr strafrechtlicher Verfolgung verbundene Strafanzeige zumutbar ist, hängt von den Umständen des Einzelfalles ab: Je schwerer die drohende Rechtsgutsverletzung, um so eher ist die Zumutbarkeit einer Anzeige zu bejahen ${ }^{637}$. Zumutbar ist das Einschreiten, wenn die vom Angehörigen gefährdeten Interessen die mit Inanspruchnahme der Behörde preisgegebenen Interessen wesentlich überwiegen, so nicht für die Abwendung von Todesgefahren ${ }^{638}$. So hat es auch der BGH bei schweren Eingriffen in die Rechtsgüter Dritter als zumutbar gesehen, auch enge Angehörige, hier den eigenen Ehemann, beim Jugendamt oder der Polizei anzuzeigen. In dem betreffenden Fall hatte die Mutter es geschehen lassen, daß ihr Ehemann die gemeinsamen Töchter sexuell schwer mißbrauchte ${ }^{639}$. Auch der Sohn hat notfalls Anzeige gegen seine Mutter und Geschwister zu erstatten, wenn sein Vater durch sie ermordet werden soll ${ }^{640}$.

Es kann aber auch bei schweren drohenden Delikten nicht von vornherein verlangt werden, daß die Polizei eingeschaltet wird. Grundsätzlich muß dem Verpflichteten die Möglichkeit offenbleiben, zunächst mit milderen Mitteln den Versuch einer Abhilfe zu unternehmen, wenn diese Erfolg versprechen. Scheitert der Versuch, soll

\footnotetext{
${ }^{635}$ BGHSt 6, 46 (58).

${ }^{636}$ Vgl. BGH NStZ 84, 164; Schwarz, S. 165.

${ }^{637}$ BGH NStZ 84, 164.

${ }^{638}$ S/S-Stree, Vor § 13, Rn. 156; BGH NJW 73, 861 (862); Schwarz, S. 168.

${ }^{639}$ BGH NStZ 84, 164.

${ }^{640}$ BGH NJW 64, 731 (732); BGH JR 64, 226 (226); Geilen, FamRZ 64, 385 (386f.); Blei, Mayer-FS, S. 129. Hier liegt allerdings eine Sonderfall vor, da der Sohn Beschützergarant, und nicht Überwachergarant ist; von einer Garantenstellung aus Ingerenz konnte nicht ausgegangen werden, da ihm ein Tatbeitrag gerade nicht nachzuweisen war; dazu auch Forster, S. $138 \mathrm{ff}$.
} 
dem Täter in aller Regel kein Vorwurf daraus gemacht werden können, daß er nicht sofort zu einem weniger schonenden Mittel gegriffen hat, so lange aus ex-ante-Sicht die Maßnahme aussichtsreich war ${ }^{641}$. Dies muß aber scharf abgegrenzt werden zu den Fällen, in denen das mildere Mittel schon von Anfang an keine Abhilfe versprach; dann nämlich muß es dem Garanten angelastet werden, daß er nicht rechtzeitig das wirksamere Mittel angewendet hat.

Fraglich ist, ob Eltern auch dann ein Handeln als unzumutbar ablehnen dürfen, wenn sie alle anderen möglichen Mittel zuvor nicht angewendet haben und nun die Anzeige bei der Polizei die einzige wirksame Methode darstellt. Beispiel: Die Eltern warten bis zum spätest möglichen Eingreifenszeitpunkt, indem sie nicht einschreiten, als der Sohn zu Hause die nötigen Vorbereitungen zum gemeinschaftlich geplanten Tötungsdelikt trifft. Erst als der Sohn zur Tatbegehung aufgebrochen ist, überlegen sie, was zu tun ist, scheuen sich aber, die Polizei zu rufen. Es wäre wohl hier als zumutbar anzusehen, daß die bisher untätigen Eltern nun zumindest das Opfer warnen oder die Polizei benachrichtigen. Hierzu zwingt die Eltern überdies die Anzeigepflicht des $\S 138$ Abs. 1 StGB, welche ihnen gem. § 139 Abs. 1 StGB bei Totschlag ausdrücklich keine Privilegierung durch ihre Eigenschaft als Angehörige einräumt (vgl. hierzu die folgenden Ausführungen unter III.).

$\mathrm{Zu}$ prüfen ist weiter, ob die Schwelle der Unzumutbarkeit von der Schwere des Delikts abhängen darf $^{642}$. Sicherlich ist es legitim anzunehmen, daß der Schutz eines Dritten vor Körperverletzung oder vor Tod bei der Abwägung der beeinträchtigten Interessen schwerer wiegt als der Umstand, daß die Eltern dazu beitragen, daß ihr Abkömmling für diese Tat bestraft wird. Daraus müßte der Schluß gezogen werden, daß bei leichten Delikten die Interessenabwägung zugunsten der Eltern ausfällt und diese nicht verpflichtet werden können, etwa wegen eines Diebstahls ihr Kind den Behörden auszuliefern. Könnte man aber nicht genauso auf die Interessenabwägung verweisen und meinen, daß die

\footnotetext{
${ }^{641}$ BGH NStZ 84, 164; ähnlich Albilt, S. 146f.; a. A. Loos/Westendorf, Jura 98, 403 (407).

${ }^{642}$ dazu auch Forster, S. 95 ff., 118.
} 
Bestrafung des Jugendlichen für ein geringeres Delikt ohnehin viel leichter und die Anzeige also den Eltern erst recht zuzumuten sei ${ }^{643}$.

$\mathrm{Zu}$ berücksichtigen ist in diesem Zusammenhang, daß eine Anzeige nicht zwingend eine Namensnennung verlangt. Es ist auch eine anonyme Anzeige möglich, die die Möglichkeit offenläßt, daß der jugendliche Delinquent vor der Tat ungesehen entkommt, also die Tat verhindert wurde, aber die Eltern dennoch nicht in die Verlegenheit bringt, an der Strafverfolgung ihres Sprößlings Anteil gehabt zu haben ${ }^{644}$.

Zum Teil wird aber ein anonymer Anruf beim Opfer als unzumutbar eingestuft, weil auch dieser voraussichtlich zur Festnahme des Angehörigen am Tatort führen würde ${ }^{645}$. Dabei wird vielleicht der staatliche Eingriff in seiner Intensität bisweilen überschätzt: Auch aus Sicht der Behörden ist die Festnahme eines Jugendlichen und seine Unterbringung in einem Jugendheim nach den Maßgaben des Jugendhilfegesetzes bzw. die Anordnung der Untersuchungshaft die ultima ratio, also erst zulässig, wenn erzieherische Maßnahmen anderer Art nicht hinreichend geeignet erscheinen, eine sich in der Tatbestandsverwirklichung offenbarende Gefahr für seine Entwicklung zu beseitigen, vgl. $\S \S 72,71 \mathrm{JGG}^{646}$. Auch die Frage, ob zumindest das Informieren der Polizei ohne Namensnennung zumutbar ist, dürfte letztlich vom Einzelfall abhängen.

Neben der Anzeige ist schließlich noch zu fragen, ob die Anwendung von physischer Gewalt Eltern stets unzumutbar ist. In einer Zeit, in der das elterliche Züchtigungsrecht trotz der Neufassung des $§ 1631$ BGB mit den darin enthaltenen Klarstellungen ${ }^{647}$ noch immer nicht aus dem

\footnotetext{
${ }^{643}$ So machen Schwarz, S. 169, Geilen, FamRZ 64, 385 (389) und Westendorf, S. 271, darauf aufmerksam, daß die Strafe bei Tötungsdelikten besonders hoch ist und sich für die Angehörigen also das Zumutbarkeitsproblem besonders gravierend zeigt. Deshalb meint er, es entspräche dem praktischen Leben wohl mehr, auch bei einem geplanten Tötungsdelikt den Angehörigen eine Anzeige nicht zuzumuten, sofern er sich auf alle andere erdenkliche Weise um die Tatverhinderung bemüht hat.

${ }^{644}$ Vgl. Schwarz, S. 167; Westendorf, S. 29.

${ }^{645}$ BGH NJW 73, 861 (862).

${ }^{646}$ Benfer, Rn. 717.

${ }^{647}$ \& 1631 Abs. 2 BGB: Kinder haben ein Recht auf gewaltfreie Erziehung. Körperliche Bestrafungen, seelische Verletzungen und andere entwürdigende Maßnahmen sind unzulässig.
} 
Denken vieler Eltern verschwunden ist $^{648}$, mag man zumindest einfache Schläge noch als zumutbares Mittel verstehen, einen Jugendlichen von der bevorstehenden Tat abzuhalten ${ }^{649}$.

Hier ist jedoch eine Abgrenzung zwischen den Mitteln der Deliktsverhinderung und der Züchtigung vorzunehmen. Die elterliche Züchtigung sollte erzieherisch auf das Kind oder den Jugendlichen wirken und erst nach einem Ungehorsam oder Verstoß gegen die von den Eltern gesetzten Regeln als Sanktion von diesen eingesetzt werden ${ }^{650}$. Demgegenüber soll die Anwendung von körperlicher Gewalt beim unechten Unterlassen den Taterfolg gerade verhindern.

Ähnlichkeiten zwischen den beiden Maßnahmen bestehen insoweit, als beide dem Zweck dienen/ dienten, auf den zu Erziehenden einzuwirken und sie möglichst schonend eingesetzt werden sollen/ sollten. Sowohl bei der Züchtigung als auch bei der Gewaltanwendung zur Deliktsverhinderung wird in die körperliche Sphäre des Kindes oder Jugendlichen eingegriffen. Im Gegensatz zum nunmehr gesetzlich aufgegebenen Züchtigungsrecht ist es zur Deliktsverhinderung erlaubt und zumutbar, auch solche Beeinträchtigungen des körperlichen Wohlbefindens $\mathrm{zu}$ verursachen, die im Rahmen des Züchtigungsrechts wegen des entwürdigenden Charakters als unzulässig einzustufen wären. Doch selbst zur Verhinderung eines Tötungsdelikts wird man einem Vater oder einer Mutter nicht auferlegen können, das eigene Kind durch eine massive Körperverletzung zu stoppen ${ }^{651}$.

Ein weiteres Problem der Zumutbarkeit ergibt sich daraus, daß Eltern selbst in die Gefahr geraten, sich der Strafverfolgung auszusetzen; dies kann geschehen durch eine eigene aktive Beteiligung an der Tat, durch

\footnotetext{
${ }^{648}$ Vgl. Albrecht, ZfJ 81, 4 (7); Ostendorf, S. 17; Gropp, Strafrecht AT, Rn. 197, weist darauf hin, daß das Schlagen von Kindern in den seltensten Fällen als Strafe eingesetzt wird, sondern es sich meist um irrationale Affekttaten handelt; zweifelnd Tröndle/ Fischer $\S 223$, Rn. 16.

${ }^{649}$ Inwieweit bei einer solchen Eskalation der familiären Lage noch eine „Überzeugung“ oder Umstimmung des Jugendlichen möglich ist, sei hier außen vor gelassen; vgl. dazu auch Geilen, FamRZ 64, 385 (389).

${ }^{650}$ Tröndle/ Fischer, § 223, Rn. 10.

${ }^{651}$ Abschreckend RG 77, 125 (127), worin die Frage erörtert wird, ob Eltern ihren Sohn der Gefahr aussetzen müßten, in ein Konzentrationslager eingewiesen zu werden.
} 
das unechte Unterlassen oder durch $\S 171$ StGB. Das Eingehen der Gefahr eigener Strafverfolgung ist zumutbar, wenn diese in ihrem Gewicht erheblich hinter den drohenden Schaden zurücktritt oder wenn die zu befürchtende Strafverfolgung das Verhalten betrifft, aus dem die Rechtspflicht zur Erfolgsabwendung erwächst ${ }^{652}$. Insoweit sind die gleichen Maßstäbe wie gegenüber der Anzeige von Angehörigen anzuwenden.

III. Ähnlichkeiten und Unterschiede zu $§ ~ 138,139$ StGB

In seiner Ausrichtung umfaßt das echte Unterlassungsdelikt des $\S 138$ StGB auch solche Handlungspflichten, denen der zur Deliktsverhinderung bestimmte Garant unter Umständen nachkommen $\operatorname{muß}{ }^{653}$ :

Abs. 1

„Wer von dem Vorhaben oder der Ausführung

6. eines Mordes, Totschlags oder Völkermordes (\$\$ 211, 212 oder 220a),

7. einer Straftat gegen die persönliche Freiheit in den Fällen des $\$ \$ 234$, $234 a, 239 a$ oder $239 b$,

8. eines Raubes oder einer räuberischen Erpressung (\$\$ 249 bis 251 oder 255) oder

9. einer gemeingefährlichen Straftat in den Fällen der $\$ \S 306$ bis 306c oder $\S 307$ Abs. 1 bis 3, des $\S 308$ Abs. 1 bis 4, des $\S 309$ Abs. 1 bis 5, der $\S 310,313,314$ oder 315 Abs. 3, des $\$ 315 b$ Abs. 3 oder der $\S 316 a$ oder $316 c$

zu einer Zeit, zu der die Ausführung oder der Erfolg noch abgewendet werden kann, glaubhaft erfährt und es unterläßt, der Behörde oder dem Bedrohten rechtzeitig Anzeige zu machen, wird mit Freiheitsstrafe bis zu fünf Jahren oder mit Geldstrafe bestraft. “

652 ähnlich Welzel, JZ 58, 494 (496); BGHSt 11, 353 (356); BGH NJW 64, 731 (732); NStZ 84, 452; Geilen, FamRZ 64, 385 (386). 
Im Zusammenhang dazu ist $§ 139$ Abs. 3 S. 1 StGB zu lesen:

„Wer eine Anzeige unterläßt, die er gegen einen Angehörigen erstatten müßte, ist straffrei, wenn er sich ernsthaft bemüht hat, ihn von der Tat abzuhalten oder den Erfolg abzuwenden, es sei denn, daß es sich um

1. einen Mord oder Totschlag (\$\$ 211 oder 212),

$2 \ldots$

3. einen erpresserischen Menschenraub ( $\$ 239 a$ Abs. 1), eine Geiselnahme (\$239b Abs. 1) ...

handelt. “.

Im Gegensatz zum unechten Unterlassungsdelikt spielt es bei $\S 138$ Abs. 1 StGB keine Rolle, ob der Erfolg der Katalogtat eintritt oder ausbleibt; Straflosigkeit tritt stets ein, wenn der Täter rechtzeitig Anzeige erstattet hat bzw. die Anzeige nur deshalb unterläßt, weil die hinreichenden Maßnahmen längst getroffen sind ${ }^{654}$. § 138 erwartet zwar nicht das Ausbleiben der Katalogtat, setzt jedoch eine bestimmte Handlung des Anzeigepflichtigen voraus. Der Unterschied liegt beim unechten Unterlassungsdelikt darin, daß es vom Eintritt des Erfolges abhängt, ob er wegen Vollendung bestraft wird ${ }^{655}$.

Im Vergleich zu der Handlung, die vom Garanten beim unechten Unterlassungsdelikt verlangt wird, erfordert $\S 138$ Abs. 1 nicht viel Einsatz. Das Optimum an geforderter Hilfe wird schon tatbestandlich auf eine Anzeige verkürzt, also auf eine Tätigkeit, die in aller Regel schon durch einen Telefonanruf erledigt ist ${ }^{656}$. Die Anzeige muß aber rechtzeitig erstattet werden, sonst trägt der Pflichtige das Risiko des Erfolgseintritts ${ }^{657}$.

Beim unechten Unterlassungsdelikt besteht die Pflicht zum Tätigwerden jedoch anders als bei $\S 138$ auch dann ${ }^{658}$, wenn der Bedrohte bereits über die bevorstehende Tat informiert ist, beispielsweise durch einen Anruf des Garanten. Entscheidend für eine Straflosigkeit des Garanten ist beim

\footnotetext{
${ }^{653}$ Vgl. Loos/Westendorf, Jura 98, 403 (407).

654 Westendorf, S. 87f., knüpft insoweit an den Erfolg als Grundlage des Handlungsgebotes an.

${ }^{655}$ Westendorf, S. 91.

${ }^{656}$ Westendorf, S. 98.

${ }^{657}$ Loos/Westendorf, Jura 98, 403 (404).
} 
unechten Unterlassungsdelikt, daß er - soweit es seine Kenntnisse und Möglichkeiten zulassen- für das Ausbleiben des Taterfolges sorgt. Findet die Tat dennoch statt, ist der er jedenfalls dann strafbar, wenn er Besseres zur Tatverhinderung hätte tun können. Zur Bedeutungslosigkeit verkommt der vorherige, nutzlose Anruf beim Opfer.

$\S 139$ Abs. 3, S. 1 stellt es dem Angehörigen zudem frei, ob er eine Anzeige erstattet oder vielmehr auf andere Weise zur Verbrechensverhinderung beiträgt und privilegiert ihn dadurch gegenüber dem Täter ohne Angehörigeneigenschaft ${ }^{659}$. Fraglich ist, ob der Ermöglichung der Straflosigkeit durch bloßes Bemühen der Tatabwendung auch eine Privilegierung gegenüber dem Garanten des unechten Unterlassungsdelikts eintritt. Grundsätzlich ist die Situation des $\S 138$ ist nicht mit einer allgemeinen Verbrechensverhinderungspflicht vergleichbar $^{660}$.

$\mathrm{Zu}$ untersuchen ist daher, wie ein Zusammentreffen von $\S 138 \mathrm{I}$ und dem unechten Unterlassen zu behandeln ist und ob die in $\S 139$ Abs. 3, S. 1 getroffenen Entscheidungen über die Zumutbarkeit auf die unechten Unterlassungsdelikte übertragen werden müssen oder dürfen. Es sind viele Fälle denkbar, bei denen sowohl das unechte Unterlassen als auch $\S 138$ Abs. 1 durch dasselbe Verhalten erfüllt werden, nämlich immer dann, wenn dem Garanten zur Abwendung des schädlichen Erfolgs nur eine Benachrichtigung des Bedrohten bzw. einer Behörde bleibt ${ }^{661}$. Beispiel: Eltern wissen, daß ihr minderjähriger Sohn aufbricht, um seinen Widersacher zu erstechen. Sie können die Tat nur verhindern, indem sie den Bedrohten oder die Polizei anrufen, unterlassen dies aber, so daß der Sohn seine Tat ausführt. Dann liegt sowohl ein Fall des $\S 138$ Abs. 1 als auch des $\S \S 212,13$ Abs. 1 vor. $§ 139$ Abs. 3 sieht hier keine Privilegierung vor. Im Gegenteil schließt $\S 139$ Abs. 3 Hs. 2 Nr. 1 eine Straffreiheit sogar ausdrücklich aus, wenn es sich bei der nicht verhinderten Tat um einen Mord oder einen Totschlag handelt. Auch Sinne des unechten Unterlassens ist bei diesem Beispiel nach den oben aufgeführten Erwägungen keine Unzumutbarkeit des Einschreitens

\footnotetext{
${ }^{658} \mathrm{Vgl.} \mathrm{Loos/Westendorf,} \mathrm{Jura} \mathrm{98,} 403$ (405); Westendorf, S. 99.

${ }^{659}$ Welzel, JZ 58, 494 (496).

${ }^{660}$ Schwarz, S. 166.

${ }^{661}$ Westendorf, S. 96; kritisch: Geilen, JuS 65, 426 (429).
} 
ersichtlich; die Eltern wären also strafbar sowohl nach $\S 138$ Abs. 1 wie auch nach $\S \S 212,13$.

Nach den oben dargestellten Voraussetzungen der Zumutbarkeit elterlichen Einschreitens dürfte es relativ unbestritten sein, hier eine Anzeigepflicht der Eltern $\mathrm{zu}$ erblicken. Daher ist es letztlich kein entscheidender Fortschritt, wenn der BGH feststellt, daß die

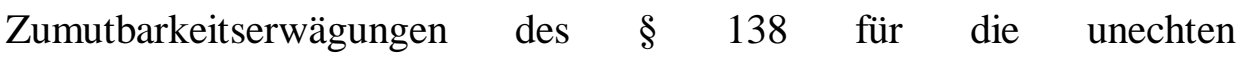
Unterlassungsdelikte zumindest indizielle Bedeutung haben ${ }^{662}$. Der BGH hat selbst angemerkt, daß diese Erwägungen auch in $\S 138$ keinen Niederschlag im Gesetz gefunden haben. § 139 Abs. 3 Hs. 2 nimmt zwar die Angehörigen explizit bei den aufgeführten schweren Straftaten von der Privilegierung aus, zeigt also deutlich, daß eine Anzeige in den dort geschilderten Fällen auf jeden Fall stattfinden muß. Daraus kann gefolgert werden, daß hier eine Unzumutbarkeit in den Fällen der schweren Kriminalität verneint wird und eine Abwägung der Interessen zu Lasten der Angehörigen geht. Außer dem Ausschluß von der Straflosigkeit enthalten $\S \S 138,139$ bezüglich der schweren Delikte aber keinerlei Anhaltspunkte, welches Verhalten als zumutbar anzusehen ist. Für die Frage, wie Delikte zu behandeln sind, die nicht $\mathrm{zu}$ den Katalogtaten des § 139 Abs. 3, S. 1 zählen, gibt die Auslegung nichts her. Im Gegenteil kann man in Schwierigkeiten kommen, beruft man sich bei der Findung von Zumutbarkeitsparametern zu sehr auf $\S 138$. Der Raub ist von $\S 139$ Abs. 3 ebenso wenig erfaßt wie die schwere Körperverletzung oder die Vergewaltigung. Mißt man dem $\S 138$ indizielle Wirkung $\mathrm{zu}$, muß man fragen, ob diese Delikte nicht schwer genug sind und daher eine Anzeige nicht zumutbar sein soll. Es könnte sogar ein Umkehrschluß aus $\S 138$ gezogen werden: Ist nicht konsequenterweise die Verhinderung aller Delikte, die nicht ausdrücklich in $\S 139$ Abs. 3, S. 1 ausgenommen sind, für Angehörige unzumutbar ?

Brisant wird die Frage nach der indiziellen Wirkung des $\S 139$ Abs. 3, S. 1 tatsächlich dann, wenn die Tat, die die Eltern nicht unterbinden, keine Katalogtat i.S.d. des $\S 139$ ist. Beispiel: Die Eltern

\footnotetext{
${ }^{662}$ Bereits oben angesprochen, BGH JR 62, 226 (226): Ehefrau E und Sohn S planen gemeinsam die Ermordung des Ehemanns und Vaters V. Ein anderer Sohn A ist nicht Tatbeteiligter, weiß aber von ihrer Planung, zeigt aber das Vorhaben nicht an.
} 
unterbinden unter den oben genannten Umständen nicht, daß der Sohn zu einem Einbruchsdiebstahl aufbricht.

Fraglich ist, ob die Unzumutbarkeitserwägungen des $§ 139$ Abs. 3, S. 1 auf die Nichtanzeige des $\S 138$ beschränkt sind, oder ob sie nicht auch auf die unechten Unterlassungsdelikte angewendet werden können. Stellt sich heraus, daß die Erwägungen aus $§ 139$ Abs. 3 nicht auf das unechte Unterlassen übertragbar sind, läuft für Angehörige mit Garantenstellung $\S 139$ Abs. 3 quasi leer. Kommt man hingegen zum Ergebnis, daß $\S 139$ Abs. 3 eine Sperrwirkung für das unechte Unterlassen hat, ist eine Strafbarkeit wegen unechten Unterlassens in all den Fällen leichterer und mittlerer Kriminalität ausgeschlossen, in denen nur eine Anzeige die Tat verhindern konnte.

Nach Schwarz soll die Bestimmung des $§ 139$ Abs. 3 über den Rahmen der unterlassenen Verbrechensanzeige hinaus Bedeutung auch für alle sonstigen Unterlassungsdelikte haben. Danach hat diese Vorschrift einen allgemeinen Rechtsgedanken, der der analogen Übertragung fähig ist und daher für alle Fälle bedeutsam wird, in denen der Angehörige wegen der Nichtverhinderung strafbarer Handlungen verantwortlich gemacht werden kann. Insoweit soll auch ein unechtes Unterlassungsdelikt nicht in Betracht kommen, wenn der Täter sich ernstlich bemüht hat, den Angehörigen von der Begehung abzuhalten ${ }^{663}$. Es soll also durch $\S 139$ Abs. 3 eine Sperrwirkung für die unechten Unterlassungsdelikte entstehen. Diese Sperrwirkung kann jedoch konsequenterweise nur für die leichteren der i.S.d. $§ 138$ anzeigepflichtigen Verbrechen gelten; sei hingegen ein Mord oder Totschlag geplant, müsse der Angehörige die Anzeige erstatten; das erfolglose Bemühen um die anderweitige Abwendung genüge nicht ${ }^{664}$.

Dem ist mit der wohl herrschenden Lehre entgegenzuhalten, daß die Zumutbarkeit beim unechten Unterlassen nicht über $\S 139$ Abs. 3 definiert werden darf. Nachdem der BGH zunächst zu Delikten, die nicht unter § 139 Abs. 3 fallen, keine Stellung genommen hatte, hat er inzwischen anerkannt, daß $\S 139$ Abs. 3 eine Sonderregelung trifft, die die Fälle der Garantenstellung und einer sich daraus ergebenden

\footnotetext{
663 Schwarz, S. 164.

664 Schwarz, S. 168.
} 
Anzeigepflicht unberührt läßt ${ }^{665}$. Auch Schröder hat - bereits zu der älteren Entscheidung des BGH- festgestellt, daß die Frage, ob die Gefahr der eigenen Strafverfolgung die Strafbarkeit ausschließe, für die unechten Unterlassungsdelikte selbständig und unabhängig von § 139 entschieden werden muß ${ }^{666}$.

Abschließend ist festzustellen, daß die Maßstäbe der $\S \S 138,139$ nicht unmittelbar auf das unechte Unterlassen übertragen werden können. Den Garanten trifft für das bedrohte Rechtsobjekt eine besondere Verantwortung, die jene aus $\S 138$ übersteigt. Das Interesse am Erhalt dieses Rechtsguts ist daher beim unechten Unterlassen deutlich höher zu bewerten als bei der Solidaritätspflicht aus $\S 138$. Mehr als eine Indizfunktion kann man $\S 139$ Abs. 2, 3 daher für die unechten Unterlassungsdelikte nicht zusprechen ${ }^{667}$.

${ }^{665} \mathrm{Vgl}$. BGH NStZ 84, 164.

${ }^{666}$ Schröder, Anm. JR 64, 227. 


\section{Teil. Die Beteiligungsform. Eltern als Täter oder Teilnehmer durch Unterlassen?}

Für eine Strafbarkeit der Eltern aus unechtem Unterlassungsdelikt kommen verschiedene Möglichkeiten der Beteiligung in Frage, von denen sich keine von vornherein ausschließen läßt. Die Strafbarkeit der Eltern könnte sich auf eigene Täterschaft - sowohl in Form der Mittäterschaft als auch der Nebentäterschaft -, auf mittelbare Täterschaft der Eltern oder auf Beihilfe am Begehungsdelikt des Minderjährigen gründen $^{668}$. Zur besseren Übersicht wird im folgenden zunächst von einem vorsätzlichen Begehungsdelikt des Kindes ausgegangen.

A. Der strafmündige Minderjährige

I. Das Nichteinschreiten gegen die vorsätzliche rechtswidrige Haupttat des Jugendlichen

\section{Einführung}

Der strafmündige Jugendliche kann selbst für seine Taten strafrechtlich zur Verantwortung gezogen werden. Das hat zur Folge, daß ein zeitliches Nebeneinander von strafbarem Begehen (durch den Jugendlichen) und strafbarem Unterlassen (durch die Eltern) vorliegt.

Somit stellt sich die Frage der Gewichtung des jeweiligen Verhaltens von Eltern und Jugendlichem zueinander. Vereinfacht gesagt gilt es zu klären, welchen Anteil der Jugendliche bzw. seine Eltern am Unrecht der Tat haben. Diese Schwerpunktsetzung entscheidet dann über die Begehungsform, also darüber, ob die Eltern wegen Täterschaft oder nur wegen Teilnahme an dem Begehungsdelikt des Jugendlichen zu bestrafen sind.

Dabei ist zunächst $\mathrm{zu}$ untersuchen, ob überhaupt eine Beziehung zwischen dem aktiven Tun des Jugendlichen und dem Unterlassen der Eltern besteht. Es ist zu klären, ob das jeweilige Unrecht von Eltern und

${ }^{667}$ Vgl. Westendorf, S. 276. 
Kind voneinander abhängig ist. Fraglich ist nämlich, ob der Taterfolg zugleich durch das aktive Tun des Minderjährigen und durch das Unterlassen der Deliktshinderung durch die Eltern zustande kommt oder ob nicht beide Verhaltensweisen isoliert voneinander betrachtet werden können. Das Tun des Jugendlichen zumindest ist von dem Untätigbleiben der Eltern losgelöst zu sehen, um seine Strafbarkeit festzustellen. Denn das Begehen des Jugendlichen wird durch das Untätigbleiben der Eltern, soweit man von der Möglichkeit einer psychischen Beihilfe durch Unterlassen absieht ${ }^{669}$, nicht beeinflußt. Der Jugendliche ist als Tatnächster notwendigerweise immer Täter, so daß sich seine Strafbarkeit unabhängig von der seiner Eltern ergibt.

Die Strafbarkeit der Eltern ist dementgegen von der ihres Kindes abhängig. Welcher Unterlassungstat sie sich schuldig machen, bestimmt sich erst durch die Tat ihres Kindes. Die Gewichtung des Unrechts der Eltern muß sich folglich an dem Zusammenhang zwischen dem Verhalten des Jugendlichen und dem seiner Eltern orientieren.

Bei der unterlassenen Deliktsverhinderung besteht jedoch gegenüber den „gewöhnlichen“ unechten Unterlassungsdelikten folgendes Problem: Hier führt nicht das Unterlassen der Eltern direkt zur Unrechtsverwirklichung, wie etwa, wenn ein Kind nicht aus dem Fluß gezogen wird und ertrinkt. Hier ermöglicht vielmehr das Unterlassen der Eltern erst, daß der Jugendliche den Taterfolg herbeiführen kann, ist also Voraussetzung für die herbeigeführte Rechtsgutsverletzung. Aus diesem Grund ist es heftig umstritten, welche Begehungsform die Eltern durch die vorsätzliche Nichthinderung an der Straftat des Minderjährigen erfüllen.

Geht man grundsätzlich davon aus, daß zunächst sowohl Täterschaft als auch Beihilfe durch die Eltern möglich sind, kommt es darauf an, wer schwerpunktmäßig die Ursache für die Rechtsgutsgefährdung begründet. Geht die Gefahr primär von dem Aktiven, also hier dem Jugendlichen, aus, gelangt man zur regelmäßigen Annahme einer Beihilfe. Dann läßt sich sagen, der Begehungstäter verstelle dem Garanten den unmittelbaren Zugang zum Erfolg, so daß die strafrechtliche Verantwortlichkeit des

${ }^{668}$ Eine genaue Aufschlüsselung der möglichen Varianten bei: Vogel, Norm und Pflicht, S. 283. 
Garanten nur auf dem Umweg über den Begehungstäter zustande kommt. Der Garant wird nur zur Randfigur des Geschehens, das heißt zum Gehilfen $^{670}$.

Betont man hingegen die Schutzpflicht, die der Überwachergarant dem Opfer schuldet, liegt es näher, für alle Fälle des Unterlassens eine täterschaftliche Verantwortlichkeit zu befürworten ${ }^{671}$. Im Gegensatz zur Beschützergarantenpflicht geht es ja beim Überwachergaranten gerade darum, die Außenwelt vor einer bestimmten Gefahr zu schützen, auf die er Einfluß hat. Aus dieser Perspektive kommt dem Garanten gegenüber dem potentiellen Opfer eine solche Verantwortung $\mathrm{zu}$, daß er diesem gegenüber als Täter in Erscheinung tritt.

Bei dieser Erkenntnis handelt es sich jedoch nur um zwei Seiten der gleichen Medaille. Es ist kaum durchführbar, die Beziehung zwischen dem Überwachergaranten und dem Begehungstäter einerseits und zwischen dem Überwachergaranten und dem Opfer andererseits ausreichend zu entwirren und auf eine einfache Formel zu bringen. Denn gerade darin liegt die Problematik: Der Überwachergarant muß zum einen alle potentiellen Opfer vor der gefährlichen Person schützen und schuldet damit in der konkreten Situation auch dem Opfer Schutz. Zum anderen hat er aber auch eine enge Beziehung zu der gefährlichen Person, durch die ihm jene Garantenstellung überhaupt erst zufällt und durch die er an das Verhalten des Täters gebunden wird. Bei dieser Ambivalenz der Pflichten des Garanten wird deutlich, daß die funktionale Einteilung in Überwacher- und Beschützergaranten sinnvoll und hilfreich ist, aber letztlich nicht messerscharf gezogen werden kann. Durch diese Erkenntnis wird das Bemühen, den Untätigen entweder mehr auf die Seite des Opfers oder auf die des Täters zu stellen, unmöglich. Eine logisch hergeleitete Eindeutigkeit kann somit nicht herbeigeführt werden $^{672}$. Ob man sich mit einer Art „dogmatischem Provisorium“ behelfen muß, wird sich in den folgenden Ausführungen zeigen.

\footnotetext{
${ }^{669}$ Hierzu siehe 4. Teil A I c) cc) Fußnote.

${ }^{670}$ Gallas, JZ 60, 686 (687).

${ }^{671}$ Sowada, Jura 86, 399 (403). Wie oben im 4. Teil A I 5 c) cc) (2) dargelegt, ist diese Pflicht nicht mit einer Obhutspflicht gleichzusetzen.

${ }^{672}$ Sowada, Jura 86, 399 (403).
} 
Das erste Problem, das sich bei der Betrachtung der Unterlassung des Aufsichtspflichtigen ergibt, ist das nach dem Grad ihres Unwerts, nach dem sich die Höhe der Strafe bestimmt. Die Beteiligung durch Unterlassen unterscheidet sich hinsichtlich der Beherrschung des Tatgeschehens qualitativ, aber nicht quantitativ von Täterschaft und Beihilfe durch aktives Tun. Sie ist ein aliud, kein minus gegenüber beiden. Anstatt der realen Einflußnahme besteht eine potentielle Beziehung zum Geschehen ${ }^{673}$. Daher ist auch fraglich für den Unwert der Unterlassung, ob er eher dem Unwert der Täterschaft oder dem der Beihilfe entspricht. Hierbei handelt es sich um eine Frage, die weder vom Gesetz beantwortet ist noch in der Literatur bisher eindeutig gelöst werden konnte ${ }^{674}$. Keinem der bestehenden Lösungsansätze kann vorgehalten werden, daß er in sich nicht schlüssig oder logisch unvertretbar sei ${ }^{675}$. Nach Roxin stellt die Abgrenzung von Täterschaft und Teilnahme bei Unterlassungen das heute wohl noch ungeklärteste Gebiet der Beteiligungslehre dar ${ }^{676}$.

Dieser Streit könnte unter Umständen vernachlässigt werden, wenn er keine oder nur geringe Konsequenzen für die Strafbarkeit des Unterlassenden hätte. Die gravierende Bedeutung der Beteiligungsproblematik ergibt sich jedoch aus der obligatorischen Strafmilderung der Beihilfe gem. § 27 Abs. 2 StGB, während $\S 13$ Abs. 2 StGB nur eine fakultative Strafmilderung vorsieht ${ }^{677}$. Fernerhin macht es einen Unterschied, ob jemand als Täter oder nur als Gehilfe eines Delikts verurteilt wird ${ }^{678}$. Und schließlich folgt aus der Entscheidung für oder gegen die Täterschaft, ob eine Straflosigkeit der versuchten Beihilfe eintritt ${ }^{679}$. Es ist daher unumgänglich, diese Problematik zu klären.

\footnotetext{
${ }^{673}$ Grünwald, GA 59, 110 (112).

${ }^{674}$ Schultz, Amtswalterunterlassen, S. 176; Sowada, Jura 86, 399 (403).

${ }^{675}$ Seier, JA 90, 382 (384).

676 Ähnlich auch Grünwald, GA 59, 110 (111), der auf ein Fehlen von grundsätzlichen Erörterungen hinweist; Roxin, Täterschaft, S. 661.

${ }^{677}$ Vgl. Busse, S. 21.

${ }^{678}$ Bereits aus der Tenorierung geht hervor, ob jemand als Täter oder "nur" als Teilnehmer bestraft wird und inwieweit aufgrund einer Milderung aufgrund von Beihilfe vorgenommen wurde.

${ }^{679}$ Vgl. Schultz, Amtswalterunterlassen, S. 176.
} 
2. Allgemeine Schwierigkeiten bei der Bestimmung der Beteiligungsform

$\mathrm{Zu}$ den allgemeinen Schwierigkeiten der Thematik lassen sich zunächst einige grundsätzliche Fragen aufwerfen, zu deren Lösung die Darstellung der anschließend behandelten Theorien beitragen soll.

Diejenigen Auffassungen, die für den Unterlassungsbereich die Täterschafts- und Teilnahmeregeln unmittelbar von den Begehungsdelikten übernehmen, sehen sich vor das unüberwindbare Hindernis gestellt, daß bei den Unterlassungsdelikten eine Unterscheidung in Täterschaft und Teilnahme zumindest in objektiver Hinsicht nicht möglich ist. Durch das bloße Nichtstun zeigen sich nach außen weder die Tatherrschaft noch der Wille, die Tat als eigene zu verwirklichen.

Diejenigen hingegen, die ausschließlich Täterschaftsregeln für den Untätigen anwenden ${ }^{680}$, verzichten auf solche, den Beteiligten begünstigende Differenzierungen (die Strafmilderung gem. § 27 StGB und die Straflosigkeit versuchter Beihilfe) und befürworten damit unter Umständen eine nicht $\mathrm{zu}$ rechtfertigende strengere Behandlung der unechten Unterlassungsdelikte gegenüber den Begehungsdelikten. Auf der anderen Seite übersehen diejenigen, die stets Beihilferegeln anwenden, daß keineswegs in allen Fällen eine obligatorische Strafmilderung oder eine Straflosigkeit des Versuchs gerechtfertigt ist.

Die Zustimmung zu einer Theorie, die generell nur Täterschaft oder nur Teilnahme für den Untätigen annimmt, setzt im übrigen voraus, daß der Gesetzgeber nicht, etwa durch die $\S \S 25 f f$. StGB, eine regelmäßige Differenzierung in Täterschaft oder Teilnahme anordnet, so daß im Bereich des Unterlassungsdelikts ein "Einheitstäter" möglich ist. Auf der anderen Seite ist zu klären, ob die $\S \S 25 \mathrm{ff}$. StGB für Unterlassungsdelikte Anwendung finden, also daraus Schlüsse für die Begehungsform beim Unterlassen $\mathrm{zu}$ ziehen sind. Dagegen könnte sprechen, daß im Unterlassungsbereich, anders als im Bereich der

\footnotetext{
${ }^{680} \mathrm{Zu}$ den einzelnen Vertretern siehe unten, Gliederungspunkt 4. ff.

${ }^{681}$ Vgl. dazu Sowada, Jura 86, 399 (402).
} 
Begehung, nicht nach objektiven Kriterien zwischen den Beteiligungsformen entschieden werden kann. Entscheidende Frage ist damit, ob das Gesetz in den $\S \S 25 \mathrm{ff}$. StGB eine Differenzierung in Täterschaft und Teilnahme für das menschliche Verhalten allgemein anordnet und sich somit sowohl auf das Begehen als auch auf Unterlassen bezieht ${ }^{682}$.

Da die Abgrenzung von Täterschaft und Teilnahme bei der unterlassenen Deliktsverhinderung nicht vom Gesetz beantwortet ist ${ }^{683}$ und somit der Auslegung überlassen ist, ob die $\S \S 25 \mathrm{ff}$. StGB auch auf das Unterlassen anwendbar sind, könnte hier eine Gesetzeslücke vorliegen. Wenn man bedenkt, daß schon die Schaffung des $\S 13$ StGB mit erheblichen Schwierigkeiten verbunden war, erscheint es jedoch unlösbar, eine so spezielle Konstellation wie die der unterlassenen Deliktsverhinderung ins Gesetz aufzunehmen. Dies liegt auch daran, daß die Beurteilung der Begehungsform nach wie vor nicht einheitlich gelöst ist. Als entscheidende Frage hat dabei allerdings zu gelten, ob die Behandlung der unterlassenen Deliktsverhinderung aus verfassungsrechtlichen Gründen kodifiziert werden $m u \beta^{684}$. Dies hängt von der Einschätzung $a b$, wann überhaupt eine Regelung kodifiziert werden muß. Angesichts so vieler anderer nicht ausdrücklich geregelten Rechtnormen im Strafgesetzbuch (man vergleiche nur die Kriterien der Abgrenzung von Täterschaft und Teilnahme beim Begehungsdelikt; die Notwendigkeit der Kausalität der Beihilfe) wird man wohl auch im vorliegenden Falle trotz des Bestimmtheitsgrundsatzes des Art. 103 Abs. 2 GG eine Kodifizierung nicht zwingend einfordern können.

Da das Gesetz, wie festgestellt, keine Aufschlüsse gibt, müssen andere Wege gefunden werden, um die Beteiligungsform zu bestimmen. Für die Untersuchung der Frage, ob Täterschaft oder Teilnahme vorliegt, bestehen im wesentlichen zwei verschiedenartige Ansätze. So wird von der Rechtsprechung und von einem Teil der Lehre das Kriterium der

\footnotetext{
${ }^{682}$ Vgl. Schmidhäuser, AT, 17/9.

${ }^{683}$ Sowada, Jura 86, 399 (403).

684 Landscheidt, führt aus, daß kaum eine Materie des Allgemeinen Teils derart von verfassungsrechtlichen Überlegungen durchdrungen sei wie das Problemfeld der Unterlassungsdelikte und verweist auf die Brisanz im Hinblick auf Art. 103 GG, vgl. Problematik der Garantenpflichten, S. $63 f$.
} 
Tatherrschaft auch für die Unterlassungsdelikte herangezogen. Andere stellen ganz auf die Garantenstellung ab. Diese verschiedenen Ansätze sind im folgenden zu untersuchen ${ }^{685}$.

3. Der Zeitpunkt des Eingreifens als Maßstab für die unterschiedlichen Voraussetzungen der Beteiligungsform

Der Gedanke, daß dem Garanten nur so lange die Täterschaft verwehrt ist, wie der Begehungstäter handelt, bedarf der näheren Überprüfung. Kann es für die Beteiligungsform des Untätigen darauf ankommen, ob der Begehungstäter die Handlung, die zum Erfolg führen soll, noch vornimmt, oder ob er sie bereits abgeschlossen und sich entfernt hat, so daß der Erfolg von allein eintreten wird ?

Eine solche Fragestellung setzt voraus, daß es auch in der Phase nach der rechtsgutsschädigenden Handlung noch auf die Garantenstellung ankommt, der Garant also nicht durch die bereits geschehene Deliktshandlung von seiner Überwacherpflicht frei geworden ist. Davon ist, wie im 3. Teil B III 2 erörtert, auszugehen.

Es mag ungereimt erscheinen, den Garanten, der die hilfsbedürftige Obhutsperson verbluten läßt, nachdem der Totschläger seinen Angriff abgeschlossen und den Tatort verlassen hat, als Unterlassungstäter einzustufen, ihn dagegen während der laufenden Tötungstat als Unterlassungsgehilfen anzusehen. Obwohl die Hilfe weit effektiver gewesen wäre, wenn der Garant den Tötungsakt von vorneherein unterbunden hätte, erhebt man gegen ihn insoweit nur den minderschweren Vorwurf der Beihilfe ${ }^{686}$.

Für eine Beihilfe des Untätigen zum Zeitpunkt, zu dem der aktive Täter noch am Werke ist, könnte sprechen, daß im allgemeinen die Überwindung des entgegenstehenden Handlungswillens des Begehungstäters größere Anforderungen an den Garanten stellt als der

\footnotetext{
${ }^{685}$ Soweit auf bereits bestehende Darstellungen verwiesen werden konnte, wurde die vorliegende Argumentation kurz gehalten.- Zu berücksichtigen ist, daß die folgenden Theorien für die Deliktshinderung einer vollverantwortlichen Person entwickelt wurden und oft für Nicht-Verantwortliche Personen zu anderen Ergebnissen kommen. Daher wird noch zu klären sein, ob die gewonnenen Ergebnisse auf die strafrechtliche Beziehung zwischen Eltern und Jugendlichen angewendet werden können.
} 
rettende Zugriff nach Abschluß des Angriffs. Das Unrecht des Unterlassenden wird also um so größer, je weiter der aktive Täter sich vom Ort des Geschehens entfernt. Eine solche Schlußfolgerung setzt allerdings voraus, daß mit der Beendigung der Tathandlung kein entgegenstehender Wille des Aktiven mehr überwunden werden muß. Das ist nicht regelmäßig so: Unter Umständen muß der Garant auch dann noch gegen den Willen des aktiven Täters ankämpfen, wenn der Aktive seine Tathandlung beendet hat, wenn nämlich der Wille des Täters durch Drohungen gegen den Garanten oder durch sonstige Beeinflussung in dem Geschehen nachwirkt.

Unter der Voraussetzung, daß der Begehungstäter den Tatort verlassen oder auch sonst keine Macht mehr über den Garanten hat, bleibt immer noch fraglich, ob dadurch der rettende Zugriff für den Garanten erleichtert wird. Dagegen wird von Sowada eingewandt, es sei für einen Bademeister erheblich einfacher, die Jugendlichen, die zum Spaß Nichtschwimmer ins Becken stoßen, durch einen strengen Blick davon abzuhalten, als den Nichtschwimmer anschließend aus dem Becken zu holen $^{687}$. Man könnte also effektiver und leichter vor dem Beginn der Schädigungshandlung etwas bewirken. Allerdings ist gerade das von Sowada gewählte Beispiel unglücklich, weil die Rechtsgutsverletzung zum ersten Eingriffszeitpunkt noch nicht begonnen hat und nur dadurch die Überwindung des entgegenstehenden Willens leichter möglich ist. Nicht untersucht ist darin, ob es für den Bademeister leichter wäre, die Übeltäter zu stoppen, wenn sie gerade dabei sind, den Nichtschwimmer ins Wasser zu stoßen, als diesen anschließend aus dem Wasser zu retten. Um von einem entgegenstehenden Täterwillen sprechen zu können, muß das Versuchsstadium der Begehungstat schon erreicht sein. Erst dann manifestiert sich der Handlungswille des aktiven Täters, gegen den der Garant vorgehen muß. Ab Eintritt des Versuchsstadiums klingt der Gedanke, daß der Garant nicht erst abwarten soll, bis der Schaden vollständig eingetreten ist, sondern daß er vielmehr die schädigende Handlung in ihrem Verlauf stoppen soll, also bereits die Ursache anstatt der Folge, plausibel.

\footnotetext{
${ }^{686}$ Seier, JA 90, 382 (384).

${ }^{687}$ Sowada, Jura 86, 399 (403).
} 
Problematisch bleibt, daß der Garant in einem ganz anderen Maße den auf den Taterfolg gerichteten Willen überwinden muß, um den Begehungstäter aufzuhalten, als wenn er niemanden mehr aufzuhalten hat, weil der Begehungstäter den Tatort verlassen hat. Er muß dann nur gegen die Folgen der Tat, nicht aber gegen den Täter angehen. Hier läuft man erneut Gefahr, die Beteiligungsform nach der jeweiligen Erfolgsabwendungsmöglichkeit zu bestimmen. Daß es schwieriger ist, den Erfolg entgegen dem Wirken des Aktivtäters zu verhindern, darf nicht dazu führen, daß automatisch daraus auf eine Beihilfe des Unterlassenden geschlossen wird. So weist auch Roxin darauf hin, daß man sich den Handlungstäter gerade nicht als mit einem Revolver Bewaffneten vorstellen dürfe, der den hilfswilligen Garanten vertreiben oder ernsthaft gefährden könne. Denn die Bestrafung wegen Unterlassens setze ja neben der Erfolgsabwendungsmöglichkeit die Zumutbarkeit des Eingreifens voraus, welche bei einer Bedrohung des eigenen Lebens gerade nicht gegeben wäre ${ }^{688}$. Die Schwierigkeit der Erfolgsabwendung als solche -unabhängig davon, ob der Untätige sich gegen einen Dritten oder gegen eine Naturgewalt behaupten muß - ist folglich auch hier irrelevant.

Geht man mit der h. M. davon aus, daß der Garant allein den Eintritt des Erfolgs zu verhindern hat, gilt seine Pflicht unabhängig davon, ob der Täter noch anwesend ist oder nicht.

4. Übernahme der Täterschaftskriterien von den Begehungsdelikten

Nach der wohl noch überwiegenden Auffassung der Rechtsprechung und der Literatur ${ }^{689}$ können die für die Begehungsdelikte entwickelten Täterschaftskriterien auf die Unterlassungsdelikte übertragen werden. Danach ist entweder der Tatherrschaftslehre, die auf das In-den-HändenHalten der Tatausführung abstellt oder der subjektiven Theorie, nach der es auf die innere Einstellung des Täters zur Tat ankommt, zu folgen.

\footnotetext{
${ }^{688}$ Roxin, Täterschaft, S. 498.

${ }^{689}$ Darstellung bei SK-Rudolphi, Vor § 13, Rn. 39; S/S-Cramer, Vor § 25, Rn. 85ff.; Ranft, ZStW 94 (1982), 815 (823ff.); Kielwein, GA 55, 225 (227); Maurach/Zipf, AT 2, S. 328; Schroeder, Der Täter, S. 105ff.
} 
Nach beiden Strömungen sind also Täterschaft oder Teilnahme durch den Unterlassenden möglich, jeweils abhängig vom jeweiligen Einzelfall.

\section{a) Tatherrschaftstheorie}

Dieser Auffassung nach gelten die für die Begehungsdelikte aufgestellten Kriterien der Tatherrschaft auch für die Unterlassungsdelikte. Danach ist Täter, wer die Tatherrschaft innehat. In diesem Sinne beherrscht derjenige die Tat, der das Tatgeschehen in den Händen hält und über das $\mathrm{Ob}$ und Wie der Tat maßgeblich entscheidet. Dabei werden subjektive und objektive Prinzipien zu einer Sinneinheit verknüpft, so daß Steuerungswille und tatsächlicher Tatanteil gleichermaßen von Bedeutung für die Bestimmung der Tatherrschaft sind ${ }^{690}$.

Das Vorliegen der Tatherrschaft soll auch bei Unterlassungsdelikten darüber entscheiden, ob beim Untätigen Täterschaft oder Beihilfe vorliegt. Der Garant, der trotz der Hinderungsmöglichkeit nicht gegen die Tat des ihm Anbefohlenen einschreitet, wäre also je nach Vorliegen der eigenen Tatherrschaft Täter oder Teilnehmer der Unterlassungsdelikts. Die Vertreter dieser Auffassung gelangen jedoch vorwiegend zur Strafbarkeit des Untätigen wegen Beihilfe ${ }^{691}$. Es ist insofern zweifelhaft, ob von den Vertretern dieser Ansicht die Tatherrschaftstheorie konsequent angewendet wird.

Fraglich ist, wann und wodurch der Garant beim Unterlassungsdelikt die Tatherrschaft, die Entscheidung über das $\mathrm{Ob}$ und Wie der Tat, innehat. Kraft seiner Stellung im Gesamtgeschehen soll der Garant immer dann die Tatherrschaft haben, wenn der Eintritt des strafrechtlichen Erfolges ausschließlich von seinem Verhalten abhängt ${ }^{692}$.

Hat der Begehungstäter den Tatort verlassen und ist eine Verhinderung des Erfolges noch möglich, ist diese Schlußfolgerung einleuchtend. Es hängt dann allein vom Garanten ab, ob er den Erfolg eintreten läßt oder den Erfolgseintritt verhindert, indem er einschreitet. Ist der Begehungstäter jedoch noch am Werke und wäre nur $\mathrm{zu}$ diesem Zeitpunkt eine Tatverhinderung durch den Untätigen möglich, ist diese

\footnotetext{
${ }^{690}$ S/S-Cramer, Vor § 25, Rn. 62.

${ }^{691}$ So jedenfalls Seier, JA 90, 382 (384); von Sowada, Jura 86, 402 als "Einheitsbeihilfe" bezeichnet.

${ }^{692}$ Kielwein, GA 55, 225 (226).
} 
Überlegung nicht sehr erhellend. Daß der Garant die Tatherrschaft besitzt, wenn der Eintritt des Erfolges ,ausschließlich von ihm abhängt“, erweist sich als Zirkelschluß. Denn es muß gerade dafür ein Kriterium gefunden werden, in welchen Fällen oder zu welchem Zeitpunkt der Erfolgseintritt ausschließlich vom Garanten abhängt.

aa) Steuerndes In-den-Händen-Halten als Tatherrschaftsmerkmal

Gegen die Übernahme der Täterschaftskriterien auf Unterlassungsdelikte spricht das schwerwiegende Argument, daß beim Unterlassen gerade von einem steuernden In-den-Händen-Halten des Tatverlaufs nicht die Rede sein kann. Wenn überhaupt, kann nur von einer potentiellen Tatherrschaft gesprochen werden. Denn das Tatunrecht des Unterlassenden liegt hier gerade darin, daß er die ihm zugängliche Tatherrschaft nicht an sich reißt, d.h. daß er die Tatherrschaft pflichtwidrig nicht ausübt. Eine Situation „lenken” i.S.d. Tatherrschaft kann schon begrifflich nur ein aktiv Handelnder. Diese Lenkung fehlt gerade bei demjenigen, der den Dingen nur ihren Lauf läßt, seinen Willen also gerade nicht umsetzt und somit die Entwicklung des Geschehens nicht beeinflußt. Da sich der Handlungsablauf durch Nichtstun nicht gestalten oder beherrschen läßt, scheidet ein Anknüpfen an die Tatherrschaft aus ${ }^{693}$.

bb) Die Erfolgsverhinderungsmöglichkeit als Tatherrschaftsmerkmal Es bliebe für eine Tatherrschaft durch Unterlassen nach dem eben Gesagten nur die potentielle Tatherrschaft in Form der Eingriffsmöglichkeit.

Wird die Tatherrschaft mit der individuellen Erfolgsabwendungsmöglichkeit identifiziert, so wäre sie jedoch mit jedem pflichtwidrigen Unterlassen bereits gegeben, da die individuelle Erfolgsabwendungsmöglichkeit gerade konstitutives Merkmal der Pflichtwidrigkeit ist ${ }^{694}$. Die Eingriffsmöglichkeit ist eine Voraussetzung der Strafbarkeit jedes Unterlassens ${ }^{695}$. Sie kann daher nicht zur Bestimmung der Tatherrschaft herangezogen werden.

\footnotetext{
${ }^{693}$ Roxin, Täterschaft, S. 463.

${ }^{694}$ Vogel, Norm und Pflicht, S. 276f.; Jakobs, AT, 29/105.

${ }^{695}$ Roxin, Täterschaft, S. 462.
} 
Dennoch wird versucht, die Tatherrschaft mit Hilfe der Erfolgsverhinderungsmöglichkeit $\mathrm{zu}$ beschreiben. Dies geschieht insbesondere, um eine Erkennbarkeit bzw. Feststellbarkeit der Tatherrschaft zu ermöglichen. Denn beim Unterlassen ist es nach außen kaum ersichtlich, ob der Täter die Tatherrschaft innehat. Dieses Problem soll dadurch entfallen, daß die Tatherrschaft vielfach mit der Möglichkeit der Erfolgsverhinderung übereinstimme, wodurch man die Tatherrschaft feststellen könne. In diesem Zusammenhang nennt Schroeder das Beispiel, in dem es dem kraftstrotzenden Mann leichter möglich wäre, die Tötung seines Kindes durch einen Dritten zu verhindern, als einem zitternden schmächtigen Mann. Ersterer wäre Täter, letzterer, indem er die wenig Erfolg versprechende Gegenwehr unterlasse und damit die Tat fördere, Gehilfe ${ }^{696}$. Hiermit ist jedoch eine zuverlässige Abgrenzung nicht zu leisten, denn zu viele unsichere Faktoren wie das Ausmaß der nötigen Kraft, die Art der vorzunehmenden Handlung und die Stärke des Handelnden spielen hier hinein ${ }^{697}$.

Vor allem aber steht einer solchen Lösung entgegen, daß danach die Möglichkeit der Erfolgsverhinderung mit der Tatherrschaft identisch sein soll $^{698}$. Die Tatverhinderungsmöglichkeit darf nicht das allein über die Täterschaft entscheidende Kriterium sein. Wenn die Tatverhinderungsmöglichkeit tatsächlich über die Tatherrschaft entschiede, ergäbe sich folgende Konsequenz: Bejahte man die Erfolgsverhinderungsmöglichkeit, läge Tatherrschaft vor und somit eine Täterschaft. Ginge man hingegen davon aus, daß eine Erfolgsabwendung nicht möglich war, müßte Straflosigkeit eintreten, weil der Unterlassende nicht verpflichtet ist, eine von vorneherein sinnlose Handlung vorzunehmen. Woraus aber soll sich danach eine Unterlassungsbeihilfe ergeben, die gemäß der Tatherrschaftslehre möglich sein muß ? Die Beihilfe müßte sich danach richten, wie groß die Möglichkeit der Erfolgsabwendung für den Garanten gewesen ist. Dies führt zu weiteren Schwierigkeiten bei der Bestimmung, ob der Untätige hätte Erfolg haben können oder nicht. Letztlich findet nur eine Verlagerung des Problems der Bestimmung der Tatherrschaft auf die

${ }^{696}$ Schroeder, Der Täter, S. 105.

${ }^{697}$ Schulz, Amtswalterunterlassen, S. 181. 
Erfolgsabwendungsmöglichkeit statt. Eine Antwort ist jedoch nicht gefunden.

$\mathrm{Zu}$ dieser Problematik nimmt auch Roxin Stellung. Er führt aus, daß ein Unterlassender dann Tatherr sein müsse, wenn die Erfolgsabwendung ohne große Mühe für ihn möglich wäre. Aber, so wendet er ein, habe auch derjenige, der nur mit Mühe das Schicksal wenden kann, den Erfolg in der Hand. Zudem deutet er die Schwierigkeit an, einigermaßen sichere Abstufungen und Grenzziehungen vorzunehmen ${ }^{699}$.

Weiter ist $\mathrm{zu}$ hinterfragen, wie im Vergleich zur eben behandelten physischen die psychische Schwäche zu bewerten ist. Hat ebensowenig derjenige eine Verhinderungsmöglichkeit, der es aus Angst oder Schrecken nicht fertig bringt, in das Geschehen einzugreifen, obwohl er physisch der Situation durchaus gewachsen wäre ? So wäre die Möglichkeit der Erfolgsverhinderung auch von der Zumutbarkeit abzugrenzen. Ob der Vater, der seinem jugendlichen Sohn zwar physisch gewachsen ist, ihn zur Not mit körperlicher Gewalt am Weitermachen hindern muß, hängt nicht zuletzt von den Gefahren $a b$, die er für sich selbst zu befürchten hat. Dies ist aber keine Frage von Täterschaft und Teilnahme mehr, sondern der Zumutbarkeit.

Roxin zeigt außerdem, wohin eine konsequente Anwendung einer so verstandenen Tatherrschaft führen müßte: Die Tatherrschaftslehre müßte immer zum Ergebnis einer Täterschaft kommen, geht man von einer regelmäßigen Eingriffsmöglichkeit aus. Die Tatherrschaft wäre nämlich immer vorhanden und damit nichtssagend. Es fehlt damit in Wirklichkeit ein Kriterium zur Bestimmung der Täterschaft ${ }^{700}$.

Schließlich spricht gegen die Erfolgsverhinderungsmöglichkeit als Täterschaftskriterium ein Vergleich mit den Begehungsdelikten. Bezogen auf die Begehungsdelikte würde der Gedanke, daß die Schwierigkeit, mit der der Täter die Tat durchführen konnte, über seine Täterschaft entscheidet, grotesk anmuten. Trotz aller Unterschiede von Tun und Unterlassen muß dieser Grundsatz bestehen bleiben. Die Begehungsform darf sich nicht allein danach bestimmen, wie einfach sich die Ausführung bzw. die Verhinderung des Erfolges für den Beteiligten darstellt.

\footnotetext{
${ }^{698} \mathrm{Vgl}$. Schulz, Amtswalterunterlassen, S. 182.

${ }^{699}$ Roxin, Täterschaft, S. 464.
} 
cc) Soziale Tatherrschaft

Schon Gallas hat die Möglichkeit einer sozialen Tatherrschaft angedeutet. Danach sei es denkbar, daß - nach seiner Auffassung ausnahmsweise - dann eine Täterschaft für den Unterlassenen gegeben sei, wenn das Wohl und Wehe so vollständig von der Erfüllung der Schutzfunktionen abhängig sei, daß das Untätigbleiben an sozialem Gewicht der Erfolgsherbeiführung durch den handelnden Täter gleichkomme ${ }^{701}$.

Arzt will an die soziale Rolle des Unterlassenden anknüpfen ${ }^{702}$. Der Inhaber einer gewichtigen sozialen Rolle sei immer als Täter zu werten, unabhängig davon, ob er handele oder unterlasse.

Nach Roxin wäre zumindest eine Tatherrschaft nach dem sozialen Sinn denkbar, wonach die Untätigkeit nicht mehr als Unterlassen, sondern als Erscheinungsform der Begehungstat erscheint. Als klassische Beispiele nennt er die Mutter, die ihr Kind verhungern läßt, und den Bahnwärter, der einen Zusammenstoß der Züge herbeiführt, indem er die Weiche nicht stellt. In diesen Fällen würde das soziale Urteil im Sprachgebrauch seinen Ausdruck finden, indem man davon spräche, daß die Mutter bzw. der Bahnwärter ihre Opfer "getötet" hätten und damit die Opfer auch ihrer Herrschaft unterlegen hätten ${ }^{703}$. Bei dem Vater hingegen, der sein von alleine ins Wasser gefallenes Kind nicht vor dem Ertrinken bewahrt oder bei dem Polizisten, der nicht gegen eine Sachbeschädigung vorgeht, sei keine solche Formulierung denkbar ("Der Vater tötet sein Kind", "Der Polizist begeht eine Sachbeschädigung"). Daraus Schlüsse zu ziehen, bedeute nicht, daß man auf die willkürlichen Unwägbarkeiten des Sprachgebrauchs abstelle. Es handele sich vielmehr um eine qualitative Andersartigkeit zwischen solchen Unterlassungen, bei denen das Nichtstun im sozialen Sinn einem Begehen gleicht, und anderem, bei dem es seinen Unterlassungscharakter behält. Niemand würde der Mutter wegen der täglichen Mahlzeiten für ihr Kind oder dem Weichensteller wegen seiner gewöhnlichen Dienstausübung als Rettern von

\footnotetext{
${ }^{700}$ Roxin, Täterschaft, S. 464.

${ }^{701}$ Gallas, Anmerkung zu BGHSt in JZ 52, S. 372.

702 Arzt, JA 80, 553 (558).

${ }^{703}$ Roxin, Täterschaft, S. 465.
} 
Menschenleben Anerkennung aussprechen. Hier würde man nicht auf den Gedanken kommen, eine ständige Abwendung von Todeserfolgen anzunehmen. Anders dagegen würde wohl ein Lob dem Vater oder dem Polizeibeamten ausgesprochen werden. Nach Roxin beruht eine solche Differenzierung darauf, daß beim Unterlassen von gesellschaftlich eingeplanten Tätigkeiten, die zur Funktionsfähigkeit des sozialen Organismus beitragen, wie Kinderernährung und Verkehrsregulierung, ein Begehen anzunehmen wäre. Wo ein Tun dagegen im gewöhnlichen Ablauf der Dinge nicht vorgesehen sei, wie bei der Lebensrettung und der Deliktsvereitelung, läge im sozialen Sinn ein Unterlassen vor.

Dennoch lehnt Roxin zu Recht eine solche Lösung insgesamt ab. Der Regelfall des Unterlassungsdelikts sei gerade der, daß der Untätige einen kraft irregulärer Umstände drohenden Schaden nicht verhindere. In diesen Fällen wäre also auch nach dem sozialem Sinn ein Unterlassen gegeben. Das würde dann jedoch bedeuten, daß keine Tatherrschaft und damit auch keine Täterschaft des Unterlassenden bestände. Ohne einen aktiven Beteiligten müßte sogar Straflosigkeit eintreten. Wäre eine solche Auffassung haltbar, müßte man die gesamte Unterlassungslehre als unbrauchbar einstufen ${ }^{704}$.

Wird die Tatherrschaft mit dem "sozialen Sinn" identifiziert, wird die bloße Beihilfe außerdem z.T. der institutionell garantierten Pflicht nicht gerecht $^{705}$. Das zeigt das Beispiel von Arzt: Danach sollen, wenn der Kapitän das Schiff auf die Klippen treiben läßt, der Kapitän als Täter, die Matrosen nur als Gehilfen zu behandeln sein. Damit wird nicht das Kriterium der Tatherrschaft, sondern das der sozialen Rolle der Beteiligten als maßgebend angesehen ${ }^{706}$. Die Frage, ob jemand aufgrund seiner sozialen Rolle besondere Hindernisse zur Erfolgsabwendung überwinden mußte (z.B. muß der Matrose den Offizier von der notwendigen Maßnahme überzeugen), dürfte aber kaum von der faktischen Erfolgsabwendungsmöglichkeit abzugrenzen sein.

Schließlich liegt durch eine Unterscheidung nach sozialen Gesichtspunkten die Gefahr nahe, daß das subjektive Strafwürdigkeitsempfinden getarnt Eingang in die Tatbestandslehre

\footnotetext{
${ }^{704}$ Roxin, Täterschaft, S. $465 f f$.

${ }^{705}$ Vgl. Vogel, Norm und Pflicht, S. 276f.; Jakobs, AT, 29/105.
} 
findet. Wonach bestimmt sich, wer welche soziale Rolle auszufüllen innehat und wie diese auszufüllen ist ? Weder Strafwürdigkeits- noch Strafzumessungserwägungen dürfen aber zur Grundlage der Täterlehre gemacht werden ${ }^{707}$. In die gleiche Richtung argumentiert Schulz, wenn er darauf hinweist, daß die rechtliche und die soziale Gewichtung sich nicht immer decken ${ }^{708}$.

dd) Ergebnis

Insgesamt ergibt sich, daß die Tatherrschaftslehre keine Anwendung auf die Unterlassungsdelikte finden kann.

b) Subjektive Abgrenzungslehre

Nach der subjektiven Theorie entscheidet die innere Haltung des Unterlassenden zur Begehungstat des anderen und zum Taterfolg darüber, ob sein pflichtwidriges Untätigbleiben als Beihilfe oder als Täterschaft zu werten ist. Wesentliches Indiz ist dabei das Interesse am Taterfolg $^{709}$.

Die Rechtsprechung folgt nach eigener Erklärung der subjektiven Theorie $^{710}$. Allerdings findet keine konsequente Befolgung der dort aufgestellten Regeln statt, vielmehr werden die subjektiven Elemente mit solchen objektiven der Tatherrschaftslehre vermischt, so daß eine Abgrenzung kaum möglich erscheint. Die innere Haltung des Unterlassenden soll zwar darüber entscheiden, ob er durch sein Untätigbleiben Täter oder Teilnehmer ist. Die innere Haltung bestimmt sich nach der Rechtsprechung jedoch nicht nur nach den subjektiven Kriterien wie dem Interesse am Erfolg und der Willensrichtung des Untätigen, sondern auch nach dem Umfang der eigenen Tatbestandsverwirklichung und der Tatherrschaft selbst ${ }^{711}$. Des weiteren wird anerkannt, daß der Hilfspflichtige regelmäßig die volle oder doch

\footnotetext{
${ }^{706}$ So zumindest Schulz, Amtswalterunterlassen, S. 181; Arzt, JA 80, 553 (558).

${ }^{707}$ Roxin, Täterschaft, S. 509.

${ }^{708}$ Schulz, Amtswalterunterlassen, S. 194.

${ }^{709}$ RGSt 74, 84 (85); BGHSt 6, 226 (229).

${ }^{710}$ BGH StrV 86, 59 (Eisenpoller-Fall); BGHSt 2, 150 (151, 155f.) (Abwendung einer Lebensgefahr für den Ehegatten); im Ergebnis auch RGSt 72, 373 (375) (Mutter läßt zu, daß Tochter ihr in der Wohnung der Mutter geborenes Kind tötet).

${ }^{711}$ BGHSt 8, 70 (73); 8, 393 (396); BGHSt 19, 135 (138f.).
} 
einen großen Teil der Herrschaft über die Sachlage habe und ihr durch sein Eingreifen die entscheidende Wendung geben könne ${ }^{712}$. Es sind also deutlich objektive Kriterien eingeflossen. In seinen neueren Entscheidungen wendet sich der Bundesgerichtshof wieder stärker der subjektiven Theorie $\mathrm{zu}^{713}$.

Wegen ihrer Uneinheitlichkeit kann zumindest die Rechtsprechung nicht als dogmatisch eigenständige Auffassung behandeln werden. $\mathrm{Zu}$ den von ihr miteinbezogenen Elementen der Tatherrschaft wurde bereits oben Stellung (vgl. 3.a) genommen. Im folgenden sollen die von der Rechtsprechung verwendeten Inhalte der subjektiven Theorie untersucht werden.

Entscheidend ist nach der subjektiven Theorie insbesondere das Interesse am abzuwendenden Taterfolg als Ausdruck eines sich die Tat des anderen $\mathrm{zu}$ eigen machenden Täterwillens. Ist hingegen die innere Einstellung des Untätigen davon geprägt, daß er sich dem Handelnden etwa weil er dessen bestimmendem Einfluß besonders unterliegt - im Willen unterordnet und das Geschehen ohne innere Beteiligung und ohne Interesse am drohenden Erfolg lediglich ablaufen läßt, soll er als Gehilfe eingestuft werden ${ }^{714}$. Roxin weist darauf hin, daß die subjektive Theorie besonders gut auf die Unterlassungsdelikte zu passen scheint: Je weniger objektive Unterschiede im Verhalten mehrerer Unterlassender aufzufinden sind, desto näher liegt es, die Abgrenzung allein nach der inneren Einstellung der Beteiligten $\mathrm{zu} \operatorname{treffen}^{715}$. Von der subjektiven Lehre wird jedoch nur ungenau umrissen, wie die innere Tatseite tatsächlich ermittelt werden kann: „Das Wesen der Unterlassungstat erlaubt es nicht, die Täterschuld aus einer Handlung des Täters zu entnehmen; sie läßt sich nur aus anderen, außerhalb des äußeren Hergangs liegenden Anhaltspunkten erschließen" ${ }^{\text {"716. }}$

Gegenüber der subjektiven Theorie als solcher bestehen bereits für den Bereich der Begehungsdelikte viele Zweifel, die hier nicht ein weiteres

\footnotetext{
712 BGHSt 2, 150 (155f.).

${ }^{713}$ BGH NStZ 92, 31 (31).

${ }^{714}$ BGH NStZ 92, 31 (31).

${ }^{715}$ Roxin, Täterschaft, S. 458.

${ }^{716}$ BGHSt 2, 150 (155f.).
} 
Mal diskutiert werden sollen ${ }^{717}$. Im Bereich der Unterlassungsdelikte muß hinzukommen, daß die innere Einstellung des Täters hier erst recht nicht erkennbar ist, weil sie sich nicht einmal durch die Art der realen Tatausgestaltung manifestieren kann. Dem könnte man zwar entgegengehalten, daß auch andere innere Vorgänge, wie etwa die Motive bei $\S 211$ StGB, festzustellen sind, die subjektive Theorie also deshalb brauchbar sei. Ein Vergleich mit $\S 211$ ist aber unpassend, denn gerade durch die Umstände einer aktiven Tötung können die damit verfolgten Motive deutlich werden.

Für die subjektive Theorie spricht, daß es im Unterlassungsbereich tatsächlich nicht nach objektiven Kriterien möglich ist, Täterschaft und Teilnahme zu unterscheiden. Da dieser Mangel im objektiven Bereich nicht dazu führen darf, daß die vom Gesetz in $\S \S 25 f f$. StGB für menschliches Verhalten allgemein angeordnete Differenzierung ignoriert wird, erscheint ein Abstellen auf subjektive Kriterien nicht abwegig. Für die Frage, wie Täter- und Teilnehmerwillen zu ermitteln sind, ergeben sich allerdings durch die subjektive Theorie keine Resultate. Die Tendenz der Rechtsprechung, grundsätzlich eine Beihilfe anzunehmen, zeugt weiter von einer eher hilflosen der Anwendung des Satzes "in dubio pro reo" als von einer dogmatisch sauberen Lösung.

Gegen die subjektive Theorie spricht weiter, daß sie gerade dort versagt, wo die Abgrenzung besonders wichtig ist: So erklärt der BGH, daß subjektive Kriterien zur Lösung der Beteiligungsproblematik beim Selbstmord ungeeignet seien, es sei vielmehr auf die Tatherrschaft abzustellen $^{718}$.

Nach Roxin versagt die subjektive Theorie, weil das Interesse am Taterfolg beim Unterlassen gänzlich unbrauchbar sei. Bestehe zwischen dem Begehungs- und dem Unterlassungstäter eine Beziehung, bei der der Unterlassende die Interessen des Aktiven berücksichtige, sei er schon kein Unterlassender mehr, sondern bereits (psychischer) Gehilfe oder Anstifter zu der Tat ${ }^{719}$. Beispiel: Der Nachtwächter einer Firma und der

\footnotetext{
717 Auch der unmittelbar die Tat Ausführende wäre u. U. nur Gehilfe, es käme zum Verstoß gegen $\S 25 \mathrm{I}$ a. Alt. StGB und zu einer beliebigen Austauschbarkeit von Täterschaft und Teilnahme; dazu vgl. LK-Roxin, § 25, Rn. $22 \mathrm{ff}$.

${ }^{718} \mathrm{Vgl}$. Schulz, Amtswalterunterlassen, S. 183; BGHSt 19, 135 (138f.).

${ }^{719}$ Roxin, Täterschaft, S. 491.
} 
Dieb vereinbaren, daß der Dieb nachts in die Firma einsteigen und Computer stehlen wird, während der Nachtwächter keinen Alarm auslösen wird. Der Nachtwächter gibt dem Dieb außerdem Ratschläge, an welchem Wochentag der Einbruch besonders günstig ist und welches Werkzeug er mitnehmen soll. Geht man davon aus, daß die aktive Tatbestandsverwirklichung der passiven vorgeht, liegt das verwerfliche Verhalten des Nachtwächters bereits in der Erteilung der Ratschläge, also in der aktiven Beihilfe, die vor dem Unterlassen des Alarmauslösens in der Tatnacht stattfindet. Wenn Roxin also insoweit meint, daß das Tatinteresse des Nachtwächters für die Behandlung des Unterlassens unbrauchbar ist, ist dem zuzustimmen.

Ein solches Tatinteresse besteht aber regelmäßig nur in den Fällen, in denen es eine irgendwie geartete Beziehung zwischen dem Aktiven und dem Passiven gibt. Das muß aber nicht der Fall sein, vielmehr kann der Unterlassende auch - vom Begehungstäter unerkannt - der Deliktsbegehung zusehen. Beispiel: Dem Nachtwächter ist es recht, daß in der Firma eingebrochen wird, weil man ihm, wie er meint zu Unrecht, zum nächsten Monat gekündigt hat. Er läßt den ihm unbekannten Dieb daher gewähren. Hier besteht ein Tatinteresse des Unterlassenden auch unabhängig von einer Beziehung zum Aktivtäter. Mit der Begründung alleine, ein Tatinteresse des Unterlassenden helfe nicht weiter, ist die subjektive Theorie daher nicht umzustoßen.

Problematischer hinsichtlich des eigenen Interesses an der Tat des Untätigen dürfte vielmehr sein, wie sich dieses anhand von objektiven Anzeichen feststellen läßt. Ob sich jemand einen finanziellen Vorteil durch die Tat eines anderen erhofft (etwa: der Sohn bringt seinen Eltern von jedem Einbruch "Geschenke" mit), läßt sich objektiv feststellen ${ }^{720}$. Anders ist es bei Beweggründen, die auf immateriellen Nutzen gerichtet sind (wenn die Eltern den Einbruch ihres Sohnes ins Nebenhaus etwa nur deshalb nicht verhindern, weil sie dem ungeliebten Nachbarn den Schaden gönnen). Das führt jedoch zum nächsten Kritikpunkt an der subjektiven Theorie.

\footnotetext{
${ }^{720}$ Vgl. OLG Braunschweig, GA 1963, 211 (211f.): Eine Mutter ließ es in ihrer Wohnung zu, daß ihr 15jähriger Sohn den von inm gestohlenen Alkohol und Tabak mit Freunden konsumierte, wobei die Mutter auch selbst mit trank und rauchte. Das OLG verurteilte wegen Begünstigung nach § $257 \mathrm{StGB}$.
} 
Die subjektive Theorie muß ihre Unterscheidungen der Beteiligungsformen allein auf die subjektiven Empfindungen des Unterlassenden stützen. Entscheidend muß also mangels anderer Anhaltspunkte sein, ob sich der Untätige über die Tatverwirklichung gefreut hat $^{721}$. Gerade solche inneren Regungen bleiben aber ohne objektive Folgen und sind richterlich nicht nachprüfbar. Zudem käme man mit einer Bestrafung, die allein an emotionalen Regungen festmacht, zu einem Gesinnungsstrafrecht !

Die subjektive Theorie kann weiterhin nicht erklären, woraus sich die Täterschaft beim unterlassenden "Alleintäter" bestimmen soll. Ist das im Fluß ertrinkende Kind ohne Zutun eines Dritten ins Wasser gefallen und wird dann vom Vater nicht gerettet, kann nicht die innere Haltung des Vaters darüber entscheiden, ob er Täter oder Teilnehmer ist. Es kann nicht darauf ankommen, daß er die Tat nicht als eigene will oder kein Interesse daran hat. Das gleiche muß aber auch für die Situation gelten, in der ein Dritter das Kind ins Wasser gestoßen hat, da das für die elterliche Erfolgsabwendungspflicht des Vaters ohne Belang ist ${ }^{722}$. Insgesamt ist daher auch der subjektiven Theorie nicht zu folgen.

5. Einheitliche Annahme einer Täterschaft oder einer Teilnahme

Die nun folgenden Auffassungen gehen davon aus, daß das Unterlassen nur einheitlich betrachtet werden kann und eine Strafbarkeit sich auf eine der beiden Beteiligungsformen festlegen muß.

Damit müssen solche Denkmodelle ausscheiden, die sowohl Täterschaft als auch Teilnahme i.S.d. $§ \S 25$ ff. StGB für möglich halten. Es kann daher zur Begründung einer anderen Auffassung weder auf die Tatherrschaft noch auf den Willen zur Tatherrschaft bzw. die innere Haltung des Unterlassenden zurückgegriffen werden.

\footnotetext{
${ }^{721}$ Vgl. Roxin, Täterschaft, S. 491.

${ }^{722}$ Roxin, Täterschaft, S. 491.
} 
a) Annahme einer grundsätzlichen Beihilfe des Unterlassenden

aa) Grünwald

Grünwald untersucht zunächst, ob nicht schon die Vorstellung, daß für die Beteiligung durch Unterlassen für die Grundsätze der Täterschaft oder der Beihilfe verwendbar seien, unrichtig ist, ob also die Beteiligung durch Unterlassen eine eigene Beteiligungsform neben Täterschaft und Beihilfe darstellt ${ }^{723}$. Er geht davon aus, daß die Begriffe Täterschaft und Beihilfe für die Beteiligung mehrerer Handelnder entwickelt worden sind und daher nicht einfach vorausgesetzt werden kann, daß die Beteiligung durch Unterlassen unter die gleichen Begriffe einzuordnen ist. Dies sei nur dann möglich, wenn es nicht einen wesensmäßigen Unterschied zwischen Tun und Unterlassen gäbe ${ }^{724}$.

Grünwald kommt zu dem Schluß, daß die Struktur der Unterlassung einheitlich ist, so daß auch nur einheitlich Täterschaft oder Teilnahme durch Unterlassen angenommen werden können ${ }^{725}$. Seiner Ansicht nach ist das Unterlassen neben der Täterschaft und der Teilnahme durch Handeln die dritte Beteiligungsform. Sie unterscheide sich von den ersten beiden dadurch, daß der Unterlassende nur eine potentielle Beziehung zu dem Geschehen habe. Die Unterscheidung der Beteiligungsformen Täterschaft und Teilnahme beruhe generell darauf, daß ihnen eine unterschiedliche Art und Stärke der Beherrschung des Geschehens eigen ist. Unter diesem Gesichtspunkt habe aber das Vorhandensein oder Fehlen der realen Einflußnahme auf das Geschehen ein beträchtliches Gewicht.

Bei der Beteiligung durch Unterlassen sei die reale Einflußnahme aber gerade kein Kriterium. Die Beteiligung durch Unterlassen könne darum weder der Täterschaft noch der Beihilfe durch Handeln gleichgesetzt werden $^{726}$.

Auch wenn die Beteiligung durch Unterlassen weder Täterschaft noch Teilnahme gleichzusetzen sei, stellt Grünwald doch zur Diskussion, ob sie der Täterschaft und Beihilfe zumindest entsprechend $\mathrm{zu}$ behandeln

\footnotetext{
${ }^{723}$ Grünwald, GA 59, 110 (111).

724 Grünwald, GA 59, 110 (111).

${ }^{725}$ Vgl. Schulz, Amtswalterunterlassen, S. 184.

${ }^{726}$ Grünwald, Unechtes Unterlassungsdelikt, S. 97, 101; GA 59, 110 (111).
} 
$\operatorname{sind}^{727}$. Anhaltspunkt und Vergleichsmaßstab seiner Überlegungen ist für Grünwald die Beihilfe durch Handeln. Der Unterlassende beherrscht danach das Geschehen noch weniger als ein aktiver Gehilfe. Im Ergebnis will Grünwald den Unterlassenden daher nach den Regeln für einen Gehilfen bestrafen.

Seine Auffassung stützt sich allein auf die folgende Überlegung: Wer als Gehilfe an der Tat eines anderen beteiligt ist, hat häufig im Anschluß daran die Möglichkeit, den Erfolg noch abzuwenden. An die Beihilfehandlung schließt also oft eine Unterlassung an. Entscheidend ist nun für die Auffassung Grünwald, daß die Beihilfe eine Ingerenz begründet, aber diese anschließende Unterlassung des Gehilfen dennoch nicht zu einer Bestrafung des ursprünglichen Gehilfen wegen Täterschaft führt. Daraus folgert Grünwald, daß die Unterlassung als solche gegenüber der Beihilfehandlung weniger schwer wiegt ${ }^{728}$. In ihrer Bewertung müsse die Unterlassung daher auch entsprechend behandelt werden, höchstens also mit der Strafe für die Beihilfe.

Probleme ergeben sich für diese Auffassung jedoch beim Beispiel eines Beschützergaranten $^{729}$ : Der Vater, der sein von einem Dritten ins Wasser gestoßenes Kind nicht rettet, wäre nur Gehilfe, während er als Täter einzustufen wäre, wäre das Kind alleine ins Wasser gefallen. Damit käme es beim Eingreifen eines Dritten $\mathrm{zu}$ einer ungerechtfertigten Begünstigung des Garanten gegenüber einer durch Naturereignisse verursachten Gefährdung ${ }^{730}$.

Grünwald wählt jedoch einen anderen Weg. Auch die ohne Mitwirkung Dritter erfolgte Unterlassung soll nur aus der Beteiligungsform der Beihilfe bestraft werden ${ }^{731}$. Wenn also eine Mutter ihr Kind verbluten läßt, so ist es für die Bewertung bedeutungslos, ob die Verletzung durch einen Dritten oder einen Unglücksfall verursacht ist. In beiden Fällen ist sie nur als Gehilfin zu bestrafen. Auf diese Weise umgeht Grünwald zwar den beschriebenen Wertungswiderspruch. Spätestens hier zeigt sich

\footnotetext{
${ }^{727}$ Grünwald GA 59, 110 (112).

${ }^{728}$ Grünwald, GA 59, 110 (113).

${ }^{729}$ Armin Kaufmann, Dogmatik, S. 269; Kielwein, GA 55, 227.

${ }^{730}$ Allerdings weist Sowada darauf hin, daß es genau solche Wertungen aber auch im Begehungsbereich gebe, Sowada, Jura 86, 399 (403); Arzt, JA 80, 553 (558f;).

${ }^{731}$ Grünwald, GA 59, 110 (115).
} 
aber das Problem von Grünwalds Entwurf der Eigenständigkeit des Unterlassens: Indem Grünwald auch die untätige Mutter, deren Kind ohne Zutun eines Dritten verletzt worden ist, nur wegen Beihilfe am Tötungsdelikt bestrafen will, gelangt er zu einer Teilnahme ohne Haupttat ! Nur durch das Konstrukt der Eigenständigkeit des Unterlassens, bei dem die Bestrafung nur zufällig aus dem für die Beihilfe entwickelten Maßstab erfolgt, ist eine solche Lösung schlüssig.

Hier entstehen Zweifel, ob die Eigenständigkeit des Unterlassens so einfach behauptet werden kann, ohne daß das Gesetz darauf irgendwelche Hinweise gäbe. Roxin wendet gegen Grünwald zutreffend ein, daß das Gesetz neben Täterschaft, Anstiftung und Beihilfe keine weitere strafbare Beteiligung kennt. Selbst wenn man außerdem eine Tat ohne Täter akzeptieren könne, würde dies zu Schwierigkeiten hinsichtlich der Anstiftung oder Beihilfe zur Unterlassung führen ${ }^{732}$. Grünwalds Ansatz muß daher unbefriedigend bleiben, da er sich zu weit vom Gesetz entfernt hat. So sehr auch Grünwalds Erkenntnisse viele wichtige Fragen aufgeworfen haben, bieten sie für das vorliegende Problem keine abschließende Lösung ${ }^{733}$.

Als anderes Argument für eine generelle Beihilfe wird zum Teil von anderen Vertretern einer Beihilfe-Theorie lapidar festgestellt, der aktive Täter verstelle, jedenfalls solange er die Tatherrschaft ausübe, dem Untätigen den unmittelbaren Zugang zum Erfolg. Es fehlt jedoch an einer Begründung, wodurch der aktive Täter dem Untätigen den Zugang zum Erfolg verstellen könnte. An anderer Stelle wird das Untätigbleiben als "negative Förderung" beschrieben ${ }^{734}$. Auch der Begriff der negativen Förderung ist aber ein bloßes Ergebnis, zu dem die Herleitung fehlt. Ebensogut könnte man stets eine Täterschaft des Untätigen bejahen, indem man von einer "negativen Täterschaft" spricht. Diese vom Wortsinn vielleicht zunächst überzeugenden Ausdrücke bleiben folglich inhaltsleer.

Kritik muß an der Auffassung, die grundsätzlich eine Beihilfe bejaht, auch insoweit geübt werden, als daß ihr teilweise die Eigenständigkeit fehlt. Sowada weist darauf hin, daß die Annahme einer Beihilfe des

\footnotetext{
${ }^{732}$ Roxin, Täterschaft, S. 468.

${ }^{733}$ Schulz, Amtswalterunterlassen, S. 184.
} 
Untätigen oft auf einer "generalisierten Tatherrschaftsbetrachtung" beruhe. Diese besteht darin, daß einige Autoren dem Garanten so lange die Tatherrschaft absprechen, wie der aktive Täter noch handele ${ }^{735}$. Damit gelangen sie automatisch zur Beihilfe, ohne daß dahinter ein eigenständiges Konzept ersichtlich wird.

Im Bereich des Versuchs führt die Unterscheidung danach, ob eine Gefahr für das Rechtsgut auf einen Dritten oder auf Naturgewalt zurückzuführen ist, schließlich zu unhaltbaren Ergebnissen. Der Vater, der irrig glaubt, daß sein Kind von einem Dritten zwecks Tötung ins Wasser geworfen worden und am Ertrinken sei, und der dem Kind nicht zu Hilfe kommt, wäre straflos, wenn das Kind gar nicht in eine Gefahrenlage gekommen ist. Da eine fremde Tat nicht vorlag, wäre nämlich von einer versuchten Beihilfe des Vaters auszugehen, die straflos ist.

Anders hingegen wäre die Wertung, wenn der Vater - wiederum irrig glaubt, sein Kind sei ohne Zutun eines Dritten in dieselbe Notlage gekommen. Er müßte nach Auffassung Grünwalds wegen versuchten Tötungsdelikts bestraft werden ${ }^{736}$.

Allerdings führt zumindest Grünwald dazu - wenn auch wenig überzeugend und in Widerspruch zu seiner sonstigen Lehre - aus, daß die Einschränkungen der Strafbarkeit der Beihilfe nicht auch für die Strafbarkeit der Unterlassung gelten. Daraus ist zu schließen, daß er den Versuch der Unterlassung als strafbar ansieht, obwohl er sie vom Unrecht nur der Beihilfe zuordnet ${ }^{737}$.

bb) Ranft

Ranft begründet die Annahme einer Beihilfe des Unterlassenden mit Akzessorietätsüberlegungen. Seiner Ansicht nach ist die Bewertung des Verhaltens des Unterlassenden abhängig vom Vorsatz und der Rechtswidrigkeit des Verhaltens des Täters. Aus dieser Abhängigkeit des Unterlassungsunrechts von der vorsätzlich und rechtswidrig begangenen aktiven Haupttat folge die Einordnung der Nichthinderung in den Bereich

\footnotetext{
${ }^{734}$ Gallas, JZ 60, 686 (687).

${ }^{735}$ Vgl. Gallas, JZ 60, 686 (687); LK-Jescheck, § 13, Rn. 57 a.E.

${ }^{736}$ Roxin, Täterschaft, S. 498f.

${ }^{737}$ Grünwald, GA 59, 110 (116ff.).
} 
der Beihilfe ${ }^{738}$. Dies soll sich daraus ergeben, daß der Vater etwa nur dann zum Einschreiten verpflichtet ist, wenn die Mutter sich dem Kind nähert, um es mit einem Schal zu erwürgen, nicht aber, wenn sie es nur mit dem Schal wärmen will. Denn dadurch sei der Vorsatz des aktiven Täters Voraussetzung für die Strafbarkeit des Untätigen. Gleichermaßen bestehe eine Abhängigkeit von der Rechtswidrigkeit der vom aktiven Täter ausgeführten Rechtsgutsverletzung. Handele der aktive Täter in Ausübung eines Rechtfertigungsgrundes, sei dem Garanten ein Eingreifen verwehrt. Angesichts dieser Abhängigkeit könne dem Unterlassen des Garanten nicht die Qualität einer Täterschaft zuwachsen.

Gegen diese Argumentation bemerkt jedoch Roxin zutreffend, daß der Garant auch in Fällen einer fahrlässigen, d.h. unvorsätzlichen Rechtsgutsgefährdung zum Einschreiten verpflichtet ist, eine Akzessorietät also hinsichtlich des Vorsatzes gerade nicht besteht. Der Unterlassende kann gerade dort Vorsatz besitzen, wo er dem aktiven Täter fehlt. Roxin ist ebenfalls darin Recht $\mathrm{zu}$ geben, daß eine Abhängigkeit der Garantenhaftung von der Rechtswidrigkeit der Handlung des Aktiven überhaupt nichts begründet. Genaugenommen handelt es sich nämlich gar nicht um ein Problem der Unterlassungsstrafbarkeit: In dem Fall, in dem der Aktive gerechtfertigt handelt, ist der "Garant" gar nicht in seiner Funktion als Garant zuständig. Insofern kann von einer Abhängigkeitsbeziehung nur schwerlich die Rede $\operatorname{sein}^{739}$.

Zum ähnlichen Ergebnis wie Roxin kommt Bloy. Auch er hat sich der Frage angenommen, ob ein Garantenunterlassen akzessorisch, also Zurechnung fremden Unrechts, sein könne, oder ob nicht vielmehr das Unrecht stets in der Person des Garanten entstehe. Zugunsten der zweiten Lösung führt Bloy an, daß Garantenpflichten als Erfolgsabwendungspflichten keine Zurechnung fremden Unrechts erlaubten. Von der Tatverwirklichung des Begehungstäters bestehe nur eine faktische, aber keine normative Abhängigkeit im Hinblick auf die Erfolgsherbeiführung. Die Abhängigkeit sei von gleicher Art wie die Abhängigkeit des Unterlassenden von Naturkräften, wenn die

\footnotetext{
${ }^{738}$ Ranft, ZStW 94 (1982), 815 (829).

${ }^{739} \mathrm{Vgl}$. Sowada, Jura 86, 399 (404).
} 
Rechtsgutsverletzung durch solche bewirkt wurde ${ }^{740}$. Das soll der Fall belegen, in dem der Garant die Begehung einer Fahrlässigkeitstat nicht hindere $^{741}$. Forderte man hier eine akzessorische Zurechnung fremden Handlungsunrechts, müßte man das Verhalten als Beihilfe durch Unterlassen zu dem betreffenden Fahrlässigkeitsdelikt auffassen; dies gehe an der Sache vorbei. Der Garant sei offensichtlich Täter einer Vorsatztat, weil sich aus dem Handeln des Begehungstäters für den unterlassenden Garanten nicht dessen Verhaltensunrecht ableite. Der Begehungstäter spiele nur als ein den Erfolgsunwert verursachender Faktor eine Rolle. Daß die Gefahr für das Rechtsgut durch das Verhalten des Begehungstäters begründet wird, hat demnach mit dem Akzessorietätsprinzip nichts zu tun. Der Garant knüpft durch sein Unterlassen keine Beziehung zum Begehungstäter und $\mathrm{zu}$ dessen Verhalten, sondern nur zum tatbestandlichen Erfolg ${ }^{742}$.

b) Annahme einer grundsätzlichen Täterschaft des Unterlassenden

aa) Darstellung der Ansicht

Ein zunehmender Teil der Literatur geht davon aus, daß grundsätzlich eine Täterschaft des Unterlassenden vorliegt ${ }^{743}$.

Im Gegensatz zu den unter 2. genannten Ansichten, die an das Kriterium der Tatherrschaft anknüpfen, und im Gegensatz zu der unter 3. a) dargestellten Auffassung von der regelmäßigen Beihilfe geht diese Lehre von einer generellen Täterschaft des Garanten aus. Unter Ablehnung der von den Gegenmeinungen verwendeten Maßstäbe soll die Erfolgsabwendungspflicht des Garanten das alleinige täterschaftskonstituierende Kriterium darstellen. Damit läßt sich zunächst festhalten, daß auch diese Ansicht die strukturelle Eigenständigkeit des Unterlassens als Ausgangspunkt hat. Denn die Garantenpflicht ist gerade spezifisches

\footnotetext{
${ }^{740}$ Bloy, JA 87, 490 (493).

${ }^{741}$ Bloy, JA 87, 490 (493); hierzu Ranft, ZStW 94 (1982), 815 (838).

${ }^{742}$ Bloy, JA 87, 490 (493).

${ }^{743}$ Armin Kaufmann, Dogmatik, S. 194; SK-Rudolphi, Vor $\S 13$, Rn. 40. Roxin, Täterschaft, S. 459ff.; Rudolphi, Gleichstellungsproblematik, S. 143; Stratenwerth, AT, Rn. 1062; Welzel, S. $201 \mathrm{ff}$.
} 
Merkmal des unechte Unterlassens und kann bei Begehungstaten nicht herangezogen werden ${ }^{744}$.

Dieser Auffassung nach kommt sonst kein anderes Kriterium zur Bestimmung der Beteiligungsform als die Garantenstellung in Betracht. Die Unanwendbarkeit der Tatherrschaftsregeln wird dabei wie folgt begründet $^{745}$. Das Tatherrschaftskriterium versage, weil jeder Untätige unabhängig davon, ob als Täter oder Gehilfe- die Tat nur geschehen lassen oder verhindern könne. Es gebe gewissermaßen keinen Schritt dazwischen. Zudem könne eine Haupttat nicht durch Unterlassen "gefördert" werden, da es in diesem Bereich nur eine hypothetische Kausalität gäbe ${ }^{746}$. Indem die Erfolgsabwendungspflicht bei jedem Garanten vorliege und es kein "Mehr- oder Weniger" gebe, sei die Konstruktion einer Tatherrschaft nicht möglich ${ }^{747}$. Die bloße Erfolgsabwendungsmöglichkeit schaffe keine Tatherrschaft, sondern begründe lediglich die Unterlassungskausalität. Das mache deutlich, daß Handlung und Unterlassen eine unterschiedliche Seinsweise zugrunde liegt. Folglich sei es ausgeschlossen, die für die Begehungsdelikte entwickelten Abgrenzungskriterien auf die unechten Unterlassungsdelikte zu übertragen $^{748}$.

So ist Armin Kaufmann der Meinung, daß die unechte Unterlassung nicht unter den Tatbestand des Begehungsdelikts fällt und sich deshalb die Fälle der unechten Unterlassung auch nicht als Teilnahme zum Begehungsdelikt konstruieren lassen. Eine Teilnahme am Begehungsdelikt durch Unterlassen sei ausgeschlossen ${ }^{749}$.

Aus diesem Ansatz folgt, daß die unechten Unterlassungsdelikte dem Bereich der Pflichtdelikte zuzuordnen sind. Täter kann nur sein, wer Garant ist. Umgekehrt folgt daraus, daß jeder, der die Sonderpflicht verletzt, bereits aufgrund dieses Verstoßes als Täter anzusehen ist. Wer eine Handlungs- oder Garantenpflicht verletzt, erfüllt also den Tatbestand

\footnotetext{
${ }^{744}$ Dieser Eigenständigkeit liegt jedoch eine andere Grundlage zugrunde als jener bei Grünwald, s.o.

${ }^{745}$ vgl. dazu oben Gliederungspunkt 3 a).

${ }^{746}$ Armin Kaufmann, Dogmatik, S. 194.

${ }^{747}$ SK-Rudolphi, Vor $\S 13$, Rn. 40.

${ }^{748}$ SK-Rudolphi, Vor $\S 13$, Rn. 40.

749 Armin Kaufmann, Dogmatik, S. 295.
} 
des Unterlassungsdelikts als Täter ${ }^{750}$. Einschränkungen erfolgen nur bei Delikten, die gar nicht durch Unterlassen begangen werden können, also bei eigenhändigen Delikten, den höchstpersönlichen Pflichtdelikten und den qualifizierten Herrschaftsdelikten (streitig hinsichtlich der Zueignungsdelikte, vgl. 3. Teil D I 6) und bei der Nichtverhinderung von Anstiftung oder Beihilfe ${ }^{751}$.

Diese "Pflichtenorientierte Einheitstäterlösung" erscheint auch konsequent, wenn man die Möglichkeit verneint, Unterlassungshandlungen in Haupt- und Beihilfehandlungen zu untergliedern $^{752}$. Da es kein Kriterium gibt, das zur Unterscheidung geeignet ist, kann nur an das Nicht-Handeln und an die Garantenstellung angeknüpft werden. Daher ist der untätige Garant zwar Randfigur im Hinblick auf das Begehungsdelikt des Dritten, aber Zentralgestalt des Garantengebotstatbestandes und ist daher als Täter anzusehen ${ }^{753}$.

Dagegen wendet Hardwig ein, daß die Garantenpflicht nicht so stark sei, daß sie die Herrschaftsstellung im allgemeinen wettmachen könne ${ }^{754}$. Er gibt jedoch zu, daß eine Täterschaft dann vorliege, wenn der Unterlassende in das Tatgeschehen planmäßig miteinbezogen sei. Wie dann eine sinnvolle Abgrenzung zwischen dem vorher eingeweihten unterlassenden Garanten und dem während der Tat erst den Tatvorsatz fassenden Unterlassenden getroffen werden kann, bleibt jedoch offen.

Für die Einheitstäterlehre wird teilweise auch das Argument vorgebracht, das unechte Unterlassen sei gem. § 13 StGB überhaupt nur strafbar, wenn es einer täterschaftlichen Verwirklichung eines Tatbestandes durch Begehen gleichstehe. Das führt zum Grundproblem der Auslegung der Unterlassungsdelikte, zur Frage nach dem Charakter der Unterlassung. Dagegen läßt sich jedoch einwenden, daß die Regelung des $\S 13$ StGB

750 Roxin, Täterschaft, S. 459; Rudolphi, Gleichstellungsproblematik, S. 143; SKRudolphi, § 13, Rn. 37; Stratenwerth, AT I, Rn. 1062. Kritik bei Hardwig, JZ 65, 667 (670).

${ }^{751}$ Haft, AT, S. 192; Stratenwerth, AT I, Rn. 1079 m.w.N.; SK-Rudolphi, Vor § 13, Rn. 42; vgl. Sowada, Jura 86, 399 (405).

752 Vogel, Norm und Pflicht, S. 277.

753 hierzu Ranft, ZStW 94 (1982), 815 (838).

754 Hardwig, JZ 65, 667 (670): Gewagt ist die Überlegung, daß Garantenhaftung nicht nur bei Unterlassungen, sondern auch bei positivem Tun Täterschaft begründen soll. 
ebensogut auf die $\S \S 26,27$ StGB zu beziehen sein könnte ${ }^{755}$, so daß dieser Gedanke nicht weiterführt.

bb) Wesentliche Einwände und Schwierigkeiten bei der Annahme einer Unterlassungstäterschaft des Garanten

(1) Der Strafrahmen - Vergleich zwischen der Unterlassungstäterschaft und der aktiven Teilnahme

Täterschaft und Teilnahme lassen sich bei der Unterlassung nicht sinnvoll unterscheiden. Dieser Umstand bildet neben der generell als geringer eingeschätzten Strafwürdigkeit des Unterlassungsdelikts eine weitere Rechtfertigung für die in $\S 13$ Abs. 2 StGB vorgesehene fakultative Strafmilderung. Begründet jede Form passiver Beteiligung eine Täterschaft, dann muß der Strafrahmen hier mindestens ebenso weit wie für alle Formen aktiver Beteiligung sein. Das müßte auch für die Beihilfe gelten, bei der nach $\S 27$ eine im Grade mit $\S 13$ Abs. 2 StGB übereinstimmende Milderung eingreift ${ }^{756}$.

Gegen die ausschließliche Anwendung von Täterschaftsregeln spricht, daß der passive Überwachungsgarant schlechter gestellt wird als der aktiv tätige Gehilfe. Während dem Garanten nur eine fakultative Strafmilderung zuteil wird (vgl. § 13 Abs. 2), ist beim Gehilfen die Strafe obligatorisch zu ermäßigen ( $\$ 27$ Abs. 2$)^{757}$. Zudem ist der Versuch für den Gehilfen straflos, jedoch für den Unterlassungstäter mit Strafe bedroht. Fraglich ist, ob dies tatsächlich eine nicht $\mathrm{zu}$ rechtfertigende strengere Behandlung der unechten Unterlassungsdelikte bedeutet. Die Bestrafung des Garanten als Täter mit den genannten Folgen ist jedoch nur dann konsequent, wenn man seine zentralen Stellung gegenüber dem ihm anvertrauten Schutzgut angemessen würdigen will. Unerträgliche Folgen in der Bestrafung sind nicht zu befürchten, da eine Strafmilderung -wenn sie auch zunächst nur fakultativ besteht- bei nur geringem Tatunrecht ohnehin zwingend erfolgen muß.

\footnotetext{
755 Schulz, Amtswalterunterlassen, S. 185.

756 Stratenwerth, AT I, Rn. 1081.
} 
(2) Konsequenz des einheitlichen Unterlassens- Strafbarkeit des Versuchs

Von verschiedenen Seiten wird auf die Schwierigkeiten hingewiesen, die sich bei einer einheitlichen Unterlassungstäterschaft für die Versuchsstrafbarkeit ergeben. Der Versuch ist nämlich, wenn man die Unterlassungstäterschaft stets bejaht, im Gegensatz $\mathrm{zu}$ allen anderen dargestellten Theorien, auch stets strafbar. Dies mag am folgenden Beispiel verdeutlich sein: Der Vater glaubt, sein Sohn sei gerade dabei, einen anderen $\mathrm{zu}$ mißhandeln, und schreitet nicht ein, obwohl es ihm möglich und zumutbar wäre. Tatsächlich probt der Sohn nur ein Theaterstück mit dem "Opfer". Nach der hier vertretenen Auffassung müßte eine Bestrafung des Vaters aus versuchter Körperverletzung durch Unterlassen erfolgen ${ }^{758}$. Ginge man statt dessen von einer Beihilfe durch Unterlassen aus, läge hier nur der Versuch der Beihilfe zur tatsächlich nicht existierenden „Tat“ des Sohnes vor, der straflos wäre.

Wer als Garant gegen eine, noch nicht zur Vollendung gelangten Tat nichts unternimmt, ist also bereits Täter eines versuchten Delikts. Demgegenüber geht derjenige straffrei aus, der eine nur versuchte Beihilfe leistet, weil der von ihm angebotene Tatbeitrag nicht angenommen wird. Während im Falle eines positiven Tuns die Hingabe eines Werkzeugs, das vom Haupttäter nicht einmal mitgeführt wird, nach allgemeiner Meinung straflose versuchte Beihilfe ist, wäre nach der Einheitstäterlösung bereits das garantenpflichtige Geschehenlassen der Entwendung eines Tatwerkzeugs ein kompletter Tatversuch, ohne daß es auf die spätere Verwendung des Werkzeugs zur Haupttat ankäme.

Nach Auffassung Roxins liegt das Problem darin begründet, daß der Gesetzgeber die Strafe für die Unterlassung nicht mit derjenigen für die Beihilfe auf einen Nenner gebracht habe. Stände die versuchte Beihilfe unter Strafe, gäbe es dieses Problem gar nicht. Es sei daher der falsche Weg, die Unterlassungstäterschaft aus diesem Grunde abzulehnen ${ }^{759}$. Es ist allerdings nicht ersichtlich, daß es sich hier um einen Irrtum oder ein Versehen des Gesetzgebers handelt, indem er die versuchte Beihilfe

\footnotetext{
${ }^{757}$ Seier, JA 90, 382 (384).

${ }^{758}$ Zum Versuch vgl. oben 3. Teil B II.
} 
straflos stellt. Und wäre eine versuchte Beihilfe tatsächlich der Strafe würdig ?

Entscheidend dürfte für die Befürworter der „Einheitstäterlehre“ eher die zentrale Stellung sein, die dem Garanten auferlegt wird. Dadurch wird auch schon die Versuchsstrafbarkeit dessen, der als Beschützer oder Überwacher für die Unversehrtheit des Rechtsguts einstehen muß, legitimiert, anders als gegenüber dem Gehilfen, der eine solche Pflicht nicht innehat.

Armin Kaufmann weist sogar auf die Absurdität eines straflosen Versuches hin. Daß der ansonsten strafbare Garant seiner Strafe entzogen werden solle, sei nicht einzusehen. Armin Kaufmann bringt dazu das folgende Beispiel: Der Schwimmeister A sieht, wie ein Kind, nachdem es von einem Dritten ins Wasser gestoßen wurde, in dem von ihm beaufsichtigten Schwimmbecken offenbar mit dem Tode ringt. Er will das Kind sterben lassen und unternimmt nichts zu seiner Rettung. Das Kind kann sich mit letzter Kraft an den Beckenrand retten ${ }^{760}$. Weshalb der Garant für solches Unterlassen nicht zur Rechenschaft gezogen werden und straflos bleiben soll, ist in der Tat nicht nachvollziehbar.

(3) Konsequenz: Jeder aktive Gehilfe zugleich ein Unterlassungstäter ?

Die pflichtenorientierte Einheitstäterlösung sieht sich einem weiteren gewichtigen Einwand ausgesetzt: Ein aktiver Gehilfe, der nach seinem Tatbeitrag den Taterfolg nicht verhindert, müßte als (Unterlassungs-) Täter aus Ingerenz bestraft werden. Da es charakteristisch ist, daß der Gehilfe den Taterfolg eintreten lassen will, wird er im Anschluß an seinen Tatbeitrag natürlich keine gegenläufige Handlung vornehmen, um diesen rückgängig zu machen. Die Unterlassung der Erfolgsverhinderung folgt also regelmäßig der aktiven Beihilfe. Die Konsequenz wäre: Jeder Gehilfe müßte als Täter bestraft werden, die Beihilfe gäbe es folglich nicht $\mathrm{mehr}^{761}$.

Grünwald meint, daß sich dieses Problem nur dann ergibt, wenn man fälschlicherweise Täterschaft und Teilnahme von der Unterlassungsseite

\footnotetext{
${ }^{759}$ Roxin, Täterschaft, S. 505.

${ }^{760}$ Armin Kaufmann, Dogmatik, S. 293f.; a. A. aber Busse, S. $19 f$.

${ }^{761}$ Vgl. Grünwald, GA 59, 110 (113).
} 
her aufrolle, wie es durch die Einheitstäterlehre geschehe ${ }^{762}$. Allerdings könnte man fragen, ob eine Abgrenzung der Beteiligungsformen nicht genauso gut vom Begehen wie vom Unterlassen her entwickelt werden kann. Unterlassen und Begehen sind zwar verschiedenartig, aber nicht verschiedenrangig.

Für die folgende Untersuchung des Zusammentreffens von aktiver Beihilfe und anschließendem Unterlassen sind zwei Gruppen von Beteiligten $\mathrm{zu}$ unterscheiden. Zum einen der aktive Gehilfe, der erst durch seine Beihilfe zum Garanten aus Ingerenz wird, zum anderen der Gehilfe, der bereits vorher Garant mit Überwacher- oder Beschützerfunktion war.

Im ersten Fall wird der aktive Gehilfe erst durch seine pflichtwidrige gefährdende Vorhandlung zum Garanten aus Ingerenz. Bilde man etwa den Fall, daß jemand einem Schläger eine Waffe zum Zuschlagen besorgt und dann auch nicht den Einsatz der Waffe verhindert. Das nachfolgende Unterlassen wäre, sofern die Deliktshinderung noch möglich und zumutbar ist, stets täterschaftlich und damit nach allgemeinen Konkurrenzerwägungen vorrangig zu berücksichtigen. Dann käme dem aktiven Gehilfen immer durch das Unterlassen der Verhinderung der Haupttat eine Bestrafung wegen (Unterlassungs-) Täterschaft zu. Die aktive Beihilfe wäre somit aufgehoben, was einem inakzeptablen Verstoß gegen das Gesetz gleichkäme.

Zur Lösung dieses Problems hat Welp vorgeschlagen, die vorsätzliche Teilnahme nicht als ingerenzbegründende Vorhandlung genügen $\mathrm{zu}$ lassen. Seiner Ansicht nach wächst der nachfolgenden Handlung offenbar kein neuer Unwert $\mathrm{zu}^{763}$. Wenn das so ist, kann aber der nachfolgenden Unterlassung nicht ein täterschaftlicher Unwert, sondern nur der Unwert einer Beihilfe zukommen ${ }^{764}$.

Dazu stellen sich mehrere Fragen: Erstens: Kann Ingerenz auch durch eine Beihilfehandlung entstehen ? Zweitens: Falls Ingerenz entsteht, ist die Garantenstellung aus Ingerenz gegenüber anderen Garantenstellungen niederrangig und begründet nur eine Beihilfe ?

\footnotetext{
${ }^{762}$ Grünwald, GA 59, 110 (114).

${ }^{763}$ Welp, Vorangegangenes Tun, S. $280 f$.
} 
Man könnte zunächst bezweifeln, daß die Beihilfe überhaupt regelmäßig eine Ingerenz begründet. Gegen eine Entstehung der Ingerenz durch die Beihilfe spricht, daß nach allgemeiner Überzeugung die bloße Mitwirkung bei der Vorbereitung einer Tat niemals die Täterschaft, sondern nur Teilnahme begründen $\mathrm{kann}^{765}$. Bei aller struktureller Unterschiedlichkeit zwischen aktivem Tun und Unterlassen ist daher fraglich, wieso beim Unterlassen die früher verwirklichte Beihilfe den Gehilfen zum anschließenden Unterlassungstäter machen soll. Dadurch, daß hier der Gehilfe zum Garanten aus Ingerenz wird, wird der Grundsatz, nach der die Hilfe bei der Vorbereitung der Tat nur zur Teilnahme führen kann, aufgehoben.

An dieser Stelle soll aber nicht das Institut der Ingerenz durch Beihilfehandlungen in Frage gestellt werden. Versteht man mit der h. M. unter Ingerenz jedwedes pflichtwidrige Verhalten, das eine gefährliche Situation entstehen läßt, ist die Beihilfe jedenfalls darunter zu fassen. Das Entstehen der Ingerenz durch aktive Beihilfe kann daher nicht ernsthaft bezweifelt werden.

Ein zweiter Ansatz sieht die Garantenstellung aus Ingerenz als niederrangig an und verneint dadurch eine Täterschaft aufgrund mangelnder Garantenstellung. Zwar ist richtig, daß zwischen den Garantenstellungen keine Differenzierung vorzunehmen ist $^{766}$. Insoweit ist Grünwald recht zu geben, der eine solche Möglichkeit mit dem Hinweis darauf ablehnt, daß die verschiedenen Garantenstellungen mit der Beherrschung des Geschehens -und somit mit der Wahl der Beteiligungsform- nichts zu tun haben ${ }^{767}$.

Eine Gleichbehandlung kann aber nur für solche Garantenstellungen gelten, die bereits zu Beginn der zeitlichen und räumlichen Einheit von Beihilfe und anschließendem Unterlassen bestehen. Gerade eine solche Einheit liegt aber bei der Garantenstellung aus Ingerenz nicht vor, da die Ingerenz durch die Beihilfehandlung erst entsteht. Erst diese Beihilfe macht das folgende Unterlassen überhaupt strafbar. Hingegen muß das Unterlassen in einem anderen Lichte gesehen werden, wenn es auch ohne

\footnotetext{
${ }^{764}$ Vogel, Norm und Pflicht, S. $278 f$.

${ }^{765}$ Vgl. Hardwig, JZ 65, 667 (670).

${ }^{766}$ Vgl. unten Gliederungspunkt 4. e).

${ }^{767}$ Grünwald, GA 59, 110 (114).
} 
eine vorangegangene Beihilfe strafbar gewesen wäre. Dies ist jedoch nicht, wie Grünwald meint, eine qualitative, sondern im zeitlichen Ablauf begründete Unterscheidung. Läge eine Garantenstellung aus Ingerenz bereits vor der Beihilfe vor, stände einer Gleichbehandlung der Fälle nichts entgegen. Hier erscheint es hingegen zulässig, nach dem Zustandekommen der Garantenpflicht in zeitlicher Hinsicht zu differenzieren. Dann könnte man eine Täterschaft des Unterlassungstäters, der zuvor als Gehilfe agierte, verneinen.

Damit ist das Problem aber noch nicht gelöst: Eine vertiefendere Untersuchung ist jedenfalls dann erforderlich, wenn man die Fälle betrachtet, in denen der Gehilfe bereits vor der Beihilfehandlung Garant ist, z. B. wie hier Überwachergarant. Dann greift das von Welp vorgebrachte Argument, der - einer vorsätzlichen Beihilfehandlung nachfolgenden - Handlung wachse kein neuer Unwert $\mathrm{zu}^{768}$, nicht ohne weiteres.

Bei Garanten wäre nämlich damit die aktive Beihilfe unmöglich, es würde immer gleich eine Bestrafung wegen Täterschaft erfolgen. Genau das muß jedoch die logische Konsequenz der Einheitstäterlösung sein. Der Garant wird immer mit der ganzen Härte der täterschaftlichen Bestrafung belegt, weil er nun einmal Zentralgestalt des Garantengebotstatbestandes ist. Wohl darf nicht völlig gleichgültig sein, wie der Garant seinen Pflichten zuwiderhandelt, ob er also „nur“ unterläßt oder ob er auch zuvor noch eine aktive Beihilfehandlung vornimmt. Ein Unterlassen, das sogar noch zusammen mit einer aktiven Beihilfe erfolgt, ist demgemäß stärker zu bestrafen als ein einfaches Unterlassen. Das ist aber eine Frage der Strafzumessung. Denn wegen mehr als wegen Täterschaft kann der Garant nun einmal nicht bestraft werden. Wenn schon oben dargelegt wurde, daß der Garant immer als Täter einzustufen ist, kann daher erst recht nichts anderes gelten, wenn der Garant, statt nur die Tatverhinderung zu unterlassen, sogar an deren Erfüllung aktiv mitwirkt.

Wollte man für den Garanten, der zugleich als aktiver Gehilfe tätig wird, nur eine Bestrafung wegen Beihilfe fordern, käme man $\mathrm{zu}$ einem Ergebnis, wie Roxin es für das folgende Beispiel beschrieben hat: Bringt

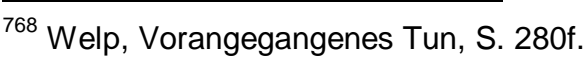


der Vater das Kind um, und erteilt die Mutter ihm dabei Ratschläge, wäre der Vater Täter und die Mutter Gehilfin des Totschlags. Verzichtet die Mutter aber auf die Ratschläge und verhält sich völlig passiv, wäre sie Unterlassungstäterin $^{769}$. Dieses Beispiel spricht dafür, eine Täterschaft durch Unterlassen auch bei vorangegangener Beihilfe $\mathrm{zu}$ bejahen. Es kann nicht sein, daß die zusätzlich begangene Beihilfe die Mutter diese auch noch vor einer höheren Strafe schützt.

Auch Roxin erwägt den soeben dargestellten Gedanken, anstatt den Unterlassungstäter "zu einem Gehilfen zu degradieren", wie es bei der Beihilfe-Theorie geschehe, umgekehrt den aktiv unterstützenden Garanten "in den Rang eines Begehungstäters aufrücken" zu lassen. Dadurch werde jedoch massiv gegen den allgemeinen Täterbegriff des Begehungsverbrechens verstoßen. Täter sei plötzlich nicht mehr nur der, der die Tatherrschaft habe, sondern jeder, der, wenn er sich nicht aktiv beteiligt hätte, wegen einer Unterlassungstat hätte zur Verantwortung gezogen werden können ${ }^{770}$. Wie Roxin bemerkt, wäre der von Grünwald an der hier vertretenen Auffassung geübte Kritik der "Aufrollung der Teilnahmelehre vom Unterlassungsdelikt her" zuzustimmen.

Es ist jedoch unzulässig, wenn Roxin hier allein auf den Täterbegriff für das Begehen abstellt. Spezifikum beim Verhalten von Garanten ist es ja, daß auch ihr Unterlassen strafrechtliche Folgen hat. Es wäre daher einseitig, nur auf die Tatherrschaft i.S.d. Begehens einzugehen. Zudem kann es nicht sein, daß derjenige, der ohnehin wegen seiner Untätigkeit als Unterlassungstäter bestraft würde, wegen seiner zusätzlichen Beihilfe nicht erst recht als Täter, sondern nur als Teilnehmer bestraft wird.

Auch Roxin kann letztlich nur feststellen, daß die Annahme einer Beihilfe durch Unterlassen im Ergebnis die bessere Lösung bringe, auch wenn dafür keine dogmatische Begründung vorliege ${ }^{771}$. Damit bekennt Roxin, daß er keine Begründung für die von ihm favorisierte Lösung aufzeigen kann. Da er hier über die Teilnahmelehre nicht zu Ergebnissen gelangt, setzt er in seinen weiteren Ausführungen bei den allgemeinen Besonderheiten der Unterlassung an und nimmt Bezug zum Strafrahmen und zur Strafmilderungsmöglichkeit des Unterlassens. Er geht davon aus,

\footnotetext{
${ }^{769}$ Roxin, Täterschaft, S. 499.

${ }^{770}$ Roxin, Täterschaft, S. 500.
} 
daß die Begehungs- und Unterlassungstäterschaft unberechtigt demselben Strafrahmen unterstellt werden. Hinsichtlich des Strafmaßes müsse die Unterlassungstäterschaft als eine Beihilfe zum Begehungsdelikt angesehen werden. Daher sei es verfehlt, die Unterlassungstäterschaft wie eine Begehungstäterschaft nach deren Strafrahmen zu beurteilen. Als Begründung, weshalb er überhaupt an der Täterschaft festhält, nennt Roxin die Qualität der sozialethischen Wertwidrigkeit, die für eine Täterschaft sprechen soll. Davon müsse jedoch die Schuldhöhe oder die individuellen Strafwürdigkeit getrennt werden. Es soll jedoch wegen der lediglich fakultativen Strafmilderung vom Einzelfall abhängen, welcher Strafrahmen für das jeweilige Unterlassen gilt, so daß nicht immer der Strafrahmen der Beihilfe gelten $\operatorname{mu} \beta^{772}$.

Indem er auf die Begehungsbeihilfe verweist und gleichzeitig einen Strafrahmen, wie er aus der aktiven Täterschaft i.S.v. $§ 25 \mathrm{StGB} z u$ entnehmen wäre, ablehnt, nähert sich Roxin aber genau jener Lehre Grünwalds, der er zuvor entgegengetreten ist. Es ist zu fragen, ob Roxin mit der Feststellung, daß der Strafrahmen der Unterlassungstäterschaft dem der aktiven Beihilfe entspreche, nicht seine bis hierhin vertretene Lehre aufgibt. Wenn er die Unterlassungstäterschaft wie eine Beihilfe behandelt, dann kommt es einem Etikettenschwindel gleich, das Verhalten des Untätigen dennoch als Täterschaft zu bezeichnen. So weist Schulz denn auch auf eine zwingende Ungereimtheit im Schuldspruch hin, da der Unterlassende zwar nach dem Strafrahmen der Beihilfe bestraft werde, jedoch als Täter verurteilt werde. Der Schuldspruch müsse auch aus dem Tatbestand erfolgen, aus dessen Strafrahmen man ihn auch bestraft, hier also konsequenterweise aus demjenigen der Beihilfe $^{773}$. Daran ändert auch der Verweis Roxins auf die bloß fakultative Strafmilderung nichts mehr. Dadurch bleibt zwar eine Bestrafung aus dem Strafrahmen der Täterschaft möglich, und Roxin hält

\footnotetext{
${ }^{771}$ Roxin, Täterschaft, S. 501.

772 Roxin, Täterschaft, S. 502.

${ }^{773}$ Vgl. Schulz, Amtswalterunterlassen, S. 168.
} 
sich die Hintertür zur Täterschaft offen ${ }^{774}$. Als Lösung zur Frage nach der Beteiligungsform kann Roxins Ansatz aber kaum angesehen werden, weil hier allgemeine Strafzumessungserwägungen dominieren.

Ansatzpunkt muß vielmehr ein anderer sein. Wenn in den Fällen eines der aktiven Beihilfe folgenden Unterlassens die Unterlassungstäterschaft zurücktreten soll, so muß auf das Konkurrenzverhältnis zwischen der aktiven Beihilfe und der Unterlassungstäterschaft abgestellt werden.

Empfindet man es als Wertungswiderspruch, den als Gehilfen tätigen Garanten grundsätzlich als Täter zu bestrafen, weil dann in der strafrechtlichen Würdigung eine aktive Beihilfe durch den Garanten entfiele, muß die aktive Beihilfe die Unterlassungstäterschaft verdrängen. Roxin erklärt das unter Bezugnahme auf seine vorherigen Überlegungen damit, daß das positive Tun, also die aktive Tätigkeit, schwerer wiege als das Unterlassen, auch wenn dieses täterschaftlich sei. So kommt Roxin bei dem Problem zu einer Bestrafung wegen Beihilfe ${ }^{775}$. Eine nähere Erklärung erfolgt hingegen nicht. So bleibt zweifelhaft, weshalb entgegen gültigen Grundsätzen nicht die Täterschaft die Teilnahme verdrängt, sondern umgekehrt ${ }^{776}$.

Welp erklärt das Problem in Übereinstimmung mit Roxin. Er begründet das Zurücktreten der Unterlassungstäterschaft damit, daß die Unterlassung von der Handlung konsumiert werde, ähnlich wie der Versuch von der Vollendung konsumiert wird ${ }^{777}$. Auch Schulz muß anerkennen, daß man mit dieser Art der Betrachtung, nämlich derjenigen des genauen Konkurrenzverhältnisses, in der Tat einen Schritt weiter ist $^{778}$.

$\mathrm{Ob}$ diese Folgerungen richtig sein können, muß ein Blick auf die Konkurrenzlehre zeigen. Grundsatz der Konkurrenzlehre ist, daß ein Delikt nur dann ein anderes verdrängt, wenn es dessen Unrecht

\footnotetext{
774 Schulz, Amtswalterunterlassen, S. 188f., weist außerdem darauf hin, daß die fakultative Strafmilderungsmöglichkeit des $§ 13$ II nicht im Hinblick auf eine Lösung der Beteiligungsproblematik geschrieben wurde.

${ }^{775}$ Roxin, Täterschaft, S. 503.

776 Schulz, Amtswalterunterlassen, S. 188f.; allerdings gilt dieser Grundsatz nur für Begehungsdelikte. $\mathrm{Ob}$ er für das Zusammentreffen von Begehungs- und Unterlassungsdelikten zutrifft, müßte erst bewiesen werden.

${ }^{777}$ Welp, Vorangegangenes Tun, S. 327.

778 Schulz, Amtswalterunterlassen, S. 189.
} 
vollständig enthält. Die aktive Beihilfe kann also nur dann das Unterlassen verdrängen, wenn sie sein Unrecht vollständig enthält ${ }^{779}$. Ein Delikt mit schärferem Strafrahmen -also hier die Unterlassungstäterschaft- kann grundsätzlich nicht von einem mit milderem -aktive Beihilfe- verdrängt werden. Ein Ausschluß des schärferen Strafrahmens läßt sich nur durch den Gedanken einer Sperrwirkung, nicht aber mit Konkurrenzerwägungen rechtfertigen ${ }^{780}$.

Wenn jedes strafbare Verhalten jedenfalls dann ein anderes verdrängen kann, wenn es dessen Unrechtsgehalt mitumfaßt, besteht jedoch auch die Möglichkeit, daß die Unterlassung im Einzelfall einmal die Handlung verdrängt $^{781}$. Eine solche Möglichkeit kann nur derjenige ablehnen, der die Unterlassung stets weniger strafwürdig als die aktive Beihilfe einstuft $^{782}$. Soll also die aktive Beihilfe das nachfolgende Unterlassen verdrängen, darf für die Konkurrenzerwägungen die Unterlassung nur den Strafrahmen der aktiven Beihilfe haben ${ }^{783}$. Eine solche Lösung dürfte aber mit der obligatorischen Milderung der Beihilfe gem. $§ 27$ gegenüber der nur fakultativen nach $\S 13$ nicht zu vereinbaren $\operatorname{sein}^{784}$.

Konsequenterweise muß daher auch für den Garanten, der Beihilfe begeht - angesichts seiner Zentralstellung für die Erfolgsabwendungeine Bestrafung wegen Täterschaft stattfinden. Es kann nicht sein, daß derjenige Garant als Täter bestraft wird, der untätig bleibt, hingegen derjenige Garant, der sogar aktiv an der Erfolgsherbeiführung mitwirkt, eine geringere Strafe erhalten sollte. Eine Beihilfe durch den Garanten,

\footnotetext{
${ }^{779}$ Schulz wendet ein, daß auf die Konkurrenz hier nicht zurückgegriffen werden kann. Um für die Konkurrenz zwischen aktiver Beihilfe und Unterlassungstäterschaft zu einem Ergebnis zu kommen, müsse nämlich wieder das Unrecht der Verhaltensweisen festgestellt werden. Finde man ein Prinzip, das erklären könne, wieso die Unterlassung auch einmal ein größeres Unrecht darstellen könne als die aktive Beihilfe, müsse die Unterlassung auch die aktive Beihilfe verdrängen können. Dann sei wegen Täterschaft zu bestrafen, Schulz, Amtswalterunterlassen, S. 200.

780 Schulz, Amtswalterunterlassen, S. 188; Grünwald, Unechtes Unterlassungsdelikt, S. 105; GA 59, 110 (113); Gallas, JZ 60, 686, Fn. 56.

${ }^{781}$ Schulz, Amtswalterunterlassen, S. 199.

${ }^{782}$ Grünwald, GA 59, 110 (115).

${ }^{783}$ Schulz, Amtswalterunterlassen, S. 188; Grünwald, Unechtes Unterlassungsdelikt, S. 105; ders. GA 59, 110 (113,115); Gallas, JZ 60, 686, Fn. 56.

${ }^{784}$ Schulz, Amtswalterunterlassen, S. 199.
} 
der bereits vor der Unterstützungshandlung abwendungspflichtig war, ist daher in der Tat ausgeschlossen.

Auch wenn man Grünwalds Ansicht folgen wollte, müßte man übrigens den unterlassenden und den als Gehilfen aktiven Garanten gleichermaßen nach $\S 27$ StGB bestrafen. Das Unrecht würde also letztlich wie bei der hier vertretenen Lösung als vergleichbar betrachtet werden.

(4) Nachfolgende Beihilfe des Garanten

Anders liegt die Situation, wenn eine der Unterlassung nachfolgende aktive Beihilfe vorgenommen wird. Wenn man der oben dargestellten, aber abgelehnten Auffassung folgte, nach der die aktive Beihilfe die Unterlassungstäterschaft verdrängt, könnte der Unterlassungstäter nämlich einfach zusätzlich zu seinem Unterlassungsunrecht eine aktive Beihilfe begehen, um der Täterstrafe zu entgehen ${ }^{785}$.

Fraglich ist jedoch, ob eine solche "nachfolgende Beihilfe" überhaupt konstruierbar ist. Eine dem Unterlassen der Deliktsverhinderung nachfolgende Beihilfe durch den Unterlassungstäter setzt voraus, daß der aktive Haupttäter schon bei der Tatausführung ist, der Gehilfe aber zunächst seinen Beitrag noch nicht geleistet hat, sondern zunächst nur die Tatverhinderung unterläßt. Zeitlich müssen erst ein Unterlassen und im Anschluß daran eine Beihilfe erfolgen. Aber wie lang muß das Unterlassen zeitlich sein ? Es genügt dafür bereits eine logische Sekunde vor dem aktiven Gehilfenbeitrag, um den untätigen Zuschauer zugleich als einen, die Haupttat nicht verhindernden Unterlassungstäter einzustufen. So betrachtet unterläßt bereits der Gehilfe, der auf den richtigen Moment wartet, um dem Haupttäter ein Werkzeug zu reichen, die Deliktshinderung.

Jeder Beihilfe geht somit eine Unterlassung voraus. Wer vorhat, an der Erfolgsherbeiführung des aktiven Täters mitzuwirken, wird auch vorher nicht versuchen, das Tun des Täters zu verhindern. Diese Beihilfe ist daher nicht anders zu behandeln als jene Beihilfe, die vor dem Unterlassen einsetzt, weil es auch dort in der Natur der Sache liegt, daß der Gehilfe nicht den Taterfolg durch eine anschließende Handlung verhindert. Es handelt sich damit um eine vom Garanten ausgeführte

${ }^{785}$ darauf weist Herzberg, Unterlassung, S. 262f.; vgl. Roxin, Täterschaft, S. 499. 
Beihilfe wie im vorangegangenen Abschnitt. Die Tatsache, daß der Unterlassende nicht nur nicht zur Deliktsverhinderung einschreitet, sondern sogar aktiv in das Geschehen eingreift, ist also auch ebenso zu würdigen, wie oben dargestellt. Da eine Bestrafung wegen der Unterlassungstäterschaft ohnehin erfolgt, muß die Beihilfe bei der Strafzumessung berücksichtigt werden, indem etwa keine Milderung aus $\S 13$ II StGB erfolgt.

c) Modifizierung der "Einheitstäterlehre" durch Roxin

Nach dem bisher Gesagten scheint die "Einheitstäterlehre" jeden Unterlassenden stets als Täter zu bestrafen, unabhängig von der Art des nicht verhinderten Delikts. Der Ausschluß jeder Unterlassungsbeihilfe könnte jedoch genauso eine Mißachtung des Gesetzes sein wie der Ausschluß jeglicher Unterlassungstäterschaft ${ }^{786}$.

Die Einheitstäterlösung wird ihrem Namen insofern nicht gerecht, als sie, anders als die Beihilfe-Lösung, die andere Beteiligungsform nicht völlig ausschließt.

Die Annahme einer strafbaren Beihilfe durch Unterlassung ist auch bei der Einheitstäterlösung nicht offensichtlich. Denn auf welche Weise soll eine Teilnahme möglich sein, wenn doch der garantenpflichtige Unterlassende immer Täter und der nichtpflichtige Unterlassende immer straflos ist? Es läßt sich sagen, daß eine Teilnahme regulär zwar ausgeschlossen ist, jedoch hilfsweise eingreifen kann. Führt jedes Unterlassen zur Täterschaft, muß der Strafrahmen der Täterschaft alle gesetzlichen Beteiligungsformen umfassen, wie es auch durch $\S 13$ Abs. 2 möglich ist ${ }^{787}$.

Roxin definiert daher die Teilnahme als eine Mitwirkung außerhalb der für den jeweiligen Tatbestand maßgebenden Täterschaft ${ }^{788}$. Täter eines Unterlassungsdelikts kann man nur beim Vorliegen von zwei Voraussetzungen werden: Erstens muß ein Unterlassungstatbestand bestehen, also die Möglichkeit, das Delikt selbständig durch Unterlassen zu begehen. Zweitens muß der Unterlassende, um Täter zu sein, eine

\footnotetext{
${ }^{786}$ Schulz, Amtswalterunterlassen, S. 191.

${ }^{787}$ Busse, S. 9. Stratenwerth, AT, S. 402, § 14, Rn. 11.

${ }^{788}$ Roxin, Täterschaft, S. 477.
} 
Erfolgsabwendungspflicht haben. Liegt eine der beiden Komponenten nicht vor, so ist nach Roxin eine Teilnahme zu bejahen ${ }^{789}$.

aa) Teilnahme wegen fehlenden Unterlassungstatbestands

Die Erfolgsabwendungspflicht hat immer nur dann eine täterschaftsbegründende Kraft, wenn die Nichthinderung eines Delikts der Unrechtsqualität einer aktiven Begehung entspricht. Fehlt es an dieser Gleichartigkeit, wirkt die Garantenstellung zwar strafbegründend, aber es gibt keine Unterlassungstäterschaft ${ }^{790}$.

Das soll anzunehmen sein bei eigenhändigen Delikten ${ }^{791}$ und bei den höchstpersönlichen Pflichtdelikten ${ }^{792}$. Sie alle haben keinen Unterlassungstatbestand $^{793}$. In diesen Fällen ist eine täterschaftliche Verwirklichung des Tatbestandes durch den Garanten ungeachtet seiner Erfolgsabwendungspflicht nicht möglich, so daß hier Teilnahme vorliegen könnte. Der Garant, der seinen Schutzbefohlenen beispielsweise nicht von einem eigenhändigen Delikt abhält, würde nur wegen Beihilfe durch Unterlassen bestraft: Unternähme der Vater nichts dagegen, daß der Sohn die Tochter sexuell (blutschänderisch) mißbrauchte, wäre der Vater als Gehilfe zu bestrafen ${ }^{794}$.

Bei den Zueignungsdelikten ist mittlerweile davon auszugehen, daß auch sie täterschaftlich durch Unterlassen begangen werden könne ${ }^{795}$. Durch die Möglichkeit der Drittzueignung im Tatbestand der $\S \S 242$ ff. StGB genügt es für den unterlassenden Garanten, daß er die Absicht hat, daß die Sache einem Dritten, z.B. seinem aktiv handelnden Abkömmling, zugeeignet wird $^{796}$. Er muß die Sache nicht mehr für sich selbst wollen.

Nunmehr ist $\mathrm{zu}$ begründen, weshalb für die Deliktsgruppen der eigenhändigen Delikte und der höchstpersönlichen Pflichtdelikte eine

\footnotetext{
${ }^{789}$ Roxin, Täterschaft, S. 477.

${ }^{790}$ Roxin, Täterschaft, S. 478.

791 Ausgenommen sollen jedoch die Tätigkeitsdelikte sein, vgl. Roxin, Täterschaft,

S. 480.

${ }^{792}$ Freund, Erfolgsdelikt, S. 258; Roxin, Täterschaft, S. 479ff.

${ }^{793}$ Genauere Untersuchung im 5. Teil C.

${ }^{794}$ Busse, S. 54f.; vgl. oben 3. Teil C I 5.

${ }^{795}$ Dazu bereits oben, 3. Teil D I 6; anders noch Freund, Erfolgsdelikt, S. 258, und Roxin, Täterschaft, S. $481 \mathrm{f}$.

${ }^{796}$ Vgl. Tröndle/ Fischer, § 242, Rn. 46.
} 
Teilnahme in Betracht kommt. Zu klären ist, weshalb beim Fehlen der genannten Kriterien ausgerechnet Teilnahme und nicht sogar Straflosigkeit vorliegen soll. Die Teilnahme darf nicht als "bloßer Auffangbegriff für Fälle gescheiterter Täterbestrafung" eingesetzt werden $^{797}$. So weist Vogel auf die Erklärungsschwierigkeiten hin, die sich in den Fällen ergeben, in denen wegen mangelnder Täterqualifikation im Ergebnis doch eine Teilnahmestrafbarkeit angenommen werden muß. Hier müßte entweder darauf Bezug genommen werden, daß die Teilnahmevorschriften Auffangtatbestände für solche Fälle darstellen, in denen keine Täterschaft vorliegt. Oder es müßte eine aushilfsweise analoge Anwendung der $\S \S 26 f f$. StGB stattfinden, was hinsichtlich des Analogieverbotes aus Art. 103 Abs. 2 GG zweifelhaft wäre ${ }^{798}$.

Roxin geht davon aus, daß der Unterlassende beim Dazwischentreten eines aktiv tatherrschaftlich Handelnden sowohl Täter eines Pflichtdelikts als auch Gehilfe eines Herrschaftsdelikts ist ${ }^{799}$. Diese Beihilfe trete jedoch hinter der Täterschaft zurück und werde daher normalerweise nicht genannt. Entfällt also die Täterschaft in den genannten Deliktsgruppen, so tritt die Beihilfe wieder hervor und führt zur Strafbarkeit. Denn nach der richtigen Auffassung Roxins gibt es nicht nur eine Täterschaft durch Unterlassen, sondern auch eine (subsidiäre) Teilnahme durch Unterlassen ${ }^{800}$. Der Beihilfe kommt eine eigenständige Bedeutung nur dort zu, wo ein selbständiger Unterlassungstatbestand nicht besteht. Hinsichtlich der Fälle, in denen ein Unterlassungstatbestand vorliegt, ist eine Täterschaft zu bejahen ${ }^{801}$. Dies widerspricht auch nicht der Auffassung, daß sich die (eigene) Unterlassungstat grundsätzlich gegenüber der (eigenen) aktiven Beihilfe durchsetzt, da es sich um eine Beihilfe durch Unterlassen, nicht durch aktives Tun, handelt.

\footnotetext{
${ }^{797}$ Vogel, Norm und Pflicht, S. 280.

${ }^{798}$ Vogel, Norm und Pflicht, S. 280.

${ }^{799}$ Roxin, Täterschaft, S. 483.

${ }^{800}$ Nicht zu verwechseln mit der Teilnahme, wie sie von der unter Gliederungspunkt 4 a) dargestellten Auffassung für den Unterlassenden gefordert wird.

${ }^{801}$ Roxin, Täterschaft, S. 485.
} 
Zusammengefaßt bedeutet dies: Bestrafte man den Unterlassenden stets wegen Täterschaft, würde das Verhalten des Unterlassenden ausschließlich in seiner Selbständigkeit gesehen, so etwa von Armin Kaufmann. Bestrafte man nur wegen Teilnahme, stellte man nur auf seine Beziehung zum Handelnden ab, wie etwa Gallas und Kielwein. In Wirklichkeit können aber nur beide Betrachtungsweisen gemeinsam der Sachlage gerecht werden: „Der pflichtwidrig Unterlassende ist Zentralgestalt des Garantengebotstatbestandes und zugleich Randfigur im Hinblick auf das Begehungsdelikt des dazwischentretenden Dritten”802. Daraus ergibt sich die Möglichkeit der Teilnahme für die Fälle, in denen die Täterschaft im Hinblick auf das eigene Unterlassen entfällt.

bb) Teilnahme bei fehlender Erfolgsabwendungspflicht

Roxin hält es weiter für möglich, eine Beihilfe durch Unterlassen auch in den Fällen zu bejahen, in denen eine Erfolgsabwendungspflicht, d.h. eine Garantenstellung, nicht besteht ${ }^{803}$. Roxin muß sich jedoch am Ende seiner Ausführungen eingestehen, daß die bestehende Beweisführung zu schmal ist, um eine Teilnahme auch ohne Abwendungspflicht guten Gewissens bejahen zu können. Da im vorliegenden Kontext eine Erfolgsabwendungspflicht durch die Eltern immer vorliegen wird, ist dieses Problem in diesem Rahmen nicht von Relevanz.

cc) Schließlich ist nach der hier vertretenen Meinung Beihilfe auch dann möglich, wenn die Handlungsmöglichkeit des Garanten sich darin erschöpft, daß er einen anderen Handlungspflichtigen zum rettenden Handeln bewegen könnte ${ }^{804}$. Zugleich könnte darin psychische Beihilfe liegen ${ }^{805}$.

\footnotetext{
${ }^{802}$ Roxin, Täterschaft, S. 499.

${ }^{803}$ Roxin, Täterschaft, S. 485ff.; vgl. Armin Kaufmann, Dogmatik, 291ff.; Kritik bei Busse,

S. 16 und Hardwig, JZ 65, 667 (670).

${ }^{804}$ Schmidhäuser, AT, 17/13.

${ }^{805}$ Lackner/Kühl, § 27, 4.
}

Exkurs: Abgrenzung des täterschaftlichen Unterlassens zur psychischen Beihilfe

Sowada weist auf die Tendenz der Rechtsprechung hin, die aktive psychische Beihilfe zuweilen unzulässig zu überdehnen und bereits bei einem schweigenden Geschehenlassen deliktischen Handelns anzunehmen (Sowada, Jura 86, 399 (402); Rudolphi, StrV 82, 518 (518); LK-Roxin, § 27, Rn. 16, 25-27) . Eine solche Anwendung 
d) Differenzierung nach Art der Garantenpflicht

aa) Darstellung

Schließlich besteht noch die Möglichkeit, die Beteiligungsform nach Art der verletzten Garantenpflicht zu bestimmen. Die Vertreter einer solchen Lösung lehnen -ebenso wie die Vertreter der zuletzt genannten Meinungen- die Tatherrschaft als Kriterium für die Täterschaft beim Unterlassungsdelikt ab. Auch sie stützen sich auf die Ausübung der Garantenpflicht als Maß für die Beteiligung. Während für die Auffassungen, die eine Beihilfe oder eine Täterschaft bejahen, jedoch die Pflichtverletzung entweder zur Beihilfe oder zur Täterschaft führt,

der psychischen Beihilfe würde dazu führen, daß der Teilnehmerkreis unzulässig auf Nicht-Garanten erweitert wird; denn beim aktiven Tun benötigt man die wesentliche Voraussetzung des unechten Unterlassungsdelikts, der Garantenstellung, nicht (Stoffers, Jura 93, 11, 15f.). Zudem würde die Verbotsnorm des $\S 27 \mathrm{StGB}$ praktisch in das allgemeine Gebot transformiert, deliktischen Handlungen anderer nicht untätig zuzusehen, sondern innen aktiv entgegenzutreten (Stoffers, Jura 93, 11, 17). § 35 würde unzulässigerweise das Unzumutbarkeitskorrektiv des unechten Unterlassungsdelikts ersetzen, und die weitere Strafmilderungsmöglichkeit des § 13 Abs. 2 StGB entfiele (Sowada, Jura 86, 399, 402). Bevor auf eine Abgrenzung zwischen aktiver und passiver Beihilfe eingegangen wird, muß untersucht werden, ob überhaupt ein Garant wegen passiver (psychischer) Beihilfe bestraft werden kann (Dabei ist zu bemerken, daß die passive Beihilfe, im Gegensatz zu der aktiven Beihilfe, fast immer eine psychische ist; ausgenommen nur der Fall, in dem der Untätige nicht den Zugriff zu Rettungsboot ermöglicht, mit dem ein anderer den Ertrinkenden retten könnte; S/S-Stree, Vor § 13, Rn. 159). Da, wie oben dargestellt, eine Bestrafung wegen Täterschaft erfolgt, kommt eine Beihilfe nur in Betracht, wenn der Untätige den Tatbestand nicht selbst verwirklichen konnte. In diesen Fällen kann ein Schweigen zur Tat eines anderen sehr wohl diesen in Sicherheit wiegen oder Bestätigung bedeuten, auch ohne daß aufmunternde Worte oder auch nur ein bestätigendes Nicken erfolgen müssen. In diesen Fällen käme auch die potentielle Strafmilderung des $\S 13$ Abs. 2 und die Milderung aus $\S 27$ zum Zuge.

Was die Abgrenzung zur aktiven Beihilfe angeht, so könnte auch das bloße Nichtstun möglicherweise eine psychische aktive Beihilfe sein. Während ein Anfeuern oder sonstiges Ermuntern zu der Tat als aktive Handlung zu werten ist, darf jedoch ein bloßes Schweigen oder Abwarten nicht unter aktives Verhalten gerechnet werden (Nicht vertretbar daher BGH StV 82, 517 (Bestrafung wegen psychischer Beihilfe durch schweigendes Dabeisein bei Erpressungsgespräch); Stoffers, Jura 93, 11, 15). Zwar ist auch der Entschluß des Täters, untätig zu bleiben, letztlich ein aktiver psychischer Vorgang. Jeder Denk- und Bewußtseinsvorgang ist jedoch eine aktive Tätigkeit. Wollte 
unterscheidet diese Meinung bei der Frage nach Täterschaft und Beihilfe nach der Art der Garantenstellung. Während der Beschützergarant Täter sein soll, ist der Überwachergarant entweder Täter, sofern er die Erfolgsabwendung noch vorher hätte verhindern können oder Gehilfe, wenn der die Erfolgsverhinderung nur durch sein Eingreifen während der Rechtsgutsverletzung hätte verhindern können ${ }^{806}$.

Aus der Sicht des Beschützergaranten, der das ihm anvertraute Gut vor jedweder Gefahr zu bewahren habe, sei nur der drohende Erfolg als solcher relevant, nicht die Frage, wie sich der Erfolg realisiere. Daher gelte für ihn bei Erfolgseintritt die Haftung als Täter.

Der Überwachergarant hingegen stehe einem Gehilfen näher. Es sei ungereimt, zwar den, der dem Mörder in helfender Absicht die Waffe liefert, als Gehilfen zu bestrafen, aber denjenigen, der den Plan erst nach der Weggabe erkennt und der sie sich vor der Ausführung der Tat nicht zurückholt, als Täter zu bestrafen.

Am konkreten Beispiel sieht das folgendermaßen aus: Der 16jährige J schießt mit einer Schleuder Steine in Richtung des 12jährigen K; die beiden Väter sehen dem Treiben zu, schreiten aber nicht ein, weil sie der Ansicht sind, daß Jungen in diesem Alter lernen müssen, sich körperlich zu behaupten, und daß ein paar Blessuren dazu gehören. Ein Stein des $\mathbf{J}$ verletzt den K. Folgt man der dargestellten Auffassung, kommt man zum Ergebnis, daß der Vater des Opfers als (Unterlassungs-)Täter zu bestrafen ist, der Vaters des Täters hingegen nur als Gehilfe.

Schmidhäuser betrachtet den untätigen Überwachergaranten als Täter, allerdings beziehen sich seine Beispiele deutlich auf nichtverantwortliche Begehungstäter, nämlich kleine Kinder und Geisteskranke, so daß nicht deutlich wird, wie er im Falle einer Nichthinderung einer selbstverantwortlichen Person entscheiden würde oder ob dies einen Unterschied machen würde ${ }^{807}$.

Bei den Obhutsgaranten differenziert Schmidhäuser danach, ob das Handeln des aktiven Täters bereits abgeschlossen ist: Wenn ja, soll Täterschaft bestehen, wenn nein, nur Beihilfe, weil dem Garanten zugute

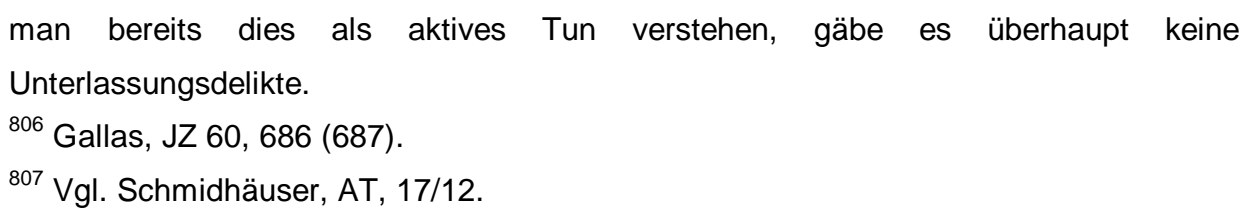


gehalten werden muß, daß er dann dem handelnden Täter erst "in den Arm fallen" muß, um den Erfolg zu verhindern. Im letzteren Fall liege eine spezifische Unterordnung des Nicht-Handelns unter das Handeln vor, der Handelnde gestalte das Geschehen in Tatherrschaft, der unterlassende Garant habe lediglich die Verhinderungsmöglichkeit und ist daher nur Gehilfe ${ }^{808}$. Zu diesem Problem gilt jedoch die hinsichtlich der Tatherrschaftstheorie und der Beihilfetheorie geübte Kritik.

Schröder will nur bei Beschützergaranten eine Täterschaft des unterlassenden Garanten anerkennen. Es bestehe dann kein Unterschied, ob der Garant gegen Naturgewalten oder gegen deliktische Angriffe untätig bleibe. Anders seien demgegenüber die Garantenstellungen zu behandeln, die sich darin erschöpfen, deliktische Angriffe von schuldhaft handelnden Personen $\mathrm{zu}$ verhindern, für die der Unterlassende verantwortlich ist ${ }^{809}$.

Nach Busse schließlich soll der unterlassende Beschützergarant ebenfalls immer Täter sein, der Überwachergarant jedoch entweder Täter oder Gehilfe. Dies begründet er damit, daß die Prinzipien der Sonderpflichtverletzung und der Tatherrschaft weiter Gültigkeit hätten ${ }^{810}$. Schulz macht jedoch geltend, daß, solange übergreifende Zurechnungsprinzipien von Handlung und Unterlassung nicht erkannt oder nicht ausgeschlossen sind, die andersartige Struktur der Unterlassung allein nicht zum Anlaß genommen werden kann, die Unterlassung als dritte Beteiligungsform immer nur als Täterschaft oder nur als Teilnahme zu bestrafen und damit jede Bedeutung der Art der Garantenstellung zu leugnen ${ }^{811}$. Daß die Kritik an der Auffassung, die die Beteiligungsform von der Garantenstellung abhängig macht, nicht auf der einheitlichen Annahme der Täterschaft beruht, soll im folgenden dargelegt werden.

\footnotetext{
${ }^{808}$ Schmidhäuser, AT, 17/12.

809 Schröder in S/S, 17. Aufl., Vor $\S 47$, Rn. 112; ebenso Rudolphi, Gleichstellungsproblematik, S. 144.

${ }^{810}$ Busse, S. 257.

${ }^{811}$ Schulz, Amtswalterunterlassen, S. 186.
} 


\section{bb) Kritik}

Gegen eine Differenzierung der Garantenstellungen spricht vor allem, $\mathrm{da} 3$ die Garantenstellungen gleichwertig sind und nicht $\mathrm{zu}$ unterschiedlicher Bewertung führen dürfen. Die einzelnen Garantenstellungen unterscheiden sich zwar in ihrer Reichweite, nämlich darin, entweder das Rechtsgut eines einzelnen vor vielen Gefahren oder die Rechtsgüter vieler vor einer einzigen Gefahr zu schützen; hinsichtlich ihres Pflichteninhalts unterscheiden sich die Garantenstellungen aber nicht: Steht fest, daß einen Garanten in Bezug auf ein bestimmtes Rechtsgut und auf einen konkreten Angriff eine besondere Rechtspflicht trifft, besteht diese immer darin, die Gefahr auch abzuwenden ${ }^{812}$.

Für eine Abstufung der Erfolgsabwendungspflichten ergibt sich im Gesetz kein Anhaltspunkt. Eine Unterscheidung in "primäre" und "sekundäre" Garantenpositionen ist auch deshalb bedenklich, weil man zur Erfolgsabwendung entweder nur verpflichtet oder nicht verpflichtet sein kann; ein "Mehr" oder "Weniger" ist nicht möglich ${ }^{813}$. Außerdem müßte erklärt werden, wieso eine Garantenstellung minderen Ranges beim Fehlen eines handelnden Dritten dennoch zur Täterschaft führen soll ${ }^{814}$.

Zudem stellt sich die Frage, weshalb nur der Überwachergarant dazu verpflichtet werden sollte, in die Tathandlung einzugreifen, nicht auch der Beschützergarant. Akzeptabel kann nur eine solche Lösung sein, die an zutreffende Unterscheidungskriterien anknüpft und den Nachweis erbringen kann, daß die Unterscheidungskriterien rechtlich wesentlich sind und damit dem unterschiedlichen Wesensgehalt von Täterschaft und Beihilfe entsprechen ${ }^{815}$.

Roxin vertritt dazu die Meinung, die Unterscheidung zwischen den Garantenstellungen nach Ursprung und Inhalt gäbe wie die Unterscheidung nach sozialem Gewicht lediglich Strafwürdigkeits- und

812 Sowada, Jura 86, 399 (407); Roxin, Täterschaft, S. 509; Rudolphi, Gleichstellungsproblematik, S. 144; SK-Rudolphi, Vor $\S 13$, Rn. 40

${ }^{813}$ Roxin, Täterschaft, S. 509.

${ }^{814}$ Roxin, Täterschaft, S. 509; Schulz, Amtswalterunterlassen, S. 200.

${ }^{815}$ Schulz, Amtswalterunterlassen, S. 197. 
Strafzumessungserwägungen wieder, gehöre aber nicht in die Täterlehre ${ }^{816}$.

Weiter ist die Zuordnung zum Kreis der Beschützer oder Gefahrquellengaranten nicht immer eindeutig möglich, vgl. das von Jakobs aufgestellte „Bademeisterbeispiel“ („Ist der Bademeister Beschützer der Gäste vor den Gefahren des Wassers oder Überwacher dieser Gefahr?"*) 817 , so daß sich diese Lehre vor die Schwierigkeit gestellt sieht, auch für diese Unterscheidung sichere Kriterien zu entwickeln.

Mit der Einheitlichkeit der Struktur der Unterlassung dürfte jedoch zugleich dargetan sein, daß die Art der Garantenstellung für die Lösung der Beteiligungsproblematik nichts hergibt ${ }^{818}$.

6. Probleme der Mittäterschaft zwischen sämtlichen an der Tat Beteiligten

a) Mittäterschaft zwischen dem untätigen Elternteil und dem aktiv handelnden Minderjährigen

Da nach der hier vertretenen Auffassung sowohl der aktiv Handelnde als auch der Untätige als Täter einzustufen sind, kommt hier eine Mittäterschaft zwischen beiden in Betracht. Eine mittäterschaftliche Begehungsweise scheitert jedoch daran, daß die Mittäterschaft für mehrere Beteiligte einheitliche Zurechnungskriterien verlangt. Da Tun und Unterlassen, wie oben gezeigt, unterschiedliche Täterbegriffe zur Folge haben, liegen einheitliche Kriterien also nicht vor ${ }^{819}$. So ist zwar der Vater, der trotz der vorhandenen Möglichkeit seinen Sohn nicht von einer Körperverletzung abhält, Unterlassungstäter und sein Sohn Begehungstäter, sie sind aber zusammen nicht Mittäter.

Dem entgegen stehen die Überlegungen, die der BGH im "GastwirtinFall" angestellt hat. Danach sollte sogar eine Bestrafung der untätigen

\footnotetext{
${ }^{816}$ Roxin, Täterschaft, S. 509.

${ }^{817}$ Jakobs, AT, 29/27; Sowada, Jura 86, 399 (407); Vogel, Norm und Pflicht, S. 282, der allerdings, an Jakobs Differenzierung angelehnt, von einer unterschiedlichen Behandlung von Garantenstellung kraft Institution und Organisationsfreiheit ausgeht. ${ }^{818} \mathrm{vgl}$. Schulz, Amtswalterunterlassen, S. 184.

${ }^{819}$ Roxin, Täterschaft, S. 470.
} 
Garantin als Mittäterin mit den Begehungstätern möglich sein, obwohl nicht einmal feststand, ob sie den Erfolg tatsächlich hätte verhindern können ${ }^{820}$.

Dahinter steht der Gedanke, daß es bei der Mittäterschaft nicht darauf ankommt, ob der konkrete Tatbeitrag erfolgskausal geworden ist. Vielmehr muß nur gefragt werden, ob die gemeinschaftliche Tat insgesamt den Erfolg kausal bewirkt hat. Während man bei gemeinschaftlichem aktiven Handeln, wobei die Tatbeiträge unterschiedlich verteilt sein können, dementsprechend auch eine Mittäterschaft bejahen kann, ist das bei einem Zusammentreffen von Tun und Unterlassen auszuschließen.

Für eine Mittäterschaft, die nicht in der Handlung begründet ist, müßte der während der Ausführung Untätige sein Minus im Handeln durch eine entsprechende Mitwirkung am Tatplan ausgeglichen haben. Das ist gerade für die hier einschlägigen Fälle, in denen die Eltern keinen weiteren Beitrag leisten, nicht gegeben. Eine Mittäterschaft von Eltern und dem ihm unterstellten Jugendlichen ist daher ausgeschlossen.

b) Die Mittäterschaft der Eltern bei gleichzeitiger Pflichtverletzung (Gemeinsame Pflichtverletzung durch Unterlassen)

aa) Mittäterschaft durch gemeinsames Unterlassen beider Elternteile Fraglich ist, ob eine Mittäterschaft zwischen beiden Eltern vorliegt, wenn sie trotz gemeinsamer Erfolgsabwendungspflicht und -möglichkeit die Tat nicht verhindern. Dieses mittäterschaftliche Unterlassen wird gemeinhin bejaht ${ }^{821}$.

(1) Bestehen eines Unterlassungsvorsatzes

Von Armin Kaufmann wird dagegen eine Mittäterschaft bei Unterlassungen abgelehnt. Nach seiner Auffassung gibt es keinen gemeinsamen Tatentschluß, weil es schon keinen Unterlassungsvorsatz gibt $^{822}$. Es ist jedoch nicht einzusehen, weshalb das Unterlassen nicht

\footnotetext{
${ }^{820}$ Vogel, Norm und Pflicht, S. 285; bezugnehmend zu BGH NJW 66, 1743.

${ }^{821}$ Roxin, Täterschaft, S. 469f.; Vogel, Norm und Pflicht, S. 285; Otto, Jura 90, 47 (49).

${ }^{822}$ Armin Kaufmann, Dogmatik, S. 189.
} 
ebenso eines Vorsatzes bedarf wie das Begehen ${ }^{823}$. Zudem wird auch vom Gesetz nicht gefordert, daß für die Mittäterschaft durch Unterlassen ein eigener Vorsatz bestehen müsse ${ }^{824}$. Armin Kaufmann beruft sich weiter darauf, daß beim Unterlassen ein arbeitsteiliges Handeln nicht möglich ist, weil das Unterlassen keine Ausführungshandlung kenne. Die Arbeitsteilung ist jedoch kein zwingendes Wesensmerkmal der Mittäterschaft, sondern nur eine typische Erscheinung ${ }^{825}$.

Eine mittäterschaftliche Begehung führt daher im Bereich des Vorsatzes nicht zu Schwierigkeiten; es gelten die für das mittäterschaftliche Begehen entwickelten Regeln.

(2) Die Unterlassung des einen als Beihilfe zur Unterlassung des anderen Dem Gedanken einer Mittäterschaft durch Unterlassen steht weiter die These entgegen, daß von zwei zusammentreffenden Unterlassungen die eine Unterlassung eine Beihilfe zur anderen sein könne ${ }^{826}$. Daß das nicht richtig sein kann, hat Grünwald zu begründen versucht: Mehrere Unterlassende beherrschen seiner Ansicht nach das Geschehen in gleicher Weise, nämlich durch die Möglichkeit der Erfolgsabwendung. An der Beherrschung des Geschehens durch den einen ändere sich nichts dadurch, daß auch ein anderer den Erfolg abzuwenden unterließe $\mathrm{e}^{827}$. Auch wenn man dieser Lehre nicht folgt, gelangt man auch nach der Einheitstäterlösung zum gleichen Ergebnis. Beide Garanten verstoßen gegen ihre gemeinsame Handlungspflicht aus der Garantenstellung und sind somit beide Täter. Es ist nicht ersichtlich, wieso die eine Unterlassung der anderen untergeordnet werden sollte.

\section{(3) Nebentäterschaft}

Schließlich ist der Fall denkbar, daß mehrere Garanten unabhängig voneinander die Erfolgsverhinderung unterlassen. Unterlassen Vater und Mutter unabhängig voneinander und ohne Wissen über das Unterlassen

\footnotetext{
${ }^{823}$ Dazu siehe 3. Teil C. I 1.

${ }^{824}$ Vgl. Roxin, Täterschaft, S. 470.

${ }^{825}$ Busse, S. 77.

${ }^{826}$ Kielwein, GA 55, 225 (226f.); RGSt 66, 71 (74); BGHSt 2, 150 (151).

${ }^{827}$ Grünwald, GA 59, 110 (123).
} 
des anderen die Verhinderung, sind sie unproblematisch als Nebentäter einzustufen ${ }^{828}$.

bb) Mittäterschaft zwischen dem tätigen und dem unterlassenden Elternteil (Gemeinsame Pflichtverletzung durch aktives Tun des einen und Unterlassen des anderen)

Weiter ist der Fall zu untersuchen, daß der eine Elternteil sich aktiv, der andere sich passiv an der Tat des Jugendlichen beteiligt. Da der Unterlassende nach hier vertretener Ansicht immer Täter ist, bleiben dafür zwei Varianten.

In der ersten Variante ist der eine Elternteil aktiver Gehilfe an der Tat seines Kindes, der andere Elternteil ist Unterlassungstäter. Dann würde eine Bestrafung der Elternteile nach eben diesen Begehungsformen erfolgen.

In der anderen Variante, für die eine Mittäterschaft der Eltern erst in Frage kommt, ist ein Elternteil aktiver Täter, der andere Unterlassungstäter. In dieser Konstellation sind also beide Eltern Täter, der eine durch Begehen, der andere durch Unterlassen. Um Täter des Begehungsdelikts sein zu können, muß dabei der aktive Elternteil Mittäter an der Tat seines Kindes oder aber Nebentäter neben seinem Kind sein. Die Rolle des anderen Elternteils ist, die Tat ${ }^{829}$ ungehindert geschehen zu lassen.

Nun ist $\mathrm{zu}$ untersuchen, ob dann auch eine Bestrafung wegen Mittäterschaft möglich ist. Beide Eltern erfüllen denselben Tatbestand und verstoßen gegen dieselbe Aufsichtspflicht. Ob sie diese Pflicht durch Tun oder Unterlassen verletzen, ist unerheblich ${ }^{830}$. Eine Mittäterschaft ist daher zu bejahen. Dem steht auch nicht entgegen, daß in anderen Fällen eine mittäterschaftliche Begehungsweise daran scheitert, daß die Mittäterschaft für die mehreren Beteiligten einheitliche Zurechnungskriterien verlangt. Das gilt aber nur dort, wo Tun und

\footnotetext{
${ }^{828}$ Vgl. Busse, S. 76; Schmidhäuser, AT, 17/8; Armin Kaufmann, Dogmatik, S. 189; Roxin, Täterschaft, S. 464.

${ }^{829}$ Hierbei ist nur auf den Tatbeitrag des Jugendlichen abzustellen, da bekanntermaßen eine Deliktsverhinderungspflicht gegenüber Ehegatten nicht besteht.

${ }^{830}$ Vgl. Roxin, Täterschaft, S. 471.
} 
Unterlassen unterschiedliche Täterbegriffe zur Folge haben und einheitliche Kriterien nicht vorliegen ${ }^{831}$. Hier ist das anders.

Roxin stellt zur Diskussion, ob nicht bereits im gemeinsamen Tatentschluß eine "psychische" Aktivität liege, so daß der Untätige in Wirklichkeit auch ein Begehungstäter sei ${ }^{832}$. Dann läge im vorliegenden Kontext eine Mittäterschaft der Eltern durch Begehen vor. Gegen eine solche Lösung spricht jedoch, daß das vereinbarte Verhalten gerade ein Unterlassen sein soll. Es ist also auf das rechtsgutsverletzende Verhalten an sich abzustellen. Andernfalls, so Roxin, müßte jedes absichtliche, ja sogar jedes bewußte Unterlassen wegen der im Bewußtseinsvorgang zum Ausdruck kommenden aktiven psychischen Energie ein Begehungsdelikt sein.

Somit kann eine Mittäterschaft vorliegen, sofern beide Täter - der eine aktiv, der andere passiv - eine gemeinsame Pflicht verletzen.

II. Sonderstellung des Jugendlichen: Der Jugendliche als Vollverantwortlicher im Sinn der Teilnahmetheorien?

Bei der Frage nach der strafrechtlichen Verantwortlichkeit der Garanten, also hier der Eltern, ist zu berücksichtigen, daß die dargestellten Theorien für die Deliktshinderung gegenüber vollverantwortlichen Personen entwickelt wurden. Für die Nichthinderung von nicht-verantwortlichen Personen kommen die Theorien zumeist zu anderen Ergebnissen, d.h. zu mittelbarer Täterschaft anstelle von Unterlassungstäterschaft oder Beihilfe. Daher steht es nicht von vornherein fest, daß die für die unterlassene Deliktshinderung entwickelten Erwägungen gegenüber Jugendlichen problemlos übernommen werden können, da diese an der Schwelle zwischen Schuldfähigkeit und Schuldunfähigkeit stehen.

Dazu ist die strafrechtliche Stellung des Jugendlichen zu betrachten. Die Unterscheidung zwischen Schuldfähigkeit und Schuldunfähigkeit des Jugendlichen wird durch $\S 3$ JGG getroffen. Auch wenn der Jugendliche

\footnotetext{
${ }^{831}$ Roxin, Täterschaft, S. 470.

${ }^{832}$ Roxin, Täterschaft, S. 471.
} 
bei Vorliegen der entsprechenden Reife ab 14 Jahren als schuldfähig und verantwortlich zumindest i.S.d. Jugendrechtes eingestuft wird, bleibt fraglich, ob er damit im Sinne der Teilnahmelehre einem Erwachsenen gleichgestellt werden kann. Es ist zu klären, ob die Aufsichtspflichtigen sich behandeln lassen müssen, als hätten sie einen vollverantwortlichen Erwachsenen handeln lassen, oder ob man ihnen den - erschwerten Vorwurf macht, sie seien nicht einmal in der Lage gewesen, eine nicht vollentwickelte Persönlichkeit aufzuhalten. Denn trotz Straffähigkeit wird der Jugendliche im Strafrecht eben nicht wie ein Erwachsener behandelt, da man seinen Erziehungsprozeß als noch nicht abgeschlossen einstuft. Die besondere Stellung des Jugendlichen könnte also dazu führen, daß der Einfluß des Unterlassenden auf den (schuldfähigen) Jugendlichen eben doch anders zu bewerten ist als der Einfluß auf einen (schuldfähigen) Erwachsenen. Roxin weist zutreffend darauf hin, daß das Problem der Tatherrschaft bei Beteiligung an Delikten Jugendlicher nur selten behandelt wird ${ }^{833}$.

Die (mittelbare) Täterschaft durch aktives Tun der Eltern lehnt Roxin zumindest dann ab, wenn der Jugendliche das Unrecht seiner Tat erkannt hat und für sie strafrechtlich voll verantwortlich ist. Er sei in diesem Fall weder bei der Willensbildung unfrei, noch im Verständnis des Geschehens beeinträchtigt. Daß er den besonderen Sanktionen des Jugendstrafrechts unterliege, habe mit den Herrschaftsverhältnissen beim konkreten Geschehen nichts zu tun ${ }^{834}$.

Auf das Unterlassen läßt sich dieser Gedanke jedoch nicht übertragen. Hier muß es vielmehr umgekehrt lauten: Wenn schon das Unterlassen der Hinderung eines Erwachsenen zur Täterschaft führt, dann erst recht das Unterlassen der Hinderung eines Jugendlichen ! Es ist daher nach der oben geführten Argumentation von einer grundsätzlichen Täterschaft der Eltern bei Taten ihrer jugendlichen Abkömmlinge auszugehen. Die unterschiedliche gesetzliche Behandlung von Jugendlichen und Erwachsenen beinhaltet lediglich die Rechtsfolgen der Tat, nicht aber in der Bestimmung des Tatvorwurfs als solchen. Der Umstand, daß ein Jugendlicher durch Erziehungsmittel anstatt durch Strafe beeinflußt

\footnotetext{
${ }^{833}$ Roxin, Täterschaft, S. 238.

${ }^{834}$ Roxin, Täterschaft, S. 240.
} 
werden soll, hat für die Verwirklichung der Tatbestandsmerkmale durch ihn ebenso wenig Relevanz wie für die Bestimmung der Beteiligungsform der Eltern.

III. Das Nichteinschreiten gegen Gehilfenbeiträge des zu überwachenden Minderjährigen

$\mathrm{Zu}$ untersuchen ist weiterhin die Situation, in der der Garant nicht die eigene Tat des zu Überwachenden, sondern nur dessen Gehilfenbeitrag zu der Tat eines Dritten nicht verhindert. Dazu zunächst ein Beispiel: Die Eltern verhindern nicht, daß ihr Sohn seine Gaspistole an einen Freund weitergibt, der damit einen Raub verübt.

Ausgangspunkt dabei muß sein, daß Eltern nur für Delikte des eigenen Kindes verantwortlich sind, in der Regel aber nicht aber für die Delikte Dritter. Fraglich ist, inwieweit auch die Beihilfehandlung des Minderjährigen ein Delikt darstellt, das von den Eltern verhindert werden muß.

Berücksichtigt man, daß der Tatbeitrag des Minderjährigen unter Umständen die Straftat des Dritten erst ermöglicht, muß man eine Verantwortlichkeit der Eltern bejahen. Die Strafbarkeit der Eltern aus der Garantenstellung beruht darauf, daß sie die Gefahren abwenden müssen, die von dem zu Überwachenden ausgehen. Gerade diese Gefahr wird aber nicht abgewendet, wenn sie es geschehen lassen, daß ihr Kind zur Verwirklichung von Straftaten zumindest beiträgt, auch wenn es als Gehilfe weder Urheber noch tatsächlich Ausführender ist.

Eine Unterlassungstäterschaft durch die Eltern dürfte in diesen Fällen ausscheiden. Wenn der Überwachergarant es durch sein Nichtstun lediglich ermöglicht, daß der zu Überwachende einen Dritten in den Stand setzt, den Tatbestand zu verwirklichen, soll auch nach Vogel eine täterschaftliche Beteiligung ausgeschlossen $\operatorname{sein}^{835}$. Auch Rudolphi will den Fall des garantenpflichtwidrigen Nichteinschreitens gegen Gehilfenbeiträge aus der Täterschaftsbestrafung ausnehmen ${ }^{836}$. Zur

\footnotetext{
${ }^{835}$ Vogel, Norm und Pflicht, S. 281.

${ }^{836}$ SK-Rudolphi, Vor § 13, Rn. 42.
} 
Begründung muß man sich vor Augen halten, daß das Unrecht der Eltern nur an der Tat zu messen ist, die der Jugendliche verwirklicht hat. Wenn der Jugendliche kein täterschaftliches Unrecht begangen hat, können die Eltern auch nicht für mehr herangezogen werden. Denn durch ihr Unterlassen haben sie auch nicht ein größeres Unrecht als das der Beihilfe verwirklicht.

Dieser Schluß ist jedoch nicht so einfach, will man nicht in Gefahr geraten, sich auf die von Ranft angestellten Akzessorietätsüberlegungen zurückzuziehen. Es mag richtig sein, daß die Eltern in bezug auf die Tat des von ihnen überwachten Jugendlichen nur eine Beihilfe ermöglichen. Im Hinblick auf den Dritten ermöglichen sie hingegen eine Haupttat durch ihr Unterlassen. Für die Kausalität, soweit man von ihr im Zusammenhang mit Unterlassen sprechen will, spielt es keine Rolle, ob der Jugendliche als Gehilfe dazwischengeschaltet ist. Eine Bestrafung wegen täterschaftlichen Unterlassens der Eltern entfällt allein deshalb, weil die Garantenstellung der Eltern sich nur auf die Aktivität des von ihnen Überwachten beschränkt, der eben nur eine Beihilfe ausführt.

Die Eltern verhindern nicht die Beihilfe zur Körperverletzung durch ihren Sohn, $\S \S 223,27$ StGB, als dieser das Opfer per Telefon an einen einsamen Ort lockt, wo es vom Haupttäter verprügelt wird. Die Eltern haben durch ihr Unterlassen die Körperverletzung überhaupt erst ermöglicht. Der Erfolg ist ihnen zuzurechnen, da ohne das Telefonat durch ihren Sohn das Tatopfer sich nicht an den Tatort begeben hätte. Die Eltern haben aber weder dem Haupttäter gegenüber eine Tatverhinderungspflicht noch dem Opfer gegenüber eine Beschützergarantenpflicht. Die Garantenpflicht erschöpft sich hier darin, die Beihilfehandlung zur unterbinden. Daher bleibt nur eine Strafbarkeit wegen $\S \S 223,27,13$ Abs. 1 und 2 StGB.

B. Der strafunmündige bzw. nicht verantwortliche Minderjährige

Nicht nur ältere Jugendliche, sondern beispielsweise auch 9jährige können durch ihr „unzähmbares“ Verhalten zum „Schrecken eines Ortes“ 
werden $^{837}$. Es muß daher auch die Deliktsverhinderungspflicht gegenüber Kindern untersucht werden.

I. Täterschaft oder Teilnahme gegenüber der Tat des strafunmündigen Kindes

Das strafunmündige Kind i.S.d. $§ 19$ StGB ist zwar selbst nicht schuldund straffähig ${ }^{838}$. Auch bei der Tat des Kindes kommen aber gleichermaßen Täterschaft und Teilnahme durch den aufsichtspflichtigen Garanten in Betracht: Die Teilnahme des Garanten an der Straftat des Kindes ist dabei aufgrund der in $\$ 29$ StGB geregelten limitierten Akzessorietät möglich. Da auch Teilnehmer nur nach der eigenen Schuld bestraft werden, könnten Eltern als Gehilfen an einer Tat des Kindes bestraft werden, während das Kind aufgrund seiner Schuldunfähigkeit wegen derselben Tat straflos bleibt.

Ungeachtet dieser Möglichkeit der Teilnahme bejaht die überwiegende Meinung in der Literatur regelmäßig dann eine mittelbare Täterschaft, wenn der Hintermann Kenntnis von der Schuldunfähigkeit des Ausführenden hat ${ }^{839}$, was bei Eltern gegenüber ihren Kindern stets der Fall ist. Dies gilt es näher zu untersuchen, da es keinesfalls selbstverständlich ist, den Eltern nur aufgrund der Schuldunfähigkeit des Kindes die Täterschaft zuzusprechen. Es hat nämlich keinen Einfluß auf die Täterschaft des Garanten, ob er die Tat eines Schuldunfähigen oder die eines Schuldfähigen nicht unterbindet. Die oben zur Unterscheidung von Täterschaft und Teilnahme beim Unterlassen ausgeführten Theorien sind im Verhältnis zwischen dem Garanten und dem schuldunfähigen aktiven Täter vielmehr ebenso anzuwenden: Die subjektive Lehre stellt auch hier darauf ab, ob der Untätige die Tat des Schuldunfähigen als eigene wollte. Die Tatherrschaftslehre fragt auch hier, ob der Untätige die Tatherrschaft über die Tat des Schuldunfähigen hatte. Und auch die

\footnotetext{
${ }^{837}$ RG WarnRspr, 1911 Nr. 33.

838 Dem strafunmündigen Kind gleichzustellen ist der Jugendliche, der nach § 3 JGG nicht verantwortlich ist, der also nach seiner sittlichen und geistigen Entwicklung nach nicht reif genug ist, um das Unrecht seiner Tat einzusehen und danach zu handeln.

${ }^{839}$ LK-Roxin, § 29, Rn. 2,4; Tröndle/Fischer, § 29, Rn. 3.
} 
Lehren, die den Unterlassenden einheitlich als Täter oder als Teilnehmer einstufen, setzen nicht an der Schuldfähigkeit des Vordermannes an.

Deshalb kann, wie teilweise in der Literatur postuliert, nicht von vornherein stets nur eine (mittelbare) Täterschaft in Frage kommen. Die Schuldunfähigkeit des Kindes macht den Garanten noch nicht automatisch zum Täter und das Kind zu seinem Werkzeug ${ }^{840}$.

Aus den oben dargestellten Erwägungen zu Täterschaft und Teilnahme beim Unterlassen (4. Teil, A.) kann der Garant auch gegenüber der Tat des schuldunfähigen Kindes nur Täter sein. Welche Folgen sich für die Unterscheidung von mittelbarer und unmittelbarer Täterschaft ergeben, wird im weiteren behandelt.

II. Abgrenzung zwischen der mittelbaren und der unmittelbaren Täterschaft durch Unterlassen

Nunmehr ist zu ermitteln, wie sich die mittelbare Täterschaft durch Unterlassen von der unmittelbaren Täterschaft durch Unterlassen unterscheidet. Fraglich ist, ob es im Rahmen des hier zugrunde gelegten Modells der Einheitstäterlehre eine mittelbare Täterschaft überhaupt geben kann.

Die mittelbare Täterschaft setzt nach h. M. ein nicht voll tatbestandsmäßiges, rechtswidriges oder schuldhaftes Handeln des direkt Handelnden voraus ${ }^{841}$. Ein solcher Mangel liegt beim Kind aufgrund seiner Schuldunfähigkeit unproblematisch vor. Weiter ist die Tatherrschaft des Hintermannes erforderlich. Gerade auf diese kommt es im Rahmen der Einheitstäterlehre jedoch nicht an, weil die Tatherrschaft sich im Unterlassen nicht manifestiert. Läßt der Hintermann die Tat eines Schuldlosen geschehen, so müssen konsequenterweise die mittelbare und

\footnotetext{
${ }^{840}$ Es muß allerdings eingeräumt werden, dass das geringe Alter des Kindes und seine stärkere Hilflosigkeit viel eher dazu führen werden, dass die Tatherrschaft des Erwachsenen zu bejahen ist und die Wahrscheinlichkeit, daß er die Tat als eigene will, mangels eines ausgeprägten Willens beim Kind sehr hoch ist. Anders als beim Jugendlichen, über den der Garant seine Herrschaft nur eingeschränkt ausüben kann, ist er im Hinblick auf das Kind in einer dominierenden Rolle.
} 
unmittelbare Täterschaft zusammenfallen, sofern es nicht gelingt, eine Abgrenzung vorzunehmen, die ohne das Tatherrschaftskriterium auskommt.

Die Tatherrschaft bei wird der mittelbaren Begehung dadurch gekennzeichnet, daß der Hintermann den Tatmittler als Werkzeug in der Hand hat und so kraft überlegener Willensherrschaft die Tatausführung beherrscht ${ }^{842}$. Der Hintermann besitzt dabei eine objektive Übermacht gegenüber dem unmittelbar Handelnden.

Die mittelbare Täterschaft durch aktives Tun erfordert jedoch zusätzlich eine eigene Initiative des Hintermannes. Der Hintermann muß den Tatmittler vor dessen Aktivwerden durch eigenes aktives Tun in den Handlungsverlauf eingeschaltet haben ${ }^{843}$. Gerade daran fehlt es beim Unterlassen der Deliktshinderung: Der Hintermann, hier also ein Elternteil, setzt das Kind nicht aus eigenem Antrieb ein, um dadurch einen Erfolg zu erzielen ${ }^{844}$. Er schaut nur tatenlos zu und billigt die Tat gegebenenfalls. Die Tat des Kindes geschieht, ohne daß der Elternteil Einfluß darauf genommen oder den Anstoß dazu gegeben hätte. Eine Benutzung des Kindes als Werkzeug wie beim aktiven Tun liegt daher nicht vor.

Ein planvolles Lenken des Kindes besteht daher zumindest nicht von Anfang an, da das Kind von sich aus mit der Tatausführung beginnt und die Eltern somit erst sukzessive in das Geschehen einbezogen werden ${ }^{845}$. Das schließt jedoch nicht aus, dass die Eltern noch rechtzeitig genug in den Geschehensablauf eingeweiht werden, um den Taterfolg verhindern zu können. Lassen sie den Dingen trotzdem ihren Lauf, liegt darin ein täterschaftliches Unterlassen.

\footnotetext{
${ }^{841}$ Wessels, AT, S. 148 , Rn. $535 \mathrm{ff}$.

${ }^{842}$ Wessels, AT, S. 149, Rn. 538; S/S-Cramer, Vor §§ 25ff., Rn. 76.

${ }^{843} \mathrm{vgl}$. Roxin, Täterschaft, S. 471.

${ }^{844}$ Eine direkter Vorsatz des Garanten hinsichtlich des Erfolges dürfte in den wenigsten Fällen vorliegen, eine Absicht ist gar nicht möglich.

${ }^{845}$ Hat der Garant hingegen die Tat des Kindes zuvor in irgendeiner Weise veranlaßt, ist er zwar mittelbarer Täter, dann aber durch Begehen und nicht durch Unterlassen, vgl. Roxin, Täterschaft, S. 472.
} 
Die Differenzierung zwischen unmittelbarer und mittelbarer Täterschaft verkommt damit bei der „Einheitstäterlösung“ zur bloßen Worthülse. So weist Schmidhäuser auch darauf hin, daß man, setzt man die Beherrschung des Tatmittlers durch den Hintermann voraus, eine mittelbare Täterschaft durch Unterlassen ablehnen und statt dessen eine unmittelbare Unterlassungstäterschaft annehmen müßte ${ }^{846}$. Er stellt aber zugleich klar, daß sich ein großes Sachproblem letztlich nicht dahinter verbirgt.

Letztlich muß man sich der Frage zuwenden, ob es für die mittelbare Täterschaft erforderlich ist, daß der Hintermann den Tatmittler komplett beherrscht und dessen Aktionen vorherbestimmen und lenken kann ${ }^{847}$.

Dieser Meinung ist Schmidhäuser wiederum nicht. Seiner Auffassung nach kann es eine mittelbare Täterschaft auch durch Unterlassen geben. Er knüpft daran lediglich die Bedingung, daß es sich bei dem durch den Aktiven verwirklichen Tatbestand um ein reines Erfolgsdelikt handelt und den Unterlassenden eine Pflicht der Sicherung gegen fremde Gefährlichkeit trifft ${ }^{848}$. Als Beispiel dazu führt er den Pfleger an, der es wissentlich geschehen läßt, daß der von ihm zu beaufsichtigende Geisteskranke einen Besucher tötet. Der Pfleger soll wegen vorsätzlichen Tötungsdelikts in mittelbarer Täterschaft zu bestrafen $\operatorname{sein}^{849}$.

Zum Begriff der mittelbaren Täterschaft gehört es nach Auffassung Grünwalds, daß in genau die Kausalkette, die sich von der Täterhandlung zum Erfolg spannt, die Handlung eines Menschen eingeschaltet ist, der infolge wissens- oder willensmäßiger Unterlegenheit nicht Täter ist. Nur auf diese Kausalkette komme es an. Bei der Unterlassung fehle eine solche Kausalkette, da der Unterlassende überhaupt keine Kausalkette auslöse. Die Fälle, die als mittelbare Täterschaft durch Unterlassen angesehen würden, z.B. bei dem Krankenpfleger im psychiatrischen Krankenhaus, der es geschehen lasse, daß sein Pflegling einen

\footnotetext{
${ }^{846}$ Schmidhäuser, AT, 17/7. Fn. 3.

847 Insofern setzt Schroeder einen falschen Akzent, wenn er allein auf den Unterschied zwischen dem Dazwischenschalten eines Menschen oder einer Naturgewalt abstellt, vgl. Schroeder, Der Täter, S. 105.

848 Schmidhäuser, AT, 17/7; ebenso Jakobs, 29. Abschnitt, Rn. 103.

${ }^{849}$ Schmidhäuser, AT, 17/7.
} 
Mitpatienten angreift, seien Fälle des Begehens durch Unterlassen ohne wesensmäßige Besonderheiten ${ }^{850}$.

Auch ohne eine vom Garanten gesetzte Kausalkette ist jedoch eine Benutzung des Vordermannes für die Zwecke des Hintermannes denkbar, was mit einem Beispiel veranschaulicht werden soll: Die überforderte Mutter des (strafunmündigen) Kindes hofft, ihr auf der Straße spielendes Kind werde von einem Fahrzeug überrollt werden und dabei zu Tode kommen. Die Verletzung anderer Verkehrsteilnehmer durch den Unfall nimmt die Mutter dabei in Kauf. Wenn der von der Mutter erwünschte Fall eintritt, kann hier - neben der vorsätzlichen Tötung des Kindes durch Unterlassen - hinsichtlich des verletzten Dritten von einer mittelbaren Täterschaft durch die Mutter gesprochen werden. Sie hatte die Möglichkeit, den von ihr vorhergesehenen Tatverlauf und -erfolg zu verhindern, und hat ihn dennoch durch ihr Kind, für dessen Taten sie Garantin ist, geschehen lassen. Das Kind merkte nicht, daß sein Tun in einen fremden Tatplan eingebunden wurde. Die Mutter hat ihr Kind in ihrem Sinne handeln lassen.

Im Grunde ist Macht, die die Mutter hier innehat, noch viel stärker, als wenn sie aktiv eingreifen müßte: Das Kind tut alles von selbst und ermöglicht den von der Mutter gewollten Erfolg, ohne daß diese selbst etwas dazu tun müßte. Nur, wenn die Mutter diesen Erfolg nicht möchte, muß sie handeln, ansonsten braucht sie nur abzuwarten. Insoweit ist es schon möglich, von der Benutzung des Kindes als Werkzeug zu sprechen.

Auch Herzberg zeigt, dass der Hintermann nicht zwingend eine Tätigkeit entfalten muß, um als mittelbarer Täter zu gelten. Ein „Lenken“, „Regieren“ oder „Veranlassen“ des Kausalprozesses soll nicht erforderlich sein. Vielmehr soll die Garantenstellung selbst bewirken, daß der Untätige angesehen wird wie einer, der den Kausalverlauf aktiv angestoßen hat; sie gleicht das Manko des aktiven Anstoßes aus ${ }^{851}$.

\footnotetext{
${ }^{850}$ Grünwald, GA 59, 110 (118).

${ }^{851}$ Herzberg, Die Unterlassung, S. 104.
} 
Das strafunmündige Kind und der nichtverantwortliche Jugendliche können daher die Werkzeugeigenschaft auch dann erfüllen, wenn ein überlegener Täter sie in Kenntnis des geschehenden Taterfolgs lediglich gewähren läßt. Das Verwenden einer anderen Person im Sinne der mittelbaren Täterschaft ist folglich auch dann gegeben, wenn der Täter nicht selbst aktiv wird, aber als Garant für das Ausbleiben des Erfolges einzustehen hat $^{852}$.

852 Konsequent daher: LG Göttingen NStZ 1985, 411; Seier, JA 90, 382 (384); Maurach/ Zipf, AT 2, S. 280; Engelsing, S. 42; Gallas, JZ 60, 686 (686f.), Fn. 69; Jakobs, AT, 


\section{Teil. Die Strafbarkeit der Eltern gemäß $§ 171$ StGB}

Die geschichtliche Entwicklung bis hin zur Schaffung des $\S 171$ StGB ist bereits eingangs weitgehend geschildert worden. Verfassungsrechtlich steht die Vorschrift des heutigen $§ 171$ im Spannungsfeld zwischen dem Prinzip des Jugendschutzes einerseits und dem Elternrecht andererseits.

Politisch kommt hier der Widerstreit zwischen dem Gedanken der sozialen Bindung und dem Liberalismus zum Vorschein. Dies läßt sich anhand von mehreren Beispielen verdeutlichen: Im Nationalsozialismus wurde der Tatbestand eingeführt, um der damaligen Forderung, der einzelne müsse eine besondere soziale Verantwortung für die Gemeinschaft übernehmen, Nachdruck zu verleihen. Aus ähnlichen politischen Erwägungen ist der Tatbestand von der DDR nicht nur übernommen, sondern sogar noch erheblich erweitert worden (vgl. § 142 StGB der DDR). Demgegenüber wollte der Alternativentwurf $f^{853}$ den Tatbestand des $\S 171$ StGB vor dem Hintergrund eines auf das Individuum ausgerichteten Strafrechts abschaffen ${ }^{854}$.

In der Strafrechtspraxis nimmt die Strafbestimmung des $\S 171$ nur eine marginale Rolle ein ${ }^{855}$. Im Jahr 1996 gab es 583 Tatverdächtige, wovon 39 Personen (nach $\S 170$ d) verurteilt wurden. Hinsichtlich der Strafen, soweit sie verhängt werden, dominiert die Freiheitsstrafe zur Bewährung $^{856}$. Daraus läßt sich schlußfolgern, daß der Unrechtsgehalt der Tat, soweit er den Grad überschreitet, bei dem aus Opportunitätsgründen eingestellt werden kann, zumeist als schwerwiegend eingestuft wird.

29/103; Ranft, ZStW 94 (1982), 815 (862, Fn. 174); a.A. Roxin, Täterschaft, S. 471.

${ }^{853}$ AE 1968, BT, Sexualdelikte usw., S. 69.

${ }^{854}$ Maurach/ Schroeder/ Maiwald, BT 2, Rn. 49.

${ }^{855} \mathrm{Vgl}$. Ostendorf, S. 14.

${ }^{856}$ Ostendorf, S. 14. 
A. Aufbau und systematische Einordnung des $§ 171$ StGB

I. Der Tatbestand des $§ 171$ und seine Merkmale

§ 171. Verletzung der Fürsorge- oder Erziehungspflicht

„Wer seine Fürsorge- oder Erziehungspflicht gegenüber einer Person unter sechzehn Jahren gröblich verletzt und dadurch den Schutzbefohlenen in die Gefahr bringt, in seiner körperlichen oder psychischen Entwicklung erheblich geschädigt zu werden, einen kriminellen Lebenswandel zu führen oder der Prostitution nachzugehen, wird mit Freiheitsstrafe bis zu drei Jahren oder mit Geldstrafe bestraft. “

1. Schutzzweck und geschütztes Rechtsgut

a) Systematik

Systematisch ist $\S 171$ unter dem 12. Abschnitt des StGB eingeordnet, der die Straftaten gegen den Personenstand, die Ehe und die Familie betrifft.

Entgegen der heutigen Auslegung der Norm, wonach durch die Vorschrift die gesunde körperliche und geistige Gesundheit von Menschen unter 16 Jahren zu schützen ist, steht $\S 171$ StGB weiterhin unter der Deliktsgruppe „Straftaten gegen den Personenstand, die Ehe und die Familie“. Damit wird nach der Systematik des Gesetzes nicht das Kind geschützt, sondern übergreifend die Familie, in der das Kind groß wird. Das ist auch deshalb nicht ganz zutreffend, weil auch Fürsorge- und Erziehungspflichtige außerhalb der Familie von der Norm betroffen werden können ${ }^{857}$.

Im 12. Abschnitt sind auch keine Tatbestände zusammengefaßt, die inhaltlich dem $\S 171$ nahekommen. Der Tatbestand der Fürsorge- und Aufsichtspflichtverletzung steht zwischen jenem über die Verletzung der Unterhaltspflicht (§170), und der Doppelehe (§ 172). $\mathrm{Zu}$ den Tatbeständen des Abschnitts über Personenstand, Ehe und Familie

${ }^{857}$ Ostendorf, S. 36 
gehören ansonsten nur noch die Verbote der Personenstandsfälschung (§169) und des Beischlafs zwischen Verwandten (§ 173).

Inhaltlich stellt $\S 171 \mathrm{im}$ Gegensatz zu seiner systematischen Einordnung eine Ergänzung zu den $\S \S 221$ (Aussetzung) und 225 (Mißhandlung von Schutzbefohlenen) dar. Man kann daher zu Recht die Frage stellen, ob $\S 171$ systematisch nicht besser bei den Körperverletzungsdelikten im 17. Abschnitt des Strafgesetzbuches aufgehoben wäre. Allerdings ist das Schutzgut des $\S 171$ vielschichtig, so daß auch eine Einordnung unter die Körperverletzungsdelikte den Umfang des Tatbestandes nicht ganz trifft: Wie noch auszuführen sein wird, schützt die Vorschrift auch die Religions- und Weltanschauungsfreiheit des Kindes, indem es die ungestörte geistige Entwicklung ermöglichen soll. Insoweit wäre auch der 11. Abschnitt des StGB betroffen. Ebenso berührt $\S 171$ StGB aufgrund des angestrebten Schutzes der körperlichen und geistigen Gesundheit die sexuellen Selbstbestimmung des Kindes und könnte dem 13. Abschnitt des StGB zugeordnet werden.

Man wird die jetzige systematische Einordnung in den 12. Abschnitt jedenfalls als überholt ansehen müssen.

\section{b) Geschütztes Rechtsgut}

Der Grundgedanke der Vorschrift ist, die besonders verantwortungslose Vernachlässigung der Fürsorge- oder Erziehungspflichten in materieller oder ideeller Hinsicht zu erfassen. Schutzobjekt ist das Kind bzw. der Jugendliche bis zum Alter von 16 Jahren $^{858}$. Der Schutz zielt dabei umfassend auf die gesunde körperliche und geistig-sittliche Entwicklung. Besondere familienrechtliche Fürsorge- und Erziehungspflichten bzw. ansprüche sind für die Rechtsgutsbestimmung ohne Bedeutung, ihre Nennung dient lediglich der Kennzeichnung des Personenkreises, der als Tätergruppe in Frage kommt ${ }^{859}$.

Das in $\S 171$ StGB geschützte Rechtsgut war nicht immer unumstritten. Zur Zeit der Entstehung des $\S 170$ d RStGB stand der Gedanke im Vordergrund, daß das Wohl des Kindes ein staatliches Rechtsgut sei und dessen Gefährdung folglich einen Eingriff in die Rechte des Staates

${ }^{858}$ Franke-Gricksch, S. 5; Maurach/ Schroeder/ Maiwald, BT 2, 63 IV, Rn. 49; S/SLenckner, § 171, Rn. 1. 
darstelle ${ }^{860}$. Demgegenüber setzte sich bald die Auffassung durch, daß eine Norm, die dem körperlichen und seelisch-sittlichen Wohl einer Person diene, auch den Schutz dieser Person bezwecke. Zwar liegt die gesunde körperliche und geistige Heranbildung der Jugend auch im Interesse des Staates, der von eben jener heranfolgenden Generation getragen wird. So betrachtet nimmt aber der Staat an allen individuellen Rechtsgütern teil. Jede Körperverletzung, jeder Diebstahl oder Betrug hat Einfluß auf das Verhalten des Opfers und seine Umgebung und damit auf die ganze Gesellschaft. Selbst wenn das Interesse der Gesamtheit so groß ist, wie dies bei der Bedeutung einer gesunden Entwicklung der Kinder angenommen werden kann, wird das individuell ausgerichtete Rechtsgut nicht zu einem Rechtsgut der Allgemeinheit ${ }^{861}$. So überwiegt heute die Ansicht, daß das Rechtsgut des $\S 171$ ausschließlich die gesunde körperliche und geistige Entwicklung von Kindern und Jugendlichen ist $^{862}$. Der Wegfall der ursprünglichen Subsidiaritätsklausel, wonach $\S 170$ d nur einen Auffangtatbestand darstellte, durch das 4 . Strafrechtsreformgesetz von 1973, macht deutlich, daß die Vorschrift ein eigenes, wichtiges Rechtsgut schützt ${ }^{863}$.

Das in $\S 171$ geschützte Rechtsgut hat besonders das Amtsgericht Wermelskirchen in einer Entscheidung hervorgehoben ${ }^{864}$. Es wird dort ausgeführt: „, Bei dem durch $\S 170$ d StGB geschützten Rechtsgut des Kindeswohls, einer gedeihlichen Entwicklung, die frei von Gefährdungen auch in psychischer Hinsicht ist, handelt es sich um ein besonders wichtiges Gut, das wie die Gesundheit, Körper und Freiheit gleich hinter dem Leben einen oberen Platz in der Rangordnung der Rechtsgüter einnimmt ... Wer dieses Rechtsgut durch einen Verstoß gegen seine Fürsorge- und Erziehungspflicht gröblich verletzt, greift deshalb besonders empfindlich in die Rechtsgüterordnung ein ... “. Das Gericht weist dabei auch die besonderen gesellschaftlichen Folgen der

\footnotetext{
${ }^{859}$ S/S-Lenckner, § 171, Rn. 1.

${ }^{860}$ Nagler, GS 116 (1942), 10 f.; in neuerer Zeit vertreten von Kaltofen, S. 63 und von Franke-Gricksch, S. 50.

${ }^{861}$ LK-Dippel, § 170 d, Rn. 3;

${ }^{862}$ Tröndle/Fischer, § 171, Rn. 2; Kaltofen, S. 68; Luther, NJW 1954, 495; S/S-Lenckner, $\S 171$, Rn. 1; Welzel, S. 429.

${ }^{863}$ Regierungsentwurf, BT-Drucksache VI/ 1552, S. 14; LK-Dippel, § 170 d, Rn. 2.

${ }^{864}$ AG Wermelskirchen NJW 99, 590 (591).
} 
Rechtsgutsverletzung hin: „... Taten solcher Art gefährden darüber hinaus- wenn sie sich häufen- Zukunftsaussichten breiter Bevölkerungskreise. Ferner besteht bei der der Angeklagten zur Last gelegten Tat in hohem Maße Ansteckungsgefahr. Mütter in ähnlichen Situationen wie die Angeklagte könnten sich ohne eindeutige und unmißverständliche Bestrafung der Angeklagten geradezu ermutigt fühlen, ihren Schutzbefohlenen nicht energisch einen Riegel vorzuschieben, wenn es um deren Gefährdung durch schlechte Gesellschaft und Versuchungen zur Begehung von Straftaten geht. “.

c) Das Kind bzw. der Jugendliche als Schutzobjekt

Die in $\S 171$ StGB zum Ausdruck kommende Stellung des Kindes bzw. Jugendlichen ist auf eine lange historische Entwicklung zurückzuführen. Noch bis in die neuere Zeit wurde das Kind unter dem Einfluß des römischen Rechts als Machtobjekt betrachtet ${ }^{865}$. Inzwischen wird das Kind als Gegenstand der gebotenen Hilfe des Stärkeren gegenüber dem Schwächeren, als Fürsorgeobjekt, betrachtet ${ }^{866}$. Die Wandlung der Auffassung von der Rechtsstellung des Kindes wird deutlich durch die Formulierung des Jugendwohlfahrtsgesetzes von $1961^{867}$, nach dessen $\S 1$. Abs. 1 ,,jedes deutsche Kind ein Recht auf Erziehung zur leiblichen, seelischen und gesellschaftlichen Tüchtigkeit" hatte ${ }^{868}$ sowie durch die neue Fassung durch $\S 1$ Abs. 1 KJHG, wonach jeder junge Mensch ein Recht auf Förderung einer Entwicklung und auf Erziehung hat.

Mit der Stellung des Kindes als Fürsorgeobjekt steht es nicht im Widerspruch, daß sich mittlerweile die Auffassung durchgesetzt hat, daß das Kind auch selbst Rechtssubjekt ist, d.h. ein mit eigenen Rechten versehenes Mitglied der demokratischen Gesellschaftsordnung. Ausgestattet mit dem Recht auf freie Entfaltung seiner Persönlichkeit, Art. 2 Abs. 1 GG, das jedem Menschen unabhängig von seinem Alter zukommt, läßt sich die Stellung als bloßes Schutzobjekt nämlich nicht aufrechterhalten $^{869}$. Dem Kind oder Jugendlichen kommt dennoch als

\footnotetext{
${ }^{865}$ Vgl. RGZ 35, 141 (142).

${ }^{866}$ Palandt-Diederichsen, Vor $\S 1626$, Rn. 1.

${ }^{867}$ BGBI. I S. 1206.

${ }^{868}$ Franke-Gricksch, S. 6; Neuhaus, Jura 90, 626 (627).

869 Vgl. Charta des Kindes der vereinten Nationen, Franke-Gricksch, S. 6.
} 
schwächerem Mitglied der Gesellschaft daneben ein besonderer Schutz zugute.

Durch die letzte inhaltliche Veränderung des § 170 d im Jahre 1973, wonach sich die Tathandlung gegen eine „Person unter 16 Jahre, die seiner Obhut anvertraut ist" richtet, wurde der langjährige Streit über die Altersbegrenzung hinfällig. Die vorherige Fassung hatte vorausgesetzt, daß sich die Tat gegen ein „Kind“ richtete, wobei bis zuletzt umstritten war, ob dies ein Mensch bis zur Vollendung des 14. Lebensjahres war oder ob der Schutz auch auf ältere Personen auszudehnen war $^{870}$. Diesem Streit hat der Gesetzgeber nunmehr ein Ende gesetzt.

\section{Täterkreis}

Der Fürsorgeanspruch richtet sich in erster Linie gegen die Eltern, $\S 1631$ BGB, und die kraft Gesetzes dazu Verpflichteten, § 1793 BGB, sowie gegen jeden, der die Pflicht vertraglich oder tatsächlich übernommen hat. Es handelt sich daher um eine kodifizierte Beschützergarantenstellung. Bei den Verpflichteten handelt es sich aus der Natur der Sache heraus um den gleichen Personenkreis wie bei den oben für $\S 13$ StGB dargestellten Überwachergaranten.

Natürlich stehen die Eltern an erster Stelle der durch die Vorschrift Verpflichteten. Hintergrund ist, daß das Kindeswohl zu ganz erheblichem Grade in den Händen der Eltern liegt, weil nach wie vor die Familie als Keimzelle der Gesellschaft anzusehen ist. Die Eltern haben die grundlegende Sozialisationsleistung $\mathrm{zu}$ erbringen. Ihre Leistung ist für die Persönlichkeitsbildung und -entfaltung des Kindes in emotionaler, sozialer und psychischer Hinsicht unersetzlich. Wegen der relativ langen menschlichen Kindheit und sozialen Unselbständigkeit ergibt sich eine viele Jahre währende Verantwortung für das Kind ${ }^{871}$. Der Tatbestand des $\S 171$ StGB geht daher von einem Zusammenhang zwischen dem Versagen der familiären Fürsorge und der Fehlentwicklung beim Kind aus.

Auch wenn eine Verwandtschaft in gerader Linie und 1. Grades nicht für die Anwendbarkeit des $\S 171$ StGB erforderlich ist, stellt sie doch der

\footnotetext{
${ }^{870}$ Darstellung bei Franke-Gricksch, S. 64.

${ }^{871}$ Franke-Gricksch, S. 10.
} 
Regelfall dar. So leitet sich der Schutz des Kindes auch im wesentlichen aus dem Elternrecht des Art. 6 GG her ${ }^{872}$, was in $§ 1626$ ff. BGB seine Ausformung findet. Dabei kann das Kindesrecht nicht eigenständig, sondern nur über den Umweg des Elternrechtes geltend gemacht werden. Die Position des Kindes ist nur akzessorisch der der Eltern angeheftet ${ }^{873}$. Das Kind hat ein Recht auf Fürsorge und Erziehung durch seine Eltern, weil den Eltern dieses Recht verfassungsmäßig zugesagt ist. Art. 6 GG gewährt dieses Recht aber nur den Eltern, nicht dem Kind selbst als Begünstigtem dieses Rechtes ${ }^{874}$. Um so deutlicher muß es zum Tragen kommen, wenn die Eltern diese Rechte nicht wahrnehmen, weil sie gewissermaßen doppelt in der Pflicht stehen, indem sie eigenes und fremdes Recht zu wahren haben. § 1626 BGB, der den Eltern die Pflicht zur Abwendung der Gefahr für körperliches oder geistig-seelisches Wohl auferlegt ${ }^{875}$, ähnelt auf auffällige Weise dem $§ 171$ StGB.

Vom Täterkreis des $\S 171$ sind nur solche Eltern ausgenommen, denen das Sorge- und Erziehungsrecht entzogen worden ist ${ }^{876}$.

\section{Tatverhalten}

\section{a) Allgemeines}

Das Tatverhalten besteht in der gröblichen Verletzung der Fürsorge- oder Erziehungspflicht, die dem Täter aufgrund seiner Garantenstellung zufällt, und als deren Folge eine Gefährdung des psychischen Entwicklung des Kindes oder des Jugendlichen eintritt ${ }^{877}$.

Der Hauptanwendungsbereich des $\S 171$ betrifft Fälle, in denen Kinder, insbesondere Kleinkinder, mangelhaft ernährt und sich selbst überlassen

\footnotetext{
872 Zum Elternrecht siehe oben, 3. Teil. Die Verwirklichung von unechten Unterlassungsdelikten durch die Eltern

${ }^{873}$ Franke-Gricksch, S. 8.

${ }^{874}$ Für das Kind kommt nur eine Geltendmachung über Art. 2 Abs. 1 GG in Betracht.

${ }^{875}$ Palandt-Diederichsen, § 1666, Rn. 15ff.; Schwab, Familienrecht, S. 252f., Rn. $481 \mathrm{ff}$. ${ }^{876}$ Brückner, S. 75.

877 Lenckner, JuS 68, 304 (306), weist zutreffend darauf hin, daß die gröbliche Verletzung der Fürsorge- und Erziehungspflichten nur von der Gefährdung des Kindeswohls abhängig gemacht werden kann. In der Tat ist die Abtrennung der Pflichtverletzung von der daraus resultierenden Gefährdung für den Schutzbefohlenen nur schwer möglich. Dennoch bleibt die Gefährdung losgelöst von der Tathandlung, so daß eine getrennte Behandlung erfolgen soll.
} 
werden oder in denen es zu regelmäßigen Mißhandlungen physischer wie psychischer Art kommt. In vorliegenden Kontext ist auf die Vernachlässigung i. S. des $\S 171$ StGB in den Grenzen einzugehen, wie sie im weitesten Sinne mit Straftaten des Kindes bzw. Jugendlichen zusammenhängt. Es soll daher im folgenden nicht auf die körperlichen und geistigen Beeinträchtigungen durch Mißhandlungen oder Vernachlässigung abgestellt werden. $\mathrm{Zu}$ berücksichtigen ist jedoch, daß auch gerade die typische Mißhandlung und die körperliche Verwahrlosung im Sinne des $\S 171$ einen strafbaren Lebenswandel herbeiführen können.

b) Inhalt der Fürsorge- und der Erziehungspflichten

Die Begriffe der Fürsorge und der Erziehung lassen sich nicht juristisch eindeutig definieren ${ }^{878}$. Entgegen dem Wortlaut des $\S 1$ JWG, der von „Recht“ und „Anspruch“ spricht, läßt sich Erziehung beispielsweise nicht einklagen. Es handelt sich nach überwiegender Auffassung nicht um ein subjektives öffentliches Recht, auch wenn es ein objektiv-rechtlich geschütztes Interesse enthalte ${ }^{879}$. Verfassungsrechtliche Grundlagen finden sich nur im Elternrecht des Art. 6 GG. Eine konkretere Befassung mit dem Kindes- und Jugendschutz findet sich im Grundgesetz nicht. Zwar ist aus dem Sozialstaatsprinzip des Art. 20 GG ein Anspruch auf „öffentliche Fürsorge“ gesetzlich festgelegt worden, vgl. § 4 BSHG, und das Recht auf Bildung herausgebildet worden ${ }^{880}$. Sowohl die Herleitung aus dem Sozialstaatsprinzip als auch aus Art. 2 GG ermöglichen nur einen allgemeinen Schutz, der aber nicht kind- und jugendspezifisch ist.

Unproblematisch beim Verständnis des Tatbestandes dürfte sein, daß eine mangelnde körperliche Fürsorge des Kindes strafwürdig ist. Dies ist nicht zuletzt auch durch die $\S \S 223,225$ StGB erfaßt. Die Fürsorgepflicht ist dabei als die Schutzpflicht zu verstehen, die gesunde körperliche Entwicklung fördern und Schäden von ihr abzuwenden. Der Maßstab ist das jeweils äußerst Erreichbare und das dem Verpflichteten

\footnotetext{
${ }^{878}$ Vgl. Krug, Jugendwohlfahrt., S. 66.

${ }^{879}$ Krug, Jugendwohlfahrt, S. 66 m.w.N.

${ }^{880}$ Abelein, DÖV 67, 375 (378).
} 
zumutbare Mögliche, wobei die persönlichen Umstände, z.B. finanziellen Ressourcen, und der Lebensstandard zu berücksichtigen sind ${ }^{881}$.

Fraglich ist, wie weit der Begriff der Fürsorge zu verstehen ist. Er kann sich nicht allein in der körperlichen Fürsorge erschöpfen, sondern muß auch emotionale Anteilnahme erfassen. Diese äußert sich dadurch, daß der Fürsorgepflichtige Trost spendet, Verständnis zeigt oder Aufmerksamkeit schenkt. Die Sorge um das seelische Wohl muß unter dem Fürsorgebegriff eingeordnet werden, weil sie sonst gar nicht im Tatbestand einzuordnen wäre. Denn die Anteilnahme an den Gefühlen und Problemen des Kindes fällt jedenfalls nicht unter den Begriff der Erziehung. Zur Erziehung dürften zwar bereits das Ratgeben oder das Besprechen von Problemen zur Lösungsfindung gehören, weil dadurch das Denken und die Entscheidungsfindung des Kindes beeinflußt werden. Die Bereitschaft, Trost zu spenden, dient für sich allein solchen Zwecken nicht. Erfaßt man also die emotionale Anteilnahme ohne Erziehungscharakter nicht mit der Fürsorge, wäre sie keine von $\S 171$ erstrebte Verhaltensweise, und ihr Unterlassen wäre kein Verstoß gegen die Fürsorge- und Erziehungspflicht. Dies würde eine Lücke darstellen, die keinen Sinn ergibt, nicht gewollt ist und wegen des dehnbaren Wortinhaltes der „Fürsorge“ auch nicht zwingend sein kann ${ }^{882}$. Der Begriff der Fürsorge muß daher so ausgelegt werden, daß er sowohl dem Schutz vor körperlichen als auch die geistigen Schädigungen umfaßt.

Es ist daher, auch wenn es allein um den Schutz des psychischen Wohls geht, weiterhin von der Fürsorge- und Erziehungspflicht zu sprechen, da die beiden Bereiche nicht zwecks einer einfacheren Terminologie künstlich auseinandergerissen werden können.

Die Erziehung unterscheidet sich von der Fürsorge als die formende geistig-seelische Einwirkung der Eltern auf das Kind, die die Anlagen und Fähigkeiten des Kindes zur Entfaltung bringt und es zur Reife der Selbstbestimmung führt ${ }^{883}$. Die Erziehungspflicht beinhaltet die richtige Anleitung des Jugendlichen. „Richtig“ bedeutet dabei nicht die

\footnotetext{
${ }^{881}$ LK-Dippel, § 170 d, Rn. 6 m.w.N.

${ }^{882}$ Dennoch wird die Sorge um das seelische Wohl in Schrifttum und Literatur gemeinhin nicht unter der Begriff der Fürsorge gefaßt.

${ }^{883}$ LK-Dippel, § 170 d, Rn. 7 m.w.N.;.
} 
Festlegung auf bestimmte Erziehungsinhalte oder Modelle. Unter Erziehung fällt alles, was noch vertretbar ist, also nicht nur herkömmliche Erziehungsmethoden. Es ist jedoch für eine Erziehung, die diesen Namen wert sein soll, ein gewisses Mindestmaß von erzieherischem Verhalten erforderlich ${ }^{884}$. Daher stellt die antiautoritäre Erziehung zumindest dann keine ,richtige“ Anleitung dar, wenn sie sich lediglich auf das „Nichterziehen“ beschränkt ${ }^{885}$.

Im Begriff der ordnungsgemäßen Erziehung ist notwendigerweise bereits die Aufsicht des Abkömmlings enthalten. Nur durch die angemessene, mit zunehmendem Alter weniger und weniger erforderliche Aufsicht kann die Erziehungspflicht umgesetzt werden. Die Fürsorge- und Erziehungspflicht geht einher mit der Aufsichtspflicht, aufgrund derer sich jeder Elternteil um die Freizeitgestaltung seines Abkömmlings kümmern muß. Die Aufsicht ist um so engmaschiger, je mehr Auffälligkeiten der Schutzbefohlene zeigt ${ }^{886}$.

Erziehung bedeutet dabei vor allem auch immer Reagieren auf kindliches oder jugendliches Fehlverhalten. Inwieweit die verbreiteten familialen Sanktionen wie Verbotssanktionen (Fernsehverbot, Ausgeh- und Kinoverbot, Taschengeldkürzung) oder psychische Sanktionen (Schweigen, Niederbrüllen, Androhung von Schlägen) geeignete und erlaubte Mittel darstellen, kann hier nicht untersucht werden ${ }^{887}$. Zu der Zulässigkeit von körperlichen Sanktionen sei auf die Ausführungen von Ursula Schneider verwiesen ${ }^{888}$ : „Es ist schlechthin keine erzieherische Ausnahmesituation vorstellbar, in der die Anwendung körperlicher Strafen unbedingt nötig ist. Eltern befinden sich Kindern gegenüber in einer Machtstellung, die sich aus der physischen und geistigen Überlegenheit der Eltern und der wirtschaftliche, rechtlichen und sozialen Abhängigkeit der Kinder ergibt. Vor diesem Hintergrund erscheint es fast paradox, daß der Eintritt von Situationen befürchtet wird, in denen Eltern nur das Mittel der körperlichen Züchtigung bleibt, um das Kind zu beeinflussen. “

\footnotetext{
${ }^{884}$ Becker, NJW 52, 1082 (1082).

${ }^{885}$ LK-Dippel, § 170 d, Rn. 7 m.w.N.

${ }^{886}$ Neuheuser, NStZ 2000, 174 (175).

${ }^{887}$ Dazu: Bussmann, S. 45ff., $67 f$.

${ }^{888}$ Ursula Schneider, Gewaltanwendung in der Familie, S. 206.
} 
c) Die gröbliche Pflichtverletzung

Allgemein gesprochen verletzt die Fürsorge- und Erziehungspflicht, wer seinem Schutzbefohlenen vermittelt, daß das hiesige Normensystem für ihn keine Geltung hat ${ }^{889}$. Hierbei sind in erster Linie Strafnormen angesprochen. Es ginge sicherlich zu weit, eine vollständige Zustimmung $\mathrm{zu}$ allen bestehenden Rechtsvorschriften zu verlangen. Nur ein für das verträgliche Zusammenleben innerhalb der Gesellschaft erforderliche Mindestmaß an Rechtstreue kann Ziel der Erziehungs- und Fürsorgepflicht sein. Das Kind oder der Jugendliche soll sich lediglich nicht außerhalb der Gesellschaft und ihres Wertesystems wiederfinden.

Die Verletzung der Fürsorge- oder Erziehungspflichten kann in aktivem

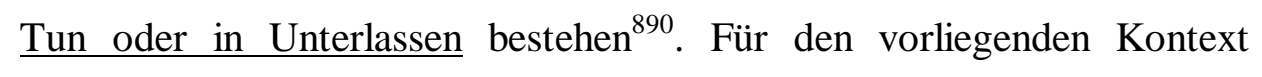
kommt als aktives Tun das Verleiten zu Straftaten bzw. als Unterlassen die Duldung von Straftaten anderer in Betracht. Letztere liegt etwa vor, wenn ein Elternteil, der davon Kenntnis hat, daß sein Schutzbefohlener seinen Alltag durch Straftaten gestaltet, gegen eine derartige Lebensweise nicht mit den erforderlichen Mitteln einschreitet. Durch sein Gewährenlassen erweckt der Elternteil bei seinem Schutzbefohlenen den Eindruck, daß dieser sich nicht um die Normen kümmern müsse. Vielmehr lohne es sich, sein Leben unter Umgehung des Normensystems zu führen und von Rechtsbrüchen zu profitieren ${ }^{891}$.

Obwohl nichts dagegen spricht, daß die Pflichtverletzung sowohl durch aktives Tun als auch durch Unterlassen begangen werden kann, im Gegenteil auf der Verwahrlosung durch Unterlassen der Schwerpunkt liegen dürfte, will Rudolphi in einer nicht nachvollziehbaren Argumentation die gröbliche Pflichtverletzung auf rein aktives Tun beschränken. Nur dadurch könne man verhindern, daß mittels des $\S 171$ das Beibehalten von herkömmlichen Erziehungsmethoden erzwungen werden könne ${ }^{892}$.

\footnotetext{
${ }^{889}$ Neuheuser, NStZ 2000, 174 (176).

${ }^{890}$ Luther, NJW 52, 403 (403); S/S-Lenckner; § 171, Rn. 4.

${ }^{891}$ Neuheuser, NStZ 2000, 174 (176).

${ }^{892}$ SK-Rudolphi, § 170 d, Rn. 11.
} 
Für die Verletzung von erzieherischen Pflichten finden sich unter anderem Beispiele in $\S 1666 \mathrm{BGB}$, der vormundschaftsgerichtliche Maßnahmen für den Fall androht, daß die Eltern das Personensorgerecht für das Kind mißbrauchen, das Kind vernachlässigen oder sich eines ehrlosen oder unsittlichen Verhaltens schuldig machen ${ }^{893}$. Die in der zivilrechtlichen Rechtsprechung veröffentlichten Fälle sind jedoch in ihrer Variationsbreite größer und erfassen auch Verhaltensweisen, die in den $\S \S 221,225$ StGB unter Strafe gestellt sind. Sie stellen nicht regelmäßig strafbedürftiges Unrecht im Sinne des $\S 171$ dar $^{894}$ und müssen daher differenziert betrachtet werden.

Der Erziehungsverpflichtete verletzt seine strafbewehrte Pflicht nicht nur dann, wenn er nichts gegen die Straftaten seines Schutzbefohlenen unternimmt, sondern auch dann, wenn er eine ungeeignete Maßnahme dagegen ergreift. Die Fürsorge- und Erziehungspflicht legt es dem Erziehungsverpflichteten auf, dem Schutzbefohlenen durch Ergreifen einer erforderlichen erzieherischen Maßnahme deutlich die Grenzen des erlaubten Handelns aufzuzeigen. Er erfüllt seine Pflicht nicht dadurch, daß er irgend etwas unternimmt. Vielmehr muß seine Handlung aus exante-Sicht eines objektiven Betrachters geeignet sein, die drohende Gefahr abzuwenden. Diese Maßnahme in gleicher Weise zu bestimmen wie bei den anderen Unterlassungsdelikten ${ }^{895}$. Insoweit wird auf die Ausführungen im 1. Teil verwiesen.

Ungeeignet sind demzufolge bei bereits mehrfach strafrechtlich aufgefallenen Kindern und Jugendlichen einzelne symbolische Handlungen wie eine verbale Ermahnung, die Duldung einer Zurechtweisung durch den Polizeibeamten oder eine Ohrfeige zu Demonstrationszwecken vor dem Polizeibeamten. Vielmehr muß der Elternteil eine Handlung ergreifen, die seinen Abkömmling aus der kriminellen Lebensweise zu lösen vermag. Wenn dieser bereits dauerhaft abgerutscht ist, soll nach Meinung einiger die dauerhafte Beaufsichtigung durch den Erziehungspflichtigen oder einen von ihm Beauftragten die einzige geeignete erzieherische Maßnahme darstellen ${ }^{896}$. Ob das wirklich

\footnotetext{
${ }^{893}$ Franke-Gricksch, S. 74.

${ }^{894}$ Franke-Gricksch, S. 75.

${ }^{895}$ Neuheuser, NStZ 2000, 174 (176).

${ }^{896}$ AG Wermelskirchen NJW 1999, 590 (591); Neuheuser, NStZ 2000, 174 (176).
} 
vom Erziehungspflichtigen überhaupt erfüllt werden kann - man denke an eine ständige Überwachung auf dem Weg zur Schule oder zur Ausbildungsstelle, während der Pausen, auf dem Rückweg - ist allerdings fraglich. Eine lückenlose Überwachung ist zumindest ab einem bestimmten Alter des Zöglings in der modernen Welt nicht durchführbar ${ }^{897}$. Die Kontrolle muß dann über andere Mechanismen sichergestellt werden, z.B. indem dem Schutzbefohlenen eine Aufgabe gegeben wird, die er in einer bestimmten Zeit erledigt haben muß und in der er also keine Zeit für „Abstecher“ hat. Ist der Erziehungsberechtigte allein nicht imstande, seinem Schutzbefohlenen zu helfen, ist er aber jedenfalls verpflichtet, die Hilfe anderer $\mathrm{zu}$ ermöglichen und $\mathrm{zu}$ unterstützen $^{898}$.

Um die Pflichtverletzung im Sinne des $\S 171$ richtig beschreiben und eingrenzen zu können, ist zunächst noch das Merkmal der Gröblichkeit zu beleuchten: Die Pflichtverletzung muß gröblich sein. Das StGB enthält keine Definition des Begriffes ,gröblich“. Das Wort erscheint zwar in verschiedenen Tatbeständen, vgl. §§ 42, 184a, 316a Abs. 1 Ziff.4 $\mathrm{StGB}^{899}$. Daraus können jedoch keine allzu weiten Folgen gezogen werden, weil dadurch kein einheitlicher Begriff herausgebildet wurde. Feststehen dürfte, daß es sich bei einer „gröblichen“ um eine besonders schwerwiegende Verletzung der Fürsorge- oder Erziehungspflichten handeln muß.

Gröblich ist die Pflichtverletzung nach ganz herrschender Meinung, wenn sie objektiv und subjektiv schwerwiegend ist ${ }^{900}$. Objektiv schwerwiegend soll sie sein, wenn sie in besonders deutlichem Widerspruch zu den Grundsätzen einer ordnungsgemäßen Erziehung

\footnotetext{
${ }^{897}$ Hierbei ist besonders an den schädlichen Einfluß Dritter auf das Kind zu denken. Diederichsen spricht zutreffend von den "schädlichen Miterziehern“ in der Gesellschaft, bei denen er aber auch das Fernsehen und die Werbung miteinbezieht, vgl. Diederichsen, NJW 98, 3471 (3472).

${ }^{898}$ AG Wermelskirchen NJW 1999, 590 (591); Neuheuser, NStZ 2000, 174 (176).

${ }^{899}$ Franke-Gricksch, S. 75; Luther, NJW 54, 493 (494)..

${ }^{900}$ Maurach/ Schroeder/ Maiwald, BT 2, § 63 IV, Rn. 50; S/S-Lenckner, § 171, Rn. 4; Tröndle/Fischer, § 171, Rn. 4.
} 
steht $^{901}$. Eine subjektiv schwerwiegende Pflichtverletzung soll vorliegen, wenn sie mit einem erhöhten Maß an Verantwortungslosigkeit begangen wurde; dies soll insbesondere der Fall sein, wenn das pflichtwidrige Unterlassen in auffälligem Mißverhältnis zur Leistungsfähigkeit des Täters steht ${ }^{902}$.

Der Einwand, daß „gröblich“ ein Merkmal sei, das allein den objektiven Unrechtscharakter der Tat beschreibe, wird jedoch zumindest von Luther erhoben. Nach Luther soll durch den Begriff nur objektiv ein besonders hoher Grad der Rechtsgutsverletzung gekennzeichnet werden. Der Verschuldensgrad dürfe dabei keine Berücksichtigung finden. Hätte der Gesetzgeber subjektive Elemente berücksichtigt wissen wollen, hätte er dies durch die Formulierung „böswillige Vernachlässigung“, wie etwa in $\S 225$, zum Ausdruck gebracht ${ }^{903}$. Vom Grundgedanken ist Luther mit dieser Argumentation zuzustimmen. Da die von ihm für die subjektive Seite angeführte „böswillige Vernachlässigung“ aber bereits eine Absicht enthält, die für $\S 171$ nicht vorzuliegen braucht, wäre dies nicht das subjektive Äquivalent zur objektiven „Gröblichkeit“. Die subjektiv schwerwiegende Pflichtverletzung würde vielmehr am treffendsten durch den Begriff der Gewissenlosigkeit umschrieben werden. Tatsächlich war die Gewissenlosigkeit bis 1973 auch Tatbestandsmerkmal des $§ 170$ d. Gewissenlos handelt, wer bewußt oder leichtfertig vorhandene Gewissensregungen, d.h. die von ihm nach seinem Herkommen, seiner Reife und seinen Lebensverhältnissen zu verlangenden Erkenntniskräfte und sittlichen Wertvorstellungen unterdrückt oder außer acht läßt $\mathrm{t}^{904}$. Gewissenlos ist das Handeln trotz vorhandenen Erkenntniskräfte und sittlicher Wertvorstellungen und das Unterdrücken für die eigene Verantwortung dem Schutzbefohlenen gegenüber ${ }^{905}$. Gewissenlosigkeit wurde z.B. für $§ 170$ d a.F. angenommen, wenn die Vernachlässigung auf

\footnotetext{
${ }^{901}$ S/S-Lenckner, § 171, Rn. 4; Tröndle/Fischer, § 171, Rn. 4. Wenn Franke-Gricksch, S. 75., die Gröblichkeit auch an dem besonders hohen Grade der Rechtsgutsverletzung festmachen will, verwischt sie dadurch den Übergang zu der Gefahr, aus der die Rechtsgutsverletzung erst entsteht.

902 S/S-Lenckner, § 171, Rn. 4; Tröndle/Fischer, § 171, Rn. 4.

${ }^{903}$ Luther, NJW 54, 493 (494).

${ }^{904}$ Luther, NJW 54, 493 (494).

${ }^{905}$ Luther, NJW 54, 493 (494).
} 
Vergnügungssucht und auf einen Hang zum bequemen Leben zurückzuführen war ${ }^{906}$.

Es würde daher dafür sprechen, daß durch die Aufgabe des Merkmals der Gewissenlosigkeit gerade die subjektive Wertung insoweit entfallen sollte, und nicht ersatzweise in den Begriff der Gröblichkeit einbezogen werden sollte. Da in $\S 171$ keine Gewissenlosigkeit mehr vorausgesetzt ist, darf sie nun nicht einfach in die Gröblichkeit der Pflichtverletzung hineingelesen werden. Darauf deutet auch der Regierungsentwurf zum 4. Strafrechtsreformgesetz hin: Darin wurde vorgeschlagen, wegen der engeren Ausgestaltung des objektiven Tatbestandes auf der inneren Tatseite auf das Merkmal ,gewissenlos“ zu verzichten $^{907}$. Dies ist so zu verstehen, daß das Merkmal ,gewissenlos“ ersatzlos zu streichen ist, weil der nunmehr konkreter gefaßte objektive Tatbestand ein ausreichendes Regulativ für eine zu weitgehende Anwendung des § 171 darstellt.

Man kann zu Recht die These aufstellen, daß derjenige, der objektiv gröblich seine Pflicht verletzt, automatisch auch subjektiv gröblich handelt, daß also die subjektive Gröblichkeit (Verantwortungslosigkeit usw.) sich in der objektiven manifestiert ${ }^{908}$. Das mag auch in den meisten Fällen, muß aber nicht in allen Fällen so sein. Bei der Mutter, die ihren Ehemann vor der Versetzung an die Ostfront besucht, weil sie ihn möglicherweise nie wieder sehen wird, und deshalb ihre Kinder nur mangelhaft versorgt zurückläßt ${ }^{909}$, oder bei der Mutter, die ihre Tochter aus Not $\mathrm{zu}$ Warenhausdiebstählen mitnimmt ${ }^{910}$, kann man zumindest trotz der objektiven Gröblichkeit darüber streiten, ob zugleich auch eine Gewissenlosigkeit vorliegt.

Der Umstand, daß die objektiv schwerwiegende Pflichtverletzung möglicherweise zugleich gewissenlos erfolgt, ersetzt nicht das tatbestandsmäßige Merkmal der Gewissenlosigkeit im Tatbestand. Die Gröblichkeit der Pflichtverletzung kann daher nur ein objektives Kriterium darstellen. Für eine subjektive Deutung des Begriffs der Gröblichkeit ist angesichts der Entscheidung des Gesetzgebers, das

\footnotetext{
${ }^{906}$ RGSt 77, 215 (216); BGH NJW 51, 282 (283).

${ }^{907}$ BT-Drucksache VI/ 1552, S. 14.

${ }^{908}$ Dazu Francke-Gricksch, S. 103 ff. m.w.N.

${ }^{909}$ RG DR 44, 657.

${ }^{910}$ Abgewandelte Entscheidung des LG Hamburg, NJW 54, 493 (494).
} 
Merkmal der Gewissenlosigkeit zu streichen, kein Raum. Ein erhöhtes $\mathrm{Maß}$ an Verantwortungslosigkeit beim Erziehungspflichtigen ist daher nicht Tatbestandsvoraussetzung. Eine tatsächliche Schlechterstellung der Verpflichteten ist aufgrund der insgesamt hohen Schwelle der Gröblichkeit aber nicht ersichtlich, zumal die auch die Gröblichkeit der Pflichtverletzung vorsätzlich erfolgen muß.

Im Regelfall genügt eine einmalige Pflichtverletzung nicht zur Annahme einer gröblichen Pflichtverletzung i.S.d. $§ 171^{911}$. Bekannt geworden ist das Urteil des BGH, wonach das einmalige Auffordern, Holz für den notleidenden Haushalt zu stehlen, noch keine Pflichtverletzung i.S.d. $\S 170 \mathrm{~d}$ darstellte ${ }^{912}$. Es ist regelmäßig eine Dauer der Handlung bzw. eine Wiederholung erforderlich, damit gröblicher Verstoß bejaht werden kann. Dazu müssen die Pflichtverletzungen einzeln festgestellt werden. Durch ständige Wiederholung oder längere Dauer können aber auch Verstöße, die für sich gesehen von geringerer Art sind, zu einer gröblichen Verletzung werden ${ }^{913}$. Weil die einzelne Handlung, für sich betrachtet, nicht ausreicht, wird die Strafbarkeit erst durch ihre Addition begründet ${ }^{914}$.

In dieser Art stellte sich der Fall dar, den 1953 das LG Hamburg zu entscheiden hatte $^{915}$. Eine Kriegerwitwe beging, zum Teil aus der Not heraus, Warenhausdiebstähle und nahm dazu ihre Tochter mit, die schwer lungenkrank war und die nach ärztlicher Weisung nur wenige Stunden am Tag aufstehen durfte. Die Tochter selbst hatte ihre Mutter vergeblich gebeten, mit den Diebstählen aufzuhören, hatte dabei an das Andenken des verstorbenen Vaters appelliert und sich erboten, ihre Briefmarkensammlung und ihre Uhr zu verkaufen. Das Kind wurde durch die Diebestouren für längere Zeit in schwere Gewissenskonflikte versetzt und in die Gefahr gebracht, selbst einen kriminellen Lebenswandel zu beginnen, ganz abgesehen von den körperlichen

\footnotetext{
${ }^{911}$ S/S-Lenckner, § 171, Rn. 4; NStZ 82, 327 (328).

${ }^{912}$ BGH NJW 52, 476.

${ }^{913}$ S/S-Lenckner, § 171, Rn. 4.

${ }^{914}$ LK-Dippel, § 170 d, Rn. 9; Schroeder, JZ 72, 651; vgl. BGHSt 8, 92 (95).

915 Rechtskrättige Entscheidung des LG Hamburg vom 20.11.1953, (34) 208/53, unveröffentlicht, zitiert bei Luther, NJW 54, 493 (494), Fn. 16.
} 
Strapazen, die diese Unternehmungen für das Mädchen bedeuteten. In diesem Fall dürften sowohl wiederholte als auch schwere Pflichtverstöße die Verurteilung begründet haben.

Auf der anderen Seite kann bereits eine einmalige Pflichtverletzung zur Verwirklichung des Tatbestandes ausreichen, wenn sie besonders hochgradig und folgenschwer ist ${ }^{916}$. Sie kann z.B. in der einmaligen Aufforderung zum Stehlen liegen, auch wenn das Kind ihr nicht nachkommt ${ }^{917}$. Eine ganz andere Frage ist es, ob dadurch auch eine Gefährdung des Kindes i.S.d. § 171 eingetreten ist. Sowohl grobe Erziehungspflichtverletzung als auch Gefährdung der psychischen Entwicklung dürften dagegen beim Mitnehmen des Schutzbefohlenen zu einem Gewaltverbrechen vorliegen. Eine grobe Pflichtverletzung durch ein einmaliges Fehlverhalten wurde auch in einem Fall vom Bundesgerichtshof untersucht, in dem eine Mutter auf der von ihr veranstalteten Fastnachtsfeier unzüchtige Handlungen der Gäste in Gegenwart ihres fast 16jährigen Sohnes duldete ${ }^{918}$.

Bejaht wurde eine gröbliche Erziehungspflichtverletzung vom Amtsgericht Wermelskirchen bei einer Mutter, die über den Zeitraum von einem Jahr und trotz wiederholter persönlicher Ermahnungen durch die Polizei nichts dagegen unternommen hatte, daß ihr strafunmündiger Sohn sich in einer Gruppe von Personen aufhielt, mit denen er regelmäßig Diebstähle beging ${ }^{919}$.

Das Dulden des dauerhaften Konsums von Drogen fällt fraglos auch unter den Begriff der gröblichen Pflichtverletzung ${ }^{920}$. Auch die einmalige Duldung von Drogenkonsum muß trotz der gesellschaftlich teilweise freizügig gehandhabten Verwendung insbesondere von Ecstasy und Marihuana bereits als eine gröbliche Pflichtverletzung eingestuft werden. In diesem Rahmen dürfte die Frage, ob auch der Genuß von hochprozentigen Alkoholika, die immerhin von Jugendlichen nicht

\footnotetext{
${ }^{916}$ Franke-Gricksch, S. 76; S/S-Lenckner, § 171, Rn. 4; Tröndle/ Fischer, § 171, Rn. 4; NStZ 82, 327 (328).

917 BGH NJW 52, 476.

${ }^{918}$ BGHSt 5, 40 (40).

${ }^{919}$ AG Wermelskirchen, NJW 99, $590 \mathrm{ff}$.

${ }^{920}$ Vgl. Neuheuser, NStZ 2000, 174 (175).
} 
erworben werden dürfen, einen gröblichen Verstoß gegen die Erziehungs- und Fürsorgepflichten darstellt, häufig zu bejahen sein.

Fraglich ist, ob Eltern nach $\S 171$ bestraft werden können, wenn sie in einer konkreten Situation keine Verhinderungsmöglichkeit haben, aber im Zeitraum zuvor ihren Fürsorge- und Erziehungspflichten nicht nachgekommen sind. Zwar machen sich die Eltern in einem solchen Fall nicht nach dem entsprechenden unechten Unterlassungsdelikt strafbar: Die vom Gesetz geforderte Handlung konnten sie nicht durchführen. Aber nach $\S 171$ ist ihnen ja in erster Linie die Erziehungspflichtverletzung vorzuwerfen, die in dem strafbaren Verhalten des Schutzbefohlenen mündet. Erst dadurch, daß die Eltern diese Pflicht im Vorfeld verletzt haben, ist es zu der Situation gekommen, daß sie nun keine Eingriffsmöglichkeit mehr haben. Es ist daher auch dann, wenn den Eltern in der konkreten Situation das Kind oder den Jugendlichen von der Tat nicht mehr abhalten können, eine strafbare Pflichtverletzung durch vorangegangenes Versagen in der Erziehung möglich.

\section{Taterfolg: Gefahr einer Schädigung in der psychischen Entwicklung}

a) Der Gefahreintritt als tatbestandlicher Erfolg

Durch die Verletzung der Fürsorge- oder der Erziehungspflicht muß die konkrete Gefahr hervorgerufen werden, daß das Kind bzw. der Jugendliche erheblichen Schaden an seiner psychischen Entwicklung nimmt, indem er etwa einen kriminellen Lebenswandel führt. Bei der Gefahr für die psychische Entwicklung des unter 16jährigen handelt es sich um den tatbestandsmäßigen Erfolg des $\S 171$ StGB, der Voraussetzung für die Erfüllung des objektiven Tatbestandes ist.

Die Erfolgsverhinderungsmöglichkeit ist tatbestandlich kodifiziert durch die Forderung an den Verpflichteten, seine Fürsorge- und Erziehungspflicht wahrzunehmen.

Hinsichtlich der Erfolgsverhinderung gelten die für die Unterlassungsdelikte ausgeführten Regeln ${ }^{921}$. Die Maßnahme zur

${ }^{921}$ Neuheuser, NStZ 2000, 174 (176). 
Verhinderung des Erfolgseintritts, hier die Wahrnehmung der Fürsorge und Erziehung, muß zum einen geeignet sein, die Gefahr abzuwenden. Weiter muß sie dem Verpflichteten möglich und zumutbar sein.

$\S 171$ enthält, wenn es als Unterlassungsdelikt auftritt, die Besonderheit, daß die Erfolgsabwendungsmöglichkeit aus rechtlichen Gründen besonders eingeschränkt sein kann. Gerade im Rahmen des Fürsorgeund Erziehungsauftrages ist die faktische Möglichkeit der Erfolgsabwendung nicht immer gleichzeitig auch eine rechtliche, d.h. rechtlich zulässige. Denn die rechtliche Zulässigkeit von erzieherischen Maßnahmen ist häufig umstritten, weil die tatsächlich angewendeten Erziehungsmaßnahmen über das rechtlich Zulässige hinausgehen; so etwa das elterliche Züchtigungsrecht ${ }^{922}$. Auf diese Weise taucht die Frage der „richtigen“ Erziehung im Rahmen der Erfolgsabwendungsmöglichkeit wieder auf ${ }^{923}$.

b) Allgemeines

Im folgenden soll insbesondere jene Gefahr für die psychischen Entwicklung des Kindes oder Jugendlichen untersucht werden, die aus der Verletzung der Erziehungspflicht erwächst.

Die Gefahr einer erheblichen psychischen Entwicklungsschädigung besteht immer dann, wenn zu befürchten ist, daß der Ablauf des normalen geistig-seelischen Reifungsprozesses dauernd oder nachhaltig gestört wird ${ }^{924}$. Die Gefahr, daß der Schutzbefohlene einen kriminellen Lebenswandel führt, ist nach allgemeiner Meinung ein Unterfall der Gefahr für die psychische Entwicklung des Schutzbefohlenen und soll die Schwelle andeuten, von der ab ein psychischer Entwicklungsschaden als erheblich anzusehen ist ${ }^{925}$. Sie wurde zur Klarstellung durch das 4 . StRG im Jahr 1973 eingeführt ${ }^{926}$. Die Einbeziehung des „kriminellen Lebenswandels" setzt daher voraus, daß man unter der psychischen Entwicklung auch die sittliche, d.h. charakterliche und ethische

\footnotetext{
922 Albrecht, ZfJ 81, 4 (7); Maurach/ Schroeder/ Maiwald, BT 2, § 63 IV, Rn. 52.

${ }^{923}$ Maurach/ Schroeder/ Maiwald, BT 2, § 63 IV, Rn. 52.

${ }^{924}$ LK-Dippel, § 170 d, Rn. 14; S/S-Lenckner, § 171, Rn. 7.

${ }^{925}$ Hanack, NJW 74, 1 (4).

${ }^{926}$ Neuheuser, NStZ 2000, 174 (177).
} 
Entwicklung des Schutzbefohlenen versteht ${ }^{927}$. Nach dem Bericht des Sonderausschusses zum Strafrechtsreformgesetz 1973 soll das Merkmal der psychischen Entwicklung aber auch nur solche Fehlentwicklungen treffen, die mit medizinisch-psychologischen Kriterien zu erfassen sind, also krankhafte Störungen und Defizite ${ }^{928}$.

Nach im Schrifttum überwiegender Meinung soll mit dem Verwendung des Begriffs des Schadens für die psychische Entwicklung der gesamte Entwicklungsprozeß des Jugendlichen geschützt werden, in dem sich die seelischen Fähigkeiten zur Bewältigung der Lebensaufgaben herausbilden. Voraussetzung dafür ist auch das Hineinwachsen in die Gesellschaft und ihr sozialethisches Normensystem, so daß die sittliche Entwicklung Teil der psychischen Entwicklung ist. Die psychische Entwicklung umfaßt die gesamte geistige Entwicklung des Menschen, deren verschiedene Bereiche sich vielfach nicht voneinander trennen $\operatorname{lassen}^{929}$. $\mathrm{Zu}$ einer gesunden Entwicklung gehört somit auch, daß der Jugendliche hinreichende Dispositionsmöglichkeiten für ein künftiges Legalverhalten vermittelt bekommt ${ }^{930}$.

Auf der anderen Seite wäre es, wie der Sonderausschuß 1973 schon erkannte, zu weitgehend, in jedem Fehlen an ethischen Grundwerten und sozial allgemein anerkannten Verhaltensweisen einen psychischer Schaden erblicken $\mathrm{zu}$ wollen ${ }^{931}$. Bei dem Jugendlichen, der einem kriminellen Lebenswandel i.S.d. § 171 nachgeht, könnte es sich auch lediglich um einen Mangel an vermittelten Werten handeln, der einer psychischen Entwicklungsschädigung noch nicht entspricht. Zwar ist es richtig, daß das Abgewöhnen einer schlechten Angewohnheit oder das Rückgängigmachen eines erlerntes Verhaltens viel schwieriger vonstatten gehen als das Erlernen. Das erlernte, falsche Verhalten muß aber trotz seiner Beständigkeit noch keine Gefahr für die psychische

\footnotetext{
${ }^{927}$ Bejahend: Franke-Gricksch, S. 78 m.w.N.

${ }^{928}$ Hanack, NJW 74, 1 (2) m.w.N.

${ }^{929}$ S/S-Lenckner, § 171, Rn. 7 m. w. N.

930 SK-Horn, $\S 170 \mathrm{~d}, \mathrm{Rn}$. 6. Darin ist kein Widerspruch zu der von Dippel vertretenen Ansicht zu sehen, wie dieser annimmt. Denn das „Heranreifen von seelischen Fähigkeiten zur Bewältigung von sozialethisch zu bewertenden Lebensaufgaben“ bei Dippel a.a.O. ist letztlich nichts anderes als die von Horn formulierte Dispositionsfähigkeit.

${ }^{931} \mathrm{Vgl}$. Franke-Gricksch, S. 89.
} 
Gesundheit des Kindes im Sinne einer medizinisch-psychologischen Sichtweise darstellen. Dies ist zum Beispiel ganz anders einzustufen, wenn die charakterlich-ethische Verwahrlosung, z.B. im sexuellen Bereich, zugleich eine krankhafte Störung des Kindes zur Folge hat ${ }^{932}$.

Fraglich bleibt indes, wie sich das bloße, also die Kindesentwicklung unberücksichtigt lassende, Abweichen von der Norm und die Entwicklungsschädigung im medizinisch-psychologischen Sinne voneinander abgrenzen lassen. Möglicherweise hilft die Eingrenzung durch den Begriff des kriminellen Lebenswandels an dieser Stelle weiter. Doch auch ein krimineller Lebenswandel kann sowohl Folge einer psychischen Schädigung als auch eines Mangels an vermittelten Werten sein. Ein Kind, das aufgrund mangelnder Betreuung kontinuierlich Horrorfilme aus der Videothek ansieht, schwere seelische Schäden erleidet und als deren Folge andere Menschen angreift ${ }^{933}$, ist anders einzustufen als ein Kind, das regelmäßig zu den Diebestouren der Mutter mitgenommen wird und aufgrund dieses verzerrten ethischen Vorbilds der Rechtsordnung keine Achtung schenkt. Während das erste Kind tatsächlich psychisch krank ist, fehlt dem anderen ,nur“ die erforderliche Sozialisation. Wenn diese Fälle dennoch gleich behandelt werden sollen, muß dies genauer begründet werden ${ }^{934}$.

Um den Begriff der psychischen Entwicklungsschädigung nicht so weit auslegen zu müssen, daß er den eigentlichen Wortsinn sprengt, bleibt es letztlich nur, den Begriff des kriminellen Lebenswandels eng auszulegen. Soll nämlich nicht jede beliebige kriminelle Karriere darunter fallen, sondern nur auffällige Auswüchse kindlicher Entwicklung, könnten sie noch unter den Begriff der psychischen Entwicklungsschädigung fallen, ohne dem Wortsinn Gewalt anzutun. So ergibt die häufig gemachte Feststellung, daß die eigenständige Erwähnung der Gefahr eines

\footnotetext{
932 Vgl. Glogauer, S. 81.

${ }^{933}$ Vgl. die Fallanalysen bei Glogauer, S. $73 \mathrm{ff}$.

${ }^{934}$ Daher zu kurz: Horn in SK, $\S 170$ d, Rn. 6, der lediglich darauf hinweist, daß im Rahmen einer verfassungskonformen Auslegung des $\S 171$ StGB jedenfalls der kriminelle Lebenswandel zur psychischen Entwicklungsschädigung zu zählen hat.
} 
kriminellen Lebenswandels im Gesetz nur den Zweck habe, den erforderlichen Grad der Verwahrlosung zu verdeutlichen ${ }^{935}$, neuen Sinn.

c) Der Begriff des kriminellen Lebenswandels

Schwierig gestaltet es sich nun, den Begriff des kriminellen Lebenswandels in feste Formen zu gießen. Wo beginnt der kriminelle Lebenswandel ?

Eine Möglichkeit ist es, den kriminellen Lebenswandel dem „Hang zu Straftaten“ i.S.d. § 66 StGB gleichzustellen ${ }^{936}$. Dies wird von Teilen der Literatur angenommen, wenn der Jugendliche nicht unerhebliche vorsätzliche Straftaten wiederholt begeht und seine Lebensführung gekennzeichnet ist durch eine besondere Hinwendung zum strafbaren Tun, etwa durch Mitgliedschaft in einer Diebesbande oder das Aufhalten im Kriminellenmilieu ${ }^{937}$.

In der Auslegung des $\S 66$ StGB hat ein Täter einen Hang zu Straftaten, wenn es aufgrund einer durch Anlage oder Übung erworbenen Neigung immer neuen Straftaten im Sinne eines eingeschliffenen Verhaltensmusters begeht ${ }^{938}$. Die Delikte dürfen nicht nur Konflikts-, Gelegenheits- oder Augenblickstaten $\operatorname{sein}^{939}$. Darauf, ob dem Täter aus seinem Verhalten ein Vorwurf zu machen ist, soll es nicht ankommen ${ }^{940}$. Auch bei noch unreifen Menschen und bei vermindert Schuldfähigen kann ein Hang zu Straftaten bestehen ${ }^{941}$.

Zweifelhaft ist allerdings, ob das Kriterium des „Hanges zu Straftaten“ überhaupt als Merkmal für einen kriminellen Lebenswandel sinnvoll verwendbar ist. Der Begriff des Hanges ist nur unzureichend umrissen. So beschreibt das Gesetz die Ursachen für den Hang nicht ${ }^{942}$. Der beharrliche, aktiv-planende Straftäter wird also nicht unterschieden von

\footnotetext{
${ }^{935}$ S/S-Lenckner, § 171, Rn. 9.

${ }^{936}$ vgl. Neuheuser, NStZ 2000, 174 (177).

${ }^{937}$ S/S-Lenckner, § 171, Rn. 9.

${ }^{938}$ BGH NStZ 88, 496; 95, 178; BGH wistra 88, 304.

${ }^{939}$ Tröndle/Fischer, § 66, Rn. 18; BGH GA 69, 25 (26); auf die Uneinheitlichkeit der Rechtsprechung in diesem Punkt verweist Kinzig, NStZ 98, 14 (14).

${ }^{940}$ Tröndle/Fischer, § 66, Rn. 18 mit einzelnen Beispielen.

${ }^{941}$ BGH NJW 57, 1932; 71, 1416 (1416); BGH GA 65, 249 (249).

${ }_{942}$ Vgl. BGH NJW 71, 1416; Tröndle/ Fischer, § 66, Rn. 19; kritisch: Kinzig, NStZ 98, 14 (14).
} 
dem passiv-antriebsschwachen Delinquenten ${ }^{943}$. Auf der anderen Seite läßt die Praxis -offenbar zwecks besserer HandhabbarkeitSchuldgesichtspunkte einfließen ${ }^{944}$. Zweifel an der Bestimmtheit des Begriffs ergeben sich weiter aus der Unmöglichkeit, den Hang zu Straftaten durch wissenschaftliche Methoden $\mathrm{zu}$ messen ${ }^{945}$ oder ihn jedenfalls im Sinne einer rationalen Theorienbildung zu erklären ${ }^{946}$.

Angesichts des ungenauen Begriffs des Hanges läßt sich daraus nicht herleiten, daß es sich dabei um eine so schwere Verhaltensabweichung handelt, die man als psychischen Entwicklungsschaden bezeichnen oder mit einem solchen vergleichen könnte. Besser gesagt, ist der „Hang“ nicht mehr als ein Synonym zum „kriminellen Lebenswandel“, aber keine Konkretisierung dieses Tatbestandsmerkmals.

Dies äußert sich durch die vielfachen, als selbstverständlich hingenommenen Tautologien wie „Neigung zur Wiederholung“ oder „fest eingewurzelte Neigung،947. Man kann daher durchaus zu dem Fazit gelangen, der Hang bestehe in nichts anderem als der nicht objektiv überprüfbaren Bewertung des urteilenden Richters anhand der vorangegangenen Straftaten ${ }^{948}$. Dabei muß mit der Gefahr gerechnet werden, daß aus der bloßen Häufung von Straftaten auf die Gewohnheitsmäßigkeit und den Hang zu schließen ist ${ }^{949}$. So gibt es auch die Vermutung, daß der Hang nur die qualifizierte Form des Rückfalls darstellt ${ }^{950}$.

Aufgrund seiner Unbestimmtheit muß der Begriff des Hangs als nicht geeignet gelten, um den kriminellen Lebenswandel i.S.d. $\S 171$ bei Kindern und Jugendlichen zu beschreiben. Hinzu kommt, daß der Begriff des Hanges für die Straftaten von Erwachsenen gebildet wurde. Die wesentlichen Indikatoren sind für Erwachsene ausgelegt. Als in der Rechtsprechung auftretende Indikatoren für das Vorliegen eines Hanges werden bei Kinzig unter anderem erziehungswidrige Verhältnisse,

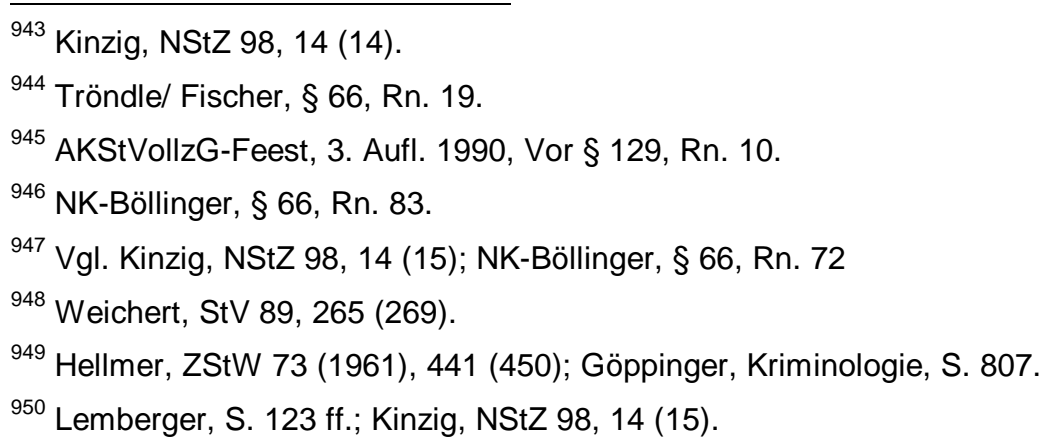


Frühkriminalität, schlechte schulische und berufliche Ausbildung, vielfache und erhebliche Vorstrafen, lange Haftaufenthalte und eine schnelle Tatabfolge genannt ${ }^{951}$. Demgegenüber befindet sich das Kind oder der Jugendliche allenfalls am Beginn einer solchen Karriere und konnte schon mangels seines Lebensalters diese Voraussetzungen für den Hang noch gar nicht erfüllen.

Sinnvoller könnte man für die vorliegende Situation von ,schädlichen Neigungen“ i.S.d. § 17 JGG zu sprechen. Die Schranke für eine schädliche Neigung ist allerdings niedriger anzusetzen als für den Hang zu Straftaten, was zu einer früheren Anwendung des $§ 171$ führen könnte. Am Beispiel jugendlicher Drogensucht als auch andere jugendpsychiatrischer Grenzfälle läßt sich veranschaulichen, daß die schädlichen Neigungen auch krankhafte Zustände umfassen und insgesamt viel weiter als der Begriff des Hanges zu fassen sind ${ }^{952}$.

Schädliche Neigungen werden als Anlage- oder Erziehungsmängel verstanden, die ohne längere Gesamterziehung des Täters i.S.d. § 17 JGG die Gefahr von Störungen der Gemeinschaftsordnung durch weitere Straftaten begründen ${ }^{953}$. Die Anlage- und Entwicklungsschäden müssen so schwer sein, daß deren Beseitigung sinnvoll nur in einem länger dauernden Strafvollzug versucht werden $\operatorname{kann}^{954}$. Zwar muß der Täter sich bereits daran gewöhnt haben, aus einer in seiner Persönlichkeit wurzelnden falschen Trieb- oder Willensrichtung $\mathrm{zu}$ handeln. Die schädliche Neigung ist dabei weniger als der Hang ${ }^{955}$. Es sollen jedoch solche Neigungen ausscheiden, die nur Ausfluß normaler Entwicklungserscheinungen sind, auch wenn sie im Augenblick als schädlich erscheinen ${ }^{956}$. Die erheblichen Persönlichkeitsmängel müssen schon vor der Tat, wenn auch verborgen, angelegt gewesen sein. Dies muß sich begründen können aus dem Lebensweg und der

\footnotetext{
${ }^{951}$ Kinzig, NStZ 98, 14 (15).

952 Mrozynski, Mkrim. 85, $1(1,16)$.

${ }^{953}$ BGHSt 11, 169 (171); Böhm, NStZ 81, 250 (250); StV 82, 335; Brunner/ Dölling, § 17, Rn. 11.

954 BGHSt 18, 207 (210).

${ }^{955}$ BGHSt 11, 169 (171); Mrozynski, Mkrim. 85, 1 (14); Seibert, MDR 62, 171.

${ }^{956}$ vgl. Brunner/ Dölling, § 17, Rn. 11.
} 
Lebensperspektive, insbesondere anhand von Störungen im Familienbereich $^{957}$

Ein Zurückgreifen auf diese Begrifflichkeit scheitert aber auch, wie beim „Hang“ daran, daß die Formulierung keine praktikable Eingrenzung bietet.

d) Bestimmtheit des Begriffs der psychischen Entwicklungsschädigung

Man wird davon ausgehen müssen, daß der Gesetzgeber den Begriff der psychischen Entwicklungsschädigung bewußt weit fassen wollte, indem er auch den kriminellen Lebenswandel ausdrücklich mit in den Tatbestand des $\S 171$ aufgenommen hat. Aus dem Begriff der „Schädigung der psychischen Entwicklung“ ist zunächst die Möglichkeit einer so weiten Auslegung nicht erkennbar, so daß ein Verstoß gegen den „nulla poena“ - Grundsatz vorliegen könnte. Dem wird durch die Aufnahme des Kriteriums des kriminellen Lebenswandels abgeholfen. Den kriminellen Lebenswandel würde man nicht generell mit einer psychisch oder psychologisch motivierten Entwicklungsschädigung verbinden, so daß seine ausdrückliche Nennung einen weiteren gesetzlichen Auslegungspielraum für die Entwicklungsschädigung ermöglicht.

Darauf, daß es durchaus als fraglich betrachtet werden kann, inwieweit ein kriminelles Verhalten als Entwicklungsschädigung aufgefaßt werden kann, deutet auch die Befürchtung des Gesetzgebers hin, ohne die ausdrückliche Erwähnung des kriminellen Verhaltens im Gesetz könnten die Gerichte hier vom Vorliegen einer psychischen Schädigung absehen $^{958}$.

Dafür, daß eine Ausdehnung des Tatbestandes auf die psychische Entwicklung teleologisch und historisch nicht fernliegend ist, spricht jedoch, daß die Gefährdung des „sittlichen Wohles“ lange Zeit hindurch Tatbestandsmerkmal des $\S 170 \mathrm{~d}$ war. Von der Entstehung des $\S 170 \mathrm{~d}$ im Jahr 1943 bis zur Änderung von 1973 war die Gefährdung des

\footnotetext{
957 Brunner, Anm. zu OLG Zweibrücken, JR 90, 304 (305), der im besonders für den Drogenbereich auf die in der Regel stabilisierenden Beziehungen zum Elternhaus hinweist.

${ }^{958}$ BT-Drucksache VI/3521, S. 16.
} 
sittlichen Wohls Tatbestandsmerkmal, wiewohl es auch wegen seiner mangelnden Bestimmtheit heftig umstritten blieb ${ }^{959}$. Bis zur Veränderung des Tatbestandes im Jahr 1973 ist daher davon auszugehen, daß auch die moralisch-charakterliche Bildung vom Tatbestand geschützt wurde ${ }^{960}$. Dafür spricht, daß nach Luther Einigkeit darüber bestand, daß unter dem geistigem Wohl i.S.d. § 1666 BGB dasselbe wie das sittliche Wohl i.S.d. $\S 170$ d a.F. zu verstehen sei ${ }^{961}$. In $\S 1666$ BGB wird das körperliche, geistige und seelische Wohl des Kindes gleichermaßen unter Schutz gestellt. Diese Schutzgüter werden gemeinhin als eine Einheit gesehen, wobei deren Abgrenzung voneinander in vielen Fällen kaum möglich ist $^{962}$.

Es deutet in den Materialien zum 4. Strafrechtsreformgesetz nichts darauf hin, daß mit der in $\S 171$ vorgenommenen Abänderung des Begriffs „sittlich“ in „psychisch“ eine inhaltliche Änderung beabsichtigt war. Vielmehr dürfte es sich bei dem Umbenennen des „sittlichen Wohls“ in „psychische Entwicklung“ um den -mißlungenen- Versuch handeln, die umstrittene Floskel ${ }^{963}$ des „Sittlichen“ durch einen konkreteren, weniger angreifbaren Begriff zu ersetzten. Wie die vorstehenden Erwägungen gezeigt haben, hat auch die Umbenennung das Problem nicht beseitigt. Vielmehr muß auch die neue Bezeichnung der ,psychischen Entwicklung“ im Lichte der alten Wortbedeutung des „sittlichen Wohls“ ausgelegt werden, soll nicht der Umfang des $\S 171$ drastisch eingeschränkt werden.

e) Konkrete Gefahr

aa) Eintritt der konkreten Gefahr

Eine konkrete Gefahr liegt vor, wenn die Entwicklungsschäden beim Schutzbefohlenen bereits eingetreten sind oder ihr Eintritt wahrscheinlich

\footnotetext{
959 Ohne nähere Begründung mit den rechtsstaatlichen Interessen für vereinbar gehalten in BGH NJW 52, 476; differenziert hingegen BayObLG NJW 52, 988 (988f.); kritisch Welzel, S. 429; Sturm, JZ 74, 1 (3); Lenckner, JuS 68, 304 (305f.).

960 Deutlich: BayObLG NJW 52, 988 (989); offen gelassen jedoch in BGH NJW 51, 282 (282).

961 Luther, NJW 52, 403 (403);

962 Palandt-Diederichsen, § 1666, Rn. 15.

${ }^{963}$ BGH NJW 52, 476.
} 
ist und bisher nur durch Zufall ausgeblieben ist. So ist die konkrete Gefahr für das Führen eines kriminellen Lebenswandels bereits gegeben, wenn der kriminelle Lebenswandel bisher ausgeblieben ist, jedoch das bislang gesetzestreue Verhalten nur auf Zufall zurückzuführen ist. Es ist aber noch nicht erforderlich, daß der Schaden für die Entwicklung schon eingetreten ist, vielmehr genügt es, daß er künftig zu erwarten ist ${ }^{964}$.

Maßgeblich ist, ob das Verhalten des Kindes oder Jugendlichen den Schluß zuläßt, daß er in seinem durch $\S 171$ StGB geschützten körperlichen und geistig-seelischen Reifungsprozeß gestört zu werden droht $^{965}$. Eine solche konkrete Gefahr ist $\mathrm{zu}$ bejahen, wenn der Schutzbefohlene unabhängig von einem konkreten Tatbeitrag im zeitlichen und räumlichen Zusammensein mit anderen Personen bei mehreren Straftaten auftritt, Mitglied einer Diebesbande ist oder sich sonst im Kriminellenmilieu aufhält ${ }^{966}$. Ob durch das regelmäßige Zusammensein mit Kriminellen und die Mitgliedschaft in einer Gruppe, die sich zur Begehung von Straftaten zusammengeschlossen hat, nicht nur die konkrete Gefahr einer psychischen Entwicklungsschädigung besteht, sondern eine solche Schädigung schon eingetreten ist, ist zweifelhaft. Man könnte zwar im Eintritt in eine Bande einen „Meilenstein der kriminellen Karriere“ sehen, mit dem der Jugendliche zum Ausdruck bringt, nunmehr „dazu“ zu gehören und die Gesetze fortan nicht mehr achten zu wollen, jedoch dürfte in den meisten Fällen eine so eindeutige Entscheidung für einen kriminellen Lebenswandel nicht feststellbar sein.

Nicht nur das strafbare Verhalten selbst, sondern auch das Verhalten danach kann Aufschluß über die Gefahr einer Entwicklungsschädigung geben: Das Fehlen von jeglichem Unrechtsbewußtsein oder Reue des Kindes nach einer Straftat ist unter Umständen ein Anhaltspunkt für den Eintritt der Gefahr ${ }^{967}$.

\footnotetext{
${ }^{964}$ Glaue, Jugendliche Rechtsbrecher, S. 9f., sieht es als Vorteil an, daß dadurch die Strafbarkeit sehr weit vorverlegt wird, so daß dem Eintritt von Schädigungen vorgebeugt werden könne.

${ }^{965}$ Maurach/Schroeder/Maiwald, BT 2, § 63, Rn. 59; Neuheuser, NStZ 2000, 174 (177).

${ }^{966}$ AG Wermelskirchen NJW 1999, 590 (590); LK-Dippel, § 170 d, Rn. 19; Preisendanz, $\S 170$ d, Rn. Anm. 4c; S/S-Lenckner, § 171, Rn. 9.

${ }^{967}$ AG Köln (unveröff. Entscheidungen) vom 7.4.1999, 613 Ls 97/98 und 28.4.1999, 532 Ds 82/99.
} 
Der Hinweis darauf, der Jugendliche sei zum Betteln angehalten oder vom Schulbesuch abgehalten worden, genügt für sich allein nicht zur Begründung einer konkreten Gefahr ${ }^{968}$. Das Schuleschwänzen, das zumeist mit Kinder- und Jugenddelinquenz einhergeht, darf für sich allein nicht bereits als Gefährdung gesehen werden, sondern vielmehr nur als Symptom für die Gefährdung der Entwicklung ${ }^{969}$.

An der konkreten Gefahr fehlt es außerdem, wenn und soweit der Verpflichtete oder ein Dritter fähig und willens sind, den Eintritt der entsprechenden Schäden zu verhindern ${ }^{970}$. Daß der Garant trotz seiner Pflichtverletzung bereit ist, den Schaden zu verhindern, dürfte für das Tatbestandsmerkmal des kriminellen Lebenswandels allerdings unrealistisch sein. Wer durch die Verletzung seiner Fürsorge- und Erziehungspflichten den Schutzbefohlenen der Gefahr aussetzt, ins kriminelle Milieu abzurutschen, ist gerade nicht fähig oder willens, den Eintritt in den kriminellen Lebenswandel noch aufzuhalten. Geringe Hoffnung mag bestehen, daß sich ein Dritter, z.B. Lehrer, Vertrauensperson usw., des Jugendlichen annimmt und ihn vor den Folgen der Pflichtverletzung seiner Eltern bewahrt. In einem solchen Fall ist aber fraglich, ob dies ein Verdienst ist, der den Eltern angerechnet werden kann. Eine Gefährdung müßte wohl trotzdem bejaht werden, da diese zunächst entstanden ist und die günstige Einflußnahme des Dritten vom Zufall abhängig ist.

Da die Aufgabe, die Gefahr zu bestimmen, mit einer Prognose über die künftige Entwicklung des Kindes verbunden ist, läßt es sich nicht verhindern, daß ,der Richter mit einer gewissen seherischen Aufgabe betraut wird“ 971 .

bb) Verursachung der Gefährdung

Der Garant muß zur Erfüllung des Tatbestandes die Gefahr entweder aktiv durch sein Verhalten herbeiführen oder durch sein Unterlassen eine

\footnotetext{
${ }^{968}$ SK-Horn, § $170 \mathrm{~d}$, Rn.7.

${ }^{969}$ Ostendorf, S. 42; vgl. AG Köln (unveröff. Entscheidungen) vom 7.4.1999, 613 Ls 97/98 und 28.4.1999, 532 Ds 82/99.

${ }^{970}$ Zum Zurücklassen eines Kindes im Bereich einer Bahnhofsmission: OLG Köln JR 1968, 308 (308); Horn, S. 169ff.

${ }^{971}$ Dies kritisch anmerkend: Luther, NJW 52, 403 (403).
} 
bereits bestehende Gefahr nicht abwenden. Der Täter ist auch verpflichtet, eine Steigerung dieser Gefahr zu verhindern ${ }^{972}$. Denn die Abwendungspflicht besteht auch dann weiter, wenn die Gefahr oder die Entwicklungsschädigung schon eingetreten ist. Geht der Jugendliche etwa schon einem kriminellen Lebenswandel nach, so besteht die Pflicht, ihn aus dem kriminellem Lebenswandel herauszuholen, z.B. gegen Mitgliedschaft des Jugendlichen in einer Diebesbande einzuschreiten ${ }^{973}$.

cc) Kausalität und Zurechnung

Der drohende oder bereits eingetretene kriminelle Lebenswandel muß durch die Fürsorge- und Erziehungspflichtverletzung zurechenbar verursacht worden sein. Die Kausalität richtet sich nach den allgemeinen Grundsätzen, d.h. die unterlassene Handlung des Erziehungsverpflichteten darf nicht hinweggedacht werden, ohne daß der Erfolg entfiele.

Der Zurechnung steht nicht entgegen, daß der Schutzbefohlene zum Zeitpunkt der Pflichtverletzung bereits einem kriminellen Lebenswandel nachging, dieser Lebenswandel also nicht mehr die Folge der Pflichtverletzung sein konnte: Das Verbleiben in diesem für das geschützte Rechtsgut schädlichen Zustand muß, wie oben bereits festgestellt, durch den Erziehungsverpflichteten beendet oder unterbrochen werden ${ }^{974}$.

Horn ist dem entgegen der Ansicht, daß der Unterlassungstatbestand nicht mehr erfüllt werden kann, sobald die Gefahr eingetreten ist ${ }^{975}$. Er stellt darauf ab, daß das strafbare Unterlassen bei $§ 171$ nur darin liege, die Gefahr entstehen zu lassen. Sei der Schaden eingetreten, ohne daß dem Verpflichteten eine Pflichtverletzung vorzuwerfen wäre, müsse er den Schutzbefohlenen nicht wieder aus der Gefahr hinausbringen.

Hier differenziert Horn m. E. nicht klar genug. Wohl ist richtig, daß der Verpflichtete ohne eine vorangegangene Pflichtvernachlässigung nicht ursächlich für den Eintritt der Gefahr sein kann. Mit dem Eintritt der Gefahr endet die Verpflichtung des Erziehungspflichtigen jedoch nicht.

\footnotetext{
972 BGHSt 8, 92 (93ff.); S/S-Lenckner, § 171, Rn. 5.

${ }^{973}$ LK-Dippel, § 170 d, Rn. 8.

${ }^{974}$ So auch Neuheuser, NStZ 2000, 174 (178); a. A. SK-Horn, § 171, Rn. 8.

${ }^{975}$ SK-Horn, § 171, Rn. 8.
} 
Es gibt keinen Hinweis darauf, daß der Erziehungspflichtige, nachdem „das Kind in den Brunnen gefallen ist“ den für ihn geltenden Verpflichtungen nicht mehr nachkommen $\mathrm{zu}$ brauchte ${ }^{976}$. Der Erziehungspflichtige bleibt vielmehr auch für das Abwehren von weiteren Gefahren verantwortlich. Sein Unterlassen kann nach einem ersten Gefahreintritt noch weitere und schwerere Gefahren für die psychische Entwicklung zur Folge haben. Die Unterlassung wäre somit auch für die weiteren Gefahren, die aus dem bereits gefährlichen Zustand noch erwachsen, ursächlich.

dd) Zumutbarkeit

Die Zumutbarkeit des verlangten Verhaltens begrenzt allgemein bei Unterlassungsdelikten die strafbewehrte Handlungspflicht. Unzumutbar ist eine Handlung, wenn sie eigene billigenswerte Interessen in erheblichem Umfang beeinträchtigt und diese in einem angemessenen Verhältnis zum drohenden Erfolg stehen ${ }^{977}$. Aufgrund des besonderen Tatbestandsmerkmals der „Gröblichkeit“ der Pflichtverletzung, welches derartige Fälle ausklammert, erlangt das Kriterium der Zumutbarkeit bei $\S 171$ keine eigenständige Bedeutung, sondern wird vielmehr im Rahmen der Abwägung der „,Gröblichkeit“ behandelt ${ }^{978}$.

\section{Subjektiver Tatbestand}

Für den subjektiven Tatbestand genügt bedingter Vorsat ${ }^{979}$. Der Vorsatz des Elternteils bzw. Aufsichtspflichtigen muß sich sowohl auf das Schutzverhältnis, d.h. seine Fürsorge- und Erziehungspflicht, auf die gröbliche Pflichtverletzung und auf die Umstände, aus denen sich konkrete Gefährdung ergibt, erstrecken.

Dem Erziehungsberechtigten kann der Vorwurf der Pflichtverletzung nur dann gemacht werden, wenn er Anlaß zu der Annahme hatte, daß

976 Ein Nichtstun des Erziehungspflichtigen würde einem Aufgeben des Schutzbefohlenen gleichkommen. Zu einem Zeitpunkt, an dem der Verpflichtete am meisten mit seiner Fürsorge- und Erziehung gebraucht würde, würde er den Schutzbefohlenen im Stich lassen.

977 S/S-Stree, Vor § 13, Rn. 155f.

${ }^{978}$ Neuheuser, NStZ 2000, 174 (178f.). 
Straftaten durch seinen Zögling begangen werden könnten ${ }^{980}$. Dies ist jedenfalls dann gegeben, wenn der Erziehungsverpflichtete Kenntnis davon hatte, daß der Schutzbefohlene in der jüngeren Vergangenheit Straftaten begangen hatte, und er mit deren Fortsetzung rechnete. Die Kenntnis kann auf verschiedene Weise erlangt worden sein, keinesfalls bedarf es dazu der Benachrichtigung durch die Strafverfolgungsbehörden. Es reicht das tatsächliche Kenntniserlangen durch den Schutzbefohlenen selbst, Nachbarn, Mitarbeiter des Jugendamtes oder des Ausländeramtes ${ }^{981}$.

Der Nachweis des Vorsatzes des Erziehungspflichtigen bezüglich der Tat des Minderjährigen dürfte nur sehr schwer zu erbringen sein $^{982}$. So müßte nachgewiesen werden, daß der Erziehungspflichtige Anlaß zu den Annahme hatte, der Zögling werde ein (neues) Delikt begehen.

Für den Vorsatz kommt es nicht darauf an, daß der Täter sein eigene Verhalten als pflichtwidrig und die Gefährdung als gröblich wertet. Auch wenn der Täter persönlich der Ansicht ist, die Pflichtverletzung wiege doch nur leicht, kann Vorsatz gegeben sein; die Kenntnis der Umstände, die diese Wertung begründen, genügt ${ }^{983}$. Andernfalls würde den Täter seine lasterhafte Einstellung und seine legere Grundhaltung vor Strafverfolgung schützen, während der Täter, der sein fehlerhaftes Tun immerhin noch erkennt, bestraft würde. Die Fehleinschätzung des Schweregrades der Pflichtverletzung begründet daher keinen Tatbestands-, sondern einen Verbotsirrtum i.S.d. § 17 StGB. Im Rahmen der Vermeidbarkeit ist dann zu überprüfen, ob der Täter zu der Bewertung seines Tuns als gröblich hätte kommen können ${ }^{984}$.

\footnotetext{
${ }^{979}$ Neuheuser, NStZ 2000, 174 (174).

${ }^{980}$ Neuheuser, NStZ 2000, 174 (176), der diese Frage allerdings zum objektiven Tatbestand zählt.

${ }^{981}$ Neuheuser, NStZ 2000, 174 (176).

${ }^{982}$ Glaue, Jugendliche Rechtsbrecher, S. $9 f$.

${ }^{983}$ LK-Dippel, § 170 d, Rn. 21; Maurach/ Schroeder/ Maiwald, BT 2, § 63 IV, Rn. 56;

Maiwald, GA 74, 255 (263).

${ }^{984}$ Maurach/ Schroeder/ Maiwald, BT 2, § 63 IV, Rn. 56; Maiwald, GA 74, 255 (263).
} 


\section{II. § 171 StGB als echtes Unterlassungsdelikt}

Da in $§ 171$ neben solchen aktiven Tätigkeiten, die der regelmäßigen und ungehemmten Entwicklung des Kindes entgegenlaufen ${ }^{985}$, hauptsächlich jede Art von Untätigkeit angesprochen wird, die dem Erziehungs- und Fürsorgezweck zuwiderläuft, stellt sich die Frage, ob der Tatbestand, soweit er nicht positives Tun erfaßt, ein echtes Unterlassungsdelikt darstellt.

Dafür spricht zunächst, daß es sich bei der im (Unterlassungs-) Tatbestand des $\S 171$ geforderten Pflicht zur Wahrnehmung der Erziehung und Fürsorge nicht um eine Erfolgsabwendungspflicht, sondern vielmehr um ein Tätigkeitsgebot handelt, wie es für ein echtes Unterlassungsdelikt typisch ist $^{986}$. Der Tatbestand, soweit er das Unterlassen betrifft, fordert ein bestimmtes Handeln, nämlich die Ausübung von Fürsorge und Erziehung. Es handelt sich also um ein Tätigkeitsgebot durch das Gesetz. Bis zu diesem Punkt hat $§ 171$ den Charakter eines echten Unterlassungsdelikts.

Problematisch stellt sich allerdings dar, daß $\S 171$ StGB nicht nur ein Handlungsgebot erwähnt, sondern noch zusätzlich einen gemißbilligten Erfolg, die Gefährdung psychischen Entwicklung. Dieser Erfolg ist zur Tatbestandsverwirklichung erforderlich und geht über das bloße Unterlassen hinaus. Solche Tatbestände sind nach einer vielfach vertretenen Auffassung gerade als unechte Unterlassungsdelikte einzustufen ${ }^{987}$. Es liege ein Erfolgsherbeiführungsverbot vor. Werde dieses Verbot nicht beachtet, würde letzten Endes gegen eine Verbotsnorm verstoßen. Dies sei gerade Merkmal des Begehungsdelikts und damit des unechten Unterlassungsdelikts.

Das Gesetz kann jedoch nicht Gebots- und Verbotsnorm zugleich sein. Andernfalls müßte es zugleich eine Handlung fordern und verbieten.

\footnotetext{
${ }^{985}$ Zur Verwirklichung des $\S 171$ durch Begehen gehören alle Arten einer „falschen“ Erziehung wie das Anlernen zur Kriminalität, das Heranführen an Drogen oder das Herstellen von schlechten Kontakten.

${ }^{986}$ vgl. oben 2. Teil B I 1.

${ }^{987}$ Welzel, S. 211.
} 
Dieser Widerspruch kann nur durch eine einheitliche Form (als Verbot oder als Gebot) gelöst werden.

Gegen die Einstufung als unechtes Unterlassungsdelikt spricht, daß eine genaue Verbotsnorm sich für $\S 171$ als Unterlassungsdelikt gerade nicht bilden läßt. Es wird lediglich verboten, daß das Kind in seiner psychischen Entwicklung gefährdet wird. Die Verbotsnorm könnte also allenfalls den Inhalt haben: „Du sollst Dein Kind nicht gefährden“. Dieses wäre jedoch als Norm viel zu unbestimmt, um Grundlage einer Strafbestimmung zu sein ${ }^{988}$. Statt dessen liegt bei $\S 171$ der Schwerpunkt darauf, wie die Gefahr für das Rechtsgut vermieden werden soll. Es ist also davon auszugehen, daß die Vorschrift nicht eine Verbotsnorm, sondern vielmehr eine Gebotsnorm des Inhaltes aufstellt: „Du sollst Dein Kind ausreichend versorgen und erziehen“. Der Tatbestand fordert in erster Linie ein bestimmtes Handeln vom Adressaten. Damit gebietet das Gesetz eine schlichte Tätigkeit, die auf ein echtes Unterlassen hindeutet $^{989}$.

Außerdem sind hier im Gegensatz $\mathrm{zu}$ den ungeschriebenen Strafbarkeitsvoraussetzungen der unechten Unterlassungsdelikte alle Tatbestandsvoraussetzungen gesetzlich aufgeführt und umschrieben. Das Kind befindet sich genau dann in einer Gefahrenlage, wenn es nicht versorgt oder erzogen wird. Zur Abwendung der Gefahr ist derjenige in der Lage, in dessen Obhut sich das Kind befindet. Der zur Abwendung

${ }^{988}$ Franke-Gricksch, S. 70 f.; Schmitt, JZ 59, 432 (432). Anders liegt es bei § 171 StGB als Begehungsdelikt. Dort lautet die Verbotsnorm: „Du sollst die Fürsorge und Erziehung Deines Kindes nicht vernachlässigen“ (und dadurch die Entwicklung des Kindes gefährden).

${ }^{989}$ Franke-Gricksch, S. 70; vgl. Armin Kaufmann, JuS 61, 173 (173f.): Kaufmann geht davon aus, daß sich die echten von den unechten Unterlassungsdelikten nur durch das äußere Kriterium unterscheiden, daß die echten vom Gesetz vertypt seien. Danach hat er folgerichtig ausgeführt, daß die jene Unterlassungen, die das Strafgesetz zusammen mit dem entsprechenden Fall der Begehung in einer Vorschrift und nach dem gleichen Strafrahmen behandelt, echte Unterlassungsdelikte seien, z.B. $\S 223 \mathrm{~b}$ (Vernachlässigung der Fürsorgepflicht mit der Folge einer Gesundheitsschädigung), $\S 121$ (Entweichenlassen Gefangener) oder $\S 123$ Abs. 1 StGB (Hausfriedensbruch durch Unterlassen des Entfernens). Diese Fälle ähnelten zwar den unechten Unterlassungsdelikten insofern, als das Unterlassen der Strafe der entsprechenden Begehung gleichgestellt werde. Das Gleichstellungsproblem sei hier aber dadurch gelöst, daß die Voraussetzungen, unter denen der Unterlassende strafbar sei, tatbestandlich umschrieben seien. 
Verpflichtete wird dabei im Tatbestand gekennzeichnet durch einen Verweis auf den gesetzlich zu Fürsorge- und Erziehung verpflichtetem Personenkreis; es handelt sich dabei um die gesetzliche Umschreibung einer Garantenstellung ${ }^{990}$. Schließlich setzt das Gesetz die Nichtvornahme einer Handlung voraus, wobei es die Handlung zwar nicht in allen Einzelheiten, wie auch in 323 c StGB, aber nicht zuletzt durch die Beispiele (Abhalten von kriminellem Lebenswandel, Prostitution) genügend beschreibt. Diese geforderte Handlung ist auch durch die Erziehungs- und Fürsorgepflicht ausreichend beschrieben ${ }^{991}$.

Schließlich liegen Charakter und Schwerpunkt der Norm auf dem Nichtvornehmen der für das Kindeswohl erforderlichen Tätigkeiten. Bereits aus der Überschrift des $\S 171$ „Verletzung der Fürsorge- und Erziehungspflicht" geht hervor, welche Tätigkeiten, nämlich Fürsorge und Erziehung, vom Adressaten der Norm erwartet werden. Während beim unechten Unterlassungsdelikt das Verbot eines aktiven Tuns im Vordergrund steht und die Begehung durch Unterlassen nur als selten benötigter Zusatztatbestand erscheint, verfolgt $\begin{aligned} & \S \\ & 171\end{aligned}$ Unterlassungstatbestand vorrangig das Ziel, ein Tun, das Sich-Sorgen und das Erziehen, zu erzwingen. Der Wortlaut des $\S 171$ stellt die Verletzung der diesbezüglichen Pflicht unter Strafe (,Wer seine Erziehungspflicht vernachlässigt...").

$\S 171$ ist daher, soweit nicht positives Tun vorliegt, als echtes Unterlassungsdelikt aufzufassen ${ }^{992}$. Das hat zur Folge, daß die Strafmilderungsmöglichkeit aus $§ 13$ Abs. 2 nicht anwendbar ist ${ }^{993}$.

\footnotetext{
${ }^{990}$ Franke-Gricksch, S. 71.

${ }^{991}$ Franke-Gricksch, S. 70.

992 LK-Dippel, § 170 d, Rn. 22; SK-Horn, § 170 d, Rn. 14; a.A. Jescheck/ Weigend, $\S 58$ III 3, S. 607; Bärwinkel, S. 22.

${ }^{993}$ SK-Horn, § 170 d, Rn. 14; Neuheuser, NStZ 2000, 174 (179), stellt aber fest, daß auch bei der Annahme eines unechten Unterlassungsdelikt eine Strafmilderung nach $\S 13$ Abs. 2 hier nicht greifen würde: Aufgrund der Gleichwertigkeit von Tun und Unterlassen bei § 171 sei eine Milderung hinsichtlich des Unterlassens nicht zulässig.
} 


\section{Allgemeine Konkurrenzfragen}

Bringt der Fürsorge- oder Erziehungspflichtige mehrere Schutzbefohlene durch sein Verhalten in die Gefahr eines Entwicklungsschadens, hängt es von den Umständen der Gefährdung des einzelnen ab, ob Handlungseinheit oder Handlungsmehrheit vorliegt ${ }^{994}$.

Mehrere Verletzungen der Fürsorge- und Erziehungspflicht aus $\S 171$ können in Tateinheit begangen werden. Es ist dabei unerheblich, ob die Pflichtverletzung durch aktives Tun oder durch Unterlassen begangen wird, da diese Begehungsformen einander voll entsprechen. Die Pflichtverletzungen stellen eine einheitliche Tat dar, wenn die einzelne, für sich allein betrachtete Handlung den Tatbestand nicht erfüllt, sondern sich vielmehr erst aus ihrer Gesamtheit der gröbliche Verstoß ergibt ${ }^{995}$.

Für das Konkurrenzverhältnis zu anderen Straftatbeständen gelten nach dem Wegfall der Subsidiaritätsklausel im Jahre 1974 die allgemeinen Grundsätze.

Im vorliegenden Zusammenhang sind nur Konkurrenzen mit solchen Tatbeständen relevant, die unter anderem dem Schutz vor kriminellem Lebenswandel dienen. Tateinheit ist mit der Teilnahme an den Straftaten des Jugendlichen ${ }^{996}$ und mit der Beihilfe bzw. Täterschaft durch Unterlassen möglich ${ }^{997}$.

\section{Rechtsfolgen}

$\S 171$ sieht als Rechtsfolge Freiheitsstrafe bis zu 3 Jahren oder Geldstrafe vor. Schon der Gesetzgeber ging davon aus, daß gegen die Täter regelmäßig eine kurze Freiheitsstrafe zu verhängen sei $^{998}$. Diese

\footnotetext{
${ }^{994}$ LK-Dippel, § 170 d, Rn. 26.

995 LK-Dippel, § 170 d, Rn. 25 m.w.N.

${ }^{996}$ LK-Dippel, § 170 d, Rn. 24.

${ }^{997}$ S/S-Lenckner, § 171, Rn. 12; ausführlich zu den Konkurrenzen mit den unechten Unterlassungsdelikten siehe 5. Teil B II.

${ }^{998}$ Bericht des Sonderausschusses, BT-Drucks. VI/3521, S. 16.
} 
Einschätzung hat sich zumindest in den wenigen Fällen, die in der Rechtsprechung entschieden worden sind, auch dort durchgesetzt. Auch bei Ersttätern sei nicht Geldstrafe, sondern eine kurze Freiheitsstrafe sachgerecht, um auf die Täter einzuwirken und die Rechtsordnung zu verteidigen $^{999}$. Die Voraussetzungen des $\S 47$ Abs. 1 dürften in der Tat bei den typischen durch $\S 171$ erfaßten Fürsorge- und Erziehungspflichtverletzungen häufig gegeben sein. Als besondere Umstände i.S.d. $§ 47$ Abs. 1 kommt vor allem eine monatelange Pflichtverletzung in Betracht, bei der der Täter frühzeitig von den Taten Kenntnis hatte und der Schutzbefohlene regelmäßig die Früchte seiner Taten in Form von Beutestücken mit in die elterliche Wohnung eingebracht hat. Der Täter zeigt durch die lange Tatdauer und die Duldung der offensichtlichen Straftaten eine besondere Gleichgültigkeit. Dies muß um so schwerer wiegen, wenn er in dieser Zeit mehrfach von staatlichen Stellen auf die Straftaten seines Schutzbefohlenen hingewiesen worden ist ${ }^{1000}$.

Es könnte aber kritisch betrachtet werden, wenn bei einem Tatbestand, der vom Gesetzgeber ausdrücklich auch mit der Sanktion der Geldstrafe versehen ist, von vornherein nur die Sanktion der Freiheitsstrafe verhängt wird. Immerhin hat der Gesetzgeber auch Fälle des $§ 171$ für möglich gehalten, in denen die Verhängung einer Geldstrafe ausreicht. Im Hinblick auf die in der Praxis $\mathrm{zu}$ vermutenden schwierigen Lebensverhältnisse der betroffenen Eltern erscheint es allerdings wenig praktikabel, der Familie auch noch das Geld zu kürzen. Die Freiheitsstrafe zur Bewährung bietet den großen praktischen Vorteil, daß über einen entsprechenden Bewährungsbeschluß Auflagen und Weisungen erteilt werden können, deren Befolgen gleichzeitig die Erfüllung der Aufsichtspflicht des Verurteilten beinhaltet. Über diese Auflagen können beispielsweise der regelmäßige Schulbesuch oder die Teilnahme an Erziehungskursen erreicht werden.

In der politischen Diskussion wird teilweise überlegt, eine Mindestfreiheitsstrafe festzusetzen und auf die Alternative der Geldstrafe zu verzichten. Durch die drohende Verurteilung zu einer Freiheitsstrafe

\footnotetext{
${ }^{999}$ AG Wermelskirchen NJW 1999, 590 (591).

1000 Neuheuser, NStZ 2000, 174 (179).
} 
als einzig mögliche Form der Bestrafung könne das Verantwortungsbewußtsein gestärkt werden ${ }^{1001}$.

Nach der von Ostendorf 1997 durchgeführten Studie in SchleswigHolstein dominiert als Sanktion bei $\S 171$ die Freiheitsstrafe zur Bewährung $^{1002}$. Das kann jedoch nicht pauschalisiert werden.

Die Dauer der verhängten Freiheitsstrafe im Jahr 1996 war von unter 6 Monaten bis zu einem Jahr relativ gleichmäßig verteilt ${ }^{1003}$; angesichts der wenigen Verurteilungen (55 Personen) lassen sich aus der Verteilung nur sehr bedingt Schlüsse ziehen.

B. Vergleich zwischen $\S 171$ StGB und den unechten Unterlassungsdelikten i.S.d. § 13 StGB

I. Inhaltliche Unterschiede

Betrachtet man die beiden Möglichkeiten, die Eltern bei Delikten ihrer Abkömmlinge strafrechtlich heranzuziehen, so muß auf die Unterschiede zwischen einer Bestrafung aus unechtem Unterlassungsdelikt und aus $\S 171$ StGB eingegangen werden.

Wichtigster Unterschied ist zunächst, daß das in den Tatbeständen geforderte Verhalten zwei unterschiedlichen Rechtsgütern dient. Bei der Deliktsverhinderungspflicht aus dem unechten Unterlassungsdelikt geht es um den Schutz der Rechtsgüter Dritter. Die Eltern sind als Überwachergaranten dafür verantwortlich, daß unbeteiligte Dritte nicht durch ihr Kind geschädigt werden. Demgegenüber sind die Eltern, die dem Gebot des $\S 171$ folgen, ihren Kindern Fürsorge und Erziehung zu geben, als Beschützergaranten für ihre eigenen Kinder tätig. Diese Norm dient dem Schutz der Rechtsgüter des Kindes bzw. Jugendlichen vor sich selbst.

Ferner sind die Anforderungen, die an das Verhalten der Eltern gestellt werden, in den Tatbeständen unterschiedlich hoch. Beim unechten

\footnotetext{
1001 Programm der CSU-Landesgruppe vom 1.8.1997, zitiert bei Ostendorf, S. 9.

1002 Ostendorf, S. 14: einer Verurteilung ohne Bewährung standen 30 mit Bewährung gegenüber.

${ }^{1003}$ Vgl. Ostendorf, S. 16.
} 
Unterlassungsdelikt wird von den Eltern erwartet, daß sie die Tat als solche verhindern; wie sie das erreichen, spielt keine Rolle. Erziehung und Fürsorge für das Kind spielen nur eine untergeordnete Rolle. Demgegenüber fordert $\S 171$ von den Eltern zwar die Beachtung der Fürsorge- und Erziehungspflichten. Alle Taten des Minderjährigen, die darüber hinaus trotz der Beachtung dieser Pflichten geschehen, fallen jedoch nicht in den Zurechnungsbereich der Eltern.

Im Vergleich zum Überwachergaranten, der eine konkrete Deliktsverhinderungspflicht zu erfüllen hat, ist die Aufgabe des aus $§ 171$ zur Erziehung Verpflichteten nur ungenau umrissen. Er soll so erziehen, daß aus dem Verhalten seines Abkömmlings keine Straftaten erwachsen wie er das tun soll, sagt das Gesetz nicht. Es handelt sich auch, anders als bei der konkreten Deliktsverhinderung, nicht um eine einmalige Situation, vielmehr wird die Forderung der richtigen Erziehung ununterbrochen an den Erziehungspflichtigen gestellt.

Hinsichtlich des Taterfolgs stellt das unechte Unterlassungsdelikt höhere Anforderungen an die Strafbarkeit, indem der Taterfolg in Form einer Straftat des Schutzbefohlenen eintreten muß. „Taterfolg“ bei $\S 171$ ist hingegen bereits die Gefährdung des psychischen Wohls des Minderjährigen auch ohne eine konkrete Tatverwirklichung.

Schließlich knüpft die Strafbarkeit beim unechten Unterlassen direkt an dem von Minderjährigen verwirklichten Delikt und dem jeweiligen Strafrahmen des Besonderen Teils an, während $\S 171$ wegen der Erziehungspflichtverletzung als solcher bestraft und unabhängig von den Folgen dieser Erziehungspflichtverletzung einen Strafrahmen von bis zu drei Jahren Freiheitsstrafe vorsieht.

\section{Konkurrenzverhältnis}

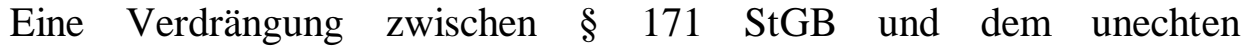
Unterlassungsdelikt besteht bei gleichzeitiger Verwirklichung beider Tatbestände nicht. $§ 171$ StGB und das unechte Unterlassungsdelikt stehen nebeneinander. Dies begründet sich bereits daraus, daß unterschiedliche Rechtsgüter geschützt werden sollen. Zudem knüpft die 
Strafbarkeit beim unechten Unterlassen direkt an dem von Minderjährigen verwirklichten Delikt an, während $\S 171$ wegen der Erziehungspflichtverletzung aus einem eigenen Strafrahmen bestraft.

In vielen Fällen dürfte daher Idealkonkurrenz vorliegen. Geht man aber von einem fast immer gleichzeitigen Vorliegen von unechtem Unterlassungsdelikt und $\S 171$ aus, mag man sich die Frage stellen, ob $\S 171$ nicht ganz überflüssig ist bzw. ob ihm angesichts seiner dehnbaren Tatbestandsmerkmale nur die Funktion eines Auffangtatbestandes für solches elterliche Verhalten zukommt, das sich nicht durch das reine Unterlassen erfassen läßt. Das würde aber voraussetzen, daß sich die Voraussetzungen der Strafbarkeiten regelmäßig decken. Das ist jedoch, wie oben dargestellt, schon aufgrund der unterschiedlichen Ausrichtung hinsichtlich der Schutzgüter nicht der Fall.

Während das unechter Unterlassen auf eine konkrete Situation abstellt, die es durch Aufsicht zu verhindern gilt, soll $\S 171$ das gesunde Aufwachsen ermöglichen, indem stetiger Erziehungseinfluß geltend gemacht wird.

Zudem sind die Voraussetzungen des $\S 171$ erheblich dadurch eingeschränkt, daß es gerade durch die Pflichtverletzung $\mathrm{zu}$ der Gefährdung der psychischen Entwicklung, in concreto zum kriminellen Lebenswandel des Kindes gekommen sein muß. Diese Hürde der Kausalität muß erst überwunden werden. Zudem erfaßt $\$ 171$ Minderjährige nur bis $\mathrm{zu} 16$ Jahren, während das unechte Unterlassungsdelikt auch Eltern betrifft, deren Abkömmlinge zwischen 16 und 18 alt sind. Ein weiterer gewichtiger Unterschied ist, daß beim unechten Unterlassen der Elternteil im Regelfall unmittelbar Täter des konkreten von ihm nicht verhinderten Delikts wird, während bei § $171 \mathrm{zu}$ einer Gefährdung des Schutzbefohlenen unter Umständen auch die Häufung von an sich minderschwerer Taten genügt. Von einer Auffangfunktion des $\S 171$ gegenüber dem unechten Unterlassen kann insoweit nicht gesprochen werden. 


\section{Teil. Verfassungsrechtliche und kriminalpolitische Aspekte}

A. Verfassungsrechtliche Überprüfung der gefundenen Ergebnisse

$\mathrm{Zu}$ untersuchen ist im folgenden, ob es mit dem Grundgesetz vereinbart werden kann, daß Eltern wegen der „Straftaten“ ihrer Kinder bestraft werden können, sei es über $\S 13$ durch die unechten Unterlassungsdelikte, sei es über $\S 171$. Es stellt sich vordergründig die Frage, ob es sich dabei um eine Bestrafung für fremdes Unrecht handelt und ob diese zulässig sein kann.

Dazu ist festzustellen, daß eine Haftung für fremdes Unrecht nicht mit unserem Strafrechtssystem vereinbar ist ${ }^{1004}$. Unser Strafrecht geht von einer persönlichen Verantwortung für das eigene Fehlverhalten aus und schließt fremdes Verhalten nicht mit ein. Das Prinzip der persönlichen Verantwortung ist auch nicht erst seit der Geltung des Grundgesetzes herrschend. Schon in der Rechtsprechung des Reichsgerichts wird dieser Grundsatz bei der Hinderungspflicht des Gewerbetreibenden für die Übertretung polizeilicher Vorschriften durch Stellvertreter hervorgehoben: Es handelt sich nicht um eine Haftung für fremdes, sondern für eigenes Verschulden ${ }^{1005}$.

Die Garantenhaftung für die Nichthinderung der fremden Tat ist unter diesem Prinzip so $\mathrm{zu}$ verstehen, daß der Pflichtige aus eigenem Verschulden und durch eigene Pflichtverletzung das rechtsgutsverletzende Geschehen (mit-)verursacht. Das Auferlegen einer Pflicht zur Deliktsverhinderung hat ihren Zweck auch keinesfalls darin, die fremde Verantwortung (z.B. des Jugendlichen) zu beseitigen oder zu übernehmen oder die fremde Nichtverantwortung (des Kindes) zu ersetzen. Die Garantenpflicht setzt deswegen auch nicht Schuldlosigkeit oder Schuldunfähigkeit voraus ${ }^{1006}$. Jedes verwirklichte Unrecht, sei es vom Elternteil oder vom Kind, wird vielmehr unabhängig von dem des anderen betrachtet.

\footnotetext{
${ }^{1004}$ Vgl. Kaltofen, S. 19.

1005 RGSt 50, 10 (14); Hsü, Garantenstellung des Betriebsinhabers, S. 162.

${ }^{1006}$ Hsü, Garantenstellung des Betriebsinhabers, S. 163.
} 
Wie dargestellt, ergibt sich eine Strafbarkeit der Eltern aus eigener Unterlassungstäterschaft bzw. aus eigener Erziehungs- und Fürsorgepflichtverletzung. Zwar ist die rechtswidrige Haupttat des Kindes Voraussetzung dafür, daß die Eltern rechtlich belangt werden können. Doch ohne die Zurechnung über die Garantenpflicht kraft Herrschaftsmacht bzw. ohne die Pflichtverletzung aus $\S 171$ erfolgt keine Bestrafung. Das elterliche Fehlverhalten ist somit Dreh- und Angelpunkt einer Bestrafung der Eltern.

Zweifel können sich aber insofern ergeben, als man die Garantenstellung kraft Herrschaftsmacht selbst in verfassungsrechtliche Zweifel zieht, jedenfalls, was die Herrschaft über Personen anbetrifft. Denn letzte Konsequenz der Garantenpflicht aus Autorität ist ja das „DafürEinstehen-Müssen“ für das Tun eines anderen. Jedoch gilt diese Überlegung nicht absolut. Eigenart der Garantenstellung kraft Herrschaftsmacht ist es, daß sie nur dort vorliegt, wo die Fähigkeit des unmittelbar Handelnden, das verwirklichte Unrecht einzusehen, gerade nicht ausgeprägt ist, also auf jeden Fall bei Kindern und Geisteskranken. Zwar liegt auch hier eine Verwirklichung von Unrecht vor, es fehlt jedoch an der Schuld des aktiven Täters. Daher macht es keinen Sinn, bei einer darauf folgenden Bestrafung des Garanten zu bemängeln, er werde für fremde Schuld bestraft.

Problematisch ist die Auferlegung der Garantenpflicht allerdings in Bezug auf den verantwortlichen Jugendlichen, da dieser selbst schuldhaft handelt. Da jeder Täter oder Teilnehmer gem. § 29 StGB aber nur nach seiner eigenen Schuld haftet, darf eine Anlastung der Schuld des Jugendlichen gegenüber dem Garanten nicht erfolgen.

Davon ist die Frage nach dem vom Jugendlichen verwirklichten Unrecht $\mathrm{zu}$ unterscheiden. Möglicherweise löst sich sich das Problem dadurch, daß der Jugendliche selbst Sanktionen ausgesetzt wird, sein eigenes Unrecht „abarbeitet“, so daß für den Garanten davon nichts mehr bleibt, was dieser verantworten müsste. Hier zeigt sich jedoch, daß eine Trennung zwischen dem Unrecht des Garanten und dem des Jugendlichen doch nicht so leicht möglich ist. Denn wenn auch keine Akzessorietät im rechtlichen Sinn besteht, soweit man eine Täterschaft 
des Garanten durch Unterlassen bejaht, so wird doch die Tat des Jugendlichen nur deshalb verwirklicht, weil der Garant sie nicht verhindert hat. Die Bestrafung für den Unterlassenden hängt natürlich davon $a b$, welches Rechtsgut durch die Handlungspflicht geschützt werden sollte. Wer seinem Kind bei einer Sachbeschädigung oder einem Diebstahl tatenlos zusieht, verwirklicht qualitativ anderes Unrecht, als wenn er einen Mord geschehen läßt. Dennoch handelt es sich immer um das eigene Unrecht des Unterlassenden.

Damit ist nicht ersichtlich, daß hier eine Zurechung fremden Unrechts erfolgt.

B. Zur tatsächlichen Lage

I. Rechtsprechung

Höchstrichterliche Entscheidungen zu den hier behandelten Deliktstypen gibt es kaum. In den Fällen, in denen ein aktiver Täter nicht von einem Garanten gehindert wurde, handelte es sich nie um eine Konstellation von Elternteil und Kind.

Nicht unberücksichtigt soll die Frage bleiben, inwieweit das zu behandelnde Thema den Erfordernissen der Praxis Rechnung trägt. $\mathrm{Zu}$ fragen ist daher, wie die Lage tatsächlich aussieht.

II. Die Polizeiliche Kriminalstatistik (PKS) 2000

Die Frage, in welchen Fällen Eltern sich strafbar machen, indem sie ihre Kinder nicht von Delikten abhalten, ist eng verwoben mit der Frage nach der Kinder- und Jugenddelinquenz. Je nach Art und Umfang der strafbaren Handlungen der Kinder und Jugendlichen kann überhaupt untersucht werden, wie sinnvoll es ist, Eltern strafrechtlich zur Verantwortung zu ziehen. 
Einen Anhaltspunkt für den Umfang der Kinderdelinquenz bzw. Jugendkriminalität bildet die Polizeiliche Kriminalstatistik. Daraus relevant sind für das hier betrachtete Thema die Angaben zur Altersstruktur der Tatverdächtigen. Durch die Veränderungen im Zuge der deutschen Wiedervereinigung ist es zweckmäßig, die Zahlen für das Bundesgebiet erst ab $1993 \mathrm{zu}$ verwerten. Während 1993 noch 88.276 $\underline{\text { Kinder }}^{1007}$ tatverdächtig waren ${ }^{1008}$, wurden es in den darauffolgenden Jahren jeweils rund 15.000 Kinder mehr, so daß sich für 1998 eine Tatverdächtigenzahl von 152.774 ergab $^{1009}$. Dies bedeutete gegenüber 1993 eine Erhöhung der registrierten Kinderdelinquenz um 73 Prozent. Seither sind die Zahlen wieder rückläufig. Im Jahr 2000 wurden 145834 Kinder als Tatverdächtige ermittelt ${ }^{1010}$, das waren 3,2 Prozent weniger als 1999. Der Ladendiebstahl war mit 46.562 Taten bei deutschen und 13.293 Taten bei den nichtdeutschen Kindern das häufigste festgestellte Delikt, gefolgt von Sachbeschädigungen und Körperverletzungen. Über die Hälfte der tatverdächtigen Kinder (51,3 Prozent) wurde wegen Ladendiebstahls erfaßt. Auffällig ist in den alten Ländern der Anstieg bei Körperverletzung um 11,9 \% durch Deutsche und 9,2 \% durch Nichtdeutsche und bei Raub um $6 \%$ bzw. 9,1\%, wobei zu erwähnen ist, daß in den neuen Ländern dieser Trend nicht zu beobachten ist (Anstieg der Körperverletzung um 0,3 \%, beim Raub Rückgang um 2,1 \%) ${ }^{1011}$.

Bezogen auf den Bevölkerungsanteil der deutschen Kinder von 8 bis 14 Jahren wurde nur eine Minderheit von 2,3 Prozent als tatverdächtig festgestellt.

Hinsichtlich der in der PKS registrierten Jugendkriminalität ${ }^{1012}$ begann die Entwicklung ab 1993 mit 207.944 Tatverdächtigen ${ }^{1013}$. In den Folgejahren kamen durchschnittlich 20.000 mehr Verdächtige hinzu, bis sich für das Jahr 1998 die bislang höchste Zahl von 302.413

\footnotetext{
${ }^{1007}$ Kind i.S.v. § 1 Abs.2 JGG, bis zur Vollendung des 14. Lebensjahres.

${ }^{1008}=4,3 \%$ aller Tatverdächtigen; von den tatverdächtigen Kindern wurde in 55,9\% wegen Ladendiebstahls ermittelt, vgl. dp special Nr. 8/89, S. 1.

${ }^{1009}=6,6 \%$ aller Tatverdächtigen.

${ }^{1010}=6,4 \%$ aller Tatverdächtigen

1011 nur Angaben zu deutschen Verdächtigen verfügbar.

1012 Jugendliche i.S.v. § 19 JGG, also 14 bis 18jährige.

${ }^{1013}=10,1 \%$ aller Tatverdächtigen.
} 
Tatverdächtigen ergab ${ }^{1014}$. Das waren $45 \%$ mehr Verdächtige als 1993. Im Jahr 2000 betrug die Zahl der tatverdächtigen Jugendlichen 294.467 ${ }^{1015}$, das waren 0,8 Prozent weniger als 1999.

Bemerkenswert ist der Rückgang der Tatverdächtigenzahlen Jugendlicher beim Ladendiebstahl zwischen 1999 und 2000, bei den deutschen Jugendlichen um 8,1 Prozent, bei den nichtdeutschen um 8,8 Prozent. Ein ähnlicher Rückgang ist beim schweren Diebstahl zu verzeichnen. Die Zahl der erfaßten Körperverletzungen stieg im Vergleich zum Vorjahr bei den deutschen Jugendlichen um 9,2 Prozent an.

$\mathrm{Zu}$ der Art der Straftaten ist festzuhalten, daß der Ladendiebstahl an erster Stelle steht (49.638 bzw. 13.929 Taten) ${ }^{1016}$, gefolgt von der Körperverletzung (30.540 bzw. 9.857 Taten).

Es zeigt sich, daß die mengenmäßig ins Auge fallenden kinder- und jugendtypischen Delikte grundsätzlich in einen Bereich fallen, der den Eltern und Erziehungsberechtigten zugänglich ist und innerhalb dessen das Verhalten der Kinder oder Jugendlichen von ihnen beeinflußt werden kann.

Die Verletzung der Fürsorge- und Aufsichtspflicht wurde im Jahr 2000 genau 1.095 mal erfaßt, was einer Senkung von fast 8 Prozent gegenüber dem Vorjahr entspricht. Es ist allerdings nicht aufschlüsselbar, in wie vielen Fällen es sich um einen Verdacht handelte, der auf einem kriminellen Verhalten eines Jugendlichen i.S.d. § 171 letzte Alternative basierte. Angesichts des seltenen Auftauchens nicht-verhinderter Jugenddelinquenz in gerichtlichen Entscheidungen dürfte es sich zumeist um die „klassische“ Kindesvernachlässigung, die zugleich die physische Verwahrlosung einschließt, gehandelt haben.

\section{Die Studie von Ostendorf 1997}

\footnotetext{
$1014=13 \%$ aller Tatverdächtigen.

$1015=12,9 \%$ aller Tatverdächtigen.

1016 Die größte Gruppe der Ladendiebe ist unter 18 Jahre alt: Nach Angaben des Hauptverbandes des Deutschen Einzelhandels waren von den ertappten Ladendieben $17 \%$ unter 14 Jahren und $14 \%$ zwischen 15 und 18 Jahren, Die Welt, 28.4.1998.
} 
Im Jahre 1997 hat Ostendorf eine kriminalpräventive Studie durchgeführt, für die er die Polizeiliche Kriminalstatistik und die gerichtliche Verurteiltenstatistik auswertete und eine Aktenanalyse aller Strafverfahren wegen $\S 171$ ( $\S 170$ d a.F.) in Schleswig-Hostein durchführte.

Danach gab es im Jahr 1997 bundesweit 1.283 Tatverdächtige ${ }^{1017}$, davon 384 Männer und 899 Frauen; in der Mehrzahl wurde gegen Frauen ermittelt, der Frauenanteil betrug 70,1\%. Dafür kann der hohe Anteil an alleinerziehenden Müttern ausschlaggebend $\operatorname{sein}^{1018}$. Die Altersgruppe der 30-40jährigen dominierte mit 588 Tatverdächtigen ${ }^{1019}$.

Im Jahr 1996 erfolgten 39 Verurteilungen; die Gruppe der Verurteilten setzte sich aus 17 Männer und 22 Frauen zusammen. Ansonsten wurde freigesprochen oder eingestellt- es ist allerdings unklar, ob diese Verfahrensbeendigungen nach $\S 170$ Abs. 2 StPO oder wegen geringer Schuld aus den Opportunitätsgründen gem. $\S \S 153,153 \mathrm{a}$ StPO erfolgten $^{1020}$

Die Art der Gefährdung wurde in $72,8 \%$ der Fälle als allgemeine Vernachlässigung beschrieben, dazu kamen bei 12,6 \% körperliche Mißhandlung und bei 11,7 \% unzureichende Ernährung und falsche Kleidung bei Kleinkindern. In 3,9 \% der erfaßten Fälle wurde der Schulpflicht nicht nachgekommen

Schließlich konnten 13,6 \% der Fälle gar nicht eingeordnet werden: Darunter fiel auch Nichtabhalten von Straftaten, insbesondere von Diebstahl sowie die fehlende Beaufsichtigung im Straßenverkehr. Auch die Studie von Ostendorf zeigt also, daß die Strafbestimmung hinsichtlich der Deliktsverhinderung in der Praxis nur eine marginale Rolle einnimmt.

1017 Die in der PKS 1998 für das Jahr 1997 abgedruckte Zahl weicht nach unten von der bei Ostendorf angegebenen Zahl ab und nennt nur 1.138 erfaßte Fälle. Dies erklärt sich unter Umständen daraus, daß in der PKS jeder erfaßte Fall nur einfach gezählt wurde, es aber teilweise mehrere Tateverdächtige (z.B. Vater und Mutter) gab, wodurch sich die absolute Zahl der Verdächtigten bei Ostendorf erhöht haben könnte.

1018 Ostendorf, S. 11.

1019 Ostendorf, S. 12.

1020 Ostendorf, S. 14. 
Von den konkreten 103 Taten gemäß $§ 171$ wurden 30 durch Nachbarn angezeigt, 31 durch die Polizei, 5 durch Exgatten, und in 7 Fällen erstatteten die Opfer des gefährdeten Kindes Anzeige.

\section{Folgerungen für ein Strafbedürfnis}

Aus der PKS läßt sich ablesen, daß es eine nicht unbeträchtliche Kinderund Jugendkriminalität gibt.

Zweifellos können aus den Angaben der PKS, wie bei jeder Statistik, nur beschränkt Schlüsse auf die wirkliche Lage gezogen werden. Spezifische Nachteile und Fehlerquellen der PKS sollen daher kurz beleuchtet werden, soweit sie die Angaben über Kinder- und Jugenddelinquenz betreffen.

Mit Recht wird auf das Dunkelfeld verwiesen. So ist nicht bekannt, in wie vielen Fällen bei der Delinquenz von Kindern überhaupt Strafanzeige erstattet wird. Zumindest ist hinsichtlich von Delikten im Familien- und Freundeskreis eine Tendenz ersichtlich, wonach die Polizei sich um eine Schlichtung ohne eine Anzeige bemüht ${ }^{1021}$. Eine solche Handhabung ist auch für das Stellen von Anzeigen gegenüber Kindern denkbar, allerdings nicht zu belegen. Es gibt auch die Vermutung, daß bei der Delinquenz von Kindern weniger Strafanzeigen erstattet würden, weil die Opfer wegen der Strafunmündigkeit nicht mit einem - wie auch immer gearteten - Erfolg der Anzeige rechneten ${ }^{1022}$ oder sonstige Anzeigehemmnisse bestehen ${ }^{1023}$. Dafür spricht die Tatsache, daß gegen Strafunmündige gar kein Ermittlungsverfahren eingeleitet werden darf, also schon mangels strafprozessualer Möglichkeiten Kinder viel seltener erfaßt werden ${ }^{1024}$. Außerdem wird -wohl zutreffend- darauf hingewiesen, daß das Dunkelfeld gerade in Fällen, in denen auch die Opfer jugendlich seien, aufgrund der geringen Anzeigebereitschaft der jugendlichen Opfer sehr groß sei, weil die Taten gar nicht erst bekannt würden ${ }^{1025}$.

\footnotetext{
${ }^{1021}$ Göppinger, Kriminologie, S. 484.

1022 Neubacher, ZRP 98, 121 (122).

${ }^{1023}$ Frehsee, ZStW 100 (1988), 290 (294).

${ }^{1024}$ Vgl. dp special Nr. 8/98, S. 2.

1025 Haas, Die Polizei 1998, 165 (166).
} 
Neubacher ${ }^{1026}$ nennt als Erklärung für den bis 1998 festgestellten Anstieg der Kinder- und Jugenddelinquenz eine mögliche Änderung des Anzeigeverhaltens; dies wird mit dem durchaus überzeugenden Argument vertreten, daß andere bisher wirksame Kontrollinstanzen (Schule, Nachbarschaft) sich der bisher übernommenen Verantwortung mit dem Fingerzeig auf die Behörden entziehen ${ }^{1027}$.

Aus diesen Überlegungen geht zwar die Existenz eines Dunkelfeldes hervor, nicht aber, wie hoch die tatsächliche Steigerung der Kinder- und Jugenddelinquenz $\mathrm{zu}$ bewerten ist bzw. ob es sich bei der derzeitig beobachteten Situation wirklich um eine Stagnation der Kriminalität handelt. Offen bleibt auch, ob die Qualität der Straftaten sich geändert hat. So wäre es gerade im Hinblick auf die Delinquenz von Minderjährigen sinnvoll, die Höhe des angerichteten Schadens konkreter zu bestimmen, um die Qualität der Taten besser zu erfassen. Dazu sollte nicht nur der Wert der entzogenen Wertgegenstände, sondern auch der Schaden bei der Zerstörung der Sicherungseinrichtungen, etwa beim Einbruch, oder die Aufwendungen für das Austauschen von Schlössern beim Raub einer Handtasche mit Wohnungsschlüsseln, erfaßt werden ${ }^{1028}$. Ein weiteres Problem für die Erfassung der Straftaten durch die Polizei usw. könnte darin liegen, daß nur sozial besonders auffällige oder bereits strafrechtlich aufgefallene Eltern in den Blickwinkel der Strafjustiz fallen, und alle anderen von einer Beachtung durch das Strafrecht ausgeschlossen bleiben. Eine schichtspezifische Wahrnehmung könnte darauf zurückzuführen sein, daß nur in diesen Fällen eine Sensibilisierung des Jugendamtes bzw. der Strafjustiz vorliegt. Für die staatliche Reaktion auf Kindesmißhandlung ist dies empirisch belegt ${ }^{1029}$, so daß nicht unwahrscheinlich ist, daß sich hinsichtlich der Kindesvernachlässigung im weiteren Sinne ähnliche Mechanismen abspielen.

\footnotetext{
${ }^{1026}$ Neubacher, ZRP 98, 121 (122).

${ }^{1027}$ Neubacher, ZRP 98, 121 (122).

Im Gegenteil geht aus polizeilichen Stellungnahmen selbst hervor, daß die PKS nur beschränkt aussagekräftig bzw. eine unzuverlässige Grundlage sei, wobei deutlich das Problem einer möglicherweise veränderten Anzeigenbereitschaft gesehen wird dp special Nr. 8/98, S. 4f.

${ }^{1028}$ Vgl. Göppinger, Kriminologie, S. 486.

${ }^{1029}$ Bussmann, S. 57f. m. w. N.
} 
Trotz der Unwägbarkeiten wird man das seit 1993 beträchtlich erhöhte Niveau der registrierten Delinquenz/ Kriminalität nicht allein auf die Methoden schieben können, durch die diese Zahlen ermittelt worden sind.

In den letzten zwei Jahren ist es zu einem leichten Rückgang der erfaßten Jugendkriminalität gekommen ${ }^{1030}$. Auch eine Stagnation ${ }^{1031}$ bzw. einem Rückgang ${ }^{1032}$ der erfaßten Fällen des $\S 171$ StGB ist zu verzeichnen. Dennoch hat die Situation noch nichts an ihrer Problematik eingebüßt ${ }^{1033}$, und es gibt keinen Grund, die bisherigen Anstrengungen einzustellen oder darin nachzulassen. Nach wie vor ist es erforderlich, verstärkt gegen die Ursachen der Kinder- und Jugenddelinquenz vorzugehen. Von den vielen Faktoren, die eine kriminelle Karriere fördern, liegen die Ursachen zu einem wichtigen Teil im Elternhaus begründet.

V. Bedeutung des Elternhauses für die Kinder- und Jugenddelinquenz

Erst wenn die Ursachen für das kriminelle Verhalten von Minderjährigen erkannt sind, kann man sich dem nächsten Schritt zuwenden, und zwar der Frage, welche Sanktionen überhaupt einen Erfolg versprechen können.

Zusammenhänge zwischen mangelndem Interesse der Eltern an der Erziehung ihrer Kinder und delinquentem Verhalten werden in der Untersuchung des Ehepaares Glueck Anfang der 60er Jahre und in der 1967 von Ruthemann vorgelegten Arbeit ebenso angesprochen wie in der neueren Studie von Traulsen. Wichtig sind dabei die Aussagen über zentrale Aspekte des elterlichen Erziehungsverhaltens ${ }^{1034}$.

Bereits die familiäre Situation ist nur schwer differenziert zu erfassen: Schulbildung, Beruf und Einkommen der Eltern, Wohngegend, Religion, Zahl der Geschwister, Beziehung zu Freunden und Verwandten gehören

\footnotetext{
${ }^{1030}$ siehe oben 6 . Teil B 2.

1031 Zwischen 1996 (1.193 Fälle) und 1999 (1.189 Fälle) hat sich die Zahl der erfaßten Fälle kaum verändert.

1032 Zum Jahr 2000 erfolgte ein Rückgang von 7,9 Prozent auf 1.095 erfaßte Fälle.

1033 Dazu siehe auch Höynck/ Sonnen, ZRP 2001, 245 (246).

1034 Wollweber, Kinderdelinquenz, S. 155.
} 
bereits zum Bereich der familiären Sozialisation ${ }^{1035}$. Berücksichtigt werden muß außerdem, daß man die familiäre Situation eines Kindes oder Jugendlichen nicht abgelöst von der übrigen Sozialisation erfassen darf. Es erscheint also von vornherein schwierig, an einem Defekt anzusetzen und diesen mit Strafe zu belegen.

Da Sozialisation und soziale Kontrolle bei Kindern und Jugendlichen besonders in der Familie zu leisten ist, ist diese jedoch auch weitgehend für das „,soziale Versagen“ ihrer Kinder und Jugendlichen verantwortlich zu machen ${ }^{1036}$.

Zumindest hinsichtlich des unechten Unterlassungsdeliktes muß berücksichtigt werden, daß es dort nur darum geht, eine konkrete Straftat durch den Minderjährigen zu verhindern. Es soll weder eine bessere Erziehung erreicht werden noch soll die familiäre Desorganisation als solche mit Mitteln des Strafrechts bekämpft werden. Die soziale Entwicklung und die konkrete Tat in der Situation sind somit, jedenfalls auf das unechte Unterlassen bezogen, in gewisser Weise voneinander unabhängig: Es ist völlig unbedeutend, ob der Jugendliche, der die Straftat begeht, bisher (scheinbar) bestens sozialisiert ist und die Eltern sich nichts in dieser Hinsicht vorwerfen zu lassen brauchen. Verhindern sie trotzdem nicht, daß ihr Sohn jemanden zusammenschlägt, sind sie genau so zur Verantwortung zu ziehen wie Eltern, in deren Familie Gewalt an der Tagesordnung ist und bei der der Jugendliche schon öfter wegen Gewaltdelikten aufgefallen ist ${ }^{1037}$. Für den Rechtsgüterschutz Dritter hat, unabhängig von Fernzielen moralischer oder pädagogischer Natur, an erster Stelle die Aufgabe $\mathrm{zu}$ stehen, zumindest eine Tatverhinderung durch die Eltern zugunsten potentieller Opfer zu erreichen.

Es muß allerdings zugestanden werden, daß die mangelnde Erziehung und Aufsicht und die denkbaren unechten Unterlassungsdelikte rein tatsächlich in engem Zusammenhang stehen dürften und eine Trennung der Ursachen für $§ 171$ und für die unterlassene Deliktshinderung häufig

\footnotetext{
1035 Lazarus, Subjektive Familienstruktur, S. $23 \mathrm{f}$.

${ }^{1036}$ Lazarus, Subjektive Familienstruktur, S. 38f.; Ursula Schneider, Gewaltanwendung in der Familie, S. $127 f$.

${ }^{1037}$ Lazarus, Subjektive Familienstruktur, S. 37.
} 
nicht erfolgen $\mathrm{kann}^{1038}$. Um so dringender ist $\mathrm{zu}$ untersuchen, wie eine bessere Erziehung bzw. Beaufsichtigung erreicht und auf ein verantwortungsbewußtes Handeln der Erziehungsberechtigten hingewirkt werden kann. Ob dafür das Strafrecht das geeignete Mittel ist, wird im folgenden zu erörtern sein.

C. Die These von der Unzulänglichkeit der bestehenden Strafbestimmungen

Es stellt sich nun die Frage, ob eine Strafbarkeit von Eltern überhaupt erforderlich und sinnvoll ist. Es ist darüber nachzudenken, ob zumindest auf die Bestrafungsmöglichkeit aus $\S 171$ verzichtet werden kann, da die unechten Unterlassungsdelikte ohnehin zu Gebote stehen ${ }^{1039}$.

Die im folgenden anzusprechenden Schwierigkeiten ergeben sich vor allem hinsichtlich $\S 171$. Das unechte Unterlassen, das in der Praxis auch die geringere Zahl der Fälle betreffen dürfte, steht insoweit weniger zur Diskussion. Dafür, daß die Nichtverhinderung von Straftaten durch das unechte Unterlassen weitgehend akzeptiert zu sein scheint, gibt es zwei Gründe: Erstens wird von der Strafbarkeit nur eine ganz bestimmte, einmalige Situation betroffen, in der elterliches Fehlverhalten -Passivitätunter Strafe gestellt wird. Insoweit bestehen im Regelfall klarere Voraussetzungen für eine Strafbarkeit als bei $\S 171$. Zweitens stellt die Verantwortlichkeit für das Handeln Dritter im Rahmen der unechten Unterlassungsdelikte kein spezifisches Eltern-Kind Problem dar, sondern ist grundsätzlich anerkannt. Die Strafbarkeit des unechten Unterlassens in Frage zu stellen hieße schließlich, das gesamte Bestehen der unechten

\footnotetext{
${ }^{1038} \mathrm{Da}$ Jugendkriminalität häufig situationsgeprägt und spontan ist, sind natürlich nicht alle Fälle von jugendlichem Fehlverhalten den Eltern anzulasten. Zu den besonders verwerflichen, mit den schwersten Schäden sowohl für das Kind als auch für die Rechtsgüter Dritter verbundenen Fällen dürften jedoch diese zählen, bei denen mangelnde Fürsorge und Erziehung und unterlassene Überwachung zusammentreffen und daraus ein Delikt entsteht.

${ }^{1039}$ Wie oben 5. Teil B II. dargelegt, stellt $§ 171$ StGB keinen Auffangtatbestand dar, das Versäumen der Fürsorge- und Erziehungspflichten steht vielmehr neben der Strafbarkeit aus dem unechten Unterlassen. Kriminalpolitisch gesehen ist ein solches Nebeneinander jedoch möglicherweise nicht erforderlich.
} 
Unterlassungsdelikte bei Überwachergaranten in Frage zu stellen. Es gibt dogmatisch keine Rechtfertigung dafür, Überwachergaranten, nur weil es sich dabei um Erziehungsverpflichtete handelt, von der Strafbarkeit auszunehmen.

An $\S 171$ stört demgegenüber bereits die Verwendung von ungenauen Begriffen wie der gröblichen Pflichtverletzung und des kriminellen Lebenswandels. Des weiteren tendiert die Vorschrift bedenklich zu einer Bestrafung wegen Lebensführungsunrechts. Darüber betrifft das von $\S 171$ gesteckte Ziel, die Fürsorge- und Erziehungspflicht der Eltern zu verbessern, einen immensen sozialen Bereich, für dessen Beeinflussung fraglich ist, ob dafür das Strafrecht das geeignete Instrument ist.

So wird die folgende Diskussion vorwiegend $\S 171$ betreffen. Die kritische Würdigung der durch Eltern unterlassenen Deliktshinderung wird in den Grundsätzen aber auch für die unechten Unterlassungsdelikte gelten.

\section{Inhaltliche Bedenken gegen $\S 171$}

Gegen $§ 171$ sprechen unübersehbar die weit dehnbaren, geradezu $\underline{\text { unbestimmten }}_{\text {Tatbestandsmerkmale }^{1040}}$. Mag man den Inhalt von Erziehungs- und Fürsorgepflichten noch greifbar ausgestalten können, beginnen die Schwierigkeiten bereits bei der Frage, von welchem Zeitpunkt an diese Pflichten verletzt sind. Oftmals wird sich das Überschreiten der zumutbaren Grenze erst in der Rückschau feststellen lassen; eine erst rückblickend erkennbarer Erziehungsfehler kann aber den Eltern nicht i.S.d. § 171 angelastet werden.

Noch vager wird es bei der Bestimmung, ob eine Gefährdung des psychischen Wohls beim Kind oder Jugendlichen eingetreten ist. In diesem Zusammenhang hat Welzel die gern zitierte Frage gestellt, ob bereits eine Erziehung im atheistischen, materialistischen, anarchistischen Sinne oder im Sinne einer verbotenen Partei das sittliche Wohl gefährdet ${ }^{1041}$. In diesen Rahmen fällt auch die Frage, ob die

\footnotetext{
1040 Vgl. auch Franke-Gricksch, S. 2.

${ }^{1041}$ Welzel, S. 429.
} 
Zugehörigkeit der Eltern zu einer neuen religiösen oder ideologischen Gemeinschaft, Sekte oder Psychogruppe das Wohl des Kindes gefährden $\operatorname{kann}^{1042}$.

Obwohl $§ 171$ insoweit nicht gelungen ist, stellt sich die Frage, wie man diese Tatbestandsmerkmale noch deutlicher fassen können sollte.

Angesichts der genannten Schwierigkeiten in der Auslegung des $\S 171$ wäre an eine Abschaffung der Vorschrift und eine Ersetzung durch eine andere Vorschrift oder aber an eine Modifizierung zu denken. Bei einer Beibehaltung des $\S 171$ ist unbedingt eine Umgestaltung derart $\mathrm{zu}$ fordern, daß für Eltern, die selbst beim Jugendamt oder anderen Stellen Hilfe suchen, von Strafe abgesehen werden kann. Dies setzt natürlich voraus, daß $\S 171$ überhaupt einmal konsequent angewendet würdeandernfalls bedarf es in der Praxis eines solchen Korrektivs wohl ohnehin nicht.

Man könnte allerdings auch an die ersatzlose Streichung des $§ 171$ StGB denken, weil möglicherweise das unechte Unterlassungsdelikt ausreichende Gewähr bietet, um elterliches Unterlassen angemessen zu ahnden. Wie oben bereits dargestellt, sind sich die unechten Unterlassungsdelikte und $\S 171$ aber nur bedingt ähnlich. Eine Streichung von $\S 171$ verbietet sich schon dadurch, daß dem Schutzgut, der physischen und psychischen Entwicklung des Kindes, durch das unechte Unterlassungsdelikt nicht Rechnung getragen würde. Gerade der Kern des zu erzwingenden Verhaltens, nämlich der verantwortliche Umgang mit dem Kind und dessen pflichtbewußte Erziehung und Sozialisation, wird durch die Bestrafung über das unechte Unterlassungsdelikt nicht berührt. Zudem bietet $\S 171$ Ansatzmöglichkeiten, auch schon im Vorfeld eines Delikts einzugreifen, während die unechten Unterlassungsdelikte erst mit der Verwirklichung des Delikts greifen. Das unechte Unterlassen stellt somit keine strafrechtliche Alternative zu $\S 171$ dar. Auch die Neuschaffung eines Tatbestandes verspricht keine Lösung.

$\mathrm{Ob} \S 171$ dennoch gestrichen werden kann, wenn an seine Stelle zivilrechtliche oder öffentlich-rechtliche Regelungen treten, wird in folgenden zu diskutieren sein.

1042 Allenspach, Schmid-FS, S. 94. 
II. Negative Auswirkungen auf die Familienstruktur

Gegen eine strafrechtliche Durchsetzung pädagogischer Maßnahmen spricht in erheblicher Weise, daß bei einer Strafverfolgung der Eltern für den Umgang mit dem Kind mit wesentlichen Konsequenzen zu rechnen ist. Im Eltern-Kind-Verhältnis kann es als Folge einer Strafverfolgung oder Verurteilung zu einem Autoritätsverlust kommen. So ist es vorstellbar, daß der sich unverstanden fühlende Jugendliche mit dem Fingerzeig auf die Verurteilung wegen $\S 171$ StGB die elterlichen Erziehungsdefizite anprangert und damit vermeintlich ein weiteres Argument dafür besitzt, den Weisungen seiner Eltern nicht Folge leisten zu müssen, nach dem Motto „Ihr seid zu meiner Erziehung ja nicht in der Lage“ oder „Ihr habt erweislich versagt, jetzt ist es ohnehin zu spät““.

Während so einerseits Animositäten von dem Minderjährigen gegen seine Eltern ausgehen können, kann die strafrechtliche Verfolgung auch dazu führen, daß Eltern sich ihren Kindern anstatt mehr um so weniger zuwenden, indem sie den Kindern ihrerseits Vorwürfe machen. Und zwar Vorwürfe, die nicht die von den Kindern begangenen Taten betreffen, sondern allein den Umstand, daß diese ihre Eltern in die Sache „hineingezogen“ haben (,Du machst uns Schande“). Es ist dabei auch nicht unbedingt $\mathrm{zu}$ erwarten, daß die Eltern berücksichtigen, daß sie strafrechtliche Konsequenzen allein wegen ihres eigenen Fehlverhaltens zu erwarten haben.

Immerhin hat man aus genau diesem Grund im Rahmen der Beratungen zum Jugendschutzgesetz nur eine Strafbarkeit von solchen Personen eingeführt, die nicht Erziehungsberechtigte sind (vgl. § $12 \mathrm{JÖSchG}^{1043}$ ),

${ }^{1043} \S 12 \mathrm{JÖSch} G$

Abs. 1: Ordnungswidrig handelt, wer als Veranstalter oder Gewerbetreibender vorsätzlich oder fahrlässig

1. entgegen $\S 3$ einem Kind oder Jugendlichen den Aufenthalt in einer Gaststätte gestattet,

2. entgegen $\S 4$ Abs. 1 ein alkoholisches Getränk oder Lebensmittel an ein Kind oder Jugendlichen abgibt oder ihm den Verzehr gestattet ,...

5. entgegen $\S 6$ Abs. 1 oder 4 einem Kind oder Jugendlichen die Anwesenheit bei einer öffentlichen Filmveranstaltung gestattet, .... 
weil man die Anwendung strafrechtlichen Zwangs aus pädagogischen Gründen ablehnte ${ }^{1044}$. Freilich erscheint das Argument, auf einen strafrechtlichen Zwang gegenüber den Erziehungsverpflichteten verzichten zu wollen, angesichts $\S 171$ StGB nicht eben überzeugend. Denn indem man bei der Schaffung von $\S 12$ JÖSchG auf eine Überarbeitung des $\S 170 \mathrm{~d}$ StGB a.F. verzichtete, setzte man sich in Widerspruch zu der Behauptung, gegen den Erziehungspflichtigen keine strafrechtlichen Mittel anwenden zu wollen. In $\S 171$ tritt nämlich jene für $\S 12$ JÖSchG angeblich ungewünschte Rechtsfolge ein, daß der Erziehungsberechtigte mit dem Strafrecht konfrontiert wird. $§ 12$ JÖSchG könnte dennoch ein Richtmaß dafür werden, nur Außenstehende strafrechtlich $\mathrm{zu}$ belangen, weil dann Folgen auf emotionaler bzw. pädagogischer Ebene zwischen dem Kind/ Jugendlichem und dem Bestraften nicht zu befürchten wären.

Ein weiteres Problem für die zwischenmenschlichen Beziehungen stellt es dar, daß sich wohl in den wenigsten Fällen die Vernehmung des Abkömmlings im Verfahren vermeiden lassen wird ${ }^{1045}$. Hier wird sich das Kind oder der Jugendliche nur mit dem Gebrauchmachen seines Zeugnisverweigerungsrechts gem. § 52 Abs. 1 Nr. 3, Abs. 2 StPO aus der persönlich sehr belastenden Situation befreien können. Denkbar ist, sofern vom Zeugnisverweigerungsrecht kein Gebrauch gemacht wird, das Geltendmachen des Auskunftsverweigerungsrecht nach $\S 55$ StPO. Danach darf der Zeuge die Auskunft auf solche Fragen verweigern, deren Beantwortung ihn selbst oder einen engen Angehörigen der Gefahr der Strafverfolgung aussetzen würden. In der vorliegenden Fallgruppe kommt das Auskunftsverweigerungsrecht gleich zweimal zum Tragen: Zum einen müßte das Kind oder der Jugendliche als Zeuge im Verfahren wegen $\S 171$ oder wegen unechten Unterlassens in erster Linie zu der von ihm begangenen (Straf-) Tat befragt werden und könnte aus diesem

Abs. 4: Mit Freiheitsstrafe bis zu einem Jahr oder mit Geldstrafe wird bestraft, wer als Veranstalter oder Gewerbetreibender

1. eine in Absatz 1 bezeichnete vorsätzliche Zuwiderhandlung begeht und dadurch wenigstens leichtfertig ein Kind oder einen Jugendlichen in seiner körperlichen, geistigen oder sittlichen Entwicklung schwer gefährdet, ...

1044 Vgl. Becker, NJW 52, 1082 (1082).

1045 Becker, NJW 52, 1082 (1082). 
Grunde die meisten Auskünfte schon verweigern. Zum anderen braucht der Jugendliche solche Fragen nicht zu beantworten, die seine Eltern belasten könnten, was den übrigen Teil der Fragen ausmachen dürfte. Faktisch kommt hier das Auskunftsverweigerungsrecht nach $\S 55$ StPO einem kompletten Aussageverweigerungsrecht gleich.

Daß Staatsanwaltschaften und Gerichte zugunsten der Eltern von der Verfahrensbeendigung nach $\S \S 153 \mathrm{ff}$. StPO nur deshalb Gebrauch machen ${ }^{1046}$, um dem Kind auf diese Weise die Vernehmung gegen seine Eltern zu ersparen, ist daher nicht erforderlich. Eine frühzeitige Einstellung erspart es dem Kind oder Jugendlichen allerdings, zunächst als Zeuge ins Verfahren miteinbezogen zu werden und eine Entscheidung darüber treffen $\mathrm{zu}$ müssen, ob vom Zeugnisverweigerungsrecht etc. Gebrauch gemacht werden soll.

Der Umstand, daß das Kind zunächst als möglicher Zeuge Teil des Verfahrens wird, sollte jedoch nicht als „Makel“ für das Verfahren aufgefaßt werden, sondern als Chance, denn nur so kann sich überhaupt erst die Möglichkeit eröffnen, im Rahmen einer Hauptverhandlung Licht in die familiären Defizite zu bringen.

Im Hinblick auf die Aussageverweigerungsrechte könnte man darüber nachdenken, ob das Kind, das hier nur deshalb als Zeuge in Frage kommt, weil es selbst eine (Straf-) Tat begangen hat, den gleichen verfahrensrechtlichen Schutz genießen darf wie etwa ein mißhandeltes Kind, das deshalb zum Zeugen wird, weil es Opfer seiner Eltern geworden ist. Im ersten Fall ist das Kind selbst „Täter“ geworden, indem es einen Dritten, das unmittelbare Opfer, geschädigt hat; zugleich ist es selbst „Opfer“ des Unterlassens seiner Eltern aus $§ 171$. Im zweiten Fall ist das Kind hingegen nur Opfer.

Die Eigenschaft als Zeuge und die damit verbundenen Rechte gelten jedoch unabhängig davon, ob der Zeuge ein Opfer, ein an der Tat Beteiligter oder sowohl Täter als Opfer in einer Person ist. An dem unzumutbaren inneren Konflikt, der durch eine Aussage gegen eigene Angehörige entsteht und der durch das Zeugnisverweigerungsrecht vermieden werden soll, ändert sich nichts dadurch, daß der kindliche Zeuge selbst delinquent geworden ist. Schließlich steht dem delinquenten

${ }^{1046}$ BGH NStZ 95, 178 (178). 
Kind in einem Verfahren gegen es selbst ein vollständiges Aussageverweigerungsrecht $\mathrm{zu}, \mathrm{da} ß$ bei einer Aufweichung des Zeugnisverweigerungsrechts zunichte gemacht würde.

Es wird teilweise befürchtet, daß es durch eine strafrechtlichen Bewehrung der Erziehungs- und Aufsichtspflichten zu einer öffentlichen Brandmarkung und Diskriminierung der Erziehungsberechtigten kommen werde ${ }^{1047}$, die ihrerseits einen weiteren Autoritätsverlust gegenüber ihren Kindern zur Folge hätte. Dies ist wohl zu dramatisch dargestellt. Eine gesellschaftliche Ächtung der Eltern ist nicht zu befürchten. Die Bestrafung von Eltern wird zumeist gar nicht an die Öffentlichkeit dringen, da im Zweifel die Verhandlung wegen der Vernehmung des Kindes gemäß § 172 Nr. 4 GVG (Vernehmung einer Person unter 16 Jahren) einen nicht-öffentlichen Charakter hat ${ }^{1048}$. Es ist daher nicht zu erwarten, daß die Verurteilung der Allgemeinheit bekannt wird, außer, das Kind oder der Jugendliche sorgt selbst dafür- dann aber ist der Autoritätsverlust schon vor der Verurteilung gegeben und ist nicht erst durch sie hervorgerufen.

Hellmuth Mayer hat betont, daß die gefährdete Familie nicht durch Sanktionen zerstört, sondern vielmehr aufgebaut werden müsse. Dies könne aber dann nicht geschehen, wenn man die Eltern wegen der Verwahrlosung ihrer Kinder ins Gefängnis stecke. Bedenke man, daß die moderne Fürsorgeerziehung die Verbindung zwischen Eltern und Kindern pflege und bestrebt sei, über ihre Leistungen das Vertrauen der Eltern zu gewinnen und so auch die Familien wieder einigermaßen zu sanieren, werde deutlich, wie verfehlt hier jedes repressive Eingreifen sei $^{1049}$. Nach der von Luther vertretenen Ansicht kann $\S 171$ nur sinnvoll angewendet werden, wenn die Strafe die ultima ratio bleibe. Er meint, daß man vom Opportunitätsprinzip großzügig Gebrauch machen müsse, weil eine geschickte Belehrung und Verwarnung mitunter größeren Nutzen stiften werde als eine Bestrafung. Nur dann, wenn Eltern und

\footnotetext{
1047 so aber Becker, NJW 52, 1082 (1082).

1048 Vgl. Bussmann, S. 236, der darauf hinweist, daß die Öffentlichkeit mit Ausnahme von Berichten über spektakuläre Fälle in den Massenmedien von den einzelnen Gerichtsverfahren keine Notiz nimmt.

1049 Mayer, Strafrechtsreform, S. 101.
} 
Erziehungsberechtigte verantwortungslos und böswillig ihre Pflichten vernachlässigten, solle die Strafverfolgung durchgeführt werden ${ }^{1050}$.

Ist es jedoch sinnvoll, eine Strafnorm aufzustellen, bei der man sich alle nur erdenkliche Mühe gibt, sie nicht anwenden zu müssen ? Sollte man in einem solchen Fall nicht konsequenterweise ganz auf eine Strafsanktion verzichten und statt dessen andere Maßnahmen ergreifen ? Nagler hat im Jahre 1911 folgende Mahnung ausgesprochen: „,Wo immer der Staat sich als ungeeignete Instanz erkennt, wird er sich ruhig dessen bescheiden und die Arbeit anderen Faktoren überlassen. Er wird ihnen nach Kräften helfend zur Seite stehen, aber er wird alles vermeiden, was die pedantische Reglementierung und die Fuchtel der Bureaukratie wieder in drohende Nähe rücken könnte“. Er weist darauf hin, daß man nicht Gesellschaft und Staat miteinander verwechseln dürfe ${ }^{1051}$. Daß der Staat für die letzten Feinheiten des sozialen Lebens sozusagen „, viel zu plumpe Finger" habe, kann pauschal nicht behauptet werden ${ }^{1052}$. Nach den eigenen Erfahrungen der Verfasserin mit vielen Richtern und Staatsanwälten, die ernsthaft bemüht waren, auf Einzelschicksale einzugehen und die Ursachen anzugehen, sind die Finger des Staates auch nicht plumper als jene von Hilfsorganisationen, die anstelle des Staates einspringen oder einspringen müssen.

Inwieweit der Staat auf das Strafrecht im familiären Bereich verzichten und sich statt dessen anderer Mittel bedienen kann, wird später noch zu untersuchen sein.

III. Bestrafung als kontraproduktiver Mechanismus

Ein weiteres Argument gegen $\S 171$ ist, daß es den Eltern durch eine Bestrafung unter Umständen erschwert wird, Hilfe zu suchen. Denn sobald Eltern sich an eine entsprechende Erziehungsstelle wenden, käme dies dem Eingeständnis gleich, das eigene Kind nicht mehr im Griff zu haben und sich somit der Begehung des $§ 171$ verdächtig gemacht zu haben.

${ }^{1050}$ Becker, NJW 52, 1082 (1082).

${ }^{1051}$ Nagler, Verbrechensprophylaxe, S. 119. 
Fraglich ist, wie dieses Dilemma umgangen werden kann. Denkbar ist zunächst, daß die Verwirklichung von Tatbestandsmerkmalen durch das freiwillige Aufsuchen einer Hilfseinrichtung gehemmt wird. Man mag dazu mit Recht anführen, daß Eltern, die sich aus eigenem Antrieb zu einer Fürsorgestelle begeben, ihrer Fürsorge- und Erziehungspflicht ja gerade nachkommen. Das Erkennen der eigenen Erziehungsdefizite für die Vergangenheit führt jedoch noch nicht automatisch dazu, daß die bereits erfüllten Tatbestandsmerkmale entfallen. Eltern, die zuvor ihre Fürsorge- und Erziehungspflichten verletzt und den Schutzbefohlenen in die Gefahr der psychischen Entwicklungsschädigung gebracht haben, können dies - jedenfalls materiellrechtlich - nach bestehender Rechtslage nicht wieder ungeschehen machen. § 171 StGB enthält keine Regelung, die ein solches Verhalten der Eltern privilegieren würde. Eine „tätige Reue“ gibt es nicht. Das Aufsuchen einer Erziehungsstelle kommt also einer Selbstanzeige der Eltern gleich, die für diese nach der aktuellen Gesetzeslage keine entlastende Wirkung hat. Denkbar sind einzig Verfahrenseinstellungen nach $\S \S 153 f$. StPO- eine dogmatisch sehr unbefriedigende Lösung ${ }^{1053}$.

VI. Keine Anwendung der bestehenden Strafnormen durch die Justiz

Zweifelhaft erscheint eine elterliche Strafbarkeit auch aufgrund der fehlenden Anwendung in der Praxis. Sowohl das unechte Unterlassungsdelikt als auch $\S 171$ StGB führen ein absolutes Schattendasein. Während sich das seltene Auftreten des unechten Unterlassungsdelikts damit erklären läßt, daß es zumeist an der unmittelbaren Verhinderungsmöglichkeit durch die Eltern fehlen dürfte, genügt eine solche Begründung für $\S 171$ nicht; es kommen allenfalls

\footnotetext{
1052 so jedoch Nagler, Verbrechensprophylaxe, S. 118.

${ }^{1053}$ Auch soziologisch ist dies problematisch. Bussmann, S. 169, weist darauf hin, daß die fehlende soziale Kontrolle der Familie z. T. darauf zurückzuführen sei, daß durch das Legalitätsprinzip Eltern und letztlich die gesamte Familie einer strafrechtlichen Verfolgung ausgesetzt würden; die latente Drohung einer strafrechtlichen Verfolgung könne dazu führen, daß eine Kommunikation mit staatlichen Einrichtungen unterbleibt.
} 
prozessuale Schwierigkeiten in Betracht ${ }^{1054}$. Fest steht, daß eine Anwendung durch die Strafverfolgungsorgane kaum stattfindet, so daß der $\S 171$ in der Praxis gescheitert zu sein scheint. Die verschwindend geringe Anzahl von veröffentlichten Entscheidungen (insgesamt drei Urteile) verdeutlicht dies; dabei ist $\mathrm{zu}$ bemerken, daß zwischen den beiden letzten veröffentlichten Entscheidungen eine Lücke von 47 Jahren klafft. Diese größtenteils auch bei Praktikern unbekannte Strafnorm ${ }^{1055}$ kann daher auch kaum den Anspruch erheben, die Prävention voranzutreiben.

V. Fehlende Akzeptanz in der Gesellschaft

Gegen eine sinnvolle Prävention durch gegen Eltern gerichtete Strafbestimmungen kann weiter sprechen, daß es in der Gesellschaft kein Bewußtsein darüber gibt, daß das Nichtabhalten des Kindes von Straftaten auch den Erziehungspflichtigen selbst der Gefahr der Strafverfolgung aussetzt. Trotz der seit Beginn der Bundesrepublik bestehenden Strafvorschriften, die diesem Ziel dienen sollten, kann von einer gesellschaftlichen Vorstellung, daß Passivität in Erziehung und Aufsicht strafbar sein kann, nicht gesprochen werden. Dabei geht es nicht um die Kenntnis des Wortlautes der Strafnormen, sondern um das Bewußtsein, daß Erziehungspflichtige durch mangelnde Aufsicht selbst eine Straftat begehen könnten ${ }^{1056}$.

Zwar kann man vermuten, daß sich auch die Eltern, deren Sprößlinge regelmäßig bei Straftaten aufgegriffen werden, grundsätzlich ihrer Pflicht bewußt sind, gegen das Treiben ihrer Kinder vorzugehen. Zweifelhaft ist jedoch, ob sie diese Pflicht als eine strafrechtlich bewehrte begreifen. Typischerweise wird das Jugendamt als die staatliche Institution gesehen, die dafür die Sanktion verhängt. Daß sich auch strafrechtliche

\footnotetext{
1054 Dazu siehe unten Teil $7 \mathrm{~V}$.

1055 So auch Ostendorf, S. 11

${ }^{1056}$ Vgl. Bussmann, S. 192 m. w. N. Das ist wohl auch darauf zurückzuführen, daß Rechtskenntnisse im Zusammenleben zwischen Eltern und Kindern häufig als unwichtig eingestuft werden (von rund $40 \%$ der bei Bussmann Befragten. Dagegen waren beim
} 
Konsequenzen für sie selbst ergeben könnten, ist den Eltern zumeist unbekannt.

Allein die fehlende Publizität kann jedoch kein Argument gegen den Sinn einer Strafvorschrift sein. Es ist vielmehr genau an diesem wunden Punkt anzusetzen und den Erziehungsverpflichteten zu vermitteln, daß sie eine - auch strafrechtlich bewehrte - Verantwortung tragen, deren Ausübung vom Staat auch kontrolliert wird. $\mathrm{Zu}$ berücksichtigen ist allerdings, daß ein Grund für die fehlende Bekanntheit der Vorschriften in der Gesellschaft darin liegen kann, daß eine Strafbarkeit von der Gesellschaft nicht erwartet oder nicht besonders gewünscht wird. Eine Ablehnung einer Strafbarkeit auch durch „Nicht-Betroffene“ mag darauf zurückzuführen, daß mit der Straftatverhinderungspflicht auch immer die Notwendigkeit der Anzeige und damit des Denunziantentums in Verbindung gebracht wird ${ }^{1057}$.

\section{Schwierigkeiten im Strafverfahren}

Das Verfahren, in dem Kinder gegen ihre Eltern und Eltern gegen ihre Kinder aussagen, muß die ermittelnden Behörden vor immense Schwierigkeiten stellen.

Bereits beim Verfahren gegen den Minderjährigen allein ergeben sich Probleme, da seine Aussagen bereits in diesem Stadium die Eltern belasten können ${ }^{1058}$. $\mathrm{Zu}$ denken ist daran, daß die Kinder oder Jugendlichen, indem sie die Hintergründe ihrer Tat beschreiben, in ihrer Vernehmung - auch unwissentlich - ihre Eltern der Verfolgung aussetzen. Dabei mag man einwenden, daß zumindest gegen ein Kind ein Ermittlungsverfahren gar nicht in Frage kommt. Es sind jedoch immer Fälle denkbar, in denen im Vorstadium eines Ermittlungsverfahrens zwar Anhaltspunkte für eine Straftat vorhanden sind, sich der Tatverdacht aber noch nicht gegen eine bestimmte Person richtet und somit eine informelle

Umgang mit Behörden (2,6 \%) und mit Handwerkern bzw. beim Kauf (5,5 \%) deutlich Befragte weniger dieser Ansicht).

1057 Vgl. zur Akzeptanz von § 138: Westendorf, S. 26.

1058 zum Verfahrensablauf im einzelnen Frehsee, ZStW 100 (1988), 290 (293 f.); Kintzi, DriZ97, 32 (32ff.). 
Befragung durchgeführt wird, von der auch ein Kind betroffen sein kann $^{1059}$. Die Etikettierung der Befragung als Anhörung hat unter Umständen nachteilige Konsequenzen, weil dem Befragten die normalerweise zwingend vorgeschriebenen Schutzrechte vorenthalten werden (Belehrung gem. $\S 136$ Abs. 1 und $\S 163$ a Abs. 4 StPO) ${ }^{1060}$. Die Eltern können zwar in Ausübung der Personensorge gem. $§ 1626$ Abs. 1 BGB die Befragung verbieten, soweit das Kind in der Gefahr ist, sich selbst zu belasten. Das setzt aber voraus, daß die Eltern sich überhaupt darum kümmern oder greifbar sind ${ }^{1061}$. Wird das Kind hingegen nicht wegen eigener Taten, sondern im Rahmen von Ermittlungen gegen seine Eltern befragt, ist sehr fraglich, ob die Eltern eine Möglichkeit haben, das Kind an der Aussage zu hindern, wenn das Kind nicht von seinem Zeugnisverweigerungsrecht Gebrauch machen will. Gegen die Aussage läßt sich, trotz der negativen Folgen für das Eltern- Kind-Verhältnis, nichts einwenden. Bei einem Kind, das Opfer familiärer Gewalt geworden ist, würde niemand fordern, daß das Kind zugunsten des Familienzusammenhalts schweigen solle. Ein solches Schweigen kann man zumindest in den Fällen des $\S 171$ StGB ebensowenig von einem vernachlässigten und verwahrlosten Kind verlangen. Denn letztlich können Kinder und Jugendliche, die von ihren Eltern so stark vernachlässigt worden sind, daß sie einen kriminellen Lebensweg eingeschlagen haben, auch als Opfer ihrer Eltern betrachtet werden.

Auch werden bereits durch alle Ermittlungsmaßnahmen gegen den delinquenten Jugendlichen die Eltern indirekt mitbetroffen, etwa durch die Durchsuchung der Wohnung nach $\S 102$ StPO, die gegen den Jugendlichen möglich ist, auch wenn die Eltern Mitinhaber des Hausrechts sind ${ }^{1062}$.

Wird die Aufnahme von Ermittlungen für nötig gehalten, um eine eventuelle Strafbarkeit der Eltern wegen Verletzung der Aufsichtspflicht nach $\S 171 \mathrm{zu}$ prüfen, ist eine informatorische Befragung entgegen der Ansicht Frehsees keinesfalls immer anstößig. Allerdings muß in diesem

\footnotetext{
${ }^{1059}$ Frehsee, ZStW 100 (290 (297).

${ }^{1060}$ Frehsee, ZStW 100 (1988), 290 (298).

${ }^{1061}$ Frehsee, ZStW 100 (1988), 290 (298) weist auf die Gefahr eines polizeilichen Mißbrauchs hin.

1062 BGH NStZ 86,84 f.; Benfer, Rn. 389.
} 
Fall eine Zeugenbelehrung des Kindes nach $§ 57$ StPO erfolgen und seine Aussagebereitschaft im Hinblick auf die mögliche Bestrafung der Eltern festgestellt werden, ggf. muß ein Pfleger bestellt werden ${ }^{1063}$.

Gem. $§ 52$ Abs. 2 S. 1 StPO dürfen Minderjährige, die wegen mangelnder Verstandesreife von der Bedeutung des Zeugnisverweigerungsrechtes keine genügende Vorstellung haben, nur vernommen werden, wenn sie zur Aussage bereit sind und ihr gesetzlicher Vertreter, im Regelfall also ein Elternteil, zugestimmt hat, $\S$ 52 Abs. 2, 2. Halbsatz bestimmt, daß der gesetzliche Vertreter von dieser Entscheidung ausgeschlossen ist, soweit es um ein gegen ihn selbst geführtes Verfahren geht ${ }^{1064}$.

Das Zeugnisverweigerungsrecht des Kindes oder Jugendlichen verhindert unter Umständen eine weitere Aufklärung des Falles. Macht der Minderjährige zu den Vorgängen in der Familie keine Angaben, ist eine Einschätzung, wie die Eltern sich verhalten haben, kaum möglich. Wenn sowohl Eltern als auch Kinder schweigen, bleibt somit prozessual keine Möglichkeit, die tatsächlichen Vorgänge ans Licht $\mathrm{zu}$ bringen ${ }^{1065}$. Insoweit wird man auf außenstehende Zeugen angewiesen sein, die jedoch nur bedingt Einblick in die innerfamiliären Vorgänge haben dürften.

VII. Zweifel hinsichtlich der präventiven Wirkung einer Strafbarkeit

Ausgangspunkt der Überlegungen dieser Arbeit war, ob das Strafrecht auch im Rahmen der Kinder- und Jugenddelinquenz immer ,zu spät kommen“ muß oder ob durch eine Strafandrohung für die Eltern eine bessere Aufsicht der Kinder ermöglicht und deren kriminelles Verhalten von vornherein unterbunden werden kann.

Nach den eben angeführten Problemen stellt sich beinahe fast von selbst die Frage, ob insbesondere eine Vorschrift wie $§ 171$ nicht mehr Schaden anrichtet als sie Nutzen bringt. Es spricht, wie eben gesehen, einiges

\footnotetext{
${ }^{1063}$ Frehsee, ZStW 100 (1988), 290 (309).

${ }^{1064}$ Kintzi, DriZ 97, 32 (34f.); zu den Einzelheiten, wenn nur einer der beiden Elternteile beschuldigt ist, siehe Brückner, S. 118.

${ }^{1065}$ Kritisch dazu Kintzi, Driz 97, 32 (34).
} 
dafür, daß sich die Situation des Kindes durch Bestrafung des pflichtvergessenen Elternteils eher verschlechtert ${ }^{1066}$. Der Sinn der Norm liegt darin, das Verantwortungsbewußtsein der Erwachsenen gegenüber den ihrer Erziehung anvertrauten Kindern und Jugendlichen zu wecken. Glaubwürdige Kriminalpolitik mißt sich aber am Maß des Erreichbaren ${ }^{1067}$. Kann $\S 171$ aufgrund des Charakters als Strafnorm überhaupt erreichen, was er bezweckt oder ist per se das gewünschte Ziel gar nicht mit dem Strafrecht zu verwirklichen?

Zwar gibt es Zweifel, ob dem Recht, insbesondere dem Strafrecht, eine verhaltensbeeinflussende Wirkung zukommt ${ }^{1068}$. Immerhin haben Studien nachweisen können, daß die Normkenntnis und die Billigung der Norm einen gewissen positiven Einfluß auf das Verhalten aufweisen. Bussmann stellt fest, daß Recht tatsächlich einen Effekt auf das Denken der Adressaten hat. Die normativen Interpretationen von Eltern über ihre Rechte hängen eng mit ihrer Interpretation rechtlicher Werte insgesamt zusammen. Bussmann kommt abschließend zum Ergebnis, daß Recht über einen hohen Aufmerksamkeits- und Orientierungswert verfügt und den Adressaten keinesfalls gleichgültig ist ${ }^{1069}$. Es zeigt sich daher, daß nicht bereits aus diesem Grund schon von einer Strafbarkeit Abstand genommen werden sollte.

Inwieweit Strafrecht hier allerdings Sinn macht bzw. inwieweit nicht besser auf andere rechtliche Möglichkeiten zurückgegriffen werden sollte, ist im Folgenden zu untersuchen.

D. Außerstrafrechtliche Maßnahmen

1066 Francke-Gricksch, S. 131. Dies kann nur vermutet werden, weil darüber - schon mangels Anwendung der Vorschrift - keine Untersuchungen vorliegen

1067 AE 1968, S. 125.

1068 Bussmann, S. 219 m. w. N.; hinsichtlich familiärer Gewalt siehe Ursula Schneider, Gewaltanwendung in der Familie, S. 194f.

1069 Bussmann, S. 242. 
Das Strafrecht stellt nur eine von vielen Möglichkeiten dar, auf elterliche Ignoranz hinsichtlich der Erziehungs- und Aufsichtspflichten zu reagieren. Das Ordnungsrecht, das Familien- und Deliktsrecht des BGB sowie das Kinder- und Jugendhilfegesetz bieten zahlreiche Optionen, um auf auffällige Kinder und auf Erwachsene, die diese unter Mißbrauch ihres Erziehungsrechts negativ beeinflussen, einzuwirken. Im Rechtsstaat ist das Strafrecht nicht Allheilmittel, sondern ultima ratio ${ }^{1070}$.

Bereits im Rahmen der Beratungen zum Jugendschutzgesetz hat man gemeint, daß das Erziehungsrecht eine $\mathrm{zu}$ hohe, sittlich fundierte Aufgabe sei, als daß sie durch strafrechtliche Bestimmungen gesichert werden könnte ${ }^{1071}$.

I. Verfassungsmäßige Pflichten hinsichtlich des Einsatzes von Strafe

Es stellen sich zwei einander ausschließende Fragen: Zum einen ist zu erörtern, ob eine verfassungsrechtliche Verpflichtung des Staates zur Strafe besteht. Ist das nicht der Fall, stellt sich von der anderen Seite her die Frage, inwieweit der Staat überhaupt strafen darf, solange ihm andere rechtliche oder sonstige Mittel zur Verfügung stehen.

In bestimmten Fällen kommt dem Gesetzgeber die Pflicht zur Strafe zu, um Schaden von Rechtsgütern abzuwenden. Es dürfte heute allgemein anerkannt sein, daß aus Grundrechten Pflichten des Staates herzuleiten sind, das in der Verfassungsnorm benannte Rechtsgut aktiv gegen Drohungen von Dritter Seite zu schützen. Solche Bedrohungen mögen von anderen Menschen kommen, sie können aber auch Ursachen in Naturvorgängen haben ${ }^{1072}$.

Möglicherweise darf der Staat in der vorliegenden Problematik nicht aus falsch verstandener Rücksicht gegenüber den Interessen der Eltern und deren Kinder den Schutz von wichtigen Rechtsgütern Dritter nur deshalb in Frage stellen, um die Familienbande nicht $\mathrm{zu}$ beeinträchtigen. $\mathrm{Zu}$ fragen ist, ob sich unerträgliche Strafbarkeitslücken auftun, wenn man die Eltern strafrechtlich nicht zur Verantwortung für die Handlungen

\footnotetext{
${ }^{1070}$ Neubacher, ZRP 98, 121 (123).

${ }^{1071}$ Becker, NJW 52, 1082 (1082).
} 
ihrer Kinder ziehen kann. Immerhin ist die Begehung fast jeder beliebigen schweren Straftat auch durch Kinder und Jugendliche möglich. Es geht nicht nur um zweitrangige Rechtsgüter, wie sie durch Ladendiebstähle oder kleinere Sachbeschädigungen beeinträchtigt werden, sondern auch um massive Körperverletzungs- oder gar Tötungsdelikte.

Zum Schutz von sich entwickelndem menschlichen Leben hat das BVerfG bereits im Jahre 1975 den Einsatz des Strafrechts grundsätzlich als zulässig erachtet, aber die Verpflichtung des Staates, Strafen auszusprechen, an besondere Bedingungen geknüpft ${ }^{1073}$. Aufgabe des Strafrechts sei es von jeher, die elementaren Werte des Gemeinschaftslebens zu schützen. Strafe könne jedoch nie Selbstzweck sein. Erst im äußersten Fall, wenn nämlich der von der Verfassung gebotene Schutz auf keine andere Weise zu erreichen sei, könne der Gesetzgeber verpflichtet sein, zum Schutze des sich entwickelnden Lebens das als ultima ratio Mittel des Strafrechts einzusetzen ${ }^{1074}$. Die strafrechtliche Schutzpflicht des Gesetzgebers besteht nur für besonders hochrangige Güter, die auch in der verfassungsrechtlichen Hierarchie der Grundrechte obenan stehen. Dazu gehören Delikte gegen das menschliche Leben, schwere Körperverletzungsdelikte sowohl gewaltsam herbeigeführte Verletzungen von Freiheit und Eigentum ${ }^{1075}$.

Von diesen Grundsätzen ist das Bundesverfassungsgericht auch in seiner Entscheidung von 1993 nicht abgewichen. Danach stellt das staatliche Strafen jenseits des Art. 26 Abs. 1 GG (Störung des friedlichen Zusammenlebens der Völker) ${ }^{1076}$ nach verfassungsrechtlichen Maßstäben zwar ein mögliches, keineswegs aber ein rechtlich zwingendes Mittel dar. Lediglich in den überaus seltenen Fällen einer denkbaren Reduzierung des gesetzgeberischen Ermessens auf Null kann in besonderen Fällen die

\footnotetext{
1072 Robbers, S. 150.

${ }^{1073}$ BVerfGE 39, 1 (44ff.); Marxen, S. 50.

1074 Robbers, S. 152.

${ }^{1075}$ Marxen, S. 55.

${ }^{1076}$ Art. 26 Abs. 1 GG: Handlungen, die geeignet sind und in der Absicht vorgenommen werden, das friedliche Zusammenleben der Völker zu stören, insbesondere die Führung eines Angriffskrieges vorzubereiten, sind verfassungswidrig. Sie sind unter Strafe zu stellen.
} 
Verpflichtung des Staates bestehen zu bestrafen ${ }^{1077}$. Die Pflicht aus Art. 26 Abs. 1, S. 2 GG, ein bestimmtes Verhalten unter Strafe zu stellen, gilt aber nur bei besonders schweren Straftaten, wie den $§ \S 211$ ff. StGB. Im übrigen ist es weitgehend Sache gesetzgeberischen Ermessens, ob der Gesetzgeber ein Rechtsgut strafrechtlich oder statt dessen mit Mitteln des Zivil- oder des Öffentlichen Rechts schützen will ${ }^{1078}$

Soweit Eltern als Unterlassungstäter schwere Straftaten gegen Leib und Leben von Menschen durch ihre Abkömmlinge nicht verhindern, könnte man daher wohl davon sprechen, daß das Grundgesetz den Gesetzgeber zur Festlegung einer Strafe verpflichtet; dieser Verpflichtung wäre der Gesetzgeber durch die Schaffung der unechten Unterlassungsdelikte auch bereits nachgekommen. Dabei geht es aber im Grunde schon gar nicht mehr um die Problematik, was gesetzlich von Eltern als Überwachergaranten gefordert werden darf oder muß. Es geht vielmehr um die Frage, wie schwer ein Delikt sein muß, daß es das friedliche Zusammenleben der Völker im Sinne von Art. 26 Abs. 1 GG gefährdet und der Gesetzgeber es unter Strafe stellen muß. Das gehört jedoch nicht $\mathrm{zu}$ der hier interessierenden Fragestellung. Bei der unterlassenen Deliktsverhinderung, die nur mittelschwere oder leichtere Straftaten betrifft, ist eine gesetzgeberische Pflicht zum Tätigwerden auf jeden Fall ausgeschlossen.

Sieht man von den Delikten der Eltern aus unechtem Unterlassen ab, so wird ihnen in $\S 171$ StGB der Mangel an Fürsorge und Erziehung vorgeworfen; auch dies kann, selbst unter schweren Umständen, keine Verpflichtung zur Schaffung - oder Beibehaltung - eines Straftatbestandes begründen.

Im Ergebnis ist festzuhalten, daß der Staat hier also keinesfalls verpflichtet ist, strafrechtlich gegen Eltern vorzugehen.

\section{Alternativen zur Strafbarkeit}

\footnotetext{
1077 Robbers, S. $152 f$.

${ }^{1078}$ Roxin, AT, § 2, Rn. 36; Robbers, S. 148.
} 


\section{1. $§ 1666 \mathrm{BGB}$}

Möglicherweise genügt zur Stärkung der elterlichen Fürsorge und Erziehung bereits die zivilrechtlichen Bestimmung des $\S \S 1666$ BGB $^{1079}$.

\section{$\S 1666$ Abs. 1. BGB. Gefährdung des Kindeswohls}

„Wird das körperliche, geistige oder seelische Wohl des Kindes oder sein Vermögen durch mißbräuchliche Ausübung der elterlichen Sorge, durch Vernachlässigung des Kindes, durch unverschuldetes Versagen der Eltern oder durch das Verhalten eines Dritten gefährdet, so hat das Familiengericht, wenn die Eltern nicht gewillt oder nicht in der Lage sind, die Gefahr abzuwenden, die zur Abwendung der Gefahr erforderlichen Maßnahmen zu treffen. “

$\S 1666$ BGB geht in seinen Möglichkeiten, amtliches Einschreiten zuzulassen, wesentlich weiter als das StGB. Das Erziehungsunvermögen der betroffenen Eltern als Anknüpfungspunkt für familienrichterliche Maßnahmen kann sich in vier Varianten äußern: Neben den beiden klassischen Fällen des Sorgerechtsmißbrauchs und der Vernachlässigung können auch unverschuldetes Versagen und die Gefährdung des Kindeswohls durch das Verhalten Dritter zu Maßnahmen führen. Ein schuldhaftes Verhalten der Eltern ist also, anders als bei $\S 171$ StGB, nicht notwendig.

Auch die Schwelle, bei der ein Eingreifen als erforderlich erachtet wird, liegt niedriger als die des $\S 171$ StGB. So liegt ein Sorgerechtsmißbrauch schon bei unnötigem schroffen Wechsel in der Erziehung, Trennung oder Abhalten des Kindes von einem Elternteil, Fernhalten von den Großeltern, Abhalten von Impfungen, Schulbesuch, Hineinzwingen in einen ungeeigneten Beruf, also bereits bei geringen, nicht erst bei gröblichen Verstößen $\operatorname{vor}^{1080}$. § 1666 BGB ist als ,zivilrechtliche

${ }^{1079}$ Dieser Ansicht war man jedenfalls schon bei der Abschaffung des $\S 143$ a.F., vgl. BT-Drucks. 1970, VI, 1552.

${ }^{1080}$ Francke-Gricksch, S. 124; Palandt-Diederichsen, § 1666, Rn. 21 ff. m.w.N. 
Strafnorm“ für pflichtwidriges Verhalten der Eltern daher schärfer als $\S 171 \mathrm{StGB}^{1081}$.

Das Eingreifen des Familiengerichts hängt schließlich davon ab, ob die Eltern entweder nicht gewillt oder nicht in der Lage sind, die Gefahr abzuwenden. Dabei stehen der vom besten Willen getragenen Hilflosigkeit der Eltern deren Unwillen, ihrer fehlenden Einsicht oder bloßen Gleichgültigkeit völlig gleich. Es spielt keine Rolle, ob sie in der Lage, aber unwillig, oder willig, aber nicht in der Lage sind ${ }^{1082}$.

Diejenigen Eltern, die durch zivilrechtliche Maßnahmen beeindruckbar sind, können nach den Regelungen der § 1631 und § 1666 BGB erreicht werden, ohne daß auf das Strafrecht zurückgegriffen werden muß. Zwar setzt das Zivilrecht $\mathrm{zu}$ einem frühen Zeitpunkt an und bietet sehr weitgehende Eingriffsmöglichkeiten, zugleich ermöglicht es aber auch, Hilfsangebote wahrzunehmen. Bei zugänglichen Eltern, die zwar gewillt, aber nicht in der Lage sind, die Gefahren von ihrem Kind abzuwenden, kann von dem Interesse ausgegangen werden, selbst Anträge i.S.d. $\S 1631$ Abs. 3 (Antrag auf Unterstützung bei der Ausübung der Personensorge) zu stellen und an einer Lösung mitzuwirken. Dem gegenüber benötigen erziehungsunwillige Eltern andere Formen der Indie-Pflichtnahme ${ }^{1083}$. Für sie stellen gerichtliche Maßnahmen einen Eingriff in ihr Privatleben dar, den sie als Sanktion empfinden und daher meist ablehnen.

Auch in der Hinsicht, daß es bei $\S 1666$ BGB nicht auf ein elterliches Verschulden ankommt, unterscheidet sich die strafrechtliche Vorgehensweise massiv von der zivilrechtlichen. Da es darum geht, den Gefahreintritt auf jeden Fall zu unterbinden, unabhängig vom eigentlicher Verursacher, ähnelt die Vorschrift dem Gefahrenabwehrrecht. § 1666 Abs. 1 BGB ist keine Strafnorm, sondern zielt in erster Linie darauf ab, die Gefahr für das Kindeswohl zu bannen. $\mathrm{Ob}$ das Verschulden irgendeiner Person zu der Gefahr geführt hat, ist nebensächlich bzw. nur soweit relevant, wie es zur Gefahrbeseitigung miteinbezogen werden muß.

\footnotetext{
${ }^{1081}$ Francke-Gricksch, S. 128.

1082 Palandt-Diederichsen, § 1666, Rn. 35.

${ }^{1083}$ Hyönck/Sonnen, ZRP 2001, 245 (247).
} 
Der Begriff des Kindeswohls führt zum eigentlichen Inhalt der Vorschrift. Die vormundschaftlichen Maßnahmen sind in erster Linie kindbezogen, auch wenn sie auf die Erziehungsverpflichteten einwirken sollen $^{1084}$. Die Eltern werden, was auch selbstverständlich ist, nicht in den Mittelpunkt der Behandlung gestellt. Es fehlt dadurch aber an der persönlichen Anknüpfung der Schuld. Dies ist im Strafrecht anders: Die gegenüber den Eltern ausgefällte Strafe hat sowohl repressive als auch präventive Wirkung. Die Strafe ist einerseits Vergeltung für ein strafbares Verhalten gegenüber den Rechtsgütern Dritter, andererseits sollen die Eltern durch die Strafe das begangene Unecht einsehen und von einer Wiederholung der Tat Abstand nehmen. Strafrechtliche Sanktionen sind insoweit täterbezogen ${ }^{1085}$. Der familienrechtlichen Alternative zur Strafe gelingt es also nicht, die Erziehungsberechtigten in den Mittelpunkt zu stellen, wie es als Ausgangspunkt für eine individuelle Einwirkung auf sie erforderlich und wünschenswert wäre.

Ein Gesetzesentwurf der CDU/CSU-Fraktion schlägt eine Ergänzung des $\S 1666$ BGB vor ${ }^{1086}$. Danach soll eine ausdrückliche Rechtsgrundlage für ein richterliches Erziehungsgespräch eingeführt werden sowie die Möglichkeit, den Eltern oder dem Inhaber der elterlichen Sorge die Weisung zu erteilen, Leistungen der Jugendhilfe in Anspruch zu nehmen oder die Befolgung von Weisungen durch das Kind mit den zumutbaren erzieherischen Mitteln herbeizuführen. Höynck und Sonnenberg halten es für überlegenswert, ob eine stärkere Nutzung der Ressource Familiengericht sinnvoll sein könnte. Die beiden Autoren ziehen es zunächst in Betracht, daß nicht kooperationsbereite Eltern hier beeindruckbar sind. Letztlich kommen sie aber zu dem Ergebnis, daß die Zielgruppe von Personen, die der genannte Entwurf im Auge hat, nämlich strafauffällige Kinder und deren Eltern, die nicht bereit sind, notwendige Hilfe zugunsten des Kindes zu beantragen oder zuzulassen, sich auch von den vorgeschlagenen Änderungen nicht beeindrucken lassen wird ${ }^{1087}$.

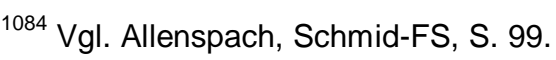

${ }^{1085}$ Allenspach, Schmid-FS, S. 99.

${ }^{1086}$ Vgl. Hyönck/Sonnen, ZRP 2001, 245 (246).

${ }^{1087}$ Hyönck/Sonnen, ZRP 2001, 245 (246f.).
} 
2. Kinder und Jugendhilfe, $\S § 27$ ff. SBG VIII

Als weitere Alternative stellen sich die Hilfsangebote aus dem Kinderund Jugendhilfegesetz (KJHG) im SBG VIII dar. Das KJHG vom 26.6.1990 ist das Ergebnis langjähriger Bemühungen zur Neuordnung der Rechtsgrundlagen der Kinder- und Jugendhilfe und trat an die Stelle des Jugendwohlfahrtsgesetzes (JWG) vom 11.8.1961 ${ }^{1088}$. Das KJHG geht von einem weiteren Verständnis von Jugendhilfe aus, indem es die Trennung der klassischen Teilfelder Jugendarbeit/ Jugendfürsorge überwindet. Es gehr nicht mehr um eine reaktive Aufrechterhaltung der öffentlichen Sicherheit und Ordnung, die Ausgrenzung verwahrloster Jugendlicher durch geschlossene Unterbringung und Arbeitserziehung oder die Rettung von Kindern vor dem gefährlichen Einfluß ihrer Eltern. Vielmehr ist nun zentrale Auftrag der Jugendhilfe, die Entwicklung junger Menschen und ihre Integration in die Gesellschaft zu fördern ${ }^{1089}$. Demzufolge steht nicht mehr der Eingriff des Staates in die elterliche Erziehungsverantwortung bei der Gefährdung des Kindeswohles (Art. 6 Abs.2 GG) im Vordergrund, sondern die Förderung und der präventive Schutz von Kindern und Jugendlichen gemäß Art. 2 Abs. $1 \mathrm{GG}^{1090}$.

Von den Regelungen ist zunächst die Erziehungsberatung gemäß $\S 28$ SGB VIII zu nennen. Erziehungsberatung ist ein wesentlicher Teil der Familienberatung, unter der die Partnerschafts-, Ehe-, Familien- und Lebensberatung ebenfalls gefaßt werden können. Erziehungsberatung wird für die Klärung und Bewältigung nicht nur individueller, sondern auch familienbezogener Probleme und der zugrunde liegenden Faktoren zur Lösung von Erziehungsfragen eingesetzt. Anlässe für die Inanspruchnahme können körperliche Auffälligkeiten, seelische Probleme, Verhaltensauffälligkeiten und Leistungsprobleme sein, wobei in der Regel mehrere dieser Probleme miteinander in Zusammenhang stehen. Die Erziehungsberatung wirkt zwar in unterschiedlichem Maße in die Privatsphäre der Familie hinein, übernimmt jedoch keine Funktion in

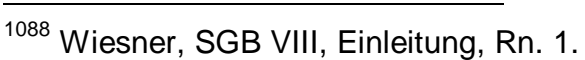

${ }^{1089}$ Wiesner, SGB VIII, Einleitung, Rn. 36f.

${ }^{1090}$ Wiesner, SGB VIII, Einleitung, Rn. 38.
} 
der Familie ${ }^{1091}$. Sie hat die Aufgabe, Kinder, aber gerade auch Eltern und Erziehungsberechtigte auf freiwilliger Basis bei der Bewältigung von individuellen und familienbezogenen Problemen $\mathrm{zu}$ helfen. Sie versteht sich dabei zugleich als begleitenden Hilfe zur Stärkung der Erziehungskraft der Familie ${ }^{1092}$.

Wingen weist darauf hin, daß der Anspruch der Eltern nach dem neuen KJHG auf Unterstützung beim Auf- und Erziehen von Kindern deutlich hervorgehoben wurde. Dies sei über die Fachöffentlichkeit kaum hinausgedrungen. Insbesondere $\S 16$ SGB VIII befaßt sich mit der Förderung der Erziehung in der Familie ${ }^{1093}$. Im Rahmen der Erziehungsberatung ist es auch möglich, Eltern zum Besuch von Kursen zu verpflichten ${ }^{1094}$.

Der nächststärkere Eingriff sowohl in das elterliche Erziehungsrecht als auch die Freiheit des Minderjährigen ist die Bestellung eines Erziehungsbeistandes nach $\S 30$ SGB VIII. Die Bestellung eines Erziehungsbeistandes durch das Jugendamt kommt dann in Frage, wenn die physische oder psychische Entwicklung gefährdet ist. Der Erziehungsbeistand unterstützt die Personensorgeberechtigten bei der Erziehung. Von entscheidender Bedeutung für den Erfolg der Erziehungsbeistandschaft ist die Bereitschaft der Personensorgeberechtigten zur Mitarbeit. Die Bereitschaft zur Mitarbeit wird man nur annehmen können, wenn die innerfamiliäre Lage nicht gänzlich verfahren ist, die Sorgeberechtigten von dem Kind noch als Vorbild angenommen werden können, die Sorgeberechtigten einsichtsfähig und nicht völlig erziehungsunfähig sind und sie das Kind nicht völlig ablehnen ${ }^{1095}$.

Darüber hinaus gehende Einschränkungen der elterlichen Sorge, wie das JWG sie bis vor kurzem kannte, vgl. $\S \S 62,63$, sind dem KJHG weitgehend fremd ${ }^{1096}$. Erziehungshilfen sind nur auf (freiwilligen) elterlichen Antrag möglich. Alle weiteren Maßnahmen werden gemäß

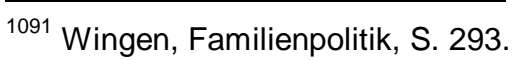

1092 Zu der Praxis vgl. Wingen, Familienpolitik, S. 294 ff.

${ }^{1093}$ Wingen, Familienpolitik, S. 298.

${ }^{1094}$ Wingen, Familienpolitik, S. 293.

1095 Neuhaus, Jura 90, 624 (628).

${ }^{1096}$ Zur früheren Rechtslage vergleiche Neuhaus, Jura 90, 624 (628).
} 
$\S \S 1666,1666 \mathrm{a}, 1671$ Abs. 5 BGB über das Familienrecht getroffen ${ }^{1097}$. Das führt dazu, daß aus dem KJHG bei fehlender Kooperation der Eltern keine weiteren Rechtsfolgen abgeleitet werden können.

\section{Sanktionierung von Eltern durch Schadensersatzansprüche ?}

In strafrechtlichen Verfahren wird oft das Strafmaß mit der Begründung gesenkt, daß der Täter durch die finanziellen Folgen der Tat (Schadensersatzansprüche) so beeinträchtigt ist, daß die Geldstrafe geringer ausfallen kann, vgl. $\$ 46$ Abs. 2 StGB. Die Schadensersatzpflichten dürften in den meisten Fällen, in denen Minderjährige Straftaten begehen, von den Eltern zu tragen sein. Die Eltern sehen sich also plötzlich in der Pflicht, für Sachbeschädigungen aufzukommen (z.B. die Reinigung einer durch Graffiti verunzierten Fassade), Schadensersatz- und Schmerzensgeldzahlungen an vom Jugendlichen Mißhandelte zu entrichten oder womöglich die Kosten für einen abgebrannten Bauernhof zu übernehmen, der durch das Zündeln des Kindes zerstört worden ist. In extremen Fällen wird man sicherlich sogar i.S.d. § 60 StGB sagen können, daß die Eltern durch zivilrechtliche Forderungen genug gestraft sind.

Die Drohung mit zivilrechtlichen Folgen läuft aber allzuoft leer, wenn die Eltern mittellos sind. Ansprüche auf Geldzahlungen können Eltern, insbesondere, wenn ohnehin eine finanziell desolate Situation vorliegt, nicht schrecken oder beeindrucken.

Hinzu kommt, daß es auch viele Delikte gibt, die für den Täter keine zivilrechtlichen Folgen haben. Dabei kann man insbesondere an das Aufdecken eines Diebstahls durch einen Jugendlichen kurz nach der Tat und die Rückgabe des Diebesgutes denken, durch die es - eher zufällig zu keinen Ansprüchen des Bestohlenen kommt. Oftmals wird auch das Opfer einer leichteren Körperverletzung oder einer Beleidigung nicht darauf dringen, daß man ihm Schmerzensgeld zahlt. In all diesen Fällen bliebe auch eine zivilrechtliche Sanktion aus. Unbestritten aber dürfte sein, daß irgendeine Art von staatlicher Reaktion erfolgen muß. Eine

1097 Staudinger-Salgo, § 1631, Rn. 21. 
Sanktionierung allein durch Schadensersatzansprüche ist daher nicht als ausreichend zu erachten.

\section{Prävention auf gesellschaftlicher Ebene}

Es ist auch daran zu denken, durch eine gesteigerte Sensibilität in der Bevölkerung eine Mitwirkung der Gesellschaft an der elterlichen Erziehung zu erreichen. Dagegen spricht in der Praxis die von Bussmann festgestellte deutliche Haltung in der Gesellschaft von der Privatheit der Familie $^{1098}$. Es herrschen Tendenzen vor wie „die Erziehung in anderen Familien geht mich nichts an“ oder ,das muß jeder selbst wissen, wie er seine Kinder erzieht“"1099. Die Familie wird auch von der Umwelt als unantastbare Tabuzone gesehen, in die man möglichst wenig eindringen will. Die zum Thema Kindesmißhandlung befragten Personen begründeten ihre Ablehnung, sich mit ihrem Wissen an eine Beratungseinrichtung zu wenden, zu 41,8 \% mit der Befürchtung, nicht in die Privatsphäre anderer Familien einzudringen und $\mathrm{zu} 34,7 \%$ als Spitzel bzw. als zu neugierig zu gelten ${ }^{1100}$. Nach den neuesten Erkenntnissen darf man also gegenwärtig nicht auf die disziplinierenden Kräfte sozialer Kontrolle im Umgang mit Straftaten innerhalb der Familie setzen. Die Abgeschlossenheit der Familie als soziales System ermöglicht nur sehr begrenzt eine soziale Kontrolle.

Es ist jedoch nicht ersichtlich, weshalb es nicht zu einem Wandel in der Gesellschaft kommen sollte. Grundsätzlich ist davon auszugehen, daß der mündige Bürger ein Mitsprache- und Mitwirkungsrecht und Verantwortung mit übernehmen möchte. Im Obrigkeitsstaat wurde die Verbrechenskontrolle allein durch Experten ausgeübt. Im demokratischen Rechtsstaat ist der Bürger bereit, an seiner Kriminaljustiz mitzuwirken und durch seine Mitwirkung seine Strafrechtspflege zu kontrollieren. Schneider zeigt insgesamt das Fazit, auch aus der Erwägung, daß die

${ }^{1098}$ Bussmann, S. 122ff.; Ursula Schneider, Gewaltanwendung in der Familie, S. 229; im Ansatz auch Schulte, Garantenstellung und Solidarität, S. 40.

1099 Ostendorf, S. 17; Bussmann, S. 122ff. Inwieweit sich diese in der Gesellschaft Einstellung ändert, wenn die Umgebung selbst durch Straftaten der Abkömmlinge dieser Familien betroffen wird, ist allerdings ungewiß.

${ }^{1100}$ Bussmann, S. 132. 
formelle Sozialkontrolle personell wie finanziell an ihre Grenzen stößt, Bürger stärker an der formellen Kontrolle zu beteiligen. Dadurch sollen Selbstregulierungsmechanismen in Kraft gesetzt und gesellschaftliche Krisenherde auch ohne Strafrecht beseitigt werden können ${ }^{1101}$. So lange dieser mögliche gesellschaftliche Wandel jedoch noch nicht vollzogen oder zumindest in seinen Ansätzen erkennbar ist, kann auf den Einsatz von Strafen, selbst in dem so sensiblen familiären Bereich, wohl nicht verzichtet werden.

Ein Bewußtsein innerhalb der Gesellschaft zu schaffen, könnte durch das sogenannte „social marketing“ vorangetrieben werden. Der Gedanke des „social marketing“ setzt an einer positiv gestalteten Bekanntmachung von Normen oder Verhaltensweisen an, die deutliche Bezüge zur Werbung aufweist. Sie knüpft daran an, daß ohne die Beteiligung der Öffentlichkeit eine Kriminalprävention nicht möglich ist. Kriminalpräventive Interventionen des Staates setzten zumindest die Duldung durch die Öffentlichkeit voraus. Damit die Wirkung staatlicher Präventionsmaßnahmen nicht durch Fehlreaktionen der Umwelt zunichte gemacht werde, soll eine, die staatliche Kriminalprävention fördernde Verhaltensmodifikation in der Öffentlichkeit angestrebt werden. Deshalb kommt der Frage, wie man die Öffentlichkeit im Sinne der Kriminalprävention informiert, überzeugt und aktiviert, zentrale Bedeutung $\mathrm{zu}^{1102}$. Die Ausgestaltung des „Marketing“ im einzelnen ist stark von dem Inhalt abhängig, der vermittelt werden soll ${ }^{103}$. Für die positive Generalprävention, bei der der Staat versucht, seine Bürger durch Argumentation zu überzeugen, spricht, daß ein eigenständiges, von innen gesteuertes Rechtsbewußtsein gebildet wird. Demgegenüber stellt der Staat bei der negativen Generalprävention die Machtfrage; er droht die Anwendung seines Gewaltmonopols an. Negative Generalprävention

\footnotetext{
${ }^{1101}$ Schneider, Kriminalpolitik, S. 10.

1102 Stoffers, Social Marketing, S. 421. $\rightarrow$ Lüderssen, Aufgeklärte Kriminalpolitik, 1998 ?

1103 Erfolgsreichstes Beispiel war in Schweden die Aktion „Höger“ zur Umstellung vom Linksverkehr zum Rechtsverkehr im Jahr 1967, Stoffers, Social Marketing, S. 422, bei der durch 130.000 Hinweisschilder und permanente Diskussionen mit den Bürgern versucht wurde, negative Einstellungen abzubauen. In Deutschland: „Schluckimpfung ist süß, Aktion Sorgenkind, S. 424.
} 
schafft bestenfalls oberflächliche äußere Anpassungsbereitschaft an sozialkonforme Verhaltensweisen ${ }^{1104}$.

Glaue hat bereits 1958 einen Katalog von Vorschlägen für einen verbesserten Jugendschutz zusammengestellt. An erster Stelle steht die wiederholte Belehrung und Aufklärung der Elternschaft sowie der älteren Kinder und Jugendlichen, der Unternehmer und Gewerbetreibenden und auch der breiten Öffentlichkeit. Als Orte der Information nennt sie Elternversammlungen und verschiedene Arten von Zusammenkünften, die Verteilung von Flugblättern, entsprechende Beiträge durch die Presse $^{1105}$.

Dieser Ansatz erscheint um so überzeugender, wenn man sich die mangelnde Publizität von professionellen Ansprechpartner sowohl bei Jugendlichen als auch bei Eltern vor Augen hält, die Bussmann in seiner Untersuchung festgestellt hat. Von den Erwachsenen konnte in der Studie von Bussmann beispielsweise nur die Hälfte Angaben über Beratungsstellen machen ${ }^{1106}$. Eine Hemmschwelle besteht überdies nicht nur gegenüber staatlichen Einrichtungen. Die gesellschaftlich bedingte und gewünschte Privatheit hat zur Folge, daß die Dinge ,unter sich“ geregelt werden sollen ${ }^{1107}$. Das macht es um so schwieriger, mit rechtlichen Verboten auf die betroffenen Eltern einzuwirken, weil dies erst recht zu einem Rückzug in die Privatheit führen kann.

Es fehlt zudem an der Bekanntmachung von Normen. Die Bekanntmachung stellt ein besonders wichtigen Kriterium zur Umsetzung von Recht dar. Dem Recht stellen sich mangels persönlichem Kontakt zwischen seinen Instanzen und den rechtsunterworfenen erhebliche Erreichbarkeitsprobleme. Nur wenige Menschen haben eigene Erfahrungen mit Instanzen sozialer Kontrolle wie Sozialarbeitern, Gerichten, Polizei und Rechtsanwälten ${ }^{1108}$.

Das Mittel des „social marketing“ kann jedoch nur unterstützend eingesetzt werden. Als solches handelt es sich auch um keine Maßnahme im eigentlichen Sinne, sondern soll lediglich ein verstärktes Denken in

\footnotetext{
1104 Schneider, Kriminalpolitik, S. 11.

${ }^{1105}$ Glaue, Schutz der Jugend in der Öffentlichkeit, S. $22 f$.

${ }^{1106}$ Bussmann, S. 124f.

1107 Bussmann, S. $131 \mathrm{f}$.

${ }^{1108}$ Bussmann, S. 237; ähnlich Neuhaus, Jura 90, 624 (625).
} 
dem gewünschten Themenbereich hervorrufen. Voraussetzung ist sogar gerade, daß bereits Normen oder gewünschte Verhaltenweisen bestehen, deren Anwendung angeregt werden soll.

III. Alternativen aus dem Polizeirecht

Wo strafrechtliche Maßnahmen nicht zulässig oder sinnvoll sind, bietet das Polizeirecht weiterhin eine Möglichkeit der Intervention ${ }^{1109}$. Da aber die Polizei nur auf einer rechtlichen Grundlage agieren darf, ist fraglich, welche das außer dem Strafrecht sein kann. Möglichkeiten, Eltern zu verantwortlicher Aufsicht und Erziehung gegenüber ihren Abkömmlingen anzuleiten, können eventuell im Gefahrenabwehrrecht gefunden werden. §6 NGefAG sieht eine Verantwortlichkeit für das Verhalten von Personen vor.

\section{§ NGefAG, Verantwortlichkeit für das Verhalten von Personen}

(1) Verursacht eine Person eine Gefahr, so sind die Maßnahmen gegen sie zu richten.

(2) Ist die Person noch nicht 14 Jahre alt, so können die Maßnahmen auch gegen die Person gerichtet werden, die zur Aufsicht über sie verpflichtet ist. ...

Merkmal der polizeirechtlichen Verantwortlichkeit ist, daß sie einsichtsund verschuldensunabhängig ist, also auch Kinder betrifft. Neben diese eigene Verantwortlichkeit des Kindes tritt die in $\S 6$ normierte Zusatzverantwortlichkeit des Aufsichtspflichtigen ${ }^{1110}$.

Allerdings kann es auch beim Polizeirecht nur darum gehen, vom Kind aktuell ausgehende Gefahren abzuwehren, also etwa durch die Ingewahrsamnahme des Amokläufers oder durch die die Sicherstellung gefährlicher Sachen ${ }^{1111}$. Von nennenswerter praktischer Bedeutung dürfte unter diesem Gesichtspunkt die Sicherung der zivilrechtlichen Ansprüche

${ }^{1109}$ Benfer, Rn. 717; Frehsee, ZStW 100 (1988), 290 (310) weist aber darauf hin, daß das Polizeirecht nicht erlauben kann, was das Strafprozeßrecht verbietet.

1110 Götz, Rn. $210 \mathrm{ff}$.

1111 Frehsee, ZStW 100 (1988), 290 (313); Neuhaus, Jura 90, 624 (625). 
des Geschädigten sein. Das Polizeirecht kann nur bedingt als Instrument für die Lösung langfristiger Probleme und für die Abwehr in Zukunft zu erwartender Gefahren eingesetzt werden. Denn die Polizei hat selbst keine eigenen Interventionsmöglichkeiten längerfristig sichernder oder bessernder Einflußnahme auf das gefährliche Individuum. Die ihr zur Verfügung stehenden Mittel der Informationsbeschaffung und aufbewahrung dienen vor allem dem schnelleren Zugriff auf den Täter bei der nächsten Straftat und somit der schnelleren Herbeiführung der präventiven Einflußnahme des Strafrechts ${ }^{1112}$. Zwar kann polizeiliches Wissen Anlaß bieten, die für die Kontrolle der Kindesentwicklung zuständigen Träger der Personensorge zu mobilisieren ${ }^{1113}$. Dadurch wird die fehlende Zuständigkeit der Polizei für diese Bereiche aber nicht ausgeglichen. Eine polizeiliche vorbeugende Verbrechensbekämpfung als dritte eigenständige polizeiliche Aufgabe zwischen Strafverfolgung und Gefahrenabwehr sieht das Gesetz nicht vor ${ }^{1114}$.

Soweit die Polizei anstelle der Jugendbehörden in diesem Bereich tätig wird, handelt sie ohne rechtliche Basis. Diese Tätigkeit im Graufeld muß jedoch nicht unbedingt nachteilig sein. Der Vorteil liegt nach Meinung Bussmanns für den Betroffenen darin, daß die Mittel der genannten Behörden nicht unmittelbar zum Zuge kommen ${ }^{1115}$. Die Polizei wird als eigenständige Interventionsinstanz mit einer Chance zum therapeutischen Effekt in der Familie angesehen. Immerhin wird der Konflikt bei Familienstreitigkeiten (,im Schatten des Rechts") in der Studie von Bussmann zu $65 \%$ durch die Polizei geschlichtet. Die Möglichkeit, daß die Polizei das Jugendamt einschalten könnte, wurde von $70 \%$ der Befragten als positive Folge gesehen. Von den Befragten sahen sogar über $50 \%$ überraschenderweise die Möglichkeit eines Strafverfahrens nicht als Nachteil an ${ }^{1116}$. Jedoch bietet sie für das Problem keine dauerhafte Lösung. Die Tätigkeit der Polizei als Interventionsinstanz, die

\footnotetext{
$\overline{1112}$ Frehsee, ZStW 100 (1988), 290 (313).

1113 Frehsee, ZStW 100 (1988), 290 (315).

1114 Zudem ist eine Verbrechensbekämpfung im Hinblick auf strafunmündige Kinder gerade nicht möglich, weil eine Anwendung des Strafrechts für Kinder gar nicht in Betracht kommt, vgl. Frehsee, ZStW 100 (1988), 290 (313).

${ }^{1115}$ Die Polizei wird daher von Bussman als eine Art „Feuerwehr“ bezeichnet, die Brände zwar löschen, sie aber nicht verhindern noch den Ursachen auf den Grund gehen kann. ${ }^{1116}$ Bussmann, S. $171 \mathrm{ff}$.
} 
unmittelbar Streitigkeiten schlichtet, das Jugendamt informiert oder an Beratungsstellen weiterverweist, kann letztlich nicht $\mathrm{zu}$ einer Entschärfung der Diskussion um die Rolle der Strafjustiz führen. Denn hier kann ein wirkungsvolles Handeln nur im Schatten der Institutionen, wie Vormundschaftsgericht oder Strafjustiz, aber keine eigenständige Intervention durchgeführt werden ${ }^{1117}$.

IV. Weitere Maßnahmen und Sanktionen

Es werden auch weitere Sanktionen diskutiert. Angesprochen wird bei Ostendorf die Kürzung von Sozialhilfe oder Kindergeld bzw. Erziehungsgeld $^{1118}$. Diese Ansätze sind jedoch als kontraproduktiv abzulehnen, weil sich die soziale Lage der betroffenen Familien dadurch nur verschlechtern würde.

Die Ausweisung von ausländischen Kindern und deren Eltern („Fall Mehmet") geht ebenfalls am Problem vorbei ${ }^{1119}$. $\$ 10$ AuslG sieht vor, daß die Anordnung von Fürsorgeerziehung und die Verhängung von Jugendstrafe die Ausweisung eines Jugendlichen zur Folge haben können. Durch die Ausweisung entzieht sich der Staat aber lediglich seiner Verpflichtung zur Erziehung hier lebender minderjähriger Ausländer ${ }^{120}$. Eine präventive Wirkung ist von einer solchen Vorgehensweise nicht zu erwarten und würde überdies nur einen Teil der Bevölkerung treffen.

Auch eine Ausgangssperre für Kinder und Jugendliche für abends und nachts ${ }^{1121}$ kann die Problematik nicht anhaltend lösen, lediglich die Tageszeit der Deliktsbegehung würde sich verschieben. Positiver Aspekt einer solchen „Sperrzeit“" wäre allerdings die bessere Kontrolle von Kindern und Jugendlichen, die damit einher ginge. Praktisch wäre eine solche Maßnahme angesichts der Freizeitaktivitäten, aber auch

\footnotetext{
${ }^{1117}$ Bussmann, S. $171 \mathrm{ff}$.

1118 Ostendorf, S. 40.

1119 Vgl. Ostendorf, S. 40.

${ }^{1120}$ Neuhaus, Jura 90, 624 (625).

${ }^{1121}$ Vorsitzender der CDU-Fraktion der Hamburger Bürgerschaft, zitiert bei Ostendorf, S. 9.
} 
angesichts der schulische Veranstaltungen der Kinder und Jugendlichen, die sich mehr und mehr auch in den Abend hinein verlagern, kaum umzusetzen.

Schließlich stellt auch die Herabsetzung der Strafmündigkeit ${ }^{1122}$ keinen sinnvollen Ansatz dar. Selbst wenn man davon ausgeht, daß die Kinder immer früher einsichtsfähiger werden, wird durch eine solche zweifelhafte, parteiübergreifend abgelehnte Maßnahme das Grundproblem, die elterliche Vernachlässigung, nicht berührt ${ }^{1123}$.

\section{E. Diskussion und Fazit}

Die außerstrafrechtlichen Ansätze bieten ein großes Potential zur Einwirkung auf Erziehungsverpflichtete. Ob insoweit auf das Strafrecht ganz verzichtet werden kann, ist Gegenstand der nun folgenden Diskussion.

Trotz der Spannungen, die eine Bestrafung der Eltern für das ElternKind-Verhältnis bedeuten kann, darf nicht einseitig auf die Nachteile einer Strafbarkeit gesehen werden. Jede Strafverfolgung ist mit Schwierigkeiten nicht nur für den Beschuldigten, sondern auch für dessen Angehörige verbunden, ohne daß man deshalb in anderen Bereichen auf den Gedanken käme, die Strafverfolgung des Beschuldigten aufzugeben ${ }^{124}$. Kinder sind grundsätzlich die Leidtragenden, wenn ihre Eltern mit dem Gesetz in Konflikt geraten. Die Bestrafung der Eltern erfolgt aber nicht im leeren, betreuungsfreien Raum. Die oben angesprochenen negativen Folgen für die Eltern-KindBeziehung können durch begleitende Maßnahmen gemildert werden.

In der strafrechtlichen Literatur herrscht dem Grunde nach Übereinstimmung, Eltern zu bestrafen, die ihre Abkömmlinge nicht von der Begehung von Straftaten abhalten, sei es durch unechtes Unterlassen

\footnotetext{
1122 Vorgeschlagen vom Vorsitzenden des Bundestagsrechtsausschusses, Rupert Scholz (CDU), Dpa-Meldung vom 14.01.2001.

${ }^{1123}$ Vgl. Schneider, Kriminalpolitik, S. 20; Höynck/Sonnen, ZRP 2001, 245 (246).

${ }^{1124}$ Eine vergleichbare Problematik stellt sich im Rahmen der Bestrafung von Eltern, die ihre Kinder nicht nur vernachlässigen, sondern auch aktiv mißhandeln. Obwohl auch hier
} 
in einer konkreten Situation oder durch das Ermöglichen eines kriminellen Lebenswandels durch fehlende Kontrolle und Einflußnahme über einen längeren Zeitraum. Demgegenüber sind in der Rechtspraxis solche Fälle kaum zur Verurteilung gelangt ${ }^{125}$. Die Ursachen für die Ablehnung sind jedoch bislang unerforscht. $\mathrm{Zu}$ vermuten sind sowohl prozessuale als auch rein tatsächliche Schwierigkeiten. Derartige Verfahren dürften oft im Hinblick auf die schwierige Beweisführung und rechtliche Würdigung eingestellt werden ${ }^{1126}$. Hier liegt noch erheblicher Forschungsbedarf. Es kann aber davon ausgegangen werden, daß die Probleme nicht im Strafrecht als solchem, sondern vielmehr in der durch jegliches Recht schwer zu erfassenden Materie liegen. Es kann daher nicht festgestellt werden, daß die strafrechtlichen Regelungen an sich unbrauchbar wären. Vielmehr stellt sich die Frage, ob das Strafrecht hier an seine ureigensten Grenzen stößt. Es ist zu klären, ob gerade das Strafrecht in diesem sensiblen Bereich überhaupt eingesetzt werden darf.

Verfassungsrechtlich steht fest, daß den hinreichend wirksamen außerstrafrechtlichen Schutzmöglichkeiten immer der Vorrang einzuräumen ist. Das Strafrecht darf erst zum Zuge kommen, wenn alle anderen Mittel der sozialen Problemlösung versagt haben (subsidiäre Natur des Strafrechts) ${ }^{1127}$. Die Beschränkung der Strafpflicht auf wenige besonders zentrale Schutzgüter zeigt - auch im internationalen Vergleich, daß Verfassungen Strafe regelmäßig als besonders scharfe Waffe ansehen. Es wird nicht als selbstverständliches Instrument, sondern vielmehr als letztes Mittel mit herausragend intensiver Ausdruckskraft empfunden $^{1128}$. Bussmann meint dazu, daß Strafrecht auch schweigen können muß, wenn es seine herausgehobene, moralisierende Stellung im Gesamtsystem des Rechts behaupten will. Es müsse seine Unterscheidbarkeit zu anderen Rechtsgebieten behalten, die es schwäche,

\footnotetext{
die Probleme weitgehend im sozialen bereich gelöst werden müssen, käme hier niemand auf den Gedanken, eine Strafbarkeit der Eltern gänzlich abzuschaffen.

1125 Neuheuser, NStZ 2000, 174 (174).

1126 Neuheuser, NStZ 2000, 174 (174).

1127 Roxin, AT, § 2, Rn. 38 / 48, Fn. 69 m. w. N.

1128 Robbers, S. 149.
} 
wenn es zur Normalität würde, wenn es leichtfertig als flankierende Maßnahme eingesetzt werde ${ }^{1129}$.

Aber auch das Argument, daß Strafrecht nur die ultima ratio sein darf, steht hier der Anwendung einer elterlichen Bestrafung wegen unterlassener Deliktshinderung bzw. § 171 nicht entgegen. In den von $\S 171$ tatsächlich betroffenen Fällen ist das Strafrecht tatsächlich als das letzte Mittel anzusehen. Dies ergibt sich aus dem überaus engen Rahmen, den $\S 171$ steckt. Für $\S 171$ muß zunächst ermittelt werden, ob eine Pflichtverletzung der Eltern vorliegt, was schon für sich allein genommen eine schwieriges Unterfangen darstellt. Weiter muß es sich um eine gröbliche Pflichtverletzung handeln. An dieser wird es immer dann fehlen, wenn zuvor Maßnahmen im Rahmen der Kinder- und Jugendhilfe oder ähnliches in Angriff genommen worden sind. Es ist auch davon auszugehen, daß die vormundschaftliche Behörde erst dann Strafanzeige erstattet, wenn das Vertrauensverhältnis zwischen Behörden, Eltern und Kind in dem Maße gestört ist, daß ein gutes Zusammenwirken zur Abwendung der Gefährdung des Kindeswohls nicht mehr möglich ist ${ }^{1130}$. Die festgestellte Pflichtverletzung muß schließlich auch noch kausal für den eingetretenen kriminellen Lebenswandel geworden sein. Spätestens an der Klippe der Kausalität dürften viele Überprüfungen ihr Ende finden. Wer will mit einer für die Anklage hinreichenden Gewißheit bestimmen, daß nicht die ihn umgebende Gruppe von Freunden den Jugendlichen ohnehin zu der strafbaren Tat gebracht hat, unabhängig davon, was die Eltern versäumt haben ? Dazu kommt noch die Schwierigkeit, den Vorsatz nachzuweisen. Ein Strafbarkeit wird also nur selten materiell zu begründen sein, ohne daß man einen Rückgriff auf Milderungsgründe und prozessuale Opportunitätsvorschriften nehmen müßte.

Die außerstrafrechtlichen Maßnahmen reichen auf verschiedene Weise für diese, nach sorgfältiger Prüfung übrig gebliebenen wirklich schweren Fälle nicht aus, um eine Prävention $\mathrm{zu}$ verbessern oder auch nur aufrechtzuerhalten. Für viele der Eltern straffälliger Kinder gilt, daß die Maßnahmen über das Jugendamt gescheitert sind, weil die Eltern die dort

\footnotetext{
${ }^{1129}$ Bussmann, S. 274.

${ }^{1130} \mathrm{Vgl}$. Allenspach, Schmid-FS, S. 100.
} 
getroffenen Regelungen nicht ernst nehmen ${ }^{1131}$. Für die Eltern, bei denen $\S 171$ ernsthaft in Betracht kommt, ist sogar mit hoher Wahrscheinlichkeit davon auszugehen. Als letztes Druckmittel besteht die Hoffnung, daß die Drohung mit dem Staatsanwalt den erforderlichen Druck und die Motivation erzeugt, sich zumindest auf Beratungs- und Hilfsangebote einzulassen. Daß am Ende nicht immer eine strafrechtliche Verurteilung stehen muß, ist selbstverständlich. So soll, wie in jedem anderen Bereich der Strafverfolgung auch, die Einstellung nach dem Opportunitätsprinzip dort stattfinden, wo es sinnvoll erscheint - aber eben nicht als Regel, sondern als Ausnahme.

Da, wie oben gezeigt, andere Druckmittel gegenüber erziehungsunwilligen Eltern nicht von Erfolg gekrönt werden ${ }^{1132}$, bliebe ohne die Strafandrohung als ultima ratio keine Möglichkeit, auf nichtkooperationswillige Eltern einzuwirken. Man mag zwar einwenden, daß Kooperation ohnehin nicht erzwungen werden kann und eine Zwangstherapie nicht zum Erfolg führen kann. Jedes menschliches Verhalten ist aber Zwängen unterworfen. Ob der Zwang durch das Strafrecht dabei eines der empfindlichsten Übel ist, die in Frage kommen, sei bestritten. Die einzige andere Alternative wäre es, die betroffenen Eltern als unbelehrbar und ihre Kinder als hoffnungslose Fälle an den Rand der Gesellschaft abzudrängen.

Die Strafbarkeit gibt weiter vielgestaltige Möglichkeiten, außerstrafrechtliche Maßnahmen durchzusetzen. So liegen im Bewährungsbeschluß verschiedene Chancen, bestimmte Handlungsweisen durchzusetzen. Die Androhung von Strafe wird in einigen Fällen die einzige Möglichkeit sein, den Besuch von

\footnotetext{
1131 „Nach jedem Diebstahl ihrer Kinder wurden die Angeschuldigten von den Straftaten in Kenntnis gesetzt. Diese unternahmen jedoch nichts, um ihre Kinder von kriminellen Taten abzuhalten. Auch auf Hilfsangebote seitens des Jugendamtes reagierten die Angeschuldigten nicht. Oftmals wurden die Kinder bereits am nächsten Tag erneut bei Trickdiebstählen angetroffen." Siehe die jeweiligen Anklageschriften, auf die in den Urteilen des AG Köln in vollem Umfang Bezug genommen wurde: (unveröff.) Entscheidungen vom 7.4.1999, 613 Ls 97/98 und 28.4.1999, 532 Ds 82/99. 1132 Hyönck/Sonnen, ZRP 2001, 245 (246f.).
} 
Erziehungskursen usw. durchzusetzen, wo freiwillige Mitarbeit nicht zu erreichen war $^{1133}$.

Zudem kommt der Strafbarkeit der Eltern eine erhebliche Symbolwirkung zu. Wie symbolisch darf aber das Strafrecht sein ? Vor dem Hintergrund der Rechtsprechung des Bundesverfassungsgerichts zum Verhältnismäßigkeitsprinzip ist jedenfalls ein Minimum an Geeignetheit und Erforderlichkeit strafrechtlicher Sanktionen zu fordern ${ }^{1134}$.

Auch wenn man der Polizei als „eigenständige Interventionsinstanz mit einer Chance zum therapeutischen Effekt in der Familie“ "1135 große präventive Aufgaben zugesteht, muß berücksichtigt werden, daß auch die Polizei letztlich nur mit dem Hintergrund der bestehenden Vorschriften im wesentlichen Strafvorschriften - in dieser Weise tätig werden kann. Ihr Handeln dient der Normverdeutlichung ${ }^{1136}$. Dazu müssen aber überhaupt Normen bestehen.

Die Einführung von Tatbeständen, die eher symbolische Charakter haben als tatsächlich in der Praxis umgesetzt werden, kritisiert auch Frehsee. Seiner Ansicht nach nähren solche Konstruktionen Zweifel, ob das Kriminaljustizsystem wirklich Kriminalitätsverhütung bezweckt ${ }^{1137}$. Da aber jedem Gesetz eine Symbolfunktion zukommt, stellt sich auch hier die leidige Frage, wo die Grenze zum noch Erlaubten gezogen werden muß. Man wird wohl zum Ergebnis kommen, daß es sich bei $\S 171$ nicht um einen rein symbolisch gemeinten Tatbestand handelt, der bei einer konsequenteren Strafverfolgung durchaus auch häufiger in der Praxis zur Entscheidung käme.

Die Symbolkraft sollte auch nicht unterschätzt werden: Nach Bussmann bedeutet allein das Kommunizieren unter Bezugnahme auf den Code des Rechts, diesen Code akzeptiert zu haben. Soweit der Code des Rechts in der Kommunikation von Menschen zirkuliere, würden ihre

\footnotetext{
$\overline{1133}$ In den USA hat die Hälfte der Staaten Gesetze erlassen, die Eltern für das kriminelle Verhalten ihrer Kinder verantwortlich machen und die sie zwingen, an Elternberatungsund Erziehungsprogrammen teilzunehmen, Schneider, Kriminalpolitik, S. 20.

${ }^{1134}$ BVerfG NJW 1975, 580 (580 ff.); Bussmann, S. 233 f. m. w. N.

${ }^{1135}$ Bussmann, S. $171 f$.

${ }^{1136}$ Vgl. Bussmann, S.179f.
} 
Wahrnehmungen und Interpretationen in diesem Sinne ,ausgerichtet “1138. Im Gegensatz zu oft ungenauen, verschwommenen Erziehungskonzepten hat das Strafrecht darüber hinaus ein vorrangiges, klar zu definierendes Ziel: Keine Straftaten durch den Minderjährigen.

Weitere Kritik an symbolischen Straftatbeständen übt Frehsee mit dem Argument, daß es oft schwierig sei, Schutzgüter zu nennen, die hinter den Verhaltensverboten ständen. Eine Appellfunktion sei kaum noch ersichtlich $^{1139}$. Davon kann zumindest in Bezug auf $\S 171$ nicht die Rede sein, da das Schutzgut hier ausreichend deutlich definiert ist.

Überdies belastet das Recht bestehende Konflikte nicht nur, sondern es bringt auch Entlastungseffekte für die Parteien, indem die Thematisierungsschwelle überschritten und auf Rechtsnormen reduziert wird. Durch eine Verrechtlichung von ungleichen Machtbeziehungen kann der stärkere Interaktionspartner z.B. an konkrete Verletzungsverbote oder das Gleichheitsgebot des Rechts angebunden werden $^{1140}$. Die Strafandrohung alleine muß dabei weder zu einer Verurteilung noch zu einer dauerhaften Lösung des konkreten Problems führen $^{1141}$. Macht man sich von dem Gedanken frei, daß das Recht „alles“ erreichen kann, stellt es bereits einen Erfolg dar, wenn es dazu beiträgt, die Sinne für die Aufsichts- und Erziehungspflichten von Eltern zu schärfen ${ }^{1142}$.

Schließlich ist nicht zu vergessen, daß durch Eltern, die die Straftaten der ihnen anbefohlenen Kinder und Jugendlichen nicht verhindern, ein teilweise erhebliches Unrecht begangen wird. Ohne eine strafrechtliche Sanktionsmöglichkeit käme hier der Vergeltungsgedanke zu kurz.

Daher muß man zum Ergebnis kommen, daß sowohl die Strafbarkeit über die Garantenstellung als auch gem. $§ 171$ aufrechtzuerhalten ist.

\footnotetext{
${ }^{1137}$ Frehsee, Fehlfunktionen des Strafrechts, S. 19.

${ }^{1138}$ Bussmann, S. 264.

${ }^{1139}$ Frehsee, Fehlfunktionen des Strafrechts, S. 18.

${ }^{1140}$ Vgl. Bussmann, S. 258f.; ausdrücklich dagegen: Feltes, Jugendrecht im Konflikt, S.

20, der eine Konfliktverschärfung erwartet und eine informelle Lösung fordert.

${ }^{1141} \mathrm{Vgl}$. Feltes, Jugendrecht im Konflikt, S. 21

1142 Feltes hat dazu bemerkt, daß es die Aufgabe des Rechts sei, Konflikte zu organisieren, ohne unbedingt eine echte Lösung oder „die Wahrheit“ zu finden, Feltes, Jugendrecht im Konflikt, S. 21.
} 
Angesichts der wachsenden Probleme im Bereich der privaten Erziehung wäre es insbesondere ein falsches Zeichen, die insoweit konkrete Norm des $\S 171$ gänzlich zu streichen. Außerstrafrechtliche Sanktionen vermögen eben gerade nicht jenes Signal zu setzen, das von einem Straftatbestand ausgeht. $\S 171$ ist trotz seiner zweifelhaften Entstehungsgeschichte kein antiquiertes Relikt einer von Obrigkeitsdenken geprägten Zeit, sondern betrifft Probleme, die sich heute in ihrer Intensität viel stärker stellen als zur Zeit seiner Entstehung. Sicherlich ist die Fassung des $\S 171$ nicht als ideal zu bezeichnen. Kritik hat die Vorschrift bislang in jeder ihrer Fassungen erhalten, was, wie erörtert, nicht nur an dem Wortlaut des Gesetzestexts, sondern der Materie an sich lag. Insgesamt stellt $\S 171$ jedoch einen akzeptablen Kompromiß im Ringen um Rechtsstaatlichkeit und gleichzeitig um praktikablen Schutz für Kinder und Jugendliche dar ${ }^{1143}$. 


\section{Teil. Schlußbetrachtung}

In dieser Arbeit wurde dargestellt, inwieweit die mangelhafte Aufsicht oder Erziehung von Kindern und Jugendlichen, wenn sie sich in strafbarem Verhalten äußert, zur strafrechtlichen Haftung der Eltern selbst führen kann. Neben dem zentralen Aspekt der Garantenstellung und ihrer Bedeutung für die Herrschaft über das Kind bzw. den Jugendlichen war es vor allem Ziel dieser Arbeit, einen möglichst umfassenden Überblick über die bisher kaum behandelte Thematik der strafrechtlichen Haftung der Eltern zu geben.

Als Ansätze für eine Strafbarkeit der Eltern ergaben sich die unechten Unterlassungsdelikte in Verbindung mit Tatbeständen aus dem Besonderen Teil sowie $§ 171$ StGB, der die Verletzung der Fürsorge- und Erziehungspflichten ausdrücklich regelt. Bei der Untersuchung zeigte sich verstärkt, daß die Elternhaftung bisher größtenteils nur zivilrechtlich untersucht worden ist, so daß in vielerlei Hinsicht noch unbekanntes strafrechtliches Terrain erschlossen werden mußte.

Nach einem geschichtlichen Rückblick wurde im vorderen Teil der Arbeit das unechte Unterlassungsdelikt in Form der unterlassenen Deliktsverhinderung behandelt, bei der die Eltern der Tatverwirklichung durch ihren Abkömmling tatenlos zusehen. Als Ansatz für die Verantwortlichkeit wegen der unterlassenen Deliktshinderung wurde gemäß der Funktionenlehre Armin Kaufmanns von der Überwachergarantenstellung der Eltern ausgegangen. Die Herleitung der Garantenstellung der Eltern aus der Herrschaft über ihre Kinder wurde erörtert und bestätigt. Im weiteren wurden die einzelnen Inhalte der Garantenpflicht sowie deren Grenzen herausgearbeitet. Hierzu gehörten Fragen nach der Delegationsmöglichkeit der Aufsichtspflicht an Dritte, die Haftung des nicht-sorgeberechtigten Elternteils und die Überlegung, ob beim verschuldeten Verlust der Herrschaftsmöglichkeit die Garantenstellung entfallen muß. Die Überlegungen zur Reichweite der Garantenpflicht wurden durch eine Untersuchung der Zumutbarkeit der Deliktsverhinderung abgeschlossen. 
Sodann wurde die Frage der Beteiligungsform der Eltern an den Delikten ihrer Abkömmlinge untersucht. Im Ergebnis zeigte sich, daß nur die generelle Annahme einer Täterschaft der Eltern der Bedeutung der Garantenstellung Rechnung trägt. Insbesondere hinsichtlich der Untersuchung der Beteiligungsform bei der unterlassenen Deliktsverhinderung zeigte sich noch erheblicher weiterer Forschungsbedarf; dies betreffend konnten hier nur kurze Anregungen gegeben werden, da andernfalls der Rahmen dieser Arbeit gesprengt worden wäre.

Hinsichtlich von $\S 171$ StGB war vor allem eine Konkretisierung und Herausarbeitung der Tatbestandsmerkmale vorzunehmen. Hierbei spielte die Auslegung der Begriffe der psychischen Entwicklungsschädigung und des kriminellen Lebenswandels eine zentrale Rolle. Sodann wurde überprüft, in welchem Verhältnis die Regelung des $\S 171$ StGB zu den zuvor behandelten unechten Unterlassungsdelikten steht. Es konnten wesentliche Unterschiede sowohl in den Voraussetzungen der Strafbarkeit als auch in der Schutzrichtung der Tatbestandstypen herausgearbeitet werden.

Schließlich waren die erlangten Resultate auf ihre Verfassungsmäßigkeit und auf die gesellschaftlichen Folgen ihrer Umsetzung hin zu untersuchen. Hierbei zeigte sich, daß in der Gesellschaft das Bewußtsein einer elterlichen Strafbarkeit kaum besteht und ein solches Bewußtsein durch die Zurückhaltung der Justiz auch nicht gefördert wird. Für diese Zurückhaltung fand sich neben den erheblichen prozessualen Problemen, die sich bei einem gegen die Eltern gerichteten Strafverfahren ergeben, der Grund, daß eine Bestrafung der Eltern zur Förderung eines besseren pädagogischen Konzepts zum Teil kontraproduktiv ist und insgesamt für sich allein keine Lösung verspricht. Im weiteren wurde diskutiert, durch welche außerstrafrechtlichen Maßnahmen die elterliche Verantwortung gestärkt werden könnte. Eine Antwort kann in dieser Hinsicht nur durch die Praxis gefunden werden. 
Im Ergebnis ist festzuhalten, daß nur starke Auswüchse elterlicher Pflichtverletzung strafwürdig bzw. mit dem Strafrecht sinnvoll erfaßt werden können. Die elterliche Pflichten müssen jedenfalls in der Öffentlichkeit gestärkt und ihre Wichtigkeit hervorgehoben werden. Dazu können und sollen die bestehenden strafrechtlichen Regelungen beitragen. Die eigentliche Problembewältigung muß aber außerhalb des Strafrechts erfolgen. 